\title{
Estudo do Jato de Baixos Níveis de Iperó e das Implicações no Transporte de Poluentes no Estado de São Paulo
}

\author{
Tese de Doutorado \\ Submetida ao Departamento de Ciências Atmosféricas \\ Instituto de Astronomia, Geofísica e Ciências Atmosféricas \\ Universidade de São Paulo \\ por \\ Hugo Abi Karam
}

No estabelecimento parcial dos requerimentos necessários para a obtenção do Grau de Doutor

Área de Concentração: Meteorologia

Orientador: Prof. Dr. Amauri Pereira de Oliveira

9 de Agosto de 2002

São Paulo, SP, Brasil 


\title{
Estudo do Jato de Baixos Níveis de Iperó e das Implicações no Transporte de Poluentes no Estado de São Paulo
}

\begin{abstract}
RESUMO
Neste trabalho, a origem dos Jatos de Baixos Níveis (JBN) noturnos de Iperó (SP) e o seu papel na dispersão de poluentes no Estado de São Paulo são investigados. Para tanto são utilizados os dados coletados nas quatro campanhas de medidas em Iperó. Utilizou-se também um modelo numérico de mesoescala não-hidrostático TVM para simular a estrutura espacial 3-D do JBN em resposta as forçantes topográficas e associadas ocupação da superfície. Os resultados observacionais indicam que o JBN ocorre em Iperó com bastante frequiência nas noites de céu claro, com intensidade variando entre 8 e $10 \mathrm{~m} / \mathrm{s} \mathrm{e}$ localizado em torno de $350 \mathrm{~m}$ acima da superfície. Os JBNs em Iperó caracterizam-se por um cisalhamento direcional, com ventos de SE na superfície e de ENE na região de máximo. Ocorrem tanto no inverno como no verão, e afetam o ciclo diurno médio do vento observado nos primeiros 100 metros na região de Iperó. Os JBNs são responsáveis pelo máximo noturno $(21: 00 \mathrm{HL})$ existente no ciclo diurno médio do vento na região. Os resultados numéricos indicam que o JBN de Iperó é resultado da ação combinada de quatro fatores: (1) circulação anabática no setor paulista do vale do Rio Paraná; (2) oscilação inercial; (3) circulação catabática noturna e (4) brisa marítima. Estes quatro fatores combinados sustentam um JBN com intensidade de 5 a $10 \mathrm{~m} / \mathrm{s}$, localizados a uma altitude de 100 a $400 \mathrm{~m}$ acima da superfície, durante maior parte da noite. O JBN simulado numericamente encontra-se localizado no setor oeste da região de convergência da circulação anabática e da brisa marítima. Esta região de convergência em baixos níveis se forma durante o dia na parte mais elevada do Estado de São Paulo que acompanha da linha do litoral (Serra do Mar e da Cantareira). O efeito do JBN sobre o transporte de poluente foi investigado com um modelo Lagrangiano de dispersão de partículas. Verificou-se que o JBN aumenta a dispersão horizontal das partículas, transportando o poluente atmosférico emitido na superfície até 250 $\mathrm{km}$ da fonte.
\end{abstract}

Palavras Chave: Jato de Baixos Níveis, Camada Limite Planetária, Efeitos Topográficos e Dispersão de Poluentes.

\begin{abstract}
This work investigates the nocturnal Low-Level Jet (LLJ) in Iperó, Brazil, and its role in the pollutant dispersion on the State of São Paulo (SP). Data of four field campaigns in Iperó-SP was used in this investigation. A mesoscale and non-hydrostatic TVM model is also used to simulate the 3D structure of the LLJ, which is a dynamic response to topography and land use. The observational results indicate that the LLJ is frequently found during clear air nights, with a maximum between 8 and $10 \mathrm{~m} \mathrm{~s}^{-1}$, located around $350 \mathrm{~m}$ above surface. The LLJ in Iperó is characterized by a directional wind shear, with SE winds near surface and ENE near to the maximum. They occur during the winter and summer, and can modify the diurnal cycle of the mean wind in the first $100 \mathrm{~m}$ in the Iperó area. The LLJ are responsible by the nocturnal maximum (21:00 LT) in the mean wind in Iperó. The numerical results indicate the Iperó LLJ is a result of four factors: (1) anabatic circulation in São Paulo sector of the Paraná River Basin; (2) inertial oscillation; (3) nocturnal katabatic circulation and (4) sea breeze. These factors, together, sustain a LLJ with jet core intensity between 5 and $10 \mathrm{~m} / \mathrm{s}$, located between 100 and $400 \mathrm{~m}$ above surface during the major of nighttime period. The simulated LLJ numerically is found in the west sector in the convergence zone of the anabatic and sea breeze circulations. This convergence flow area appears during the daytime above the more elevated areas in the State of São Paulo, i.e., along mountains aligned parallel to coastline (Serra do Mar and Cantareira). The effects of the LLJ in a pollutant transport were investigated using a Lagrangian Particle Dispersion model coupled to the mesoscale model TVM. The results show that the LLJ increases the horizontal dispersion of the particles released near surface in Iperó and is able to transport the pollutant up to $250 \mathrm{~km}$ downwind the source.
\end{abstract}

Key word: Low-Level Jet; Planetary Boundary Layer; Topographic Effects and Pollutant Dispersion.

Este trabalho foi financiado pela Fundação de Amparo a Pesquisa do Estado de São Paulo (FAPESP) Ref. Processo 97/02843-0 


\section{DEDICATÓRIA}

Para minha querida filha Marcela.

\section{AGRADECIMENTOS}

Manifesto meu agradecimento ao Prof. Dr. Amauri P. Oliveira - orientador desse trabalho - e também à Prof. Dra. Jacyra R. Soares do Grupo de Micrometeorologia do IAG-USP.

Minha gratidão estende-se aos professores, amigos e colegas da pós-graduação: Dra. Sônia M. Stivari, Dr. Airton Xavier, Dra. Teresinha Xavier, Bondezan Paulino, Paulo Takeshi, Reinaldo Hass, Edmilson Freitas, Dóris Veleda, Dr. Jorge Furlan, Dr. Edílson Marton, Edson P. Marques Filho, Maxsuel M. R. Pereira, Antonio Jaschke Machado e André L. F. de Souza.

Gostaria de expressão meu reconhecimento à Fundação de Amparo à Pesquisa do Estado de São Paulo (FAPESP), que financiou meu projeto de doutorado e ao Instituto de Astronomia, Geofísica e Ciências Atmosféricas (IAG) da Universidade de São Paulo (USP), onde o projeto foi realizado. 


\section{ÍNDICE}

Capítulo 1 - Introdução

1.1 Revisão Bibliográfica 5

1.2 JBN no Brasil 17

1.3 Mecanismos Geradores $\quad 27$

$\begin{array}{ll}1.4 \text { Objetivos } & 30 \\ 1.5 \text { Justificativa do Estudo } & 36\end{array}$

1.5 Justificativa do Estudo $\quad 36$

1.6 Conteúdo dos Capítulos 38

Capítulo 2- Metodologia $\quad 39$

2.1 O Modelo TVM 39

2.1.1 Camada de Interface $\quad 41$

2.1.2 Camada Atmosférica 44

2.1.3 Esquema Numérico $\quad 49$

2.2 Inicialização $\quad 50$

2.2.1 Topografia $\quad 50$

2.2.2 Tipos de Superfície $\quad 51$

2.3 Modelo de Dispersão de Partículas $\quad 59$

2.4 Metodologia de Interpolação $\quad 60$

Capítulo 3 - Resultados Observacionais $\quad 64$

3.1 Experimento de Iperó $\quad 64$

3.2 Estrutura Vertical dos JBN em Iperó 67

3.2.1 Dados Originais de Balão-Cativo 67

3.2.2 Dados Interpolados $\quad 73$

3.2.2.1 Estrutura Vertical Média Horária 76

3.3 Influência do JBN na Evolução Horária dos Campos de 82

Superfície

3.4 Efeito da Grande-Escala sobre o JBN 99

Capítulo 4 - Resultados Numéricos 109

4.1 Escoamento à Superfície $\quad 111$

4.1.1 Simulação L100 111

4.1.2 Simulação L400 114

4.1.3 Simulação L800 $\quad 115$

4.1.4 Simulação L1500 120

4.2 Análise dos Campos no Corte (x, z) 121

4.3 Estrutura Vertical do JBN 127

4.4 O JBN de Iperó e a Circulação da Brisa 130

4.5 Análise dos Efeitos da Topografia e Cobertura da Superfície $\quad 135$

4.5.1 Características do Escoamento Médio 136

4.5.2 Efeito do Fator 1: Temperatura 136

4.5.3 Efeito do Fator 2: Tipos de Superfície 139

4.5.4 Efeito de Interação entre Topografia e Tipo de 139

Superfície

4.6 Distribuição do Máximo de Velocidade 143

4.7 Modelo Conceitual 145

Capítulo 5 - Efeitos do JBN sobre a Trajetória de um Poluente Inerte Emitido 148 
de Iperó

5.1 Caracterização do Poluente 148

5.2 Dispersão na Região de $100 \mathrm{~km}$ por $100 \mathrm{~km}$ à volta de Iperó $\quad 150$

Regional

5.3 Evolução Temporal da Nuvem de Poluente em Escala 155

5.4 Interação entre Fontes de Poluentes em Escala Regional $\quad 158$

Capítulo 6 - Conclusões $\quad 162$

6.1 Detalhamento 163

6.2 Recomendações para Trabalhos Futuros 169

$\begin{array}{ll}\text { Referências Bibliográficas } & 171\end{array}$

APÊNDICE A - Transformação do Termo de Difusão Horizontal 183

APÊNDICE B - Estrutura Vertical do Vento Observada durante os 185

Experimentos de Iperó

APÊNDICE C - Mapa de Projeção 


\title{
LISTA DE FIGURAS
}

\author{
Figura
}

Página

\section{Capítulo 1}

Figura 1.1 Representação idealizada da estrutura vertical de um Jato de Baixos Níveis. Este jato aparece em associação ao desenvolvimento de uma CLP estável e à presença de uma inversão térmica de superfície $(\partial \theta \partial \mathrm{z}<0)$. $\mathrm{O}$ cisalhamento da velocidade do vento provoca turbulência abaixo e acima do máximo do jato.

Figura 1.2 (a) Freqüência de ocorrência do JBN na Grande Planície do EUA e (b) posição média do eixo do JBN (BONNER, 1968). Em (b) mostra-se também as cotas de altitude da topografia.

Figura 1.3 Variabilidade horária dos JBNs da Grande Planície dos EUA segundo critério de classificação de BONNER (1968).

Figura 1.4 Diagrama esquemático dos elementos relevantes de um intenso transporte de umidade e calor via JBN desde a Amazônia até a região da Argentina, Paraguai e Uruguai (MARENGO, 2002).

Figura 1.5 Modelo conceitual de AUGUSTINE e CARACENA (1994) mostrando o papel da convergência do vento na dianteira do JBN e da zona de frontogênese na localização e formação de um grande Complexo Convectivo de Mesoescala. As linhas tracejadas representam as isotermas que são aproximadas pela convergência do vento. Figura adaptada para o Hemisfério Sul.

Figura 1.6 Representação da oscilação inercial do vetor velocidade do vento no nível de pressão de $850 \mathrm{hPa}$, em Bauru, na noite entre os dias (a) 23 e 24; (b) 24 e 25 e (c) 26 e 27 de janeiro de 1983. Apresenta-se na figura os vetores correspondentes ao vento geostrófico $\left(\mathbf{v}_{\mathrm{g}}\right)$; à velocidade do vento à $18 \mathrm{~h}\left(\mathbf{v}_{18}\right)$ e à 24 horas $\left(\mathbf{v}_{24}\right)$, conforme observados em Bauru (círculos pequenos abertos). O conjunto de círculos pequenos preenchidos, distribuídos ao longo da circunferência da oscilação inercial, representam posições sucessivas da ponta do vetor velocidade, tomadas em sentido anti-horário e intervaladas de uma hora. O quadro (d) representa o escoamento associado à presença da Crista de Alta Pressão no Estado de São Paulo. Um quarto do período inercial (P/4) corresponde a 7,5 h em Bauru.

Figura 1.7 Evolução temporal da direção e da velocidade do vento observadas em Iperó durante a terceira e quarta campanhas de medidas, realizadas em julho de 1992 e março de 1993. Observações efetuadas com uma torre de $10 \mathrm{~m}$ (T) e por Balão Cativo (B).

Figura 1.8 Isolinhas do contorno topográfico para uma área contendo as regiões Sudeste, Sul e parte da região Centro-Oeste do Brasil, mostrado em intervalos de $200 \mathrm{~m}$. A linha mais espessa mostra a fronteira política do Estado de São Paulo. Os quadrados concêntricos na posição geográfica de Iperó, SP $\left(47,65^{\circ} \mathrm{W} ; 23,40^{\circ} \mathrm{S}\right)$ apresentam lados de dimensão aproximada 1500, 800, 400 e $100 \mathrm{~km}$ correspondentes aos domínios das simulações numéricas. A linha ST indica a orientação do corte vertical da topografia apresentada na Figura 1.9 (adiante).

Figura 1.9 Seção transversal na topografia da região sudeste do Brasil ao longo da Corte ST (Figura 1.8), onde se destaca a localização do Litoral Paulista (A); Serra do Mar (B); do município de Iperó (C); da calha do Rio Paraná (D) e das planícies, igarapés e igapós do Pantanal (E). 
Figura 1.10 Exemplos dos perfis verticais de (a) velocidade e (b) direção do vento associados à ocorrência de um JBN em Iperó-SP, na noite do dia 12 para 13 de março de 1993, durante o período da Quarta Campanha Micrometeorológica.

Figura 1.11 Representação de dois mecanismos de aceleração do escoamento devidos: (a) à oscilação inercial da estrutura vertical do vento médio na CLP para Hemisfério Sul e (b) à intensificação do gradiente da função de corrente de um escoamento potencial (nãodivergente) sobre um obstáculo pelo efeito de BERNOUILLE.

Figura 1.12 Efeito mecânico de bloqueio e canalização associado aos alísios que penetram pelo litoral brasileiro pela região amazônica, alcançando a barreira topográfica da Cordilheira dos Andes.

Figura 1.13 Efeito do bloqueio das Montanhas Rochosas sobre a conservação da Vorticidade Potencial (VP) de uma parcela de ar que se desloca desde a região do Golfo do México, passando pelo Texas, até o Oklahoma e Kansas (MOORE, 2002).

Figura 1.14 Representação do efeito do aquecimento diferencial da CLP sobre terreno inclinado da Grande Planície a leste das Montanhas Rochosas (EUA), em mesoescala, mostrando as isolinhas de velocidade do vento associadas aos JBN noturno (HOECKER, 1963; McNIDER e PIELKE, 1981). Inicialmente, ao final da tarde, o vento sopra de Leste, da planície para a montanha. A seguir, gira em sentido horário sob a ação da força de CORIOLIS, i.e., para a direita no Hemisfério Norte, resultando em um JBN de componente Sul.

Figura 1.15 Acoplamento de um JAN (flecha branca) e de JBN (flechas verde ou azul) nas regiões de entrada e saída do JAN, respectivamente, efetivada por circulações secundárias ageostróficas, entre a alta e a baixa troposfera (linhas tracejadas) em planos perpendiculares ao eixo do JAN. O lado equatorial (polar) da entrada (saída) do JAN apresenta divergência, o que induz movimentos verticais ascendentes compensatórios na troposfera média. $\mathrm{O}$ gráfico original de UCCELLINI e JOHNSON (1979) foi adaptado para o Hemisfério Sul.

Figura 1.16 Modelo conceitual das células de circulação no Estado de São Paulo.

\section{Capítulo 2}

Figura 2.1 Representação do domínio atmosférico e do solo, mostrando camadas com solução distinta utilizadas nas simulações do modelo TVM.

Figura 2.2 Topografia da superfície (modelo GTOPO30) sobre as regiões Sul e Sudeste do Brasil, com área $1500 \mathrm{~km} \times 1500 \mathrm{~km}$, centrada em Iperó.

Figura 2.3 Topografia da superfície (modelo GTOPO30) sobre as regiões Sul e Sudeste do Brasil, com área $800 \mathrm{~km} \times 800 \mathrm{~km}$, centrada em Iperó.

Figura 2.4 Topografia da superfície (modelo GTOPO30) sobre regiões dos Estados de São Paulo, Paraná e Minas Gerais, com área 400 km × 400 km, centrada em Iperó.

Figura 2.5 Topografia da superfície (modelo GTOPO30) sobre a região do Estado de São Paulo, com área $100 \mathrm{~km} \times 100 \mathrm{~km}$, centrada em Iperó.

Figura 2.6 Distribuição do tipo de superfície (modelo IGPB) sobre as regiões Sul e Sudeste do Brasil, com área $1500 \mathrm{~km} \times 1500 \mathrm{~km}$, centrada em Iperó.

Figura 2.7 Distribuição do tipo de superfície (modelo IGPB) sobre as regiões Sul e Sudeste 
Figura 2.8 Distribuição do tipo de superfície (modelo IGPB) sobre as regiões dos Estados de São Paulo, Paraná e Minas Gerais, com área 400 km × 400 km, centrada em Iperó.

Figura 2.9 Distribuição do tipo de superfície (modelo IGPB) sobre região do Estado de São 58 Paulo, com área $100 \mathrm{~km} \times 100 \mathrm{~km}$, centrada em Iperó.

Figura 2.10 Representação da estrutura vertical da turbulência induzida pelo cisalhamento vertical num JBN.

\section{Capítulo 3}

Figura 3.1 Oscilação inercial do vetor ageostrófico do vento (i.e, do vetor diferença entre o vetor velocidade do vento real e o vetor velocidade do vento geostrófico) durante um período de 7,5 h, correspondente a 1/4do período da oscilação inercial em Iperó (30 horas). O vetor ageostrófico é o vetor que oscila inercialmente no período inercial. Os valores iniciais são: vento geostrófico com intensidade de $3 \mathrm{~m} \mathrm{~s}^{-1}$ de direção ENE; velocidade do vento observado de $4 \mathrm{~m} \mathrm{~s}^{-1}$ e direção $\mathrm{W}$ (correspondente ao final do período vespertino em Iperó no dia 71). O giro anti-horário se dá centrado no ponto indicado por $\oplus$.

Figura 3.2 Evolução temporal dos perfis meteorológicos associados ao desenvolvimento de um JBN em Iperó registrado em sondagens de balão cativo entre dias do ano (decimais) 71,12 e 72,28. Os gráficos mostram: (a) os pontos de sondagem com dados disponíveis e a mascara para a região onde não há dados; (b) temperatura absoluta do $\operatorname{ar}\left({ }^{\circ} \mathrm{C}\right)$; (c) temperatura potencial $(\mathrm{K})$; (d) umidade relativa $(\%)$; (e) umidade específica $\left(\mathrm{g} \mathrm{kg}^{-1}\right)$; (f) componente zonal do vento $\left(\mathrm{ms}^{-1}\right)$; (e) componente meridional do vento $\left(\mathrm{ms}^{-1}\right)$; $(\mathrm{g})$ velocidade do vento $\left(\mathrm{ms}^{-1}\right)$ e (h) direção do vento (graus)

Figura 3.3 Comparação dos perfis interpolados de velocidade e direção do vento (linhas contínuas) com os perfis observados por balão-cativo (pontos) para diferentes horários da noite do dia 12 para 13 de março de 1993. As linhas contínuas mostradas às $18 \mathrm{~h}$ (alto desta figura) são provenientes da aplicação desta mesma metodologia de interpolação, mas utilizando-se dados dos horários anteriores.

Figura 3.4 Estrutura vertical média horária durante a Primeira Campanha em Iperó para: (a) componente zonal; (b) componente meridional; (c) velocidade do vento e (d) direção do vento (representada por uma imagem composta de píxeis).

Figura 3.5 Estrutura vertical média horária durante a Segunda Campanha em Iperó para: (a) componente zonal; (b) componente meridional; (c) velocidade do vento e (d) direção do vento.

Figura 3.6 Estrutura vertical média horária durante a Terceira Campanha em Iperó para: (a) componente zonal; (b) componente meridional; (c) velocidade do vento e (d) direção do vento.

Figura 3.7 Estrutura vertical média horária durante a Quarta Campanha em Iperó para: (a) componente zonal; (b) componente meridional; (c) velocidade do vento e (d) direção do vento.

Figura 3.8 Curvas hodógrafas do vetor velocidade do vento resultante calculadas para três níveis da torre em Iperó: (a) $10 \mathrm{~m}$, (b) $60 \mathrm{~m} \mathrm{e} \mathrm{(c)} 80 \mathrm{~m}$. As barras de erro foram obtidas considerando-se que o erro da média obedece a uma distribuição de t-Student. O período de dados compreende 24 meses entre junho de 1992 e junho de 1994.

Figura 3.9 Média mensal das curvas hodógrafas do vetor resultante do vento observado em Iperó para níveis de 10 m, 60 m e 80 m, durante: (a) Inverno (Julhos de 1992-93) e (b) 
Verão (Março de 1992-93).

Figura 3.10 Componentes zonal e meridional do vetor velocidade do vento resultante calculadas para três níveis da torre em Iperó: (a) $10 \mathrm{~m}$, (b) $60 \mathrm{~m}$ e (c) $80 \mathrm{~m}$. As barras de erro foram obtidas considerando que o erro da média obedece a uma distribuição de tStudent. O período de dados considerado compreende um período de dois anos entre 1992 e 1994, com amostragem de $15 \mathrm{~min}$.

Figura 3.11 Velocidade do vetor vento resultante (quadrados) e velocidade média do vento (círculos) calculadas para três níveis da torre em Iperó: (a) $10 \mathrm{~m}$, (b) $60 \mathrm{~m}$ e (c) $80 \mathrm{~m}$. As barras de erro foram obtidas considerando que o erro da média obedece a uma distribuição de t-Student. O período de dados considerado compreende um período de dois anos entre 1992 e 1994.

Figura 3.12 Direção da resultante do vetor velocidade do vento calculada para três níveis da torre em Iperó: (a) $10 \mathrm{~m}$, (b) $60 \mathrm{~m}$ e (c) $80 \mathrm{~m}$. As barras de erro foram obtidas considerando que o erro da média obedece a uma distribuição de t-Student. O período de dados considerado compreende um período de dois anos entre 1992 e 1994, com amostragem de 15 min.

Figura 3.13 Distribuição horária dos Quantis 12.5\%; 25\% 37.5\%; 50\% (mediana) 62.5\%; $75 \%$ e $87.5 \%$ obtidos para três níveis na torre de Iperó: (a) $10 \mathrm{~m}$; (b) $60 \mathrm{~m} \mathrm{e} \mathrm{(c)} 80 \mathrm{~m}$.

Figura 3.14 Fator de rajada calculado da razão entre quantis 50,0\%; 62,5\%; 75,0\% e 87,5 \% obtidos para três níveis na torre de Iperó: (a) $10 \mathrm{~m}$; (b) $60 \mathrm{~m}$ e (c) $80 \mathrm{~m}$ da analise de dois anos (1992-1993) com amostragem de 15 min.

Figura 3.15 Persistência horária observada em Iperó para três níveis da torre (a) 10 m, (b) $60 \mathrm{~m}$ e (c) $80 \mathrm{~m}$. As barras correspondem ao erro da média horária.

Figura 3.16 Distribuição horária da Energia Cinética por unidade de Volume de Ar $\left(\mathrm{J} \mathrm{m}^{-3}\right)$ para os três níveis da torre em Iperó: (a) $10 \mathrm{~m}$, (b) $60 \mathrm{~m}$ e (c) $80 \mathrm{~m}$.

Figura 3.17 Distribuição horária da Potência Utilizável por unidade de Área da Turbina (W $\mathrm{m}^{-2}$ ) para os três níveis da torre em Iperó: (a) $10 \mathrm{~m}$, (b) $60 \mathrm{~m} \mathrm{e} \mathrm{(c)} 80 \mathrm{~m}$.

Figura 3.18 Evolução média horária da altura $\left(\mathrm{z}_{\mathrm{NCL}}\right)$ do nível de condensação por levantamento (NCL) em Iperó, utilizada como estimativa da evolução da altura (h) da CLP. Em miniatura, apresenta-se a dispersão dos pontos utilizados nos cálculos (entre 1100 e 2100 pontos por horário). As barras verticais correspondem ao desvio-padrão e ao erro da média.

Figura 3.19 Evolução da média horária da temperatura potencial do ar $(\theta)$ para o nível de $10 \mathrm{~m}$ da torre em Iperó. As barras verticais correspondem ao desvio-padrão e ao erro da média.

Figura 3.20 Evolução da média horária: (a) da temperatura do ar para o nível de $10 \mathrm{~m}$ da torre em Iperó; (b) da diferença de temperatura entre o nível localizado a $10 \mathrm{~m}$ e os níveis de 60 e $80 \mathrm{~m}$ da torre; (c) da diferença de temperatura do ar entre os níveis de $10 \mathrm{~m}$ na torre e o nível de condensação por levantamento e (d) da diferença de temperatura entre a temperatura do bulbo seco e do ponto de orvalho, no nível de $10 \mathrm{~m}$ da torre em Iperó. As barras verticais correspondem ao desvio-padrão e ao erro da média.

Figura 3.21 Quatro cenários de grande-escala hipotéticos: (a) pré-frontal; (b) frontal; (c) Alta do Atlântico (bloqueios) e (d) baixas pressões. A linha diagonal representa a linha-decosta separando continente à esquerda e oceano Atlântico à direita. As setas maiores indicam JBN induzindos pelo terreno inclinado (a) e (c) ou JBN frontais (b) e as flechas de linhas finas indicam a direção do vento àsuperfície. 
Figura 3.22 Representação de um desenvolvimento de uma frente fria intensa implicando na formação de um jato frontal de direção Sul: (a) fase inicial do desenvolvimento mostrando o cavado em altitude favorável ao desenvolvimento do sistema e (b) sistema frontal plenamente desenvolvido (oclusão) associado à formação de uma circulação fechada na alta troposfera. As setas em negrito indicam o JBN.

Figura 3.23 (a) Evolução temporal do perfil vertical da temperatura do ar $\left({ }^{\circ} \mathrm{C}\right)$ para a primeira campanha do experimento micrometeorológico em Iperó - SP - entre 11/03/1993 e 22/03/1993. Detalhes entre $1000 \mathrm{hPa}$ e $100 \mathrm{hPa}$. Fonte de dados: reanálise do NCEP; (b) Detalhe do mesmo gráfico entre $1000 \mathrm{hPa}$ e $700 \mathrm{hPa}$.

Figura 3.24 (a) Evolução temporal do perfil vertical da componente zonal do vento ( $\mathrm{m} \mathrm{s}^{-1}$ ) para a primeira campanha do experimento micrometeorológico em Iperó - SP - entre 11/03/1993 e 22/03/1993. Detalhes entre $1000 \mathrm{hPa}$ e $100 \mathrm{hPa}$. Fonte de dados: reanálise do NCEP ; (b) Detalhe do mesmo gráfico entre $1000 \mathrm{hPa}$ e $700 \mathrm{hPa}$.

Figura 3.25 (a) Evolução temporal do perfil vertical da componente meridional do vento (m $\mathrm{s}^{-1}$ ) para a primeira campanha do experimento micrometeorológico em Iperó - SP - entre 11/03/1993 e 22/03/1993. Detalhes entre $1000 \mathrm{hPa}$ e $100 \mathrm{hPa}$. Fonte de dados: reanálise do NCEP; (b) Detalhe do mesmo gráfico entre $1000 \mathrm{hPa}$ e $700 \mathrm{hPa}$.

Figura 3.26 Evolução temporal do perfil vertical de umidade relativa do ar (\%) para a primeira campanha do experimento micrometeorológico em Iperó - SP - entre 11/03/1993 e 22/03/1993, entre $1000 \mathrm{hPa}$ e $700 \mathrm{hPa}$.

\section{Capítulo 4}

Figura 4.1 Campo de vento horizontal a $15 \mathrm{~m}$ acima da superfície: (a) à $18 \mathrm{~h}$ (12 h de simulação) e (b) à $06 \mathrm{~h}$ ( $24 \mathrm{~h}$ de simulação). A topografia é indicada pelos contornos e escala de cinzas. Iperó corresponde ao ponto central do domínio de $100 \mathrm{~km}$ por $100 \mathrm{~km}$ (da simulação L100).

Figura 4.2 Campo de vento horizontal a $15 \mathrm{~m}$ acima da superfície: (a) æ̀ $18 \mathrm{HL}$ (12 h de simulação) e (b) æ̀ $06 \mathrm{HL}$ ( $24 \mathrm{~h}$ de simulação). A topografia é indicada pelos contornos e escala de cinzas. Iperó corresponde ao ponto central do domínio de $400 \mathrm{~km}$ por $400 \mathrm{~km}$ (da simulação L400).

Figura 4.3 Campo de vento horizontal a $15 \mathrm{~m}$ acima da superfície: (a) à $18 \mathrm{HL}$ (12 h de simulação) e (b) à $06 \mathrm{HL}$ ( $24 \mathrm{~h}$ de simulação). A topografia é indicada pelos contornos e escala de cinzas. Iperó corresponde ao ponto central do domínio de $800 \mathrm{~km}$ por $800 \mathrm{~km}$ (da simulação L800).

Figura 4.4 Campo da média diária (24 h) da temperatura: (a) da superfície e (b) do ar para a altura de $14 \mathrm{~m}$ acima da superfície. Iperó corresponde ao ponto central do domínio de 800 $\mathrm{km}$ por $800 \mathrm{~km}$ (simulação L800). Note-se: (1) o arco térmico formado pelas montanhas à volta da Depressão Periférica em SP e (2) as altas temperaturas do ar ao longo do Vale do Rio Ribeira de Iguape.

Figura 4.5 Campo de vento horizontal a $14 \mathrm{~m}$ acima da superfície: (a) à $18 \mathrm{~h}$ (12 h de simulação) e (b) à $06 \mathrm{~h}$ ( $24 \mathrm{~h}$ de simulação). A topografia é indicada pelos contornos e escala de cinzas. Iperó corresponde ao ponto central do domínio de $1500 \mathrm{~km}$ por $1500 \mathrm{~km}$ (da simulação L1500).

Figura 4.6 Corte vertical (x; z) passando por Iperó $(x=750 \mathrm{~km}$, linha $A B$ da Figura 4.18) mostrando a temperatura potencial (escala de cores) e a componente zonal (isolinhas de contorno) para (a) 18 h e (b) 6 h do tempo local. Resultados da simulação L1500. 
Figura 4.7 Corte vertical (x; z) passando por Iperó (x = 750 km, linha AB da Figura 4.18) mostrando a energia cinética turbulenta (escala de cores) e a componente meridional (isolinhas de contorno) para (a) $18 \mathrm{~h}$ e (b) $6 \mathrm{~h}$ do tempo local. Resultados da simulação L1500.

Figura 4.8 Estrutura vertical do momento associada ao JBN simulada e observada æ̀ $3 \mathrm{~h}$ em Iperó no dia 13 de Março de 1993. Apresenta-se em (a) a componente zonal e em (b) a componente meridional. Na legenda as linhas indicadas por 100, 400, 800, 1500, Obs e Interp correspondem, respectivamente, æ̀ simulações L100, L400, L800, L1500, observações de balão-cativo e ao conjunto de dados interpolados (conforme descrição do item 2.4, i.e., utilizando-se o modelo 1-D e assimilação 4-D das sondagens observacionais realizadas Iperó).

Figura 4.9 Hodógrafa do vetor velocidade do vento: (a) simulada para os níveis verticais $\mathrm{Z}^{*}$ = 30, 67, 114, 172, 246, 337 e 452 m (simulação L1500); (b) observada durante o inverno (c) idem para verão nos níveis de $10 \mathrm{~m}, 60 \mathrm{~m}$ e $80 \mathrm{~m}$ na torre em Iperó (quadrados, círculos e triângulos, respectivamente). Os números indicam a hora local.

Figura 4.10 Linhas de pontos orientadas NW-SE entre Iperó e litoral (pontos $\times$ ) e entre São Paulo e litoral (pontos +) mostradas sobre as linhas de contorno da topografia. A área do CEA encontra-se junto ao ponto 3 do alinhamento a esquerda e a área da Região Metropolitana de São Paulo compreende o seguimento definido pelos pontos 3 e 8 do alinhamento àdireita.

Figura 4.11 Evolução temporal diurna da velocidade e direção do vento àsuperfície ( $\sigma$ = 15 m) simulado ao longo da linha de pontos na direção NW-SE (entre Iperó e litoral de SP) apresentada na Figura 4.10. Os gráficos assinalados por (a), (b), (c) e (d) são evoluções temporais da velocidade do vento $\left(\mathrm{m} \mathrm{s}^{-1}\right)$; e gráficos (e), (f), (g) e (h) são evoluções da direção do vento. Resultados da simulação L800.

Figura 4.12 Evolução temporal diurna da velocidade e direção do vento àsuperfície $(\sigma=15$ m) simulado ao longo da linha de pontos na direção NW-SE (entre Jundiaí e litoral de SP) apresentada na Figura 4.10. Os gráficos assinalados por (a), (b), (c) e (d) são evoluções temporais da velocidade do vento $\left(\mathrm{m} \mathrm{s}^{-1}\right)$; e gráficos (e), (f), (g) e (h) são evoluções da direção do vento. Resultados da simulação L800.

Figura 4.13 Média dos ensaios numéricos do planejamento experimental $2^{2}$ ì $6 \mathrm{~h}(24 \mathrm{~h}$ de simulação) para níveis (a) $15 \mathrm{~m} \mathrm{e}$ (b) $337 \mathrm{~m}$ da coordenada $\sigma$ (aqui chamada $\mathrm{z}^{*}$ ) seguindo a topografia. A topografia é representada pela escala em tons de cinza e as isotacas, pela escala em roxo.

Figura 4.14 Efeito do Fator 1 (i.e., topografia) sobre o resultado do experimento com $2^{2}$ ensaios numéricos æ̀ $6 \mathrm{~h}$ (24 h de simulação) para níveis (a) $15 \mathrm{~m}$ e (b) $337 \mathrm{~m}$ da coordenada $\sigma\left(\mathrm{z}^{*}\right)$ seguindo a topografia. A topografia é representada pela escala em tons de cinza e as isotacas, pela escala em roxo.

Figura 4.15 Efeito do Fator 2 (i.e., tipos de superfície) sobre o resultado do experimento com $2^{2}$ ensaios numéricos à $6 \mathrm{~h}$ (24 h de simulação) para níveis (a) $15 \mathrm{~m} \mathrm{e} \mathrm{(b)} 337 \mathrm{~m} \mathrm{da}$ coordenada $\sigma\left(\mathrm{z}^{*}\right)$ seguindo a topografia. A topografia é representada pela escala em tons de cinza e as isotacas, pela escala em roxo.

Figura 4.16 Efeito de interação entre fatores 1 e 2 (i.e., Topografia e Tipos de Superfície) sobre o resultado do experimento com $2^{2}$ ensaios numéricos æ̀ $6 \mathrm{~h}$ ( $24 \mathrm{~h}$ de simulação) para níveis (a) $15 \mathrm{~m}$ e (b) $337 \mathrm{~m}$ da coordenada $\sigma$ ( $\left.\mathrm{z}^{*}\right)$ seguindo a topografia. A topografia é representada pela escala em tons de cinza e as isotacas, pela escala em roxo.

Figura 4.17 Campo de vento horizontal para $14 \mathrm{~m}$ acima da superfície æ̀ $18 \mathrm{~h}$ (tempo médio local). A topografia está indicada pela escala e contornos. O circulo no centro indica a posição geográfica de Iperó. As letras A e B definem a posição da secção transversal 
vertical apresentada na Figura 4.6. Vetor velocidade máximo apresenta módulo igual a 7,46 $\mathrm{m} \mathrm{s}^{-1}$.

Figura 4.18 Campo de vento horizontal para $\sigma=15 \mathrm{~m}$ acima da superfície æ̀̀ $3 \mathrm{~h}$ (tempo local). A velocidade do vento para a superfície $\sigma=337 \mathrm{~m}$ seguindo da superfície ( $\mathrm{z} \approx 321$ $\mathrm{m})$ é indicada pela escala em roxo. A topografia é indicada pela escala em tons de laranja. O círculo aberto indica a posição de Iperó. As letras A e B definem a posição da secção transversal mostrada na Figura 4.6. Vetor velocidade máximo apresenta módulo igual a $8,81 \mathrm{~m} \mathrm{~s}^{-1}$.

Figura 4.19 Perspectiva da topografia regional no domínio $1500 \mathrm{~km} \times 1500 \mathrm{~km}$ sobreposta pela velocidade do vento (em tons de azul) para o nível de $337 \mathrm{~m}$ acima da superfície æ̀ $3 \mathrm{~h}$ da hora local em Iperó. A região de Iperó localiza-se junto ao centro da figura nas coordenadas $(750.000 \mathrm{~m} ; 750.000 \mathrm{~m})$.

Figura 4.20 Modelo Conceitual de formação da Camada Limite caracterizada por cisalhamento do vento horizontal sobre a porção leste do Planalto Paulista, i.e., sobre Platô Paulista e Depressão Periférica. A célula de circulação convectiva formada na escarpa da Serra do Mar em associação com a brisa do litoral projeta-se ligeiramente sobre a célula desenvolvida sobre a encosta inclinada do Planalto Paulista (porção leste da bacia do Rio Paraná). A região entre as duas células é caracterizada por cisalhamento do vento horizontal, e esse cisalhamento pode implicar em aumento da dispersão de poluentes na região do Platô Paulista e circunvizinhança (através do termo de produção mecânica de ECT). Uma parcela de ar, originalmente no ramo inferior da célula de circulação da brisa marítima, segue para o interior de SP pelo ramo superior da célula de circulação do interior.

\section{Capítulo 5}

Figura 5.1 (a) Mapa Geográfico do Estado de São Paulo. A área de estudo está indicada pelo quadrado no centro, representando $100 \mathrm{~km}$ por $100 \mathrm{~km}$. (b) A topografia da área de estudo. A fonte emissora de radionuclídeos está localizada no centro das Figuras, e corresponde àposição geográfica do Centro Experimental Aramar (CEA) (PEREIRA et alli, 2001).

Figura 5.2 Média de $24 \mathrm{~h}$ do logaritmo da concentração de radionuclídeos $\left[\log \left(\mu \mathrm{g} \mathrm{m} \mathrm{m}^{-3}\right)\right]$ na atmosfera, para a camada de espessura $30 \mathrm{~m}$ sobre a superfície topográfica na área de estudo sob condições: (a) instáveis e (b) estáveis na CLP. A fonte pontual contínua está localizada no centro do domínio. As isolinhas do logaritmo da concentração são mostradas em sobreposição æ̀ curvas de nível da topografia.

Figura 5.3 Gráfico da hodógrafa simulada para período de 24 h no nível intermediário da camada 0-30 $\mathrm{m}$ acima da superfície do terreno complexo.

Figura 5.4 Vista lateral de todas as partículas no volume de $250 \mathrm{~km}$ por 250 por $3 \mathrm{~km}$ æ̀ $6 \mathrm{~h}$ da manhã (i.e., após $24 \mathrm{~h}$ de simulação). O círculo indica a posição da fonte e a seta, a altura aproximada do máximo do jato.

Figura 5.5 Vista de topo da nuvem de poluentes de poluente em dispersão na atmosfera emitida a partir de fonte localizada junto àsuperfície $(\mathrm{z}=10 \mathrm{~m})$ no $\mathrm{CEA}$ em Iperó (localizado no centro da área mostrada) para os horários: (a) 12 h, (b) 18 h, (c) 24 h e (d) 06 h. A Figura foi construída a partir da simulação L1500 e os resultados apresentados no domínio topográfico de $400 \mathrm{~km} \times 400 \mathrm{~km}$.

Figura 5.6 Representação da interação entre plumas emitidas de diferentes pontos à superfície no Estado de São Paulo, em vista de topo. As cores das partículas em dispersão estão associadas à diferentes fontes emissoras: em vermelho para fonte em Cubatão (RPB); em preto para São Paulo Capital (SP); em roxo para Iperó (CEA); em verde para Registro 
(REG); em ocre para Bauru (BAU); em cinza esverdeado para Sertãozinho (SER); em marrom para São José do Rio Preto (SJR); em azul escuro para Araçatuba (ARA) e em azul cobalto para Presidente Prudente (PPR). A topografia está representada ao fundo pela escala de cores entre azul claro e laranja; a linha de contorno mais elevada na figura corresponde à cota de $600 \mathrm{~m}$ e as áreas em laranja escuro correspondem a áreas ainda mais elevadas (Serra do Mar; Serra Geral à SW no PR e Mantiqueira à NE em MG).

\section{Capítulo 6}

Figura 6.1 Comparação entre as evoluções diurnas da velocidade e direção do vento à superfície $(\mathrm{z}=14 \mathrm{~m})$ em Iperó simulada para diferentes extensões do domínio horizontal do modelo (1500 km, 800 km, 400 km e 100 km).

Figura 6.2 Proposta de localização das radiossondagens para experimento de observação de JBN no Estado de São Paulo ao longo da linha de corte SE-NW, indicada na Figura 1.5 do Capítulo 1. As letras indicam a localização aproximada de (A) Aeroporto de Santos; (B) Bairro Cota 500 m na escarpa da Serra do Mar; C: Aeroporto de São Paulo; D: Aeroporto de Sorocaba; (E) Aeroporto de Bauru; (F) Margem do Rio Paraná; (G) ponto na Serra de Maracaju; (I) margem do Rio Negro; (J) Pantanal e (K) ponto a oeste do Pantanal.

\section{Apêndice B}

Figura B.1 Perfis verticais da velocidade e direção do vento para os dias da Primeira Campanha de Iperó, correspondentes à noites dos dias (a) 15-16, (b) 16-17, (c) 17-18, (d) 18-19, (e) 19-20 e (f) 20-21 de Março de 1991.

Figura B.2 Perfis verticais da velocidade e direção do vento para os dias da Segunda Campanha de Iperó, correspondentes à noites dos dias (a) 16-17, (b)17-18, (c)18-19 e (d) 19-20 de Março de 1992.

Figura B.3 Perfis verticais da velocidade e direção do vento para os dias da Terceira Campanha de Iperó, correspondentes à noites dos dias (a) 29-30, (b) 30-31, (c) 31 de Julho - 01 de Agosto, (d) 01-02, (e) 02-03, (f) 03-04, (g) 04-05, (h) 06-07 e (i) 07-08 de Agosto de 1992.

Figura B.4 Perfis verticais da velocidade e direção do vento para os dias da Quarta Campanha de Iperó, correspondentes æ̀ noites dos dias (a) 09-10, (b) 10-11, (c) 11-12, (d) 12-13, (e) 13-14, (f) 14-15, (g) 15-16, (h) 16-17 e (i) 17-18 de Março de 1993.

\section{Apêndice C}

Figura C.1 Um mesmo comprimento $|\mathrm{L}|$ mostrado sobre três superfícies diferentes utilizadas em modelos da atmosfera. Estas superfícies são: (a) a superfície de um plano de projeção; (b) a superfície de uma esfera com raio igual ao raio médio da Terra e (c) a superfície de um geóide. A projeção das extremidades dos vetores curvilíneos sobre o plano e esfera correspondem a dois pontos diferentes sobre o geóide, embora os três vetores apresentem mesmo comprimento (NÚÑ̃Z, 2000). 


\section{LISTA DE TABELAS}

\section{Tabela}

Página

\section{Capítulo 1}

Tabela 1.1 Parâmetros significativos dos JNB observados durante projeto RADASP/1993. A altitude de Bauru é aproximadamente $650 \mathrm{~m}$. Dados compilados de CÁRDENAS (1990).

Tabela 1.2 Componentes do vento geostrófico e de vento médio, para o nível de pressão de $850 \mathrm{hPa}$, observados ao final da tarde e à meia-noite associados ao desenvolvimento do JBN de três dias de janeiro de 1983, durante o Projeto RADASP em Bauru (Fonte de dados: Figura 4.3 e Tabela 3 de CÁRDENAS,1990).

Tabela 1.3 Critérios de classificação para jatos de baixos níveis.

\section{Capítulo 2}

Tabela 2.1 Parâmetros físicos da superfície e do solo que foram associados à classificação IGBP.

Tabela 2.2 Classificação global dos tipos de superfície segundo o programa International Geosphere Biosphere Programme (IGBP).

\section{Capítulo 3}

Tabela 3.1 Período e número de sondagens efetuadas durante as 4 campanhas de medidas em realizadas em Iperó, $\mathrm{SP}$.

Tabela 3.2 Precipitação acumulada observada durante as quatro campanhas em Iperó (OLIVEIRA,1993).

Tabela 3.3 Ocorrência de JBN durante as Campanhas Observacionais em Iperó. A letra "V" indica ocorrência de JBN na noite, a letra "F" indica não ocorrência e "-" indica ausência de dados.

Tabela 3.4 Distribuição de freqüências relativas, para três horários de julho e janeiro, segundo a direção do vento para a estação da Fazenda Ipanema em Iperó, SP (KARAM e OLIVEIRA, 1998).

\section{Capítulo 4}

Tabela 4.1 Domínio e resolução utilizada nas simulações do JBN de Iperó. O ponto central da grande numérica corresponde àposição geográfica de Iperó. Número de pontos de grade $50 \times 50 \times 25$.

\section{Capítulo 5}

Tabela 5.1 Localização geográfica dos pontos de emissão utilizados na simulação com domínio horizontal de área 1500 km x 1500 km centrado em Iperó. 


\section{LISTA DE SÍMBOLOS}

\section{Símbolo Significado}

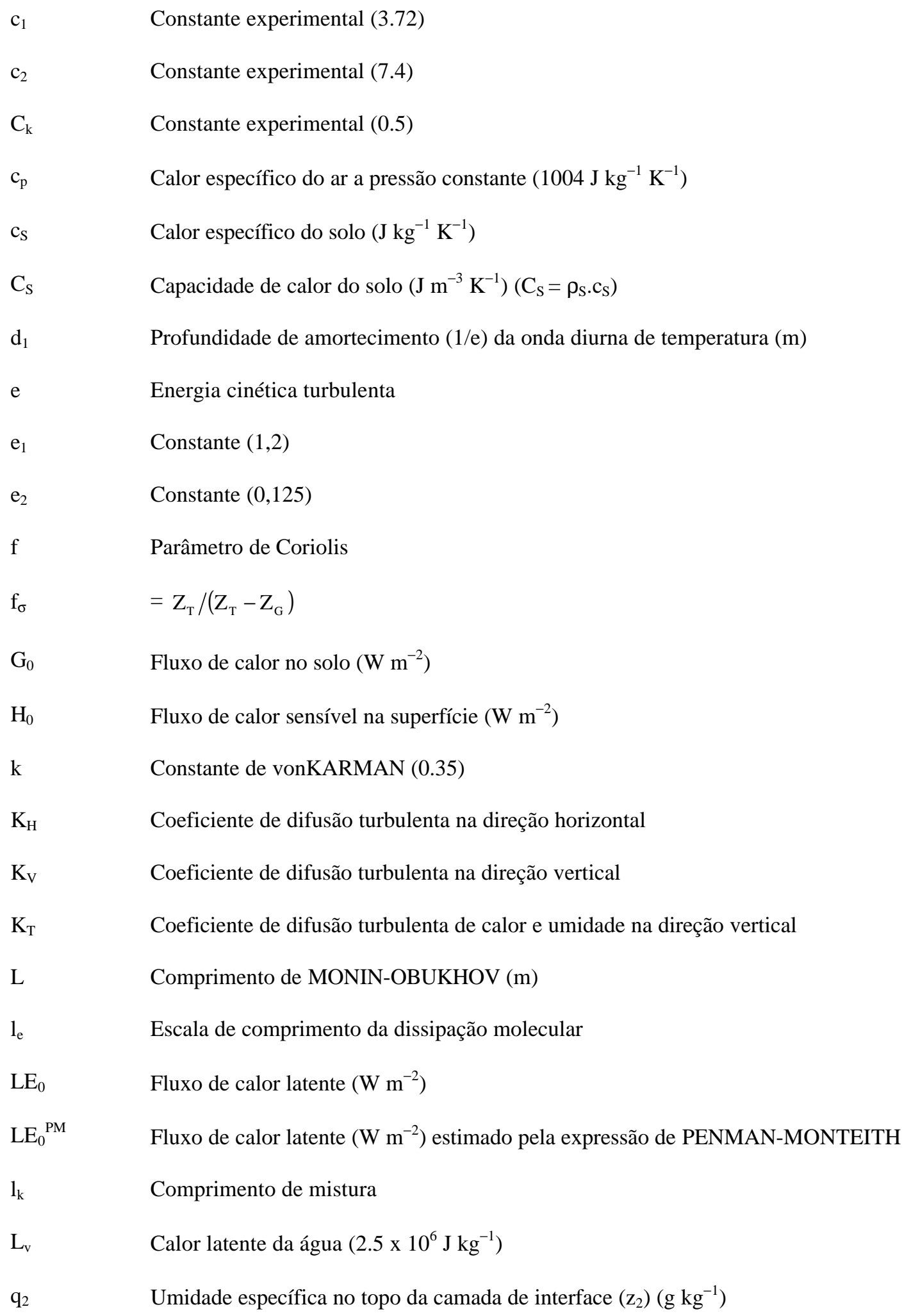




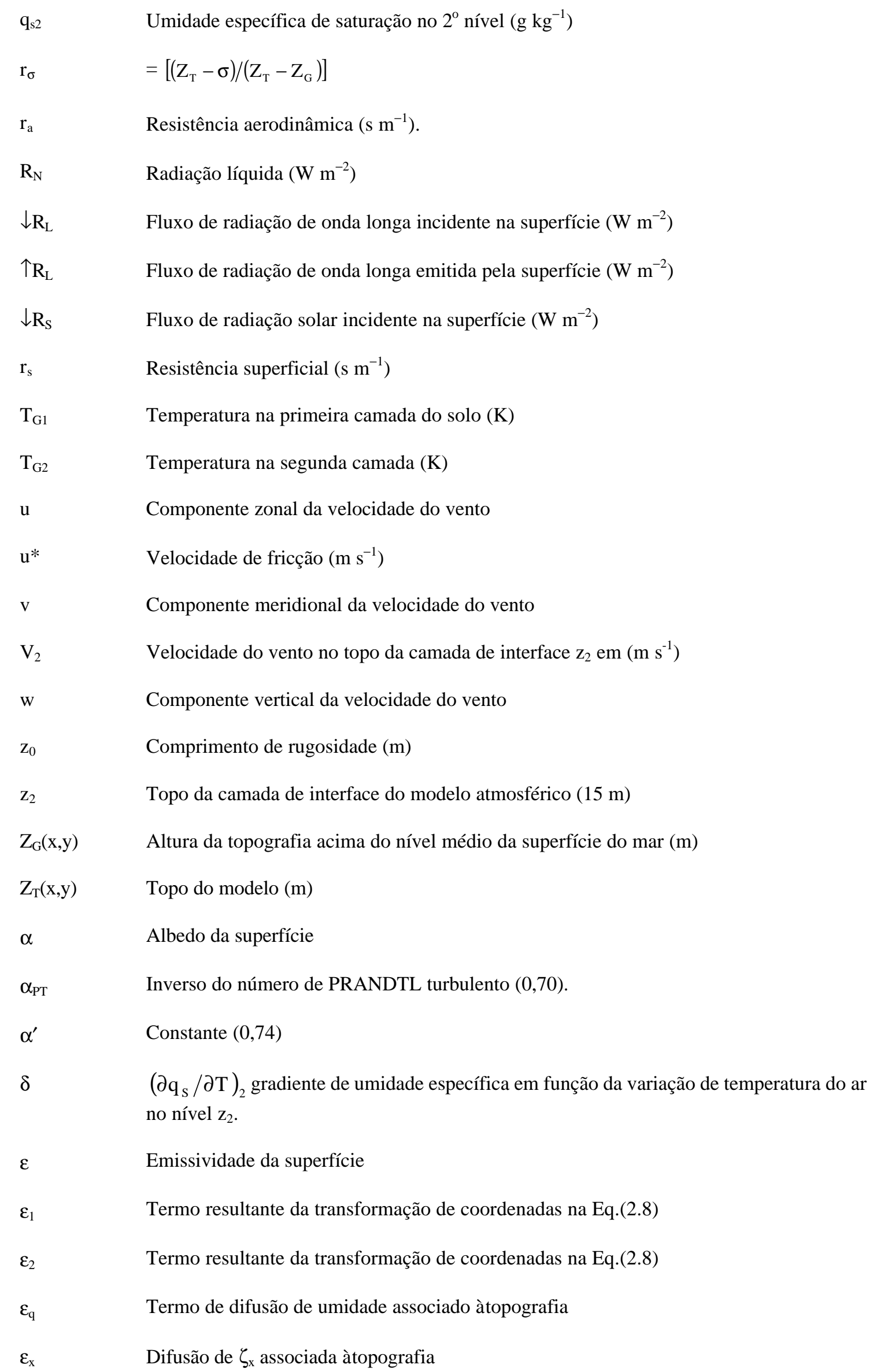




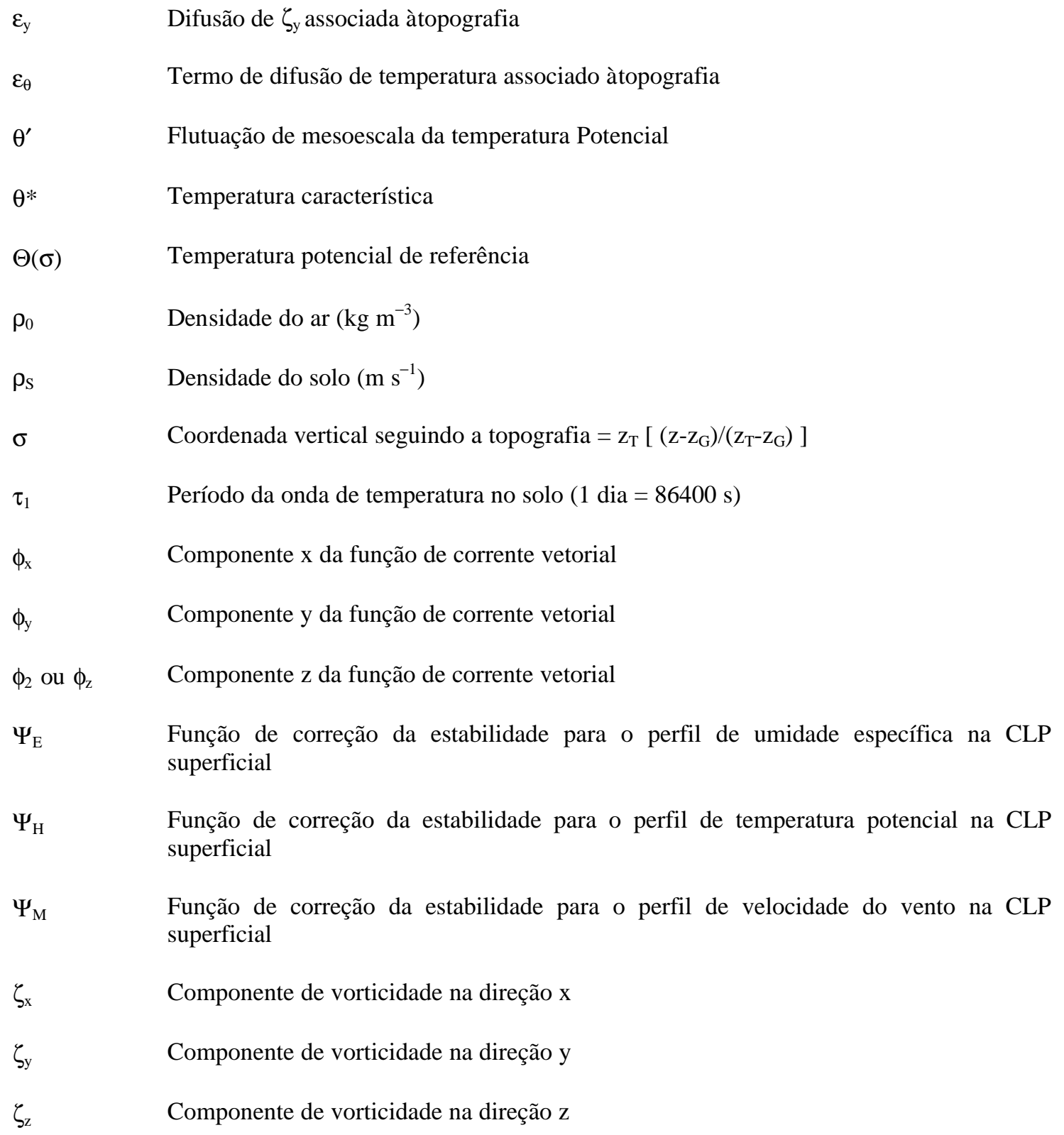




\section{CAPÍTULO 1}

\section{Introdução}

O termo jatos de baixos níveis (JBN), que em inglês é escrito low-level jet (LLJ), foi introduzido por MEANS (1952) para descrever uma zona de forte intensidade do escoamento de Sul, abaixo de $850 \mathrm{hPa}$, no centro-sul da Grande Planície dos Estados Unidos (ZHONG et alli, 1996, WHITEMAN et alli, 1997).

$\mathrm{O}$ conceito de JBN nasce em analogia ao conceito de jatos de altos níveis (JAN). Os JANs foram observados intensivamente durante a Segunda Guerra Mundial, sendo uma resposta geostrófica da atmosfera ao gradiente meridional de temperatura entre os pólos e o equador. De forma diferente, os JBNs têm sua origem determinada pela dinâmica de diversos fenômenos presentes na Camada Limite Planetária (CLP) ${ }^{1}$.

Os JBNs podem ser classificados como movimentos do ar em mesoescala $\beta$ com escala horizontal característica entre 20 e $200 \mathrm{~km}$ e totalmente contidos nos dois primeiros quilômetros da atmosfera, onde uma forte oscilação diurna do vento é seguida por aceleração noturna (WU e RAMAN, 1996).

Durante o período noturno, a evolução temporal do vento na camada do JBN difere da evolução à superfície, onde o resfriamento radiativo implica no aparecimento de uma inversão térmica de superfície. Neste caso, desenvolve-se uma CLP estratificada estável, caracterizada por um desacoplamento em relação às camadas acima, resultando em ventos fracos bem junto à superfície durante a noite e na presença de JBN acima da CLP estável (Figura 1.1). A ocorrência do JBN pode também implicar no aparecimento de rajadas de vento na superfície (CÁRDENAS, 1990).

Os JBNs são fenômenos tipicamente noturnos observados em associação ao desenvolvimento diurno da CLP. Durante o período diurno, a turbulência na CLP convectiva é mantida pela produção térmica e pela produção mecânica de Energia Cinética Turbulenta (ECT). Durante o período noturno, a turbulência é mantida pela

\footnotetext{
${ }^{1}$ A CLP é a camada de escoamento turbulento da atmosfera em contato direto com superfície.
} 
produção mecânica de ECT e dissipada pela destruição térmica de ECT associada à estratificação estável induzida pelo resfriamento radiativo da superfície. Durante o período noturno, a intensidade da turbulência na CLP estável é menor se comparada àquela encontrada durante o período diurno. Neste caso, a CLP não se apresenta subdividida em camadas como no caso convectivo (i.e., camadas de difusão molecular, superficial, de mistura e transição). Mas é muito comum se observar presença de uma camada de mistura residual (CR) acima da CLP estável, remanescente da camada de mistura (CM) do período diurno (VENKATRAM e WYNGAARD, 1988; SORBJAN, 1986, 1987; ACEVEDO, 2001).

A CLP tem sua origem ligada aos processos turbulentos associados ao balanço de energia da superfície. As variações horizontais das propriedades aerodinâmicas, térmicas e radiativas da superfície também podem afetar significativamente a estrutura dinâmica da CLP. Além disso, a presença de vales e montanhas pode induzir contrastes térmicos suficientemente intensos modificando não só a estrutura termodinâmica como também a estrutura dinâmica da CLP (GYR e RYS, 1995).

\section{Definição de JBN}

De um ponto de vista cinemático, WIPPERMANN (1973) definiu o JBN como a região do escoamento que apresenta um máximo da velocidade localizado dentro da camada com espessura de $2 \mathrm{~km}$ acima da superfície. De um ponto de vista dinâmico, os jatos podem ser considerados como uma resposta complexa do escoamento ao ciclo diurno da forçante térmica ${ }^{2}$ na $C L P$, apresentando um máximo bem definido no perfil vertical da velocidade.

Neste trabalho, o JBN é definido de forma pragmática, somo sugere STULL (1988: cap. 12) sempre que se encontra um máximo relativo na estrutura vertical da velocidade do vento com intensidade maior que $2 \mathrm{~m} \mathrm{~s}^{-1}$ dentro da camada atmosférica entre a superfície e $1500 \mathrm{~m}$ (Figura 1.1).

\footnotetext{
${ }^{2}$ Forçante térmica refere-se aqui às forças de grandiente de pressão induzidas por contrastes térmicos sobre a superfície (p.ex.: associadas à gradientes horizontais do fluxo de calor sensível) relativas à presença de fronteiras oceano-continente, terrenos inclinados e/ou montanhas, distribuição de solos mais secos e úmidos, onde ocorreu precipitação, de diferentes tipos de cobertura da superfície, como presença de áreas de floresta e de campos, além das forçantes de pressão induzidas pela passagem de sistemas frontais e sistemas precipitantes e convectivos na região etc.
} 


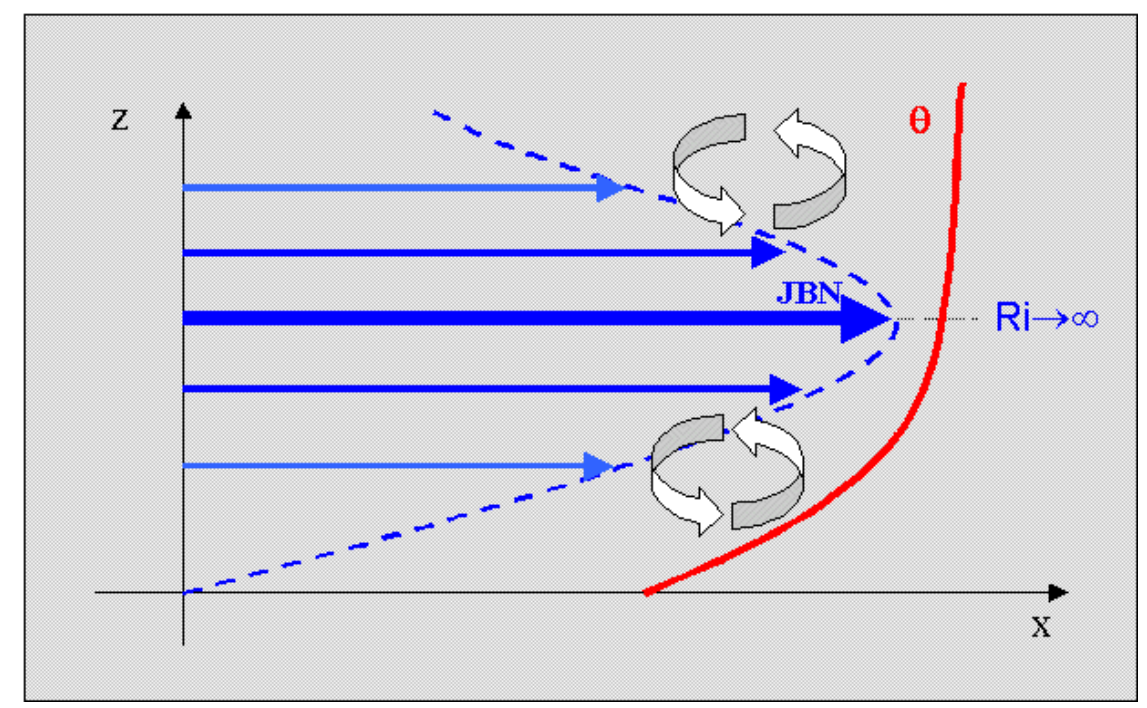

Figura 1.1 Representação idealizada da estrutura vertical de um Jato de Baixos Níveis. Este jato aparece em associação ao desenvolvimento de uma CLP estável e à presença de uma inversão térmica de superfície $(\partial \theta \partial \mathrm{z}>0)$. O cisalhamento da velocidade do vento provoca turbulência abaixo e acima do máximo do jato.

\section{Caracterização dos JBN}

- Velocidade máxima: típicamente apresentam velocidade máxima $\geq 12,5 \mathrm{~ms}^{-1} \mathrm{e}$ direção SE-SW (p.ex.: o JBN da Grande Planície);

- Ambientes convectivos: os JBN são observados em ambientes convectivos e pré-convectivos;

\section{- Altura do máximo:}

750-1000 m AGL ${ }^{3}$ (BONNER, 1968, MWR), extensão dos dados: 2 anos;

1000 m AGL (MITCHELL et alli, 1995, WAF);

300-600 m AGL (ARRIT et alli, 1997, MWR), dados: 1 ano;

100-200 m AGL (STULL, 1988, cap. 12.5) com máximos de velocidade entre

10-20 $\mathrm{m} \mathrm{s}^{-1}$ (extremos: altura de máximo de $900 \mathrm{~m}$ e velocidade de $30 \mathrm{~m} \mathrm{~s}^{-1}$ ).

- Extensão horizontal: o JBN pode apresentar largura de centenas de km e comprimento de milhares de km (BONNER, 1966, 1968; STULL, 1988) apresentando um aspecto geométrico que lembrar àquele de uma folha, i.e., a dimensão horizontal do jato supera em muito a sua dimensão vertical.

\footnotetext{
${ }^{3}$ AGL (above ground level) é a sigla para acima do nível da superfície.
} 
- Turbulência: MAHRT et alli (1979) determinaram que o número de RICHARDSON $^{4}$ é maior (menor) que 0,5 para o nível de altura do máximo do JBN (acima do máximo). Nos níveis acima do máximo do jato, o cisalhamento do vento continua intenso, mas estabilidade estática é relativamente reduzida em comparação aos níveis abaixo do máximo, podendo resultar em maior presença de turbulência.

\section{Formação dos JBN:}

- Associado a dinâmica da CLP sobre superfícies complexas - De acordo com STULL (1988): (a) durante a noite, o vento na CLP estável para o nível de $10 \mathrm{~m}$ acima da superfície reduz-se, podendo freqüentemente tornar-se calmo, já os ventos mais acima podem ser acelerados a velocidades supergeostróficas no fenômeno chamado jato de baixos níveis ou jato noturno; (b) a direção do vento freqüentemente gira com a altura abaixo do máximo do jato noturno tipicamente em sentido antihorário (horário) no Hemisfério Sul (Norte); (c) as camadas de ar estratificadas estavelmente ${ }^{5}$ na CLP estável tendem a suprimir a turbulência, enquanto o desenvolvimento do jato noturno aumenta o cisalhamento do vento, o que tende a gerar turbulência. Note-se, por exemplo, que o JBN sobre a região da Grande Planície aparece em associação à inversão térmica de superfície, com freqüência na primavera, máximo junto ao topo da inversão noturna (sob condições sinóticas quiescentes) para aingir seu máximo desenvolvimento (i.e., intensidade) entre 1 e $3 \mathrm{~h}$;

- Acoplado ao Jato de Altos Níveis (JAN) - JBNs podem ocorrem abaixo da região de saída (entrada) de um JAN apresentando escoamento de ar que se

\footnotetext{
${ }^{4} \mathrm{O}$ número de RICHARDSON fluxo $\left(\mathrm{R}_{\mathrm{f}}\right)$ é dado pela razão entre os termos de empuxo (positivo=produção, negativo=consumo) e de produção mecânica (sempre positivo) da equação prognóstica da energia cinética turbulenta, i.e., $\left.\mathrm{R}_{\mathrm{f}}=\left(\mathrm{g} / \theta_{0}\right)<\mathrm{w} \theta^{\prime}\right\rangle /\left[\left\langle\mathrm{u}_{\mathrm{i}} \mathrm{u}_{\mathrm{j}}{ }^{\prime}\right\rangle \partial \mathrm{V} / \partial \mathrm{z}\right]$. Usualmente, o número de RICHARDSON fluxo é avaliado utilizando-se a formulação do número de RICHARDSON gradiente $\left(\mathrm{R}_{\mathrm{i}}\right)$ dada por $\mathrm{R}_{\mathrm{i}}=\left(\mathrm{g} \theta_{0}\right)(\partial \theta \partial \mathrm{z}) /\left[(\partial \mathrm{v} \partial \mathrm{z})^{2}+(\partial \mathrm{v} \partial \mathrm{z})^{2}\right]$ ou quando dispomos apenas de medidas em pontos discretos $\mathrm{R}_{\mathrm{f}}$ pode se estimado pelo número de RICHARDSON bulk $\left(\mathrm{R}_{\mathrm{b}}\right)$ calculado por $\mathrm{R}_{\mathrm{b}}=\left(\mathrm{g} \theta_{0}\right) \Delta \theta \Delta \mathrm{z} /\left[(\Delta \mathrm{u})^{2}+(\Delta \mathrm{v})^{2}\right]$. Desta forma, o número de RICHARDSON mede a tendência de um escoamento turbulento tornar-se laminar quando $\mathrm{R}_{\mathrm{f}}>+1$ ou $\mathrm{R}_{\mathrm{i}}>+1$ ou de um escoamento laminar tornar-se turbulento quando onde $R_{f}<+1$ ou $R_{i}<R_{c}$, sendo $R_{c}$ estimado entre $+0,21$ e $+0,25$. Quando a espessura da camada de ar é suficientemente fina $R_{b}$ será uma boa aproximação de $R_{i}$, assim como $R_{c} \sim+0,25$. Mas quando a camada de ar é espessa, o valor de $R_{b}$ dependerá do espaçamento vertical $\Delta z$, e os gradientes serão representativos do valor médio na camada, implicando em valores de $R_{b} \gg R_{i}>R_{f}(S T U L L, 1988)$. Conseqüentemente, no caso de estimativas de $R_{f}$ por $\mathrm{Rb}$, valores bem maiores de $\mathrm{R}_{\mathrm{c}}$ são utilizados, tipicamente da ordem de $+1 \mathrm{a}+3$ para guarantir valores realísticos da difusão turbulenta de calor e momento na CLP estável em simulações numéricas de mesoescala. Nos modelos numéricos de mesoescala, os valores de $\mathrm{R}_{\mathrm{c}}$ são dados em função de $\Delta \mathrm{z}$ para pontos discretos acima da CLP.

${ }^{5}$ Diz-se que a camada de ar possui estratificação estática estável quando $\partial \theta \partial \mathrm{z}>0$, instável quando $\partial \theta \partial \mathrm{z}<0$ e neutra quando $\partial \theta \partial z=0$. A estabilidade ou instablidade se refere à capacidade da parcela de retornar a sua posição original após uma pequena perturbação (deslocamento) na vertical. A estrutra vertical típica da temperatura potencial $\theta$ na CLP estável é mostrada na Figura 1.1.
} 
inclina para cima pelo lado $\mathrm{S}(\mathrm{N})$ do $\mathrm{JAN}$ em direção à região de maior divergência do JAN como uma resposta isalobárica ${ }^{6}$ (Hemisférico Sul). Neste caso, os eixos dos JBN e JAN são praticamente perpendiculares.

\subsection{Revisão Bibliográfica}

De acordo com STULL (1985), os JBNs têm sido observados em diferentes locais da Terra:

- Europa (SLADKOVIC e KANTER, 1977; KRAUS et alli, 1985);

- África (ANDERSON, 1976; HART et alli, 1978);

- América do Norte (BLACKADAR, 1957; BONNER, 1968);

- América do Sul (LETTAU, 1967);

- Austrália (MALCHER e KRAUS, 1983; BROOK, 1985; GARRAT, 1985).

No entanto, o JBN da Grande Planície norte-americana é o mais conhecido.

MEANS (1952) foi o primeiro a estabelecer uma relação entre a distribuição de tempestades e a ocorrência de jatos sobre o terreno inclinado da Grande Planície Central dos Estados Unidos. Esta relação foi posteriormente investigada por PITCHFORD e LONDON (1962).

De acordo com WHITEMAN et alli (1997), o JBN da Grande Planície tem sido bem documentado através de estudos observacionais (IZUMI e BARAD, 1963; HOECKER, 1963; PARISHI et alli, 1988; FRISCH et alli, 1992); por análises teóricas (BLACKADAR, 1957; WEXLER, 1961; HOLTON, 1967), e por simulações numéricas (McNIDER e PIELKE, 1981; PAEGLE e McLAWHORN, 1983; FAST e McCORCLE, 1990; ZHONG et alli, 1996).

A natureza complexa dos jatos noturnos sobre a Grande Planície tem sido apontada por diversos pesquisadores desde o Experimento de O'Neill de 1953

\footnotetext{
${ }^{6}$ Isalóbaras. - De acordo com PETTERSEN (1956), “a distribuição das variações barométricas na superfície por unidade de tempo podem ser expressas por $\partial \mathrm{p} / \partial \mathrm{t}=\mathrm{b}(\mathrm{x}, \mathrm{y}, \mathrm{t})$. Num dado momento $\mathrm{t}=\mathrm{t}_{0}$, temse $\partial \mathrm{p} / \partial \mathrm{t}=\mathrm{b}\left(\mathrm{x}, \mathrm{y}, \mathrm{t}_{0}\right)=$ constante, o que define uma isalóbara. Quando o gradiente isalobárico difere de zero, i.e., $\nabla(\partial \mathrm{b} / \partial \mathrm{t})<0$ ou $\nabla(\partial \mathrm{b} / \partial \mathrm{t})>0$, os campos de pressão dos sistemas atmosféricos (sistemas de alta e baixa pressão, pontos de cela etc) estão em movimento".
} 
(LETTAU, 1990). Essa complexidade surge da interação de fenômenos de grandeescala e mesoescala dentro da CLP. Para SMITH et alli (1997), o JBN noturno é um fenômeno comum sobre o terreno inclinado entre o vale do Rio Mississipe e as Montanhas Rochosas (BONNER, 1968; MITCHELL et alli, 1995), que tem sido considerado um contribuidor importante ao desenvolvimento de tempestades noturnas, precipitações intensas, de complexos convectivos de mesoescala e de enchentes inesperadas (WALLACE, 1975). De acordo com esses pesquisadores, a formação dos jatos noturnos é resultado da sobreposição dos escoamentos geostrófico de grandeescala e ageostrófico — esse último, associado à evolução diurna da CLP sobre o terreno inclinado (FAST e McCORCLE, 1990; SAVIJARVI, 1991).

A climatologia básica do JBN da Grande Planície foi estabelecida originalmente por BONNER (1968), utilizando dados de radiossondagens. BONNER (1968) analisou dois anos de dados obtidos de 47 estações de radiossondagem espalhadas pelos EUA, nas quais as sondas foram lançadas em dois horários sinóticos, 12 h e 00 h GMT (Tempo Médio do meridiano de Greenwich), para estabelecer uma climatologia (básica) e a cinemática dos JBN na Grande Planície do centro-oeste norte-americano (BONNER, 1968; BONNER et alli, 1968). Essa climatologia mostra que: (1) os JBN são mais freqüentes sobre a Grande Planície, com freqüência máxima de ocorrência sobre Oklahoma e Kansas; (2) o JBN médio é de Sudoeste, com máxima velocidade entre 18.5 e $24.2 \mathrm{~m} \mathrm{~s}^{-1}$ abaixo de $500 \mathrm{~m}$; (3) variações diurnas foram identificadas na freqüência dos JBN, sendo mais freqüentes nas sondagens do começo da manhã que na sondagem do tarde; (4) os JBN são mais freqüentes em Agosto e Setembro, ao final do verão (estação quente) e início do outono nos EUA; e (5) a altura do máximo e sua intensidade variam caso a caso. Não há uma correlação forte entre a altura do máximo e a altura da inversão térmica de superfície.

Na Figura 1.2 nota-se a posição do JBN em relação ao terreno inclinado à Leste das Montanhas Rochosas.

A climatologia de BONNER abriu caminho para a série de estudos-de-caso e também para outras climatologias com maior resolução espacial e temporal. 

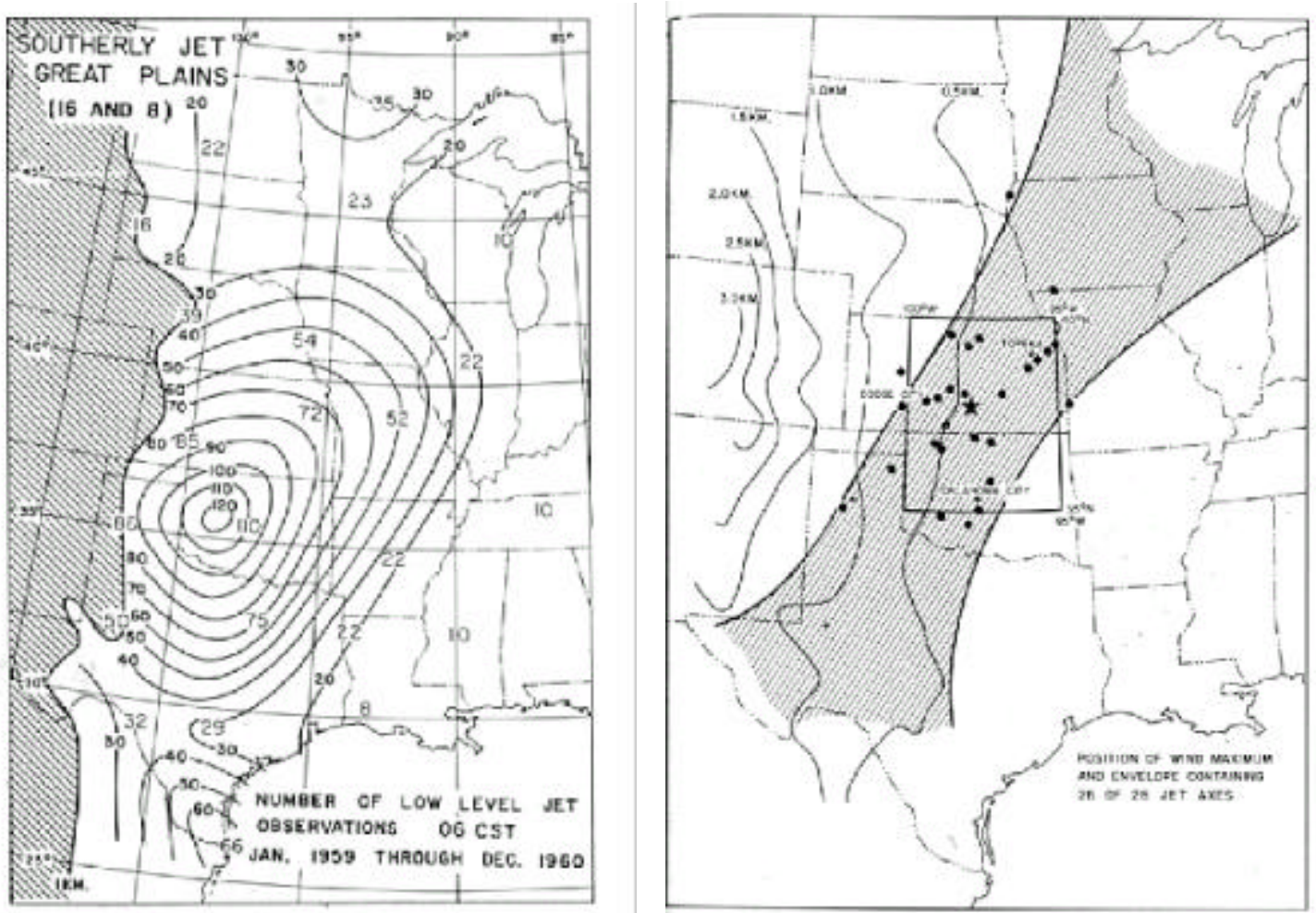

Figura 1.2 (a) Frequiência de ocorrência do JBN na Grande Planície do EUA e (b) posição média do eixo do JBN (BONNER, 1968). Em (b) mostra-se também as cotas de altitude da topografia.

ARRITT et alli (1997) mostram que eventos de JBN de Sul na grande Planície apresentam-se associados a intensas anomalias de geopotencial, em relação à média sazonal. Para mostrar isto, eles construíram mapas de geopotencial compondo eventos distintos de JBN sobre a área dos EUA, para níveis altos e médios da troposfera durante a estação quente de 1993. Eles sugerem que o JBN na Grande Planície durante o período quente provê o mecanismo de interação entre as escalas regional (de precipitação) e os padrões de circulação de grande-escala (também GAGE et alli, 1999). Assim, o JBN de Sul mostra-se associado a um cavado ${ }^{7}(-60 \mathrm{~m})$ em $500 \mathrm{hPa}$ com mínimo no Centro Norte dos EUA, mas cobrindo praticamente todo o país e a duas cristas, a mais intensa, a Noroeste no Oceano Pacífico (+90 m) e outra menos intensa localizada à Nordeste dos EUA e Atlântico Norte (+30 m). Há um cavado anômalo

\footnotetext{
${ }^{7}$ Cavado é nome dado às regiões de baixa pressão na alta troposfera. Neste caso, a altura geopotencial da superfície isobárica (i.e., de pressão constante) apresenta-se semelhante a uma calha, com o eixo da calha orientado aproximadamente na direção Norte-Sul. Em altos níveis, o cavado corresponde à baixa pressão em superfície, definindo uma estrutura vertical do sistema baroclínico. Cavado e crista definem uma onda no escoamento na alta troposfera com propagaçãoao longo do círculo de latitude (p.ex., uma onda de ROSSBY), e correspondendem, respectivamente, às áreas de mínimo e máximo da altura geopotencial.
} 
sobre o Oeste dos Estados Unidos e Canadá e uma Crista anômala sobre o Oceano Pacífico, a Leste, em $500 \mathrm{hPa}$ e também acima em $200 \mathrm{hPa}$. Ainda de acordo com ARRIT et alli (1997), este campo padrão de JBN lembra o campo de geopotencial precursor de enchentes (flood look-alike) que afetam o Centro Norte dos Estado Unidos, obtido por composição por MO et alli (1995); o que reforça muito os elos entre JBN e eventos extremos de precipitação (MEANS, 1952; PITCFORD e LONDON, 1962). Esses trabalhos mostram quais são as situações do escoamento de grande-escala associadas ao desenvolvimento dos JBNs mais intensos. Os jatos mais intensos de SW na Grande Planície são favorecidos quando ocorrem no setor quente de um ciclone extratropical (pré-frontal), com o centro de Baixa Pressão a N ou a NE do local (p.ex., Oklahoma). O escoamento de grande-escala define o cenário de desenvolvimento e intensificação do JBN. Por outro lado, o efeito térmico da topografia sobre o escoamento e dinâmica da CLP tem um papel importante sobre a formação e a sustentação do JBN da Grande Planície.

O JBN noturno é um importante contribuidor ao fluxo de vapor de água em escala continental sobre a Grande Planície dos EUA (RASMUNNON, 1967; HELFAND e SCHUBERT, 1995), especialmente no período quente. O JBN da Grande Planície transporta ar da massa de ar tropical (úmida e potencialmente instável) desde o Golfo do México até a região de maior freqüência de tempestades noturnas nos EUA.

WHITEMAN et alli (1997) sumarizaram um período de dois anos, no qual foram realizadas oito radiossondagens diárias lançadas, a partir da estação observacional (ARM SGP CART), localizada na fronteira entre Kansas e Oklaroma, junto à posição horizontal do máximo climatológico do jato. Nesta climatologia identificam as características essenciais do JBN de Norte, que foi associado à condição pós-frontal, à alta pressão, menores temperaturas e umidade específica ${ }^{8}$.

MITCHELL et alli (1995, WAF) desenvolveram uma climatologia de freqüência horária dos JBNs na Grande Planície dos EUA (Figura 1.3), durante o verão norteamericano, utilizando dados de Abril e Setembro de 1991 e 1992 obtidos com a rede de perfiladores de mesoescala WPDN (Wind Profiler Demonstration Network) da NOOA. De acordo com MITCHELL et alli, os JBNs mais intensos, classsificados segundo os

\footnotetext{
${ }^{8}$ Umidade específica (q) é a massa do vapor de água por unidade de ar úmido, $q=\rho_{v} / \rho$ (adimensional) onde $\rho_{\mathrm{v}}$ é a densidade do vapor de água e $\rho$ é a densidade do ar. Por outro lado, a razão de mistura (r) é definida como a massa de vapor de água por unidade de ar seco $r=\rho_{v} / \rho_{d}$ onde $\rho_{d}$ é a densidade do ar seco. A relação entre $q$ e $r$ é dada por $q=r /(1+r)$ ou $r=q /(1-q)$.
} 
critérios II e III de BONNER (1968), apresentam um ciclo diurno bem definido, o que torna evidente a dependência desses jatos dos processos da CLP.

FRISCH et alli (1992) utilizaram dados de Radar Doppler para investigar a estrutura vertical da turbulência associadas ao JBN da Grande Planície. O conhecimento da estrutura turbulenta dos JBN (i.e., variâncias e covariâncias) permite definir os valores dos parâmetros necessários aos modelos de dispersão de poluentes.

Entre estudos de caso destacam-se:

O jato do Golfo da Califórnia investigado por DOUGLAS (1995) utilizando dados médios recolhidos durante 35 dias de observações, de trajetórias de balão-piloto, durante o período de verão do experimento SOUTHWEST AREA MONSOON PROJECT (SWAMP-1990). Em 75\% dos dias disponíveis observou-se um JBN de direção Sul bastante intenso, com eixo orientado na direção paralela ao eixo do Golfo e máxima intensidade localizada a $300 \mathrm{~m}$ acima da superfície.
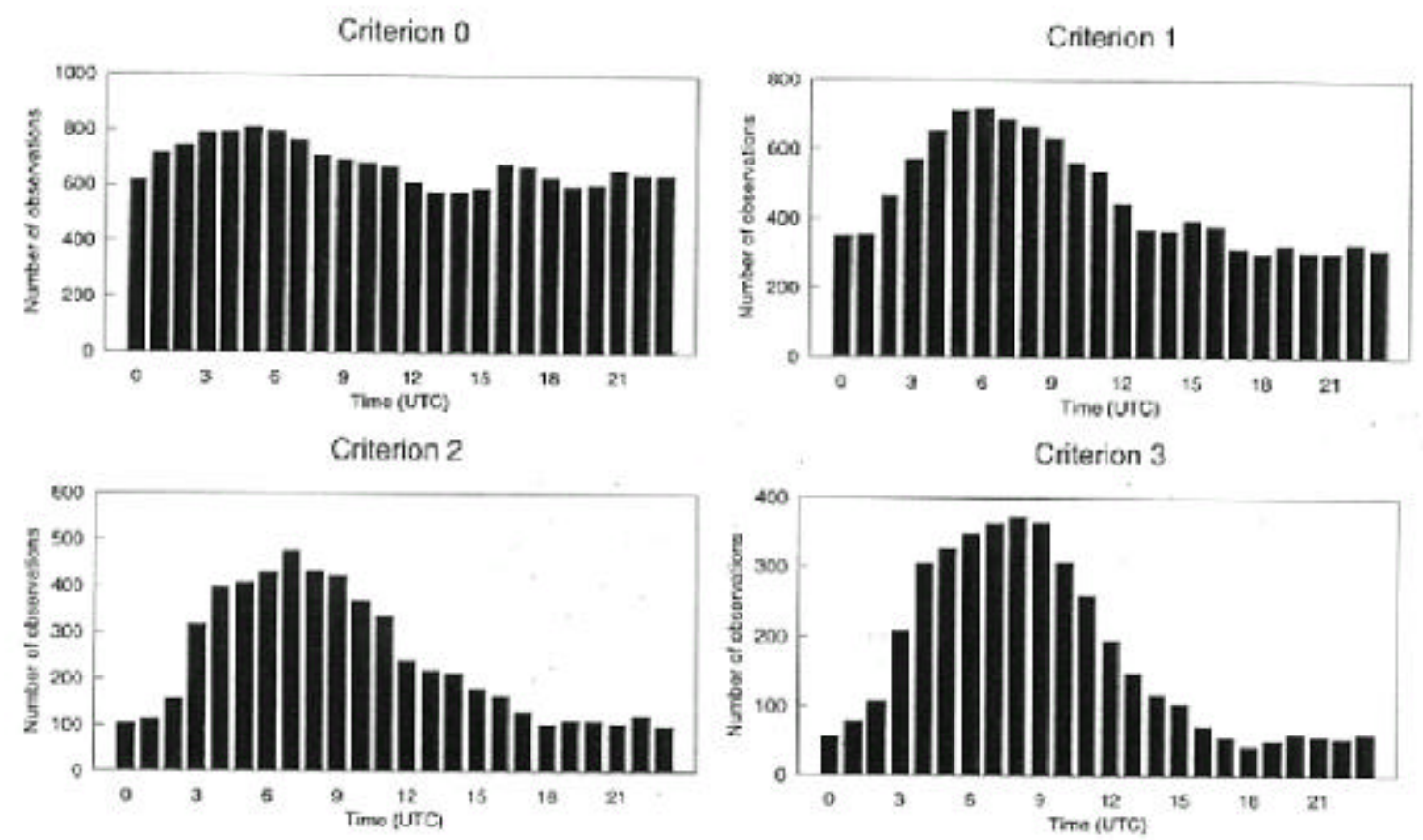

Figura 1.3 Variabilidade horária dos JBNs da Grande Planície dos EUA (segundo critério de classificação de BONNER, 1968) conforme MITCHELL et alli (1995, WAF)

De acordo com MAY (1995), o JBN noturno da Austrália, de escala continental, ocorre no norte da Austrália numa região de topografia razoavelmente plana (100 m por 
$100 \mathrm{~km})$. Este jato é claramente associado com uma oscilação inercial ${ }^{9}$. A máxima intensidade do JBN localiza-se a $600 \mathrm{~m}$ acima da superfície às $7 \mathrm{~h}$ e apresenta amplitude inferior a $10 \mathrm{~m} \mathrm{~s}^{-1}$ (região do Monte Isa). O JBN do norte australiano pode ser também afetado pela brisa marítima que chega a penetrar $500 \mathrm{~km}$ no interior e para baroclinia induzida por topografia levemente inclinada da região. MAY fez sua análise dispondo de observações tomadas em perfilador de vento instalado na reagião do Monte Isa (Nordeste da Austrália), mostrando que o JBN observado pode ser entendido como uma resposta direta à oscilação inercial sobre o escoamento ageostrófico ${ }^{10}$ diurno da CLP, mas que também está associado a outros processos, porque a velocidade angular mostrase maior e a amplitude mostra-se menor que aquela esperada. Além disso, há um amortecimento da intensidade do vento no JBN durante a madrugada após as 4 h, que não é inercial.

Os JBNs na América do Sul foram estudados apenas parcialmente do ponto de vista observacional e numérico. Os JBNs localizados a direita e esquerda da Cordilheira dos Andes se destacam por sua extensão e persistência. Esses jatos apresentam direção do quadrante $\mathrm{N}$ no flanco oriental (no lado amazônico) e S no flanco ocidental (lado do Pacífico) dos Andes (IBAÑEZ, 1995). No Chile, o Antofogasta Field Experiment investigou o JBN sobre a região do deserto de Antofogasta à Oeste dos Andes (RUTLLAND e ULRIKSON, 1979). Esse experimento observou um jato JBN noturno de direção NE, que pode ser observado durante todo o período noturno. Nas primeiras horas da manhã, a persistência direcional desse jato é quebrada e o jato gira de NE para SW, para definir um jato diurno, que persiste durante todo o período diurno.

Mais recentemente, a conferência VAMOS/CLIVAR/WCRP (2002, http://wwwcima.at.fcen.uba.ar/sallj) debateu o JBN do lado oriental dos Andes, conhecido por Jato de Baixos Níveis da América do Sul (ASLLJ) ressaltando suas características, variabilidade, relação com desenvolvimento de precipitação convectiva, simulações numéricas e suas relações com ondas de ROSSBY e outros fenômenos de grandeescala. De acordo com VERA (2002): (a) o JBN à Leste dos Andes é modulado pela fronteira orográfica dos Andes, que atua bloqueando e canalizando a circulação de leste dos Alísios Equatoriais que penetra pelo litoral norte e nordeste do Brasil, passando pela

\footnotetext{
${ }^{9}$ Oscilação inercial é o movimento do ar resultante de apenas das forças de pressão e Coriolis (inercial) sobre um estado inicial (condição inicial). Neste caso, o vetor de velocidade do vento oscila em torno do vetor vento geostrófico.
} 
região Amazônica e também por circulações ciclônicas na baixa troposfera, tanto no verão como no inverno; (b) os SALLJ mais intensos são favorecidos por condições associadas às perturbações ciclónicas que ocorrem durante propagação de trens de ondas baroclínicas na alta troposfera (i.e., por cenários caracterizados por sucessão de ondas de ROSSBY na alta troposfera entre o Pacífico Leste e a AS); (c) SALLJ aparecem na latitude $18^{\circ} \mathrm{S}$ alcançando $30^{\circ} \mathrm{S}$ na forma de jatos intensos sobre a região do Chaco, onde ocorrem precipitações por atividade de Sistemas Convectivos de Mesoescala (SCM); (d) os SCM podem ser mantidos por advecção de ar tropical, potencialmente quente e úmido, via transporte pelo JBN localizado na região — cerca de $80 \%$ dos SCM no Centro da AS ocorrem durante períodos de intenso SALLJ com vento de Norte; (e) $45 \%$ da precipitação austral de verão sobre a Bacia do Prata pode ser explicada pela ocorrência de eventos de JBN; (f) SALLJ estão associados a cavados na média e alta troposfera sobre o Sul da AS; crista na média e alta troposfera sobre a costa Sul do Brasil; temperatura acima da normal no Sul do Brasil, Paraguai, Uruguai e NE da Argentina e abaixo da normal sobre o Centro e Sul da Argentina; zona baroclínica intensa sobre a região central da Argentina (i.e., ventos cisalham com a altura); precipitação acima da normal sobre o $\mathrm{S}$ do Brasil, Uruguai, Sul do Paraguai e NE da Argentina; e abaixo do normal sobre regiões Norte e Central do Brasil e ausência de uma Zona de Convergência do Atlântico Sul (ZCAS) ${ }^{11}$ significativa (g) a intensificação de SALLJ está relacionada à períodos de ZCAS inativa e vice-versa (Figura 1.4).

\footnotetext{
${ }^{10}$ Escoamento ageostrófico é dado pela diferente entre o escoamento real do ar e o escoamento geostrófico, definido pelo vento geostrófico.

${ }^{11}$ ZCAS é uma faixa de convergência dos ventos em baixos níveis sobre uma faixa que cruza a AS, caracterizada pela sua grande extensão e presença de nebulosidade convectiva e precipitação. A ZCAS estende-se desde a Amazônia até a região Sul ou Sudeste do Brasil, sendo formada preferencialmente nos meses de verão e permanência por períodos que se prolongam de dias até semanas. A convergência dos ventos é definida pelo padrão de ventos dos alísios de $\mathrm{NE}$ e pelo escoamento de ar polar de $\mathrm{S}$ associado à chegada de frentes-frias. A entrada das frentes-frias à região ao sul da ZCSA permite a organização da faixa de convecção através do interior do continente. A persistência da ZCAS está associada aos padrões mais estáveis do escoamento de grande-escala, como bloqueios, grandes ondas de ROSSBY (no escoamento de oeste da alta troposfera), ocorrência de ciclones na alta troposfera sobre o Nordeste do Brasil e aos fenômenos de escala-global (como o El Niño e as posições e intensidade da Célula de Hadley do Hemisfério Sul pertencente ao movimento de Circulação Geral da atmosfera da Terra).
} 


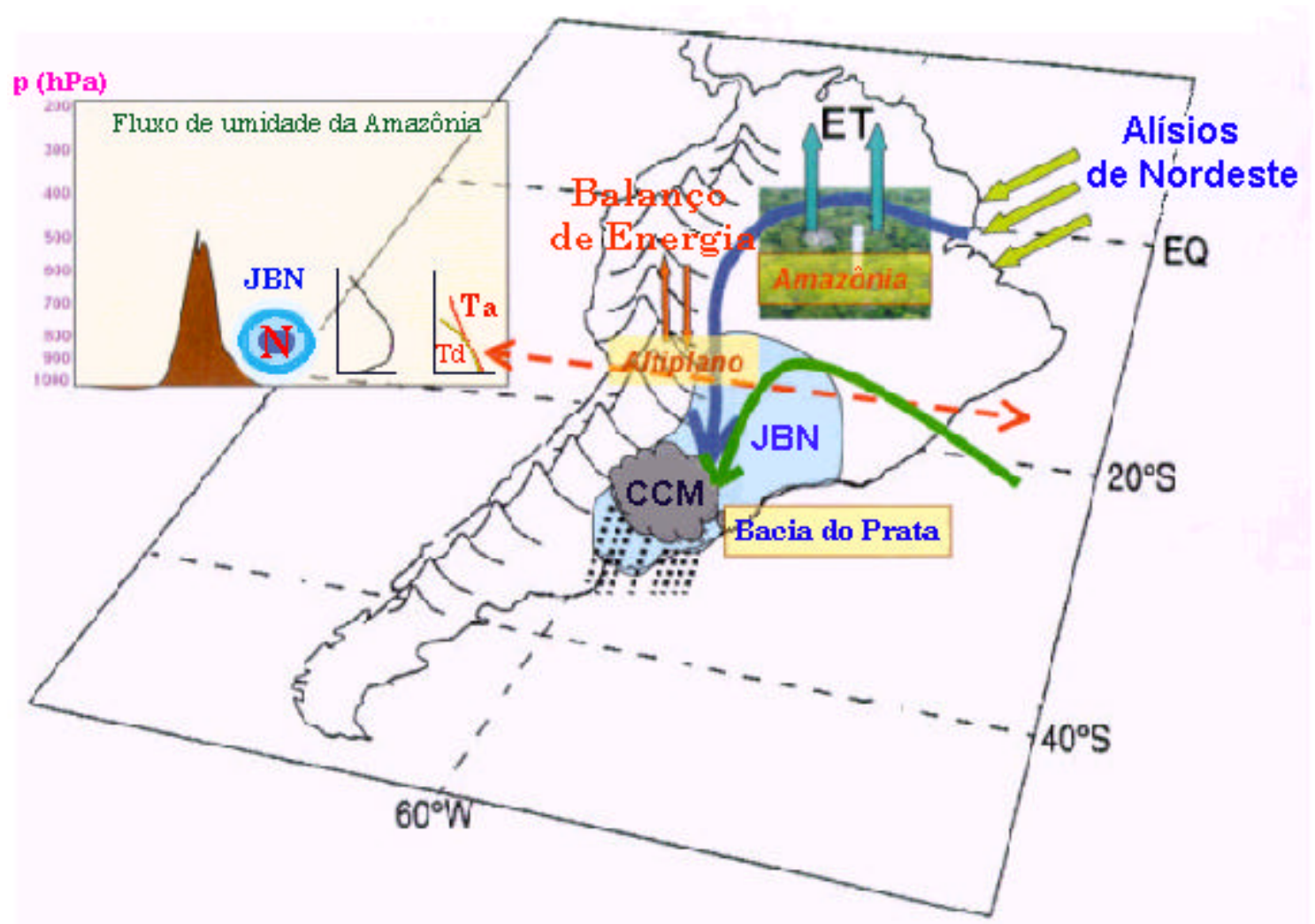

Figura 1.4 Diagrama esquemático dos elementos relevantes de um intenso transporte de umidade e calor via JBN desde a Amazônia até a região ao norte da Argentina, Paraguai e Uruguai (MARENGO, 2002).

De acordo com LETTAU (1990), os JBN sobre o deserto chileno não podem ser explicados isoladamente pelo mecanismo de oscilação inercial. A estrutura vertical desses jatos é consistente com uma forçante térmica gerada pelo aquecimento diferencial da superfície inclinada na face oeste da Cordilheira dos Andes. Esse aquecimento diferencial da encosta inclinada da Cordilheira leva a formação de gradientes de pressão responsáveis pela formação de escoamentos anabáticos de W, que sobem a encosta ocidental dos Andes. Neste caso, a força de Coriolis provoca o desvio do escoamento anabático originalmente de W para SW (Coriolis faz o vento girar para a esquerda no Hemisfério Sul e para a direita no Hemisfério Norte). Durante a noite, o resfriamento do ar sobre o terreno inclinado faz surgir um escoamento catabático de direção $\mathrm{E}$, que desce a montanha em direção aos vales, mas que vai se desviando pela ação da força de Coriolis para definir um JBN de NE.

Modelos teóricos de desenvolvimento de JBN tem sido propostos para a América do Sul (PAEGLE e PAEGLE, 1983). Esse tipo de modelo apresenta antecipação da hora de ocorrência do máximo do JBN em função da latitude, devido ao 
ao aumento do período inercial com a redução da latitude, isto é $\mathrm{P}_{\mathrm{i}}=1 /\|\mathrm{f}\|=$ $1 /\|2 \Omega \cdot \operatorname{sen}(\varphi)\|$ onde $\varphi$ é a latitude e $\Omega$ é o valor absoluto da velocidade angular de rotação Terra, sendo $\Omega=2 \pi /(24 \times 3600)\left(\right.$ rad. $\left.^{-1}\right)$. De acordo com esses pesquisadores, para baixas latitudes o modelo teórico prevê um máximo de convergência junto às montanhas durante o período noturno. Contudo, na AS há ainda dificuldade em se obter o conjunto existente de observações necessário para confirmar ou não essa previsão teórica. Para a área dos EUA, a hora de convergência máxima do escoamento prevista por esse tipo de modelo teórico está em boa concordância com a hora de máxima atividade convectiva noturna encontrada a N-NE da Grande Planície. A variação da hora de máximo também tem sido confirmada parcialmente por simulações numéricas de alta resolução ${ }^{12}$ horizontal $(\sim 50 \mathrm{~km})$ em domínio aninhado de $1800 \mathrm{~km}$ e assimilação 4-D (ZHONG et alli, 1996).

Diversos pesquisadores (PRANDTL, 1942; SAVIJ̈̈RVI, 1991; ZHONG et alli, 1996; WU e RAMAN, 1997 etc) têm investigado os efeitos térmicos e aerodinâmicos da cobertura heterogênea da superfície e da inclinação da encosta na indução e desenvolvimento de JBNs, dos quais inferimos que: (a) a inclinação desempenha o papel de escala para a intensidade do escoamento (anabático/catabatico) resultante; em concordância com a forma tensorial (i.e., válida para qualquer sistema de coordenadas) da equação do momento escrita para um escoamento particular sobre um plano inclinado (FITZJARRALD, 1984; FAST e McCORCLE, 1990); (b) para grandes inclinações do terreno, os parâmetros descritores da convecção térmica não escalam com a função seno como seria esperado (SCHUMANN, 1990); (c) as heteorogeneidades da superfície (tipo de solo, conteúdo de água do solo, presença de vegetação etc associadas à distribuição da precipitação na área e à topografia e presença de terreno inclinado em escala regional) podem ter um impacto importante sobre a formação e manutenção do JBN, definido o local de ocorrência do jato, intensidade, fase e estrutura vertical (WU e RAMAN, 1977; FAST e McCORCLE, 1990).

O papel da CLP marítima sobre o JBN foi estudado por BURK e THOMPSON (1996) utilizando o modelo de HAURWITZ (1947) que descreve o escoamento associado ao gradiente de pressão de grande-escala, à força de Coriolis e a uma força de pressão de mesoescala de evolução temporal periódica (induzida pelo contraste térmico continente-mar e período 24 horas). Desta forma puderam reproduzir a forma geral da

\footnotetext{
${ }^{12}$ Do ponto de vista dos modelos de grande-escala.
} 
hodógrafa elíptica observada sobre a costa oeste do EUA (Califórnia). Como a curva hodógrafa foi construída com médias horárias das componentes do vento observadas, $\mathrm{u}$ e v, concluíram que a variação temporal ou diária da força de pressão de mesoescala é a principal responsável pela carácter elíptico da hodografa associada ao JBN observado no litoral da Califórnia, não se tratando de uma oscilação inercial pura.

CHEN et alli (1997) utilizaram os dados observados no experimento TAMEXIOP-5 ao sul da China e simulações numéricas para estudar o evento de JBN associado a um ciclone extratropical. Seus testes de sensibilidade mostraram que o aquecimento troposférico devido liberação de calor latente na área de precipitação, tem um papel muito importante sobre a ciclogênese observada e sobre a intensificação do escoamento de sudoeste do JBN na CLP. O aprofundamento inicial (queda da pressão superficial) do ciclone a sotavento e o desenvolvimento do escoamento de sudoeste em baixos níveis são causados pelo movimento vertical associado à chegada de uma onda curta no campo de pressão da alta troposfera. O JBN transporta ar quente, úmido desde sua fonte de umidade mais ao sul. O JBN a frente do centro do ciclone se intensifica pela força de Coriolis atuando sobre os ventos ageostróficos (que cruzam as isóbaras), resposta ao aumento do gradiente de pressão e é intensificado pelo aquecimento convectivo. Os ventos ageostróficos cruzando os contornos de pressão, próximos ao núcleo do jato (core jet) na baixa troposfera, são relacionados aos ventos isalobáricos ${ }^{13}$ que aparecem em resposta a forçante de ar superior ${ }^{14}$, e são intensificados pela liberaçao de calor latente. $\mathrm{O}$ aquecimento por calor latente resulta no aumento da espessura da baixa troposfera sobre o ciclone de baixo nível (ou da alta troposfera à frente da posição do ciclone), define uma configuração ainda mais favorável ao desenvolvimento ciclônico. Efeitos combinados da precipitação e advecção quente à frente do centro do ciclone excedem o resfriamento adiabático e aumentam o contraste térmico horizontal em baixos níveis. A circulação secundária e a conversão baroclínica se intensificam. Esses processos interagem de forma não-linear levando posterioriormente a um aprofundamento da pressão do ciclone e também a uma maior intensificação do JBN (retroalimentação). Os resultados observacionais e numéricos de CHEN et alli (1997)

\footnotetext{
${ }^{13}$ Vento isalobárico em coordenadas $(\mathrm{x}, \mathrm{y}, \mathrm{z}, \mathrm{t})$ é um tipo de vento que resulta da não-estacionariedade do campo de pressão, sempre apontando para os núcleos negativos do campo de variação temporal da pressão (PETTERSSEN, 1956).

${ }^{14}$ Neste caso, a aproximação do cavado de onda-curta em altitude que define configuração favorável à dinâmica baroclínica, de acordo com a teoria quase-geostrófica (SUTCLIFFE, 1947; TRENBERTH, 1978).
} 
sugerem que a intensificação do JBN é aproximadamente relacionado à variação local do gradiente de geopotencial que ocorre conforme o ciclone a sotavento da cordilheira do Himalaia aprofunda-se e move-se para leste.

A relação entre nuvens e JBN é um fato observacional. De acordo com GHAN e BIAN (1996) o que faz os JBN serem particularmente importantes na definição de programas voltados ao estudo de nuvens é que diversas observações têm mostrado que os JBN desempenham um papel vital na formação de nuvens da primavera e verão sobre a Grande Planície (MEANS, 1952; PITCHFORD e LONDON, 1962; BONNER, 1968; BALLING, 1985, PARISH et alli, 1988). Oscilações diurnas da velocidade dos jatos são consideradas responsáveis pelos máximos anômalos e noturnos da freqüência de tempestades (e conseqüentemente, da freqüência de nuvens do tipo $\mathrm{Cb}$ que lhes são associadas) observadas pelo meio-oeste dos EUA (WALLACE, 1975). Entretanto, apesar das simulações do JBN da Grande Planície dos EUA com Modelos de Circulação Global (MCG) mostrarem que o JBN é um fenômeno robusto (do ponto de vista da realização numérica e de sua ocorrência na simulação), o máximo pronunciado de freqüência de tempestade associada com os JBN não pode ser bem simulada com MCG (i.e., a correlação não é bem simulada).

De acordo com GHAN e BIAN (1996), embora os MCG possam simular JBN de forma robusta (com alta e baixa resolução) falham na estimativa da nebulosidade associada à presença do JBN. Por isso, eles levantaram a hipótese de que os máximos noturnos de tempestades na Grande Planície possam não estar realmente associados ao JBN. Neste caso, a localização do máximo de tempestades na região de JBN seria uma coincidência resultante de outros processos, como por exemplo, da advecção da convecção iniciada sobre as Montanhas Rochosas para leste, realizada pelos ventos prevalescentes. Entretanto, a questão não está fechada, desde que investigações numéricas do efeito da resolução com MCG e das diferentes parametrizações de cúmulos precisam ser realizadas.

Já de acordo com AUGUSTINE e CARACENA (1994), tanto a frontogênese (acúmulo das linhas de contornos da temperatura) como a convergência causada pelo JBN a sua frente podem ser elementos chave para a formação e desenvolvimento dos CCM sobre a Grande Planície nos EUA ${ }^{15}$ (Figura 1.5).

\footnotetext{
15 Provavelmente, tanto a frontogênese como a convergência vento-abaixo são sensíveis à resolução horizontal dos modelos numéricos. Note-se que valores absolutos da velocidade verticais e da
} 


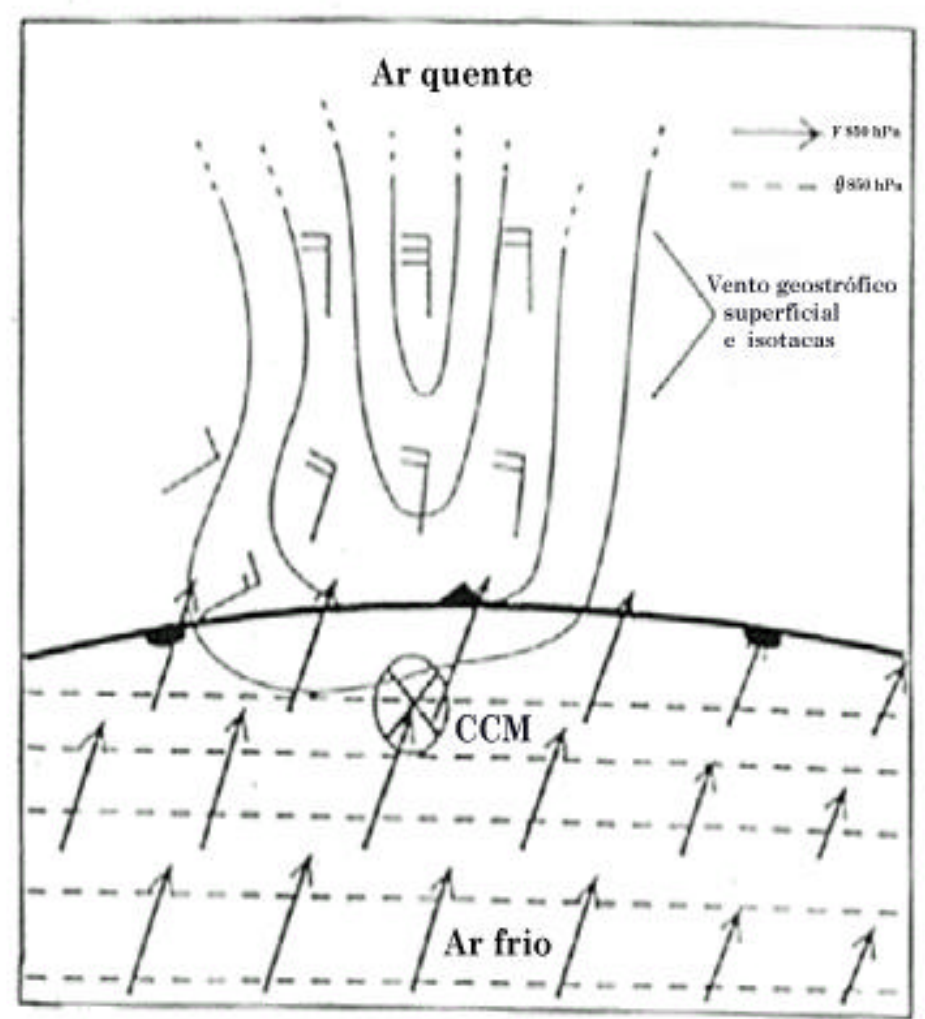

Figura 1.5 Modelo conceitual de AUGUSTINE e CARACENA (1994) mostrando o papel da convergência do vento na dianteira do JBN e da zona de frontogênese na localização e formação de um grande Complexo Convectivo de Mesoescala. As linhas tracejadas representam as isotermas que são aproximadas pela convergência do vento. Figura adaptada para o Hemisfério Sul.

De acordo com AFANASYEV e PELTIER (1998) topografias de estrutura 2-D podem induzir processos não-lineares de instabilização e jatos associados às instabilidades do tipo KELVIN-HELMOLTZ e KELVIN-PELTIER.

O papel do JBN no transporte regional tem sido assinalado por diferentes pesquisadores. O efeito da dispersão do JBN na Grande Planície sobre nuvens de elemento traço foi medida durante experimento de campo nos EUA conduzido por MORAN e PIELKE (1996a e 1996b). Neste experimento, determinaram a trajetória e mediram a concentração de uma nuvem de traçador emitida da superfície, o que lhes permitiu confrontar resultados numéricos de um modelo de dispersão de partículas e os valores de concentração observados. 


\subsection{JBN no Brasil}

No Brasil, JBN noturnos têm sido observados em diversos locais, no Estado de São Paulo (CARDENAS, 1990; OLIVEIRA, 1993), ao longo do vale do Rio Paraná (STIVARI, 1999); em Candiota, RS (MORAES et alli, 1996).

Em São Paulo esses jatos foram observados durante os experimentos:

(a) RADASP-II em Janeiro de 1983 na região de Bauru (CÁRDENAS, 1990) (Tabela 1.1);

(b) Experimento Micrometeorológico de Iperó, composto de quatro campanhas de observação: 11 a 22 de março de 1991; 9 a 21 de março de 1992; 28 de julho a 7 de agosto de 1992; 8 a 21 de março de 1993, três campanhas no período de verão e uma no inverno (OLIVEIRA, 1993; MOLNARY, 1993).

Os JBNs observados na região central do Estado de São Paulo foram estudados por CÁRDENAS (1990) com radiossondagens tomadas em Bauru em janeiro de 1983. Nos três casos de estudo de JBN apresentados por CÁRDENAS, a máxima velocidade variou entre 11 e $23 \mathrm{~m} \mathrm{~s}^{-1}$ e a direção do vento foi de SE e NE, com o jato contido em uma camada do jato de espessura entre 335 e $1054 \mathrm{~m}$; levantando evidências de que os JBN observados em Bauru se estendem horizontalmente por todo o Planalto Paulista e de que estão associados à oscilação inercial.

CÁRDENAS (1990) descreveu detalhadamente três JBN noturnos observados nos dias 24, 25 e 27 de janeiro de 1983, em Bauru, durante o projeto RADASP II. Neste pequeno intervalo de tempo (três dias), duas frentes frias passaram por São Paulo. Deste ponto de vista, os jatos de baixos níveis observados no estudo de Cárdenas podem ser considerados como uma resposta efetiva (acelerada) do campo de vento da CLP, por conservação de massa, às frentes-frias que se sucederam.

Os JBN noturnos formaram-se e desenvolveram-se, dois no período pós-frontal e um no período pré-frontal. Jatos pós-frontais apresentaram direção média de SE (muito próximo a zona frontal) e giro horário do vento com a altura (i.é, advecção fria geostrófica inicialmente), e o jato pós-frontal de CÁRDENAS apresentou direção média de NE, com giro horário do vento na vertical (advecção fria geostrófica). Neste caso, as frentes-frias não passaram diretamente sobre o interior de São Paulo no período, mas tiveram trajetórias litorâneas, permitindo que o prolongamento da área da alta pressão 
polar do oceano, sobre o litoral, até o interior de SP. CÁRDENAS mostra a importância da entrada da crista de alta pressão (vista na carta de superfície) sobre a região central do Estado de São Paulo.

A penetração da crista em SP, com circulação anticiclônica e ventos de NE, cria um cenário de grande-escala que é favorável à oscilação inercial dos ventos na parte da CLP que desacopla durante a noite, e ao mesmo tempo indica o afastamento do sistema frontal para o Oceano Atlântico, permitindo a penetração de nova frente-fria pelo litoral sul do Brasil. Portanto a projeção da crista de alta pressão desde o litoral por sobre o inteiror do Estado de São Paulo caracteriza a transformação da massa de ar polar, originalmente fria e seca, para quente e estaticamente instável.

Nestes casos, o JBN desenvolve-se em resposta à: (a) oscilação inercial, (b) baroclinicidade de mesoescala, isto é, ao gradiente de pressão originado do aquecimento diferencial do aclive do Planalto Paulista, no inteiro, (c) ao desacoplamento noturno da camada residual, acima da inversão de superfície, (c) baroclinicidade sinótica, isto é, ao padrão de circulação de grande-escala com penetração da crista de alta pressão, em superfície.

A baroclinicidade de grande-escala está associada ao ajuste do vento geostrófico com a altura (i.e., ao vento térmico). Um cenário sinótico pós-frontal estava presente durante as duas primeiras ocorrências de JBN analisadas por CÁRDENAS. Nestes casos, havia advecção de ar quente nos níveis abaixo do máximo do jato; e fria acima do máximo. Esta estrutura de advecção promove instabilidade termodinâmica, o que poderia originar tempestades no interior. Por outro lado, a advecção quente nos baixos níveis tende a aquecer a massa de ar fria na retaguarda frontal.

Diagramas da oscilação inercial do escoamento associada ao vento geostrófico e vento médio na CLP ao final da tarde são mostrados na Figura 1.6, para condições iniciais similares àquelas encontradas na camada residual durante o Experimento RADASP-II (Tabela 1.2) em Bauru-SP. Da análise dessa figura, entende-se que a oscilação inercial, tomada isoladamenta, não é suficiente para explicar as intensidades dos JBNs observados durante o período considerado (24 a 27 de janeiro de 1983), pois o período inercial de $30 \mathrm{~h}$ é muito longo comparado à duração da noite (12 h) e a intensidade do vento resultante ao final da noite devido à oscilação inercial é menor do que a observada em dois dos três eventos considerados. Neste caso, outras forçantes associadas tanto à superfície, à topografia e à forçante de maior escala precisam ser consideradas e investigadas. A variação da direção do vento observado, às $24 \mathrm{~h} \mathrm{em}$ 
Bauru, na seqüência de dias, é possivelmente mais associada à passagem da crista de Alta Pressão pelo Estado de São Paulo (Figura 1.6 d) do que a oscilação inercial do vento.

\begin{tabular}{|c|c|c|c|c|c|c|}
\hline $\begin{array}{c}\text { Data } \\
(00: 00 \mathrm{HL})\end{array}$ & $\begin{array}{c}\text { Situação } \\
\text { sinótica }\end{array}$ & $\begin{array}{l}\text { Altitude do } \\
\text { máximo (m) }\end{array}$ & $\begin{array}{c}\text { Velocidade } \\
\text { máxima } \\
\left(\mathrm{m} \mathrm{s}^{-1}\right)\end{array}$ & $\begin{array}{l}\text { Espessura } \\
\text { da Camada } \\
\text { (m) onde } \\
\mathrm{v}>10 \mathrm{~m} \cdot \mathrm{s}^{-1}\end{array}$ & $\begin{array}{c}\text { Velocidade } \\
\text { do Vento } \\
\text { Geostrófico } \\
\left(\mathrm{m} \cdot \mathrm{s}^{-1}\right) \mathrm{em} \\
850 \mathrm{hPa}\end{array}$ & $\begin{array}{l}\text { Direção } \\
\text { (graus) do } \\
\text { Vento } \\
\text { Geostrófico } \\
\text { em } 850 \mathrm{hPa}\end{array}$ \\
\hline \multirow[t]{2}{*}{$\begin{array}{l}\text { 24/01/1983 } \\
\text { JBN pós- } \\
\text { frontal }\end{array}$} & $\begin{array}{l}\text { Crista de alta } \\
\text { pressão da } \\
\text { Alta Polar ao } \\
\text { Sul de Bauru }\end{array}$ & $\begin{array}{c}1050 \mathrm{~m} \\
(400 \mathrm{~m} \\
\text { acima da } \\
\text { superfície })\end{array}$ & $23 \mathrm{SE}$ & 1054 & 7 & $\begin{array}{c}\text { 100-ESE } \\
\text { advecção } \\
\text { quente } \\
\text { abaixo e } \\
\text { fria acima } \\
\text { do máximo }\end{array}$ \\
\hline & $\begin{array}{l}\text { Passagem } \\
\text { frontal }\end{array}$ & & & & & \\
\hline $\begin{array}{l}\text { 25/01/1983 } \\
\text { JBN pós- } \\
\text { frontal }\end{array}$ & $\begin{array}{l}\text { Crista de alta } \\
\text { pressão da } \\
\text { Alta Polar ao } \\
\text { Sul de Bauru }\end{array}$ & $\begin{array}{c}1200 \\
(550 \mathrm{~m} \\
\text { acima da } \\
\text { superfície })\end{array}$ & $14 \mathrm{SE}$ & 1110 & 7 & $\begin{array}{l}\text { 120-ESE } \\
\text { advecção } \\
\text { quente }\end{array}$ \\
\hline 26/01/1983 & $\begin{array}{l}\text { Passagem } \\
\text { frontal }\end{array}$ & & & & & \\
\hline $\begin{array}{l}\text { 27/01/1983 } \\
\text { JBN pré- } \\
\text { frontal }\end{array}$ & $\begin{array}{l}\text { Crista de alta } \\
\text { pressão da } \\
\text { Alta do } \\
\text { Atlântico Sul } \\
\text { ao Norte de } \\
\text { Bauru }\end{array}$ & $\begin{array}{c}2110 \\
(1460 \mathrm{~m} \\
\text { acima da } \\
\text { superfície) }\end{array}$ & $11 \mathrm{NE}$ & 335 & 7 & $\begin{array}{c}\text { 50-NE } \\
\text { advecção } \\
\text { fria }\end{array}$ \\
\hline
\end{tabular}

Tabela 1.1 Parâmetros significativos dos JNB observados durante projeto RADASP/1993. A altitude de Bauru é aproximadamente $650 \mathrm{~m}$. Dados compilados de CÁRDENAS (1990).

CÁRDENAS caracteriza a evolução dos JBN noturnos segundo três estágios denominados estágio inicial, maduro e de dissipação.

No caso de origem baroclínica no Estado de São Paulo, também a brisa marítima pode gerar um jato de NE no parte oeste da célula convectiva (Figura 1.16). No caso da célula convectiva associada à encosta do Planalto Paulista, um jato de SW se estabelece na parte leste da célula. Todos estes mecanismos são modulados pelas condições sinóticas. 
As observações realizadas em Iperó durante as campanhas de medidas (OLIVEIRA e SAKAY, 1991, 1992; OLIVEIRA, 1992, 1993; et alli, 1994; et alli, 1995) indicaram a existência de um ciclo diurno no campo do vento em superfície, com ventos de NW durante parte do dia e de SE durante parte de noite (Figura 1.7). Como o Planalto Paulista possui uma inclinação aproximada de 1:1000 km:km para Noroeste (Figuras 1.8 e 1.9), foi levantada a hipótese de que parte desse regime de ventos poderia estar associada a uma circulação térmica induzida pela topografia local.

Esta hipótese foi testada numericamente por KARAM (1995) demonstrando que a inclinação da topografia do interior do Estado de São Paulo (Figura 1.9) é suficiente para manter uma circulação local com ventos de NW (vento anabático) durante o dia e $\mathrm{SE}$ (catabático + giro antihorário do vento anabático) na CMR durante a noite. Neste trabalho, foi utilizada a versão hidrostática do modelo TVM, o que limitou a sua aplicação a regiões compreendidas entre as longitudes $52^{0}$ e $48^{0} \mathrm{~W}$, onde a topografia regional não é acidentada (apenas ondula) e inclina-se suavemente (Figura 1.9).

Outras simulações numéricas 3-D, realizadas com a versão hidrostática e nãohidrostática, do modelo TVM têm confirmado o papel relevante da topografia sobre a circulação do interior paulista, dando suporte adicional à hipótese de que o efeito térmico da topografia inclinada do Planalto Paulista é realmente capaz de sustentar uma circulação na CLP (KARAM e OLIVEIRA, 1998; KARAM et alli, 2001). Adicionalmente, essas simulações mostram circulações associadas à geração e manutenção de JBN noturnos de direção SE em superfície, que se estendem sobre o Planalto Paulista, em uma camada de profundidade comparável à altura da CLP.

MOLNARY (1993) identificou JBN na região de Iperó, com intensidade variando de 5 a $10 \mathrm{~m} \mathrm{~s}^{-1}$ e altura entre 100 e $500 \mathrm{~m}$. Um modelo numérico de três camadas foi utilizado por MOLNARY para mostrar que esses JBN podem ser explicados em termos do efeito de oscilação inercial, quando a condição inicial do escoamento é definida de forma apropriada.

Os JBN observados em Iperó são muito mais baixos do que os observados por CÁRDENAS (1990) em Bauru e menos intensos. Na Figura 1.10 são apresentados os perfis verticais de velocidade e direção observados durante o experimento realizado em março de 1993, em Iperó. O JBN nesta noite se formou em torno de $400 \mathrm{~m}$ a 1 h (hora local), com intensidade de $9 \mathrm{~m} \mathrm{~s}^{-1}$, permanecendo estável até às $8 \mathrm{~h}$. Na altura onde ocorre a máxima velocidade, o JBN mostra-se de E, durante todo o período; enquanto, 
nas camadas mais próximas da superfície a direçãio do escoamento é SE. A maior parte do cisalhamento direcional esta concentrada entre os níveis 200 e $300 \mathrm{~m}$.

\begin{tabular}{|c|c|c|c|}
\hline & $\left(\mathrm{u}_{\mathrm{g}}, \mathrm{v}_{\mathrm{g}}\right)\left(\mathrm{m} \mathrm{s}^{-1}\right)$ & $(\mathrm{u}, \mathrm{v})_{18 \mathrm{~h}}\left(\mathrm{~m} \mathrm{~s}^{-1}\right)$ & $(\mathrm{u}, \mathrm{v})_{24 \mathrm{~h}}\left(\mathrm{~m} \mathrm{~s}^{-1}\right)$ \\
\hline dia 23 de janeiro & $(-5,2 ; 5,2)$ & $(1,0 ; 3,0)$ & $(-14,2 ; 2,2)$ \\
\hline dia 24 de janeiro & $(-5,0 ; 5,0)$ & $(-2,5 ; 2,5)$ & $(-10,2 ; 5,9)$ \\
\hline dia 26 de janeiro & $(-4,7 ; 4,7)$ & $(2,0 ;-2,5)$ & $(-4,6 ;-3.9)$ \\
\hline
\end{tabular}

Tabela 1.2 Componentes do vento geostrófico e de vento médio, para o nível de pressão de 850 $\mathrm{hPa}$, observados ao final da tarde e à meia-noite associados ao desenvolvimento do JBN de três dias de janeiro de 1983, durante o Projeto RADASP em Bauru (Fonte de dados: Figura 4.3 e Tabela 3 de CÁRDENAS,1990).

Os JBN com características similares foram observados em todos os quatro experimentos realizados em Iperó: dois casos em março de 1991; um caso em março de 1992 e dois casos em março de 1993 e dois casos em Julho de 1992. Deve ser ressaltado que a freqüência dos JBN pode ser bem maior do que a registrada em Iperó, pois as observações de balão cativo só puderam ser efetivadas quando a velocidade do vento era inferior a $10 \mathrm{~m} \mathrm{~s}^{-1}$.

Comparando as observações com resultados de um modelo de fechamento de segunda ordem, OLIVEIRA et alli (1995) mostraram que estes JBN podem ser explicados em termos de um gradiente horizontal de pressão de 0,25 mb / $100 \mathrm{Km}$, orientado na direção NW-SE, provavelmente induzido pelo aquecimento diferencial da CLP devido à inclinação do Planalto Paulista.

A Figura 1.10 apresenta um dos JBN observados em Iperó durante as Campanhas Observacionais. Os perfis verticais apresentados são resultado de uma metodologia de interpolação conjunta dos dados observacionais (i.e., dados de balãocativo, dados de superfície tomados em torre e dados de grande-escala). Nesta figura, pode-se observar a estrutura vertical típica do JBN em Iperó. Durante o período noturno nota-se que:

(1) o JBN intensifica-se;

(2) a altura da velocidade máxima ascende para atingir $400 \mathrm{~m}$ às $8 \mathrm{~h}$; 
(3) a espessura da camada do jato aumenta e também sua capacidade de transporte de escalar, umidade, calor e momento;

(4) o cisalhamento direcional da velocidade do vento aumenta a medida que o JBN se intensifica;

(5) o cisalhamento direcional do vento é menor junto a superfície onde o cisalhamento do módulo da velocidade do vento é muito intenso (i.e., da ordem de $\left.0,08 \mathrm{~s}^{-1}\right)$.

Diversos pesquisadores têm destacado o papel da topografia no Estado de São Paulo na geração e sustentação de células de circulação direta em mesoescala no Estado de São Paulo. Para KARAM (1995), o JBN observado na região de Iperó sobre uma região de suave inclinação topográfica correspondente à parte oeste da bacia do Rio Paraná está associado a uma circulação secundária com ventos de sudeste, resultante da oscilação inercial do ramo inferior da circulação desacoplada no período noturno. Esta hipótese encontra embasamento no conjunto de evidências observacionais e numéricas.

Este trabalho investiga os efeitos da célula de circulação associada à brisa marítima e à escarpa da Serra do Mar sobre o JBN observado em Iperó. Neste caso, o objetivo é entender os mecanismos de geração e sustentação dessa circulação atmosférica, induzida por contrate térmico e aerodinâmico da superfície, considerando seu papel sobre a dinâmica do JBN observado em Iperó. 


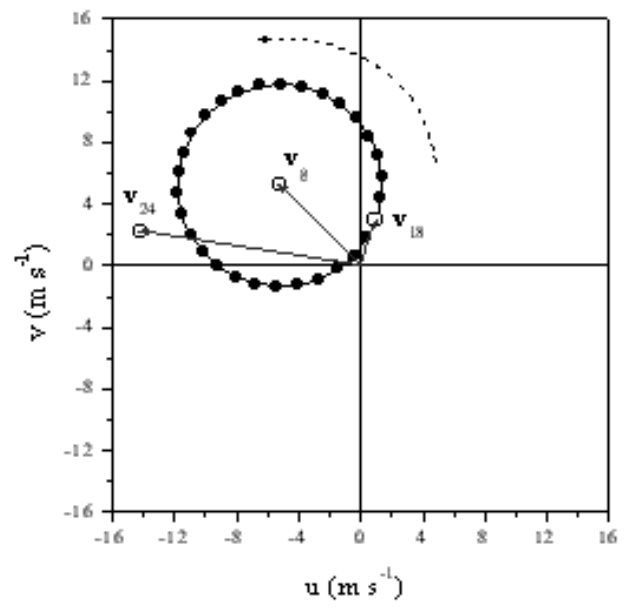

(a) 23 a 24 de janeiro de 1983

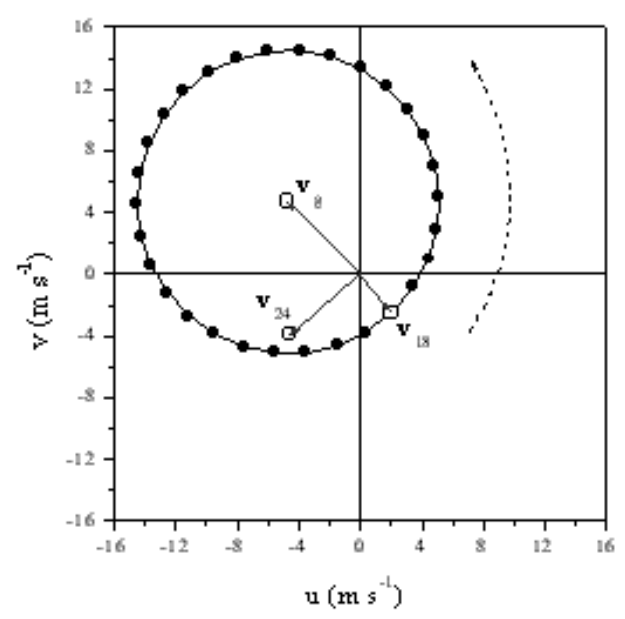

(c) 26 a 27 de janeiro de 1983

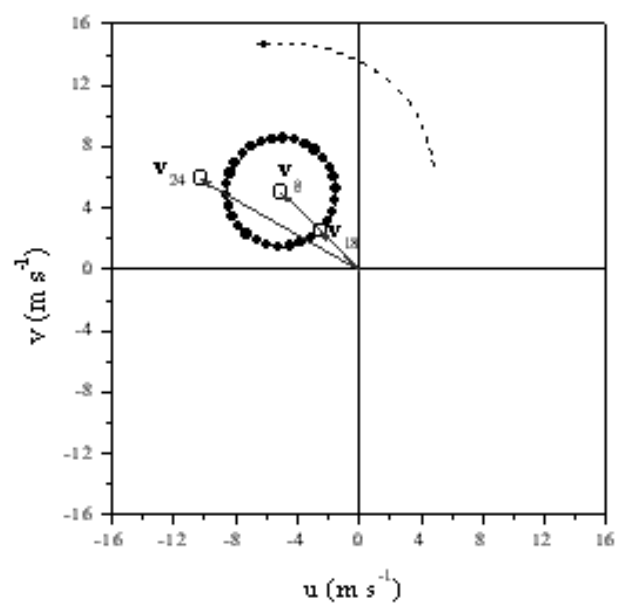

(b) 24 a 25 de janeiro de 1983

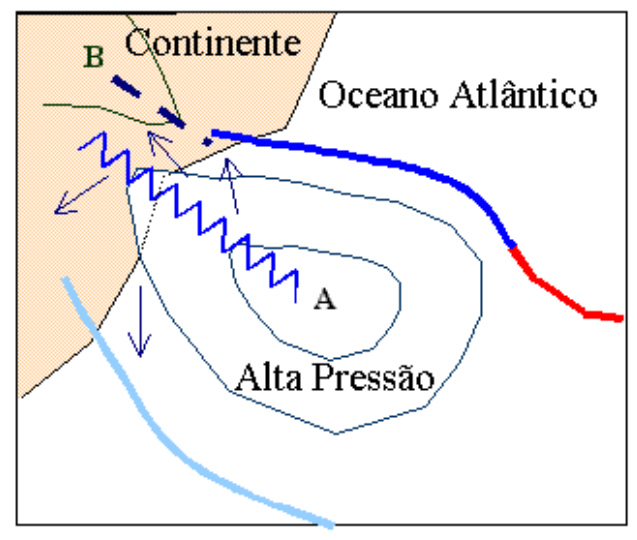

(d) Presença de crista de alta pressão

Figura 1.6 Representação da oscilação inercial do vetor velocidade do vento no nível de pressão de $850 \mathrm{hPa}$, em Bauru, na noite entre os dias (a) 23 e 24; (b) 24 e 25 e (c) 26 e 27 de janeiro de 1983. Apresenta-se na figura os vetores correspondentes ao vento geostrófico $\left(\mathbf{v}_{\mathrm{g}}\right)$; à velocidade do vento às $18 \mathrm{~h}\left(\mathbf{v}_{18}\right)$ e às 24 horas $\left(\mathbf{v}_{24}\right)$, conforme observados em Bauru (círculos pequenos abertos). $\mathrm{O}$ conjunto de círculos pequenos preenchidos, distribuídos ao longo da circunferência da oscilação inercial, representam posições sucessivas da ponta do vetor velocidade, tomadas em sentido anti-horário e intervaladas de uma hora. O quadro (d) representa o escoamento associado à presença da Crista de Alta Pressão no Estado de São Paulo. Um quarto do período inercial (P/4) corresponde a 7,5 h em Bauru. 

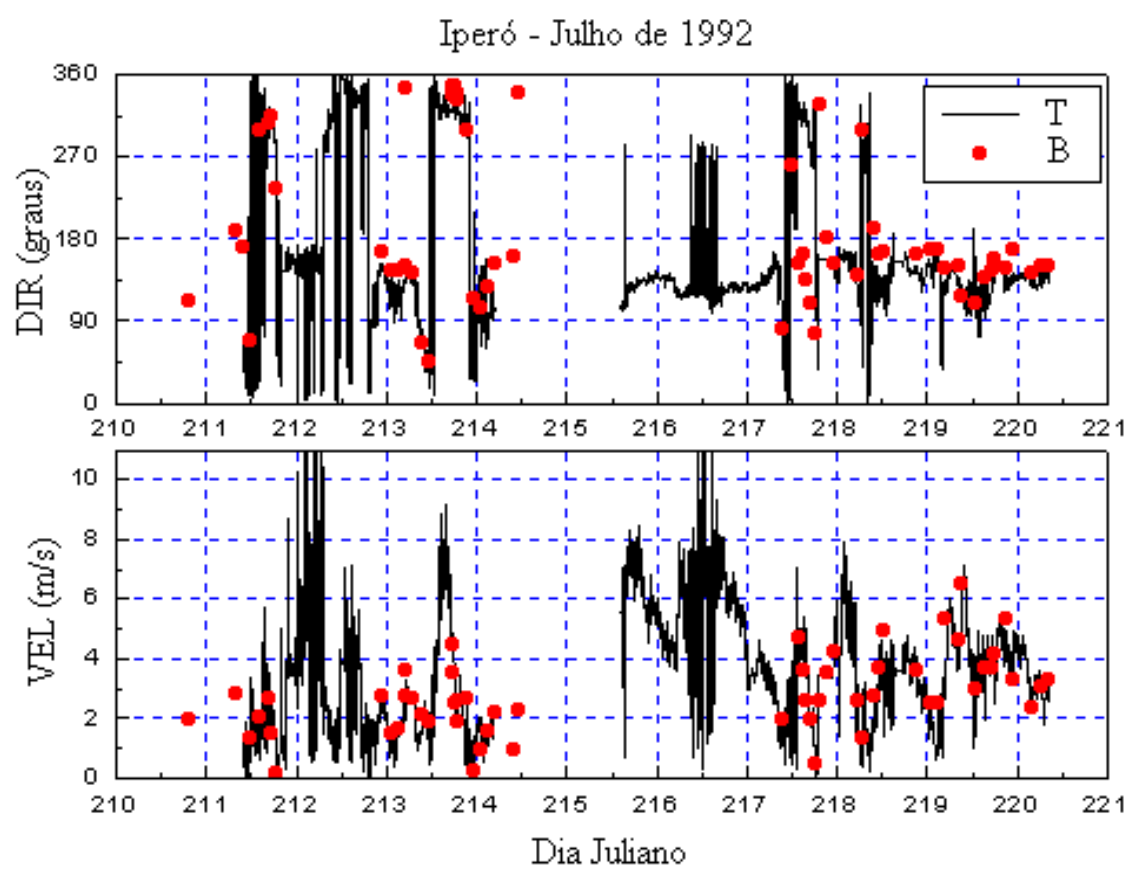

Iperó - Março de 1993
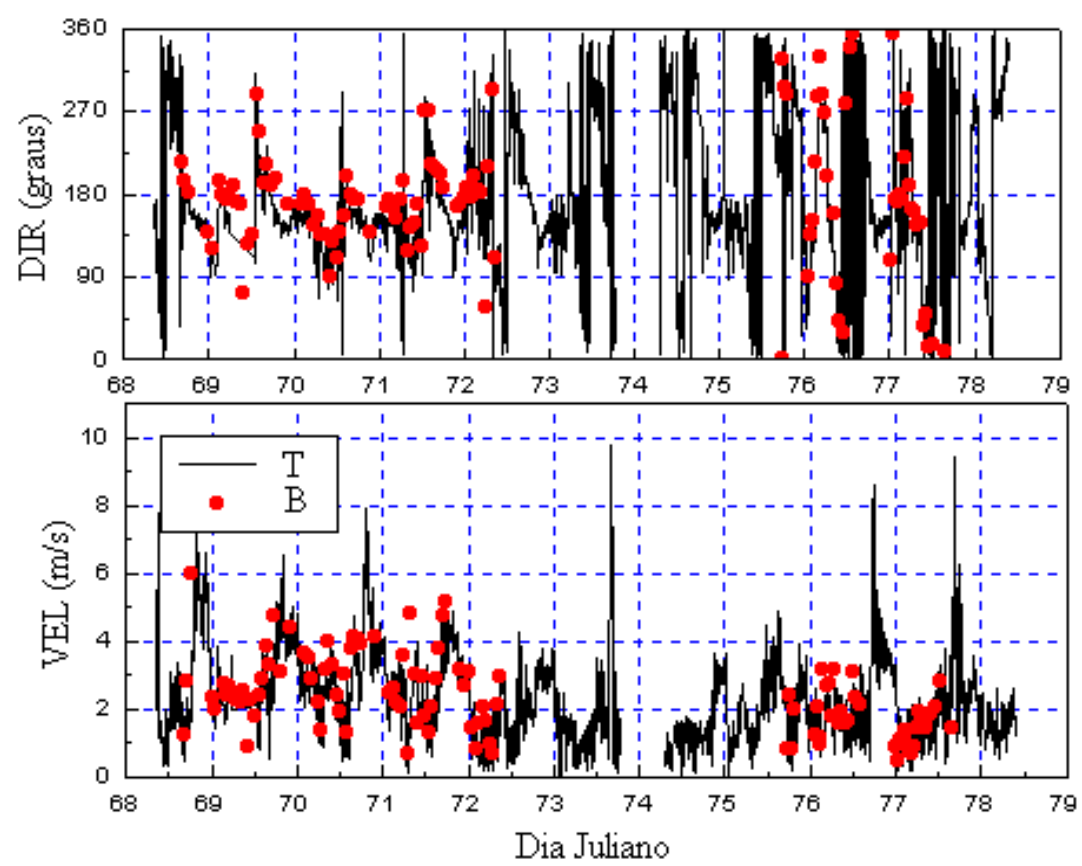

Figura 1.7 Evolução temporal da direção e da velocidade do vento observadas em Iperó durante a terceira e quarta campanhas de medidas, realizadas em julho de 1992 e março de 1993. Observações efetuadas com uma torre de $10 \mathrm{~m}$ (T) e por Balão Cativo (B). 


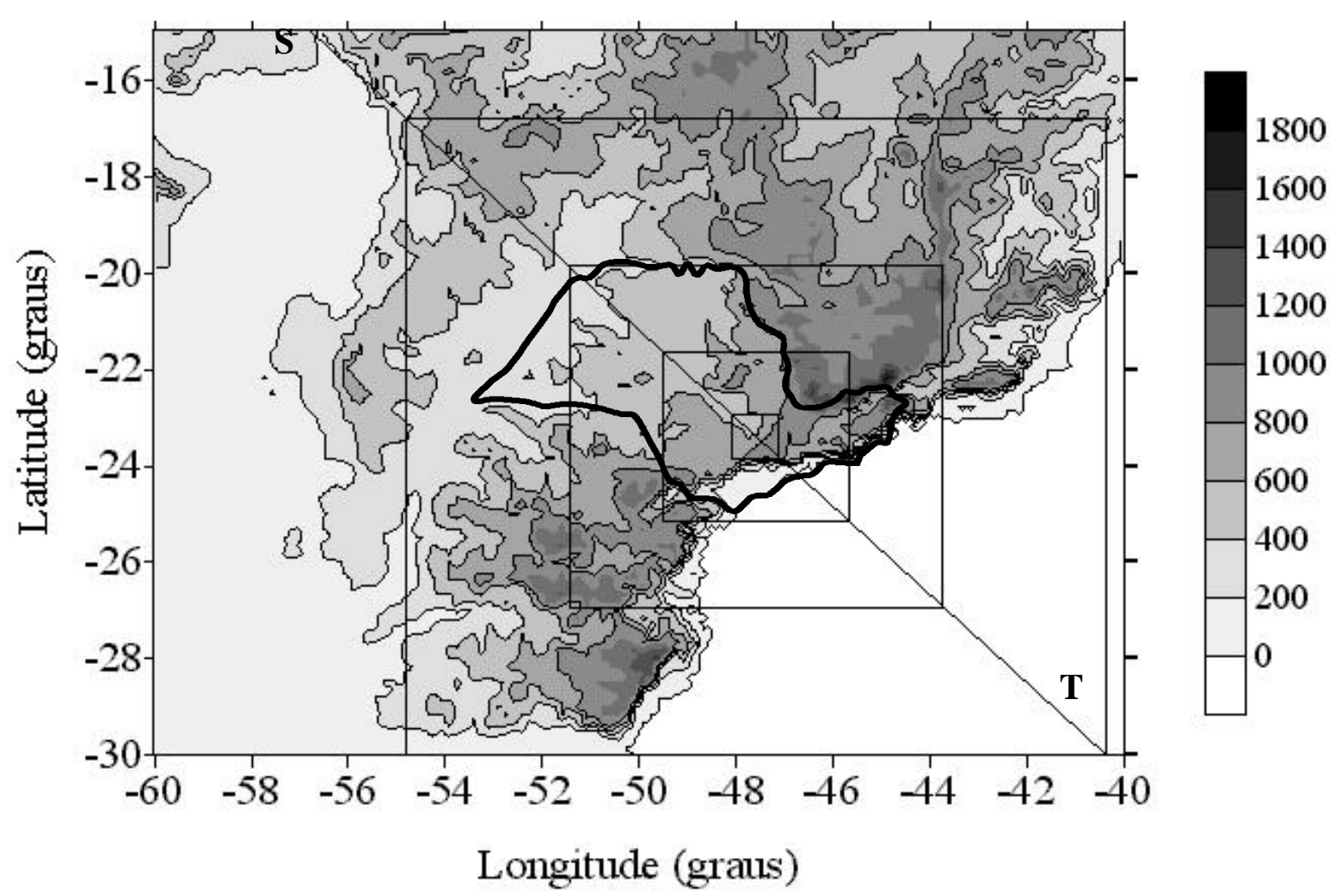

Figura 1.8 Isolinhas do contorno topográfico para uma área contendo as regiões Sudeste, Sul e parte da região Centro-Oeste do Brasil, mostrado em intervalos de $200 \mathrm{~m}$. A linha mais espessa mostra a fronteira política do Estado de São Paulo. Os quadrados concêntricos na posição geográfica de Iperó, SP $\left(47,65^{\circ} \mathrm{W} ; 23,40^{\circ} \mathrm{S}\right)$ apresentam lados de dimensão aproximada 1500 , 800,400 e $100 \mathrm{~km}$ correspondentes aos domínios das simulações numéricas. A linha ST indica a orientação do corte vertical da topografia apresentada na Figura 1.9 (adiante).

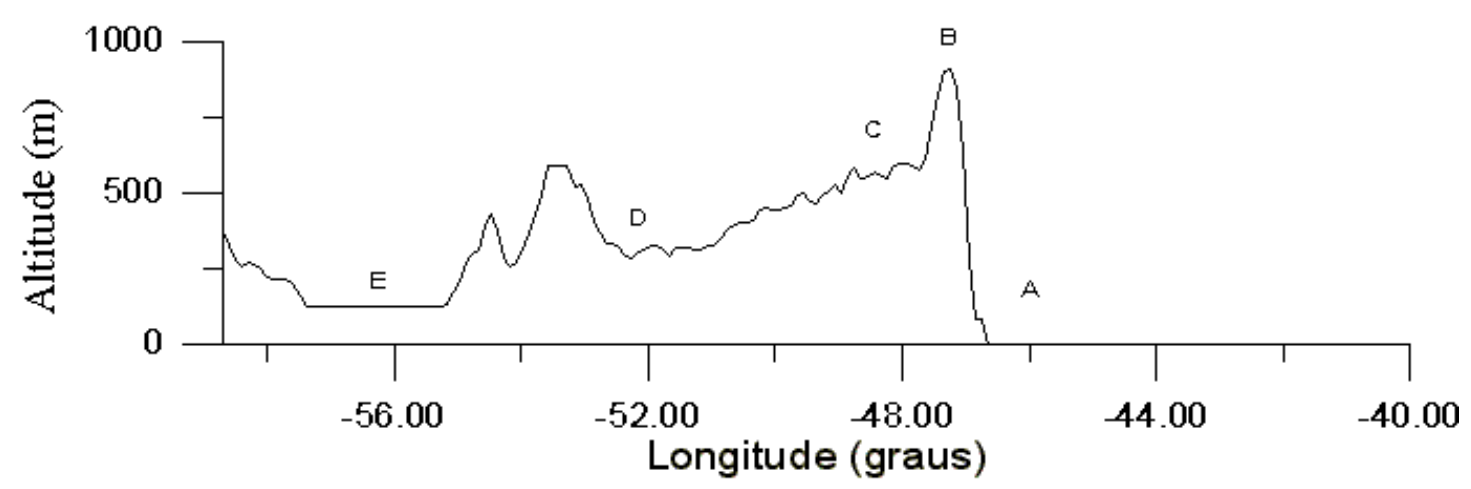

Figura 1.9 Seção transversal na topografia da região sudeste do Brasil ao longo da Corte ST (Figura 1.8), onde se destaca a localização do Litoral Paulista (A); Serra do Mar (B); do município de Iperó (C); da calha do Rio Paraná (D) e das planícies, igarapés e igapós do Pantanal (E). 


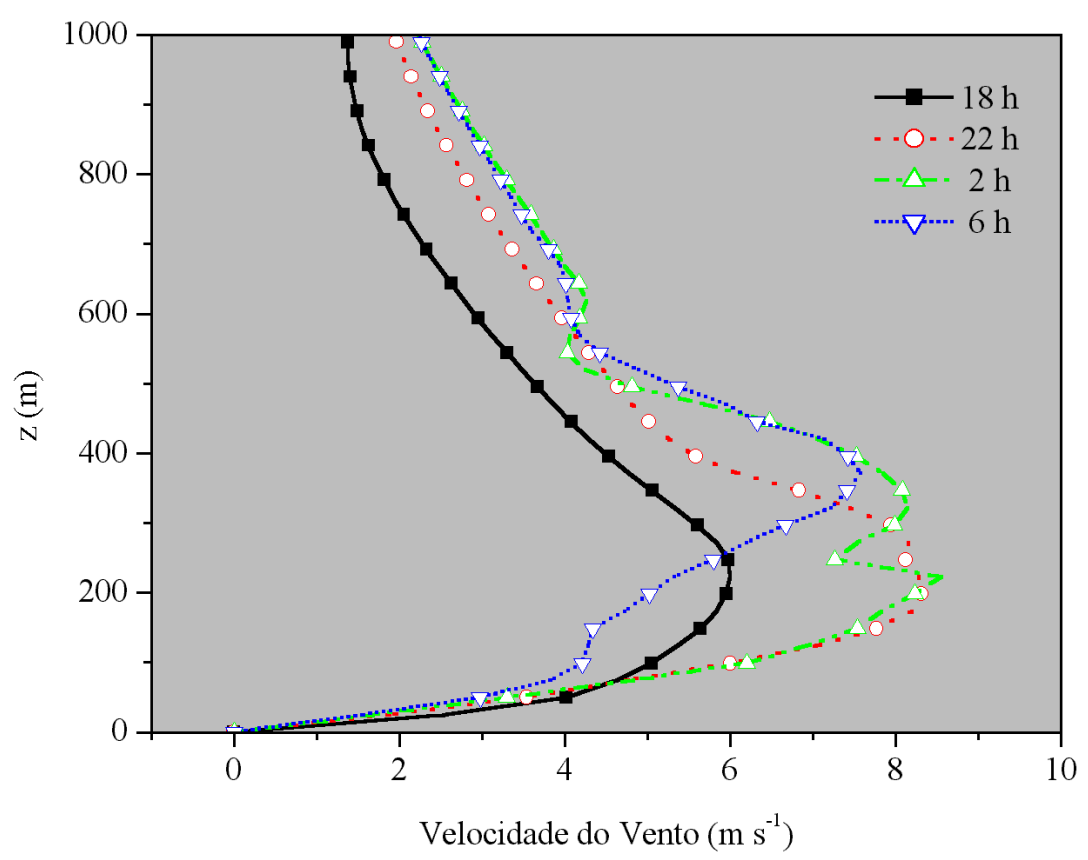

(a)

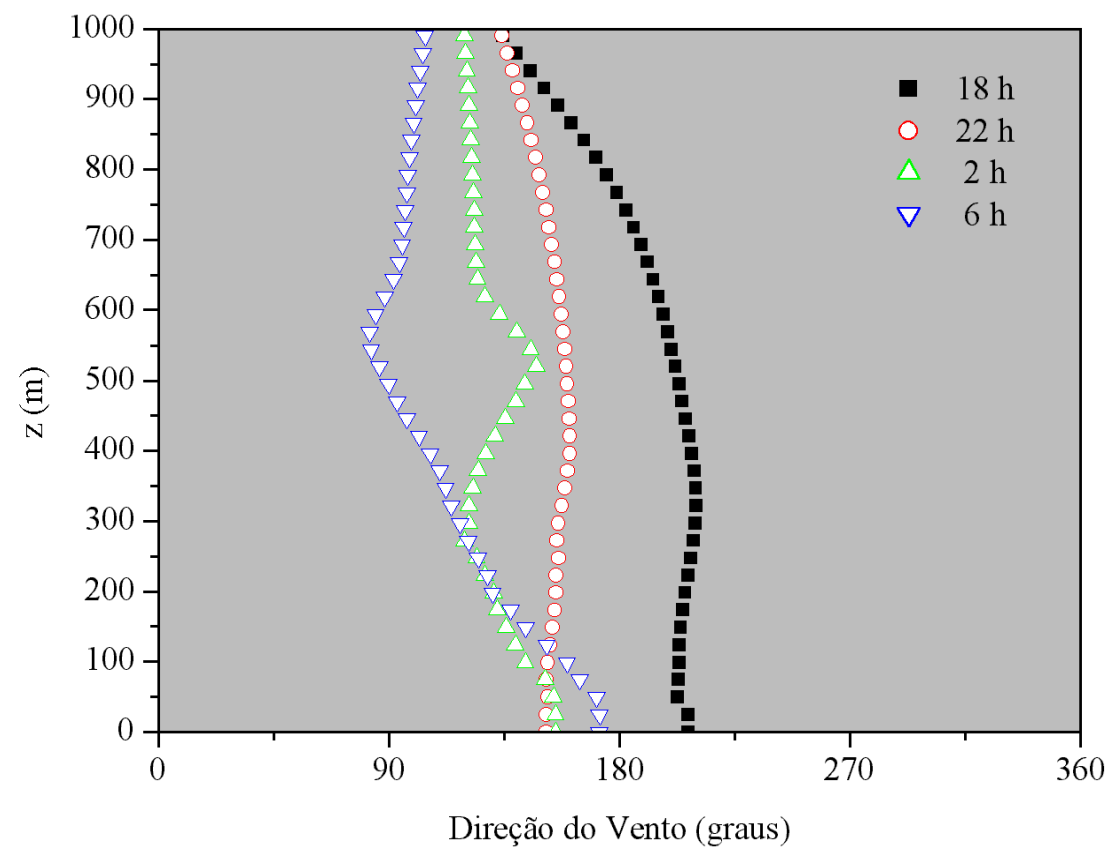

(b)

Figura 1.10 Exemplos dos perfis verticais de (a) velocidade e (b) direção do vento associados à ocorrência de um JBN em Iperó-SP, na noite do dia 12 para 13 de março de 1993, durante o período da Quarta Campanha Micrometeorológica. 


\subsection{Mecanismos Geradores}

De acordo com KRAUS et alli (1985) entre os fenômenos associados aos JBNs encontram-se: (i) baroclinicidades de escala sinótica associadas aos sistemas de tempo; (ii) baroclinicidades associadas com terrenos inclinados; (iii) frentes; (iv) acelerações advectivas; (v) bifurcações, canalizações e confluências ao redor de barreiras montanhosas; (vi) brisas marítima e terrestre; (vii) ventos de vale e montanha e (viii) escoamentos inerciais. Um ou mais dessas causas podem atuar conjuntamente para a formação e/ou sustentação de um JBN.

\section{Mecanismos de geração:}

(a) Oscilação inercial;

(b) Aquecimento diferencial da topografia inclinada;

(c) Conservacão da vorticidade potencial;

(d) Gradientes de pressão de mesoescala devido aos gradientes horizontais (E-W) da taxa de resfriamento radiativo e umidade do ar da CLP;

(e) Efeitos de grande-escala (divergência em $200 \mathrm{hPa}$ associada ao JAN);

(f) Efeitos mecânicos da topografia: bloqueios, canalizações e acelerações.

A seguir, descreve-se detalhadamente esses mecanismos de geração:

Oscilação inercial. Mecanismo proposto por BLACKADAR (1957), ocorre quando a aceleração do vento na CLP está apenas sujeita à força do gradiente de pressão e à força de Coriolis, implicando que a componente ageostrófica do vento oscile inercialmente ao redor do vetor do vento geostrófico, definindo o circulo inercial (Figura 1.11 a). Neste mecanismo supõe-se o desenvolvimento do jato em um período correspondente à metade do período inercial $\mathrm{P}=|\mathrm{f}|^{-1}$ (p.g., DUTTON, 1995), onde f é o parâmetro de Coriolis ( $\mathrm{f} \cong-5,8 \times 10^{-5} \mathrm{~s}^{-1}$ para latitude de São Paulo). Para Iperó, pela oscilação inercial o máximo do JBN se desenvolveria após 15 h (um período longo considerado longo demais se comparado à duração da noite);

Efeitos topográficos. A topografia apresenta dois tipos de efeitos: mecânicos e térmicos. Entre os efeitos mecânicos destacam-se: a canalização; o bloqueio associado às barreiras (Figura 1.12); aos pontos de estagnação associados à conversão de energia cinética em potencial; a formação de ondas de gravidade e de sotavento; a zona de quebra de onda; a aceleração vento-abaixo por efeitos não-lineares e ressonância (neste caso, que a extensão horizontal do jato está associada à largura do vale); a bloqueios 
topográficos, a pontos de estagnação do escoamento e à aceleração do escoamento sobre montanhas, como aqueles que podem ser descritos pela equação de BERNOUILLE ${ }^{16}$, i.e., escoamentos POTENCIAIS que são muito importantes sobre topografia complexa (Figura 1.11 b). Entre os efeitos térmicos destacam-se os escoamentos resultantes dos ventos catabáticos e anabáticos, i.e., associados à brisa de montanha-vale e de valemontanha, respectivamente.

Efeitos baroclínicos. Esses efeitos baroclínicos ocorrem devido ao contraste térmico que se estabelece entre: terra-água, vale-montanha (Figura 1.14), solo úmido e solo seco, devido variações da cobertura vegetal e à presença de massas de ar diferentes na dianteira e retaguarda das frentes-frias entre outras possibilidades. No caso das frentes-frias que se propagam de SE para NW sobre a AS pode-se identificar tipicamente três jatos: dois JBNs e um JAN através de um corte vertical de coordenadas $(\mathrm{y}, \mathrm{z}) . \mathrm{Na}$ estrutura do escoamento frontal, há ventos de NW à dianteira e ventos de SE na retaguarda da frente-fria para as camadas de ar mais próximas da superfície. Acima (abaixo) da zona frontal (i.e., do plano muito inclinado que separa as massas de ar fria e quente, que apresenta inclinação da ordem de 1:500), o jato frontal se forma de NW (SE) (MALONE, 1951). No caso de jatos associados a frentes-frias, a altitude do máximo depende das características específicas da frente-fria (WHITEMAN et alli, 1997) e das esteiras transportadoras ${ }^{17}$ (BROWNING, 1982 e RAY, 1986), mas pode existir uma relação entre a distância até a zona frontal em superfície e a altura do máximo do JBN na retaguarda da frente-fria.

\section{Transporte meridional de vorticidade potencial e escoamentos que impingem} montanhas. WEXLER (1961) estabeleceu uma descrição simples e qualitativa para o JBN das Grandes Planícies baseando-se na conservação da vorticidade absoluta; que tem sido freqüentemente empregada para explicar as variações do cisalhamento horizontal e curvatura de correntes movendo-se nas direções sul-norte. "Se $(f+\zeta) / D$ é constante para uma coluna individual que se move para norte, então conforme $\mathrm{f}$, o

\footnotetext{
${ }^{16}$ A equação de BERNOULLI ao longo de uma linha-de-corrente pode ser escrita como $\mathrm{u}^{2}=\mathrm{U}_{0}^{2}-\left(2 \Delta \mathrm{p} / \rho_{0}+\mathrm{N}^{2} \eta^{2}\right)$

onde $\Delta \mathrm{p}$ é a diferença de pressão entre o ponto $(\mathrm{x}, \mathrm{y}, \mathrm{z})$ e o ponto na mesma elevação mas longínquo de coordenadas $(\infty, \infty, \mathrm{z})$; $\mathrm{N}$ é a freqüência de BRUNT-VÄISÄLÄ; $\mathrm{U}_{0}(\mathrm{z})$ velocidade no ponto distante vento-abaixo onde a densidade hidrostática é dada por $\rho=\rho_{0}\left(1-z \mathrm{~N}^{2} / \mathrm{g}\right)$ e $\eta$ é o deslocamento vertical da superfície de densidade acima da superfície $\eta(\mathrm{x}, \mathrm{y}, \mathrm{z})$ que sobre a superfície do terreno coincide com a topografia $\mathrm{h}$, isto é, $\eta(\mathrm{x}, \mathrm{y}, \mathrm{z})=\mathrm{h}(\mathrm{x}, \mathrm{y})(\mathrm{SMITH}, 1989)$.

${ }_{17}$ As esteiras transportadoras são identificadas num sistema de coordenada isentrópica $\left(\begin{array}{lll}\theta & \text { cte. })\end{array}\right.$ lagrangiano, i.e., colocado sobre o centro de baixa da frente-fria que se desloca.
} 
parâmetro de Coriolis, aumenta com o aumento da latitude, $\zeta$, a vorticidade relativa e D, a espessura da coluna de ar, precisa diminuir. Se D mantém-se constante, a coluna precisa adquirir mais vorticidade anticiclônica relativa a Terra. Se esta é convertida principalmente em cisalhamento anticiclônico, então haverá desenvolvimento de uma corrente de escoamento com altas-velocidades na fronteira oeste do escoamento, junto às montanhas impingidas pelo escoamento. De acordo com WEXLER, à medida que a corrente de ar se aproxima da fronteira montanhosa a velocidade meridional aumenta exponencialmente; a espessura da camada diminui com a raiz quadrada da distância, desde que o fluxo de massa torna-se nulo no limite da montanha, apresentando um máximo à cerca de $140 \mathrm{~km}$ de sua fronteira, diminuindo com a distância do limite oeste. Para KRISHNAMURTI e WONG (1979), esse mecanismo pode explicar a aceleração do escoamento do jato equatorial na Somália (NE da África), resultante do escoamento inicial meridional, que transporta de sul para norte uma coluna de ar oriunda do Anticiclone do Oceano Índico. O escoamento cruza o Equador, tendo as montanhas da África oriental servindo de fronteira topográfica a oeste. $\mathrm{O}$ jato resultante, ao norte do Equador, que apresenta curvatura ciclônica transporta parte do ar marítimo que vai alimentar a Monsão durante o verão indiano.

O efeito do bloqueio das Montanhas Rochosas sobre a conservação da Vorticidade Potencial (VP) de uma parcela de ar que se desloca desde a região do Golfo do México até o Oklahoma e Kansas sobre os EUA está representado na Figura 1.13. Como se pode considerar, por hipótese, que $\partial \mathrm{u} / \partial \mathrm{y} \cong 0$ ao longo das Montanhas Rochosas (alinhadas na direção $\mathrm{S}$ para $\mathrm{N})$ e como a VP é definida por $\mathrm{VP}=(\mathrm{f}+\partial \mathrm{u} / \partial \mathrm{y}-$ $\partial \mathrm{v} / \partial \mathrm{x}) / \Delta \theta=$ constante tem-se com o deslocamento das parcelas de ar de $\mathrm{S}$ para $\mathrm{N}$ um aumento de f que ocorre simultaneamente a uma redução de $\partial v / \partial x$. Essa redução de $\mathrm{dv} / \mathrm{dx}$ pode implicar em dois efeitos: (a) em um forte cisalhamento da velocidade do vento (i.e., ventos mais intensos ocorrem a Oeste, junto às Rochosas) ou (b) uma curvatura ciclônica do escoamento (i.e., um giro horário para o Hemisfério Norte). De acordo com SCHAEFER (1982), o efeito da conservação da VP tem importância menor, podendo aumentar a amplitude da oscilação diurna do vento na CLP entre 10 e $20 \%$.

Complexos Convectivos (CCM). O escoamento na CLP se acelera em direção a área apresentando queda de pressão, esta última associada ao desenvolvimento noturno do CCM (Figuras 1.5 e 1.15); 
Outros. Destaca-se a aceleração do vento que passa por vales estreitos ou afunilados (como ocorre em certos vales dos Paises Nórdicos). O escoamento que impinge uma cadeia de montanhas passa pelos vales. Neste caso, o valor e a constância do vento de escala sinótica é importante na definição de JBN localizados, assim como a pista de vento (fetch) será responsável pela duração do fenômeno.

A Tabela 1.3 apresenta critérios de classificação de JBN encontradas na literatura. Entre os critérios existem aqueles (a) baseados somente na intensidade e altura do máximo (STULL, 1988; WHITEMAN et alli, 1997 e BONNER, 1968) e (b) aqueles baseados tanto no valor e altura do máximo como também na presença de cisalhamento direcional (OLIVEIRA e FITZJARRALD, 1993, 1994). O critério do cisalhamento direcional foi utilizado pelos pesquisadores citados para classificar JBN sob condições ambientes intensamente convectivas da Amazônia.

Para UCCELLINI e JOHNSON (1979), os efeitos não-lineares ocorrem simultaneamente à queda de pressão no ciclone extratropical devido ao aquecimento diabático da troposfera média por precipitação e à queda (aumento) da pressão em baixos (altos) níveis. O acoplamento do JAN e do JBN pode se dar através de uma circulação secundária que se estabelece no plano perpendicular ao eixo do JAN (Figura 1.15).

\subsection{Objetivos}

Neste trabalho utiliza-se a versão não-hidrostática do modelo de mesoescala, denominado TVM, para simular as circulações induzidas e modificadas pela topografia no interior do Estado de São Paulo e determinar o seu papel na formação dos JBN.

De acordo com DUTTON (1995), a utilização de modelagem permite organizar e documentar o conhecimento; revelar as relações entre causa e efeito; testar conhecimentos; revelando questões para pesquisa e observação; predizer mudanças na estrutura de forçantes ou variações dos parâmetros essenciais e prever o comportamento evolucionário da atmosfera. 
Utiliza-se também uma rotina lagrangiana de dispersão de partículas para determinar o papel dos JBN sobre o transporte de curto e médio alcance de um poluente inerte, emitido continuamente por uma fonte pontual localizada na superfície.

\begin{tabular}{|c|c|c|}
\hline TIPO & CRITÉRIO DE CLASSIFICAÇÃO & REFERÊNCIA \\
\hline $\begin{array}{l}\text { Definido de } \\
\text { forma } \\
\text { pragmática }\end{array}$ & $\begin{array}{l}\text { Quando se encontra um máximo relativo na estrutura vertical } \\
\text { da velocidade do vento com intensidade maior que } 2 \mathrm{~m} \mathrm{~s}^{-1} \\
\text { nos primeiros } 1500 \mathrm{~m} \text { da atmosfera acima da superfície. }\end{array}$ & STULL (1988: cap. 12) \\
\hline $\mathrm{J} 0$ & $\mathrm{v}_{\text {máx }} \geq 10 \mathrm{~ms}^{-1} \mathrm{e}\left(\mathrm{v}_{\max }-\mathrm{v}_{3 \mathrm{~km}}\right) \geq 5 \mathrm{~ms}^{-1}$ & WHITEMAN et alli (1997) \\
\hline J I & $v_{\text {máx }} \geq 12 \mathrm{~ms}^{-1}$ e $\left(\mathrm{v}_{\max }-\mathrm{v}_{3 \mathrm{~km}}\right) \geq 6 \mathrm{~ms}^{-1}$ & \multirow{3}{*}{ BONNER (1968a) } \\
\hline J II & $v_{\text {máx }} \geq 16 \mathrm{~ms}^{-1} \mathrm{e}\left(\mathrm{v}_{\text {máx }}-\mathrm{v}_{3 \mathrm{~km}}\right) \geq 8 \mathrm{~ms}^{-1}$ & \\
\hline J III & $\mathrm{v}_{\operatorname{máx}} \geq 20 \mathrm{~ms}^{-1} \mathrm{e}\left(\mathrm{v}_{\max }-\mathrm{v}_{3 \mathrm{~km}}\right) \geq 10 \mathrm{~ms}^{-1}$ & \\
\hline $\mathrm{J} 1$ & 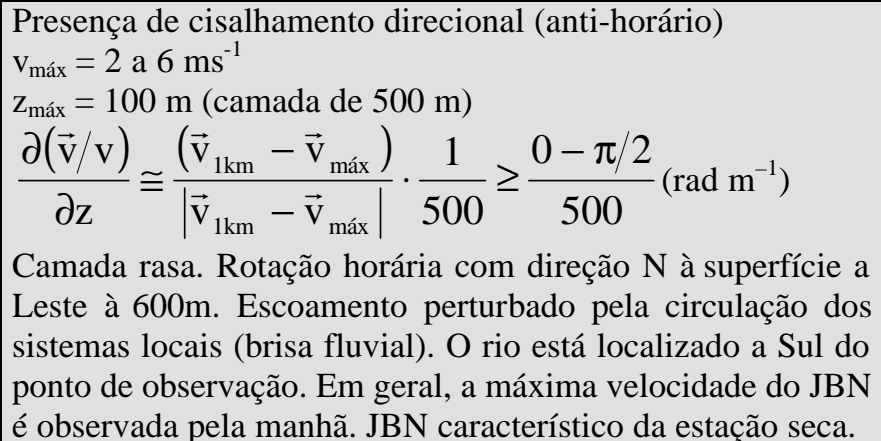 & \multirow{2}{*}{$\begin{array}{l}\text { OLIVEIRA e } \\
\text { FITZJARRALD } \\
\text { (1993-1994). }\end{array}$} \\
\hline $\mathrm{J} 2$ & 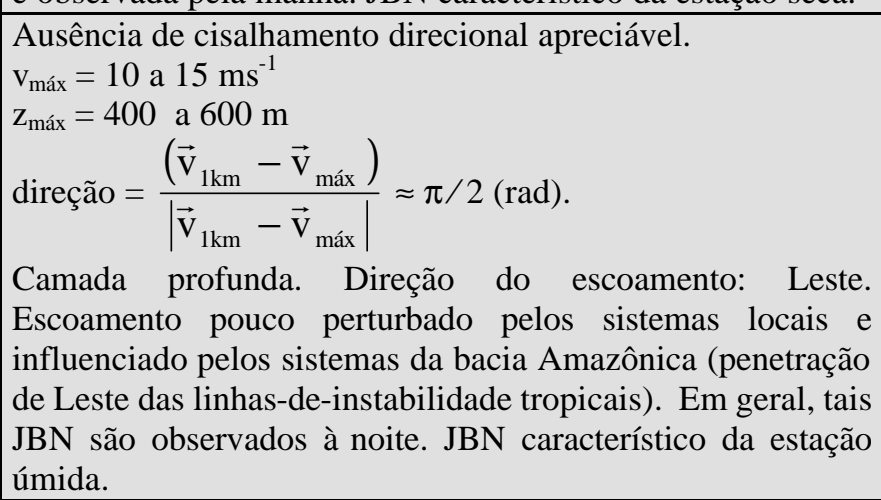 & \\
\hline
\end{tabular}

Tabela 1.3 Critérios de classificação para jatos de baixos níveis. 


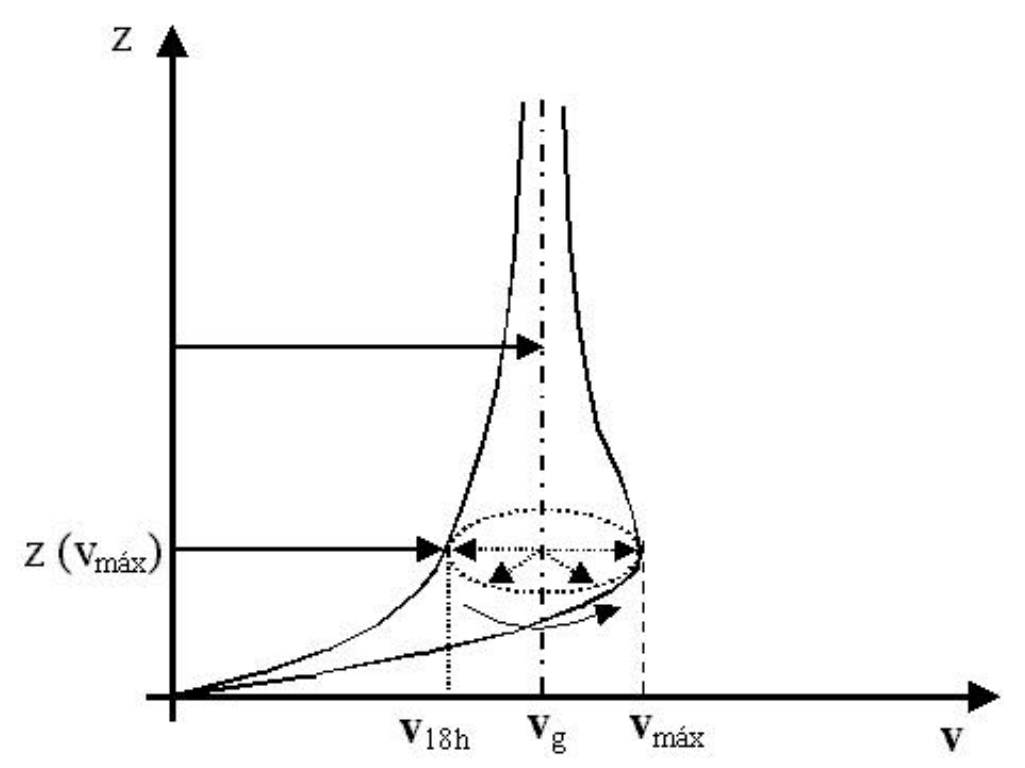

(a)

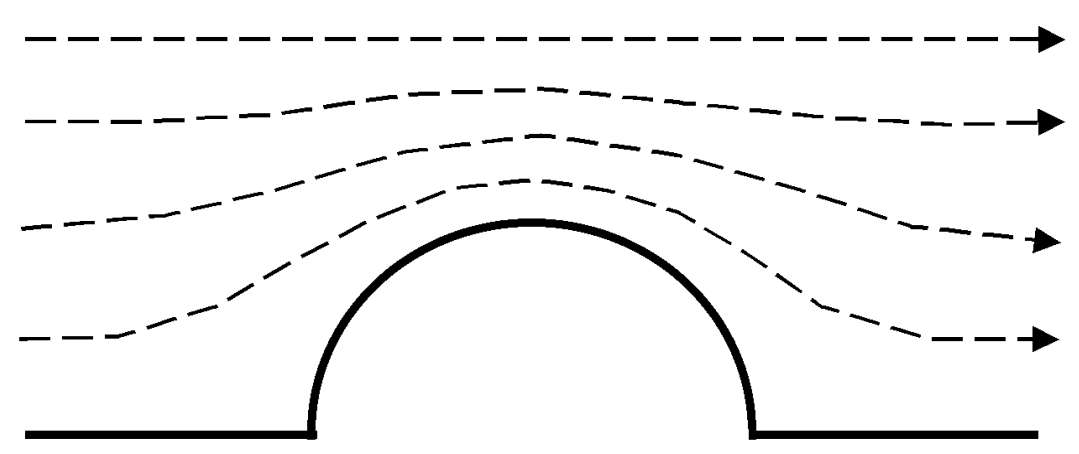

(b)

Figura 1.11 Representação de dois mecanismos de aceleração do escoamento devidos: (a) à oscilação inercial da estrutura vertical do vento médio na CLP para Hemisfério Sul e (b) à intensificação do gradiente da função de corrente de um escoamento potencial (não-divergente) sobre um obstáculo pelo efeito de BERNOUILLE. 


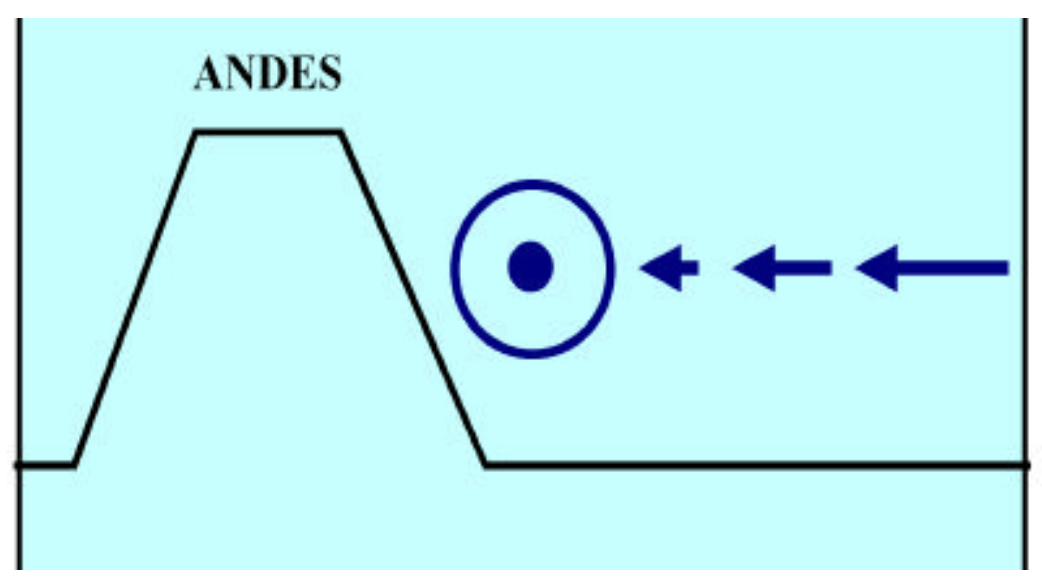

Figura 1.12 Efeito mecânico de bloqueio e canalização associado aos alísios que penetram pelo litoral brasileiro pela região amazônica, alcançando a barreira topográfica da Cordilheira dos Andes.

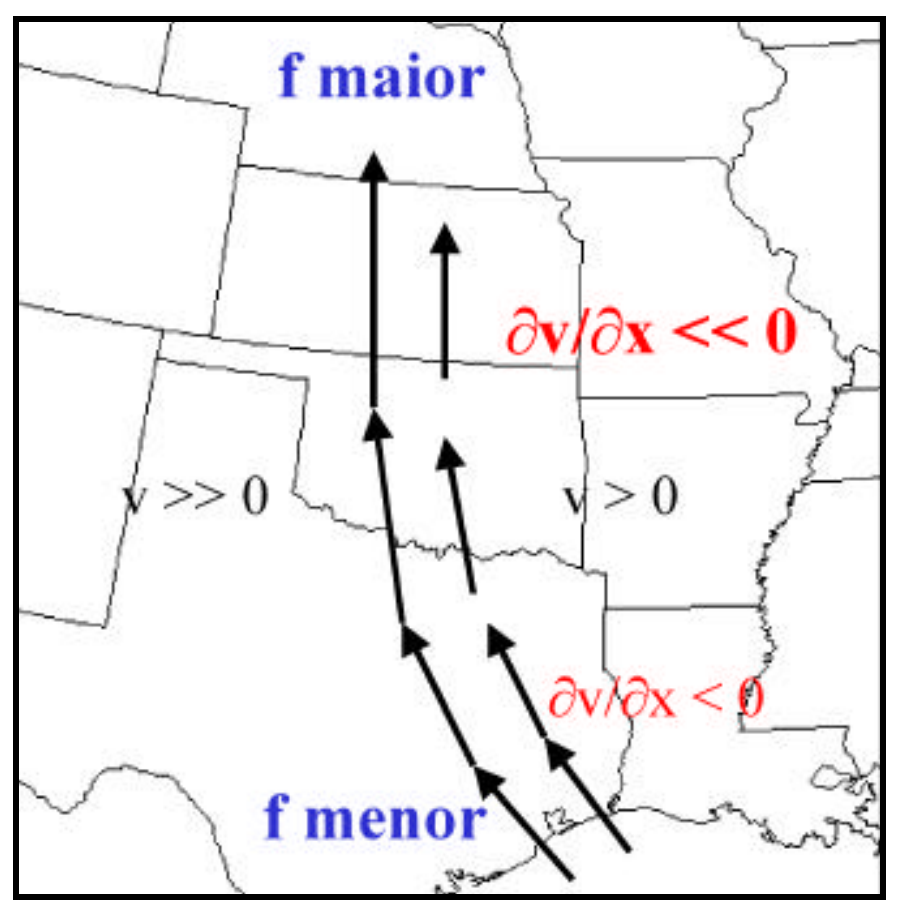

Figura 1.13 Efeito do bloqueio das Montanhas Rochosas nos EUA sobre a conservação da Vorticidade Potencial (VP) de uma parcela de ar que se desloca desde a região do Golfo do México, passando pelo Texas, até o Oklahoma e Kansas (MOORE, 2002). 


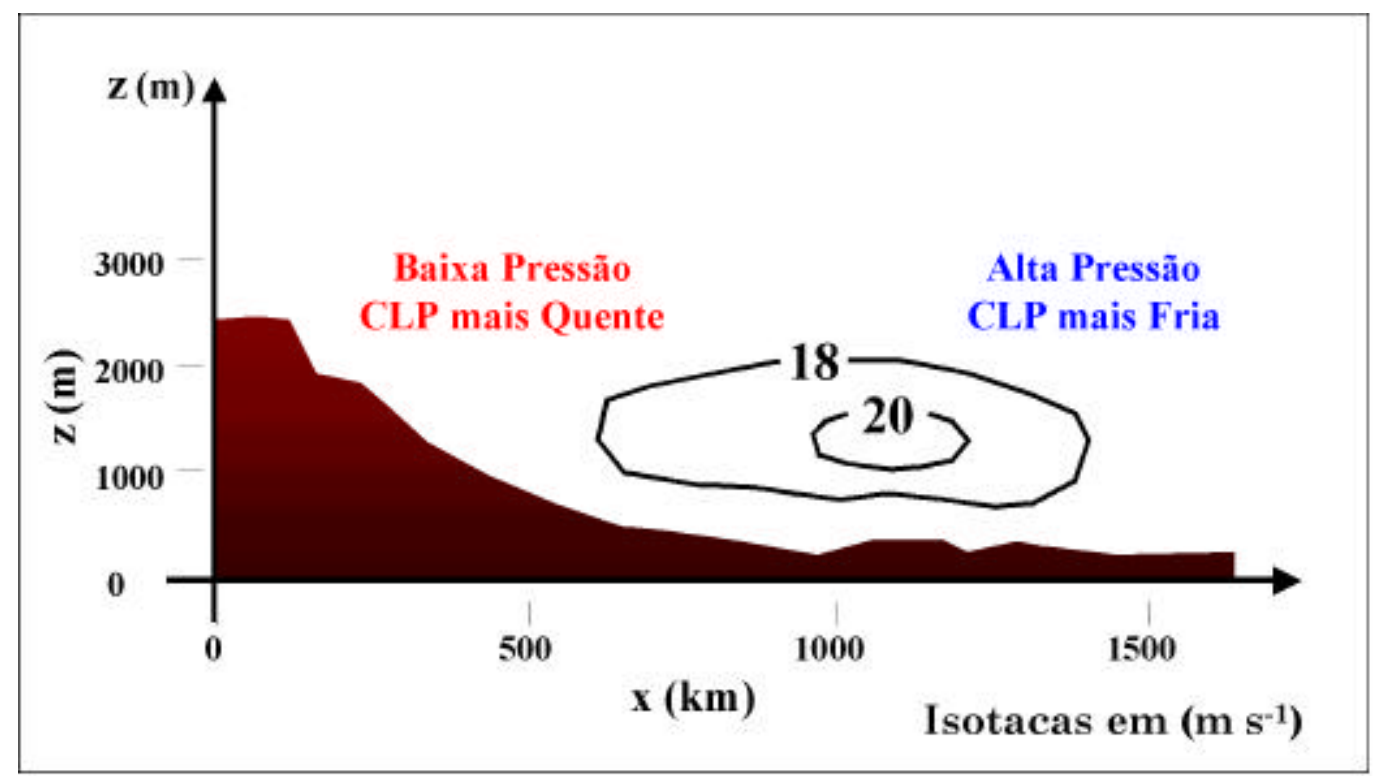

Figura 1.14 Representação do efeito do aquecimento diferencial da CLP sobre terreno inclinado da Grande Planície a leste das Montanhas Rochosas (EUA), em mesoescala, mostrando as isolinhas de velocidade do vento associadas ao JBN noturno (HOECKER, 1963; McNIDER e PIELKE, 1981). Inicialmente, ao final da tarde, o vento sopra de Leste, da planície para a montanha. A seguir, gira em sentido horário sob a ação da força de CORIOLIS, i.e., para direita no Hemisfério Norte, resultando em um JBN de componente Sul.

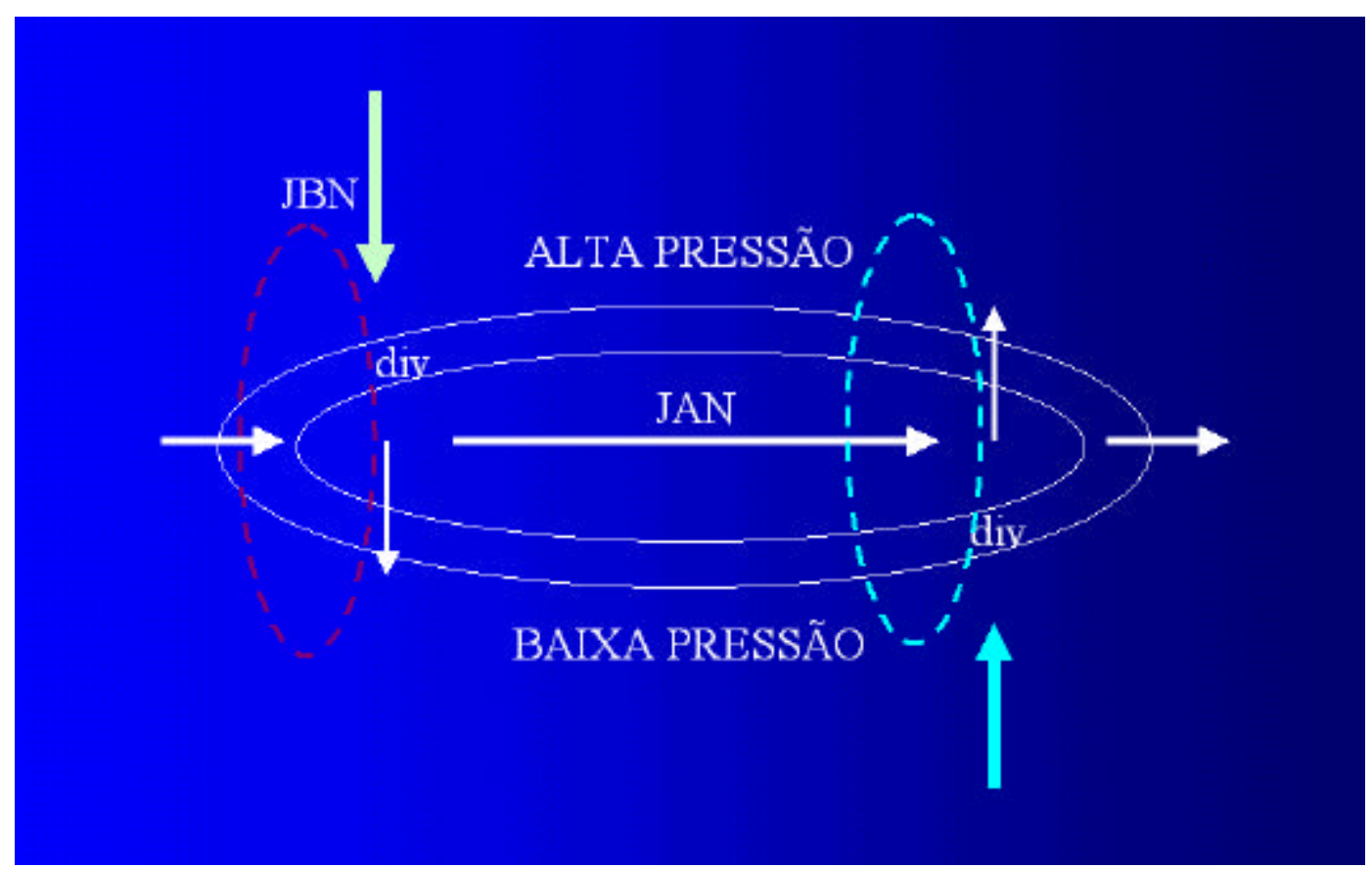

Figura 1.15 Acoplamento de um JAN (flecha branca) e de JBN (flechas verde ou azul) nas regiões de entrada e saída do JAN, respectivamente, efetivada por circulações secundárias ageostróficas, entre a alta e a baixa troposfera (linhas tracejadas) em planos perpendiculares ao eixo do JAN. O lado equatorial (polar) da entrada (saída) do JAN apresenta divergência, o que induz movimentos verticais ascendentes compensatórios na troposfera média. O gráfico original de UCCELLINI e JOHNSON (1979) foi adaptado para o Hemisfério Sul. 
A estrutura dinâmica da CLP no Estado de São Paulo é também afetada pela brisa marítima a leste; por circulações induzidas pela topografia complexa (anabática, catabática, canalizações) e pelo JBN. Esses fenômenos concentram-se na CLP e, portanto, para serem simulados numericamente pelo modelo de forma adequada e integrada é necessário considerar-se o papel da resolução na representação da estrutura vertical e da extensão do domínio espacial associados a esses fenômenos. Portanto, a primeira questão a considerada nesta pesquisa foi: qual é a resolução espacial necessária e a dimensão do domínio para simular de forma adequada estes fenômenos?

Uma vez respondida esta primeira questão; investiga-se a origem do JBN observados no Estado de São Paulo e testa-se duas hipóteses com respeito à formação desses JBN (Figura 1.16), considerando-o como uma:

(1) Oscilação inercial do ramo continental da brisa marítima que desacopla da superfície durante a noite (e que avança sobre o interior) e

(2) Oscilação inercial do ramo oriental da célula convectiva do Planalto Paulista que desacopla da superfície durante a noite.

Determinada a origem dos JBN, a próxima questão abordada nesta pesquisa foi: qual o papel dos JBN na trajetória de um poluente inerte emitido continuamente por uma fonte pontual na superfície?

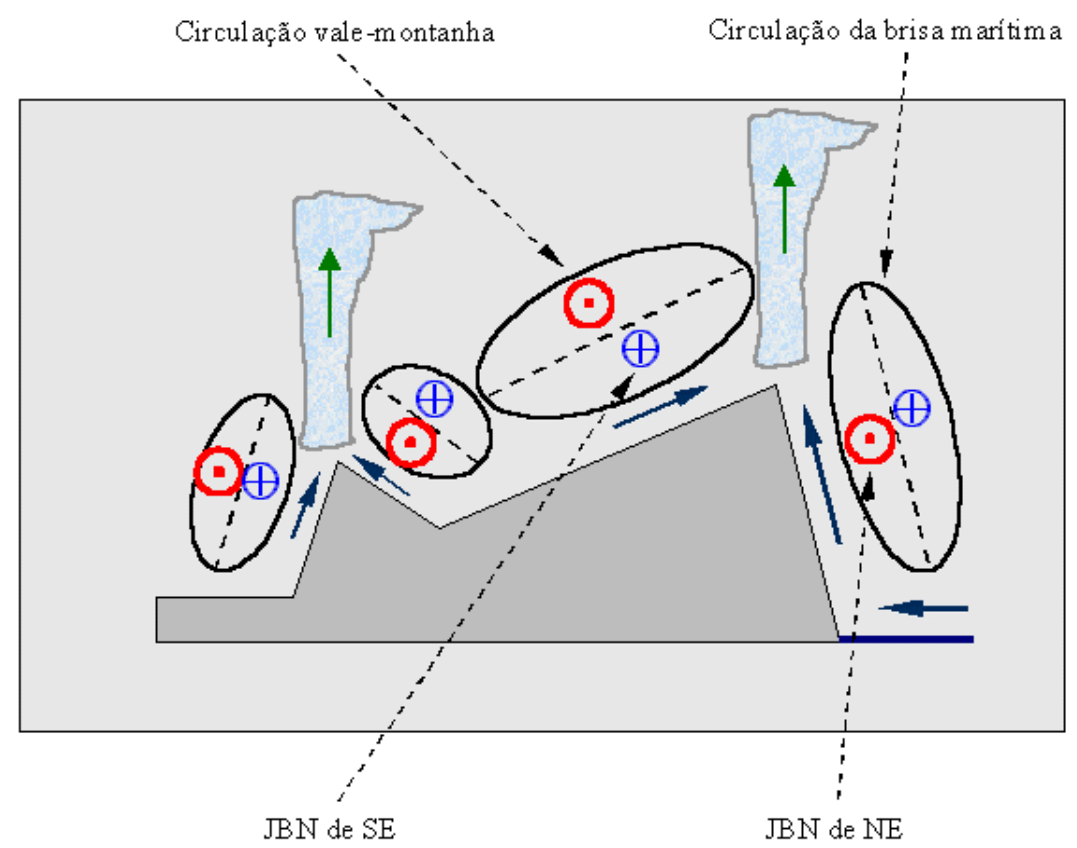

Figura 1.16 Modelo conceitual das células de circulação no Estado de São Paulo. 


\subsection{Justificativa do Estudo}

As principais motivações deste estudo são:

- A meteorologia da região de Iperó não é bem conhecida, especialmente do $\mathrm{JBN}$;

- Há uma fonte de radionuclídeos localizada no Centro Experimental ARAMAR (CEA) da Marinha Brasileira;

Os JBN podem ser induzidos por vários mecanismos, muitos deles de escala espacial menor ou igual à resolução espacial dos modelos de previsão de grande-escala (i.e., tipicamente $100 \mathrm{~km}$ ). Entretanto, a previsão precisa dos JBN seria muito desejável porque são fenômenos: (a) que podem ocorrem de forma simultânea ou mesmo preceder tempestades severas ${ }^{18}$; (b) que têm grande efeito sobre a dispersão de poluentes atmosféricos; (c) que afetam a dinâmica de incêndios florestais e (d) que se interrelacionam com processos de ciclogênese dos sistemas convectivos de mesoescala.

Os JBNs são elementos importantes no entendimento das circulações induzidas na baixa atmosfera. De acordo com WHITEMAN (1997), na Grande Planície dos EUA, os JBN transportam vapor de água e calor até a região de formação de tempestades, induzindo seu disparo na região de convergência do vento localizada à frente do jato (BONNER, 1968a e 1968b). O JBN também contribui para definir um cenário de circulações atmosféricas favoráveis ao desenvolvimento de Linhas de Instabilidade (LI). Neste caso, é comum que essas LI se alinhem em padrões perpendiculares à direção do eixo do jato.

Diversos estudos mostram o papel dos JBN no desenvolvimento de sistemas de precipitação convectiva localizada (WU e RAMAN, 1998). Por exemplo, os complexos convectivos de mesoescala (CCM), que também são fenômenos categoricamente noturnos, ocorrem em associação a um JBN que transporta ar potencialmente instável oriundo do lado equatorial e a um JAN que dá suporte a uma circulação divergente na alta troposfera. A interação entre o JAN e o JBN resulta em uma circulação secundária ageostrófica no plano vertical (y,z), normal ao eixo do JAN e tangente ao eixo do JBN.

\footnotetext{
${ }^{18}$ Dado o que ocorre no centro-oeste dos EUA.
} 
Enquanto muitos têm enfatizado o papel da CLP na formação dos JBN da Grande Planície dos EUA, p.ex., UCCELLINI e JOHNSON (1979) explicam-no em relação ao desenvolvimento sinótico do ciclone extratropical, ou seja, da ciclogênese que ocorre a sotavento das Montanhas Rochosas nos EUA, em associação aos efeitos da não-estacionariedade do campo de pressão. O padrão de vento isalobárico é similar ao padrão do vento ageostrófico que cruza as isopletas de geopotencial para área do jato, exceto na região de saída e entrada do JAN. Neste último caso, os ventos ageostróficos são aparentemente causados pelo termo advectivo-inercial, associado (a) às variações da velocidade do vento ao longo do eixo do jato e (b) à curvatura do escoamento (UCCELLINI e JOHNSON, 1979; SHAPIRO e KENNEDY, 1981).

Outro impacto do JBN é sobre escala de dispersão regional e local, que modifica a trajetória, a difusão e a forma da pluma. Neste caso dois fenômenos podem atuar: (1) o cisalhamento do vento médio dentro do jato age sobre a variância de posição das partículas aumentando a dispersão na horizontal ao longo do eixo do jato (SAWFORD, 1999) e (2) a turbulência gerada por instabilidade hidrodinâmica associada a pontos de inflexão do perfil vertical de vento do JBN (LANDAHL e MOLLO-CHRISTENSEN, 1986).

A presença de JBN é um fator de aumento do potencial de risco e periculosidade de incêndios florestais. Incêndios que ocorrem em condições de intenso cisalhamento do vento frequientemente se tornam incontroláveis. Para simular numericamente incêndios florestais, CLARK et alli (1996) têm acoplado modelos numéricos da CLP a modelos de incêndios. Seus resultados mostram não somente a capacidade desses modelos de descrever importantes características dos incêndios observados na natureza, como também destaca o papel do termo solenoidal do balanço de vorticidade horizontal. A presença de ventos fortes e/ou JBN é capaz de incrementar o incêndio, pois a turbulência gerada e os ventos intensos podem deslocar eficientemente o material ainda quente e não rescaldado.

Os JBN também podem ter papel destacado na polinização regional, na disseminação de pragas agrícolas e de seus vetores biológicos (p.g., insetos), devendo ser levados em conta na definição das estratégias de Manejo Integrado de Pragas (MIP) agrícolas. Os jatos na baixa troposfera também são rotas naturais de migração de aves, moscas, mariposas etc (IRWIN, 1999; GAGE et alli, 1999; WESTBROOK e ISARD, 1999; AYLOR, 1999; BYRNE, 1999; SHIELDS e TESTA, 1999 e JEGER, 1999). 
Durante o período noturno, a presença de JBN pode gerar turbulência, implicando em mistura, transporte de momento na vertical e rajadas em superfície (CÁRDENAS, 1990).

Uma caracterização detalhada do JBN observado no Estado de São Paulo pode contribuir para um melhor entendimento:

(a) das circulações atmosféricas sobre terreno complexo da região;

(b) do processo de dispersão de poluentes no interior do Estado de São Paulo;

(c) do mecanismo de disparo de tempestades no interior;

(d) dos processos associados ao aparecimento de rajadas noturnas em superfície.

Em última análise, os resultados obtidos podem contribuir para:

(1) melhoria da previsão de tempo em mesoescala e

(2) maior compreensão dos efeitos das circulações locais do Estado de São Paulo sobre a dispersão de poluentes atmosféricos em escala regional.

\subsection{Conteúdo dos Capítulos}

O Capítulo 2 descreve a metodologia aplicada às observações disponíveis e o modelo numérico utilizado. Os resultados observacionais são discutidos no Capítulo 3. Os resultados numéricos são mostrados no Capítulo 4. Os impactos do JBN de Iperó sobre a dispersão de poluentes no Estado de São Paulo estão descritos no Capítulo 5. Finalmente, o Capítulo 6 sumariza as principais conclusões deste trabalho, recomendando para o futuro o estudo e investigação das questões em aberto. Ao final, um Apêndice detalha alguns pontos assinalados no texto. 


\section{CAPÍTULO 2 \\ Metodologia}

Neste capítulo apresentamos sucintamente a metodologia empregada, compreendendo: (i) o modelo numérico de mesoescala; (ii) a topografia utilizada; (iii) os tipos e parâmetros de superfície empregados; (iv) o modelo de dispersão de partículas lagrangiano e (v) a rotina de interpolação utilizando modelo 1-D com fechamento de segunda-ordem e assimilação 4-D de dados observacionais esparsos.

\subsection{O Modelo TVM}

O modelo TVM foi desenvolvido originalmente por BORNSTEIN (1975) para estudar as circulações atmosféricas bidimensionais e hidrostáticas em mesoescala associadas à presença de ilhas de calor urbanas. Essa primeira versão denominada URBMET foi utilizada para simular a estrutura da CLP sobre áreas urbanas localizadas em terrenos planos (BORNSTEIN e ROBOCK, 1976). Posteriormente, o modelo foi expandido para uma grade tridimensional com o objetivo de simular interações entre o dossel urbano e sistemas de escala sinótica na cidade de Nova Iorque (BORNSTEIN et alli, 1987 a e b). Essa versão 3-D foi então chamada de Three-dimensional Vorticity Model (TVM), mantendo a estrutura computacional do URBMET e introduzindo-se os efeitos da topografia no modelo pela utilização de equações da vorticidade escritas agora em um sistema de coordenadas $\sigma-z$ (original de GAL-CHEN e SOMERVILLE, 1975 a e b) seguindo-se a topografia (BORNSTEIN et alli, 1996). A versão hidrostática do modelo, mais conhecida por Topography Vorticity-Mode Mesoscale model, é descrita por SCHAYES e THUNIS (1990). De acordo com THUNIS et alli (1980), o modelo TVM é apropriado para simular escoamentos atmosféricos de mesoescala- $\beta$ (ORLANSKI, 1975) associados à convecção rasa (DUTTON, 1976).

No Brasil, o TVM tem sido aplicado para simular circulações na CLP termicamente induzidas pela topografia na região de Iperó, no Estado de São Paulo, e para avaliar o campo de concentração de $\mathrm{SO}_{2}$ na região de Candiota, no Estado do Rio Grande do Sul (KARAM, 1995; KARAM et alli, 1996 a e b). 
Em 1995, THUNIS desenvolveu a versão não-hidrostática do modelo TVM. Esta versão, que é utilizada aqui, define uma função vetorial de corrente tridimensional, sujeita à transformação de GAUGE, e usada para recuperar os campos das componentes zonal, meridional e vertical da velocidade do vento. A partir dessa versão, os resultados obtidos com o modelo TVM baseiam-se na solução numérica das componentes horizontais da vorticidade e na recuperação das três componentes do vento, a partir das inter-relações entre os campos tridimensionais da vorticidade, função de corrente vetorial e velocidade do vento - simplificadas pela transformada de GAUGE. Esta versão foi aplicada por ORGAZ e FONTEZ (1998) para simular a brisa marítima na região de Aveiro, em Portugal e por MARTÍN et alli (2001 a e b) para produzir uma série de simulações das circulações de mesoescala no centro da Península Ibérica sob condições de Baixa Térmica. O objetivo neste último caso foi caracterizar o escoamento sobre o terreno complexo à volta de Madri, mapeando a variabilidade das trajetórias de ar poluído, simuladas nestas condições, e fortemente influenciadas pelo ciclo de aquecimento e resfriamento intenso da superfície.

Uma descrição detalhada da versão não-hidrostática do TVM pode ser obtida em THUNIS (1995). Dado o fato de que todas as circulações investigadas aqui são induzidas por contrastes térmicos entre pontos diferentes da superfície, as sub-rotinas do modelo que tratam dos processos superficiais serão descritas em maior detalhe a seguir.

O modelo TVM pode ser dividido em duas camadas atmosféricas e duas camadas de solo (Figura 2.1). A primeira camada na atmosfera é uma camada de interface, entre a superfície e a atmosfera, onde os parâmetros são estimados de relações diagnósticas e equações prognósticas descrevendo os processos da superfície (i.e., trata-se de uma camada de acoplamento entre os processos da superfície e os processos atmosféricos). A segunda camada representa a maior parte da atmosfera e é localizada entre o topo da camada de interface e o topo da atmosfera no modelo. Nela, todos os parâmetros meteorológicos são prognosticados a partir das equações do movimento. A característica particular do modelo TVM é a utilização da equação da vorticidade. Ela elimina a necessidade de tratar explicitamente a pressão. As profundidades das duas camadas de solo equivalem basicamente à extensão vertical dos ciclos diurno e sazonal da temperatura no solo. 


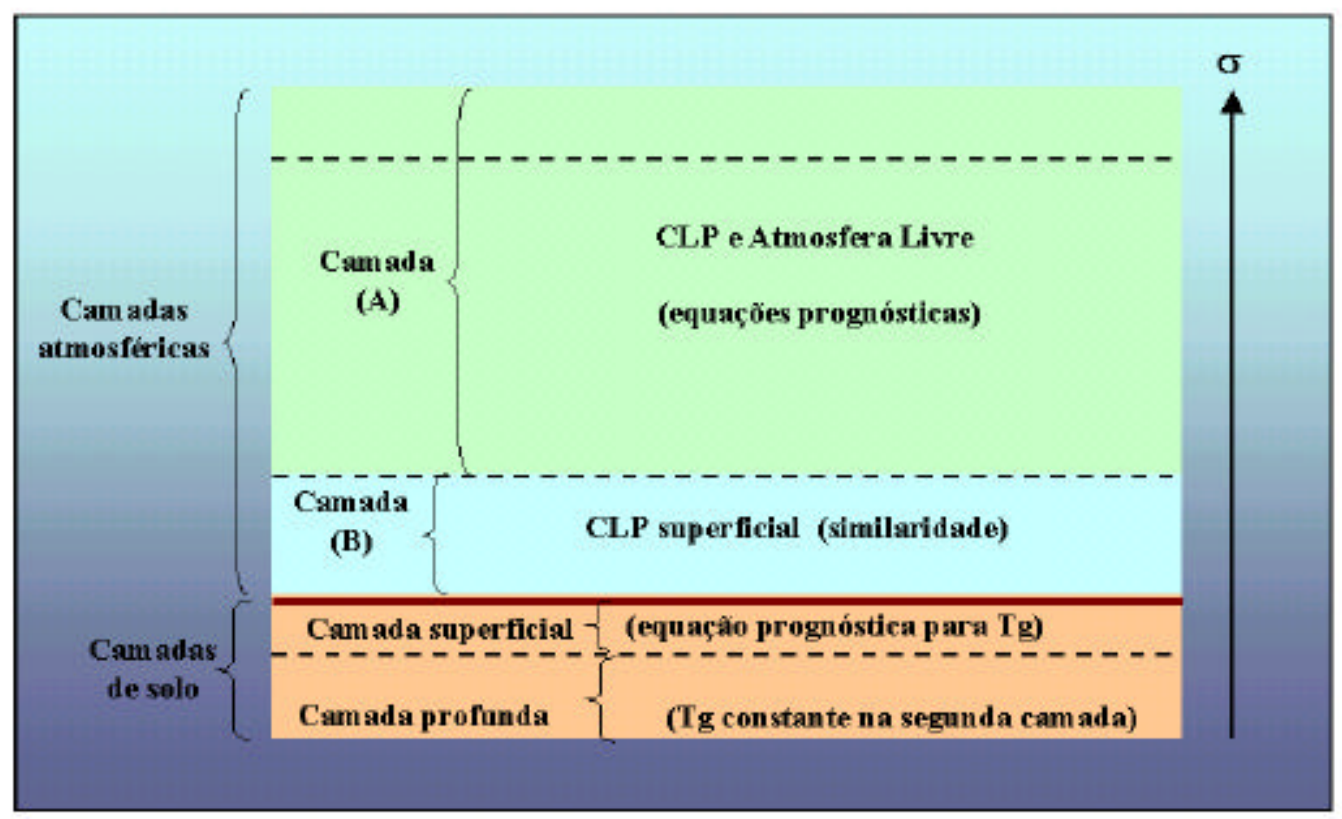

Figura 2.1 Representação do domínio atmosférico e do solo, mostrando camadas com solução distinta utilizadas nas simulações do modelo TVM.

\subsubsection{Camada de Interface}

A camada de interface é composta dos dois primeiros níveis verticais da grade de discretização e representam a camada superficial da atmosfera. O primeiro ponto de grade $\left(\mathrm{z}_{1}\right)$ está localizado na altura correspondente ao comprimento de rugosidade $\left(\mathrm{z}_{0}\right)$. O segundo ponto de grade $\left(z_{2}\right)$ está localizado dentro da camada superficial e define o topo da camada de interface.

A temperatura potencial $\left(\theta_{1}\right)$ no primeiro nível é assumida igual à temperatura da superfície ( $\left.\mathrm{T}_{\mathrm{G} 1}\right)$, que por sua vez é estimada a partir da equação da temperatura $\left(\mathrm{T}_{\mathrm{G} 1}\right)$ da superfície do solo:

$$
\frac{\partial \mathrm{T}_{\mathrm{G} 1}}{\partial \mathrm{t}}=-\mathrm{c}_{1} \frac{\mathrm{G}_{0}}{\mathrm{c}_{\mathrm{s}} \rho_{\mathrm{s}} \mathrm{d}_{1}}-\mathrm{c}_{2} \frac{\left(\mathrm{T}_{\mathrm{G} 1}-\mathrm{T}_{\mathrm{G} 2}\right)}{\tau_{1}},
$$

onde $c_{1}$ e $c_{2}$ são constantes; $G_{0}$ é o fluxo de calor à superfície do solo; $c_{s}$ é a capacidade térmica do solo; $\rho_{\mathrm{s}}$ é a densidade do solo; $\mathrm{d}_{1}$ é a profundidade da atenuação do ciclo diurno da temperatura do solo; $\mathrm{T}_{\mathrm{G} 2}$ é a temperatura na segunda camada, mantida constante durante a simulação e $\tau_{1}$ é o período do ciclo diurno da temperatura do solo.

O fluxo de calor na superfície do solo $\left(\mathrm{G}_{0}\right)$ é estimado como um resíduo da equação de balanço de energia $G_{0}=(1-\alpha)\left(\downarrow R_{S}\right)_{0}+\left(\downarrow R_{L}\right)_{0}+\left(\uparrow R_{L}\right)_{0}+\left(H_{0}+L E_{0}\right)$, onde $\left(\downarrow R_{S}\right)_{0}$ é o fluxo vertical de radiação solar incidente na superfície (irradiância), que é estimada considerando-se a 
atenuação atmosférica em virtude da presença dos gases constituintes da atmosfera, proposta por McDONALD (1960) e ATWATER e BROWN (1974); $\alpha$ é o albedo da superfície; $\left(\downarrow R_{L}\right)_{0}$ é a irradiância de onda longa na superfície emitida pela atmosfera para baixo, estimada de acordo com SAZAMORI (1968) considerando-se as distribuições verticais do gás $\mathrm{CO}_{2}$ e vapor de água; $\left(\uparrow \mathrm{R}_{\mathrm{L}}\right)_{0}$ é a irradiância de onda longa emitida para cima pela superfície, obtida da expressão de STEFANBOLTZMAN. A irradiância solar refletida da superfície é estimada da irradiância solar incidente e do albedo superficial $(\alpha)$. Os efeitos de nuvens não são considerados nos fluxos radiativos descritos acima. $\mathrm{O}$ valor de $\left(\downarrow \mathrm{R}_{\mathrm{L}}\right)_{0}$ é calculado a cada hora e os outros componentes da radiação são avaliados a cada passo de tempo. Por convenção, os fluxos de energia orientados para cima são considerados positivos e vice-versa.

O fluxo turbulento de calor sensível $\left(\mathrm{H}_{0}\right)$ é estimado da seguinte expressão: $\mathrm{H}_{0}=-\rho_{0} \mathrm{c}_{\mathrm{p}} \mathrm{u}^{*} \theta^{*}$, onde $\mathrm{u}^{*}$ e $\theta^{*}$ são, respectivamente, a velocidade de atrito e a escala de temperatura característica na camada superficial; $\rho_{0}$ é a densidade do ar e $c_{p}$ é o calor específico a pressão constante do ar. A velocidade de atrito é uma medida representativa da escala característica da flutuação turbulenta de momento na CLP superficial, sendo estimada no modelo pela Teoria de Similaridade de MONIN-OBUKHOV (PANOFSKY e DUTTON, 1984; STULL, 1988 entre outros). O fluxo turbulento de calor latente $\left(\mathrm{LE}_{0}\right)$ é estimado da seguinte expressão $\mathrm{LE}_{0}=-\rho_{0} \mathrm{~L}_{\mathrm{v}} \mathrm{u}^{*} \mathrm{q}^{*}$, onde $\mathrm{q}^{*}$ é a escala característica da umidade específica na camada superficial e $\mathrm{L}_{\mathrm{v}}$ é o calor latente de evaporação da água.

As escalas características são diagnosticadas em termos da magnitude da velocidade do vento $\left(\mathrm{V}_{2}\right)$ tomada no nível vertical $\left(\mathrm{z}_{2}\right)$ e dos gradientes verticais de temperatura potencial e umidade específica na camada de interface de acordo com as expressões da similaridade de MONIN-OBUKHOV para a camada limite superficial:

$$
\begin{aligned}
& \mathrm{u} *=\mathrm{V}_{2} /\left\{(1 / \kappa)\left[\ln \left(\mathrm{z}_{2} / \mathrm{z}_{0}\right)-\Delta \Psi_{\mathrm{M}}\right]\right\} \\
& \theta^{*}=\left(\theta_{2}-\theta_{0}\right) /\left\{\left(\alpha^{\prime} / \kappa\right)\left[\ln \left(\mathrm{z}_{2} / \mathrm{z}_{0}\right)-\Delta \Psi_{\mathrm{H}}\right]\right\} \\
& \mathrm{q}^{*}=\left(\mathrm{q}_{2}-\mathrm{q}_{0}\right) /\left\{\left(\alpha^{\prime} / \kappa\right)\left[\ln \left(\mathrm{z}_{2} / \mathrm{z}_{0}\right)-\Delta \Psi_{\mathrm{E}}\right]\right\}
\end{aligned}
$$

onde $\theta_{0}$ e $q_{0}$ são, respectivamente, a temperatura potencial e a umidade específica no primeiro nível do modelo $\left(\mathrm{z}_{0}\right)$; $\alpha^{\prime}$ é uma constante (o inverso do número de PRANDTL $\cong 0,74$ ); $\mathrm{k}$ é a constante de vonKARMAN, $\Psi_{\mathrm{M}}, \Psi_{\mathrm{H}}$ e $\Psi_{\mathrm{E}}$ são as funções de correção da estabilidade atmosférica de MONINOBUKHOV para a velocidade do vento, temperatura potencial e umidade específica na camada superficial, respectivamente, $\Delta \Psi=\Psi\left(\mathrm{z}_{2}, \mathrm{~L}\right)-\Psi\left(\mathrm{z}_{0}, \mathrm{~L}\right)$ e L é o comprimento de MONIN- 
OBUKHOV. A temperatura potencial $\left(\theta_{0}\right)$ é assumida igual à temperatura da camada superficial do solo $\left(\mathrm{T}_{\mathrm{G} 1}\right)$.

A umidade específica superficial $\left(\mathrm{q}_{0}\right)$ é considerada seguindo a relação ${ }^{1}$ :

$$
\frac{\partial \mathrm{q}_{0}}{\partial \mathrm{t}}=\frac{\mathrm{LE}_{0}^{\mathrm{PM}}-\mathrm{LE}_{0}}{\left(\mathrm{z}_{2}-\mathrm{z}_{0}\right) \mathrm{L}_{\mathrm{v}} \rho_{0}},
$$

onde $\mathrm{LE}_{0}{ }^{\mathrm{PM}}$ é o fluxo turbulento de calor latente, estimado pela expressão de PENMANMONTEITH (GARRAT, 1994):

$$
\mathrm{LE}_{0}^{\mathrm{PM}}=\frac{-\ddot{\mathrm{a}}\left(\left(\mathrm{R}_{\mathrm{N}}\right)_{0}-\mathrm{G}_{0}\right)+\rho_{0} \mathrm{c}_{\mathrm{p}}\left(\mathrm{q}_{\mathrm{S} 2}-\mathrm{q}_{2}\right) / \mathrm{r}_{\mathrm{a}}}{\ddot{a}+\left(\mathrm{c}_{\mathrm{p}} / \mathrm{L}_{\mathrm{v}}\right)\left(1+\mathrm{r}_{\mathrm{S}} / \mathrm{r}_{\mathrm{a}}\right)}
$$

onde $\delta$ é a razão de variação da umidade específica na saturação em relação à temperatura $\left(\partial \mathrm{q}_{\mathrm{s}} / \partial \mathrm{T}\right)_{2} ; \mathrm{q}_{\mathrm{s} 2}$ e $\mathrm{q}_{2}$ são respectivamente a umidade especifica na saturação e a umidade específica do ar na temperatura do nível vertical $z_{2}$ do modelo; $r_{a}$ e $r_{S}$ são respectivamente a resistência aerodinâmica e da superfície (no caso de representar uma camada de vegetação, $\mathrm{r}_{\mathrm{S}}$ pode ser chamada de resistência estomática, em referência à resistência oferecida pelos estômatos à passagem do vapor de água), respectivamente e $\left(\mathrm{R}_{\mathrm{N}}\right)_{0}$ é o fluxo de radiação líquido na superfície. $\mathrm{O}$ sinal negativo aplicado ao primeiro termo do lado direito é necessário para compensar a convenção adotada para o fluxo.

A resistência aerodinâmica é estimada da teoria de similaridade de MONIN-OBUKHOV que permite escrever

$$
\mathrm{r}_{\mathrm{a}}=\left[\ln \left(\mathrm{z}_{2} / \mathrm{z}_{0}\right)-\Delta \Psi_{\mathrm{M}}\right] \cdot\left[\ln \left(\mathrm{z}_{2} / \mathrm{z}_{0}\right)-\Delta \Psi_{\mathrm{E}}\right] /\left(\mathrm{k}^{2} \mathrm{~V}_{2}\right)
$$

\footnotetext{
${ }^{1}$ Nota - Conceitualmente, a equação (2.2) implica que a evolução temporal da umidade na primeira camada atmosférica do modelo é forçada pelas condições de evapotranspiração devido à presença de vegetação na superfície. Note-se que a formulação de PENMAN-MONTEITH $\left(\mathrm{LE}_{0}^{\mathrm{PM}}\right)$ resulta da combinação dos métodos aerodinâmicos e do balanço de energia. Portanto, a equação (2.2) permite o acoplamento efetivo entre as condições de superfície e àquelas do topo da primeira camada de interface, na qual o fluxo é essencialmente aerodinâmico $\left(\mathrm{LE}_{0}\right)$.
} 
As expressões descritas acima são aplicadas para estimar os fluxos sobre os 17 tipos da classificação de superfície do International Geosphere Biosphere Programme (IGBP), incluindo florestas, áreas de cultivo agrícola, campos e corpos de água. Os parâmetros utilizados para caracterizar cada tipo de superfície são apresentados na Tabela 2.1. Nela, o valor atribuído à temperatura da primeira camada de solo, $\mathrm{T}_{\mathrm{G} 1}$, foi usada como condição inicial e $\mathrm{T}_{\mathrm{G} 2}$ foi mantida constante durante as simulações. Sobre as áreas cobertas por água a temperatura superficial foi mantida constante.

\subsubsection{Camada Atmosférica}

Acima da camada de interface a evolução temporal e espacial das estruturas dinâmicas, termodinâmicas e da umidade são prognosticadas com equações diferenciais para vorticidade $(\vec{\zeta} \equiv \nabla \times \vec{v})$, temperatura potencial e umidade específica, baseadas na aproximação de Boussinesq das equações primitivas. No modelo são utilizadas somente as componentes horizontais da vorticidade, uma conseqüência da transformada de GAUGE aplicada à relação entre a vorticidade, a função de corrente vetorial e velocidade do escoamento.

As equações prognósticas das componentes do vetor vorticidade (p.ex., DUTTON, 1976, 1986) são:

(a) para componente $\mathrm{x}$ :

$$
\begin{aligned}
& \frac{\mathrm{d} \zeta_{1}}{\mathrm{dt}}+\zeta_{1} \mathrm{D}_{23}-\left(\zeta_{2} \frac{\partial \mathrm{u}}{\partial \mathrm{y}}+\zeta_{3} \frac{\partial \mathrm{u}}{\partial \mathrm{z}}\right)=\frac{\partial \alpha_{0}}{\partial \mathrm{z}} \frac{\partial \mathrm{p}}{\partial \mathrm{y}}-\frac{\partial \alpha_{0}}{\partial \mathrm{y}}\left(\frac{-\mathrm{g}}{\alpha_{0}}\right) \\
& +\mathrm{f} \frac{\partial \mathrm{u}}{\partial \mathrm{z}}+\frac{\partial}{\partial \mathrm{y}}\left(\mathrm{uf}_{2}\right)+\mathrm{K}_{\mathrm{H}}\left(\frac{\partial^{2} \zeta_{1}}{\partial \mathrm{x}^{2}}+\frac{\partial^{2} \zeta_{1}}{\partial \mathrm{y}^{2}}\right)+\mathrm{K}_{\mathrm{V}} \frac{\partial^{2} \zeta_{1}}{\partial \mathrm{z}^{2}}
\end{aligned}
$$

(b) para componente y:

$$
\begin{aligned}
& \frac{\mathrm{d} \zeta_{2}}{\mathrm{dt}}+\zeta_{2} \mathrm{D}_{31}-\left(\zeta_{1} \frac{\partial \mathrm{v}}{\partial \mathrm{x}}+\zeta_{3} \frac{\partial \mathrm{v}}{\partial \mathrm{z}}\right)=+\frac{\partial \alpha_{0}}{\partial \mathrm{x}}\left(\frac{-\mathrm{g}}{\alpha_{0}}\right)-\frac{\partial \alpha_{0}}{\partial \mathrm{z}} \frac{\partial \mathrm{p}}{\partial \mathrm{x}} \mathrm{e} \\
& +\mathrm{f} \frac{\partial \mathrm{v}}{\partial \mathrm{z}}+\mathrm{K}_{\mathrm{H}}\left(\frac{\partial^{2} \zeta_{2}}{\partial \mathrm{x}^{2}}+\frac{\partial^{2} \zeta_{2}}{\partial \mathrm{y}^{2}}\right)+\mathrm{K}_{\mathrm{v}} \frac{\partial^{2} \zeta_{2}}{\partial \mathrm{z}^{2}}
\end{aligned}
$$

(c) para componente $\mathrm{z}$ : 


$$
\begin{aligned}
& \frac{\mathrm{d} \zeta_{3}}{\mathrm{dt}}+\zeta_{3} \mathrm{D}_{12}-\left(\zeta_{1} \frac{\partial \mathrm{w}}{\partial \mathrm{x}}+\zeta_{2} \frac{\partial \mathrm{w}}{\partial \mathrm{y}}\right)= \\
& -\mathrm{fD}_{12}+\frac{\partial}{\partial \mathrm{y}}\left(\mathrm{wf}_{2}\right)+\mathrm{K}_{\mathrm{H}}\left(\frac{\partial^{2} \zeta_{3}}{\partial \mathrm{x}^{2}}+\frac{\partial^{2} \zeta_{3}}{\partial \mathrm{y}^{2}}\right)+\mathrm{K}_{\mathrm{v}} \frac{\partial^{2} \zeta_{3}}{\partial \mathrm{z}^{2}}
\end{aligned}
$$

onde $\mathrm{d} / \mathrm{dt}=\partial / \partial \mathrm{t}+\mathrm{u} \partial / \partial \mathrm{x}+\mathrm{v} \partial / \partial \mathrm{y}+\mathrm{w} \partial / \partial \sigma$ é o operador derivada material e $\mathrm{D}_{12}, \mathrm{D}_{31}$ e $\mathrm{D}_{23}$ são, respectivamente, as divergências bidimensionais dadas por:

$$
\mathrm{D}_{12}=\left(\frac{\partial \mathrm{u}}{\partial \mathrm{x}}+\frac{\partial \mathrm{v}}{\partial \mathrm{y}}\right)=-\frac{\partial \mathrm{w}}{\partial \mathrm{z}} ; \quad \mathrm{D}_{31}=\left(\frac{\partial \mathrm{u}}{\partial \mathrm{x}}+\frac{\partial \mathrm{w}}{\partial \mathrm{z}}\right)=-\frac{\partial \mathrm{v}}{\partial \mathrm{y}} \quad \text { e } \quad \mathrm{D}_{23}=\left(\frac{\partial \mathrm{v}}{\partial \mathrm{y}}+\frac{\partial \mathrm{w}}{\partial \mathrm{z}}\right)=-\frac{\partial \mathrm{u}}{\partial \mathrm{x}} .
$$

De forma similar à versão hidrostática do modelo TVM (SCHAYES e THUNIS, 1990; SCHAYES et alli, 1996), a versão não-hidrostática simplifica a expressão das divergências $\mathrm{D}_{23} \mathrm{e}$ $\mathrm{D}_{31}$, desconsiderando os termos de inclinação de vórtices e da divergência associados à componente vertical da vorticidade ${ }^{2}$, resultando em:

$$
\frac{\mathrm{d} \zeta_{1}}{\mathrm{dt}}-\zeta_{1} \frac{\partial \mathrm{u}}{\partial \mathrm{x}}-\left(\zeta_{2} \frac{\partial \mathrm{u}}{\partial \mathrm{y}}\right)=+\frac{\partial \alpha_{0}}{\partial \mathrm{z}} \frac{\partial \mathrm{p}}{\partial \mathrm{y}}-\frac{\partial \alpha_{0}}{\partial \mathrm{y}}\left(\frac{-\mathrm{g}}{\alpha_{0}}\right)+\mathrm{f} \frac{\partial \mathrm{u}}{\partial \mathrm{z}}+\frac{\partial}{\partial \mathrm{y}}\left(\mathrm{uf}_{2}\right)+\mathrm{K}_{\mathrm{H}}\left(\frac{\partial^{2} \zeta_{1}}{\partial \mathrm{x}^{2}}+\frac{\partial^{2} \zeta_{1}}{\partial \mathrm{y}^{2}}\right)+\mathrm{K}_{\mathrm{v}} \frac{\partial^{2} \zeta_{1}}{\partial \mathrm{z}^{2}}
$$

$\mathrm{e}$

$$
\frac{\mathrm{d} \zeta_{2}}{\mathrm{dt}}-\zeta_{2} \frac{\partial \mathrm{v}}{\partial \mathrm{y}}-\left(\zeta_{1} \frac{\partial \mathrm{v}}{\partial \mathrm{x}}\right)=+\frac{\partial \alpha_{0}}{\partial \mathrm{x}}\left(\frac{-\mathrm{g}}{\alpha_{0}}\right)-\frac{\partial \alpha_{0}}{\partial \mathrm{z}} \frac{\partial \mathrm{p}}{\partial \mathrm{x}}+\mathrm{f} \frac{\partial \mathrm{v}}{\partial \mathrm{z}}+\mathrm{K}_{\mathrm{H}}\left(\frac{\partial^{2} \zeta_{2}}{\partial \mathrm{x}^{2}}+\frac{\partial^{2} \zeta_{2}}{\partial \mathrm{y}^{2}}\right)+\mathrm{K}_{\mathrm{v}} \frac{\partial^{2} \zeta_{2}}{\partial \mathrm{z}^{2}}
$$

Diversos autores (SIEVERS e ZDUNKOWSKI, 1986; SIEVERS, 1995, , $1997 \mathrm{e}$ THYER, 1966) têm mostrado que apenas duas componentes da vorticidade são suficientes para definir-se a relação entre os vetores vorticidade, função de corrente e velocidade do vento, para um escoamento tridimensional não divergente, pela consideração da transformada de GAUGE junto à Lei de BIOT-SAVART da hidrodinâmica.

A topografia é levada em consideração na integração do sistema de equações do modelo através de uma transformação do sistema de coordenadas. $\mathrm{O}$ sistema de coordenas utilizado $\mathrm{S}^{\prime}=(\mathrm{x}$, y,$\sigma$ ), original de GAL-CHEN e SOMERVILLE (1975), segue a topografia na base do modelo (Figura 2.1), onde a coordenada vertical transformada $\sigma$ (ou z*) é dada por

$$
\sigma=\mathrm{z}_{\mathrm{T}}\left(\frac{\mathrm{z}-\mathrm{z}_{\mathrm{G}}}{\mathrm{z}_{\mathrm{T}}-\mathrm{z}_{\mathrm{G}}}\right)
$$

\footnotetext{
${ }^{2}$ Nota - Os termos de inclinação da vorticidade planetária (f $\partial u / \partial z$ e f $\partial v / \partial z$ ) são mantidos.
} 
O resultado é um sistema de coordenadas que segue exatamente a topografia em sua base e que se torna mais e mais horizontal com a elevação na vertical. Assim, as equações da vorticidade para as componentes horizontais, para o sistema seguindo a topografia, são escritas como:

$$
\begin{aligned}
\frac{\mathrm{d} \zeta_{1}}{\mathrm{dt}}= & \frac{\mathrm{g}}{\theta_{0}}\left(\frac{\partial \theta^{\prime}}{\partial \mathrm{y}}-\frac{\partial \theta^{\prime}}{\partial \sigma} \frac{\partial \mathrm{z}_{\mathrm{G}}}{\partial \mathrm{y}} \mathrm{r}_{\sigma}\right)+\zeta_{\mathrm{l}}\left[\frac{\partial \mathrm{u}}{\partial \mathrm{x}}-\frac{\partial \mathrm{u}}{\partial \sigma} \frac{\partial \mathrm{z}_{\mathrm{G}}}{\partial \mathrm{x}} \mathrm{r}_{\sigma}\right]+\left[\frac{\mathrm{f}}{\mathrm{f}_{\sigma}} \frac{\partial \mathrm{u}}{\partial \sigma}+\zeta_{2}\left(\frac{\partial \mathrm{u}}{\partial \mathrm{y}}-\frac{\partial \mathrm{u}}{\partial \sigma} \frac{\partial \mathrm{z}_{\mathrm{G}}}{\partial \mathrm{y}} \mathrm{r}_{\sigma}\right)\right] \\
& +\left\{\mathrm{K}_{\mathrm{H}}\left[\frac{\partial^{2} \zeta_{1}}{\partial \mathrm{x}^{2}}+\frac{\partial^{2} \zeta_{1}}{\partial \mathrm{y}^{2}}\right]+\frac{1}{\mathrm{f}_{\sigma}^{2}} \frac{\partial}{\partial \sigma}\left[\mathrm{K}_{\mathrm{v}} \frac{\partial \zeta_{1}}{\partial \sigma}\right]+\varepsilon_{1}\right\}
\end{aligned}
$$

As formas finais implementadas no código do modelo (THUNIS, 1995) são:

$$
\begin{aligned}
\frac{\mathrm{d} \zeta_{2}}{\mathrm{dt}}= & -\frac{\mathrm{g}}{\theta_{0}}\left(\frac{\partial \theta^{\prime}}{\partial \mathrm{x}}-\frac{\partial \theta^{\prime}}{\partial \sigma} \frac{\partial \mathrm{z}_{\mathrm{G}}}{\partial \mathrm{x}} \mathrm{r}_{\sigma}\right)+\zeta_{2}\left(\frac{\partial \mathrm{v}}{\partial \mathrm{y}}-\frac{\partial \mathrm{v}}{\partial \sigma} \frac{\partial \mathrm{z}_{\mathrm{G}}}{\partial \mathrm{y}} \mathrm{r}_{\sigma}\right)+\left[\frac{\mathrm{f}}{\mathrm{f}_{\sigma}} \frac{\partial \mathrm{v}}{\partial \sigma}+\zeta_{1}\left(\frac{\partial \mathrm{v}}{\partial \mathrm{x}}-\frac{\partial \mathrm{v}}{\partial \sigma} \frac{\partial \mathrm{z}_{\mathrm{G}}}{\partial \mathrm{x}} \mathrm{r}_{\sigma}\right)\right], \\
& +\left\{\mathrm{K}_{\mathrm{H}}\left[\frac{\partial^{2} \zeta_{2}}{\partial \mathrm{x}^{2}}+\frac{\partial^{2} \zeta_{2}}{\partial \mathrm{y}^{2}}\right]+\frac{1}{\mathrm{f}_{\sigma}{ }^{2}} \frac{\partial}{\partial \sigma}\left[\mathrm{K}_{\mathrm{v}} \frac{\partial \zeta_{2}}{\partial \sigma}\right]+\varepsilon_{2}\right\}
\end{aligned}
$$

onde $\zeta_{1}$ e $\zeta_{2}$ são as componentes do vetor vorticidade 3-D nas direções x e y, respectivamente; $\mathrm{r}_{\sigma}=$ $\left(\mathrm{z}_{\mathrm{T}}-\sigma\right) /\left(\mathrm{z}_{\mathrm{T}}-\mathrm{Z}_{\mathrm{G}}\right)$ e $\mathrm{f}_{\sigma}=\mathrm{z}_{\mathrm{T}} /\left(\mathrm{z}_{\mathrm{T}}-\mathrm{Z}_{\mathrm{G}}\right) ; \theta$ ' corresponde à perturbação de mesoescala da temperatura potencial; f é o parâmetro de Coriolis $\left(\mathrm{s}^{-1}\right) ; \mathrm{K}_{\mathrm{M}}$ e $\mathrm{K}_{\mathrm{V}}$ são os coeficientes de difusão turbulenta para direções horizontal e vertical, respectivamente e $\varepsilon_{1}$ e $\varepsilon_{2}$ são parcelas próprias às equações escritas no sistema coordenadas seguindo a topografia. Note-se que para o sistema de coordenadas cartesianas, $\mathrm{S}=(\mathrm{x}, \mathrm{y}, \mathrm{z})$, essas últimas parcelas são nulas (Apêndice).

As equações para conservação da umidade específica e da termodinâmica no sistema transformado são dadas, respectivamente, por:

$$
\frac{\mathrm{d} \theta}{\mathrm{dt}}=-\frac{1}{\rho_{0} \mathrm{c}_{\mathrm{P}}}\left(\frac{1}{\mathrm{f}_{\sigma}} \frac{\partial \mathrm{R}_{\mathrm{N}}}{\partial \sigma}\right)+\left[\mathrm{K}_{\mathrm{H}}\left(\frac{\partial^{2} \theta}{\partial \mathrm{x}^{2}}+\frac{\partial^{2} \theta}{\partial \mathrm{y}^{2}}\right)+\frac{1}{\mathrm{f}_{\sigma}^{2}} \frac{\partial}{\partial \sigma}\left(\mathrm{K}_{\mathrm{T}} \frac{\partial \theta}{\partial \sigma}\right)+\varepsilon_{\theta}\right]
$$

$\mathrm{e}$

$$
\frac{\mathrm{dq}}{\mathrm{dt}}=\left[\mathrm{K}_{\mathrm{H}}\left(\frac{\partial^{2} \mathrm{q}}{\partial \mathrm{x}^{2}}+\frac{\partial^{2} \mathrm{q}}{\partial \mathrm{y}^{2}}\right)+\frac{1}{\mathrm{f}_{\sigma}^{2}} \frac{\partial}{\partial \sigma}\left(\mathrm{K}_{\mathrm{T}} \frac{\partial \mathrm{q}}{\partial \sigma}\right)+\varepsilon_{\mathrm{q}}\right] .
$$

Nestas equações, $\theta$ corresponde à temperatura potencial: $\theta=\Theta(\sigma)+\theta^{\prime}$ onde $\Theta(\sigma)$ é a temperatura potencial de referência (estado básico considerado constante); q é a umidade específica; $\mathrm{K}_{\mathrm{T}}$ representa os coeficientes de difusão turbulenta de temperatura potencial e umidade específica ao longo da direção vertical; e $\varepsilon_{\theta}$ e $\varepsilon_{\mathrm{q}}$ representam termos da equação escrita no sistema de coordenadas seguindo a topografia que não aparecem na equação escrita para o sistema de coordenadas cartesianas. O aquecimento diabático no modelo é representado pela Equação (2.5), que descreve o resfriamento por divergência da irradiância de onda longa conforme proposto por SAZAMORI (1968). Os termos $\varepsilon_{\theta}$ e $\varepsilon_{\mathrm{q}}$, que dependem das derivadas segundas da topografia, são 
termos menores (de segunda-ordem) em relação aos demais termos da difusão turbulenta e não são considerados no modelo.

Os coeficientes de difusão turbulenta usados nas equações acima são estimados pelas seguintes expressões $\mathrm{K}_{\mathrm{V}}=0.5\left[\mathrm{l}_{\mathrm{K}} \mathrm{e}^{1 / 2}\right]$ e $\mathrm{K}_{\mathrm{T}}=1.3 \mathrm{~K}_{\mathrm{V}}$, onde (e) é a Energia Cinética Turbulenta (ECT) por unidade de massa igual a $\left(\overline{\mathrm{u}^{\prime 2}}+\overline{\mathrm{v}^{\prime 2}}+\overline{\mathrm{w}^{\prime 2}}\right) / 2 ; \alpha_{\mathrm{PT}}=0.74$ é o valor do inverso do número de PRANDTL turbulento e $l_{\mathrm{k}}$ representa o comprimento de mistura definido por THERRY e LACARRÈRE (1983) para a difusão turbulenta.

A evolução temporal da ECT é obtida através da equação prognóstica (PANOFSKY e DUTTON, 1984; STULL, 1988 entre outros):

$$
\frac{\mathrm{de}}{\mathrm{dt}}=\frac{\mathrm{K}_{\mathrm{V}}}{\mathrm{f}_{\sigma}{ }^{2}}\left[\left(\frac{\partial \mathrm{u}}{\partial \sigma}\right)^{2}+\left(\frac{\partial \mathrm{v}}{\partial \sigma}\right)^{2}\right]-\frac{\mathrm{g}}{\theta_{0}} \frac{\mathrm{K}_{\mathrm{T}}}{\mathrm{f}_{\sigma}} \frac{\partial \theta}{\partial \sigma}+\left[\mathrm{K}_{\mathrm{H}}\left(\frac{\partial^{2} \mathrm{e}}{\partial \mathrm{x}^{2}}+\frac{\partial^{2} \mathrm{e}}{\partial \mathrm{y}^{2}}\right)+\frac{1,2}{\mathrm{f}_{\sigma}{ }^{2}} \frac{\partial}{\partial \sigma}\left(\mathrm{K}_{\mathrm{v}} \frac{\partial \mathrm{e}}{\partial \sigma}\right)+\varepsilon_{\mathrm{e}}\right]-0,125 \frac{\mathrm{e}^{3 / 2}}{1_{\mathrm{e}}}
$$

onde $l_{e}$ é o comprimento de mistura turbulento para a dissipação de ECT (THERRY e LACARRÈRE, 1983). De forma similar às Equações (2.3) e (2.6), aqui, o termo $\varepsilon_{\mathrm{e}}$ é resultante da transformação de coordenadas dos termos de difusão e não são considerados no modelo ${ }^{3}$.

Um modelo de fechamento do tipo (e- $\varepsilon$ ) é utilizado para obter-se a taxa de dissipação de ECT no tempo, o coeficiente de difusão vertical e a escala do comprimento de mistura turbulento. Neste tipo de fechamento da turbulência, duas equações prognósticas são resolvidas numericamente, a primeira é a equação da ECT e a segunda é uma equação para a taxa de dissipação de ECT, ou seja, para $\varepsilon$.

Os coeficientes de difusão turbulenta na vertical $\left(K_{V}\right.$ e $\left.K_{H}\right)$ e o comprimento de mistura para a dissipação de ECT $\left(l_{\mathrm{e}}\right.$ ) são dados em função dos valores da energia cinética turbulenta e da taxa de dissipação, ou seja, $\mathrm{K}_{\mathrm{V}}=0,033\left(\mathrm{e}^{2} / \varepsilon\right), \mathrm{l}_{\mathrm{e}}=0,033\left(\mathrm{e}^{3 / 2} / \varepsilon\right)$ e $\mathrm{K}_{\mathrm{H}}=1,3 \mathrm{~K}_{\mathrm{V}}$. Uma equação para a taxa de dissipação $(\varepsilon \equiv \partial \mathrm{e} / \partial \mathrm{t})$ pode ser resolvida simultaneamente com a equação da ECT utilizando-se formulação semi-implícita proposta por DELEERSNIJDER (1992).

Os modelos atmosféricos utilizando vorticidade consideram duas idéias básicas: (a) eliminar o gradiente de pressão das equações de momento; (2) satisfazer as condições divergência nula de forma implícita. De acordo com SIEVERS e ZDUNKOWSKI (1986), SIEVERS (1995, 1997) e THYER (1966) e outros autores, o campo do vetor vorticidade $\vec{\zeta}=\left(\zeta_{1}, \zeta_{2}, \zeta_{3}\right)$ pode ser relacionado a uma função vetorial de corrente $\vec{\phi}=\left(\phi_{1}, \phi_{2}, \phi_{3}\right)$ através da Lei de BIOT-SAVART da hidrodinâmica $\vec{\zeta} \equiv \nabla \times(\nabla \times \vec{\phi})$ onde $\overrightarrow{\mathrm{v}} \equiv \nabla \times \vec{\phi}$. De acordo com KATZ e PLOTKIN (1991), a

\footnotetext{
3 Em termos de sua ordem de grandeza, esses termos são importantes quando a curvatura da topografia é suficientemente grande, o que pode ocorrer em simulações de alta resolução, quando se tem $\Delta x<1 \mathrm{~km}$.
} 
equação $\vec{\zeta}=-\nabla \times(\nabla \times \vec{\phi})=\nabla(\nabla \cdot \vec{\phi})-\nabla^{2} \vec{\phi}$ pode ser simplificada pela escolha de um campo vetorial de corrente cujo divergente seja nulo $(\nabla \cdot \vec{\phi}=0$, o que é simplesmente outra forma de afirmar-se a não-divergência do escoamento $\nabla \cdot \vec{v}=0$ ); e disto, decorre imediatamente $\vec{\zeta}=-\nabla^{2} \vec{\phi}$. A utilização da transformada de $\mathrm{GAUGE}^{4}$ na equação $\vec{\omega}=-\nabla^{2} \vec{\phi}$ permite eliminar-se a variação vertical da componente vertical do vetor função de corrente $\phi_{3}$, o que é suficiente para se escrever:

$$
\left[\begin{array}{c}
\frac{1}{\mathrm{f}_{\sigma}^{2}} \frac{\partial^{2} \phi_{1}}{\partial \sigma^{2}}+\alpha_{\mathrm{nh}}\left(\frac{\partial^{2} \phi_{1}}{\partial \mathrm{y}^{2}}-\frac{\partial^{2} \phi_{2}}{\partial \mathrm{y} \partial \mathrm{x}}+\varepsilon_{\phi 1}\right) \\
\frac{1}{\mathrm{f}_{\sigma}^{2}} \frac{\partial^{2} \phi_{2}}{\partial \sigma^{2}}+\alpha_{\mathrm{nh}}\left(\frac{\partial^{2} \phi_{2}}{\partial \mathrm{x}^{2}}+-\frac{\partial^{2} \phi_{1}}{\partial \mathrm{x} \partial \mathrm{y}}+\varepsilon_{\phi 2}\right)
\end{array}\right]=\left[\begin{array}{l}
\zeta_{1} \\
\zeta_{2}
\end{array}\right],
$$

onde $\alpha_{\mathrm{nh}}=1$ para versão não-hidrostática e 0 para versão hidrostática. Note-se que as parcelas $\varepsilon_{\phi 1} \mathrm{e}$ $\varepsilon_{\phi 2}$ são, em geral, diferentes de zero, desde que a equação acima seja escrita para o sistema de coordenadas seguindo a topografia (que não seja plana). Para o sistema de coordenadas cartesianas tem-se $\varepsilon_{\phi 1}$ e $\varepsilon_{\phi 2}$ nulas. Conseqüentemente, as componentes do momento serão:

$$
\begin{aligned}
& \mathrm{u}=-\frac{1}{\mathrm{f}_{\sigma}} \frac{\partial \phi_{2}}{\partial \sigma} \\
& \mathrm{v}=+\frac{1}{\mathrm{f}_{\sigma}} \frac{\partial \phi_{1}}{\partial \sigma} \\
& \mathrm{w}=\left(\frac{\partial \phi_{1}}{\partial \mathrm{y}}-\frac{\partial \phi_{2}}{\partial \mathrm{x}}\right)+\left(\frac{\partial \phi_{1}}{\partial \sigma} \frac{\partial \mathrm{z}_{\mathrm{G}}}{\partial \mathrm{y}}-\frac{\partial \phi_{2}}{\partial \sigma} \frac{\partial \mathrm{z}_{\mathrm{G}}}{\partial \mathrm{x}}\right) \mathrm{r}_{\sigma}
\end{aligned}
$$

A relação entre as componentes do vetor da velocidade nos sistemas transformado (u, v, w) e cartesiano ( $\tilde{\mathrm{u}}, \tilde{\mathrm{v}}, \tilde{\mathrm{w}})$ são dadas por (SYNGE e SCHILD, 1949; THOMPSON et alli, 1985; DUTTON, 1986; XUE et alli, 1995; MALISKA, 1995):

$$
\left\{\begin{array}{c}
\tilde{u}=u \\
\tilde{v}=v \\
\tilde{w}=f_{\sigma} w+r_{\sigma}\left(\frac{\partial \phi_{1}}{\partial \sigma} \frac{\partial z_{G}}{\partial y}-\frac{\partial \phi_{2}}{\partial \sigma} \frac{\partial z_{G}}{\partial x}\right)
\end{array}\right\} .
$$

\footnotetext{
${ }^{4}$ A transformada de GAUGE define uma classe de funções tais que $\nabla \times \overrightarrow{\mathrm{B}}=\nabla \times(\overrightarrow{\mathrm{B}}+\nabla \lambda)$ onde $\lambda$ é um campo escalar qualquer, desde que $\nabla \times(\nabla \lambda) \equiv 0$. Como $\lambda$ pode ser definida arbitrariamente, pode-se defini-la igual a integral $\lambda \equiv-\int_{0}^{\sigma} \overrightarrow{\mathrm{k}} \cdot \nabla \vec{\phi} \mathrm{d} \sigma$. A utilização dessa integral vertical implica que $\overrightarrow{\mathrm{v}}=\nabla \times \vec{\phi} *$ onde $\vec{\phi} *=\left(\phi_{1}, \phi_{2}, \mathrm{c}=\right.$ cte $)$.
} 


\subsubsection{Esquema Numérico}

Inicialmente, dentro da camada de interface, a temperatura potencial e a umidade específica do primeiro nível do modelo são estimadas usando-se um esquema em diferenças finitas no tempo do tipo Euler avançado para Equações (2.1) e (2.2). Nesta camada, todos os fluxos turbulentos e a ECT são estimados analiticamente utilizando-se expressões tomadas da teoria de similaridade de MONIN-OBUKHOV e considerando-se a umidade específica e temperatura potencial estimadas previamente para o primeiro nível.

Acima da camada de interface, as equações (2.3) e (2.7) são resolvidas pelo método de diferenças finitas. Primeiramente, a equação (2.7) para a ECT é solucionada e usada para estimar os coeficientes e a altura da CLP. Este último parâmetro é definido como a altura onde o valor da ECT diminui para $10 \%$ de seu valor à superfície. A seguir, resolve-se, seqüencialmente, as equações prognósticas da temperatura potencial, umidade específica e das componentes da vorticidade (Equações 2.3 a 2.6). Cada termo das equações é resolvido, seqüencialmente, utilizando-se as técnicas equation splitting-up (MARCHUK, 1974) e time splitting (HALTINER e WILLIAMS, 1980; PIELKE, 1984). A solução numérica das equações (2.3) a (2.7) é consideravelmente simplificada por essa técnica, que decompõe cada uma das equações em um subconjunto de equações unidimensionais. Neste caso, a estabilidade numérica do conjunto de termos (equação) é garantida pela estabilidade de cada de suas partes (termos de transporte, forças externas e difusão), resolvidas seqüencialmente por métodos numéricos independentes. As componentes da velocidade do vento são estimadas das componentes do vetor função de corrente (Equação 2.8).

Utiliza-se o método de passo fracionado de MARCHUK (1974) em associação método de time splitting (PIELKE, 1984). O objetivo do passo fracionário é subdividir a solução do problema mais geral em seus processos elementares, como a ação de forças externas, advecção, difusão etc e resolvê-los um a um de forma seqüencial. O objetivo do time splitting é aumentar a resolução temporal dos termos mais instáveis numericamente. Neste trabalho, o passo difusivo é cinco vezes menor que o passo advectivo. Para cada passo do termo de advecção são dados cinco passos do termo de difusão vertical. A cada passo de integração, a relação inteira entre o número de passos difusivo e advectivo é calculada.

Os termos de advecção nas Equações (2.3) a (2.7) foram resolvidos numericamente e de forma seqüencial em cada dimensão utilizando-se o esquema numérico Third Order Piecewise Parabolic Method (PPM) (CARPENTER et alli, 1990). Este esquema consiste em ajustar arcos de 
parábola (positivamente definidos) ao campo discreto da variável sendo advectada, o que resulta em uma solução positivamente definida.

Os termos de difusão são calculados usando-se o esquema explícito de EULER avançado no tempo e centrado no espaço, FTCS. A Equação diferencial elíptica (2.8) é numericamente resolvida pelo método gradiente bi-conjugado (PRESS et alli, 1986).

Todas as variáveis são colocadas em posições alternadas na discretização espacial, definindo uma grade do tipo $\mathrm{C}$.

\subsection{Inicialização}

A condição inicial utilizada nas simulações deste trabalho supõe que o papel das forçantes de grande-escala é menor comparado ao papel das forçantes associadas à superfície e à topografia. Por isso, utiliza-se um escoamento de grande-escala com intensidade $1 \mathrm{~m} \mathrm{~s}^{-1}$ de direção NE, suficientemente fraco para não mascarar os efeitos superficiais.

\subsubsection{Topografia}

Os dados de topografia foram obtidos do modelo global de topografia (GTOPO30), com resolução de 0,008333 grau, no sistema de coordenadas LAT/LON, 30 segundos de arco ou $1 \mathrm{~km}$ de resolução nominal na horizontal, considerado o esferóide ${ }^{5}$ WGS84. O modelo GTOPO30 é um modelo de elevação digital (DEM) global resultante de um esforço colaborativo do U.S. Geological Survey's EROS Data Center em Sioux Falls, South Dakota.O endereço do portal onde se pode obter a descrição dos formatos e parâmetros do conjunto de dados é http://www.cr.usgs.gov/glis/hyper/gtopo 30. O download da topografia para qualquer área da Terra pode ser feito a partir do portal: http://edcdaac.usgs.gov/gtopo30.htm. Os dados estão disponíveis desde 1993 através do EROS Data Center. O GTOPO30 foi utilizado neste trabalho para obter a topografia em cada ponto de grade. Programas numéricos foram escritos para selecionar os dados binários da topografia na área de interesse e uma interpolação sobre a grade obteve os valores pela escolha do elemento mais próximo. 
O conjunto de dados do GTOPO30 apresenta as seguintes características:

(a) Os dados são globais cobrindo toda a extensão das latitudes de 90 graus Sul a 90 graus Norte e na extensão total das longitudes de 180 graus oeste até 180 graus leste;

(b) $\mathrm{O}$ espaçamento de grade é $30 \mathrm{~s}$ de arco (0,008333 grau), resultando em arquivo com 21.600 linhas e 43.200 colunas;

(c) O sistema de coordenadas LON/LAT, em unidades em graus e décimos de grau, referenciado pelo esferóide WGS84;

(d) A máxima (mínima) elevação é 8.752 m (-407 m);

(e) As áreas do oceano são identificadas pelo valor -9999;

(f) Áreas costeiras com terras-baixas são indicadas por valor de elevação maior ou igual $1 \mathrm{~m}$, permitindo-se a identificação da linha fronteira oceano-continente.

(g) Pequenas ilhas do oceano com diâmetro médio menor que 1 km não são mapeadas.

Os dados GTOPO30 são fornecidos planificados de acordo com dois tipos diferentes de projeções: (a) Lambert Azimutal de Área Igual (Lambert Azimuthal Equal Area Projection) e (b) Homolosina Goode Ininterrupta (Interrupted Goode Homolosine Projection); ambas descritas de forma detalhada por STEINWAND (1994) e STEINWAND et alli (1995). Neste trabalho, utilizaram-se dados de acordo com a projeção Lambert Azimutal de Área Igual, tomando-se os parâmetros da projeção fornecidos no portal do GTOPO30 para carregar os arquivo GTOPO30 correspondente a América do Sul (AS) no aplicativo de visualização GeoVu (freeware). Este aplicativo permite separar um subdomínio do domínio da AS - correspondente ao maior domínio horizontal das simulações realizadas - assim como, mudar o formato binário dos dados para ASC.

A região de interesse foi escolhida de forma que Iperó ficasse localizada na posição central da região. Os dados do arquivo GTOPO30 foram selecionados para as regiões de área: (a) $1500 \mathrm{~km}$ $\times 1500 \mathrm{~km}$; (b) $800 \mathrm{~km} \times 800 \mathrm{~km}$; (c) $400 \mathrm{~km} \times 400 \mathrm{~km}$ e (d) $100 \mathrm{~km} \times 100 \mathrm{~km}$ (Figuras 2.2, 2.3, 2.4 e 2.5). A utilização de diferentes escalas espaciais permitirá estudar o efeito das escalas horizontais da topografia sobre a circulação induzida.

\subsubsection{Tipos de Superfície}

Os dados de cobertura da superfície utilizados na definição das condições de fronteira à superfície no modelo TVM foram obtidas dos arquivos de dados disseminados na Internet

\footnotetext{
${ }^{5}$ Figura geométrica no espaço tridimensional que aproxima a superfície da Terra.
} 
(BELWARD, 1996) do Global Land Cover Characterization Project (GLCC) do International Geosphere Biosphere Programme (IGBP). Os portais com a descrição dos conjuntos de dados e download encontram-se em http://landcover.usgs.gov/ e http://edcdaac.usgs.gov/glcc/glcc.html/, respectivamente. No IGBP participam o Earth Resources Observation System (EROS), o Earth Data Center (EDC), o Active Archive Center (DAAC), o U.S. Geological Survey (USGS) entre outros. O campo de cobertura da superfície foi definido pelo IGBP baseado em médias nominais de 1-km, sobre o mapa de base na projeção tipo Lambert Azimutal de Área Igual. As fontes originais dos dados utilizados pelo IGBP são dados coletados com o sensor radiométrico Advanced Very High Resolution Radiometer (AVHRR) a bordo de satélite, entre 1992-93.

Os tipos de superfície da classificação IGBP são dados na Tabela 2.1. Para assimilação dos parâmetros físicos, aerodinâmicos e termodinâmicos da superfície, vegetação e solo no modelo numérico TVM estabeleceu-se a associação dos tipos de superfície da classificação IGBP com parâmetros relevantes da superfície, solo e vegetação (Tabela 2.2).

A Figura 2.1 apresenta a distribuição do tipo de superfície (classificação IGPB) sobre a área do Estado de São Paulo de $100 \mathrm{~km} \times 100 \mathrm{~km}$ centrada em Iperó. Os tipos predominantes na área mostrada correspondem a plantações dentro de um mosaico de vegetação natural (tipo 14); áreas com plantações extensas (tipo 12) e áreas com campos e campinas (tipo 10). 

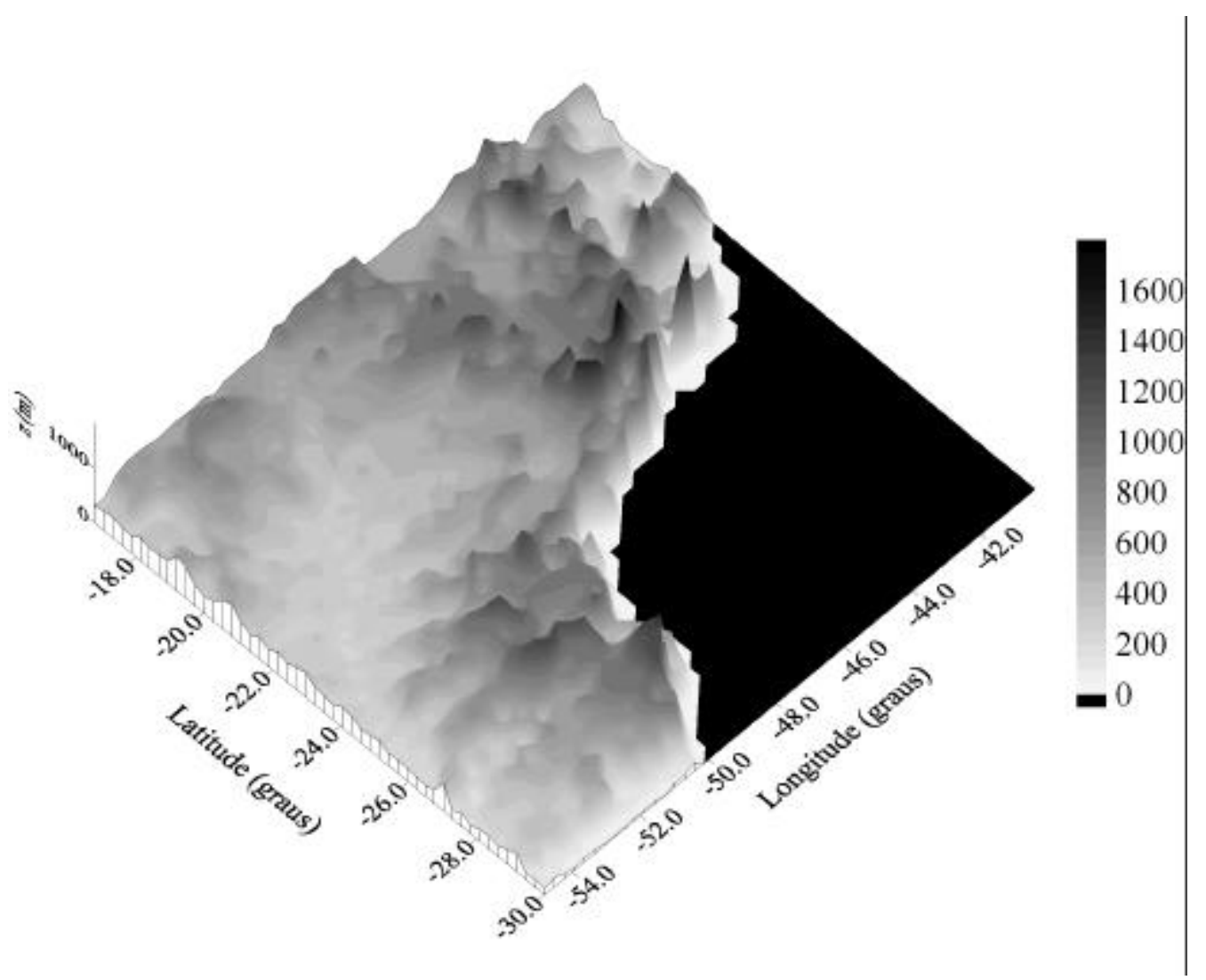

Figura 2.2 Topografia da superfície (modelo GTOPO30) sobre as regiões Sul e Sudeste do Brasil, com área $1500 \mathrm{~km} \times 1500$ km, centrada em Iperó.

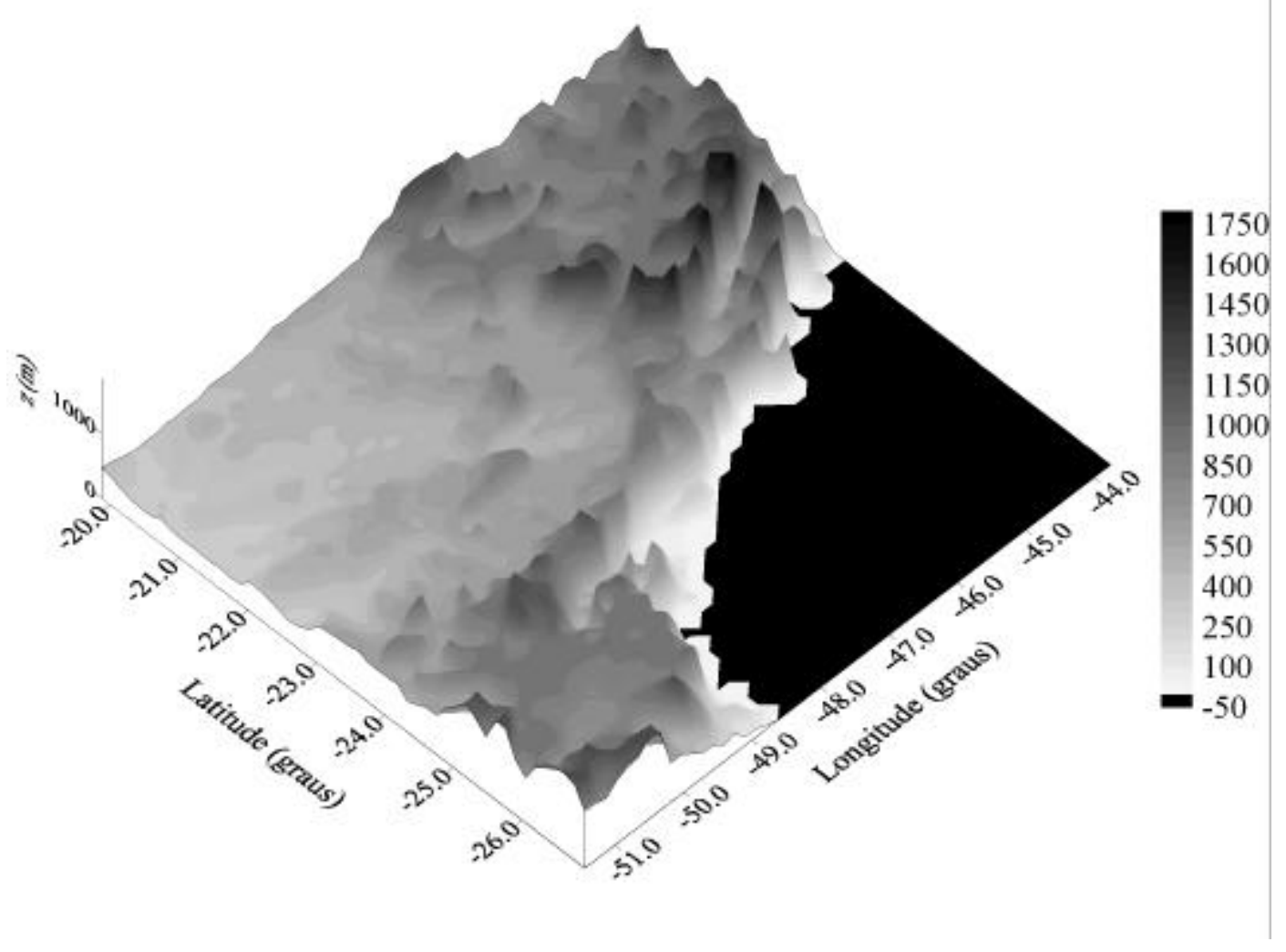

Figura 2.3 Topografia da superfície (modelo GTOPO30) sobre as regiões Sul e Sudeste do Brasil, com área $800 \mathrm{~km} \times 800 \mathrm{~km}$, centrada em Iperó. 


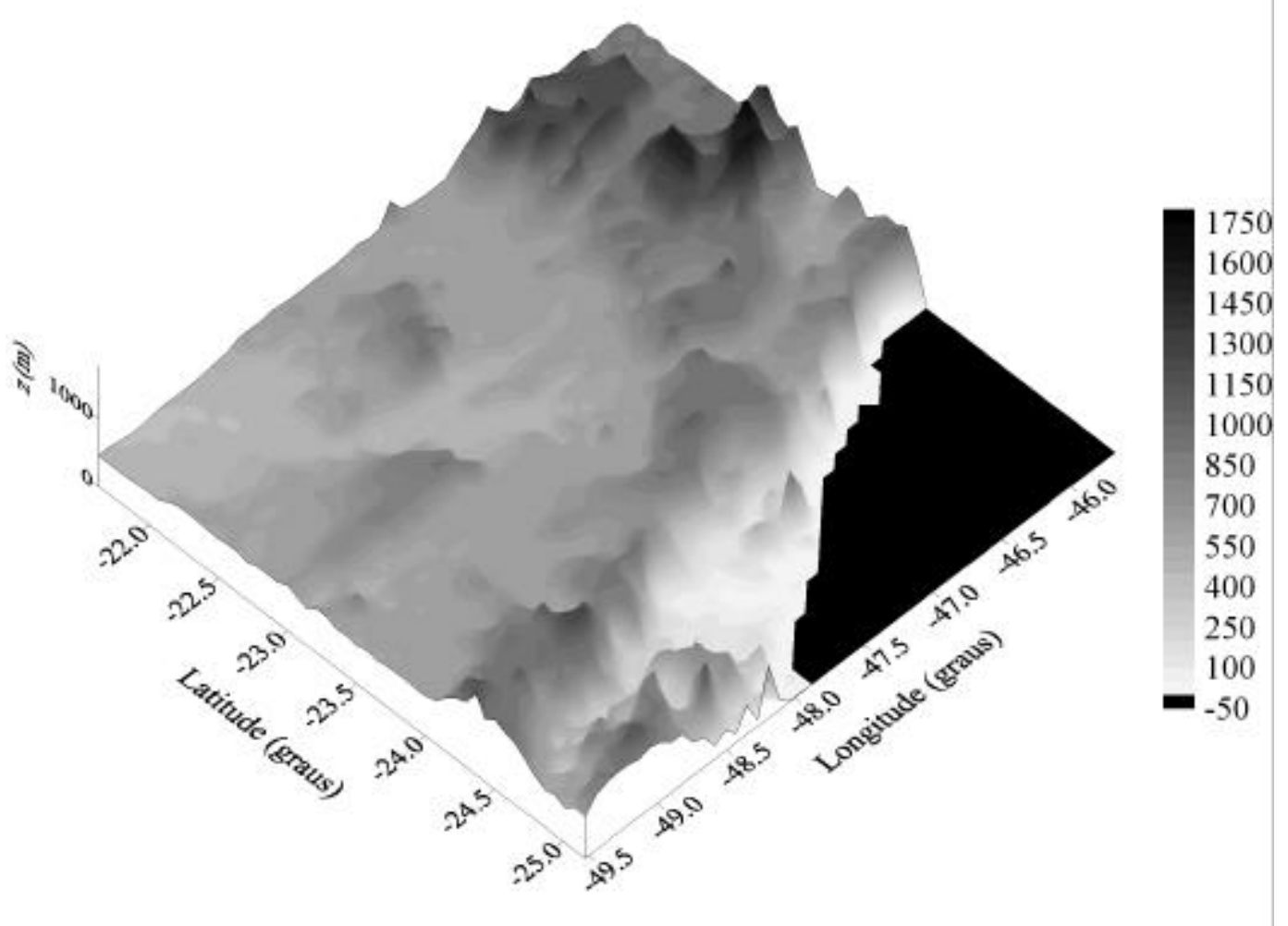

Figura 2.4 Topografia da superfície (modelo GTOPO30) sobre regiões dos Estados de São Paulo, Paraná e Minas Gerais, com área 400 km × 400 km, centrada em Iperó.
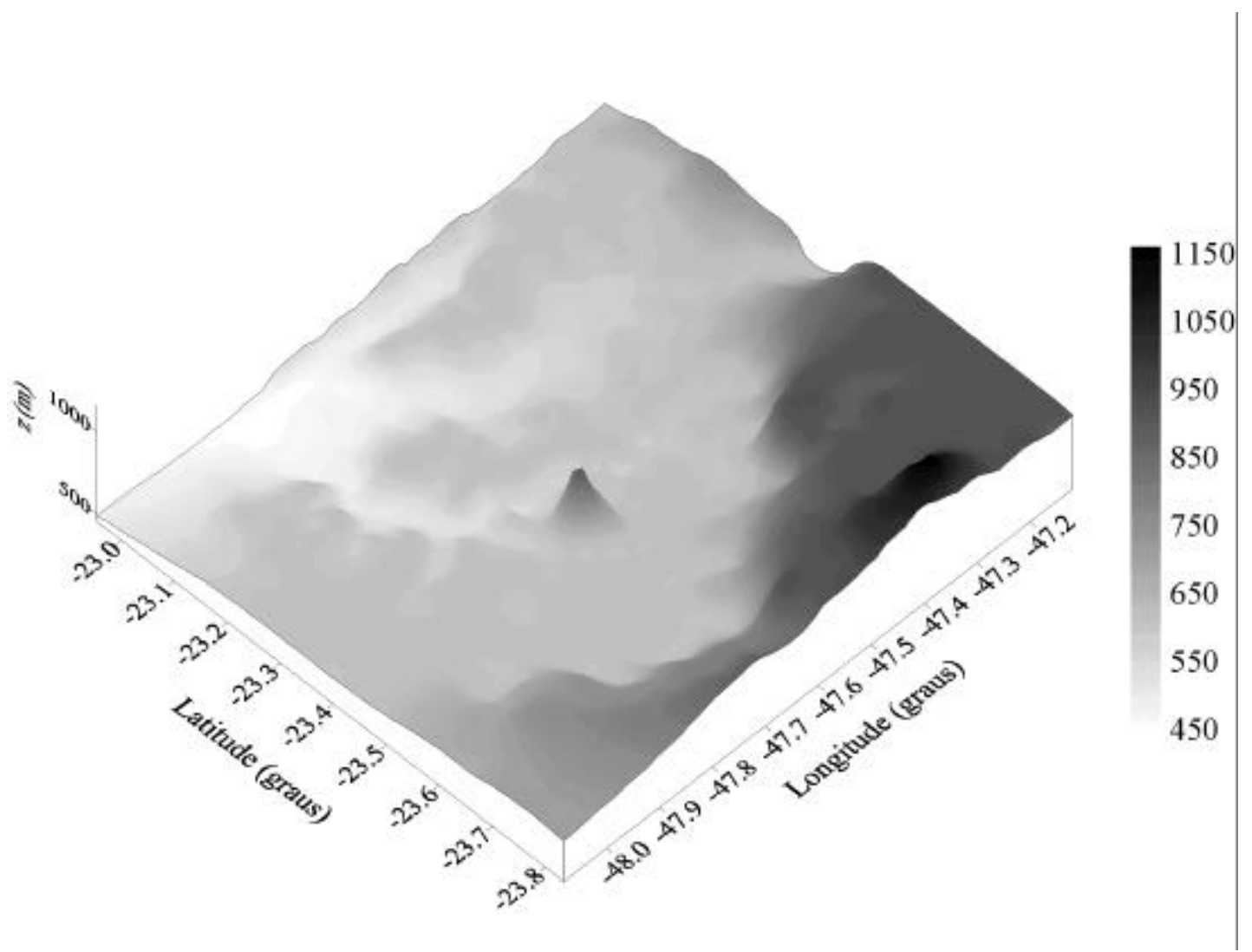

Figura 2.5 Topografia da superfície (modelo GTOPO30) sobre a região do Estado de São Paulo, com área $100 \mathrm{~km} \times 100 \mathrm{~km}$, centrada em Iperó. 


\begin{tabular}{|c|c|c|c|c|c|c|c|c|}
\hline Índice & Tipo & $\alpha$ & $\varepsilon$ & $\mathrm{r}_{\mathrm{S}}\left(\mathrm{s} \mathrm{m}^{-1}\right)$ & $\begin{array}{l}\mathrm{C}_{\mathrm{S}} \times 10^{6} \mathrm{C} \\
\left(\mathrm{J} \mathrm{kg}^{-1} \mathrm{~K}^{-1}\right)\end{array}$ & $\mathrm{z}_{0}(\mathrm{~m})$ & $\mathrm{T}_{\mathrm{G} 1}(\mathrm{~K})$ & $\mathrm{T}_{\mathrm{G} 2}(\mathrm{~K})$ \\
\hline 1 & Floresta de pinheiros úmida & 0,13 & 0,95 & 75,0 & 2,72 & 0,800 & 299,15 & 299,15 \\
\hline 2 & Floresta tropical úmida & 0,12 & 0,95 & 50,0 & 2,76 & 1,000 & 299,15 & 299,15 \\
\hline 3 & Floresta de pinheiros decídua & 0,14 & 0,95 & 80,0 & 2,66 & 0,500 & 299,15 & 299,15 \\
\hline 4 & Floresta tropical decídua & 0,16 & 0,93 & 80,0 & 2,70 & 0,500 & 299,15 & 299,15 \\
\hline 5 & Floresta mista & 0,14 & 0,95 & 100,0 & 2,50 & 0,600 & 299,15 & 299,15 \\
\hline 6 & Cobertura arbustiva fechada & 0,16 & 0,95 & 100,0 & 2,42 & 0,300 & 299,15 & 299,15 \\
\hline 7 & Cobertura arbustiva aberta & 0,18 & 0,95 & 150,0 & 2,42 & 0,100 & 299,15 & 299,15 \\
\hline 8 & Serrado ou savana alta & 0,19 & 0,95 & 150,0 & 2,42 & 0,100 & 299,15 & 299,15 \\
\hline 9 & Savana baixa & 0,20 & 0,95 & 180,0 & 2,42 & 0,050 & 299,15 & 299,15 \\
\hline 10 & Campinas & 0,19 & 0,92 & 200,0 & 2,42 & 0,010 & 299,15 & 299,15 \\
\hline 11 & Terras permanentemente úmidas & 0,14 & 0,95 & 50,0 & 3,89 & 0,020 & 299,15 & 299,15 \\
\hline 12 & Plantação, terra agrícola. & 0,17 & 0,92 & 100,0 & 2,76 & 0,050 & 299,15 & 299,15 \\
\hline 13 & Urbano ou área construída & 0,18 & 0,88 & 300,0 & 2,26 & 0,500 & 299,15 & 299,15 \\
\hline 14 & Plantação e mosaico de vegetação natural & 0,15 & 0,92 & 150,0 & 2,76 & 0,200 & 299,15 & 299,15 \\
\hline 15 & Neve e gelo & 0,55 & 0,95 & 400,0 & 2,05 & 0,002 & 299,15 & 299,15 \\
\hline 16 & Solo nu ou esparsamente vegetado & 0,23 & 0,85 & 400,0 & 1,50 & 0,005 & 299,15 & 299,15 \\
\hline 17 & Corpo de água & 0,08 & 0,98 & 10,0 & 4,18 & 0,001 & 299,15 & 299,15 \\
\hline
\end{tabular}

Tabela 2.1 Parâmetros físicos da superfície e do solo que foram associados à classificação IGBP. 


\begin{tabular}{|c|c|c|}
\hline $\mathrm{n}$ & Global Land Cover Legend & Legenda da Cobertura Superfície Global \\
\hline 1 & EVERGREEN NEEDLELEAF FOREST & floresta de pinheiros úmida \\
\hline 2 & EVERGREEN BROADLEAF FOREST & floresta tropical úmida \\
\hline 3 & DECIDUOUS NEEDLELEAF FOREST & floresta de pinheiros decídua \\
\hline 4 & DECIDUOUS BROADLEAF FOREST & floresta tropical decídua \\
\hline 5 & MIXED FORESTS & floresta mista \\
\hline 6 & CLOSED SHRUBLANDS & cobertura arbustiva fechada \\
\hline 7 & OPEN SHRUBLANDS & cobertura arbustiva aberta \\
\hline 8 & WOODY SAVANNAS & serrado ou savana alta \\
\hline 9 & SAVANNAS & savana baixa \\
\hline 10 & GRASSLANDS & campinas \\
\hline 11 & PERMANENT WETLANDS & terras permanentemente úmidas \\
\hline 12 & CROPLANDS & plantação, terra agrícola \\
\hline 13 & URBAN AND BUILT-UP & urbano ou área construída \\
\hline 14 & CROPLAND/NATURAL VEGETATION MOSAIC & plantação e mosaico de vegetação natural \\
\hline 15 & SNOW AND ICE & neve e gelo \\
\hline 16 & BARREN OR SPARSELY VEGETATED & solo nu ou esparsamente vegetado \\
\hline 17 & WATER BODIES & corpo de água \\
\hline
\end{tabular}

Tabela 2.2 Classificação global dos tipos de superfície segundo o programa International Geosphere Biosphere Programme (IGBP). 


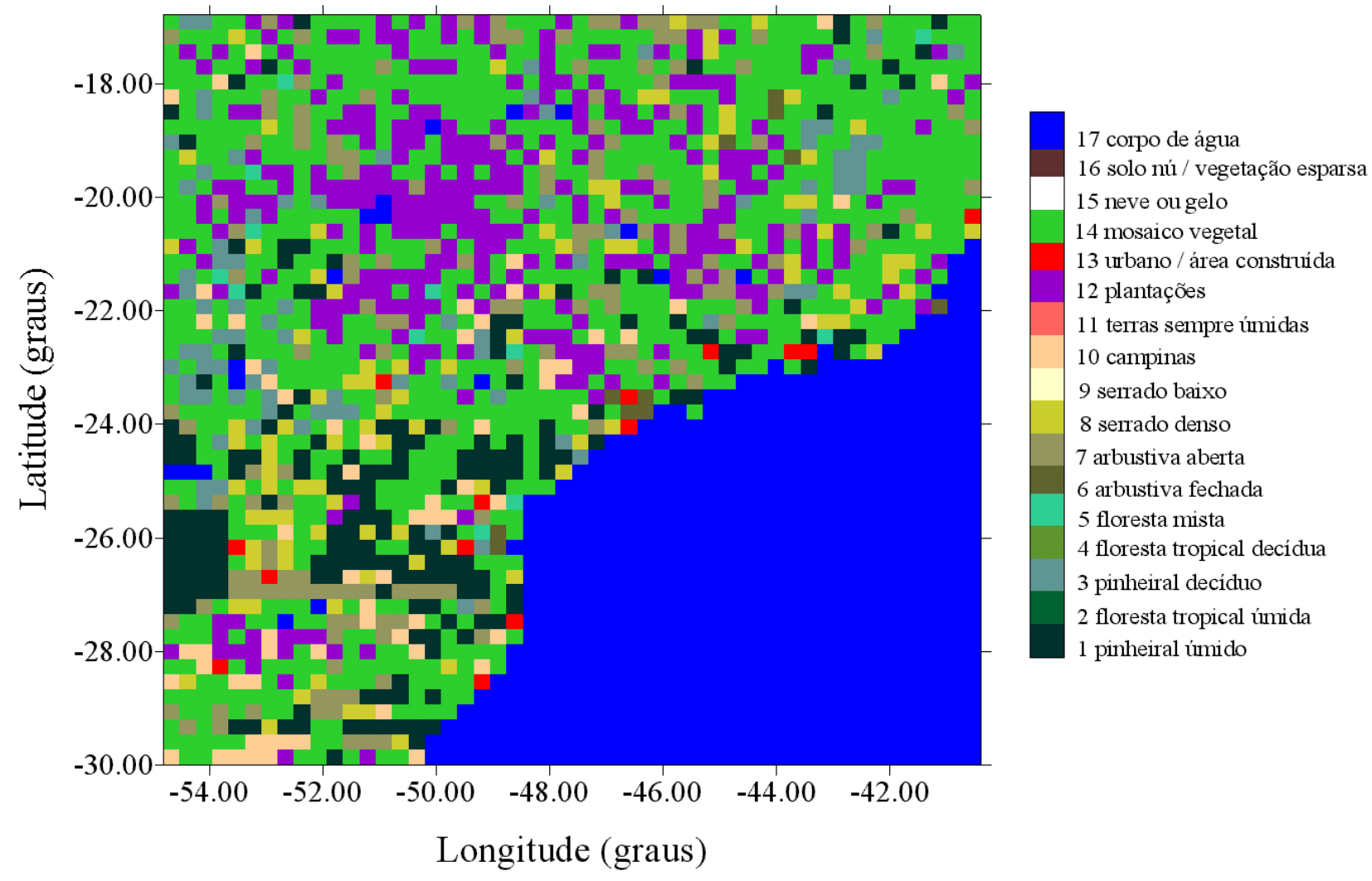

Figura 2.6 Distribuição do tipo de superfície (modelo IGPB) sobre as regiões Sul e Sudeste do Brasil, com área 1500 km × 1500 km, centrada em Iperó.

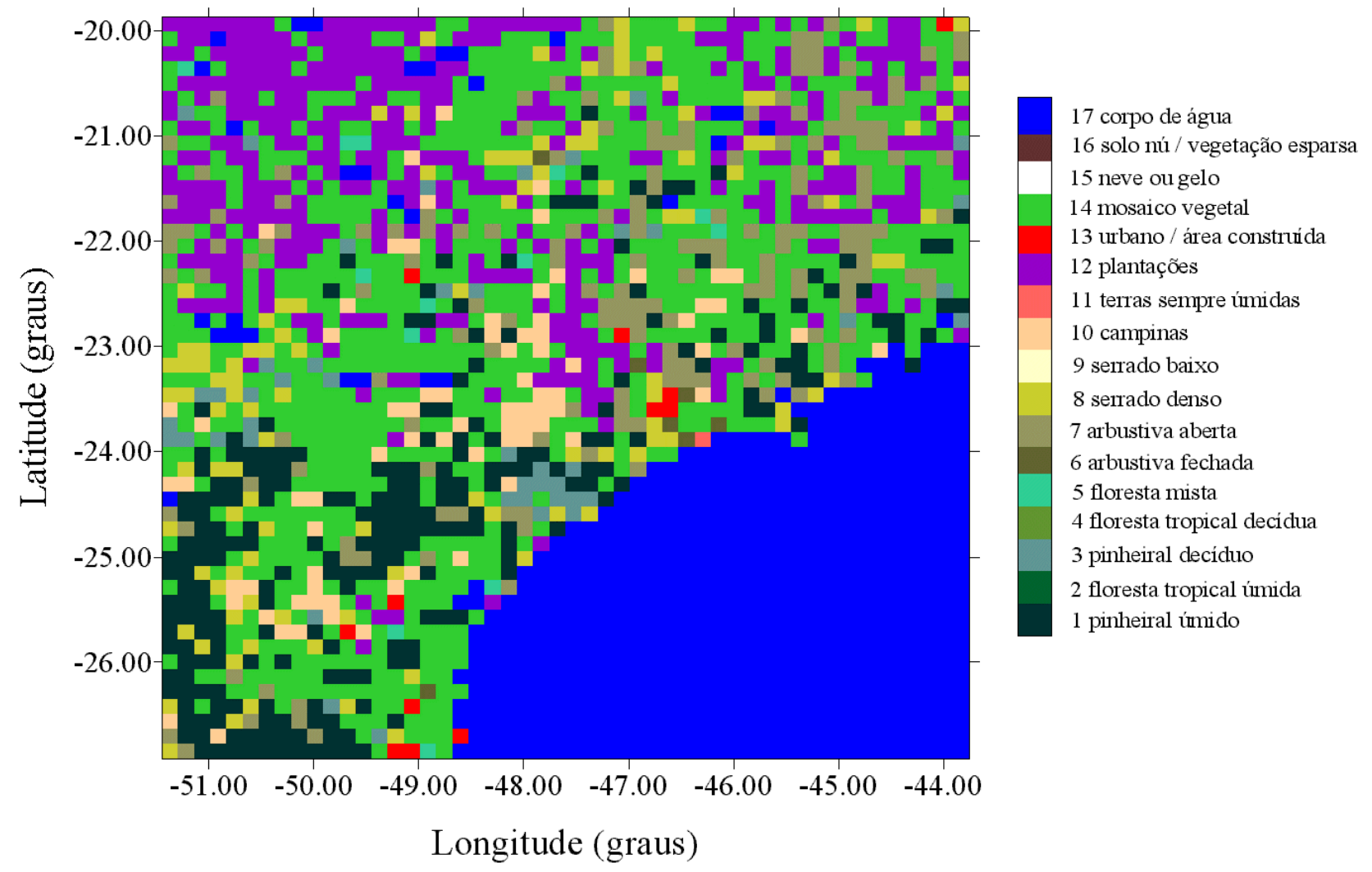

Figura 2.7 Distribuição do tipo de superfície (modelo IGPB) sobre as regiões Sul e Sudeste do Brasil, com área $800 \mathrm{~km} \times 800 \mathrm{~km}$, centrada em Iperó. 


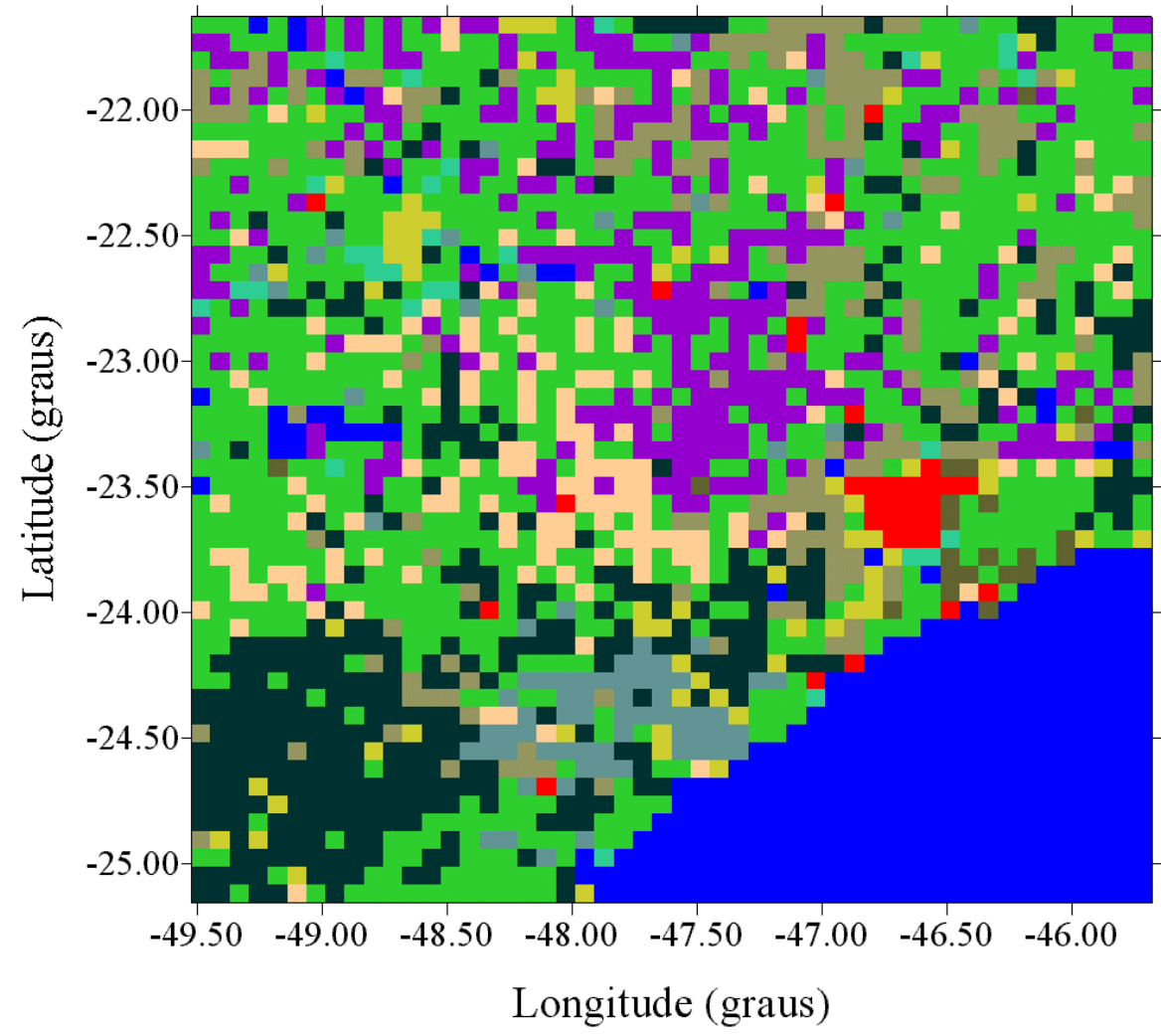

17 corpo de água

16 solo nú / vegetação esparsa

15 neve ou gelo

14 mosaico vegetal

13 urbano / área construída

12 plantações

11 terras sempre úmidas

10 campinas

9 serrado baixo

8 serrado denso

7 arbustiva aberta

6 arbustiva fechada

5 floresta mista

4 floresta tropical decídua

3 pinheiral decíduo

2 floresta tropical úmida

1 pinheiral úmido

Figura 2.8 Distribuição do tipo de superfície (modelo IGPB) sobre as regiões dos Estados de São Paulo, Paraná e Minas Gerais, com área 400 km × 400 km, centrada em Iperó.

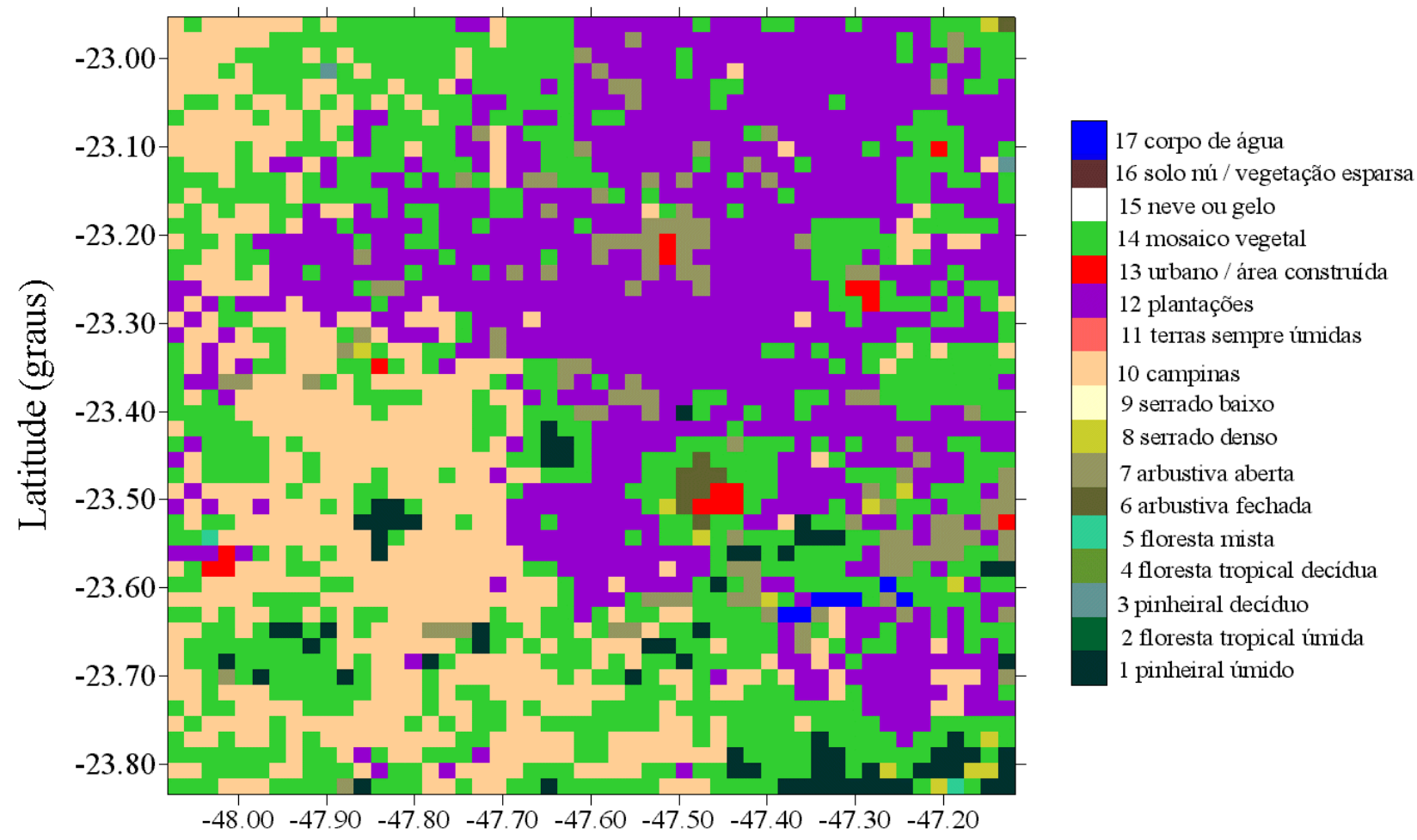

Longitude (graus)

Figura 2.9 Distribuição do tipo de superfície (modelo IGPB) sobre região do Estado de São Paulo, com área $100 \mathrm{~km} \times 100 \mathrm{~km}$, centrada em Iperó. 


\subsection{Modelo de Dispersão de Partículas}

As variâncias das componentes da velocidade do vento são estimadas considerando-se isotropia, em relação à distribuição de energia cinética turbulenta $\sigma_{\mathrm{u}_{\mathrm{i}}}^{2}=2 \mathrm{e} / 3$ nas três direções coordenadas. As condições de fronteira inferior e forçantes externas usadas nas simulações foram tomadas considerando-se uma atmosfera não perturbada, com céu claro; velocidade do vento geostrófico $1 \mathrm{~m} \mathrm{~s}^{-1}$ e direção NE.

A dispersão atmosférica é simulada usando uma versão modificada da equação diferencial estocástica de LANGEVIN, onde condições de turbulência não homogênea são consideradas explicitamente (LEGG e RAUPACH, 1982). Todas as trajetórias são calculadas pelo acoplamento direto da equação de LANGEVIN ao modelo de mesoescala TVM, na forma de sub-rotinas. A equação de LANGEVIN é resolvida numericamente pelo uso do método de diferenças finitas avançado no tempo (EULER forward):

$$
\mathrm{u}_{\mathrm{i}}(\mathrm{t}+\Delta \mathrm{t})=\mathrm{a} \overline{\mathrm{u}}_{\mathrm{i}}(\mathrm{t})+\mathrm{b} \sigma_{\mathrm{u}_{\mathrm{i}}} \xi_{\mathrm{i}}+(1-\mathrm{a}) \Gamma_{\mathrm{L}} \frac{\partial \sigma_{\mathrm{u}_{\mathrm{i}}}^{2}}{\partial \mathrm{x}_{\mathrm{i}}} \delta_{\mathrm{i} 3},
$$

onde $\mathrm{u}_{\mathrm{i}}(\mathrm{t}+\Delta \mathrm{t})$ é a velocidade Lagrangiana de cada partícula no tempo $(\mathrm{t}+\Delta \mathrm{t}) ; \overline{\mathrm{u}}_{\mathrm{i}}(\mathrm{t})$ com $i=1,2,3$ representam as componentes da velocidade da partícula, respectivamente, nas direções x, y e z e tempo t, estimadas do campo de velocidades do modelo (euleriano) considerados como médias de REYNOLDS sobre o elemento de volume ${ }^{6}$; $\xi_{\mathrm{i}}$ é um número aleatório caracterizado por função densidade de probabilidade (f.d.p.) Normal $^{7}$ com média zero e variância unitária; $\Gamma_{\mathrm{L}}$ é a escala de tempo lagrangiana integral, tomada aqui igual a $200 \mathrm{~s}$ para as componentes $u, v$ e $20 \mathrm{~s}$ para $w$ (ZANNETTI, 1990); $\delta_{\mathrm{i} 3}$ é o tensor Delta de KRONECKER; $\Delta$ t é o passo de tempo, igual a $9 s$, utilizado na solução numérica da equação de LANGEVIN e $a$ e b são os coeficientes determinístico e estocástico da equação de LANGEVIN, aqui determinados de acordo com a teoria de difusão de TAYLOR (1921) para turbulência homogênea e isotrópica (MONIN e YAGLOM, 1983), que

\footnotetext{
${ }^{6}$ A hipótese por trás dessa identidade é que o campo de velocidades lagrangianas das partículas, em média no elemento de volume, seja aproximado pelo campo de velocidade do escoamento atmosférico (dado pela média de REYNOLDS no elemento de volume). Esta hipótese em modelagem de partículas pode ser considerada como a "hipótese zero" - sendo uma hipótese de trabalho. Note-se que o campo de escoamento atmosférico é conhecido geralmente para um sistema de coordenadas euleriano (i.e., fixo) e que o campo de velocidade das partículas seja dado num referencial lagrangiano, i.e., as velocidades são conhecidas somente sobre as partículas.

${ }^{7}$ A f.d.p. Normal é obtida a partir de uma f.d.p. uniforme construída pela sub-rotina randu.f da IBM (PACITTI e ATKINSON, 1983). A rotina randu.f gera de números pseudo-aleatórios de distribuição uniforme no intervalo entre $0 \mathrm{e}$ 1. Multiplica-se tais números aleatórios por 1,3 para obter-se novos números pseudo-aleatórios denominados (c,d,e) ainda com distribuição uniforme, mas no intervalo $-1,3$ e $+1,3$. Os números pseudo-aleatórios de distribuição Normal $\left(\xi_{1}, \xi_{2}, \xi_{3}\right)$ são obtidos efetuando-se $\xi_{1}=0,8 \sin (\mathrm{c}) / \cos (\mathrm{c}), \xi_{2}=0,8 \sin (\mathrm{d}) / \cos (\mathrm{d})$ e $\xi_{3}=0,8 \sin (\mathrm{e}) / \cos (\mathrm{e})$.
} 
resultam iguais às funções autocorrelação $\mathrm{a}=\exp \left(-\Delta \mathrm{t} / \Gamma_{\mathrm{L}}\right)$ e descorrelação $\mathrm{b}=\left(1-\mathrm{a}^{2}\right)^{1 / 2}$, respectivamente. A primeira parcela do lado direito da equação de LANGEVIN é conhecido como termo determinístico; o segundo de termo aleatório e o terceiro de termo de correção. Apesar desses nomes, cada um dos termos da equação de LANGEVIN apresenta natureza estocástica.

A concentração media $\mathrm{C}(\mathrm{x}, \mathrm{y}, \mathrm{z}, \mathrm{t})$ é calculada totalizando-se o número de partículas $\mathrm{N}$ em cada célula da grade numérica, a cada hora como segue (NGUYEN et alli, 1997; GRAHAN e MOYEED, 2001)

$$
C(x, y, z, t)=\sum_{i=1}^{n} \frac{m_{i}}{\Delta x \Delta y \Delta z},
$$

onde $\mathrm{m}_{\mathrm{i}}$ é a massa de cada partícula e $\Delta \mathrm{x}, \Delta \mathrm{y}, \Delta \mathrm{z}$ são espaçamentos de grade nas direções $x, y$ e $z$, respectivamente.

\subsection{Metodologia de Interpolação}

Um modelo de fechamento de segunda-ordem (MFSO) unidimensional foi utilizado para interpolar dinamicamente dos dados esparsos originais. Os objetivos dessa interpolação são:

(a) Realizar um acoplamento dos dados observacionais que possuem origem diversa (Experimento de Iperó, NCEP e torre de ARAMAR);

(b) Interpolar dinamicamente os dados esparsos (no tempo e na vertical), obtendo-se um conjunto completo de dados para o período dos Experimentos em Iperó;

(c) Utilizar esses dados interpolados para descrever a estrutura vertical do JBN, caracterizando-o.

O JBN é um escoamento na CLP, que pode ser considerado complexo. Por exemplo, a estrutura vertical do JBN com seu cisalhamento vertical da velocidade do vento é capaz de sustentar regiões de turbulência em diferentes camadas ao longo da vertical ${ }^{8}$ (Figura 2.10).

\footnotetext{
${ }^{8}$ As parametrizações tradicionais, como a Teoria $\mathrm{K}$, podem ser utilizadas somente de forma restrita na descrição dos efeitos da turbulência do JBN. Neste caso, uma definição precisa da escala de mistura turbulenta constitui-se um problema de difícil solução, desde que o nível de máxima velocidade jato, onde $\mathrm{Ri} \rightarrow \infty$, tende a separar as camadas turbulentas (induzidas pelo cisalhamento vertical) com a formação de uma camada estável.
} 


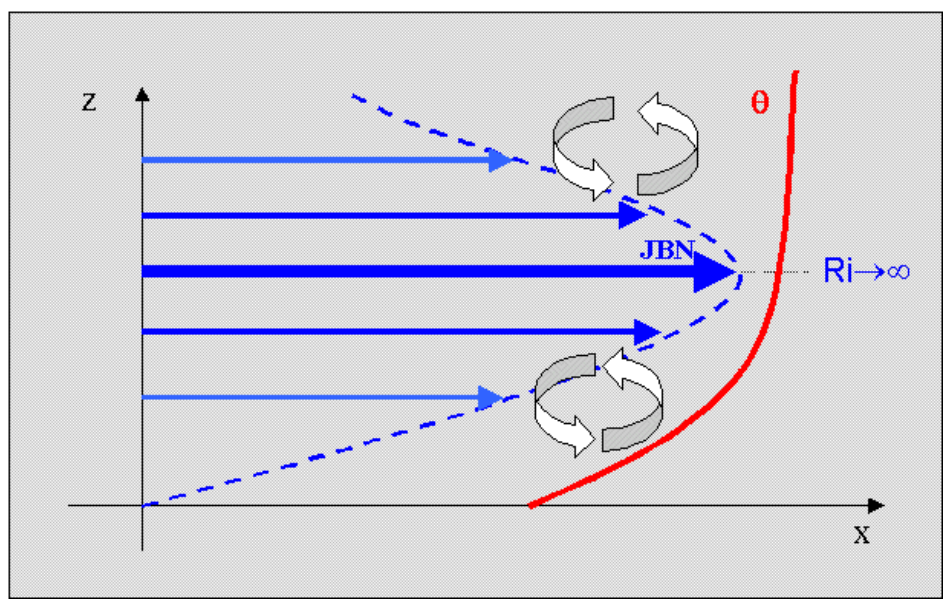

Figura 2.10 Representação da estrutura vertical da turbulência induzida pelo cisalhamento vertical num JBN.

Para combinar os dados foi utilizado um modelo numérico que resolve as equações das variáveis médias e as equações de variância e covariância conforme descritas por OLIVEIRA e FITZJARRALD (1994) e OLIVEIRA et alli (1996). Estas equações correspondem ao modelo fechamento de segunda-ordem (unidimensional) conforme proposto por MELLOR e YAMADA (1982), empregando parametrizações baseadas na Teoria K e numa escala única para mistura turbulenta (escala mestra).

Para simular o escoamento médio na CLP, precisa-se estimar os fluxos que compõe o tensor de Reynolds. Para isto, utiliza-se aqui uma técnica de fechamento de segunda ordem. O MFSO consiste de resolver as equações dos momentos de segunda ordem das flutuações turbulentas; obtidas das equações do momento médio de Reynolds e da termodinâmica, pelo fechamento das incógnitas restantes através de parametrização dos momentos de terceira ordem. Em adição às equações prognosticas das variáveis médias, o modelo consiste de 10 equações prognósticas, escritas para as componentes do tensor de Reynolds, componentes do fluxo turbulento e variâncias escalares (MELLOR e YAMADA, 1982; STULL, 1988; SORBJAN, 1989; OLIVEIRA e FITZJARRALD, 1994; OLIVEIRA et alli, 1996):

(a) Variâncias da velocidade (i=1,2, sem somatória):

$$
\begin{gathered}
\frac{\partial \overline{\mathrm{u}_{\mathrm{i}}^{\prime} \mathrm{u}_{\mathrm{i}}^{\prime}}}{\partial \mathrm{t}}=-2 \overline{\mathrm{w}^{\prime} \mathrm{u}_{\mathrm{i}}^{\prime}} \frac{\partial \mathrm{u}_{\mathrm{i}}}{\partial \mathrm{z}}-\frac{1}{\tau_{\mathrm{IM}}}\left(\overline{\mathrm{u}_{\mathrm{i}}^{\prime} \mathrm{u}_{\mathrm{i}}^{\prime}}-\frac{\mathrm{q}^{2}}{3}\right)-\frac{2}{3} \frac{\mathrm{q}^{2}}{\tau_{\mathrm{DM}}}+\frac{\partial}{\partial \mathrm{z}}\left(\mathrm{K}_{\mathrm{V}} \frac{\partial \overline{\mathrm{u}_{\mathrm{i}}^{\prime} \mathrm{u}_{\mathrm{i}}^{\prime}}}{\partial \mathrm{z}}\right), \\
\frac{\partial \overline{\mathrm{w}^{\prime} \mathrm{w}^{\prime}}}{\partial \mathrm{t}}=\frac{\mathrm{g}}{\theta_{0}} \overline{\mathrm{w}^{\prime} \theta^{\prime}}-\frac{1}{\tau_{\mathrm{IM}}}\left(\overline{\mathrm{w}^{\prime} \mathrm{w}^{\prime}}-\frac{\mathrm{q}^{2}}{3}\right)-\frac{2}{3} \frac{\mathrm{q}^{2}}{\tau_{\mathrm{DM}}}+\frac{\partial}{\partial \mathrm{z}}\left(\mathrm{K}_{\mathrm{V}} \frac{\partial \overline{\mathrm{w}^{\prime} \mathrm{w}^{\prime}}}{\partial \mathrm{z}}\right),
\end{gathered}
$$

(b) Covariâncias do tensor de Reynolds (i=1,2): 


$$
\frac{\partial \overline{\mathrm{u}_{\mathrm{i}}^{\prime} \mathrm{w}^{\prime}}}{\partial \mathrm{t}}=\frac{\mathrm{g}}{\theta_{0}} \overline{\mathrm{w}^{\prime} \mathrm{u}_{\mathrm{i}}^{\prime}}-\overline{\mathrm{w}^{\prime} \mathrm{w}^{\prime}} \frac{\partial \mathrm{u}_{\mathrm{i}}}{\partial \mathrm{z}}-\frac{\overline{\mathrm{u}_{\mathrm{i}}^{\prime} \mathrm{w}^{\prime}}}{\tau_{\mathrm{IM}}}+\frac{\partial}{\partial \mathrm{z}}\left(\mathrm{K}_{\mathrm{V}} \frac{\partial \overline{\mathrm{w}^{\prime} \mathrm{u}_{\mathrm{i}}^{\prime}}}{\partial \mathrm{z}}\right)
$$

(c) Covariâncias de fluxo $(x=\theta, q)$ :

$$
\frac{\partial \overline{u_{i}^{\prime} x^{\prime}}}{\partial t}=-\overline{u_{i}^{\prime} x^{\prime}} \frac{\partial u_{i}}{\partial z}-\overline{u_{i}^{\prime} w^{\prime}} \frac{\partial x}{\partial z}-\frac{\overline{u_{i}^{\prime} x^{\prime}}}{\tau_{\mathrm{IX}}}+\frac{\partial}{\partial z}\left(K_{T} \frac{\partial \overline{u_{i}^{\prime} x^{\prime}}}{\partial z}\right)
$$

(d) Variâncias de escalar ( $\mathrm{x}=\theta$ ou q):

$$
\frac{\partial \overline{\mathrm{x}^{\prime} \mathrm{x}^{\prime}}}{\partial \mathrm{t}}=-2 \overline{\mathrm{w}^{\prime} \mathrm{x}^{\prime}} \frac{\partial \mathrm{x}}{\partial \mathrm{z}}-\frac{\overline{\mathrm{x}^{\prime} \mathrm{x}^{\prime}}}{\tau_{\mathrm{Dx}}}+\frac{\partial}{\partial \mathrm{z}}\left(\mathrm{K}_{\mathrm{T}} \frac{\partial \overline{\mathrm{x}^{\prime} \mathrm{x}^{\prime}}}{\partial \mathrm{z}}\right)
$$

onde $\mathrm{q}^{2}=\left(\overline{\mathrm{u}^{\prime 2}}+\overline{\mathrm{v}^{\prime 2}}+\overline{\mathrm{w}^{\prime 2}}\right)$ é o dobro da energia cinética turbulenta por unidade de massa $\left(\mathrm{q}^{2}=2 \mathrm{e}\right)$, sendo $\mathrm{e}=0,5\left(\overline{\mathrm{u}^{\prime 2}}+\overline{\mathrm{v}^{\prime 2}}+\overline{\mathrm{w}^{\prime 2}}\right) ; \tau_{\mathrm{D}}$ são escalas características da dissipação molecular de momento $(\mathrm{M})$; variância escalar para $\theta$ e $\mathrm{q}(\mathrm{X})$; $\tau_{\mathrm{I}}$ são escalas de tempo características para destruição das covariâncias de momento $(\mathrm{M})$, escalares $\theta$ e $\mathrm{q}(\mathrm{x})$ e redistribuição da variância de momento $(\mathrm{M})$ induzida pelo termo de tendência de retorno à isotropia; $\mathrm{K}$ é o coeficiente de difusão turbulenta da variância e covariância dessas variáveis, parametrizadas como $K_{V}=0.201 \mathrm{e}^{0.5}$ e $K_{T}=1.67 K_{V}$. As escalas características são parametrizadas como: $\tau_{\mathrm{DM}}=16.61 \mathrm{e}^{-0.5}, \tau_{\mathrm{DX}}=10.11 \mathrm{e}^{-0.5}, \tau_{\mathrm{IM}}=0.921 \mathrm{e}^{-}$ ${ }^{0.5}$ e $\tau_{\mathrm{IX}}=0.741 \mathrm{e}^{-0.5}$, onde $l$ é proporcional à altura acima da superfície para os níveis inferiores e praticamente constante mais acima, definida aqui como $1 / 1=1 /(\kappa z)+1 / 1_{0}$, onde $\kappa$ é a constante de vonKARMAN e $1_{0}=10 \%\left(\int_{0}^{z_{\mathrm{c}}}(\mathrm{e} \cdot \mathrm{z}) \mathrm{dz} / \int_{0}^{z_{\mathrm{c}}} \mathrm{e} \mathrm{dz}\right)$ onde os limites da integração são a superfície $\mathrm{z}$ igual a zero e a altura $\mathrm{z}_{\mathrm{c}}$ igual ao topo da CLP. Note-se que YM-75 considerou $\mathrm{z}_{\mathrm{c}}$ como a altura do topo do modelo. No modelo implementado aqui, considera-se $\mathrm{z}_{\mathrm{c}}$ variável no tempo, permitindo-se obter: (a) uma escala de tempo de dissipação da turbulência comparável a duração do período de transição convectivo para estável e (b) um desacoplamento noturno acima do topo da CLP estável.

Uma assimilação quadrimensional foi realizada de forma similar ao processo de resfriamento newtoniano (newtonian nudging) (HOVERMALE, 1986; HALTINER e WILLIAMS, 1980). Por exemplo, a equação que descreve a assimilação da temperatura potencial $(\theta)$ no modelo 1-D é:

$$
\frac{\partial \theta}{\partial \mathrm{t}}=\frac{\theta_{0}-\theta}{\tau_{\theta}}
$$

onde $\theta_{0}$ é a temperatura potencial observada, sendo assimilada, e $\tau_{\theta}$ é a escala de tempo do processo de assimilação. Considerou-se o valor de $\tau_{\theta}$ igual a uma hora como apropriado para descrever os 
processos de ajuste externo na CLP, em acordo com a frequiência das observações disponíveis para os perfis verticais obtidos durante o Experimento de Iperó.

A assimilação de dados no modelo 2-D é aplicada a cada ponto da grade do plano de corte temporal $(\mathrm{z}, \mathrm{t})$ proporcionalmente à freqüência de observações disponíveis à volta do ponto, i.e., em cada elemento de grade. Desta forma, regiões e períodos desprovidos de observações são mais ajustados pelo modelo 1-D que aquelas regiões e períodos nos quais a densidade de informações observacionais é maior. 


\section{CAPÍTULO 3}

\section{Resultados Observacionais}

Neste capítulo, (1) apresentam-se as Campanhas de Medidas nas quais foi observado o JBN em Iperó; (2) investiga-se a estrutura vertical do JBN durante as Campanhas em Iperó; (3) analisa-se a influência do JBN nos dados de superfície observados na região de Iperó e por fim, (4) analisa-se a relação entre a estrutura vertical do vento de grande-escala e a presença de JBN em Iperó.

Neste estudo, os dados de balão-cativo, de superfície e de grande-escala para o período das Campanhas do Experimento de Iperó foram interpolados de forma conjunta.

O objetivo principal desse capítulo é descrever o JBN observado em Iperó e sua relação com medidas efetuadas em superfície (i.e., em escala local) e em altitude (i.e., em grande-escala).

\subsection{Experimento de Iperó}

A Tabela 3.1 apresenta os períodos das campanhas observacionais em Iperó, realizadas por OLIVEIRA (1993). Os dados observados de Iperó foram utilizados para (a) definir parâmetros de entrada básicos do modelo de mesoescala TVM (i.e., temperatura potencial do estado básico, temperatura do solo, perfis verticais típicos de temperatura e umidade) e (b) definir a verdade observacional a ser comparada com os resultados de simulação.

As observações são utilizadas para definir o estado inicial da atmosfera no modelo, ou seja, para determinar suas condições iniciais. O estado inicial escolhido procurou refletir as condições típicas encontradas nos dias de céu claro durante as campanhas em Iperó. Considerou-se ainda um escomento inicial com ventos muito fracos, da ordem de $1 \mathrm{~m} \mathrm{~s}^{-1}$, para representar condições de ausência de forçantes de grande-escala. Desta forma, o escoamento resultante pode ser considerado como conseqüência somente das forçantes topográficas e da cobertura da superfície.

O conjunto de dados disponíveis é consideravelmente grande. Durante o período de Março de 1991 e 1993 foram realizadas 4 campanhas de medidas em Iperó. Conta-se com 286 sondagens utilizando Balão Cativo e cerca de 22 sondagens utilizando radiossonda (Tabela 3.1). 
De acordo com OLIVEIRA (1993), tanto os dados de Balão Cativo quanto de Radiossonda foram verificados através de uma análise de consistência com os dados de superfície; resultando desta análise dois novos arquivos de dados para cada sondagem. O primeiro arquivo derivado das sondagens na CLP em Iperó denominado de "arquivo padrão" contém 14 colunas com os seguintes parâmetros: \{ano, dia Juliano, hora, pressão, altura, temperatura do bulbo seco, temperatura do bulbo úmido, umidade relativa, velocidade do vento, direção do vento, temperatura potencial, razão de mistura, componente zonal e componente meridional\}, sendo que estes parâmetros correspondem aos valores medidos nos níveis de observação. Já o segundo arquivo contém, além destes parâmetros, mais duas colunas com os parâmetros \{altura e número de Richardson\}. Neste segundo arquivo, os dados foram interpolados em uma grade regular com espaçamento de 5 metros para os dados de Balão Cativo e de 50 metros para os dados de Radiossonda.

Com estes dados pode-se determinar a evolução espacial (vertical) e temporal da CLP (componentes zonal e meridional do vento, temperatura potencial e razão de mistura) com resolução temporal de hora (tempo aproximado entre duas sondagens consecutivas). Assim, foi possível realizar o levantamento dos casos de JBN durante as campanhas observacionais em Iperó (Tabela 3.3).

No capítulo seguinte (capítulo 4) comparam-se os JBN simulados aos JBN observados em Iperó.

Além das sondagens verticais realizadas com Balão Cativo e Radiossonda, durante as campanhas de medidas indicadas na Tabela 3.1, foram efetuadas medidas contínuas com freqüência variando de 1 a $10 \mathrm{~Hz}$ das três componentes do vento (u, v, w), da flutuação de temperatura e densidade do vapor de água do ar através de sensores de resposta rápida (anemômetro sônico, termômetro de arame fino e higrômetro de Kripton), instalados em uma torre de $12 \mathrm{~m}$. Nesta torre estavam instalados também sensores de resposta lenta, que forneceram medidas da temperatura e umidade relativa do ar em três níveis. Através destas medidas, OLIVEIRA (1993) pode estimar os fluxos verticais turbulentos de calor sensível, latente e de momento em três níveis, checando a consistência dos dados e descrevendo o balanço de energia nos níveis atmosféricos junto à superfície.

Durante estas campanhas de medidas, simultaneamente, foram efetuadas observações de radiação solar global, refletida, líquida, radiação de onda longa emitida pela superfície e pela atmosfera, além de estimativas do fluxo de calor no solo em dois níveis $(1$ e $7 \mathrm{~cm})$, temperatura do solo em três níveis $(1,7$ e $15 \mathrm{~cm})$, umidade do solo (a $7 \mathrm{~cm})$ e de observações contínuas de pressão atmosférica e da precipitação (Tabela 3.1). Estas observações permitiram determinar as componentes do balanço de energia na superfície e das características do transporte de calor e 
umidade no solo. Todos estes parâmetros encontram-se disponíveis na forma de valores médios de 5 minutos para todas as quatro campanhas de medidas (OLIVEIRA, 1993).

\begin{tabular}{|c|c|c|c|}
\hline Campanha & Período & Balão Cativo & Radiossonda \\
\hline Primeira & 11 a 21 de março de 1991 & 88 & - \\
\hline Segunda & 9 a 20 março de 1992 & 34 & 13 \\
\hline Terceira & 28 de julho a 7 de Agosto de 1992 & 58 & - \\
\hline Quarta & 8 a 21 março de 1993 & 106 & 9 \\
\hline Total & & 286 & 22 \\
\hline
\end{tabular}

Tabela 3.1 Período e número de sondagens efetuadas durante as 4 campanhas de medidas em realizadas em Iperó, SP.

\begin{tabular}{|c|c|}
\hline Campanhas de campo em Iperó & $\begin{array}{c}\text { Dia Juliano } \\
\text { (precipitação observada) }\end{array}$ \\
\hline $\begin{array}{l}11 \text { a } 22 \text { de Março de } 1991 \text { (dias Julianos 70-81) } \\
\text { (final de verão) } \\
\text { (superfície coberta de grama de } 0,1 \mathrm{~m} \text { de altura) } \\
\text { (perturbações de baixa pressão, pouco intensas, dias Julianos } \\
72,78 \text { e } 80 \text { ). }\end{array}$ & $\begin{array}{l}72(15) \\
78 \text { (14.), entre 06-12 HL (19 de } \\
\text { Março de 1991) } \\
80 \text { (18.), entre 18-24 HL (20 e } 21 \\
\text { Março de 1991) }\end{array}$ \\
\hline $\begin{array}{l}\text { 09 - } 21 \text { de Março de } 1992 \text { (dias Julianos 69-81) } \\
\text { (final de verão) } \\
\text { (superfície coberta de milho de altura } 1,7 \mathrm{~m} \text { ) } \\
\text { (dataloger inundado sem operação } 1 \text { noite) } \\
\text { (duas frentes-frias nos dias Julianos } 75 \text { e } 81 \text { ). }\end{array}$ & $\begin{array}{l}75(0,2) \\
76(22) \\
77(16) \\
78(27) \\
79(12)\end{array}$ \\
\hline $\begin{array}{l}28 \text { de Julho a } 07 \text { de Agosto de } 1992 \text { (dias Julianos 209-219) } \\
\text { (inverno) } \\
\text { (superfície com cobertura de grama de altura } 0.2 \mathrm{~m} \text { ) } \\
\text { (intensa frente fria sem precipitação). }\end{array}$ & (NENHUMA) \\
\hline $\begin{array}{l}08 \text { a } 21 \text { de Março de } 1993 \text { (dias Julianos 67-80) } \\
\text { (final de verão) } \\
\text { (superfície com cobertura de milho de altura 0,5 m). }\end{array}$ & $\begin{array}{c}76(1,9) \\
77(3,1) \\
78(6)\end{array}$ \\
\hline
\end{tabular}

Tabela 3.2 Precipitação acumulada observada durante as quatro campanhas em Iperó (OLIVEIRA, 1993).

A Tabela 3.3 sumariza o total de ocorrências de JNB, que foram observados durantes as Campanhas em Iperó. Nas noites com ocorrência de JBN em Iperó (Apêndice), nota-se um intenso cisalhamento da velocidade do vento na Camada Limite Superficial (CLS) durante o período noturno. Em conseqüência deste fato, cisalhamentos da velocidade do vento intensos da ordem de 0,04 a $0,10 \mathrm{~s}^{-1}$ nos primeiros $100 \mathrm{~m}$ podem ser considerados como indícios relevantes da presença de JNB em Iperó.

De acordo com o observado em Iperó, aproximadamente $2 / 3$ das noites de final do verão apresentarão JBN. No inverno, os dados disponíveis indicam que de cada 5 noites, 4 apresentarão 
JBN. Para o conjunto de todo o experimento em Iperó, tem-se 20 ocorrências de jatos para 28 noites de observação. Portanto, 71,4\% das noites apresentam JBN ou 5 em cada 7 noites.

\begin{tabular}{|c|c|c|c|c|c|c|c|c|c|c|c|c|c|}
\hline & \multicolumn{12}{|c|}{ Noite entre os dias } & \\
\hline $\begin{array}{l}\text { Campanhas } \\
\text { de Março }\end{array}$ & $\begin{array}{c}09- \\
10\end{array}$ & $\begin{array}{l}10- \\
11\end{array}$ & $\begin{array}{l}11- \\
12\end{array}$ & $\begin{array}{l}12- \\
13\end{array}$ & $\begin{array}{l}13- \\
14\end{array}$ & $\begin{array}{l}14- \\
15\end{array}$ & $\begin{array}{l}15- \\
16\end{array}$ & $\begin{array}{l}16- \\
17\end{array}$ & $\begin{array}{l}17- \\
18\end{array}$ & $\begin{array}{l}18- \\
19\end{array}$ & $\begin{array}{l}19- \\
20\end{array}$ & $\begin{array}{l}20- \\
21\end{array}$ & $\begin{array}{l}\text { Fração } \\
\text { de dias } \\
\text { com V }\end{array}$ \\
\hline 1991 & - & - & - & - & - & - & V & V & $\mathrm{V}$ & $\mathrm{V}$ & V & V & $6 / 6$ \\
\hline 1992 & - & - & - & - & - & - & - & $\bar{F}$ & $\mathrm{~V}$ & $\mathrm{~F}$ & $\bar{F}$ & - & $1 / 4$ \\
\hline 1993 & $\mathrm{~V}$ & $\mathrm{~V}$ & $\mathrm{~V}$ & $\mathrm{~V}$ & $\mathrm{~F}$ & $\mathrm{~F}$ & $\mathrm{~F}$ & $\mathrm{~V}$ & $\mathrm{~V}$ & - & - & - & $6 / 9$ \\
\hline $\begin{array}{l}\text { Estimativa da } \\
\text { probabilidade }\end{array}$ & & & & & & & & & & & & & $\begin{array}{c}13 / 19= \\
68,4 \% \\
\approx 2 / 3 \\
\text { dias }\end{array}$ \\
\hline
\end{tabular}

\begin{tabular}{|c|c|c|c|c|c|c|c|c|c|c|}
\hline & \multicolumn{7}{|c|}{ Noite entre os dias } & \\
\hline $\begin{array}{c}\text { Campanha de } \\
\text { Julho/Agosto }\end{array}$ & $29-$ & $30-$ & $31-$ & $01-$ & $02-$ & $03-$ & $04-$ & $05-$ & $06-$ & Fração de dias com \\
\hline $\mathbf{1 9 9 2}$ & $\mathrm{V}$ & $\mathrm{V}$ & $\mathrm{V}$ & $\mathrm{V}$ & $\mathrm{V}$ & $\mathrm{V}$ & $\mathrm{F}$ & $\mathrm{V}$ & $\mathrm{F}$ & $\mathrm{V}$ \\
\hline $\begin{array}{l}\text { Estimativa da } \\
\text { probabilidade }\end{array}$ & & & & & & & & & & $77,8 \% \approx 4 / 5$ dias \\
\hline
\end{tabular}

Tabela 3.3 Ocorrência de JBN durante as Campanhas Observacionais em Iperó. A letra "V" indica ocorrência de JBN na noite, a letra "F" indica não ocorrência e "-_" indica ausência de dados.

\subsection{Estrutura Vertical dos JBN em Iperó}

\subsubsection{Dados Originais de Balão-Cativo}

Para exemplificar a evolução temporal da estrutura vertical dos JBN s observados em Iperó, apresenta-se, neste item, a estrutura vertical de um jato típico, observado na noite entre os dias $12 \mathrm{e}$ 13 de Março de 1993 (entre dias 71 e 72 do ano de 1993) ${ }^{1}$ da Quarta Campanha (Figura 3.2). Os dados utilizados neste estudo de caso são constituídos pelas sondagens de balão-cativo disponíveis para esta noite (Figura 3.2 a).

\footnotetext{
${ }^{1} \mathrm{O}$ número do dia refere-se ao dia do ano, contado entre 1 e 365 para anos normais e de 1 a 366 para anos bissextos.
} 
A evolução temporal dos perfis de (a) temperatura do ar, (b) temperatura potencial, (c) umidade relativa e (d) umidade específica mostram o desenvolvimento típico de uma CLP convectiva durante o dia e de uma CLP estável durante a noite.

A temperatura do ar junto àsuperfície variou entre a mínima de $22{ }^{\circ} \mathrm{C}$ e a máxima de $28{ }^{\circ} \mathrm{C}$. A temperatura potencial variou a superfície entre $295 \mathrm{~K}$ e $306 \mathrm{~K}$, respectivamente. Nota-se o desenvolvimento de uma camada de mistura no período da tarde do dia 71, com mais de $800 \mathrm{~m}$ de altura, seguida pelo desenvolvimento de uma CLP estável no período noturno (Figura 3.2 b).

O período de transição, ao final da tarde e início da noite do dia 71, parece se estender por 4 h, entre $17 \mathrm{~h}$ e $21 \mathrm{~h}$ (Figura 3.2 b). Durante esse período, nota-se uma variação rápida da temperatura da superfície. A variação térmica neste dia é da ordem de $2 \mathrm{~K} \mathrm{~h}^{-1}$, mostrando a típica forma signoidal (forma de "S") para a temperatura em função do tempo. Note-se que a forma de variação destacada em Iperó está em conformidade com aquela observada em localidades em latitude média (ACEVEDO, 2001).

Durante a noite, observa-se o desenvolvimento de uma inversão térmica de superfície com gradiente vertical $0.025\left({ }^{\circ} \mathrm{C} \mathrm{m}^{-1}\right)$ e altura máxima entre 100 e $130 \mathrm{~m}$, alcançada entre 5 e 6 horas da manhã, no dia 72 (Figura 3.2 b e 3.2 c). Nota-se um crescimento monotônico da altura da inversão de superfície durante todo o período estável (entre 21 h e 6 h). A transição do período da manhã, conforme aparece no dia Juliano 71 (Figura 3.2 b e 3.2 c) é bem mais rápida, comparada àquela da transição da tarde.

O mínimo de umidade relativa ocorre próximo à $14 \mathrm{~h}$ (dia 71); enquanto o máximo de umidade específica ocorre ao final da tarde, i.e., æ̀ 18 h (Figura 3.2 d e 3.2 e). Um máximo secundário de umidade específica ocorre em volta do meio-dia do dia 71, provavelmente associado ao fluxo turbulento de calor latente originado na superfície.

O máximo primário de umidade (Figura 3.2 e) parece estar associado à mudança da direção do vento (Figura 3.2 i), ao transporte de ar mais úmido, que após as 18 h sopra vindo da região montanhosa a SE. Este escoamento de SE traz a massa de ar marítima, já com suas características parcialmente modificadas pela elevação na Serra do Mar e contato com a superfície. O ar, que sobe a escarpa da Serra do Mar, ao mesmo tempo que se resfria por expansão adiabática também se aquece não-adiabáticamente, pelo contato com a superfície e por precipitação. O ganho de energia não-adiabática pode ser responsável pela manutenção da intensidade do escoamento, conforme a frente de brisa sobe a escarpa.

No período convectivo (i.e., diurno), a direção do vento aparece de W e NW entre 12 e $15 \mathrm{~h}$ (dia 71), que é seguido por um vento de NE entre 15 e $18 \mathrm{~h}$ (Figura 3.2 f e 3.2 g). A partir das $19 \mathrm{~h}$ a direção do vento torna-se de S e SE, que aparecem de forma persistente durante toda ànoite (e 
também para parte da estrutura vertical do JBN). Note-se, que se trata de um giro anti-horário no tempo. Quando se observa a estrutura vertical, na Figura 3.10 i, observa-se também cisalhamento vertical da direção do vento, isto é, na estrutura vertical do JBN. Este cisalhamento vertical também se dá no sentido anti-horário. Ambos, o giro temporal e o cisalhamento direcional na vertical são indicadores de oscilação inercial na CLP de Iperó. Portanto, para o caso em estudo, o mecanismo de oscilação inercial mostra-se sua importância para explicar a variação temporal e a estrutura espacial da direção do vetor velocidade do vento - sendo um dos mecanismos atuantes. Mas, tomado de forma isolada, a oscilação inercial não explica o JBN observado (i.e., não é suficiente).

Dados de grande-escala (NCEP), correspondentes ao período considerado nesse caso típico, indicam vento geostrófico com velocidade entre 3 e $5 \mathrm{~m} \mathrm{~s}^{-1}$ e direção ENE, para o nível de $850 \mathrm{hPa}$, sobre Iperó. A velocidade máxima do JBN observado na noite do dia 71 para 72 é aproximadamente $10 \mathrm{~m} \mathrm{~s}^{-1}$ (Figura 3.2 h). O vento médio observado na CLP æ̀ 16 horas (dia 71) apresentou velocidade de $4 \mathrm{~m} \mathrm{~s}^{-1}$ e direção W. Considerando-se essas condições, a oscilação inercial (Figura 3.1) promove uma oscilação inercial da camada desacoplada durante a noite. Esta oscilação inercial em Iperó apresenta período inercial ${ }^{2}$ de $30 \mathrm{~h}\left(\mathrm{P}_{\mathrm{i}}=1 /|\mathrm{f}|\right)$.

Do ponto de vista qualitativo, a oscilação inercial é responsável pela direção do JBN observada na camada residual durante a noite entre os dias 71 e 72. Neste caso, o desvio ageostrófico é medido em relação à velocidade do vento geostrófico de $850 \mathrm{hPa}$; enquanto que a condição inicial para a oscilação inercial é dada pelo campo de vento na CLP ao final da tarde. Para Iperó, essas condições de vento àtarde estão associadas a múltiplos fatores, entre eles citam -se: os efeitos mecânicos da topográfica como bloqueios e canalizações, efeitos da rugosidade e tipo de superfície, entrada de brisa marítima ${ }^{3}$ e da circulação gerada sobre a Serra do Mar, escoamentos anabáticos e catabáticos, modificação da massa de ar devido æ̀ troc as adiabáticas e não adiabáticas com a superfície sobre a escarpa da Serra do Mar, da dinâmica interna da CLP e do entranhamento de calor e momento pelo topo da CLP e o correspondente acoplamento com as condições de grande-

\footnotetext{
${ }^{2}$ Nota - Desde que o período inercial $\mathrm{P}_{\mathrm{i}}$ é $30 \mathrm{~h}$ em Iperó e o período do ciclo diurno é $24 \mathrm{~h}$ tem-se o mímino múltiplo comum de 120 h (i.e., 5 dias). Portanto, somente a cada 5 dias a oscilação inercial está em fase com as oscilações do vento associadas ao ciclo diurno, podendo se reforçar mutuamente.

${ }^{3}$ Nota - Embora a frente da brisa marítima possa atingir a localização de Iperó, essa ocorrência é contingente, pois depende de condições muito favoráveis da forçante de escala sinótica (ventos de direção SE suficientemente intensos e de céu claro). Essas condições são mais frequentes nas situações pós-frontais de verão, quando as frentes-frias são relativamente fracas. A elevação da massa de ar marítima desde o litoral até o topo da Serra do Mar transforma a energia cinética do escoamento em energia potencial. Como conseqüência, a velocidade do escoamento no topo da Serra é reduzida, implicando em redução acentuada da energia cinética da frente-de-rajada da brisa, que teria sua capacidade de propagação rumo ao interior muito reduzida. O caso é outro, (a) quando durante a elevação na Serra ocorre liberação de calor latente por precipitação, ou (b) quando a encosta está fortemente aquecida pela radiação solar. Nestas últimas condições, o interior na região de Sorocaba pode ser atingido pela frente de propagação da brisa.
} 
escala. Note-se que estes fatores podem aparecer em conjunto, sem predomínio de um sobre o outro, ou de forma independente, em que um ou dois se destacam como mais importantes.

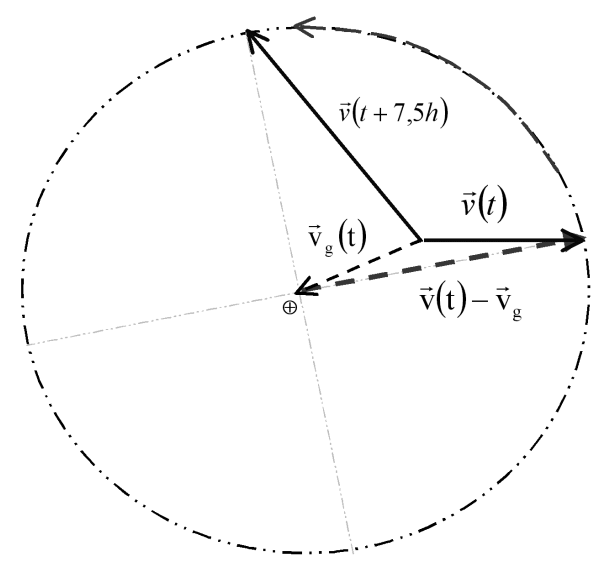

Figura 3.1 Oscilação inercial do vetor ageostrófico do vento (i.e, do vetor diferença entre o vetor velocidade do vento real e o vetor velocidade do vento geostrófico) durante um período de $7,5 \mathrm{~h}$, correspondente a $1 / 4$ do período da oscilação inercial em Iperó (30 horas). O vetor ageostrófico é o vetor que oscila inercialmente no período inercial. Os valores iniciais são: vento geostrófico com intensidade de $3 \mathrm{~m} \mathrm{~s}^{-1}$ de direção ENE; velocidade do vento observado de $4 \mathrm{~m} \mathrm{~s}^{-1}$ e direção $\mathrm{W}$ (correspondente ao final do período vespertino em Iperó no dia 71). $\mathrm{O}$ giro anti-horário se dá centrado no ponto indicado por $\oplus$.

A brisa é responsável pelo esfriamento e umidecimento do ar sobre o Platô Paulista, onde se localiza a cidade de São Paulo. Do ponto de vista teórico, os efeitos não-lineares de transporte do vento implicam que a intensidade e direção da circulação da célula do interior podem ser moduladas pela presença da célula de circulação da brisa no litoral, mesmo a uma distância de $100 \mathrm{~km}$.

As células de circulação do interior e do litoral apresentam estrutura vertical do vento diferenciada. A célula de maior circulação tende a predominar se ela estiver sendo advectada (transportada) em direção à outra, o que pode levar a um deslocamento parcial ou total da célula com menor circulação. O cisalhamento do vento que ocorre na zona de contato entre essas duas células pode resultar em aumento de turbulência, mistura horizontal, implicando consequientemente em difusão de propriedades conservativas (massa de poluentes inertes, momento linear, angular etc). Assim, de um ponto de vista teórico, espera-se que a parte leste da célula convectiva do interior apresente características, em parte similares àquelas da célula convectiva do litoral, como resultado da advecção ou por difusão na CLP, ambos efeitos não-lineares.

A direção do vento junto ao máximo do JBN mostra-se freqüentemente de NE. Na superfície ventos do quadrante SE predominam. As hipóteses levantadas quanto à origem desta estrutura vertical da direção do JBN são: (a) a estrutura vertical reflete a direção do vento geostrófico associado à condições de grande-escala da circulação média associada à Alta do 
Atlântico Sul (no topo) e a direção do escoamento em superfície de origem térmica; (b) reflete a modulação causada pela célula de circulação do litoral (brisa mais efeito da escarpa da Serra do Mar) que modifica a estrutura vertical do ramo leste da célula convectiva do interior e (c) reflete ambos os mecanismos.

(a) Pontos com dados disponíveis do balão cativo

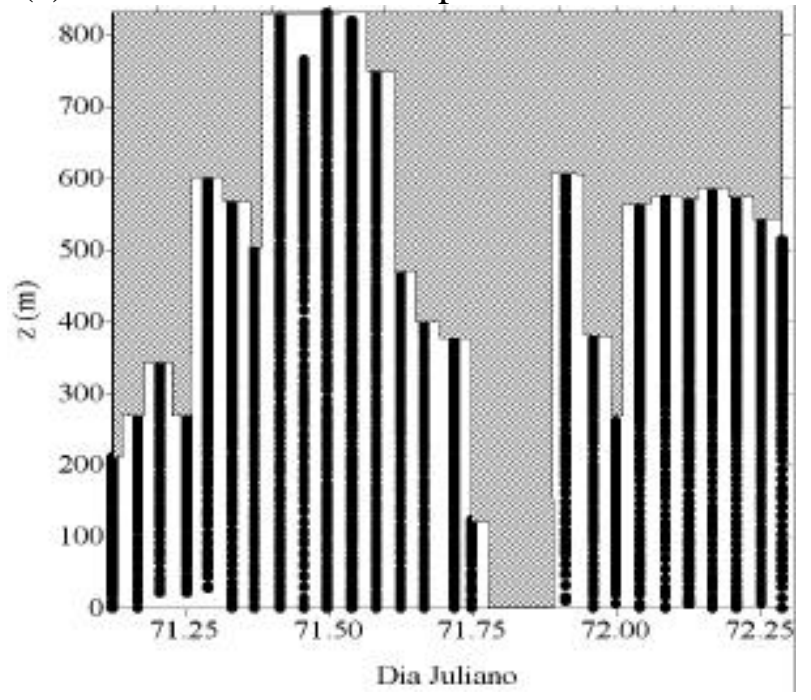

(b) Temperatura do ar $\left({ }^{\circ} \mathrm{C}\right)$

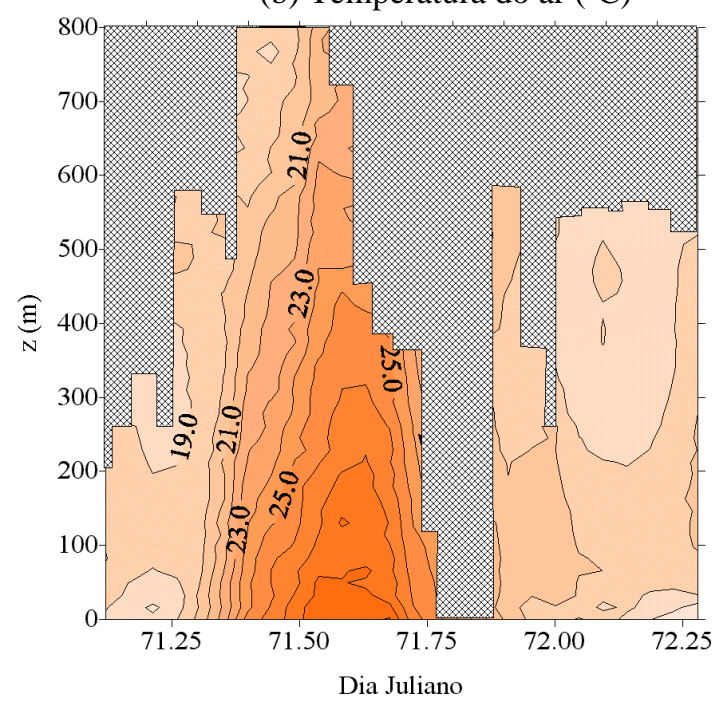

(c) Temperatura potencial $(\mathrm{K})$

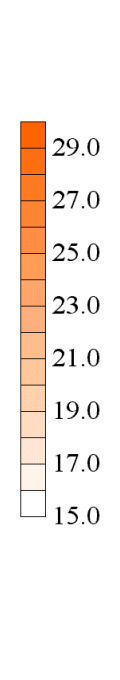

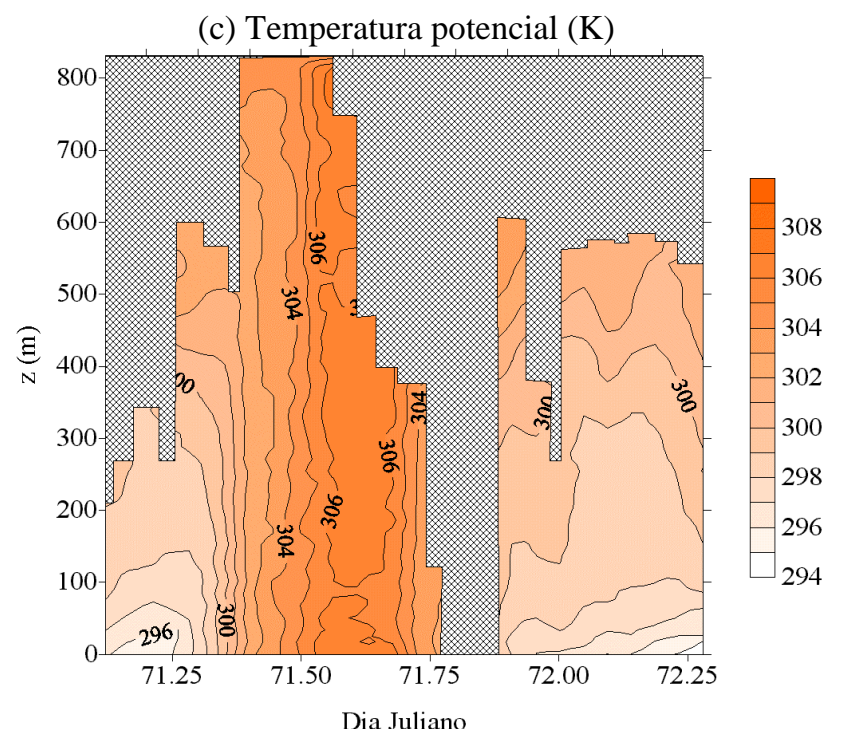

Figura 3.2 Evolução temporal dos perfis meteorológicos associados ao desenvolvimento de um JBN em Iperó registrado em sondagens de balão cativo entre dias do ano (decimais) 71,12 e 72,28. Os gráficos mostram: (a) os pontos de sondagem com dados disponíveis e a mascara para a região onde não há dados; (b) temperatura absoluta do ar $\left({ }^{\circ} \mathrm{C}\right)$; (c) temperatura potencial $(\mathrm{K})$; (d) umidade relativa $(\%)$; (e) umidade específica $\left(\mathrm{g} \mathrm{kg}^{-1}\right)$; (f) componente zonal do vento $\left(\mathrm{ms}^{-1}\right)$; (e) componente meridional do vento $\left(\mathrm{ms}^{-1}\right) ;(\mathrm{g})$ velocidade do vento $\left(\mathrm{ms}^{-1}\right)$ e (h) direção do vento (graus). 
(d) Umidade relativa (\%)

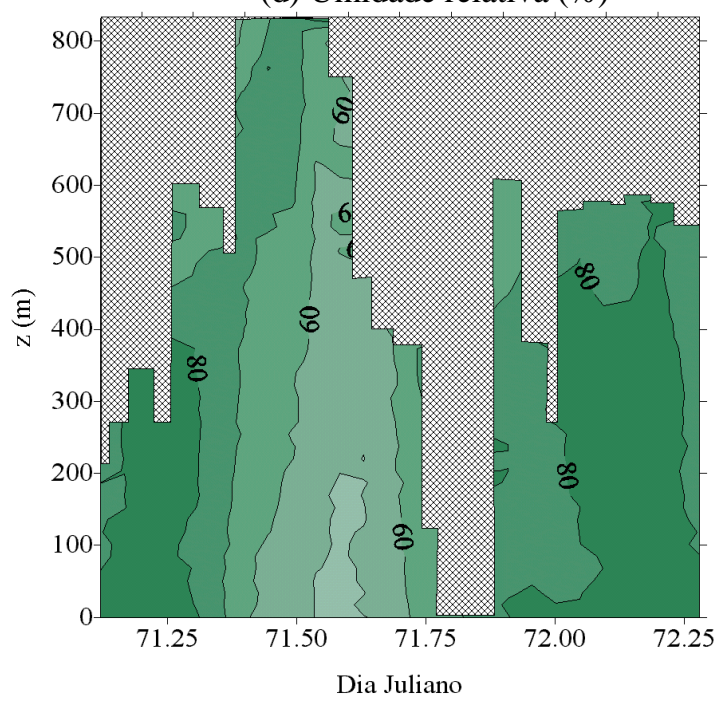

(f) Componente zonal do vento $\left(\mathrm{m} \mathrm{s}^{-1}\right)$

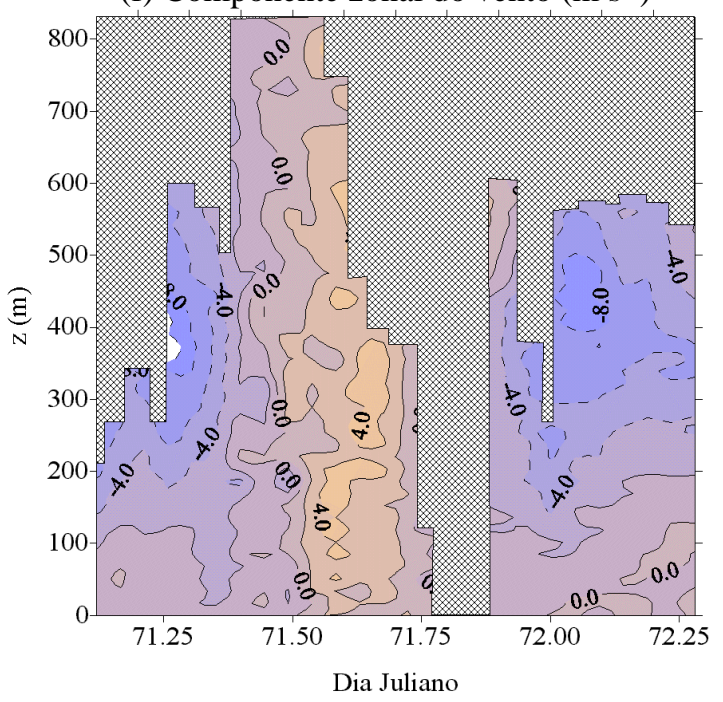

(h) Velocidade do vento $\left(\mathrm{m} \mathrm{s}^{-1}\right)$

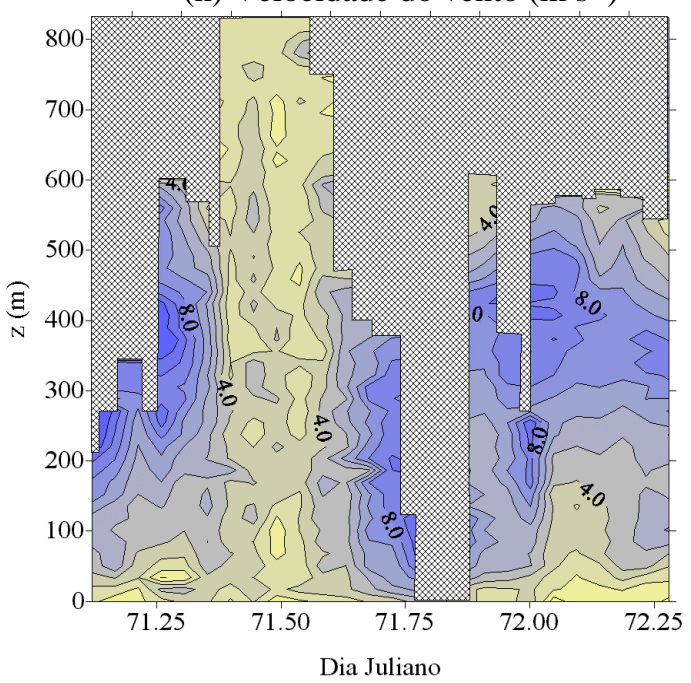

(e) Umidade específica $\left(\mathrm{g} \mathrm{kg}^{-1}\right)$

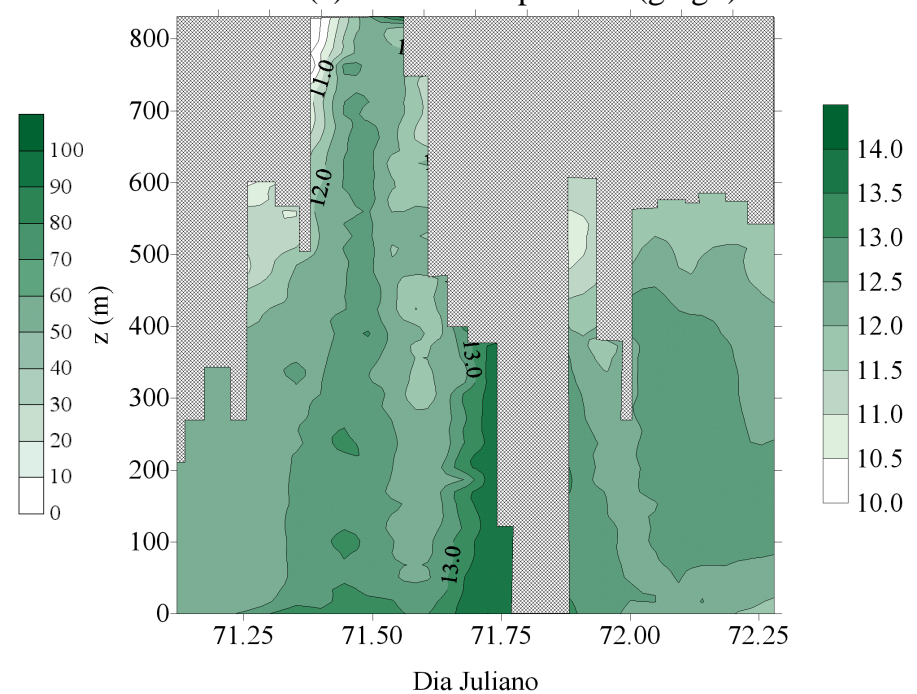

(g) Componente meridional do vento $\left(\mathrm{m} \mathrm{s}^{-1}\right)$

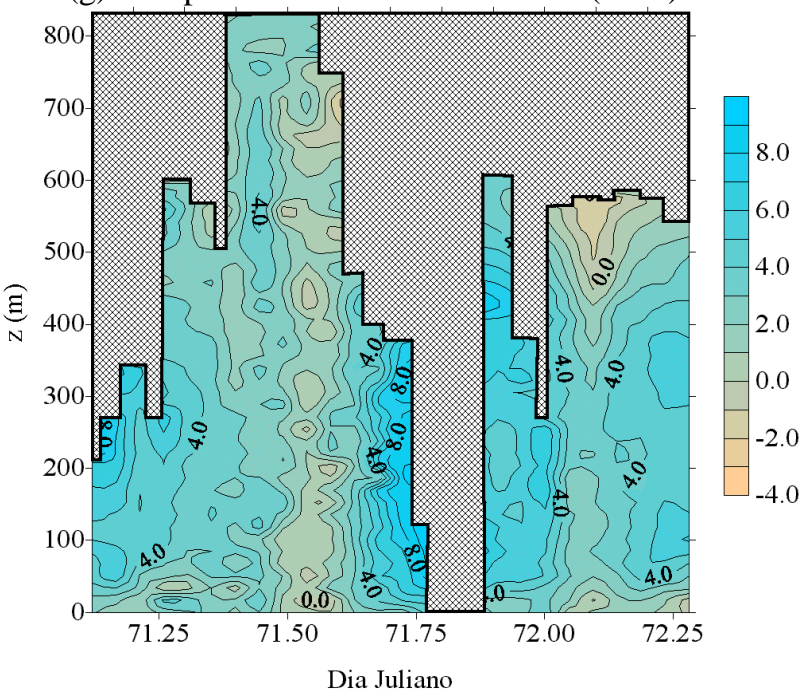

(i) Direção do vento (graus)

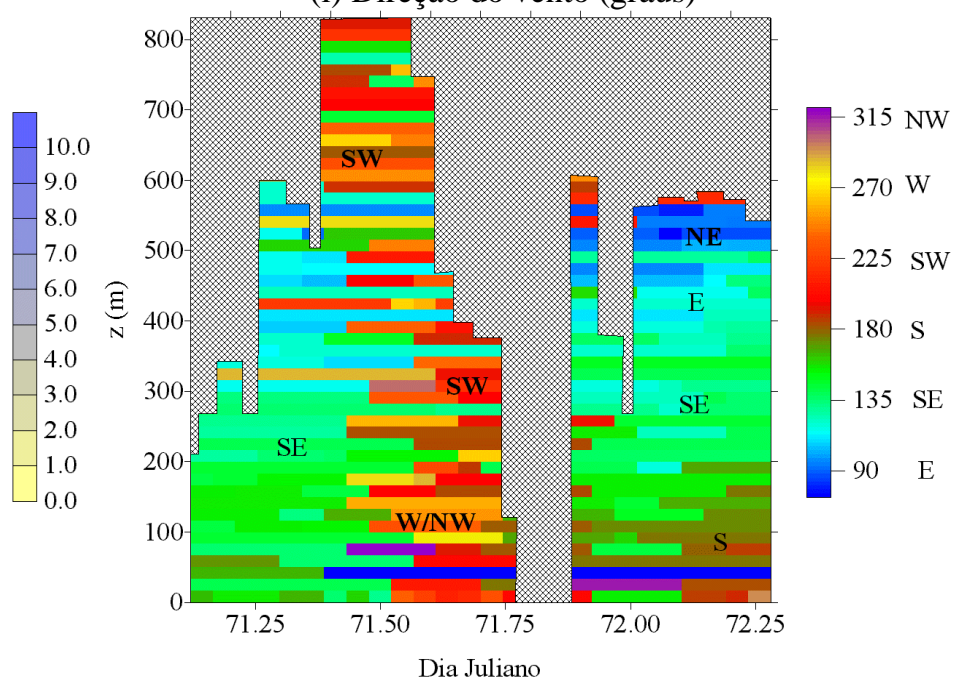

Figura 3.2 (continuação). 


\subsubsection{Dados Interpolados}

Os dados disponíveis para as 4 campanhas do Experimento em Iperó foram interpolados para se obter um conjunto único segundo uma discretização regular no tempo (horária) e no espaço (na vertical a cada $25 \mathrm{~m}$ ). Para isso, utilizou-se um modelo prognóstico 1-D com fechamento de segunda-ordem para integrar os dados de diferentes origens segundo um esquema de nudging (a cada hora).

Para validar a rotina de interpolação, perfis obtidos da interpolação foram comparados aos dados originais de balão-cativo. A Figura 3.3 exemplifica essa comparação para a noite entre dias 12 e 13 de março de 1993. A comparação mostra que:

1. A metodologia de interpolação é sensível a variação temporal do perfil vertical que ocorre em associação ao JBN, indicando que a escala de tempo do nudging utilizada $(1 \mathrm{~h})$ é apropriada para a assimilação dos dados esparsos utilizados;

2. Devido ao fato de utilizar-se um esquema do tipo Euler avançado para discretização da assimilação temporal na interpolação, os perfis verticais obtidos na interpolados refletem as variações temporais na hora imediatamente posterior a que elas ocorreram nos dados medidos. Portanto, a interpolação temporal segue um esquema de primeira-ordem;

3. A sondagem interpolada para níveis acima da máxima altura alcançada pelo balão-cativo é mais influenciada pelos dados de grande-escala utilizados como condição de fronteira superior a $850 \mathrm{hPa}$ (i.e., a Reanálise do NCEP);

4. O esquema de interpolação suaviza a informação, gerando um valor máximo $20 \%$ inferior ao observado nas sondagens de balão-cativo.

5. A interpolação dos diferentes dados reduz a variabilidade das observações podendo ser interpretada como um resultado médio ou combinação;

6. O esquema de interpolação captura as feições e variações temporais mais importantes do JBN.

No capítulo 4, compara-se o resultado numérico do modelo tridimensional TVM com os resultados observacionais interpolados. 
$18 \mathrm{~h}$
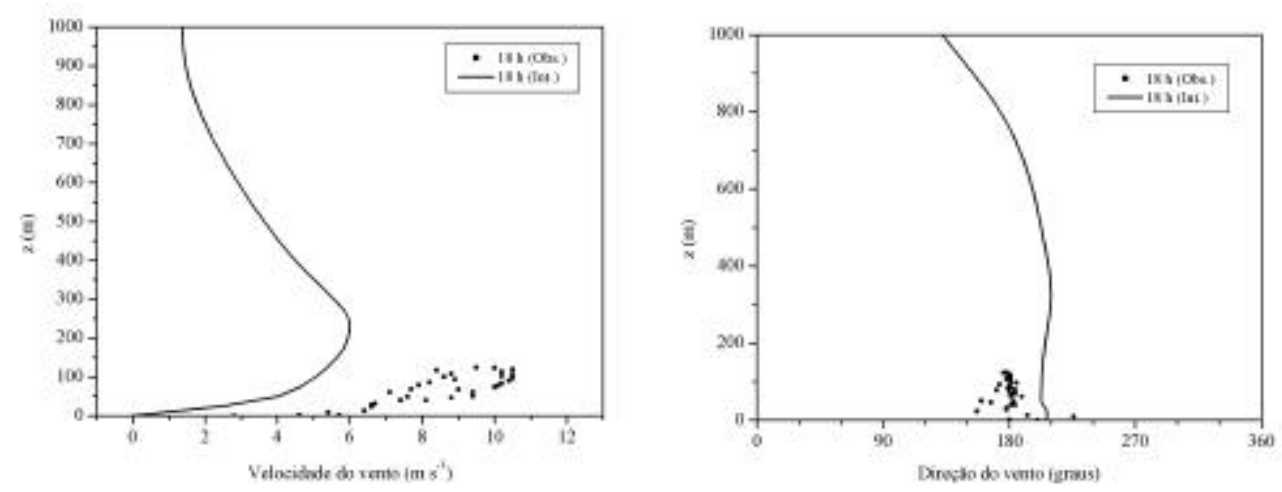

$22 \mathrm{~h}$
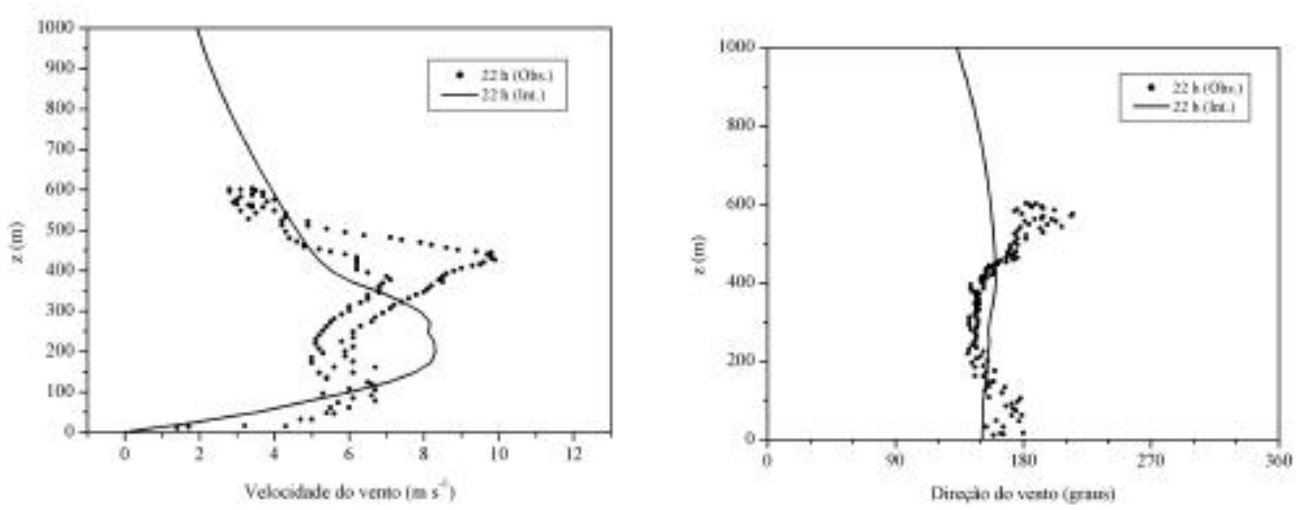

$0 \mathrm{~h}$
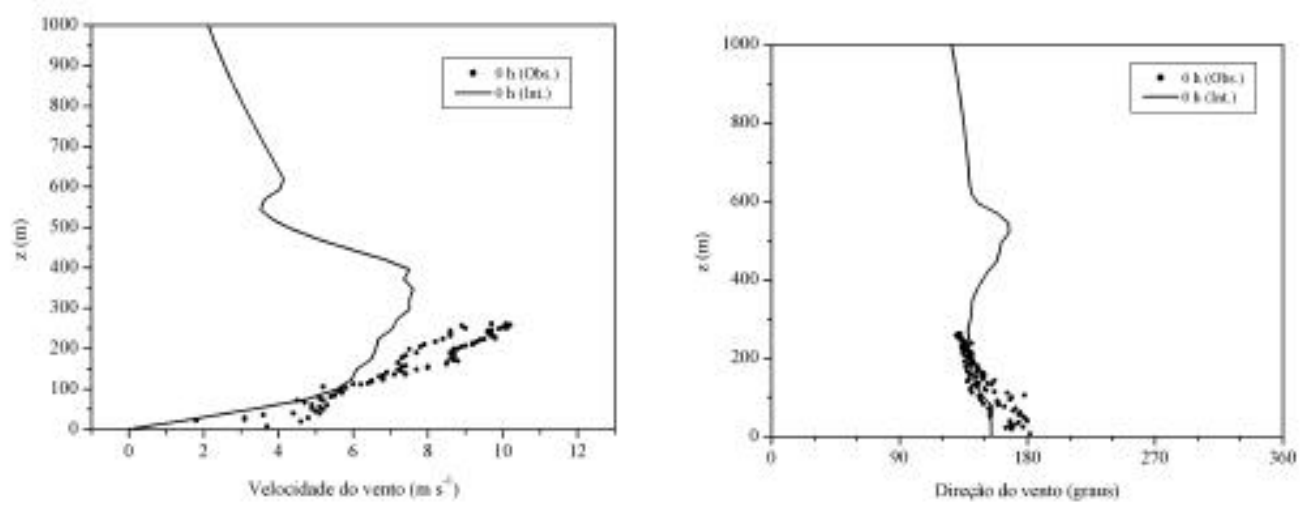

Figura 3.3 Comparação dos perfis interpolados de velocidade e direção do vento (linhas contínuas) com os perfis observados por balão-cativo (pontos) para diferentes horários da noite do dia 12 para 13 de março de 1993. As linhas contínuas mostradas à $18 \mathrm{~h}$ (alto desta figura) são provenientes da aplicação desta mesma metodologia de interpolação, mas utilizando-se dados dos horários anteriores. 
$2 \mathrm{~h}$
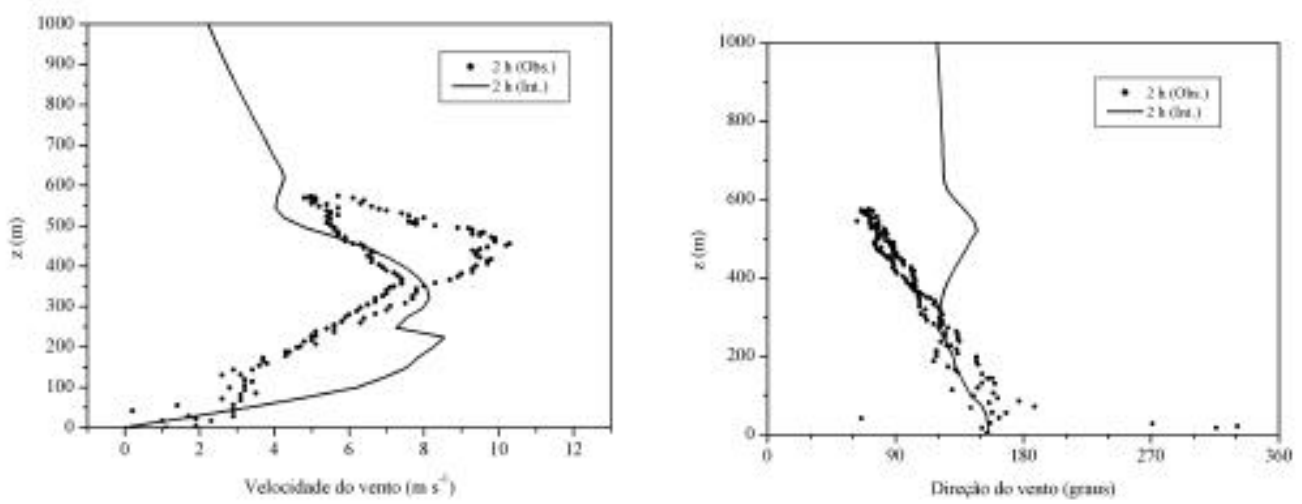

$4 \mathrm{~h}$
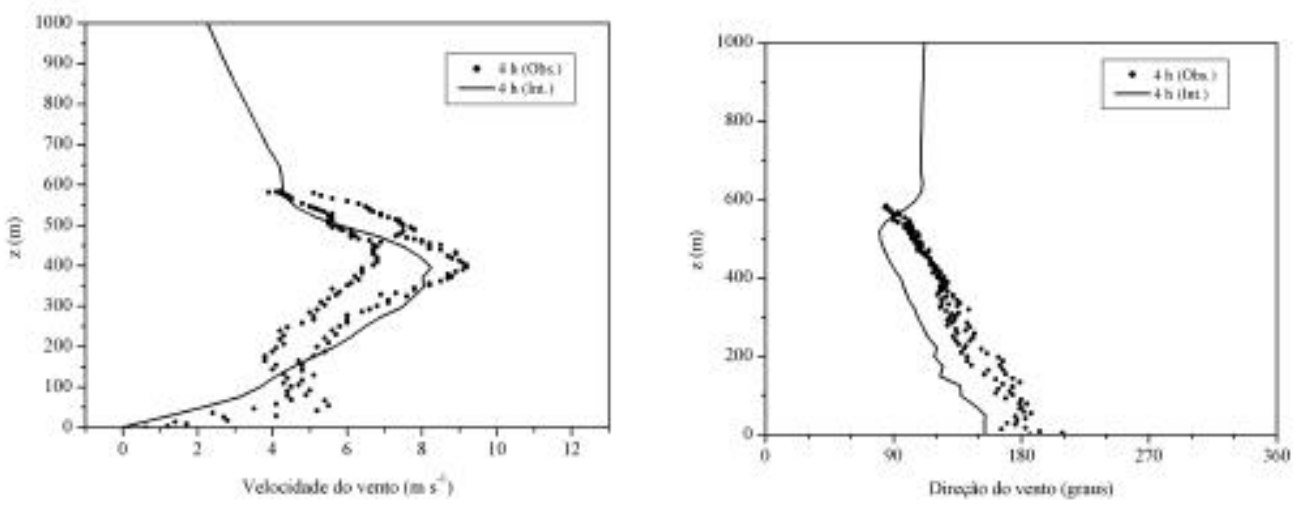

$6 \mathrm{~h}$
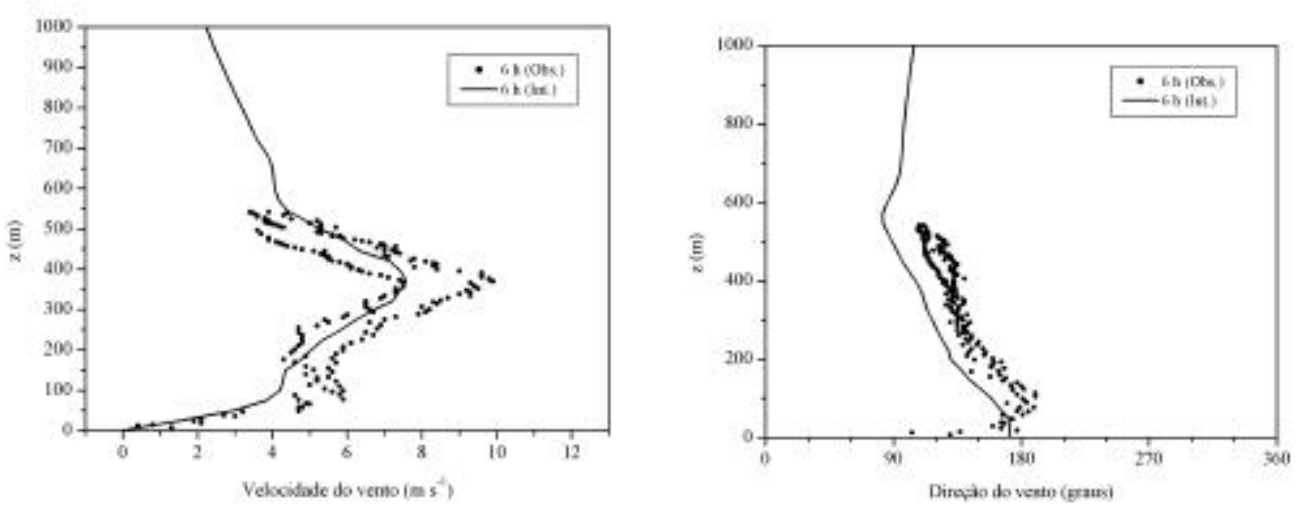

Figura 3.3 (continuação) 


\subsubsection{Estrutura Vertical Média Horária}

Médias horárias dos perfis verticais interpolados foram determinadas para o período das campanhas em Iperó. A evolução temporal da estrutura vertical média obtida é mostrada nas Figura

\section{4 a Figura 3.7.}

As principais características do JBN médio podem ser destacadas:

1. As campanhas I, II e IV ocorridas em março de 1991, 1992 e 1993 apresentam estruturas verticais do JBN que apresentam semelhanças entre si. Por exemplo, todas apresentam: (a) desenvolvimento de jatos noturnos; (b) cisalhamento direcional na estrutra vertical do JBN; (c) redução da velocidade do vento na CLP convectiva (entre 12 e 18 h) etc;

2. O JBN apresenta cisalhamento direcional na camada entre a superfície e $500 \mathrm{~m}$, entre as $0 \mathrm{~h}$ e $10 \mathrm{~h}$ da manhã, que pode ser notado nas estruturas verticais das componentes zonal e meridional ou diretamente na distribuição vertical da direção do vento (Figuras 3.4 d, 3.5 d e 3.7 d);

3. Ao final da tarde, a estrutura térmica da CLP convectiva, define a estrutura vertical inicial na qual o JBN aparecerá. Esta estrutura inicial é caracterizada por ausência de cisalhamento direcional do vento e ventos mais fracos à 18 h. Durante o período da Quarta Campanha, o enfraquecimento do vento no período convectivo ocorre mais cedo, entre $12 \mathrm{~h}$ e $15 \mathrm{~h}$, provavelmente pela quase ausência de forçante de grande-escala (i.e., os ventos em $850 \mathrm{hPa}$ são muito fracos, da ordem de $1 \mathrm{~m} \mathrm{~s}^{-1}$ );

4. A velocidade máxima média, embora alisada pela interpolação, dá uma idéia da intensidade média do vento no JBN: $6 \mathrm{~ms}^{-1}$ para a I Campanha; $5 \mathrm{~ms}^{-1}$ para a II Campanha; $8 \mathrm{~ms}^{-1}$ para a III Campanha (inverno) e $5 \mathrm{~ms}^{-1}$ para a IV Campanha;

5. A altura do máximo foi: $400 \mathrm{~m}$ para a I Campanha; $550 \mathrm{~m}$ para a II Campanha; $400 \mathrm{~m}$ para a III Campanha entre 250 e $300 \mathrm{~m}$ para a IV Campanha;

6. O JBN torna-se mais intenso à medida que a noite segue, alcançando uma máxima velocidade entre 0 e $9 \mathrm{~h}$. O escoamento na camada entre a superfície e $500 \mathrm{~m}$ apresenta uma aceleração média durante todo o período noturno nas Campanhas I, II e III e entre 18 e $3 \mathrm{~h}$ para a Campanha IV;

7. Uma vez, formado o máximo do JBN, este apresenta uma tendência a elevar-se na CLP, o que pode ser notado na estrutura vertical média das Campanhas; 
8. Para ventos da forçante externa em $850 \mathrm{hPa}$ (i.e., ventos de grande-escala) mais intensos, o máximo do JBN aparece mais elevado na vertical (Campanhas II e III) e vice-versa (Campanhas I e IV);

9. O cisalhamento direcional no JBN é claramente discernível para as Campanhas I, II e IV, durante as campanhas realizadas em Março (i.e., para o período de final de verão e início de outono). Esse cisalhamento direcional na estrutura vertical da direção do vento é discernível para o período noturno das Figuras 3.4 d, 3.5 d e 3.7 d;

10. O jato apresenta cisalhamento da direção do vento, caracterizado por ventos do quadrante $S$ abaixo do máximo e ventos do quadrante $\mathrm{N}$ acima do máximo (Campanhas I, II e IV). 


\section{Primeira Campanha}
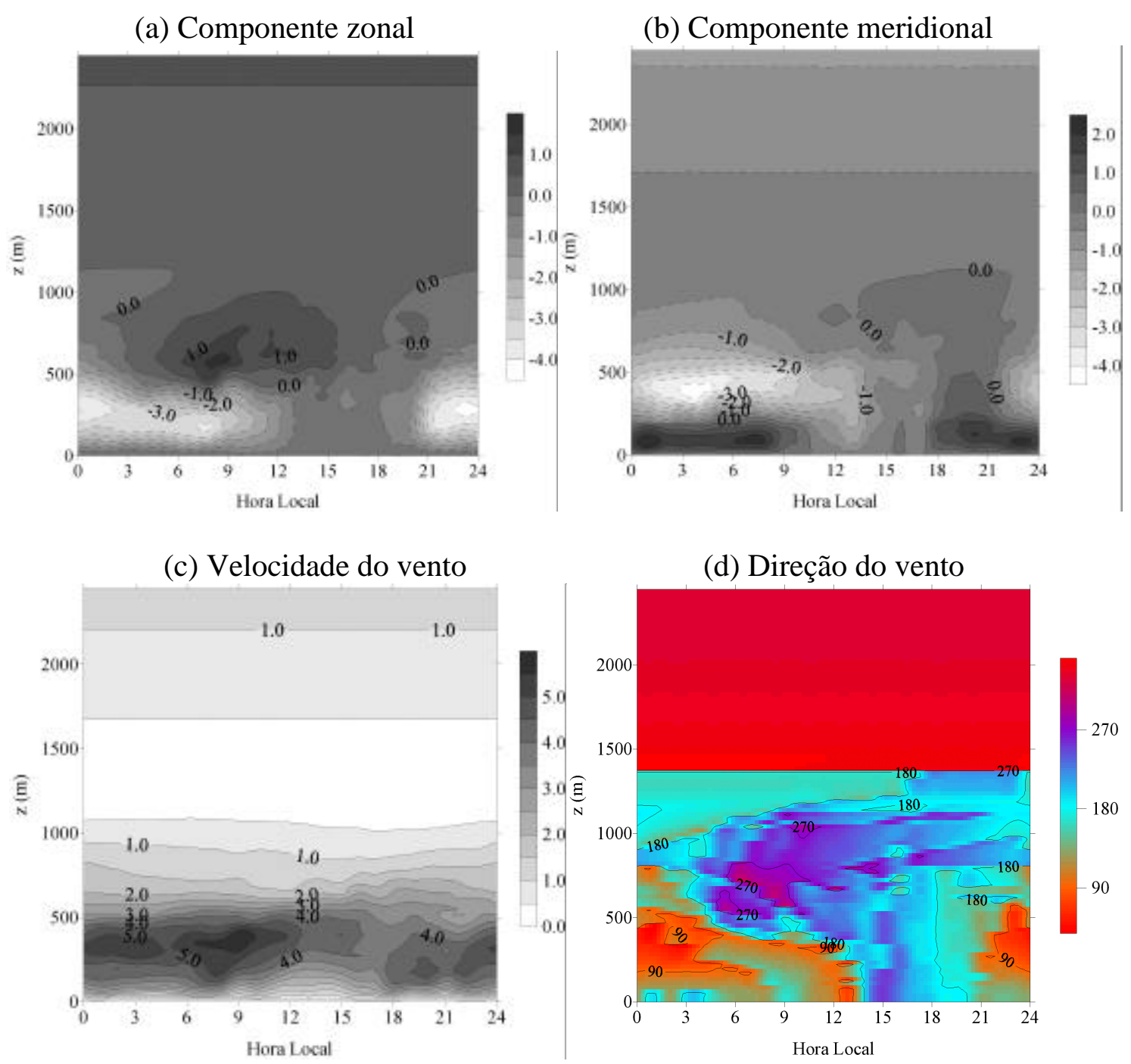

Figura 3.4 Estrutura vertical média horária durante a Primeira Campanha em Iperó para: (a) componente zonal; (b) componente meridional; (c) velocidade do vento e (d) direção do vento (representada por uma imagem composta de píxeis). 
Segunda Campanha
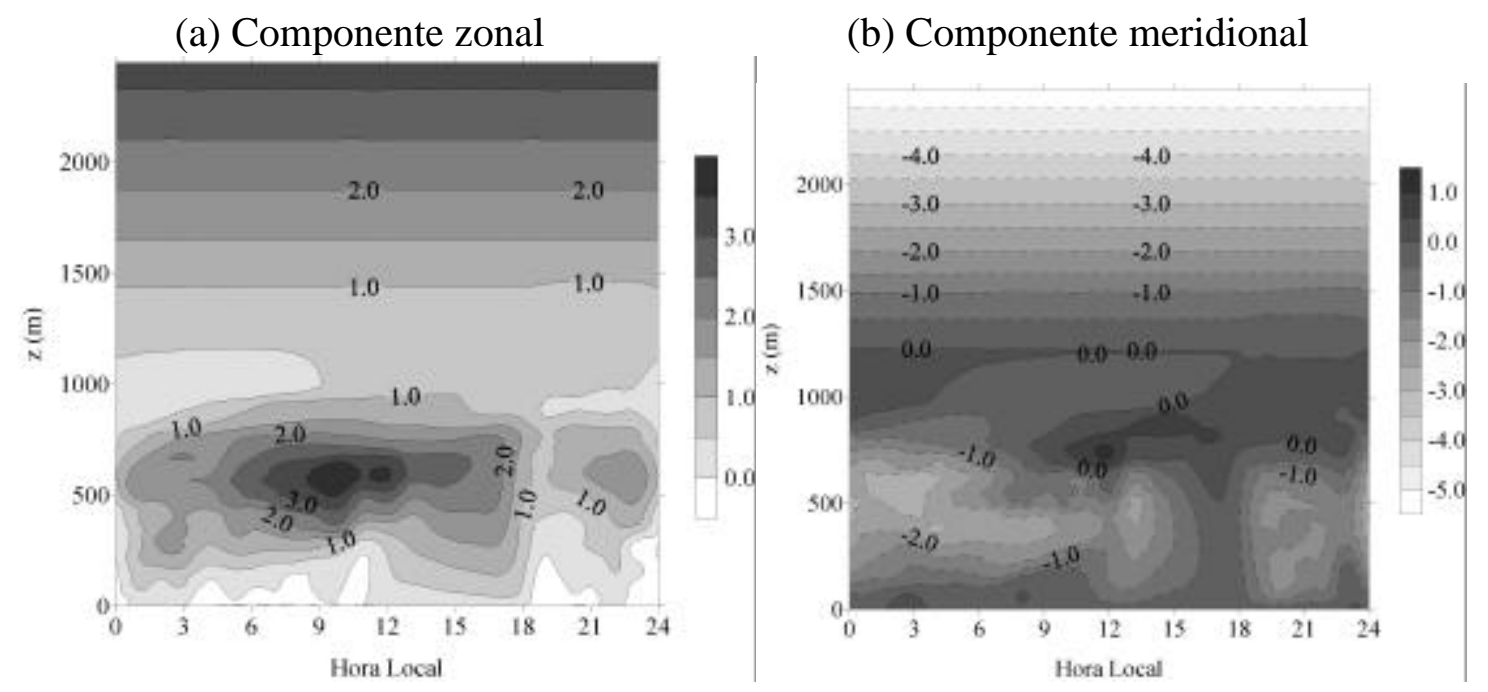

(c) Velocidade do vento

(d) Direção do vento
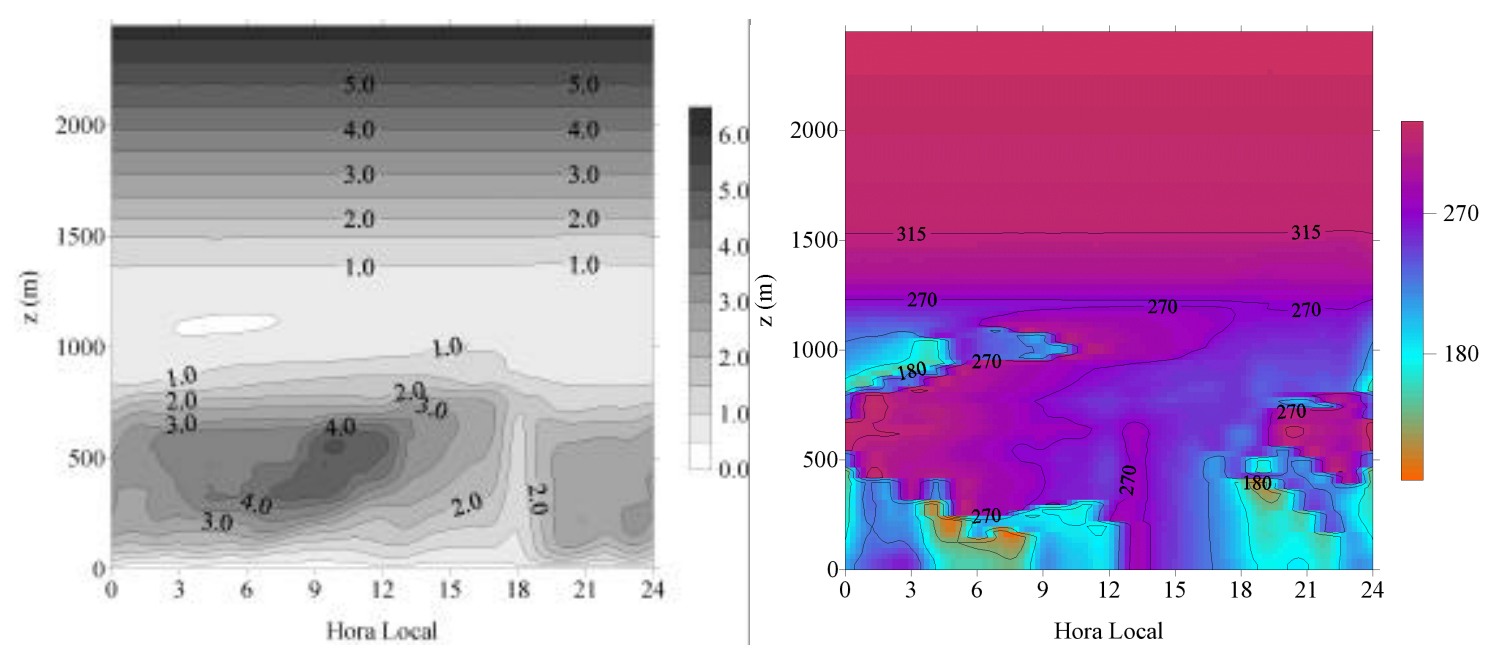

Figura 3.5 Estrutura vertical média horária durante a Segunda Campanha em Iperó para: (a) componente zonal; (b) componente meridional; (c) velocidade do vento e (d) direção do vento. 
Terceira Campanha

(a) Componente zonal

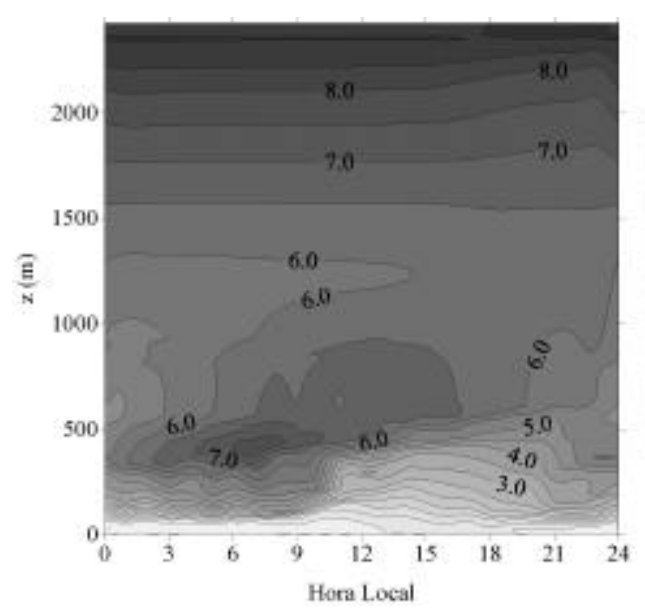

(c) Velocidade do vento

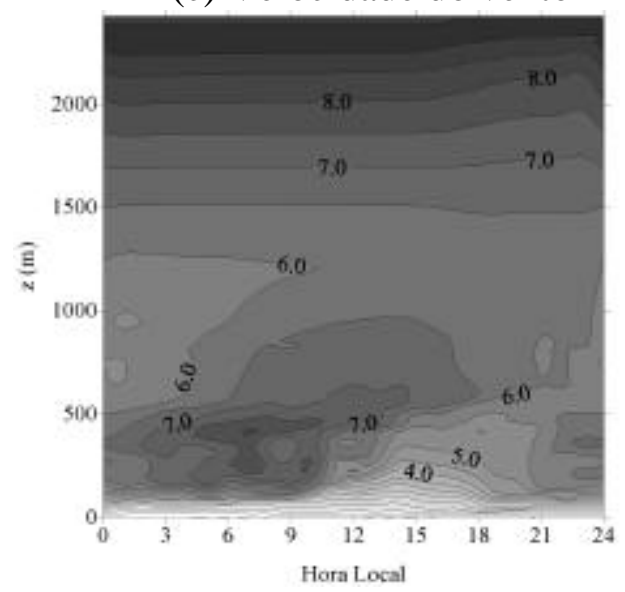

(b) Componente meridional

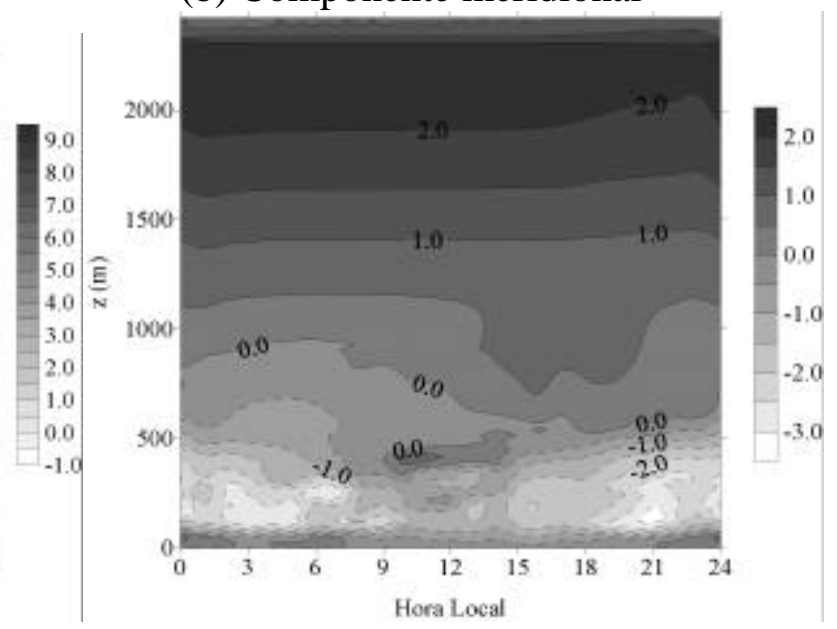

(d) Direção do vento

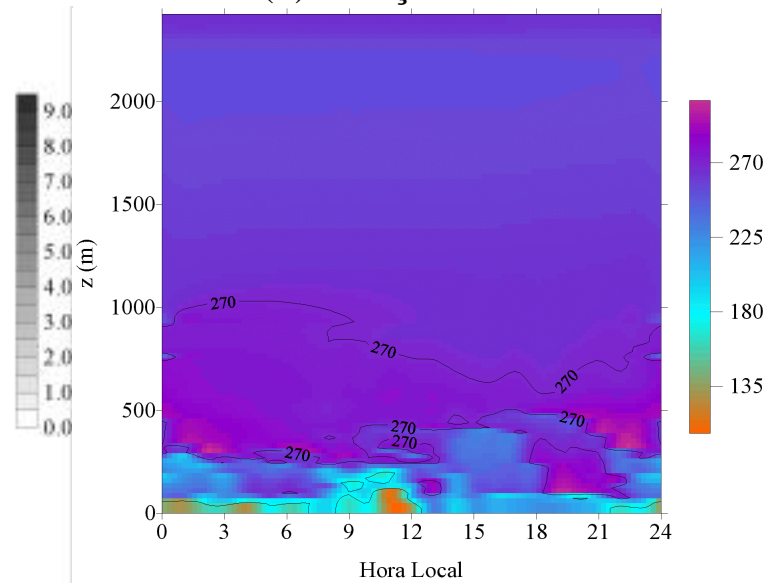

Figura 3.6 Estrutura vertical média horária durante a Terceira Campanha em Iperó para: (a) componente zonal; (b) componente meridional; (c) velocidade do vento e (d) direção do vento. 


\section{Quarta Campanha}

(a) Componente zonal

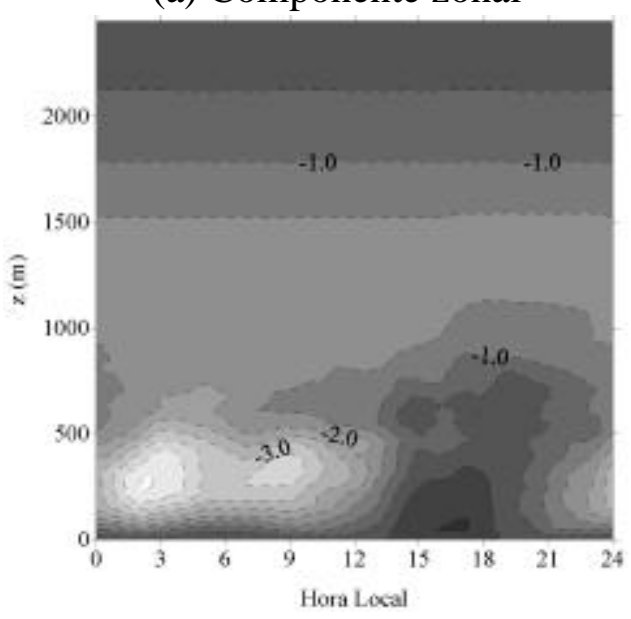

(c) Velocidade do vento

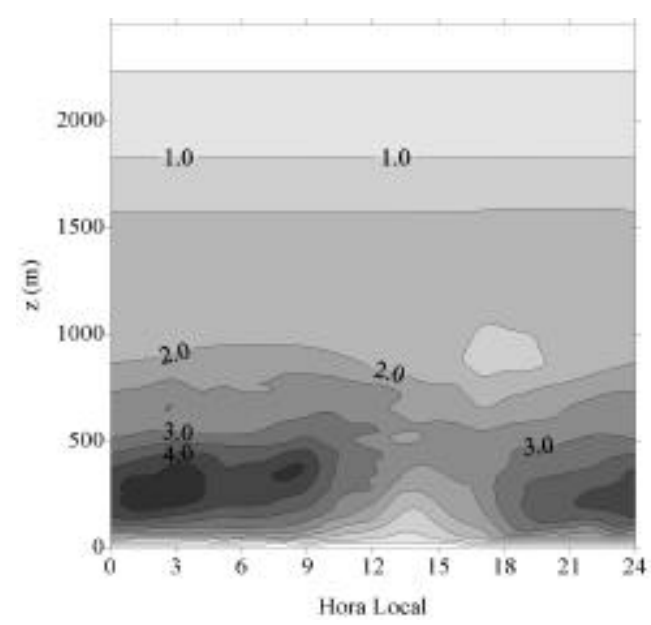

(b) Componente meridional

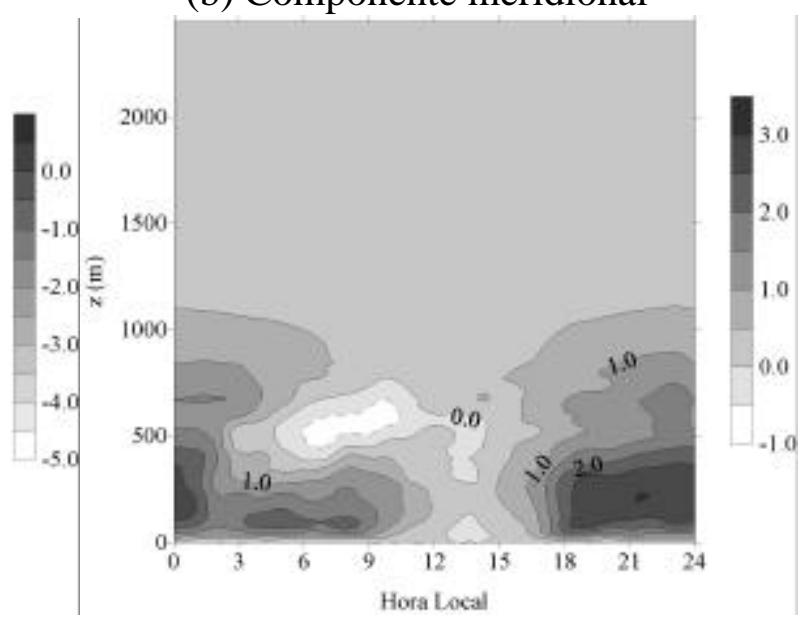

(d) Direção do vento

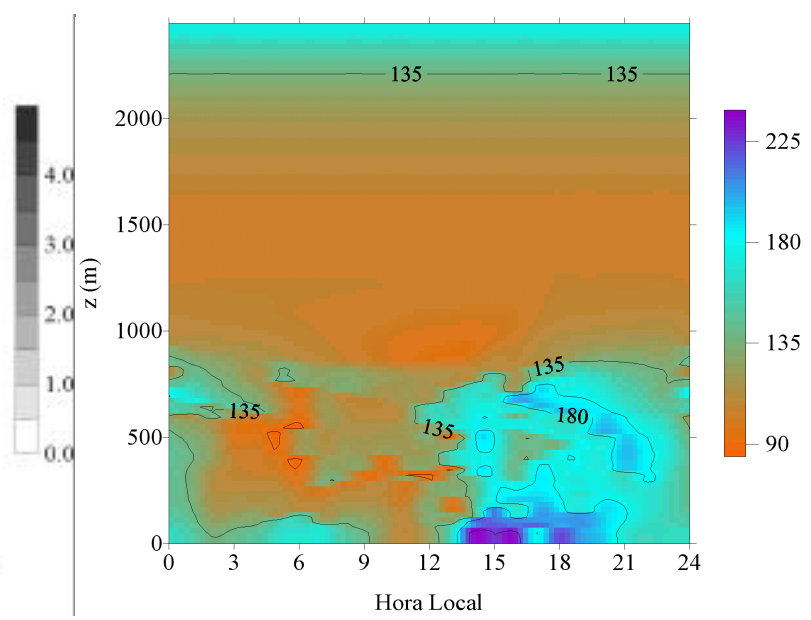

Figura 3.7 Estrutura vertical média horária durante a Quarta Campanha em Iperó para: (a) componente zonal; (b) componente meridional; (c) velocidade do vento e (d) direção do vento. 


\subsection{Influência do JBN na Evolução Horária}

\section{dos Campos de Superfície}

Neste item investiga-se os efeitos do JBN sobre a variabilidade temporal da velocidade do vento medida na CLP superficial no Centro Experimental ARAMAR (CEA) da Marinha do Brasil em Iperó-SP, para os níveis de 10 m, 60 m e 80 m acima da superfície. As possíveis relações entre o JBN e os escoamentos superficiais são explicadas com base na continuidade do escoamento, na coerência espacial, temporal e nos efeitos da topografia (local e regional à volta de Iperó), que podem modificar o escoamento junto àsuperfície.

Descrição do escoamento superficial - O ciclo diurno do vento àsuperfície em Iperó foi observado primeiramente por OLIVEIRA (1993) durante as campanhas de observação no CEA em Iperó. A direção do vento na superfície de Iperó apresenta um ciclo diurno marcado por um giro completo em sentido anti-horário, isto é, S-SE no período noturno, para E-NE na manhã, N-NW à tarde e novamente para S-SE (KARAM, 1995; e OLIVEIRA, 1998). Os dados de superfície obtidos durante as campanhas de observação no CEA (OLIVEIRA, 1993) apresentam grande coerência espacial e temporal com dados medidos a $10 \mathrm{~m}, 60 \mathrm{~m}$ e $80 \mathrm{~m}$ acima da superfície em outra torre no CEA, e também em relação a dados da estação da Fazenda Ipanema, localizada a 5 km para SE do CEA. Durante o período noturno, a direção predominante do vento é de Sul. Durante o período convectivo, a direção do vento gira em sentido anti-horário, passando pela direção NW aproximadamente ao meio-dia.

Medidas de vento tomadas à 10m, 60 m e 80 m, em Iperó, com frequiência de amostragem de 15 min foram utilizadas para calcular a distribuição de freqüência horária da velocidade, direção, média horária e desvio padrão do vento para um período de 2 anos (JUL 1992 àJUN 1994).

A seguir, mostram-se os valores médios horários do vetor velocidade do vento para Iperó considerando-se todo o período de dois anos, entre 1992 e 1994.

As hodografas (Figura 3.8) construídas para três níveis da torre em Iperó, 10 m , 60 m e 80 $\mathrm{m}$ indicam intenso cisalhamento do vento, $(\partial \mathrm{v} / \partial \mathrm{z}) \approx 0,043 \mathrm{~s}^{-1}$, entre os níveis $10 \mathrm{~m}$ e $80 \mathrm{~m}$, durante o período noturno. Este cisalhamento é produto do giro anti-horário da resultante do vetor vento.

Após atingir a máxima velocidade, pouco antes das 21 horas, o vetor resultante diminui sua intensidade, provavelmente devido ao desacoplamento da CLP superficial associado à 
intensificação da inversão de superfície. Este desacoplamento pode ser observado durante a madrugada (entre 0 e $6 \mathrm{~h}$ da manhã) ${ }^{4}$ na camada entre a superfície e $80 \mathrm{~m}$, conforme é indicado pela formação de uma camada de inversão térmica de superfície (p.ex., visível na estrutura vertical da temperatura potencial do ar mostrada na Figura 3.2 c). A inversão térmica de superfície provoca o desacoplamento entre as camadas devido ao efeito estabilizador sobre as parcelas de ar, o que implica em redução substancial tanto da turbulência como do transporte de momento entre diferentes níveis na vertical.

A direção do vento resultante pouco varia durante o período noturno. Quase toda oscilação anti-horária do vetor vento ocorre no período diurno, durante as transições da manhã e final da tarde.

A intensidade absoluta do vetor resultante é muito pequena no período entre 12 e 15 horas. $\mathrm{O}$ valor deste vetor mostra-se inferior a $1 \mathrm{~m} \mathrm{~s}^{-1} \mathrm{em}$ média. É muito provável, que esse pequeno valor da resultante média horária ocorra devido à flutuações das componentes zonal e meridional em torno do zero no período convectivo. Já a intensidade do vetor velocidade do vento instantâneo mostra-se bem maior, variando entre 2,5 e $5,5 \mathrm{~m} \mathrm{~s}^{-1}$ entre os níveis de 10 e 80 metros na torre.

A curva hodógrafa resultante apresenta um formato elíptico no nível de $80 \mathrm{~m}$. O eixo principal da elipse está orientado na direção SE-NW. Essa orientação indica qual é a direção e sentido do cisalhamento inferior do JBN em Iperó.

Para os níveis de $60 \mathrm{~m}$ e $10 \mathrm{~m}$, os efeitos da topografia local podem modificar a forma elíptica da hodógrafa. Neste caso, local se refere a algumas centenas de metros àvolta do ponto de medida.

A Figura 3.9 apresenta as hodógrafas calculadas para dois julhos e marços de 1992 e 1993, que representam respectivamente o final do verão e inverno em Iperó. As hodógrafas construídas baseiam-se no vetor médio resultante $\sum\left(\mathrm{u}_{\mathrm{i}}, \mathrm{v}_{\mathrm{i}}\right)$. A metodologia para a construção dessas curvas é a mesma utilizada na construção da hodógrafa anual.

A comparação da curva hodógrafa de verão, de inverno e anual indica que:

1. Durante o verão, a hodógrafa desloca-se em direção ao quarto-quadrante indicando ventos de NW durante a tarde, especialmente a $60 \mathrm{~m}$ e $80 \mathrm{~m}$ na torre. No inverno, durante a tarde, ventos resultantes de SW são mais freqüentes;

2. O cisalhamento do vento é mais intenso durante os meses de inverno para a camada entre a superfície e $80 \mathrm{~m}$ na CLP. Uma explicação plausível é o incremento do vento que ocorre nos meses de inverno quando a região de Iperó é sujeita àentrada freqüente de frentes-frias;

\footnotetext{
${ }^{4}$ Todos os horários indicados neste trabalho se referem à hora local, salvo mensão em contrário.
} 
3. A forma elíptica é predominante no período de verão, aparecendo nos níveis $10 \mathrm{~m}, 60 \mathrm{~m}$ e $80 \mathrm{~m}$ em Iperó. O eixo principal é orientado na direção SE-NW. Durante o inverno, a forma elíptica aparece de forma mais clara no nível $80 \mathrm{~m}$, enquanto nos níveis inferiores há indícios marcantes de bloqueio topográfico e/ou efeitos aerodinâmicos da distribuição de rugosidade superficial. Durante o inverno, no nível de $10 \mathrm{~m}$, o desacoplamento é muito intenso ànoite, resultand o que a forma da elipse aparece muito mais deformada.

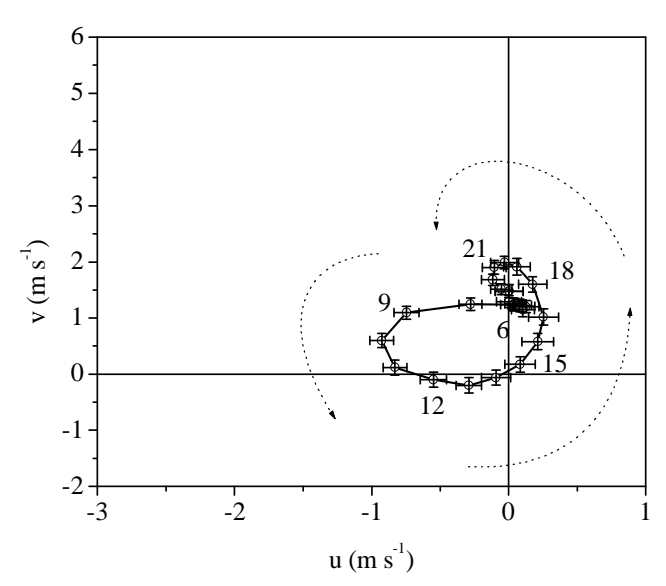

(a)

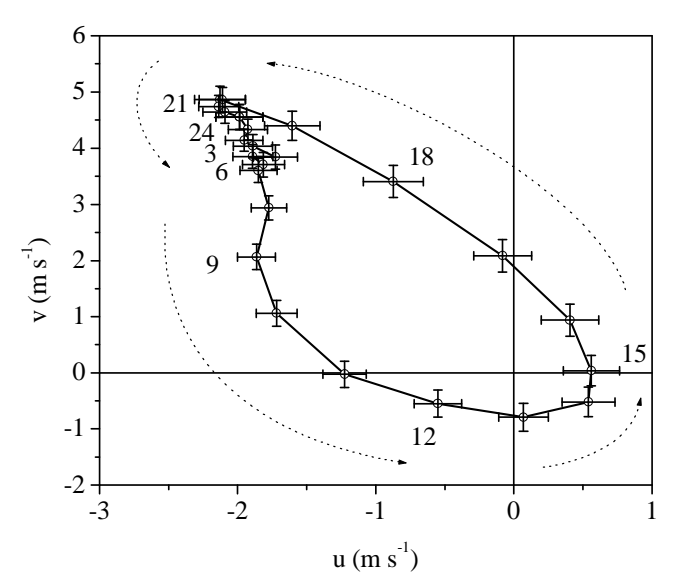

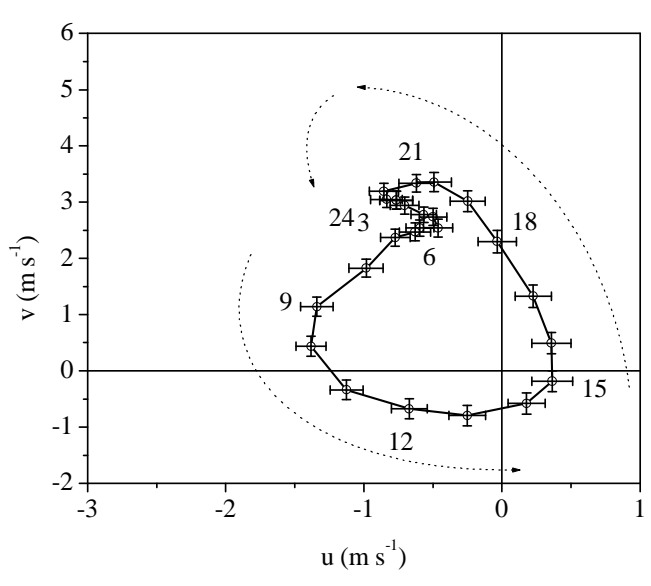

(b)

(c)

Figura 3.8 Curvas hodógrafas do vetor velocidade do vento resultante calculadas para três níveis da torre em Iperó: (a) $10 \mathrm{~m}$, (b) $60 \mathrm{~m}$ e (c) $80 \mathrm{~m}$. As barras de erro foram obtidas considerando-se que o erro da média obedece a uma distribuição de t-Student. $O$ período de dados compreende 24 meses entre junho de 1992 e junho de 1994.

A análise da distribuição de freqüência do vento em Iperó medida ao longo da torre de $80 \mathrm{~m}$ ressalta a coerência espacial e temporal do ciclo diurno do vento na camada limite superficial em Iperó (KARAM e OLIVEIRA, 1998). 
A estrutura vertical do vento na CLP superficial e sua evolução temporal ao longo do dia mostram-se consistentes com observações à superfície da Fazenda Ipanema e com períodos de inverno e verão tomados em separado (Tabela 3.4).

A seguir, apresentam-se gráficos da distribuição das médias horárias das variáveis observadas no período de dois anos na torre de $80 \mathrm{~m}$ localizada nas instalações do CEA em Iperó, ao longo do dia. Primeiramente, analisa-se a variação horária das componentes médias zonal e meridional do vento (Figura 3.10).

Inverno

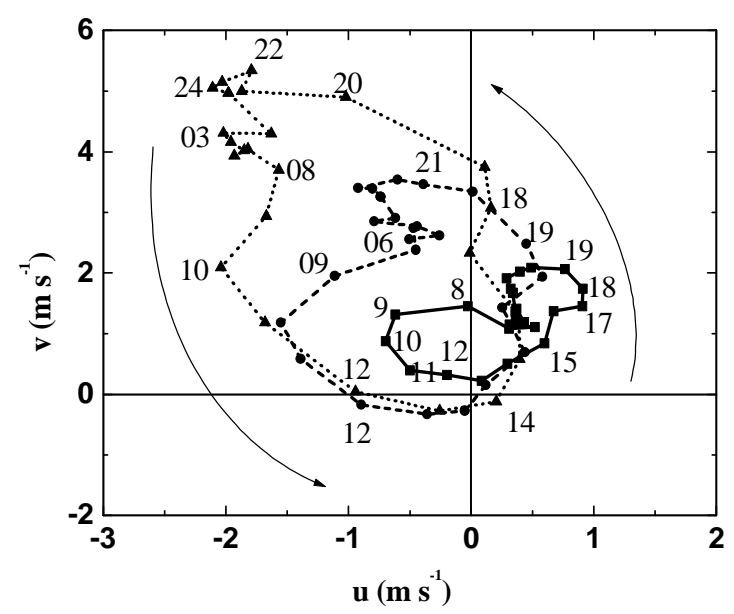

Verão

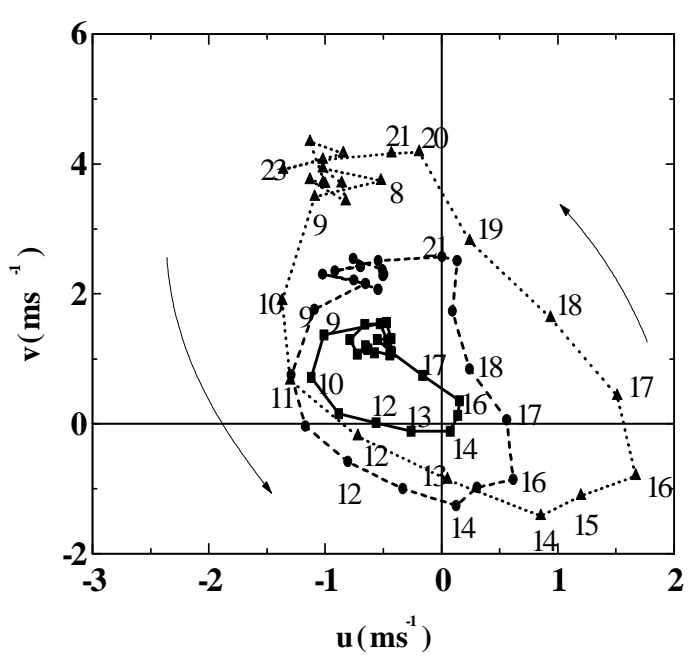

Figura 3.9 Média mensal das curvas hodógrafas do vetor resultante do vento observado em Iperó para níveis de 10 m, 60 m e 80 m, durante: (a) Inverno (Julhos de 1992-93) e (b) Verão (Março de 1992-93).

Nota-se que a componente meridional apresenta maior variação comparada à componente zonal (Figura 3.10). Para o nível de $80 \mathrm{~m}$ da torre tem-se uma diferença marcante e pode ser associada a dois regimes diferentes: (1) noturno associado à presença de cisalhamento vertical em superfície e JBN acima e (2) diurno, associado ao aumento da convecção térmica, turbulência e fricção, o que resulta em redução dos valores absolutos de ambas as componentes.

As variações de ambas as componentes ocorre basicamente durante o período diurno. Durante o período noturno, as componentes médias horárias praticamente não variam muito. As variações do período diurno caracterizam um giro da direção do vetor resultante do vento médio horário.

A velocidade do vento resultante é calculada de acordo com PANOFSKY e BRIER (1968) e apresentada na Figura 3.11. Por outro lado, a velocidade média do vento, instantânea, é calculada 
considerando-se o módulo da velocidade do vento como um escalar qualquer, sendo mostrada na Figura 3.11.

Um parâmetro importante é a persistência do vetor velocidade do vento (PANOFSKY e BRIER, 1956; ARRIT et alli, 1997). A persistência indica o grau de consistência da direção do vetor velocidade do vento dentro em uma série temporal de observações. Em nosso caso, para períodos de uma hora.

A persistência é definida pela razão entre a Velocidade do Vento Resultante e a Média da Velocidade do Vento instantâneo. Quando a direção do vento se mantém invariável durante um intervalo de tempo, a persistência será unitária neste intervalo. Por outro lado, se a direção do vento é variável (distribuindo-se em todas as direções) ou se sopra metade do tempo em uma direção e a outra metade do tempo na direção oposta, a persistência será nula. A velocidade do vento resultante é sempre menor ou igual à média das velocidades individuais do vento.

Para os níveis de 60 e 80 m o mínimo da velocidade média instantânea ocorre no início da manhã (linha de círculos preenchidos na Figura 3.11 a e b). Para o nível de 10 m, encontra-se o mínimo entre $0 \mathrm{~h}$ e $6 \mathrm{~h}$, provavelmente em conseqüência do intenso desacoplamento da camada superficial causado pela presença da inversão térmica superficial. Por outro lado, o mínimo da velodidade resultante ocorre durante o período de maior convecção, i.e., à tarde (linha com quadrados abertos na Figura 3.11). Isto pode ser entendido considerando-se a baixa persistência direcional durante o período da tarde, que implica em redução do valor da velocidade resultante (obtida das componentes u e v médias).

O máximo da velocidade do vento instantâneo ocorre ao final da tarde (Figura 3.11). A causa do máximo ao final da tarde parece estar associada ao final do período convectivo, ao desacoplamento da superfície e a formação do JBN acima da camada superficial.

No caso de Iperó, as maiores diferenças entre a velocidade do vetor resultante do vento e a média da velocidade do vento ocorre no período diurno, durante o qual elementos de rajadas e flutuações intensas das componentes do vento aparecem devido a maior intensidade da turbulência — de origem térmica — o que reduz muito o valor da persistência. Durante o período noturno a persistência direcional aumenta muito em Iperó, mantendo-se em um patamar praticamente constante durante o período noturno.

A evolução horária da direção do vetor resultante do vento nos primeiros $80 \mathrm{~m}$ da CLP é apresentada na Figura 3.12. Os gráficos mostram, de forma clara, a oscilação diurna do vento, em sentido anti-horário, que é característica em Iperó.

Durante o período noturno, a direção do vento resultante é de $\mathrm{S}$ a superfície (e SE mais acima), soprando praticamente, do quadrante $S$ durante toda ànoite. 


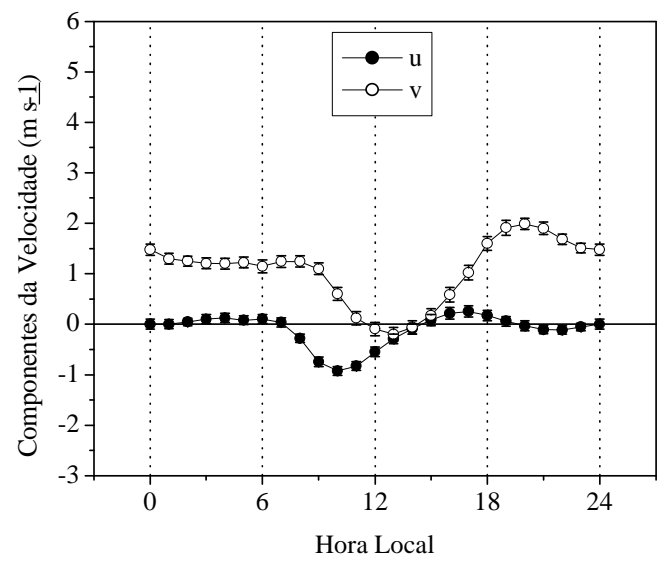

(a)

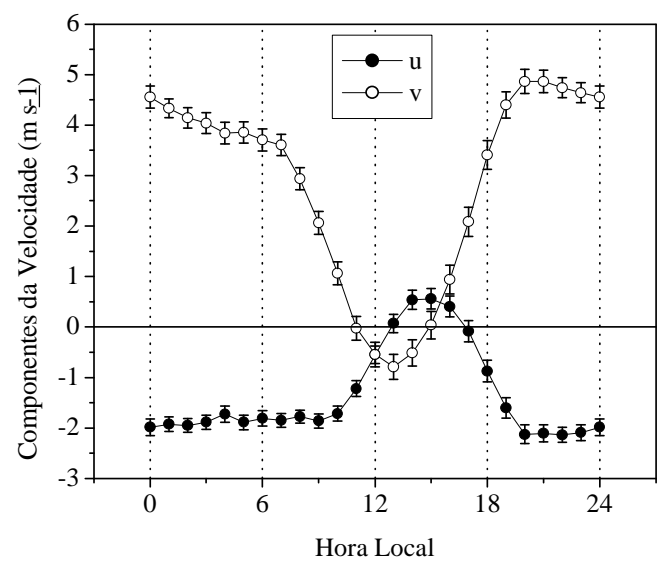

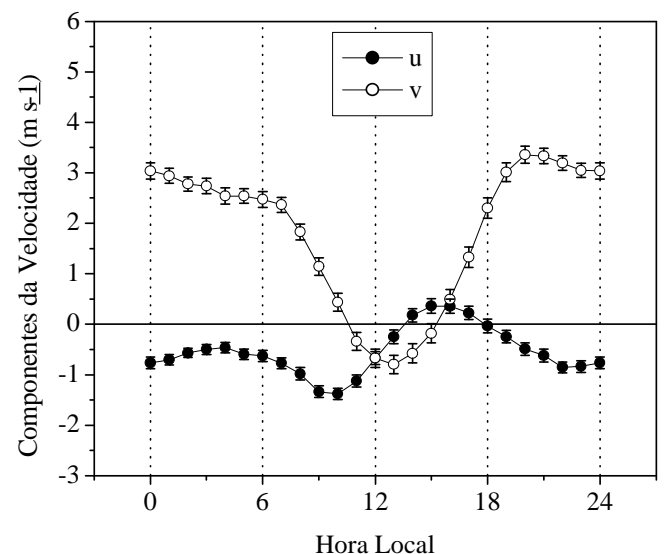

(b)

(c)

Figura 3.10 Componentes zonal e meridional do vetor velocidade do vento resultante calculadas para três níveis da torre em Iperó: (a) $10 \mathrm{~m}$, (b) $60 \mathrm{~m}$ e (c) $80 \mathrm{~m}$. As barras de erro foram obtidas considerando que o erro da média obedece a uma distribuição de t-Student. O período de dados considerado compreende um período de dois anos entre 1992 e 1994, com amostragem de 15 min.

Durante o período convectivo, o vetor resultante gira em sentido anti-horário, começando pela manhã de S, passando por SE, NE, e N ao meio-dia; para então soprar de NW, W e SW àtarde, até alcançar a direção S (SE mais acima) no final da tarde. Portanto ocorre um giro completo de 360 graus durante o período entre 6 da manhã e 6 da tarde (período convectivo). 
Define-se aqui o fator de rajada ${ }^{5}$ como a razão entre os quantis ${ }^{6}$ (Figura 3.13) mais energéticos e o quantil da mediana. A Figura 3.14 apresenta a distribuição horária das razões $\mathrm{q}_{7} / \mathrm{q}_{4}$, $\mathrm{q}_{6} / \mathrm{q}_{4}, \mathrm{q}_{5} / \mathrm{q}_{4}$, e $\mathrm{q}_{4} / \mathrm{q}_{4}$, nas quais, o quantil $\mathrm{q}_{4}$ é a mediana da distribuição.

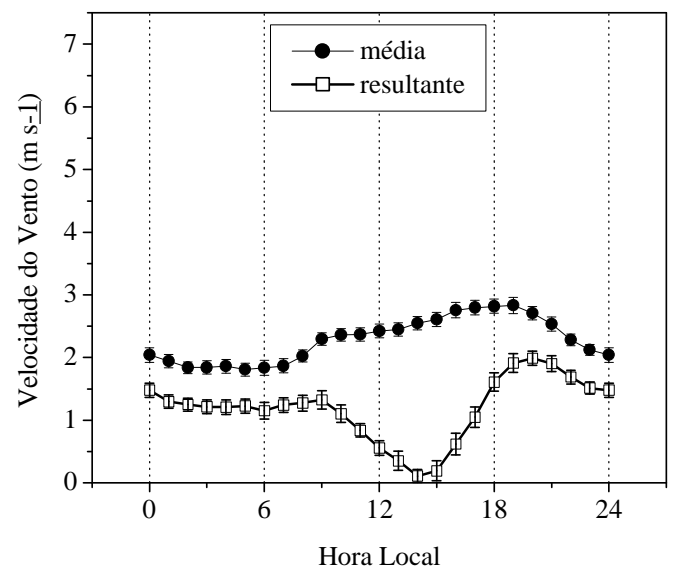

(a)

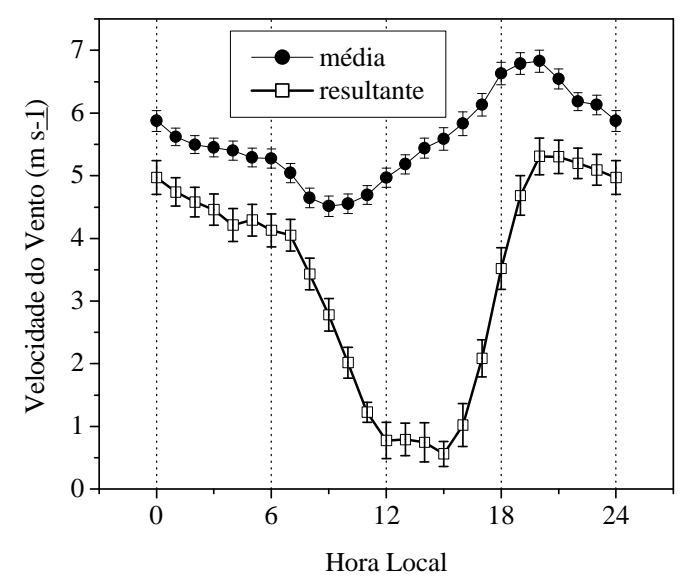

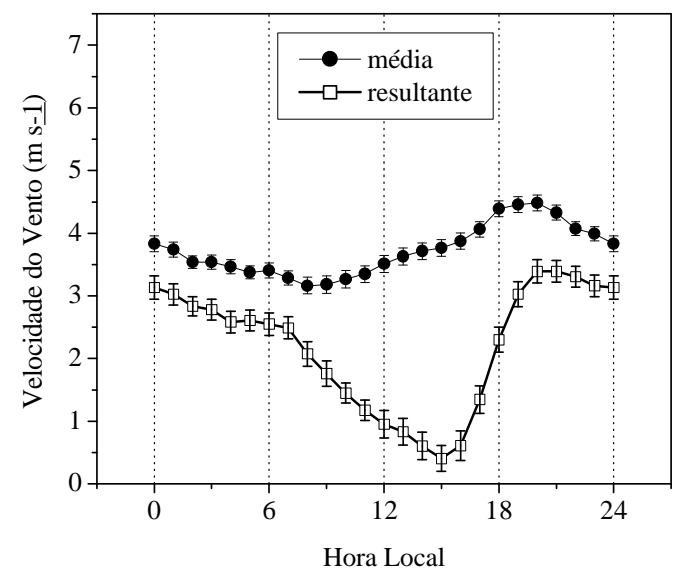

(b)

(c)

Figura 3.11 Velocidade do vetor vento resultante (quadrados) e velocidade média do vento (círculos) calculadas para três níveis da torre em Iperó: (a) $10 \mathrm{~m}$, (b) $60 \mathrm{~m}$ e (c) $80 \mathrm{~m}$. As barras de erro foram obtidas considerando que o erro da média obedece a uma distribuição de t-Student. $\mathrm{O}$ período de dados considerado compreende um período de dois anos entre 1992 e 1994.

${ }^{5}$ O fator de rajada é um parâmetro derivado da análise de séries temporais de velocidade do vento. Seu valor pode ser estimado pela razão entre a intensidade da máxima de velocidade observada e a velocidade média do vento em um dado período considerado. O período considerado pode ser horário, resultando em um fator de rajada horário ou ser maior, para a noite toda, p.ex., como fez CARDENAS (1990). Neste trabalho, propõe-se o cálculo do fator de rajadas referido à razão entre quantis horários.

${ }^{6}$ Os quantis são certos valores da grandeza considerada que separam intervalos de variação no espaço amostral, que são caracterizados por apresentarem cada qual uma mesma probabilidade de ocorrência. Por exemplo, a mediana é um quantil de $50 \%$ pois separa a distribuição em dois intervalos (pontos do espaço amostral maiores e menores que a mediana) de forma que ambos os intervalos apresentam uma mesma probabilidade de ocorrência, i.e., 50\%. Neste trabalho, utiliza-se 7 quantis para separar 8 intervalos do espaço amostral, cada qual com probabilidade de $12,5 \%$. 
No nível de $10 \mathrm{~m}$ da torre obtém-se dois máximos do fator de rajada $\mathrm{q}_{7} / \mathrm{q}_{4}$ indicando rajadas que ocorrem em 12,5\% do tempo, no intervalo de uma hora. Neste caso, o fator é de 2,2 vezes, indicando que ventos apresentam intensidade 2,2 vezes maior que o valor da mediana da velocidade esperada. Estes máximos ocorrem durante o período convectivo, em horário próximo as $9 \mathrm{~h}$ e as 15 h. Esses horários são, respectivamente, anterior e posterior ao máximo de convecção térmica na CLP — que por hipótese deve ocorrer próximo æ̀ 12 h. O mesmo padrão se repete para níveis de 60 m e 80 m na torre de Iperó.

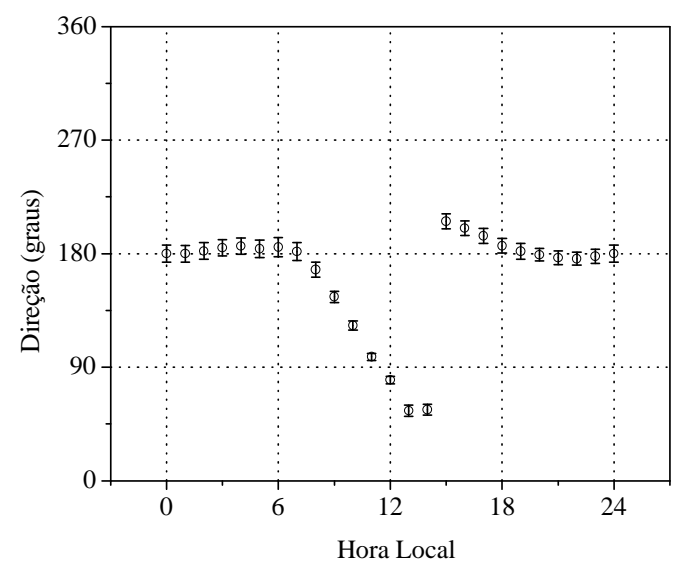

(a)

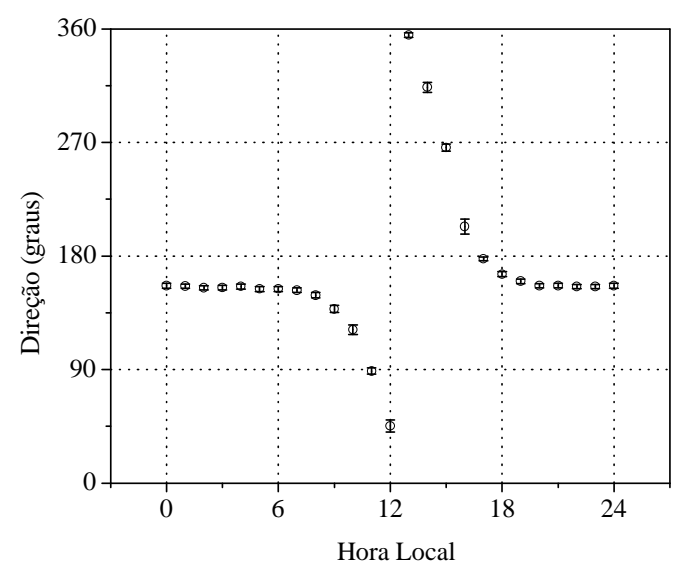

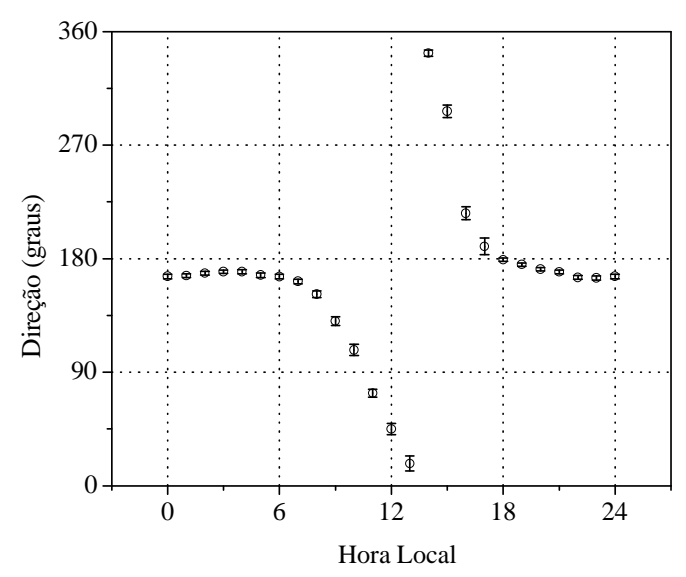

(b)

(c)

Figura 3.12 Direção da resultante do vetor velocidade do vento calculada para três níveis da torre em Iperó: (a) $10 \mathrm{~m}$, (b) $60 \mathrm{~m}$ e (c) $80 \mathrm{~m}$. As barras de erro foram obtidas considerando que o erro da média obedece a uma distribuição de t-Student. O período de dados considerado compreende um período de dois anos entre 1992 e 1994, com amostragem de 15 min.

As rajadas mostram-se ainda mais destacadas no período convectivo, dois picos eqüidistantes do máximo da convecção térmica e fator de rajada de valor aproximadado 2,2. $\mathrm{O}$ fator 
de rajadas do quantil 7 tende a um valor praticamente constante de 1,5 durante a noite no nível de $80 \mathrm{~m}$ da torre.

A metodologia apresentada aqui difere da metodologia clássica que se baseia na análise do gráfico da velocidade (rajada ou média horária) máxima anual versus o logaritmo do período de retorno em anos (entre 0 e 200 anos) (LEE, 1978). Neste caso, os períodos de retorno referem-se ao período de tempo, medido em anos, necessário para que se observe novamente um certo valor máximo da velocidade média horária (ou da rajada máxima anual) encontrada em um ano. Neste trabalho, não há dados suficientes para estimar-se os períodos de retorno (seria necessária dispor-se de uma série temporal mínino de 10 anos) e, porquanto, se estuda a distribuição horária das rajadas ao longo do dia.

A Figura 3.15 apresenta os gráficos da distribuição da persistência média horária. A Figura mostra que a Persistência é intensa durante a noite e pequena durante o dia. Valores noturnos estão acima de $75 \%$ para níveis 60 e $80 \mathrm{~m}$, e acima de $60 \%$ para nível $10 \mathrm{~m}$. Já os valores durante período diurno, principalmente àtarde, mostram -se abaixo de $25 \%$ para todos os níveis da torre de $80 \mathrm{~m}$.

A Persistência deve ser analisada em conjunto com a direção do vento resultante. Quando isto é feito, mostra-se que a direção do escoamento na CLP estável em Iperó, é determinada e coerente, possivelmente definida pelo JBN durante a noite. Os gráficos também demostram que Persistência aumenta com a altura nos primeiros 80 metros da CLP estável, ou seja, em direção à localização do máximo do jato.

Durante o período convectivo (diurno) o baixo valor da Persistência (abaixo de 25\%) indica flutuações da direção do vento de todas as direções. Essas flutuações são causadas, possivelmente, por rajadas associadas àpresença de grandes -turbilhões na camada limite convectiva.

Os valores de persistência obtidos neste estudo para a condição de contorno inferior do jato em Iperó - segundo sua distribuição média horária — são comparáveis aos valores obtidos para a distribuição espacial da persistência, por ARRITT et alli (1997) para o JBN sobre Grande Planície nos $\mathrm{EUA}^{7}$. Deste ponto de vista, os valores de persistência obtidos para Iperó fornecem um indício da presença do JBN acima da CLP estável.

\footnotetext{
7 Os valores obtidos por ARRIT et alli foram tabulados seguindo o critério de classificação proposto por BONNER: para os JBN. Isto é para JBN: do Tipo (1) observaram persistência acima de $20 \%$ à Noroeste da área e máximo de $80 \%$ ao sul de Oklaroma e Texas; JBN do Tipo (2), acima de $30 \%$ ao Norte e máximo de $90 \%$ em Arkansas e JBN do Tipo (3), a persistência ficou acima de $30 \%$ a Neste e Noroeste, com máximo de $70 \%$ no Texas e Lousiana.
} 


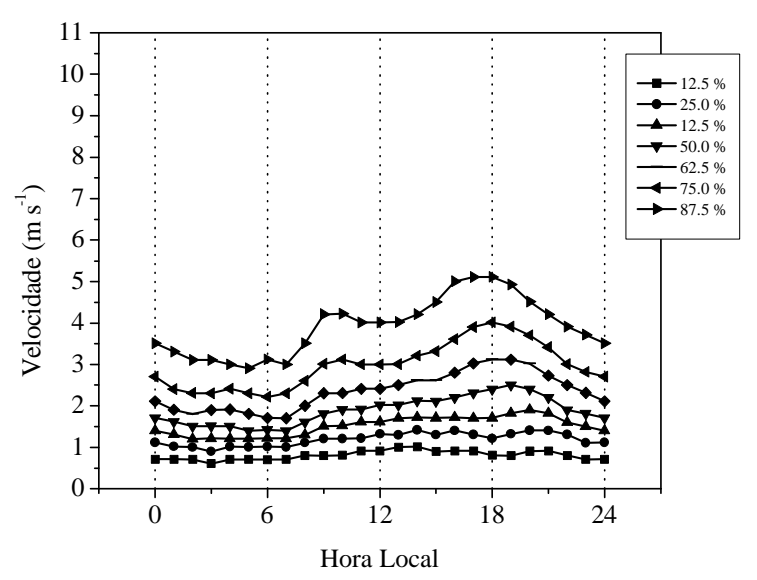

(a) $10 \mathrm{~m}$

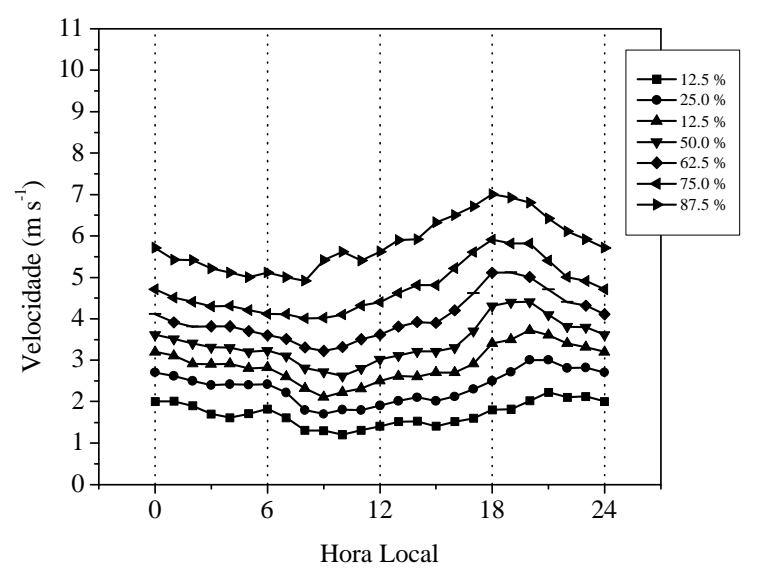

(b) $60 \mathrm{~m}$

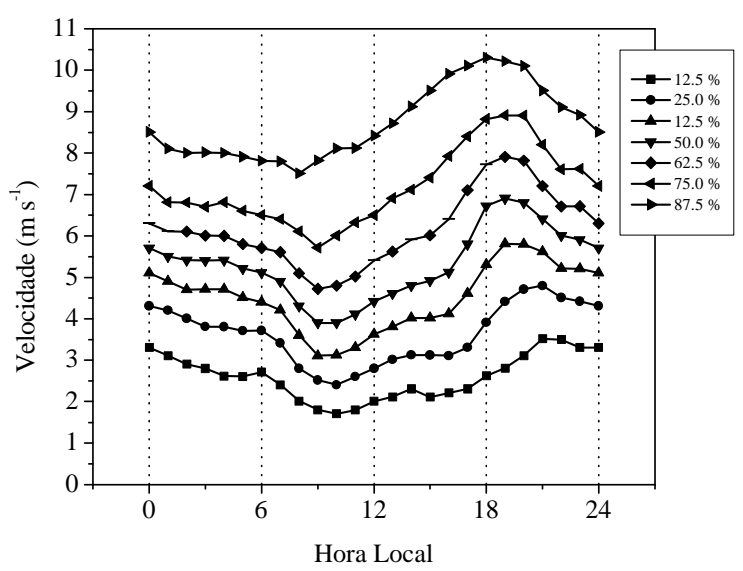

(c) $80 \mathrm{~m}$

Figura 3.13 Distribuição horária dos Quantis 12.5\%; 25\% 37.5\%; 50\% (mediana) 62.5\%; 75\% e $87.5 \%$ obtidos para três níveis na torre de Iperó: (a) $10 \mathrm{~m}$; (b) $60 \mathrm{~m}$ e (c) $80 \mathrm{~m}$.

É interessante neste ponto, apontar o potencial eólico na região de Iperó em associação a presença do JBN noturno. A energia cinética média e o potêncial eólico estão associados à energética do escoamento. Para avaliar-se o potencial eólico na área de Iperó, calculou-se a energia cinética média por unidade de volume em Iperó (Figura 3.16) e a potência disponível para produção de energia eólica, por unidade de área (Figura 3.17). A interpretação dos gráficos obtidos leva em conta o seguinte exemplo prático. Por hipótese, considere-se que a energia eólica de Iperó seja utilizada para girar uma turbina instalada no topo de uma torre de $80 \mathrm{~m}$, acionada por uma hélice de raio $10 \mathrm{~m}$. Para este exemplo, o gráfico da Figura 3.17 fornece a máxima potência utilizável, por unidade de área, de valor $125 \mathrm{~W} \mathrm{~m}^{-2}$, que correspondente aproximadamente ao valor médio de 24 h. A multiplicação deste valor pela área da turbina fornece a potência obtida, em watts. 
Multiplicando-se a potência obtida pelo número de horas no mês, calcula-se a energia disponível em Wh/mês (watt hora por mês). Neste caso, efetuando-se as contas, determina-se que a energia disponível coletada por esta única turbina em Iperó é suficiente para abastecer cerca de 538 casas com consumo mensal de $210 \mathrm{kWh} / \mathrm{mês}$.

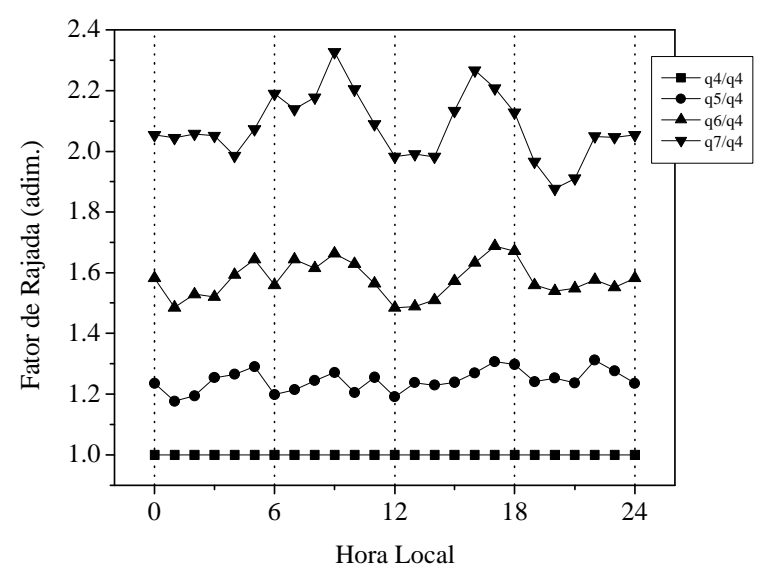

(a) $10 \mathrm{~m}$

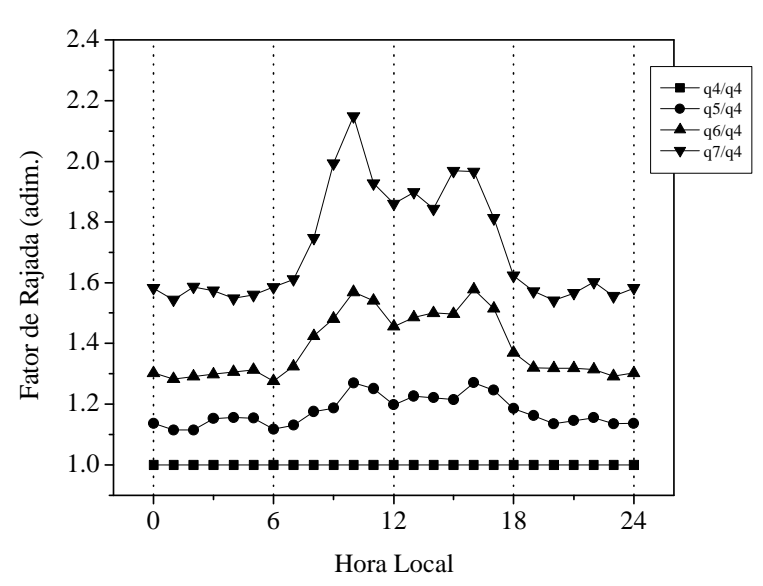

(b) $60 \mathrm{~m}$

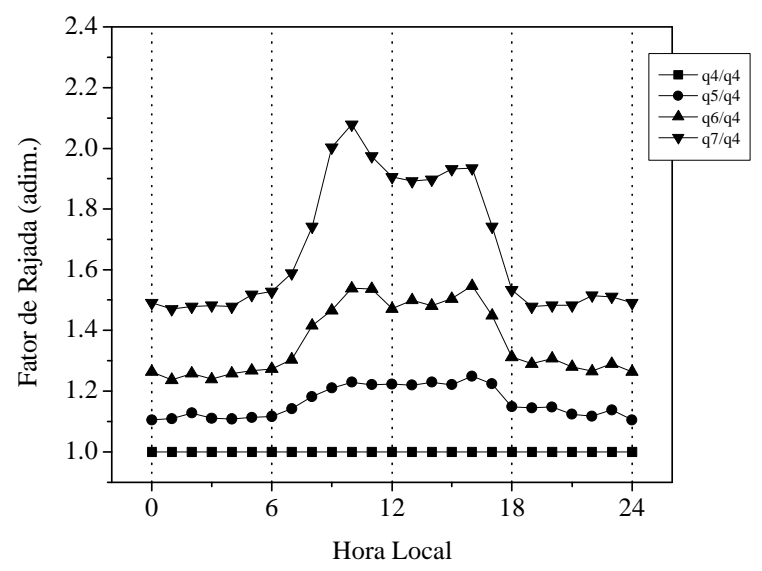

(c) $80 \mathrm{~m}$

Figura 3.14 Fator de rajada calculado da razão entre quantis 50,0\%; 62,5\%; 75,0\% e 87,5 \% obtidos para três níveis na torre de Iperó: (a) $10 \mathrm{~m}$; (b) $60 \mathrm{~m} \mathrm{e}$ (c) $80 \mathrm{~m}$ da analise de dois anos (1992-1993) com amostragem de 15 min. 

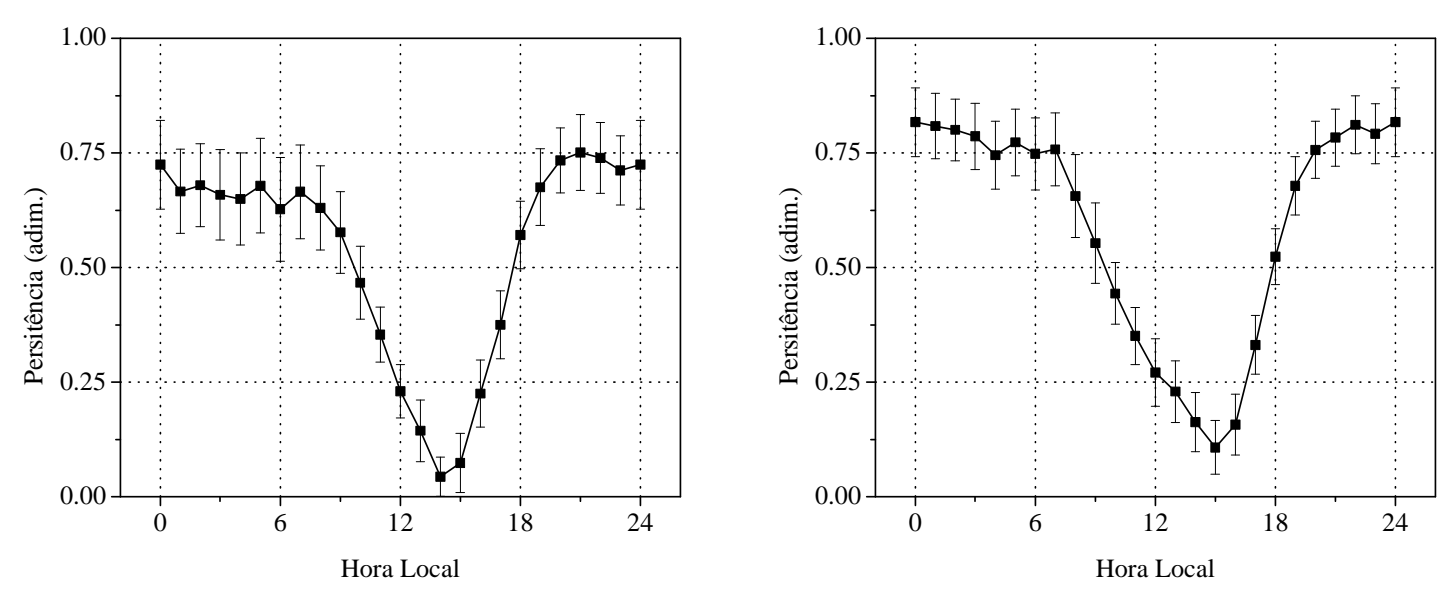

(a) $10 \mathrm{~m}$

(b) $60 \mathrm{~m}$

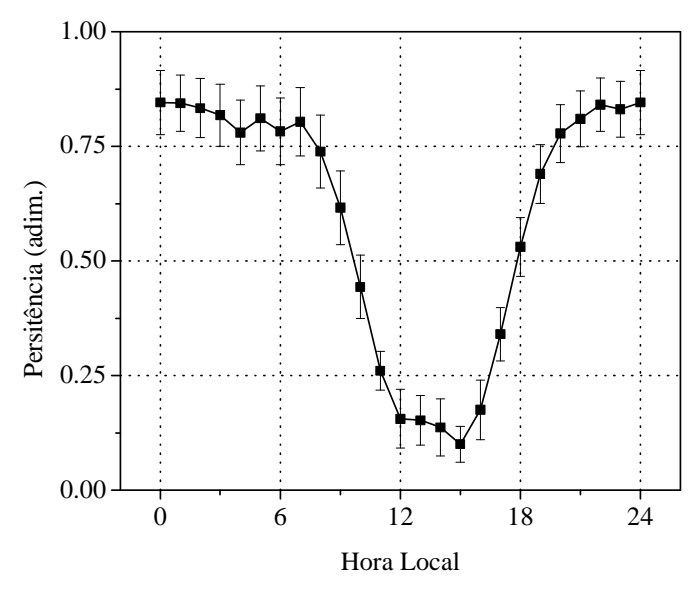

(c) $80 \mathrm{~m}$

Figura 3.15 Persistência horária observada em Iperó para três níveis da torre (a) 10 m, (b) 60 m e (c) $80 \mathrm{~m}$. As barras correspondem ao erro da média horária.

A Figura 3.18 apresenta a evolução horária média da altura do nível de condensação por levantamento (NCL), obtido de acordo com BOLTON (19800). O NCL é definido para a altura na qual uma parcela de ar úmido resfriado por levantamento adiabático, a partir da superfície, tem seu conteúdo de vapor de água condensado. A taxa de resfriamento adiabático com a altura é de $10^{\circ} \mathrm{C}$ $\mathrm{km}^{-1}$.

Nota-se que o valor mínimo da altura do NCL igual a $250 \mathrm{~m}$ ocorre próximo æ̀ $6 \mathrm{~h}$, isto é, ao final do período estável; e um valor máximo de $1500 \mathrm{~m}$ é atingido cerca das 15 h, no período convectivo.

A variância horária da altura é máxima (mínima) no período convectivo (estável). 
No período convectivo, a maior variabilidade horária da altura do NCL pode ser relacionada teoricamente àpresença de nuvens do tipo cúmulos de bom tempo (WILDE et alli, 1985).

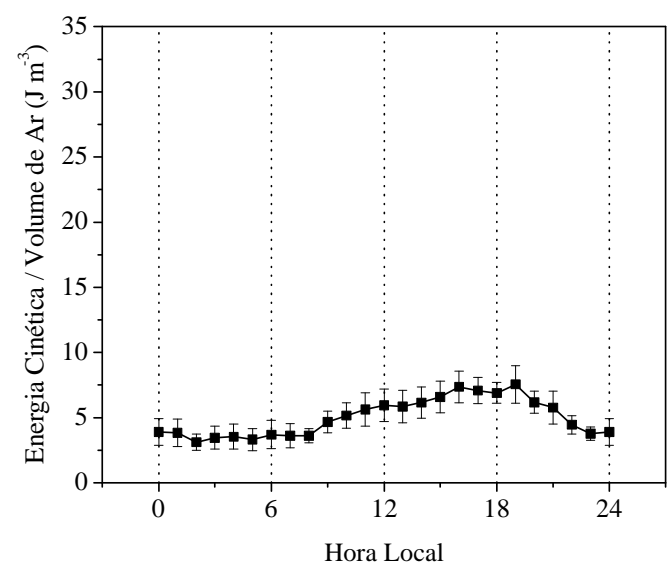

(a) $10 \mathrm{~m}$

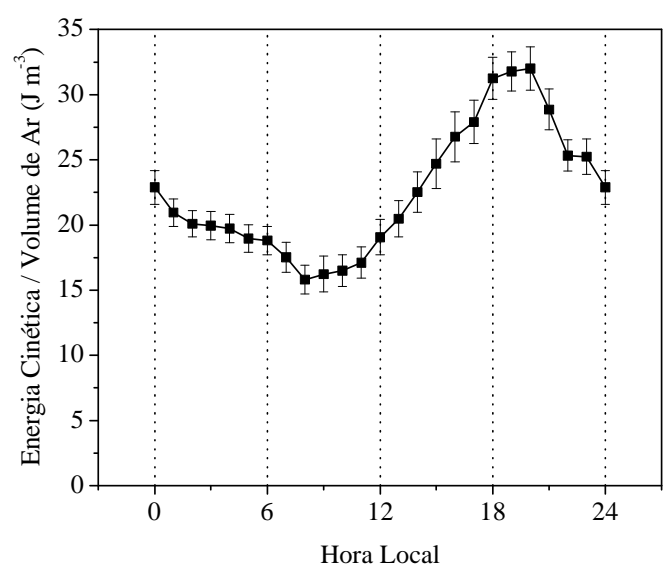

(c) $80 \mathrm{~m}$

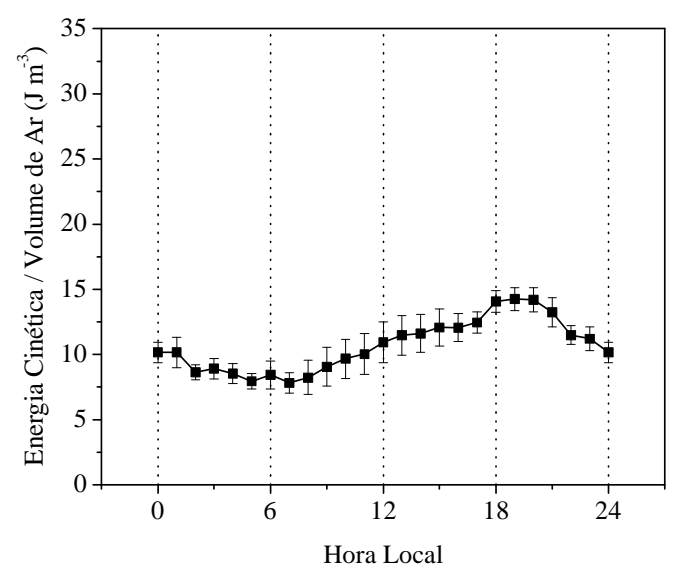

(b) $60 \mathrm{~m}$

Figura 3.16 Distribuição horária da Energia Cinética por unidade de Volume de Ar $\left(\mathrm{J} \mathrm{m}^{-3}\right)$ para os três níveis da torre em Iperó: (a) 10 m, (b) 60 m e (c) 80 m.

Durante a noite, a menor variabilidade e a baixa altura do NCL podem indicar, do ponto de vista teórico, presença de nuvens do tipo estratos (nuvens baixas, em camadas pouco profundas na vertical), essas últimas podem se formar sobre as calhas dos rios secundários na região de Iperó.

A evolução da temperatura potencial média horária no nível de $10 \mathrm{~m}$ da torre (Figura 3.19) indica um valor mínimo noturno de 295,5 K às 6 h (local) e um máximo diurno de 304,5 K à 15 h. 


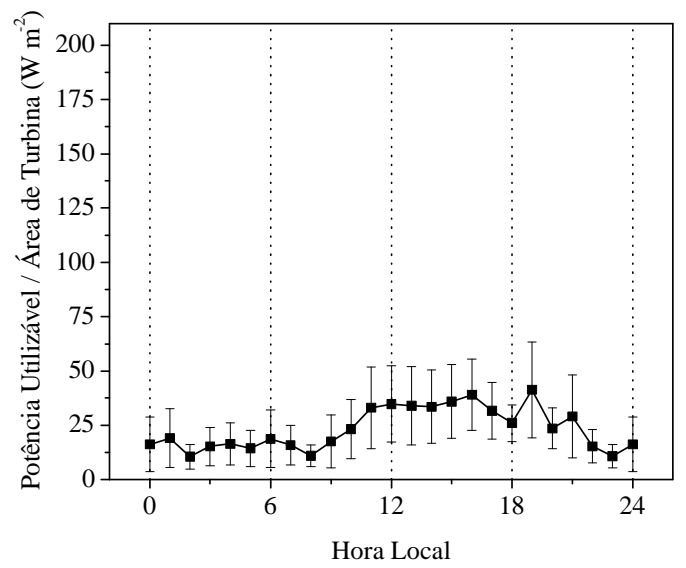

(a) $10 \mathrm{~m}$

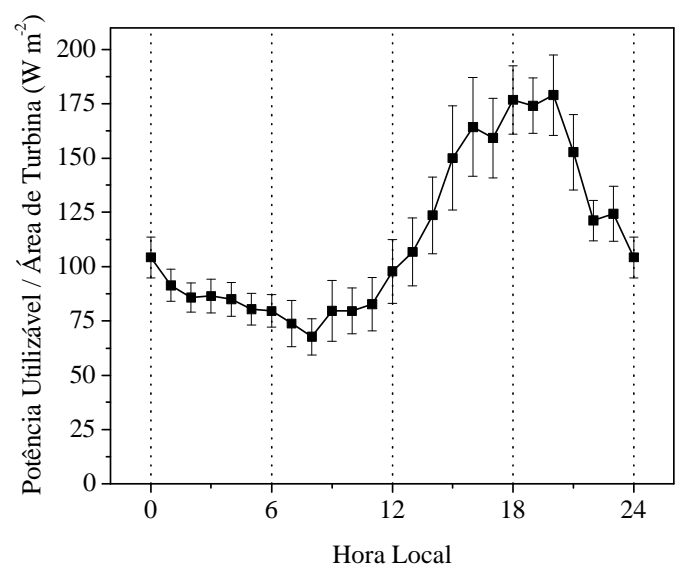

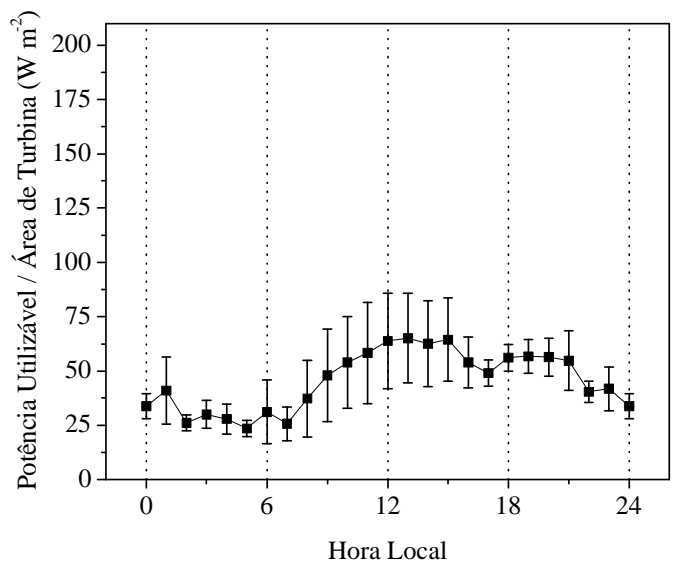

(b) $60 \mathrm{~m}$

(c) $80 \mathrm{~m}$

Figura 3.17 Distribuição horária da Potência Utilizável por unidade de Área da Turbina (W $m^{-2}$ ) para os três níveis da torre em Iperó: (a) 10 m, (b) 60 m e (c) 80 m.

As médias horárias da temperatura do ar no nível de $10 \mathrm{~m}$ da torre mostram um mínimo de $17,0{ }^{\circ} \mathrm{C}$ e um máximo de $25,5^{\circ} \mathrm{C}$.

Os incrementos de temperatura na vertical da torre, entre os níveis de 10 e $60 \mathrm{~m}$ e entre 10 e $80 \mathrm{~m}$, indicam que o maior crescimento do NCL está associado a um perfil vertical instável, isto é, a temperatura diminui com a altura com um gradiente superior ao gradiente adiabático de $-10{ }^{\circ} \mathrm{C} \mathrm{km}^{-}$ ${ }^{1}$ (Figura 3.20).

Para diferenças de altura de 50 e $70 \mathrm{~m}$, o gradiente adiabático mostra um decréscimo da temperatura de -0.5 e $-0.7{ }^{\circ} \mathrm{C}$, respectivamente. Portanto o valor de $-1,6{ }^{\circ} \mathrm{C}$ do período convectivo é superadiabático — ou seja, muito instável. Já durante o período noturno, o gradiente é menos intenso e oposto em sinal, isto é positivo — indicando a presença de uma camada de inversão 
superficial - com gradientes médios de 0,008 e $0,006{ }^{\circ} \mathrm{C} \mathrm{m}^{-1}$ entre níveis $10 \mathrm{~m}$ e $60 \mathrm{~m}$ e entre níveis 10 e $80 \mathrm{~m}$, respectivamente.

As médias horárias das diferenças de temperatura do ar em relação àtemperatura do ponto de orvalho $\left(\mathrm{T}_{-} \mathrm{T}_{\mathrm{d}}\right)$ e do NCL $\left(\mathrm{T}-\mathrm{T}_{\mathrm{NCL}}\right)$ apresentam uma evolução similar ${ }^{8}$, em sua forma, àquela da altura do NCL (compare-se Figura 3.18 com Figura 3.20).

A coerência espacial do campo de vento descrito para o ponto do CEA em Iperó foi verificada considerando-se dados da Estação Meteorológica da Fazenda Ipanema ${ }^{9}$, localizada a cerca de $5 \mathrm{~km}$ a SE do CEA.

Uma estatística desses dados foi executada, resultando na distribuição de frequiências em função da direção do vento, dada na Tabela 3.4. Os dados considerados foram medidos à 09:00, 15:00 e 21:00 HL dos meses de janeiro e julho, num total de cinco janeiros $(1984,1985,1987,1988$ e 1989) e de seis julhos (1984,1985,1986, 1987,1988 e 1989). Os dados foram classificados segundo oito classes de direção para obter a distribuição de freqüência.

Ventos de N e NW são freqüentes à 15 h e ventos de S e SE à 21 h e 9 h. Esta oposição entre as direções predominantes da tarde e da noite indica a presença de uma oscilação ou ciclo diurno na direção do vento. Estas oscilações também estão presentes na direção de vento observada durante as quatro campanhas realizadas no CEA em Iperó.

Indícios de um bloqueio do escoamento superficial aparecem na distribuição da direção do vento. As direções W, E, NE e SW apresentam baixa freqüência de ocorrência. O escoamento nestas direções pode estar sendo bloqueado pela topografia do Morro de Araçoiaba, à SW, localizado a $10 \mathrm{~km}$ do ponto de observação, que se eleva $300 \mathrm{~m}$ acima do vale do rio Sorocaba. Adicionalmente, sondagens realizadas durante as campanhas em Iperó mostram uma perturbação da direção do vento para uma camada superficial com espessura entre 150 e $200 \mathrm{~m}$. Nesta camada ventos do quadrante sul são freqüentes enquanto que ventos de W, E, NE e SW apresentam baixa freqüência. A observação desta camada é um indício adicional do efeito de bloqueio do Morro de Araçoiaba.

\footnotetext{
${ }^{8}$ Diferentes pesquisadores tem descrito as relações entre o estado térmico, a estabilidade estática e a umidade relativa disponível na parcela de ar junto à superfície (STULL, 1976ab, 1985; DEARDORFF et alli, 1980; WILDE et alli, 1985; SOUZA et alli, 2000).

${ }^{9}$ Esta estação meteorológica pertence ao Centro de Engenharia Agrícola do Ministério da Agricultura (CENEA).
} 


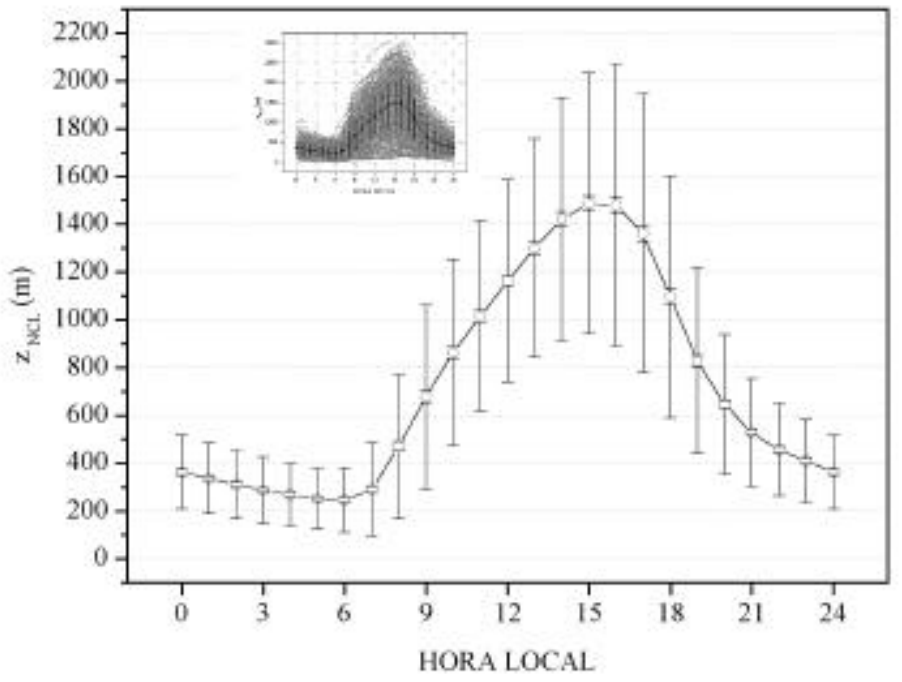

Figura 3.18 Evolução média horária da altura $\left(\mathrm{z}_{\mathrm{NCL}}\right)$ do nível de condensação por levantamento (NCL) em Iperó, utilizada como estimativa da evolução da altura (h) da CLP. Em miniatura, apresenta-se a dispersão dos pontos utilizados nos cálculos (entre 1100 e 2100 pontos por horário). As barras verticais correspondem ao desvio-padrão e ao erro da média.

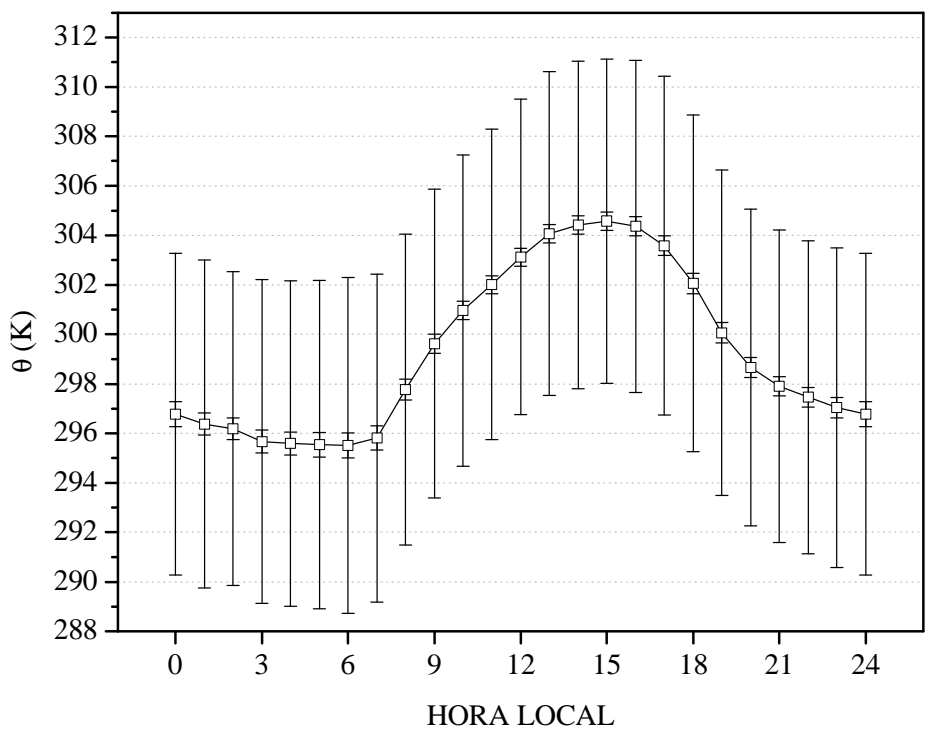

Figura 3.19 Evolução da média horária da temperatura potencial do ar $(\theta)$ para o nível de $10 \mathrm{~m}$ da torre em Iperó. As barras verticais correspondem ao desvio-padrão e ao erro da média. 


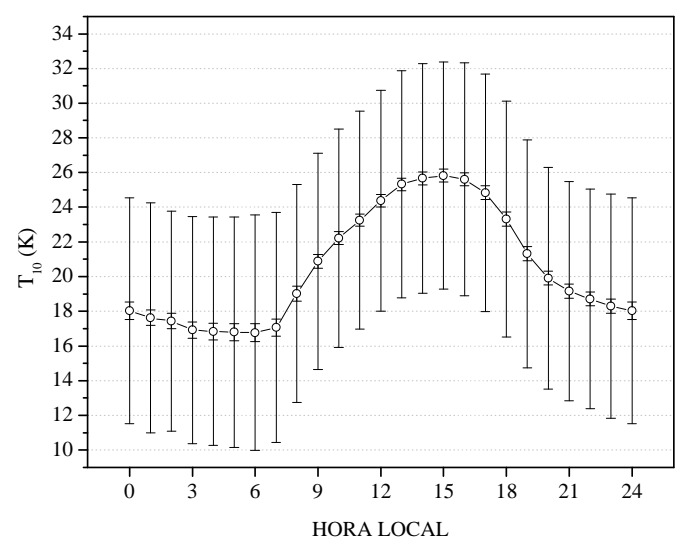

(a)

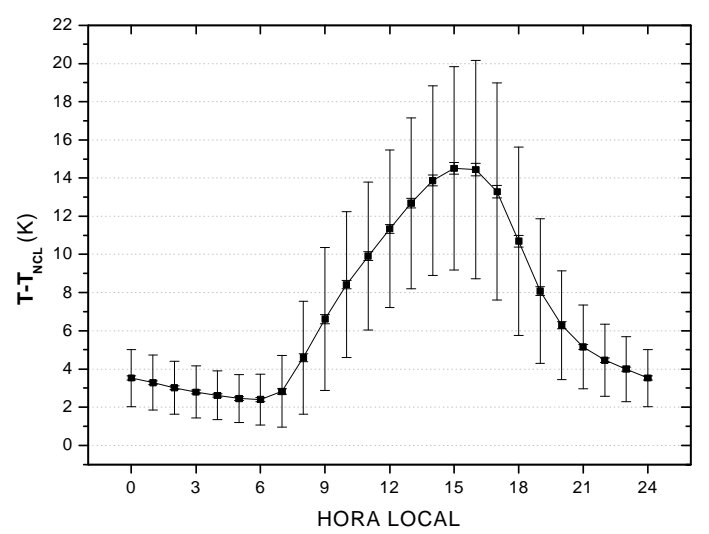

(c)

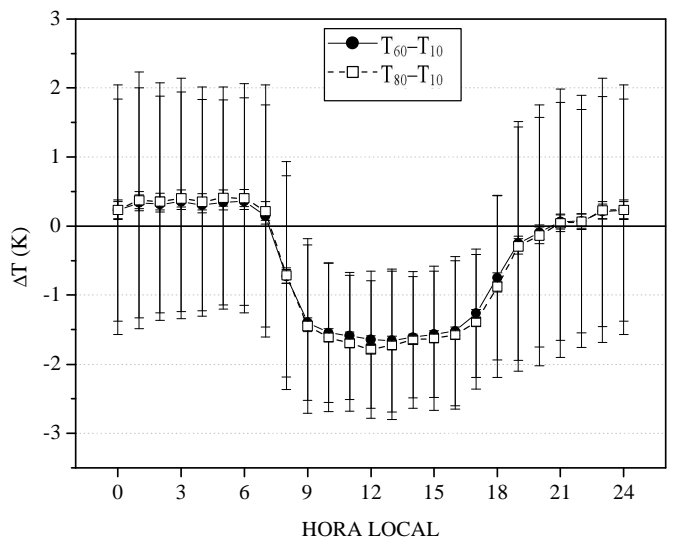

(b)

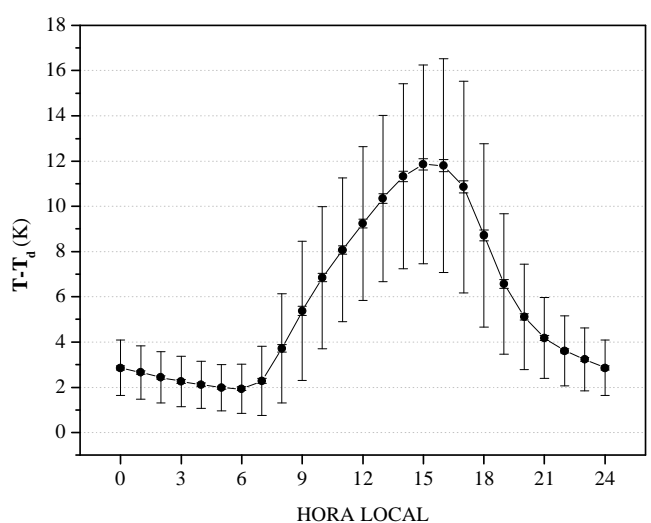

(d)

Figura 3.20 Evolução da média horária: (a) da temperatura do ar para o nível de $10 \mathrm{~m}$ da torre em Iperó; (b) da diferença de temperatura entre o nível localizado a $10 \mathrm{~m}$ e os níveis de 60 e $80 \mathrm{~m}$ da torre; (c) da diferença de temperatura do ar entre os níveis de $10 \mathrm{~m}$ na torre e o nível de condensação por levantamento e (d) da diferença de temperatura entre a temperatura do bulbo seco e do ponto de orvalho, no nível de $10 \mathrm{~m}$ da torre em Iperó. As barras verticais correspondem ao desvio-padrão e ao erro da média.

\begin{tabular}{|c|r|r|r|r|r|r|}
\hline & \multicolumn{3}{|c|}{ JULHO } & \multicolumn{3}{|c|}{ JANEIRO } \\
\cline { 2 - 6 } & $\mathbf{0 9} \mathbf{h}$ & $\mathbf{1 5} \mathbf{h}$ & $\mathbf{2 1} \mathbf{h}$ & $\mathbf{0 9} \mathbf{h}$ & $\mathbf{1 5} \mathbf{h}$ & $\mathbf{2 1} \mathbf{~}$ \\
\hline $\mathbf{N}$ & $8,90 \%$ & $17,85 \%$ & $15,18 \%$ & $16,56 \%$ & $29,13 \%$ & $13,91 \%$ \\
\hline $\mathbf{N E}$ & $1,57 \%$ & $0,06 \%$ & $1,57 \%$ & $7,28 \%$ & $3,97 \%$ & $0,66 \%$ \\
\hline $\mathbf{E}$ & $0,00 \%$ & $0,00 \%$ & $0,00 \%$ & $0,66 \%$ & $0,00 \%$ & $0,00 \%$ \\
\hline $\mathbf{S E}$ & $16,75 \%$ & $17,28 \%$ & $22,51 \%$ & $15,90 \%$ & $14,57 \%$ & $21,86 \%$ \\
\hline $\mathbf{S}$ & $17,80 \%$ & $20,42 \%$ & $16,75 \%$ & $21,86 \%$ & $17,22 \%$ & $27,15 \%$ \\
\hline $\mathbf{S W}$ & $2,09 \%$ & $2,62 \%$ & $2,62 \%$ & $0,01 \%$ & $1,99 \%$ & $0,66 \%$ \\
\hline $\mathbf{W}$ & $0,52 \%$ & $1,05 \%$ & $0,00 \%$ & $0,00 \%$ & $3,31 \%$ & $1,32 \%$ \\
\hline $\mathbf{N W}$ & $2,62 \%$ & $11,52 \%$ & $6,28 \%$ & $7,28 \%$ & $14,57 \%$ & $0,66 \%$ \\
\hline Calmaria & $49,74 \%$ & $23,04 \%$ & $35,08 \%$ & $29,14 \%$ & $15,23 \%$ & $33,77 \%$ \\
\hline
\end{tabular}

Tabela 3.4 Distribuição de frequiências relativas, para três horários de julho e janeiro, segundo a direção do vento para a estação da Fazenda Ipanema em Iperó, SP (KARAM e OLIVEIRA, 1998). 
A distribuição de freqüências encontrada para a Fazenda Ipanema mostra-se coerente com a análise de hodógrafas realizada para o CEA em Iperó. Portanto, existe coerência espacial e temporal nos dados analisados. Isto é, do ponto de vista estatístico, existe semelhança entre os dois pontos que foram comparados.

A descrição dos campos observacionais de superfície pode ser relacionada à presença do JBN em Iperó considerando-se que:

1. O JBN é um fenômeno freqüente na área de Iperó e que afeta a dinâmica superficial da CLP no local;

2. Existe grande coerência espacial (primeiros $100 \mathrm{~m}$ da CLP) e temporal do escoamento na circunvizinha do CEA em Iperó,

3. A hodografa horária do vento superficial indica a presença do JBN durante o período noturno através do intenso cisalhamento da velocidade do vento e persistência direcional de $\mathrm{SE}$;

4. O máximo de velocidade média do vento na superficie durante o início do período noturno em Iperó está associado ao desenvolvimento do JBN acima;

5. O JBN de Iperó tem um papel importante nos períodos de transição incrementando a turbulência noturna junto à superfície, permitindo a formação de uma camada de inversão superficial mais profunda durante o período noturno;

6. O JBN modifica a evolução e dinâmica da CLP estável, através do aumento do cisalhamento vertical do vento e consequente produção mecânica de turbulência. $O$ aumento da turbulência noturna pode ser um fator importante no crescimento da altura da inversão térmica de superfície observada a noite em Iperó.

\subsection{Efeito da Grande-Escala sobre o JBN}

Neste item, procura-se mostrar que JBN descritos nos itens anteriores para Iperó ocorrem predominantemente durante situações com predomínio de céu claro, vento pouco intenso (i.e., da ordem de $1 \mathrm{~m} \mathrm{~s}^{-1}$ ) e intensa incidência de radiação solar — padrões característicos das situações pré-frontais de verão.

Os períodos de realização dos Experimentos em Iperó correspondem ao final de verão. As observações de JBN realizadas então foram majoritariamente feitas em situações pré-frontais, marcadas por tempo "bom" (i.e., pelas condições descritas acima). Em associação a estas condições, 
os dados de grande-escala mostram de forma clara a presença de oscilações diurnas nos campos de temperatura e momento para Iperó, dentro de uma camada de pelo menos $1000 \mathrm{~m}$, correspondente à altura da CLP convectiva. Essas oscilações são características do período pré-frontal, ocorrendo dois a 3 dias após o posicionamento do JAN subtropical, associado à chegada do cavado de uma onda curta de grande-escala sobre a região Sudeste do Brasil. A chegada do cavado de altitude (200 $\mathrm{hPa}$ ) e as condições pré-frontais são favoráveis ao apareceimento das oscilações diurnas no campo de vento em grande-escala.

O período de tempo no qual as oscilações diurnas nos campos de grande-escala são mais destacadas (i.e., no período de verão) coincidem com os períodos de observação de JBN em Iperó (i.e., Experimentos de OLIVEIRA, 1993). Portanto, embora as resoluções verticais e temporais dos dados de grande-escala não permitam a identificação de JBN, ela indica oscilações diurnas na CLP de Iperó, o que é um indício (de grande-escala) da ocorrência de JBN em Iperó.

Durante o período de inverno, as oscilações diurnas, dos campos nos dados de grandeescala, aparecem sobrepostas ao escoamento de escala sinótica associado à passagem de frentes frias pela região, sendo portando mascaradas. Por isso, espera-se a ocorrência mais freqüente de JBN frontais durante o inverno.

Os efeitos da baroclinia de grande-escala ${ }^{10}$ (i.e., o cisalhamento vertical do vento geostrófico), efeitos associados à não estacionariedade do campo de pressão e a taxa de entranhamento no topo da $C L P^{11}$ podem afetar o desenvolvimento do JBN em Iperó.

Entre os padrões sinóticos que ocorrem sobre o Estado de São Paulo destacam-se quatro cenários básicos (1) padrão pré-frontal; (2) padrão frontal; (3) padrão com predomínio de altas pressões e (4) padrão com predomínio de baixas pressões (Figura 3.21).

Quando a circulação de escala sinótica está sob a influência do padrão pré-frontal predomina sobre a região do Estado de São Paulo advecção de ar quente do interior (Figura 3.21 a). O aquecimento antecede a chegada da frente-fria, aumentando o grandiente térmico na direção N-S. Isto acontece, conjuntamente com um aumento progressivo da pressão atmosférica que antecede a queda de pressão associada à passagem da frente-fria nos dias seguintes. O cenário pré-frontal é favorável ao desenvolvimento de circulações locais, provocadas pelos efeitos de aquecimento diferencial da superfície. JBNs aparecem comumente associados àpresença de terrenos inclinados encontrados junto a cadeias montanhosas com Andes, Rochosas, Himalaia etc.

\footnotetext{
10 É reconhecida a importância da baroclinia para o desenvolvimento de JBN noturnos intensos (com máxima velocidade típica de $26 \mathrm{~m} \mathrm{~s}^{-1}$ ) de SW sobre a Grande Planície dos EUA. Isto é, valores tão intensos são obtidos pelo efeito do termo de cisalhamento do vento geostrófico.

${ }^{11}$ Presença de mistura turbulenta junto ao topo da CLP, em geral associada ao cisalhamento do vento de escala sinótica e também ao fluxo turbulento de calor, gerado pelo aquecimento da superfície.
} 


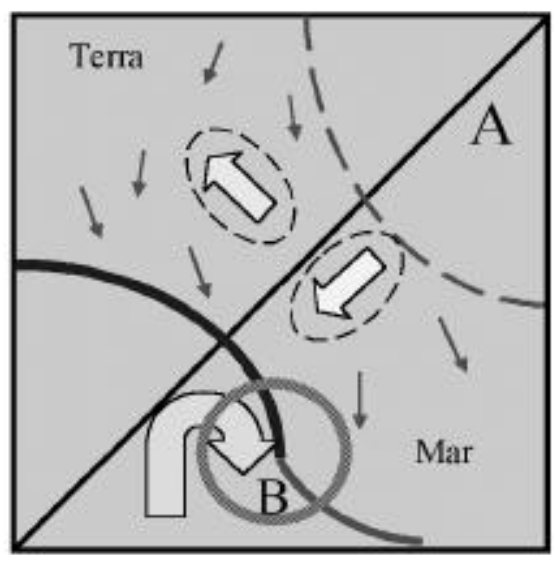

(a)

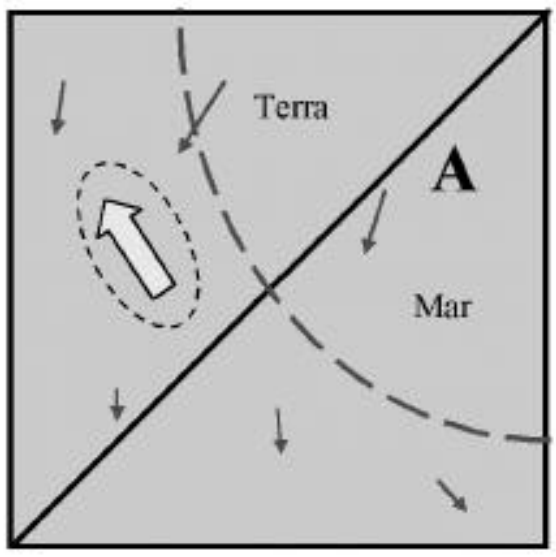

(c)

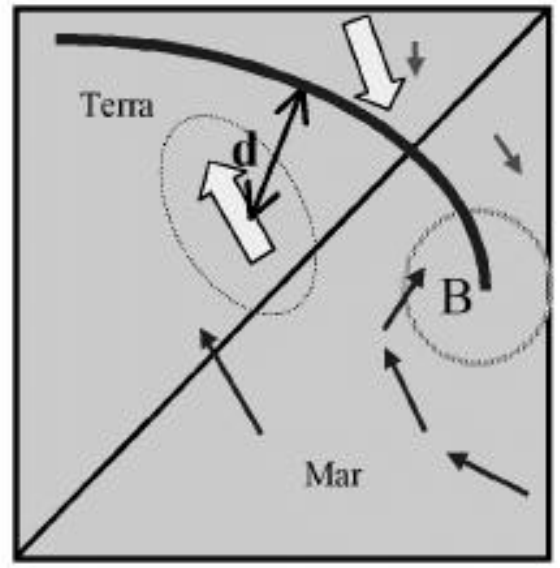

(b)

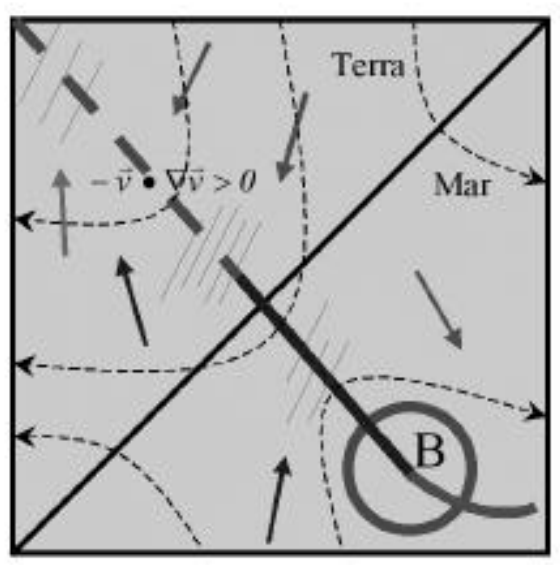

(d)

Figura 3.21 Quatro cenários de grande-escala hipotéticos: (a) pré-frontal; (b) frontal; (c) Alta do Atlântico (bloqueios) e (d) baixas pressões. A linha diagonal representa a linha-de-costa separando continente à esquerda e oceano Atlântico à direita. As setas maiores indicam JBN induzidos pelo ter reno inclinado (a) e (c) ou JBN frontais (b) e as flechas de linhas finas indicam a direção do vento à superfície.

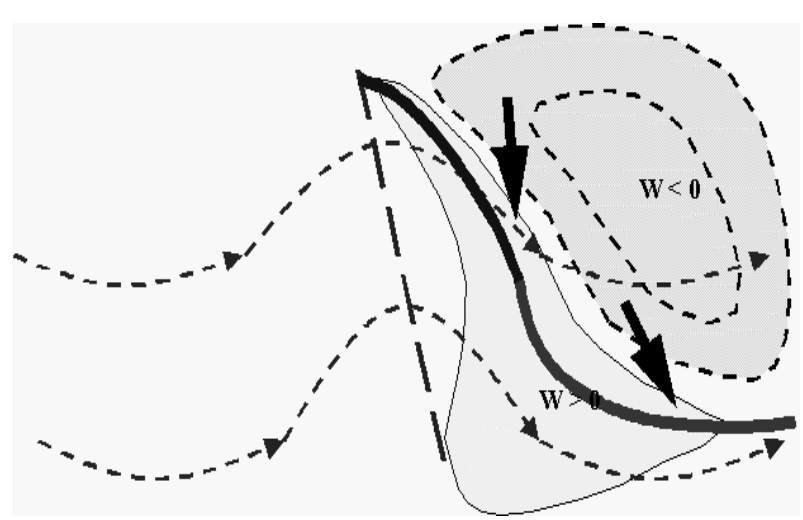

(a)

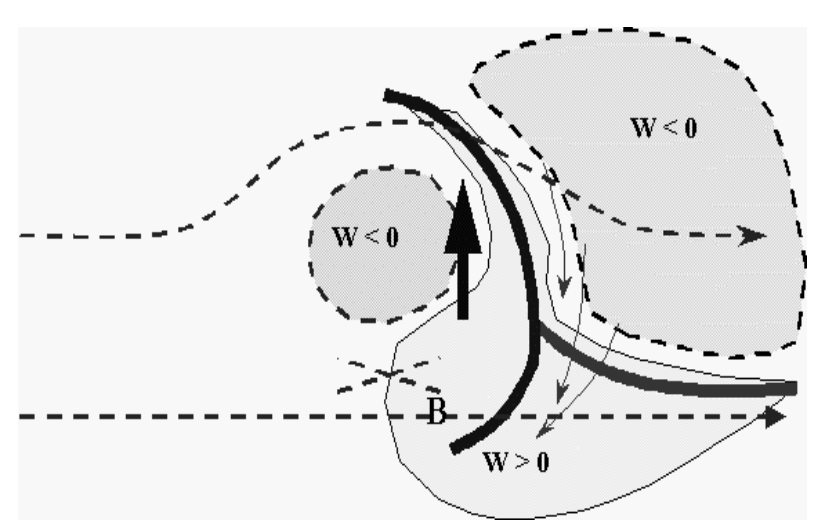

(b)

Figura 3.22 Representação de um desenvolvimento de uma frente-fria intensa implicando na formação de um jato frontal de direção Sul: (a) fase inicial do desenvolvimento mostrando o cavado em altitude favorável ao desenvolvimento do sistema e (b) sistema frontal plenamente desenvolvido (oclusão) associado à formação de uma circulação fechada na alta troposfera. As setas em negrito indicam o JBN. 
Quando a circulação é frontal (Figura 3.16 b), a estrutura de escoamento tridimensional do sistema baroclínico da frente-fria ocasiona jatos tanto de baixos níveis com de altos níveis na troposfera. Em baixos níveis, ocorrem os JBN frontais de NW adiante da frente-fria e de SE em sua retaguarda. ARRIT et alli (1997) e UCCELINNI (1980) apresentam evidências da associação dos JBN (frontais) com a presença de anomalias e variações temporais do campo de pressão na alta e baixa troposfera. Conceitualmente, a passagem de frentes-frias mais intensas no Estado de São Paulo compõe um quadro favorável à ocorrência de JBN frontais de componente Sul dentro da massa de ar polar (Figura 3.22).

O cenário de predomínio de altas pressões (Figura 3.21 c) ocorre durante situações de bloqueio sinótico, em que extensas áreas de alta pressão e anomalias positivas de temperatura ocorrem sobre o Brasil, impedindo que frentes-frias avancem em direção ao equador. Em geral, os bloqueios ocorrem em associação a intensificação do jato de altos níveis subtropical. Nestas condições, caracterizadas por intenso aquecimento da superfície e ventos fracos, também podem ocorrer JBN associados à circulações induzidas pelo aquecimento diferencial da superfície e por terrenos inclinados.

O cenário de predomínio de baixas pressões (Figura 3.21 d) ocorre durante verões em que Zona de convergência do Atlântico Sul (ZCAS) prevalesce sobre a região. Neste caso, tempestades convectivas são comuns e a região toda está sob influência de escoamentos convergentes. O detalhamento da estrutura espacial do escoamento, associado à áreas de precipitação, necessita de ferramentas específícicas (p.ex., RADAR), desde que diferentes escalas caracterizem o escoamento.

Os cenários mais favoráveis ao desenvolvimento dos JBN estudados neste trabalho são aqueles em que há predomínio de altas pressões (Figura 3.21 a e 3.21 c). Neste caso, o escoamento é caracterizado por um movimento vertical descendente pouco intenso (subsidência sinótica), pouca nebulosidade, desenvolvimento da CLP convectiva e ausência de forçantes sinóticas de maior importância para o escoamento (i.e., ventos fracos de escala sinótica).

Utilizaram-se dados sinóticos compilados pelo NCEP (KALNAY et al., 1996), disponíveis no IAG/USP, para determinar a evolução temporal dos perfis verticais das variáveis durante os períodos correspondentes æ̀̀ quatro campanhas em Iperó. As figuras apresentadas a seguir se referem somente a análise referente à Primeira Campanha em Iperó (Figuras 3.22 a 3.25). As variáveis mostradas são: (a) temperatura, (b) componente zonal do vento, (c) componente meridional do vento e (d) umidade relativa. Em termos gerais, os resultados obtidos para as demais campanhas confirmam os resultados que são destacados a seguir. As demais campanhas de final de verão não se diferenciam quanto à características básicas que são destacadas a seguir para a Primeira Campanha. Já a campanha de inverno (a terceira) diferencia-se por apresentar ventos 
superficiais moderados associados à passagem de frentes-frias e pelos ciclos diurnos estarem modulados por este escoamento sinótico.

A Primeira Campanha de observações em Iperó ocorreu entre 11 e 22 de março de 1991. O período caracterizou-se pela passagem de duas frentes frias, com seus respectivos períodos pré e pós-frontais. Durante os períodos pré-frontais observou-se predomínio de altas pressões. Embora tenham ocorrido nuvens e precipitação no período, a incidência de radiação solar à superfície manteve-se suficientemente intensa para provocar: (a) ciclos diurnos de aquecimento da superfície e (b) destacados desenvolvimentos da CLP convectiva.

O campo térmico apresentado na Figura 3.22 mostra oscilações de período 24 h (destacadas na Figura 3.22 b) associadas ao ciclo diurno na CLP. A amplitude da oscilação diminui com a altura. Este fato indica que a forçante desta oscilação está na superfície. Existe uma oscilação de período mais longo (sinótico) aparente na evolução temporal. São 2 períodos apresentando tendência de aquecimento, sendo que ambos antecederam a entrada de frentes-frias. Durante a passagem das frentes, a temperatura sofreu uma ligeira queda.

A evolução dos perfis da componente zonal do vento é apresentada na Figura 3.24. Observam-se também ciclos diurnos da componente zonal, ventos de $\mathrm{W}$ à tarde e ventos de $\mathrm{E}$ à noite.

A evolução temporal da estrutura da componente meridional (Figura 3.25) também apresenta ciclos diurnos com ventos de $\mathrm{N}$ àtarde e ventos de $\mathrm{S}$ ànoite. $\mathrm{A}$ amplitude destes ciclos é maior nos períodos pré-frontais (entre dias 9 e 15 e entre 17 e 21 de março). Os ciclos diurnos de u e v estendem-se na vertical por uma profundidade comparável a altura da CLP. Durante a passagem frontal, a componente zonal mostra-se de Leste e a componente meridional de Sul. Neste caso, embora a componente zonal mantenha-se negativa e a meridional positiva, a amplitude delas permanece oscilando, mas não o suficiente para mudar o sinal da componente (zonal de E para W e meridional de $\mathrm{S}$ para $\mathrm{N}$ ), como ocorre nos períodos pré-frontais.

Essas oscilações mostram-se persistentes no tempo e se esvaecem com a altura, indicando que suas forçantes encontram-se na superfície (i.e., como a fonte de calor do fluxo turbulento de calor sensível e sua distribuição espacial associada aos tipos de superfície, as forçantes topográficas, etc).

Os JBN observados durante as noites das campanhas em Iperó, pela utilização de balãocativo lançado e recolhido tipicamente a cada hora, não aparecem nos dados de grande-escala da reanálise do NCEP-NCAR. Isto é uma conseqüência da baixa resolução temporal dos dados da reanálise, o que não permite capturar o aparecimento, desenvolvimento, sustentação dos JBNs no interior paulista. Considerando-se que os perfis da reanálise são construídos para a região de São 
Paulo com sondagens lançadas apenas uma vez ao dia à 9 h (12 h GMT), isto é, no início do período convectico, não se espera que os dados apresentem nada além de indícios da presença do JBN noturno, que para o horário da sondagem já deve mostrar-se descaracterizado pela mistura turbulenta do período convectivo.

Por outro lado, a reanálise assimila os dados de superfície e as sondagens de forma integrada em um modelo global, implicando que os ciclos de aquecimento e resfriamento da superfície são mostrados - como poderá ser notado na Figura 3.23. Mesmo assim, os JBN de Iperó que apresentam o máximo de velocidade tipicamente entre 200 e 600 m não se mostram nos dados da reanálise. Portanto, ou os JBN são fenômenos locais ou eles não podem ser capturados de forma realística pelo conjunto de dados do NCEP na atual resolução temporal de $6 \mathrm{~h}$ e espacial de $250 \mathrm{~km}$.

Durante os períodos pré-frontais, o sinal das componentes zonal do vento em $750 \mathrm{hPa}$ tende a acompanhar o sinal dessas componentes na alta troposfera correspondente a região de entrada do JAN (entre dias 13 e 15 e entre 19 e 21 na Figura 3.24). Isto mostra que durante os períodos préfrontais, associados a presença de JAN, o acoplamento entre os escoamentos nabaixa e alta troposfera é maior. Desde que o entranhamento junto ao topo da CLP é responsável por esse acoplamento, isso pode indicar que a taxa de entranhamento é maior nos períodos pré-frontais devido à presença de alguma turbulência adicional nos níveis médios da troposfera associada ao JAN.

O ciclo diurno também aparece na evolução dos perfis de umidade relativa (Figura 3.26). A linha de contorno de umidade relativa igual a 70\% fornece uma indicação da altura da CLP durante o período. Em relação à precipitações diárias acumuladas ( 14-18 mm, que são valores pequenos) nos dias 12, 18 e 20 de março de 1991 ocorre um aprofundamento da camada com umidade acima de $90 \%$. As precipitações iniciam um período de aumento da profundidade da camada úmida, que praticamente dobra sua extensão vertical. O topo médio da camada úmida pode ser localizado entre 900-920 hPa.

A presença dos ciclos diurnos nos dados de grande-escala é mais um indício que é favorável à hipótese de que a topografia inclinada do Estado tem um papel importante na definição das circulações observadas na CLP de Iperó e na formação de JBN sobre o Planalto Paulista. Neste caso, os ciclos das componentes zonal e meridional de grande-escala para a posição Iperó permitem contruir curvas hodógrafas elípticas indicando a presença de forçantes outras que a oscilação inercial pura. Entre essas forçantes pode-se listar os efeitos de aquecimento diferencial associados à brisa marítima e àtopografia inclinada do interior de SP.

No capítulo seguinte apresentam-se outras evidências de que os JBNs em Iperó são uma resposta complexa da CLP, dependente da interação de diferentes escalas topográficas e tipos de 
superfície. Os JBNs não podem assim ser explicados somente da consideração de fatores locais, emboram dependam deles.

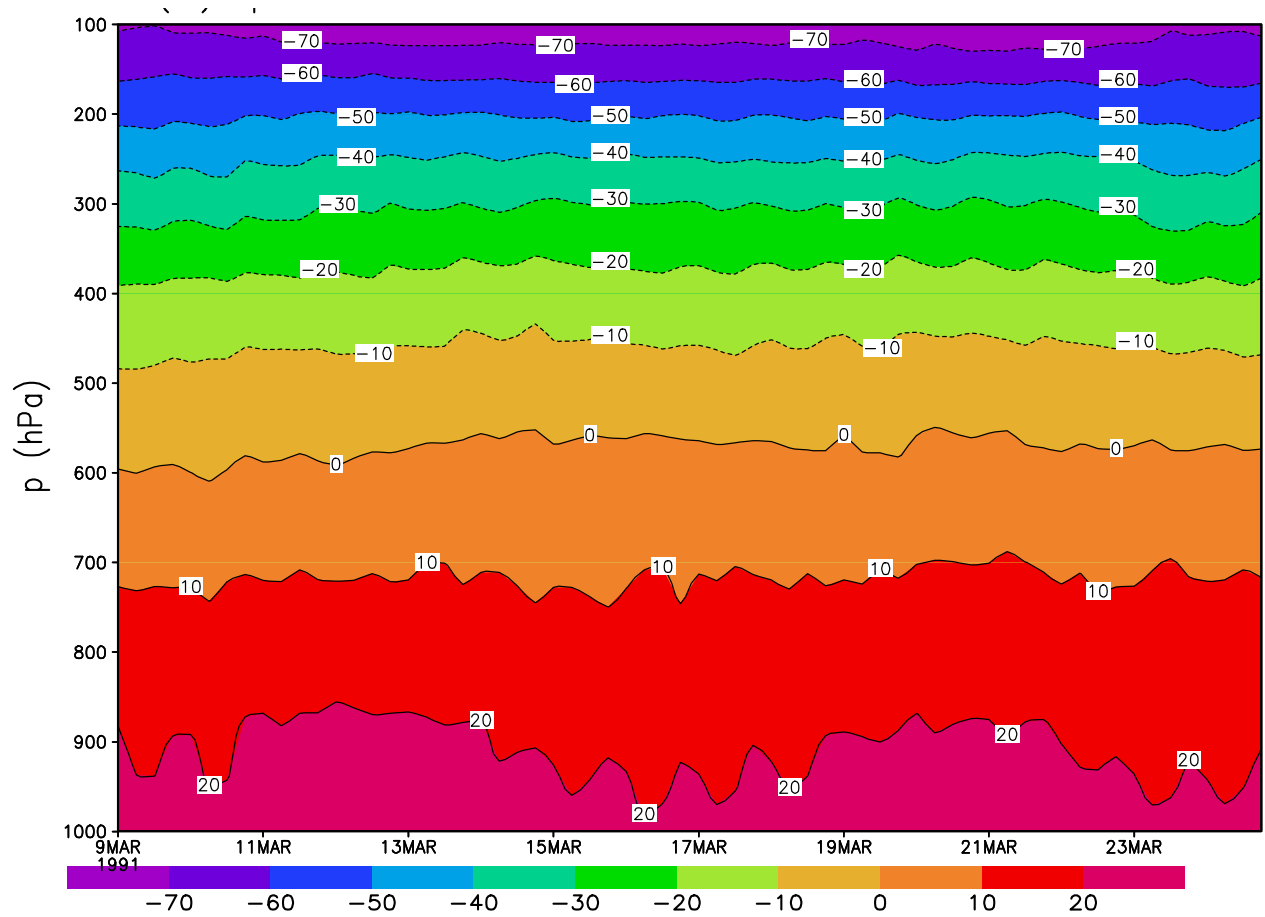

(a)

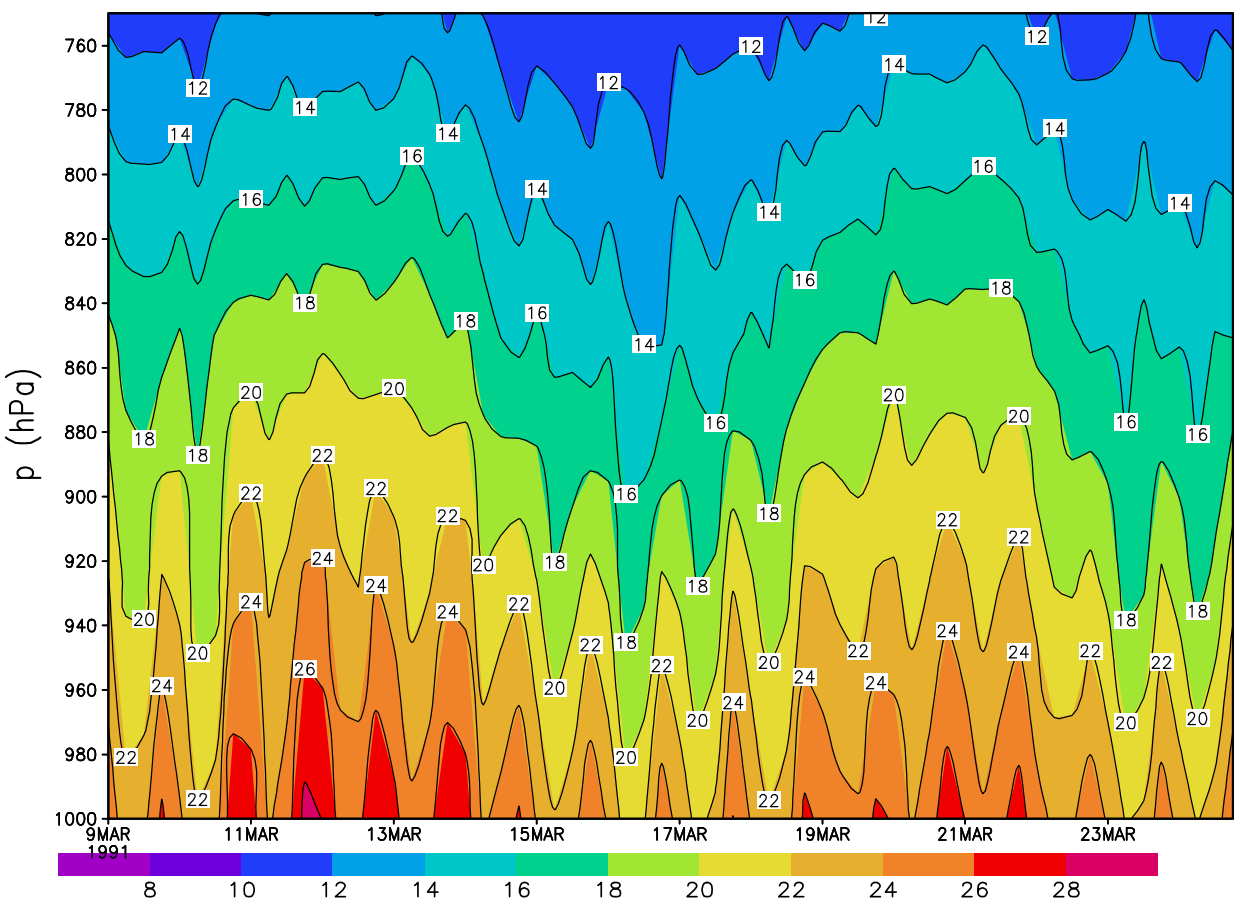

(b)

Figura 3.23 (a) Evolução temporal do perfil vertical da temperatura do ar $\left({ }^{\circ} \mathrm{C}\right)$ para a primeira campanha do experimento micrometeorológico em Iperó - SP - entre 11/03/1993 e 22/03/1993. Detalhes entre $1000 \mathrm{hPa}$ e $100 \mathrm{hPa}$. Fonte de dados: reanálise do NCEP; (b) Detalhe do mesmo gráfico entre $1000 \mathrm{hPa}$ e $700 \mathrm{hPa}$. 


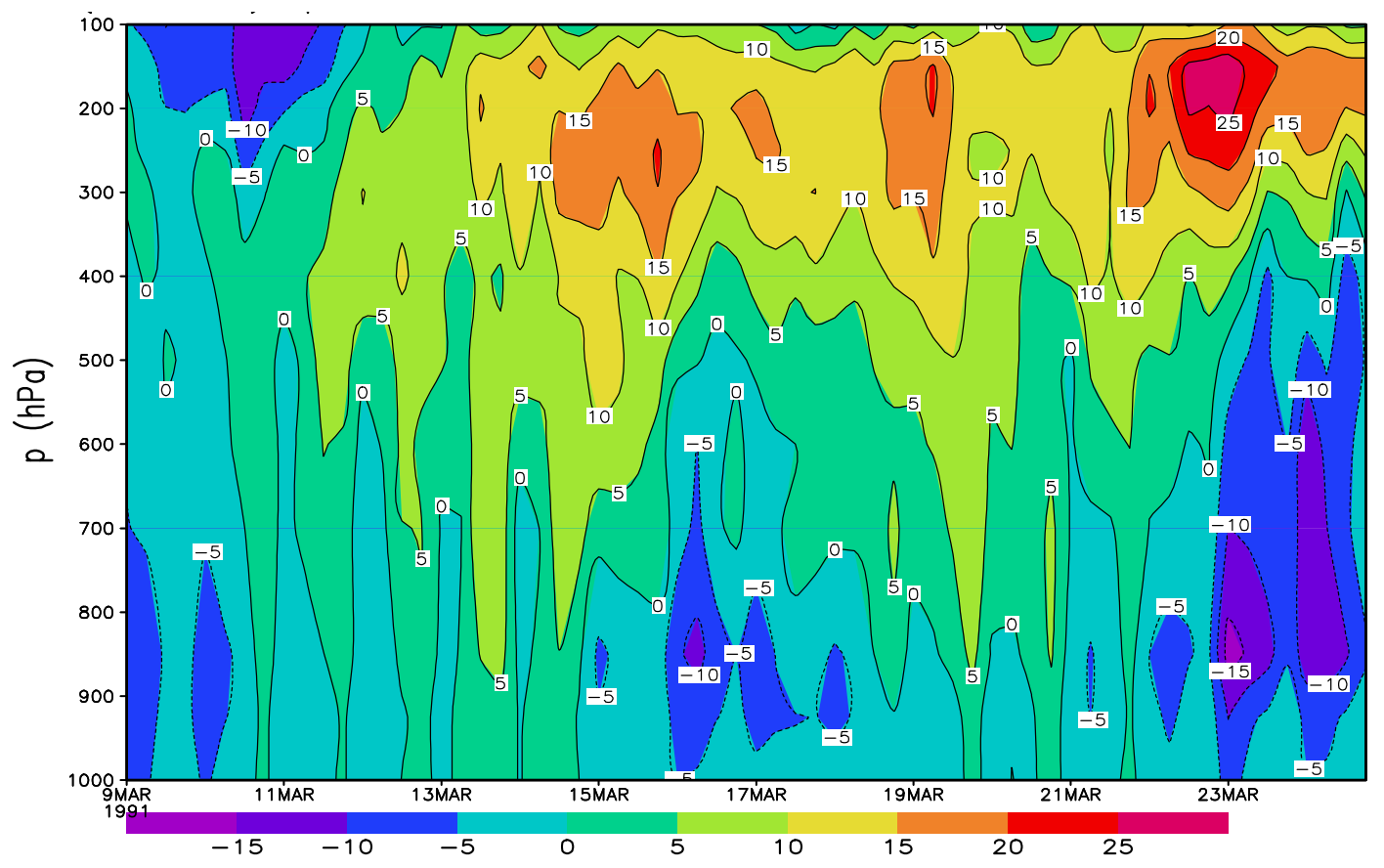

(a)

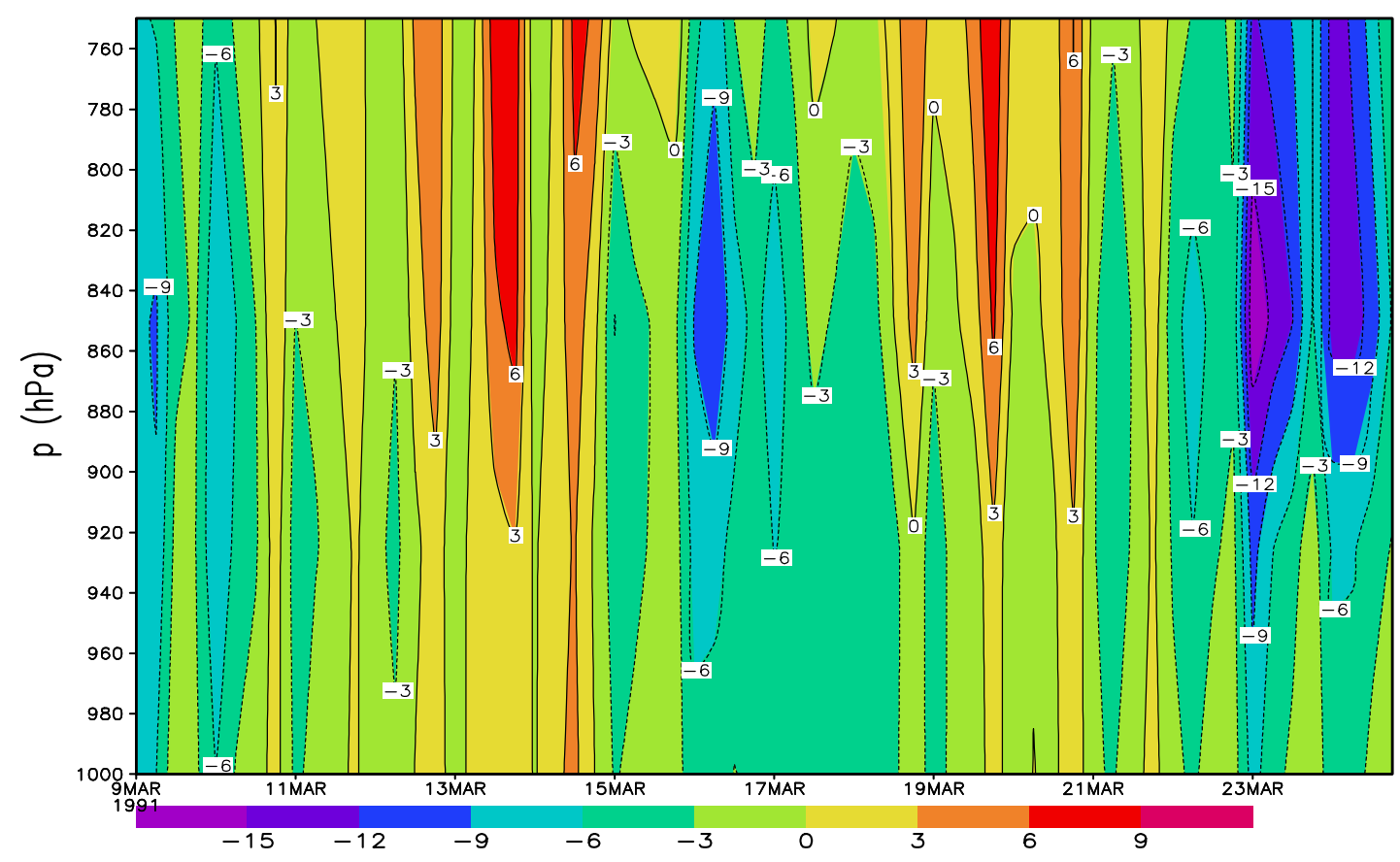

(b)

Figura 3.24 (a) Evolução temporal do perfil vertical da componente zonal do vento $\left(\mathrm{m} \mathrm{s}^{-1}\right)$ para a primeira campanha do experimento micrometeorológico em Iperó - SP - entre 11/03/1993 e 22/03/1993. Detalhes entre $1000 \mathrm{hPa}$ e $100 \mathrm{hPa}$. Fonte de dados: reanálise do NCEP ; (b) Detalhe do mesmo gráfico entre 1000 $\mathrm{hPa}$ e $700 \mathrm{hPa}$. 


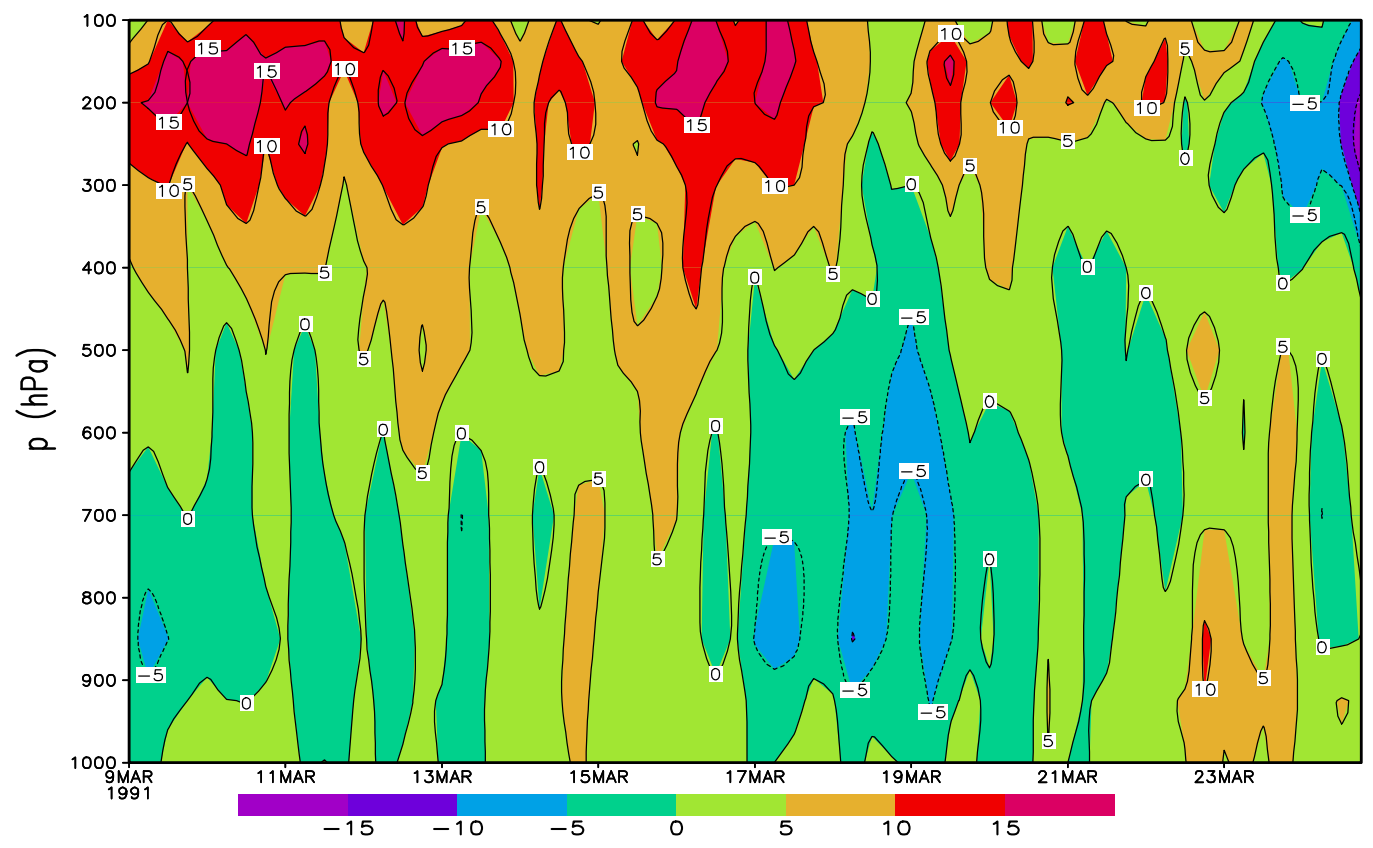

(a)

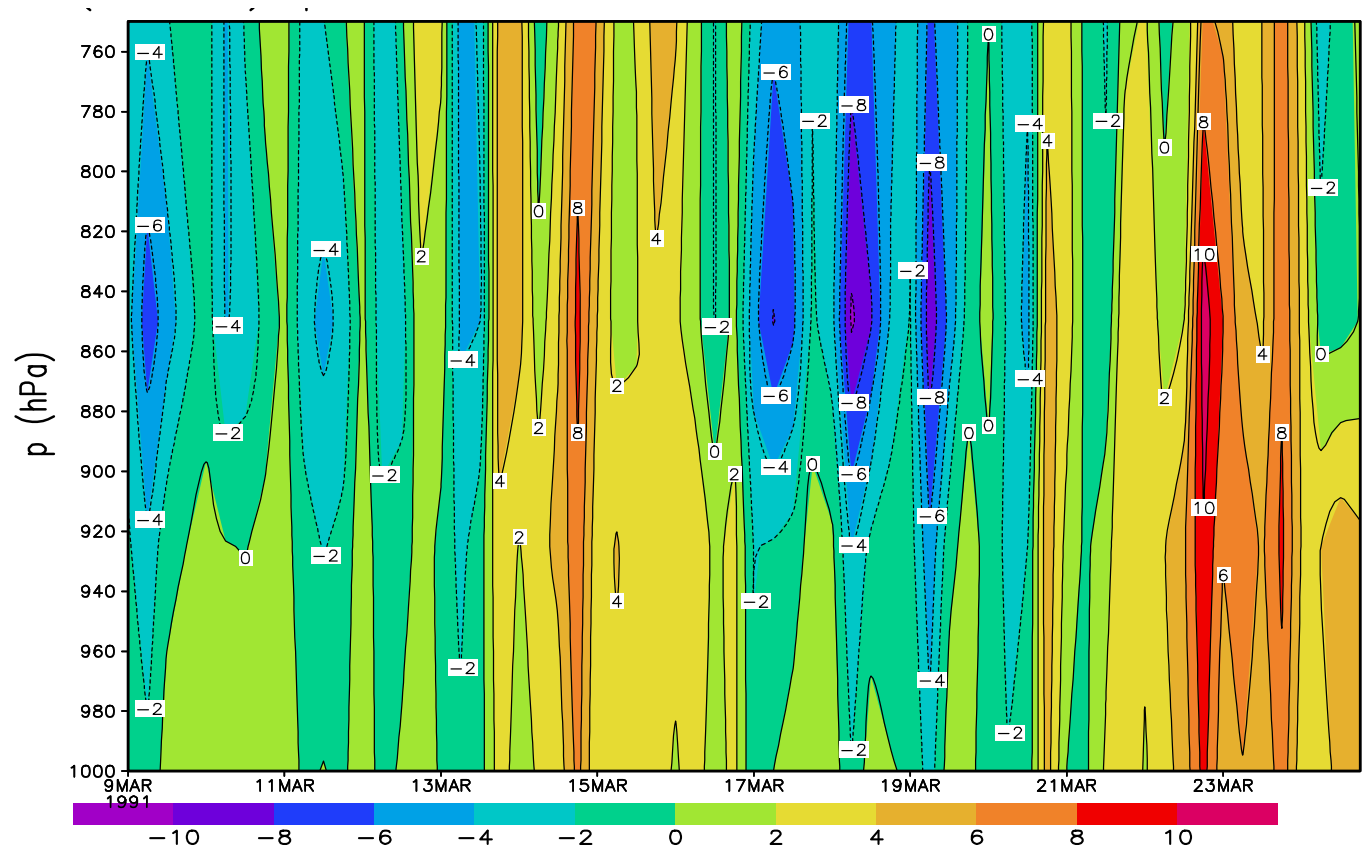

(b)

Figura 3.25 (a) Evolução temporal do perfil vertical da componente meridional do vento $\left(\mathrm{m} \mathrm{s}^{-1}\right)$ para a primeira campanha do experimento micrometeorológico em Iperó - SP - entre 11/03/1993 e 22/03/1993. Detalhes entre $1000 \mathrm{hPa}$ e $100 \mathrm{hPa}$. Fonte de dados: reanálise do NCEP; (b) Detalhe do mesmo gráfico entre $1000 \mathrm{hPa}$ e $700 \mathrm{hPa}$. 


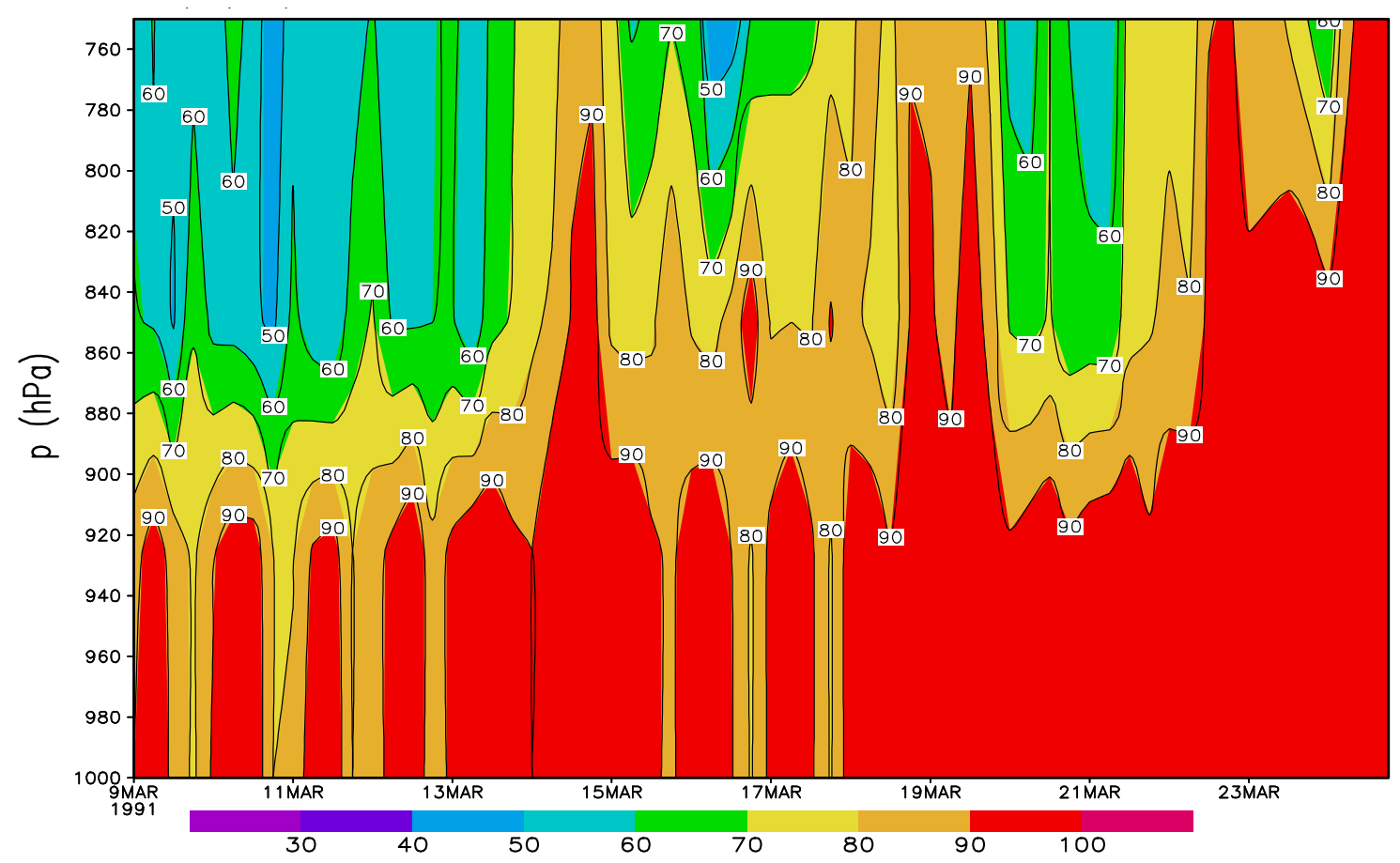

Figura 3.26 Evolução temporal do perfil vertical de umidade relativa do ar (\%) para a primeira campanha do experimento micrometeorológico em Iperó - SP - entre 11/03/1993 e 22/03/1993, entre 1000 hPa e 700 hPa. 


\section{Capítulo 4}

\section{Resultados Numéricos}

Neste capítulo investiga-se o JBN de Iperó do ponto de vista numérico. Para isso, o modelo TVM não-hidrostático foi utilizado para gerar uma série de simulações empregando diferentes domínios horizontais caracterizados por diferentes resoluções ${ }^{1}$.

A Tabela 4.1 lista as quatro simulações escolhidas para apresentar o efeito do domínio horizontal sobre a formação, desenvolvimento e sustentação do JBN durante a noite no interior do Estado de São Paulo. A resolução horizontal utilizada foi variada entre 2 e $30 \mathrm{~km}$, respectivamente para domínios horizontais entre $100 \mathrm{~km}$ e $1500 \mathrm{~km}$.

A discretização da grade na vertical é mantida a mesma para todas as simulações. Um total de 25 pontos foi utilizado na discretização vertical, correspondentes às seguintes posições coordenadas: $0 ; 30 ; 67 ; 114 ; 172 ; 246 ; 337 ; 452 ; 595 ; 774 ; 997 ; 1276 ; 1626 ; 2062 ; 2608 ; 3290$; $4143 ; 5209 ; 6409 ; 7609 ; 8809 ; 10.009 ; 11.209 ; 12.409 ; 13.609$. A resolução vertical varia de forma logarítmica (KARAM, 1995) sendo igual a 30 m junto à superfície e 1200 m para o topo do modelo.

As quatro resoluções horizontais diferentes foram utilizadas com o objetivo de identificar e quantificar o efeito da inclusão de diferentes escalas da topografia. Por exemplo, o ensaio experimental chamado L1500 utiliza baixa resolução horizontal e abrange uma extensa área do Sudeste, Centro-Oeste e Sul do Brasil, o que permite simular os efeitos da superfície regional sobre o escoamento na CLP. Já o ensaio numérico L100 apresentando resolução horizontal relativamente maior (i.e., $2 \mathrm{~km}$ ) permite simular efeitos da topografia local, como os efeitos associados ao Morro de Araçoiaba - uma elevação topográfica destacada na paisagem do vale do Rio Sorocaba localizado $5 \mathrm{~km}$ à Sudoeste do CEA, em Iperó. Nesta simulação devido à limitada extensão horizontal do domínio $(100 \mathrm{~km})$ o escoamento obtido não pode representar o efeito da topografia de

\footnotetext{
${ }^{1}$ O modelo TVM permite a utilização de grades com espaçamento horizontal variável. Este tipo de grade também tem sido empregada no grupo de micrometeorologia do IAG-USP para obter escoamentos que envolvem resolução múltipla, de forma similar ao que é feito em modelos que utilizam aninhamento de grades (i.e., 2, 3, ..., n grades). A principal vantagem da utilização de grades com resolução variável em relação à técnica de aninhamento é que a transferência especial de valores da grade de maior resolução para a grade de menor resolução não ser necessária, desde que a grade variável é única. No caso de grades aninhadas, a transferência é geralmente feita por interpolação. Outra vantagem é o fato da informação ser transferida diretamente entre as escalas de resolução - da maior para a menor e da menor para a maior - o que define um protocolo de transferência two-way de forma direta (i.e., como numa rua de mão-dupla). Uma desvantagem da grade de resolução variável é que o erro de truncamento também é variável (mas limitado).
} 
escala regional $(1500 \mathrm{~km})$. Assim, as diferentes simulações devem ser consideradas como complementares. A apresentação e discussão do conjunto das quatro simulações com domínios horizontais diferentes compõem um quadro geral dos efeitos da topografia e da cobertura superficial sobre o escoamento local e regional. Mostra-se que a extensão do domínio tem um efeito sobre o JBN de Iperó simulado.

\begin{tabular}{|c|c|c|c|}
\hline Nome da Simulação & Domínio horizontal & Resolução horizontal & Resolução vertical \\
\hline L100 & $100 \mathrm{~km} \times 100 \mathrm{~km}$ & $2 \mathrm{~km} \times 2 \mathrm{~km}$ & \multirow{2}{*}{$\begin{array}{c}\text { Variável entre mínimo de } 30 \\
\text { m e máximo de } 1200 \mathrm{~m}\end{array}$} \\
\hline L400 & $400 \mathrm{~km} \times 400 \mathrm{~km}$ & $4 \mathrm{~km} \times 4 \mathrm{~km}$ & \\
\hline L1500 & $800 \mathrm{~km} \times 800 \mathrm{~km}$ & $8 \mathrm{~km} \times 8 \mathrm{~km}$ & \\
\hline
\end{tabular}

Tabela 4.1 Domínio e resolução utilizada nas simulações do JBN de Iperó. O ponto central da grade numérica corresponde à posição geográfica de Iperó. Número de pontos de grade 50 x 50 x 25 .

Diversos pesquisadores (ORLANSKI, 1975; FAST e McCORCLE, 1990; ZHONG et alli, 1996) têm mostrado que a extensão do domínio horizontal constitui-se fator muito importante para o entendimento das circulações do vento na CLP, i.e., a extensão do domínio define as escalas da topografia que serão incorporadas como condição de contorno do problema, podendo modificar a dinâmica das forças envolvidas no escoamento resultante. Neste caso, os parâmetros adimensionais que controlam o escoamento são o Raio de Deformação de ROSSBY e os Números de FROUDE horizontal e vertical (ADRIAN, 1995). Também nos Estudos de Impacto Ambiental a definição da extensão do domínio a ser considerado constitui-se uma etapa inicial importante (CTMSP, 1997).

Uma das características mais importantes e que, muitas vezes, não é levada em conta em modelos de simulação de área limitada é o posicionamento simétrico da grade horizontal em relação ao ponto geográfico de interesse - que neste trabalho é o CEA em Iperó. Isto é importante porque a presença assimétrica das topografias em relação ao foco de estudo, na simulação pode gerar forças de gradiente de pressão associadas a escoamentos não observáveis ${ }^{2}$. Muitas vezes, porções da topografia excluídas da área de simulação poderiam compensar as acelerações induzidas por topografias incluídas de forma não apropriada (PIELKE, 1984).

\footnotetext{
${ }^{2}$ Nota - O ideal neste caso seria a utilização de um domínio horizontal circular, que não é prático.
} 
A razão entre as resoluções vertical e horizontal $(\Delta \mathrm{z} / \Delta \mathrm{x})$ permaneceu entre 1:1000 e 1:100. A ordem de grandeza destes valores é comum em simulações de mesoescala ${ }^{3}$, caracterizando escoamentos em que o gradiente vertical das variáveis é muito maior que o gradiente horizontal. A estabilidade da solução numérica que utiliza maior resolução foi controlada através de um pequeno aumento da resolução temporal (de $90 \mathrm{~s}$ para $60 \mathrm{~s}$ ).

\subsection{Escoamento à Superfície}

Apresenta-se nesta seção resultados numéricos que permitem discutir o papel da extensão horizontal do domínio da simulação sobre o escoamento à superfície, na região caracterizada por terreno complexo, tanto do ponto de vista da topografia, bastante acidentada, como da ocupação humana e dos tipos de superfície (água, florestas, plantações, campos etc).

\subsubsection{Simulação L100}

A simulação L100 com domínio de extensão $100 \mathrm{~km}$ e resolução $2 \mathrm{~km}$ mostra o efeito de topografia local (vales e montanhas) controlando o escoamento superficial. À noite, canalizações e bloqueios do escoamento são muito pronunciados. O morro de Araçoiaba da Serra com elevação de média de $400 \mathrm{~m}$ acima do nível médio da planície do Rio Sorocaba (a $550 \mathrm{~m}$ ) para Iperó é suficientemente elevado e largo para bifurcar o escoamento catabático que desce as áreas mais elevadas correspondentes os topos da escarpa da Serra do Mar, em seu lado Noroeste, para o interior (Figura 4.1).

Durante o período noturno (período diurno) ocorre divergência (convergência) sobre as áreas mais elevadas do terreno, indicando a presença de ventos catabáticos à noite e anabáticos durante o dia (Figura 4.1).

Ainda durante a noite, áreas de maior aceleração do escoamento, resultando em isotacas ${ }^{4}$ mais intensas, aparecem junto æ̀ encostas com aclives acentuados e também devido ao efeito que as

\footnotetext{
${ }^{3}$ Nota - A razão $\Delta \mathrm{z} / \Delta \mathrm{x}$ utilizada em modelos do tipo LES da ordem de 1:1.

${ }^{4}$ Nota - Curvas de mesmo valor de velocidade do vento.
} 
feições topográficas convexas sobre o escoamento de drenagem (catabático) que desce para a região da Depressão Periférica, onde se localiza o vale do Rio Sorocaba (Figura 4.1). Desta forma, a forma convexa da Depressão Periférica contribui para que os ventos sejam muito fracos durante o dia em seu interior (i.e., Sorocaba está em uma área do interior paulista conhecida por sua temperatura e fraco vento). Por outro lado, a topográfica da região induz aceleração do escoamento através dos vales dos rios Sorocaba e Tietê durante a noite.

Apesar dessa aceleração gerar ventos de SE que atingem extensas áreas (25 km por $50 \mathrm{~km}$ ) (Figura 4.1 b), apresenta na simulação uma extensão vertical limitada pela altura da CLP estável durante a noite.

Do ponto de vista da formação do JBN, o escoamento catabático contribui para o desenvolvimento de um escoamento de SE, que corresponde qualitativamente ao observado na base do JBN em Iperó. Portanto, a corrente de drenagem pode ser considerada um elemento importante na definição das condições de fronteira inferior necessária ao desenvolvimento do JBN de Iperó; notadamente, um jato que apresente cisalhamento direcional (SE em superfície e NE no nível de $600 \mathrm{~m})$.

Do ponto de vista da produção de turbulência na CLP estável, a deformação horizontal do campo de escoamento durante a noite, e o correspondente cisalhamento horizontal e vertical associados à feições topográficas mais destacadas, como é o Morro de Araçoiaba, pode alterar a distribuição de ECT na região de Iperó (PEREIRA, KARAM e OLIVEIRA, 2000; 2001).

Do ponto de vista da dispersão de poluentes são notáveis as implicações, principalmente o aumento da dispersão noturna associada ao cisalhamento horizontal e vertical do escoamento. Do ponto de vista operacional, a utilização de modelos baseados na teoria de pluma gaussiana, utilizando-se dados de vento extrapolados de forma simples para pontos distantes das estações de observação mostra-se inapropriada, para a área do interior paulista, devido à complexidade dos efeitos da superfície e topografia sobre o escoamento. 
(a) Simulação à $18 \mathrm{~h}$

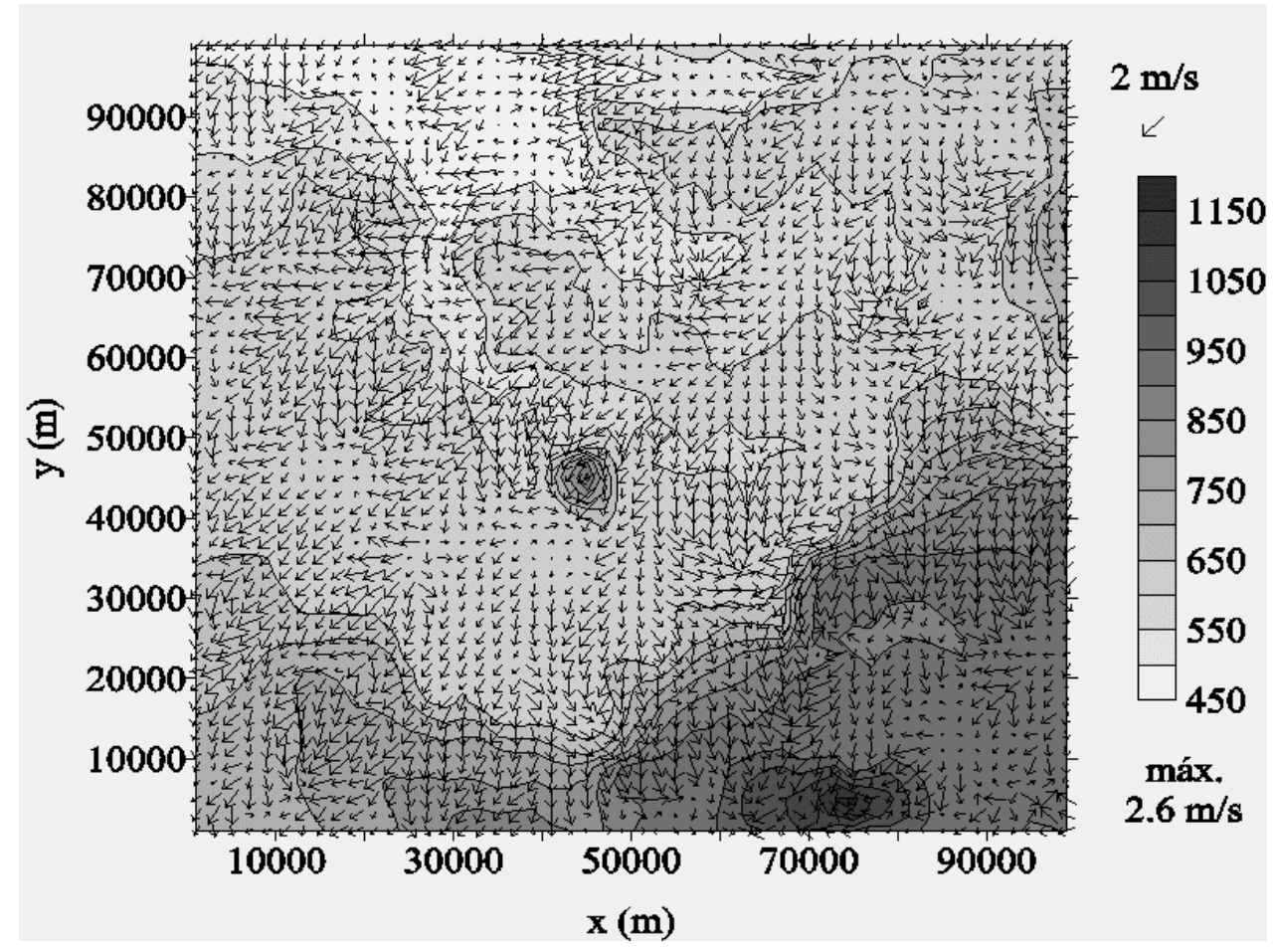

(b) Simulação às $06 \mathrm{~h}$

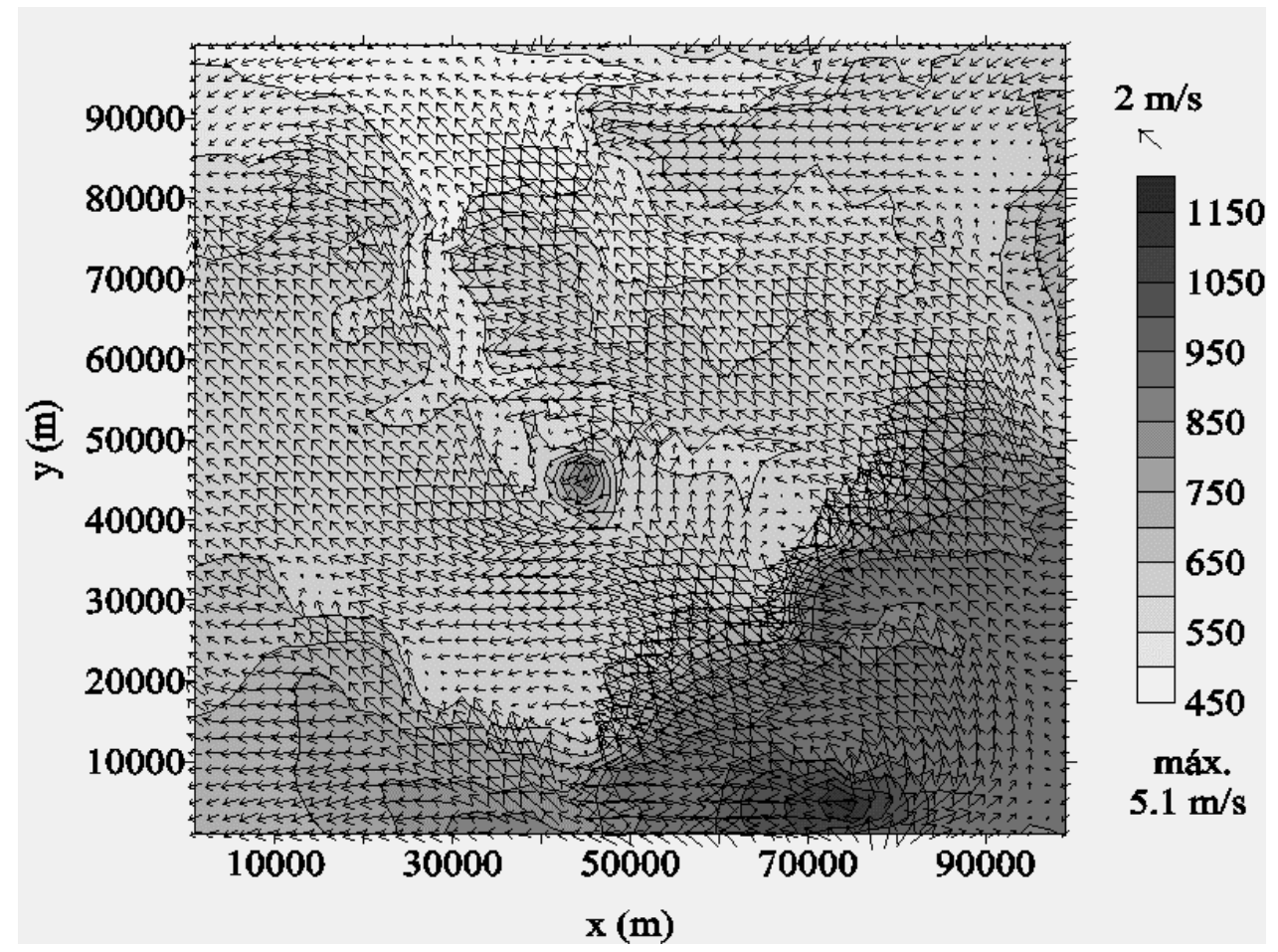

Figura 4.1 Campo de vento horizontal a $15 \mathrm{~m}$ acima da superfície: (a) à $18 \mathrm{~h}$ (12 h de simulação) e (b) às 06 h (24 h de simulação). A topografia é indicada pelos contornos e escala de cinzas. Iperó corresponde ao ponto central do domínio de $100 \mathrm{~km}$ por $100 \mathrm{~km}$ (da simulação L100). 


\subsubsection{Simulação L400}

A simulação no domínio de extensão 400 km e resolução de 4 km (Figura 4.2) confirma em linhas gerais as feições mais importantes do escoamento obtido na simulação de área mais limitada, i.e., $100 \mathrm{~km}$ (simulação L100). Mas adicionalmente, incorpora superfícies e topografias não descritas na simulação anterior, especialmente o contraste superficial entre continente e oceano.

O escoamento resultante na simulação L400 mostra a presença de:

- Brisa marítima durante o período diurno (i.e., convectivo), que ascende pela encosta íngreme da Serra do Mar e atinge privilegiadamente o Platô (relativamente mais baixo) onde se encontra a Grande São Paulo;

- Durante o período convectivo, o escoamento na região da Depressão Periférica é muito fraco a superfície, sendo predominantemente anabático na ausência de forçantes externas;

- Durante o período noturno, o escoamento catabático na região da Depressão Periférica é mais importante, definindo um escoamento de Sudeste ao longo de toda a Depressão Periférica. Neste caso, ventos de SE aparecem especialmente na região de Sorocaba e Iperó (Figura 4.2 b);

- Brisa terrestre é muito mais fraca que a brisa marítima simulada, sendo mais importante na área de restinga do Vale do Ribeira de Iguape e também diretamente sobre as encostas íngremes da escarpa da Serra do Mar. Neste caso, o escoamento da brisa marítima de Sudeste/Nordeste, gerado no período convectivo, é significativamente enfraquecido pela forçante de pressão associada àbrisa terrestre;

- Esta simulação não mostra evidência de que a brisa marítima penetre na região de Sorocaba e Iperó, parecendo ser bloqueada em superfície pelo terreno mais elevado da Escarpa da Serra do Mar, que possuem mais altitude que o Platô de São Paulo;

- O escoamento a superfície de direção SE na região sorocabana parece estar associado ao vento catabático que desce a encosta inclinada a partir dos cimos da Serra do Mar em direção ao interior para Noroeste;

- Isto não quer dizer que a brisa não afete a estrutura vertical do escoamento em Iperó, apenas que pela superfície a brisa pode ser bloqueada pela topografia da Serra do Mar, na ausência de forçantes externas de grande-escala mais favoráveis a advecção da frente da brisa, desde 
o litoral até o interior. De acordo com INNOCENTINI (1981), estudos de sensibilidade da brisa têm indicado o papel importante da advecção térmica para que a brisa propague em direção ao interior. Como na simulação mostrada (L400) não há forçante externa a propagação da brisa em direção ao interior é muito limitada (e também bloqueada pela topografia da Serra do Mar).

\subsubsection{Simulação L800}

Com domínio de extensão $800 \mathrm{~km}$ por 800 km essa simulação mostra um destacado controle da temperatura média diurna decorrente da variação da altitude da topografia (Figura 4.3). O relevo da região à volta de Iperó nesta escala mostra-se muito acidentado, destacando-se as feições direcionais dos acidentes geográficos como da Serra do Mar, que se alinha de SW para NE (Figura 4.3).

Durante o período convectivo (Figura 4.4 a) a circulação associada àbrisa marítima domina o escoamento em superfície ao longo da escarpa da Serra do Mar, atingindo os terrenos mais elevados, cerca de $50 \mathrm{~km}$ para noroeste da linha do litoral. Além dessa posição, no interior de SP, o regime de escoamento passa a ser caracterizado por ventos anabáticos associados ao efeito térmico da topografia local e regional.

Junto as Serras de Botucatu e São Carlos aparecem acelerações anabáticas do escoamento junto à cuestas ${ }^{6}$, juntamente do lado onde o aclive é maior. Durante o período convectivo, o vale do Rio Tietê aparece como uma área de divergência do escoamento.

Os terrenos elevados da Serra Geral do Paraná, onde se localiza Curitiba, mostram-se mais afetados pela brisa marítima devido à entrada da frente-de-brisa tanto pelo vale do Rio Ribeira de Iguape, ànordeste do pla tô curitibano, como pela entrada à leste pela escarpa da Serra do Mar do Paraná. Note-se que o vale do Rio Ribeira tem um papel de caminho topográfico natural para a entrada do ar marítimo desde o litoral paulista até a parte oriental do platô da Serra Geral no Paraná.

\footnotetext{
${ }^{5}$ Nota - A cidade de São Paulo localiza-se um Platô que é semicircunscrito por montanhas da Serra da Cantareira ao Norte, cimos da Serra do Mar à Sudoeste, por exemplo, em Itapecerica da Serra, e ao Nordeste, junto a Salesópolis e à nascente do Rio Tietê.

${ }^{6}$ Nota - As cuestas são morros elevados apresentando declive suave no flanco que é voltado para o interior.
} 
(a) Simulação à $18 \mathrm{~h}$

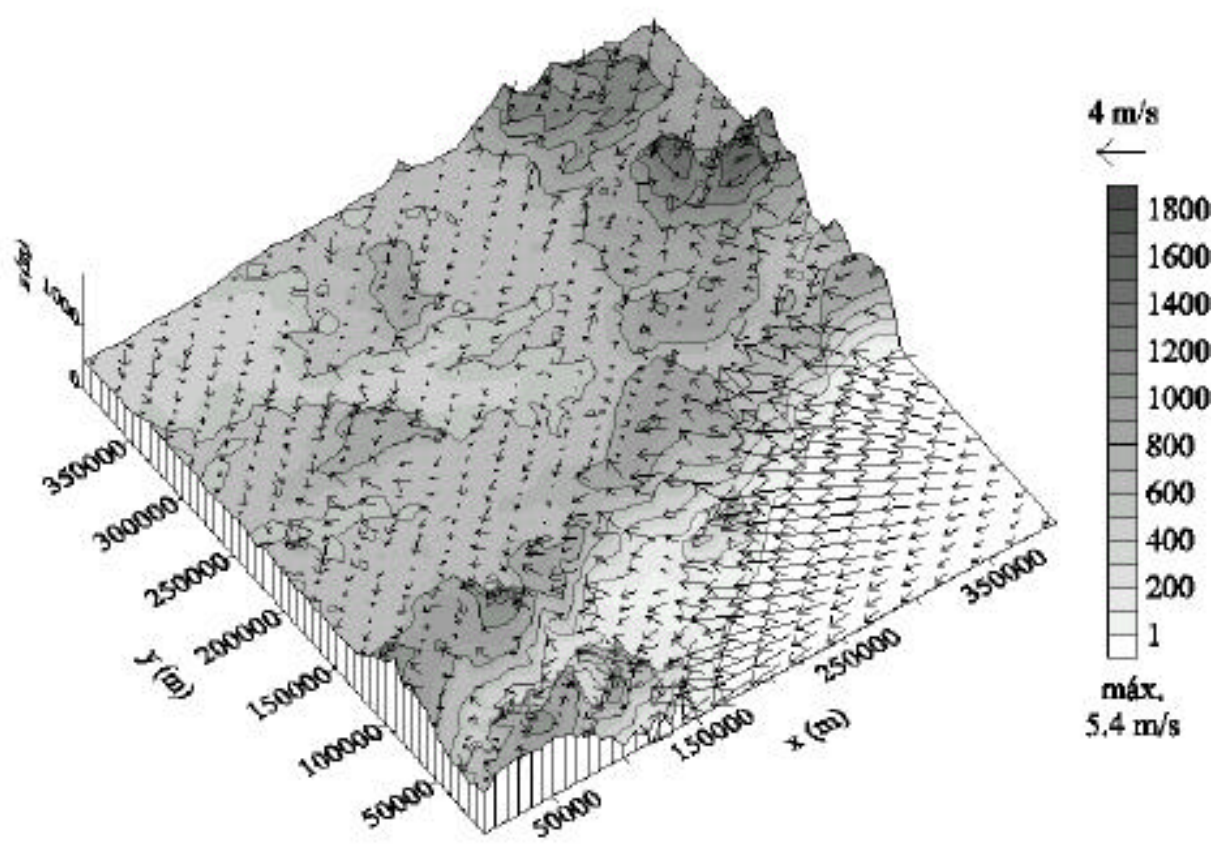

(b) Simulação æ̀̀ $6 \mathrm{~h}$

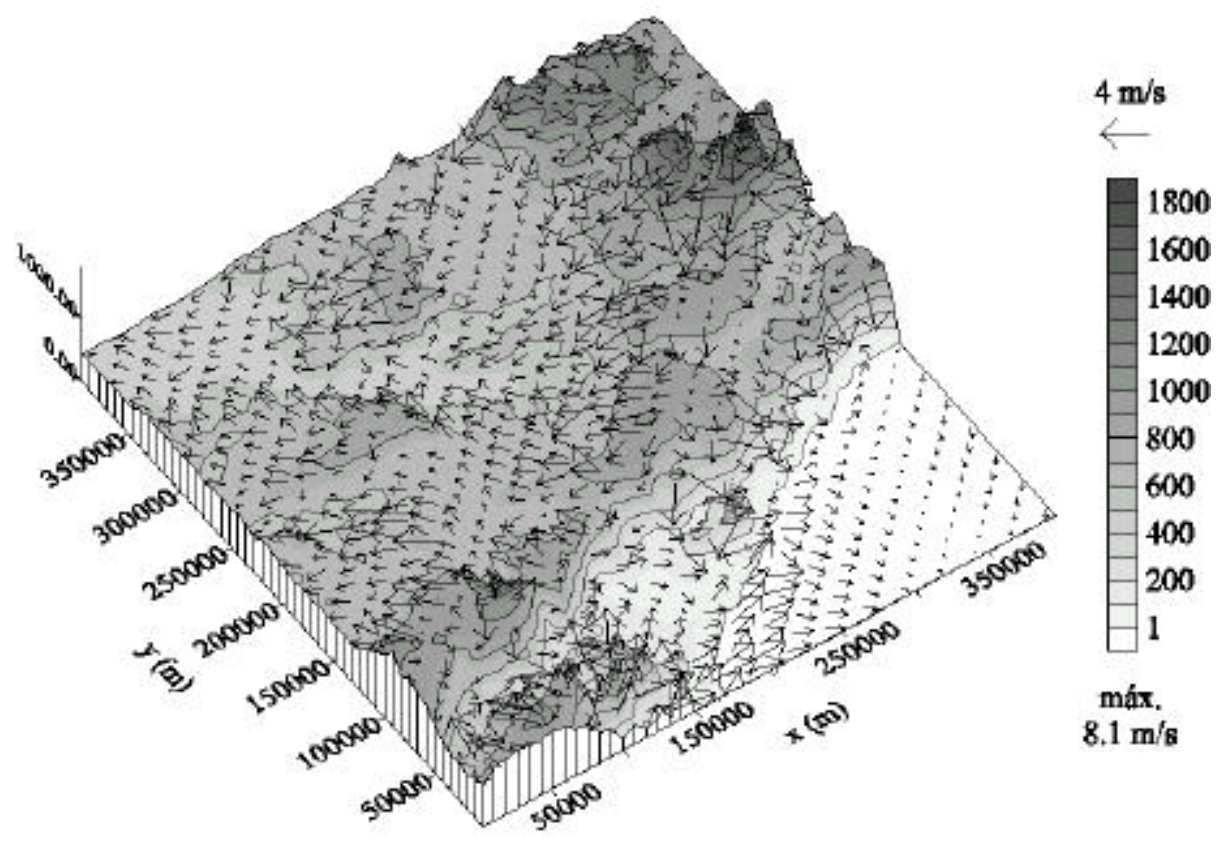

Figura 4.2 Campo de vento horizontal a 15 m acima da superfície: (a) æ̀ 18 h (12 h de simulação) e (b) à $06 \mathrm{~h}$ ( $24 \mathrm{~h}$ de simulação). A topografia é indicada pelos contornos e escala de cinzas. Ip eró corresponde ao ponto central do domínio de $400 \mathrm{~km}$ por $400 \mathrm{~km}$ (da simulação L400). A Região Metropolitana de São Paulo encontra-se àvolta do ponto de coordenadas (200 km, 300 km). 
Durante o período noturno o escoamento apresenta as seguintes características:

1. A brisa terrestre mostra uma notável convergência sobre a área oceânica à frente do litoral sul do Estado de São Paulo (Figura 4.4 b). Esta convergência é uma consequiência da forma côncava da linha de costa e da topografia da escarpa que a segue;

2. Nota-se intensa divergência do escoamento sobre os cimos da Serra do Mar. Esta divergência separa os escoamentos superficiais do litoral e do interior;

3. Intensa convergência do escoamento aparece ao longo dos vales dos rios paulistas, especialmente no vale do Rio Tietê;

4. Ventos de SE e E aparecem a superfície ao longo da Depressão Periférica e região de Iperó.

Note-se a tendência de aumento da intensidade do vento máximo seguindo-se as simulações L100, L400 e L800 (através das figuras mostradas).

Efeito térmico - Em decorrência da variação espacial da temperatura média da superfície e do ar aparecem forças de gradiente de pressão horizontais entre áreas apresentando diferentes temperaturas. Destaca-se o contraste térmico na área alongada do platô da Serra do Mar — que segue todo o litoral Sul e Sudeste do Brasil — em relação æ̀ temperaturas médias encontradas sobre o Oceano Atlântico e no interior paulista para uma mesma altitude. Desta forma, as áreas mais elevadas da topografia se estabelecem como fontes elevadas de fluxo de calor sensível e latente para a atmosfera; i.e., devido (a) ao transporte turbulento ou (b) à convergência média de massa, momento, calor e umidade nestas áreas, pelo escoamento de mesoescala. A "fonte elevada de calor" pode ser localizada pela distribuição horizontal de Temperatura Potencial (figura não apresentada), correspondendo aproximadamente à áreas mais claras na Figura 4.4.

A distribuição das médias diárias da temperatura do solo e do ar seguindo-se a topografia é mostrada na Figura 4.4. Estas distribuições foram obtidas por média aritmética das 24 saídas horárias dos campos bidimensionais à superfície da simulação L800.

Os escoamentos simulados (L800) para os tempos correspondentes aos finais do período convectivo e estável são mostrados na Figura 4.3. Nota-se a existência de uma concordância qualitativa em relação æ̀ simulações de área mais limitada (L100 e L400), embora, as intensidades absolutas do escoamento médio apresentem um aumento progressivo conforme a extensão do domínio aumente de $100 \mathrm{~km}$ para $400 \mathrm{~km}$ e de $400 \mathrm{~km}$ e para $800 \mathrm{~km}$. Este fato indica o efeito da incorporação de escalas topográficas de maior escala sobre a intensidade do escoamento. 
(a) Simulação æ̀s $18 \mathrm{~h}$

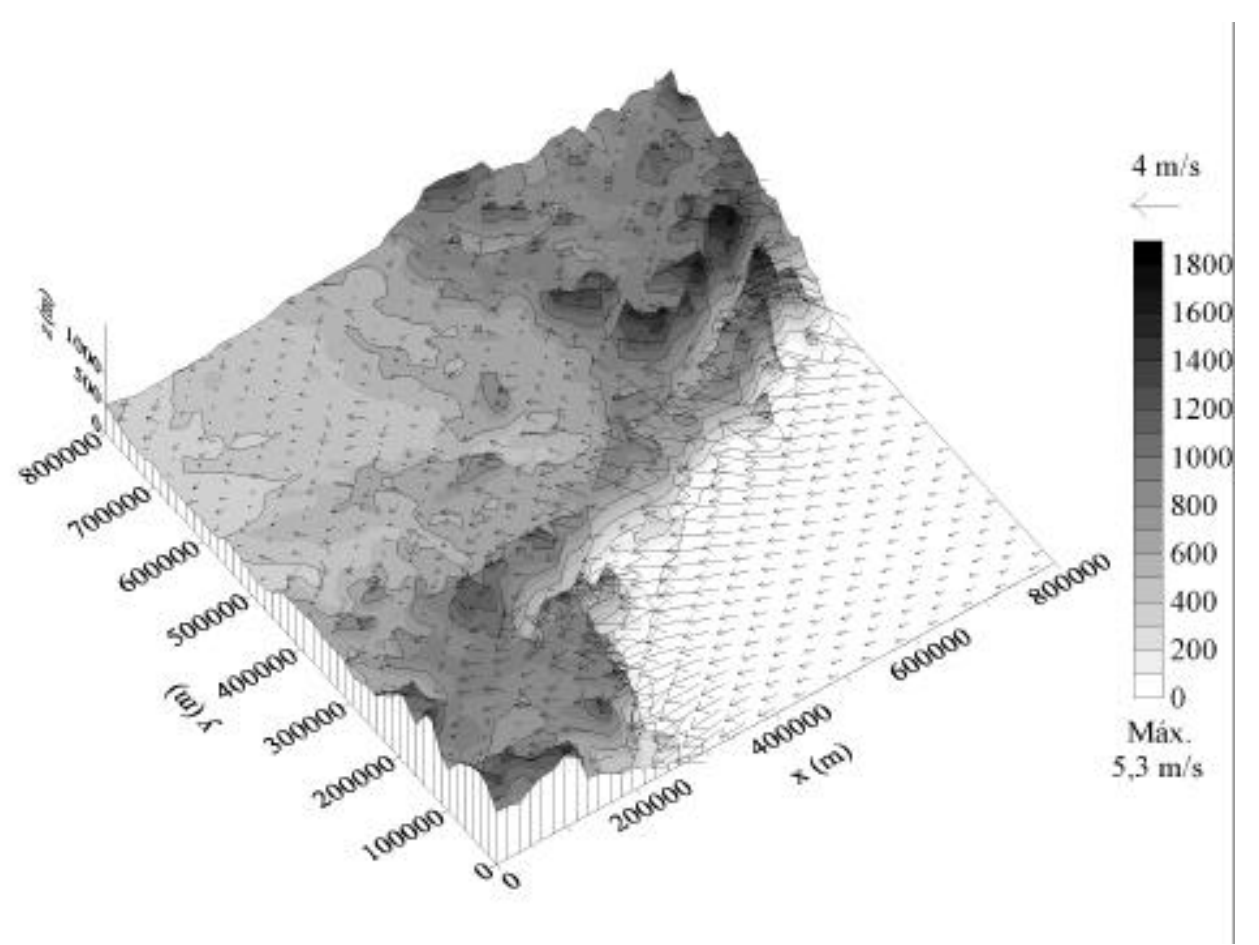

(b) Simulação à $6 \mathrm{~h}$

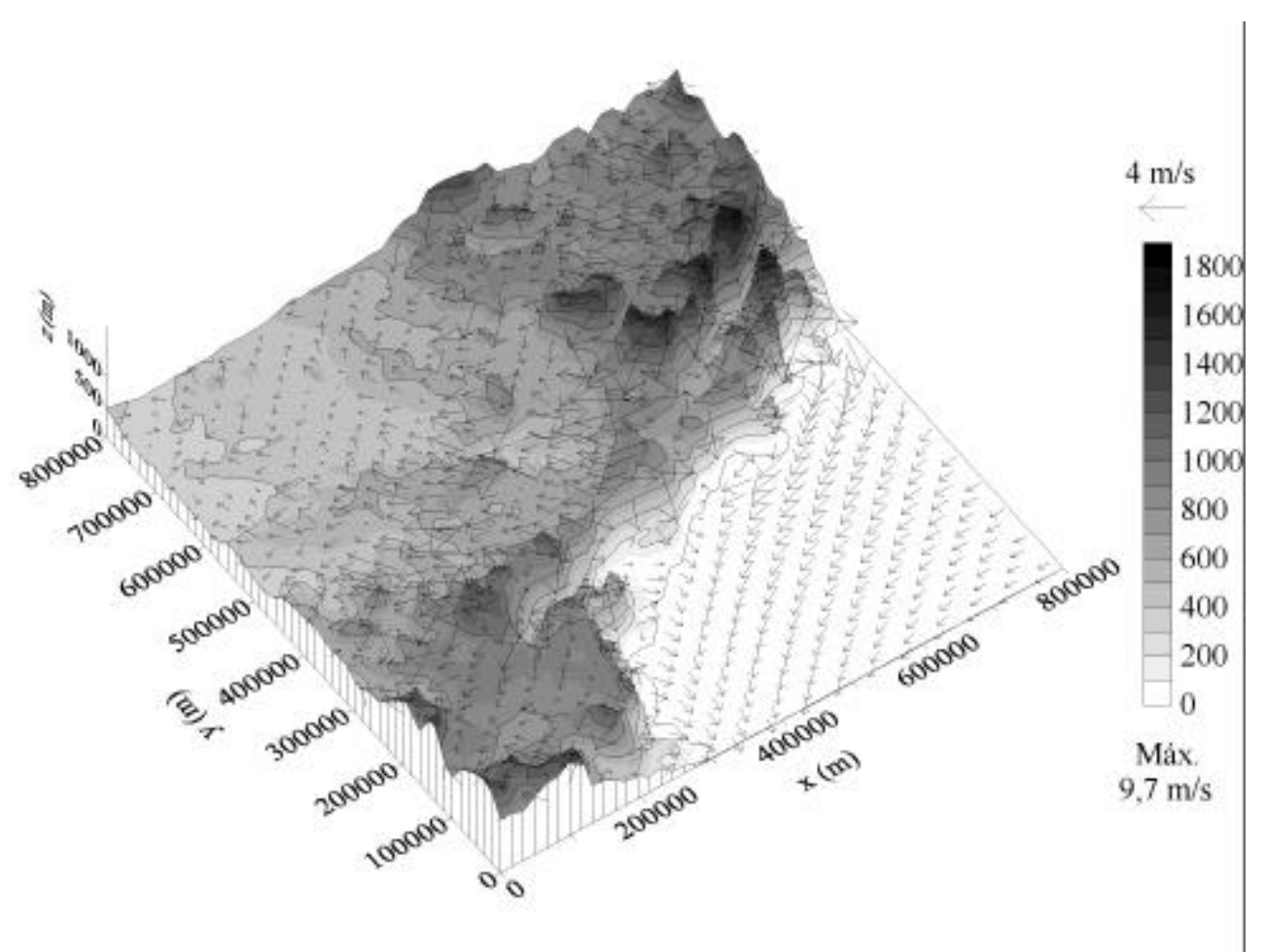

Figura 4.3 Campo de vento horizontal a 15 m acima da superfície: (a) æ̀ 18 h (12 h de simulação) e (b) à 06 h (24 h de simulação). A topografia é indicada pelos contornos e escala de cinzas. Iperó corresponde ao ponto central do domínio de $800 \mathrm{~km}$ por $800 \mathrm{~km}$ (da simulação L800). 


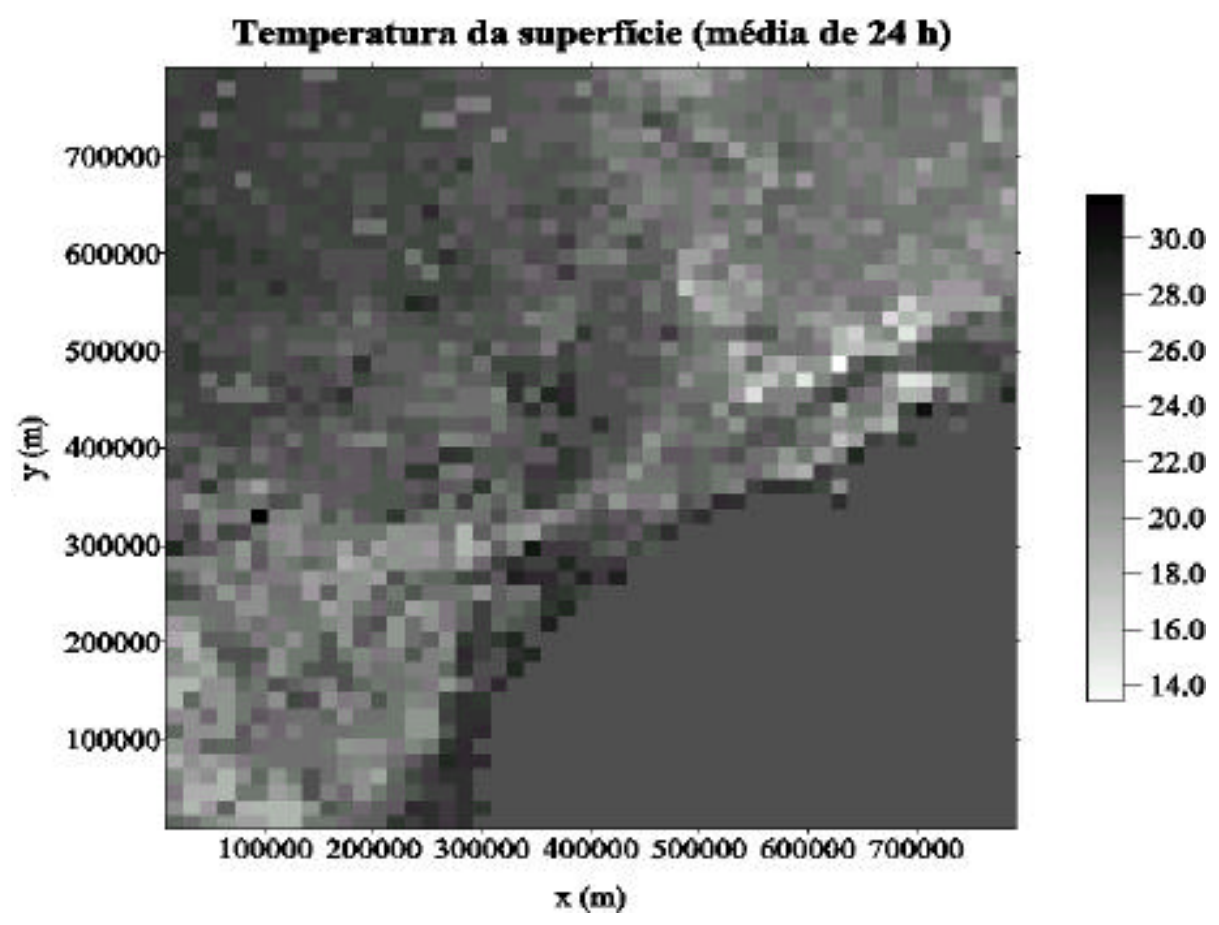

(a)

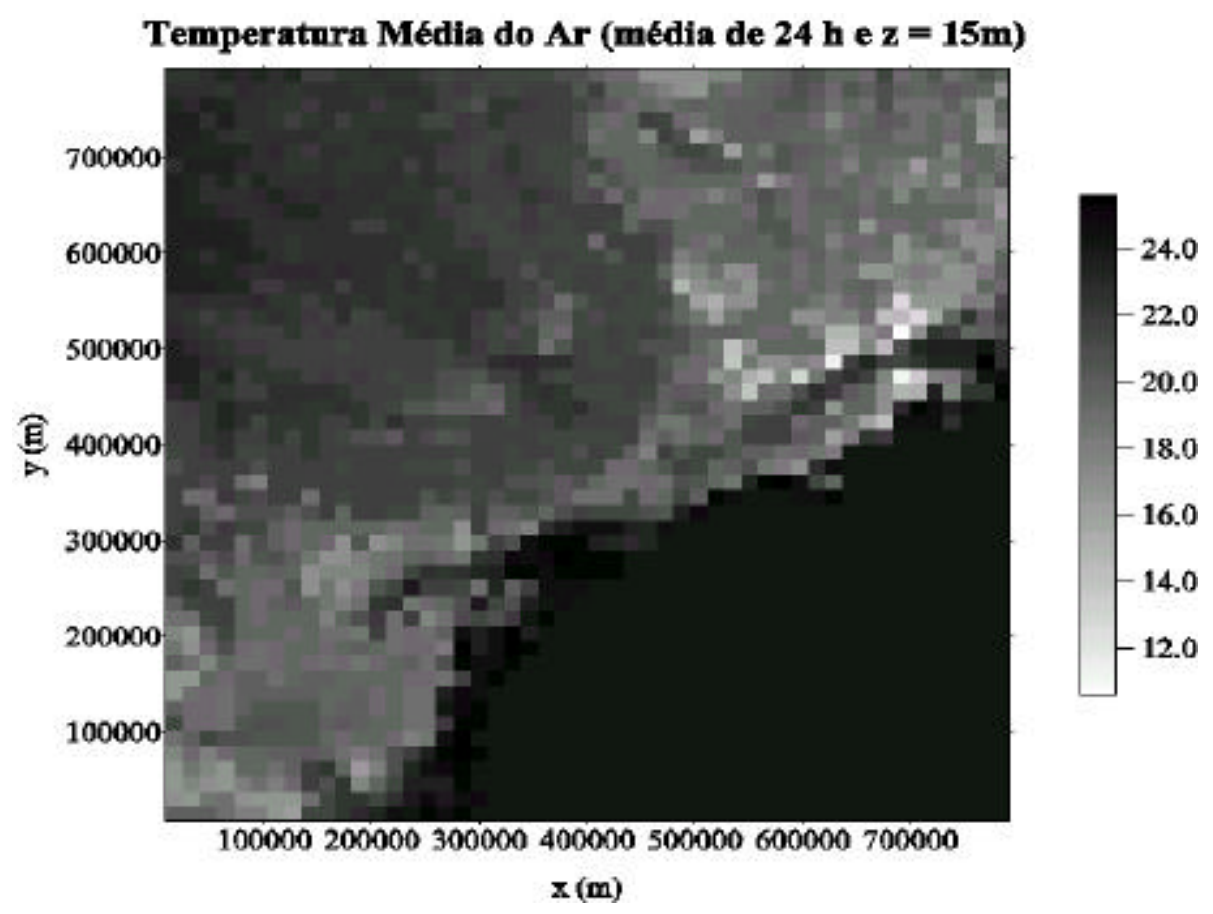

(b)

Figura 4.4 Campo da média diária $(24 \mathrm{~h})$ da temperatura: (a) da superfície e (b) do ar para a altura de $14 \mathrm{~m}$ acima da superfície. Iperó corresponde ao ponto central do domínio de $800 \mathrm{~km}$ por $800 \mathrm{~km}$. Note-se: (1) o arco térmico formado pelas montanhas àvolta da Depressão Periférica em SP e (2) as altas temperaturas do ar ao longo do Vale do Rio Ribeira de Iguape. Campos médios obtidos a partir das 24 saídas horárias dos campos bidimensionais àsuperfície para a simulação L800. 


\subsubsection{Simulação L1500}

A seguir, apresenta-se as principais características do escoamento superficial obtido para a simulação L1500 (domínio 1500 km por $1500 \mathrm{~km}$ ).

Durante o período convectivo (Figura 4.5 a) nota-se que:

(a) A brisa marítima domina o escoamento ao longo da faixa litorânea, mas sua penetração no interior não é maior que $50 \mathrm{~km}$. A barreira de energia potencial estabelecida pela escarpa da Serra do Mar e a ausência de forçantes de maior-escala (por exemplo, gradientes de pressão de escala sinótica) não permitem à frente de brisa avançar além dos cimos da Serra do Mar em direção ao interior;

(b) No interior, escoamentos associados ao efeito térmico da topografia dominam, resultando em convergência sobre as áreas mais elevadas do terreno e divergência sobre as mais baixas. Notese o efeito mecânico da topografia também está presente, sendo menor durante o período convectivo (diurno) e mais importante no período estável (noturno);

(c) A área correspondente da Depressão Periférica em SP, onde se encontra Iperó, é afetada por escoamento de pequena intensidade e divergência do campo do vetor vento;

(d) Ao longo do vale do Rio Tietê, o campo de escoamento mostra-se divergente;

(e) A formação de áreas de convergência do escoamento sobre os terrenos mais elevados (morros, montanhas, cimos de escarpa) indica que essas áreas podem ser áreas de formação de nuvens profundas (áreas de maior probabilidade de formação de $\mathrm{Cb} \mathrm{s}$ ) ${ }^{7}$.

Durante o período estável (Figura 4.5 b) tem-se que:

(a) A brisa terrestre enfraquece muito o escoamento diurno associado à brisa marítima sobre os aclives da escarpa da Serra do Mar;

(b) Em todos os vales dos rios que aparecem nessa extensa área (1500 km por $1500 \mathrm{~km})$ percebese convergência do escoamento;

(c) Sobre o Oceano o escoamento mostra-se de NE ao longo da região oceânica que segue a linha da costa Sul e Sudeste do Brasil. Isto é resultado da ação da força de Coriolis sobre o escoamento originalmente perpendicular à costa (brisa marítima), que gira para a esquerda no Hemisfério Sul;

\footnotetext{
${ }^{7}$ Note-se que a maioria das parametrizações de nuvens convectivas aplicadas em modelos numéricos de mesoescala utiliza como critério de disparo da tempestade a presença de convergência em baixos níveis, em particular na camada abaixo da base da nuvem (KUO, 1965, 1974; COTTON e ANTHES, 1989).
} 
(d) Vento de componente E, SE aparecem na região central da grade correspondente a localização de Iperó, o que é consistente com os resultados obtidos nas simulações de área mais limitada (L100, L400 e L800);

(e) O valor da intensidade máxima do vento simulado aumenta com o aumento da escala horizontal do domínio, indicando a importância da incorporação da topografia regional para simulação da intensidade dos escoamentos de origem local (na superfície e em seus efeitos térmicos e mecânicos).

\subsection{Análise dos Campos no Corte $(\mathrm{x}, \mathrm{z})$}

As Figuras 4.6 e 4.7 apresentam resultados sobre o plano de corte (x, z) para a temperatura potencial $(\theta)$; energia cinética turbulenta $(\mathrm{ECT})$; componente zonal (u) e componente meridional (v) do vento (v) passando pela latitude de Iperó (linha $\mathrm{AB}$ na Figura 4.18, correspondente àposição $\mathrm{x}$ = $750 \mathrm{~km}$ ) para dois horários: (a) $18 \mathrm{~h}$ e (b) 6 h do tempo local.

Período convectivo - O exame distribuição das componentes do vento sobre o plano $(\mathrm{x}, \mathrm{z})$ à 18 h evidencia dos seguintes pontos:

1. Nota-se desenvolvimento de duas células de circulação principais associadas à CLP sobre o Estado de São Paulo. A primeira com circulação anti-horária sobre o Planalto Paulista (i.e., a célula do interior) e a segunda, uma célula de circulação horária associada àbrisa marítima e a topografia da escarpa da Serra do Mar (i.e., a chamada célula da brisa);

2. A circulação da célula da brisa e escarpa é mais intensa que aquela da célula sobre o Planalto Paulista (Figuras 4.6a e 4.7a);

3. A componente zonal inverte de sinal em relação ao sinal em superfície a cerca de $2000 \mathrm{~m}$ acima da superfície para ambas as células de circulação, indicando a existência de um escoamento de returno para leste sobre a célula de circulação do litoral e para oeste sobre a célula do interior (Figura 4.6a e b);

4. As profundidades do ramo inferiores dessas células de circulação são dadas aproximadamente: (a) pela altura da CLP convectiva para a célula do interior æ̀ $18 \mathrm{~h}$ 
(Figura 4.7 a) e (b) e pela altura da CLP marítima - sobre o oceano - para a célula do litoral às $6 \mathrm{~h}$ (Figura $4.7 \mathrm{~b})$;

5. Durante o período convectivo, o exame da penetração da componente zonal do vento pela superfície a leste do Estado de São Paulo mostra que a célula da brisa não penetrou além da Serra da Cantareira (que se localiza ao norte da capital São Paulo) (Figura 4.6 a);

6. Uma zona de convergência com ventos dos quadrantes Oeste (vindos do interior) e Leste (vindos do litoral) aparece sobre a região correspondente ao vale do Paraíba do Sul à $18 \mathrm{~h}$ (Figura 4.6 a), indicando uma área de possível formação preferencial de nebulosidade, para as condições representadas pela simulação;

7. Próximo a Serra da Cantareira, sobre a área correspondente a Grande São Paulo, nota-se intenso cisalhamento direcional do vento (SE àleste e W àoeste da área) indicando a zona de contato entre os ramos inferiores das células de circulação do litoral e interior (Figuras 4.6 a e 4.7 a). Esse cisalhamento na intensidade e direção do vento acaba por gerar um máximo na intensidade da turbulência ao final do período convectivo exatamente sobre a área correspondente a cidade de São Paulo, àleste da Serra da Cantareira (Figura 4.7 a);

8. A altura da CLP convectiva média simulada no interior é de aproximadamente $1500 \mathrm{~m}$. A altura da CLP no interior segue aproximadamente a topografia, apresentando também variações associadas àconvergência do escoamento (Figura 4.7 a);

Período estável - A distribuição das componentes do vento sobre o plano $(\mathrm{x}, \mathrm{z})$ à $6 \mathrm{~h}$ indica que:

1. Sobre o Planalto Paulista, a componente zonal (u) aparece com sinal negativo estendendo-se desde a Serra do Mar até $500 \mathrm{~km}$ para interior ao longo da latitude de Iperó (Figura 4.6 b). Não se trata da brisa marítima desde que não há nesta simulação condições favoráveis de propagação da brisa pelo interior, ou seja, não há um escoamento de grande-escala de SE com intensidade tal que justifique uma propagação da frente-de-brisa. De outra forma, o sinal negativo da componente zonal no interior está associado ao escoamento catabático que se estabelece sobre o terreno inclinado do Planalto Paulista, à inversão de temperatura em superfície e às condições da CLP estável;

2. O JBN noturno na longitude de Iperó (correspondente àabscissa $\mathrm{x}=750 \mathrm{~km}$ na Figura 4.6 b) apresenta componente zonal negativa $(\mathrm{u}<0)$. O máximo negativo desta componente é aproximadamente encontrado na altura de $300 \mathrm{~m}$ acima da superfície;

3. Nota-se uma componente meridional (v) de sinal positivo (ventos do quadrante $S$ ) junto à superfície em associação ao JBN de Iperó. A componente meridional positiva parece 
se estender pelo Planalto Paulista, mostrando um máximo em intensidade sobre a encosta oeste do vale do Rio Paraná $(x=300 \mathrm{~km})$, para a altura aproximada de $200 \mathrm{~m}$ acima da superfície;

4. Ainda na Figura 4.7 b sobre a posição de Iperó $(x=750 \mathrm{~km})$ e aproximadamente $1 \mathrm{~km}$ acima da superfície pode-se notar a existência de um máximo positivo na componente meridional ( $\mathrm{v}>0$ ), com intensidade $1 \mathrm{~m} \mathrm{~s}^{-1}$, o que indica o predomínio da componente Sul no JBN de Iperó;

5. Na Figura 4.7 b também pode ser notada a existência de um máximo do vento horizontal sobre a Serra do Mar $(x=1000 \mathrm{~km})$, com máximo de velocidade de aproximadamente $4,5 \mathrm{~m} \mathrm{~s}^{-1}$ e direção NE no nível de $500 \mathrm{~m}$ para as $3 \mathrm{~h}$, sem apresentar propagação significativa em direção ao interior;

6. Durante o período noturno, o valor de ECT à superfície sobre o continente é bem pequeno, com exceção das áreas da topografia mais inclinadas, nas quais existe intenso cisalhamento vertical do vento. Por outro lado, sobre o Oceano Atlântico ocorrem valores aproximados de $0,35\left(\mathrm{~m}^{2} \mathrm{~s}^{-2} \mathrm{~kg}^{-1}\right)$ associados àpresença de uma CLP convectiva sobre o mar. Nesta simulação, a camada limite atmosférica sobre o oceano mostra-se estável (instável) durante o dia (noite) (Figuras 4.7 a e b) devido à inexistência de variação da temperatura da superfície do mar no modelo e ao aquecimento e resfriamento radiativo da camada superficial do ar. Essas características estão em concordância com a descrição climatológica e dinâmica da CLP sobre oceano (OKE, 1978) e outros corpos de água, como lagos (ZILITINKEVICH, 1991). 
(a) Simulação às $18 \mathrm{~h}$

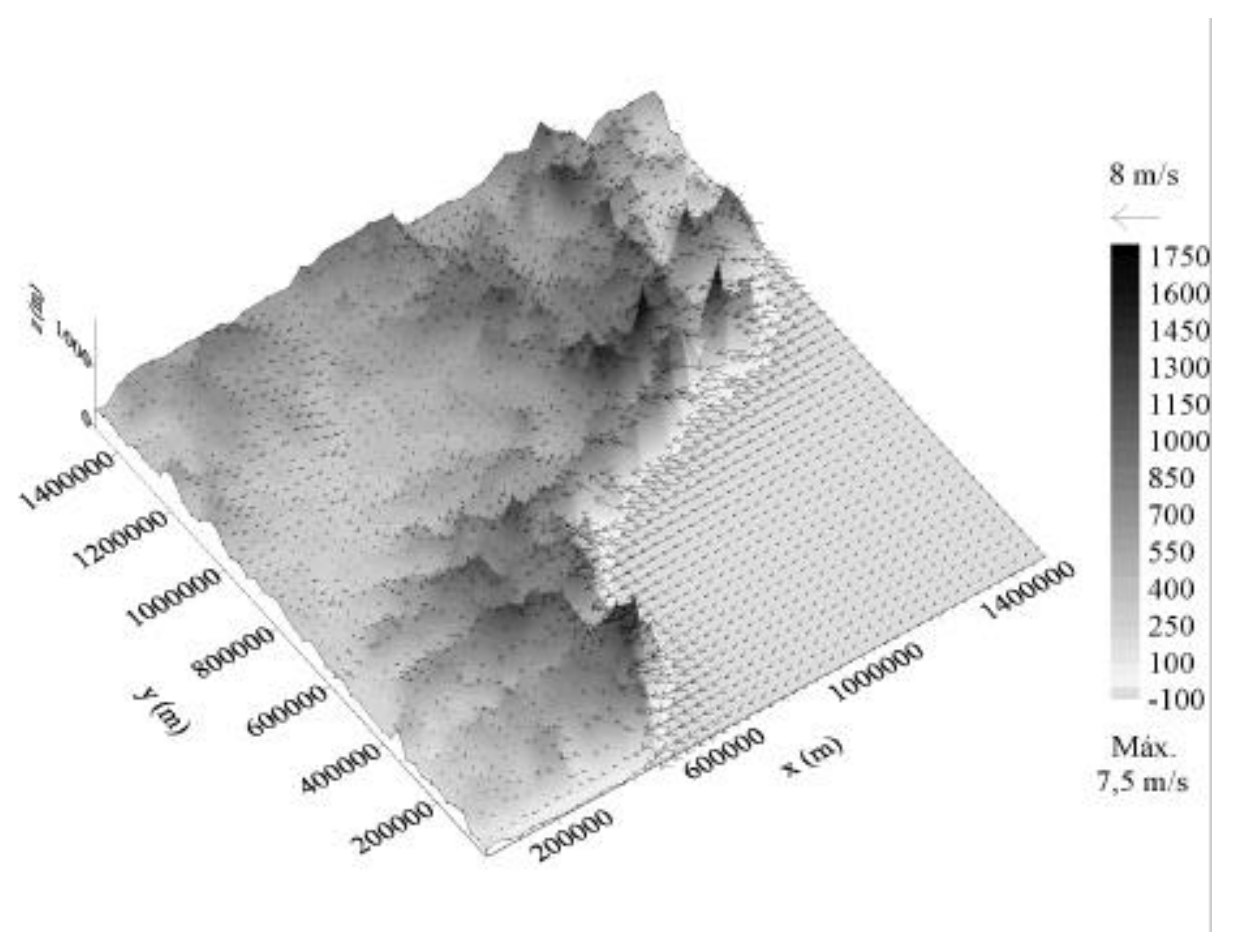

(b) Simulação às $6 \mathrm{~h}$
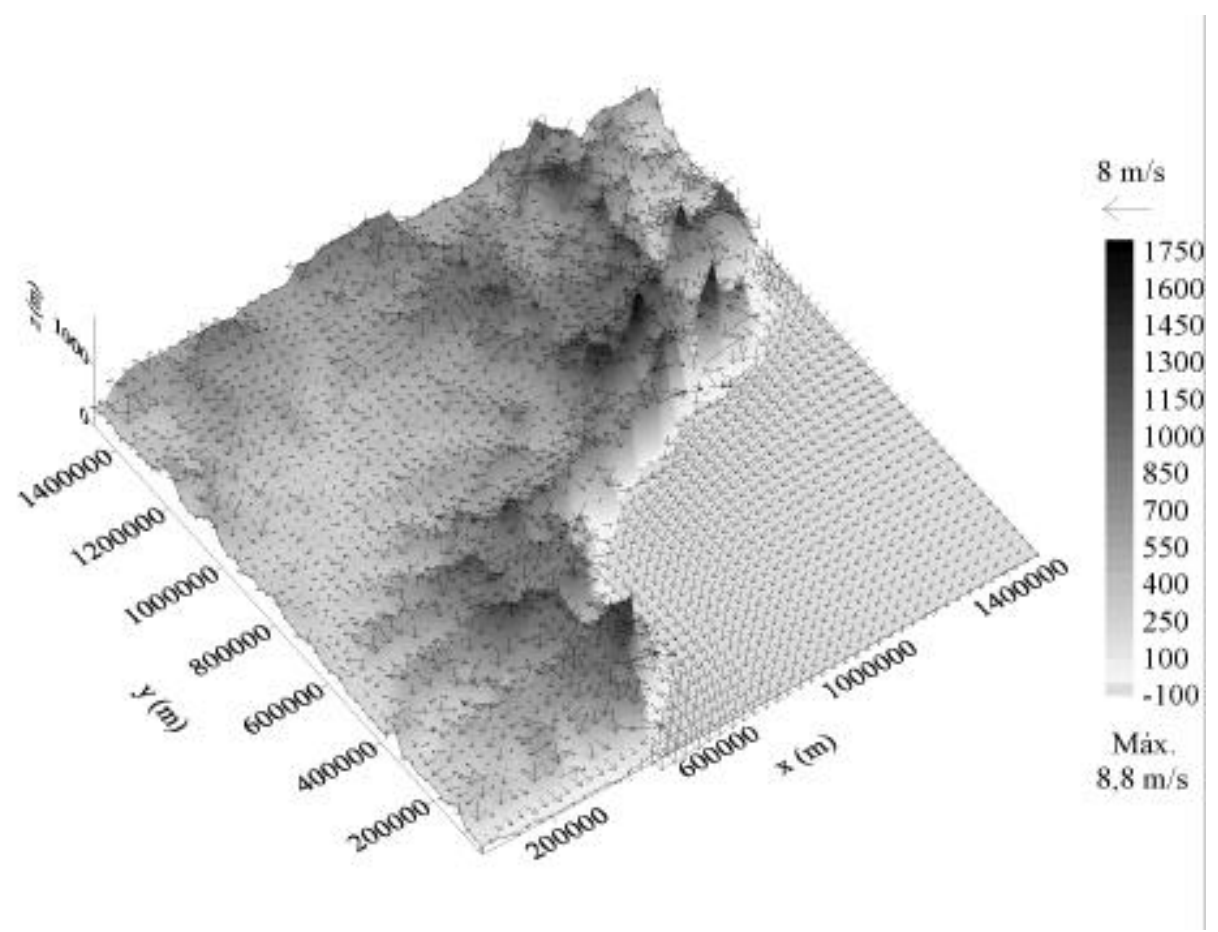

Figura 4.5 Campo de vento horizontal a $14 \mathrm{~m}$ acima da superfície: (a) à $18 \mathrm{~h}$ (12 h de simulação) e (b) æ̀ $06 \mathrm{~h}$ ( $24 \mathrm{~h}$ de simulação). A topografia é indicada pelos contornos e escala de cinzas. Iperó corresponde ao ponto central do domínio de $1500 \mathrm{~km}$ por $1500 \mathrm{~km}$ (da simulação L1500). 


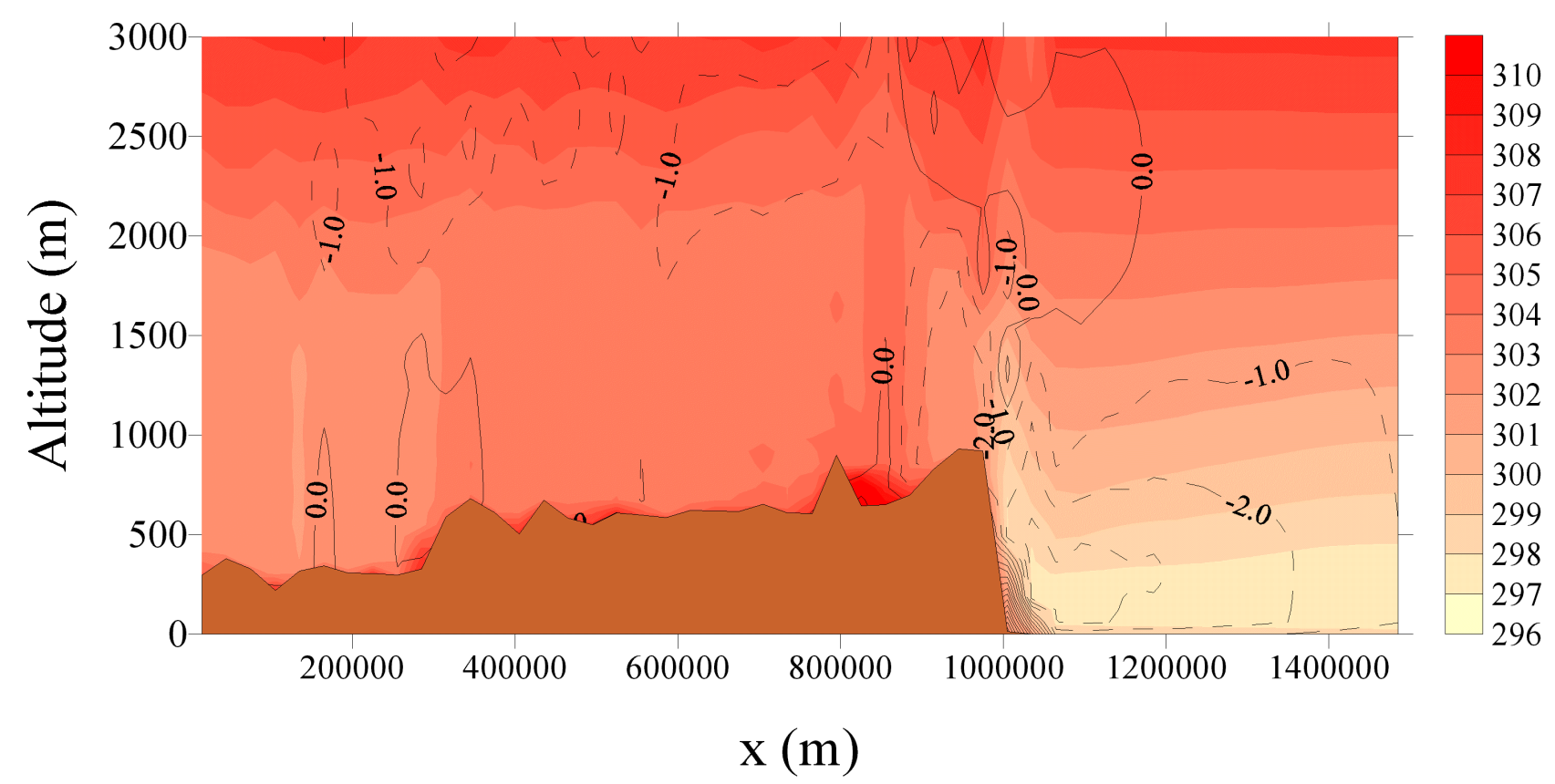

(a)

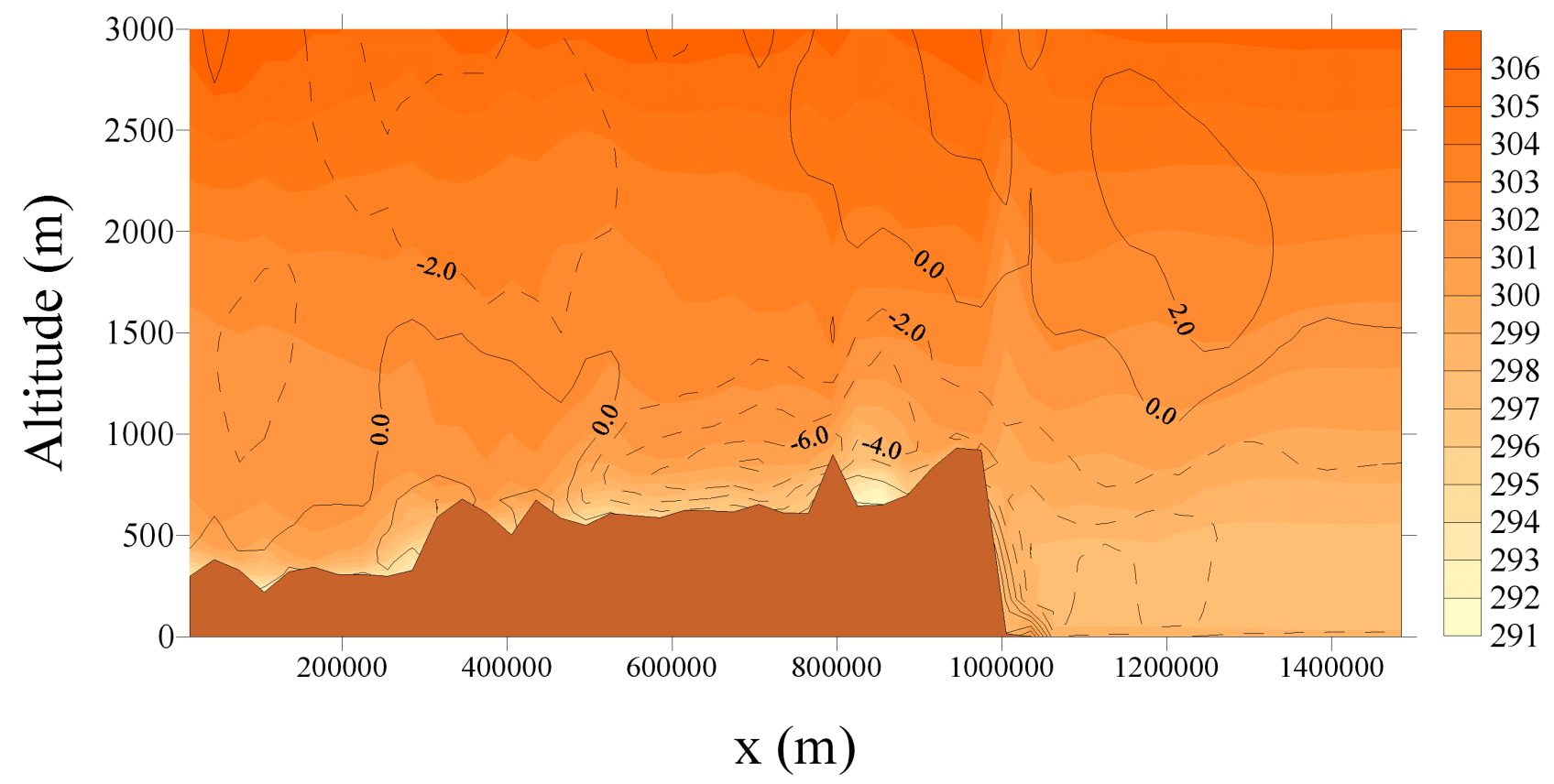

(b)

Figura 4.6 Corte vertical $(x ; z)$ passando por Iperó $(x=750 \mathrm{~km}$, linha $A B$ da Figura 4.18) mostrando a temperatura potencial (escala de cores) e a componente zonal (isolinhas de contorno) para (a) 18 h e (b) 6 h do tempo local. Resultados da simulação L1500. 


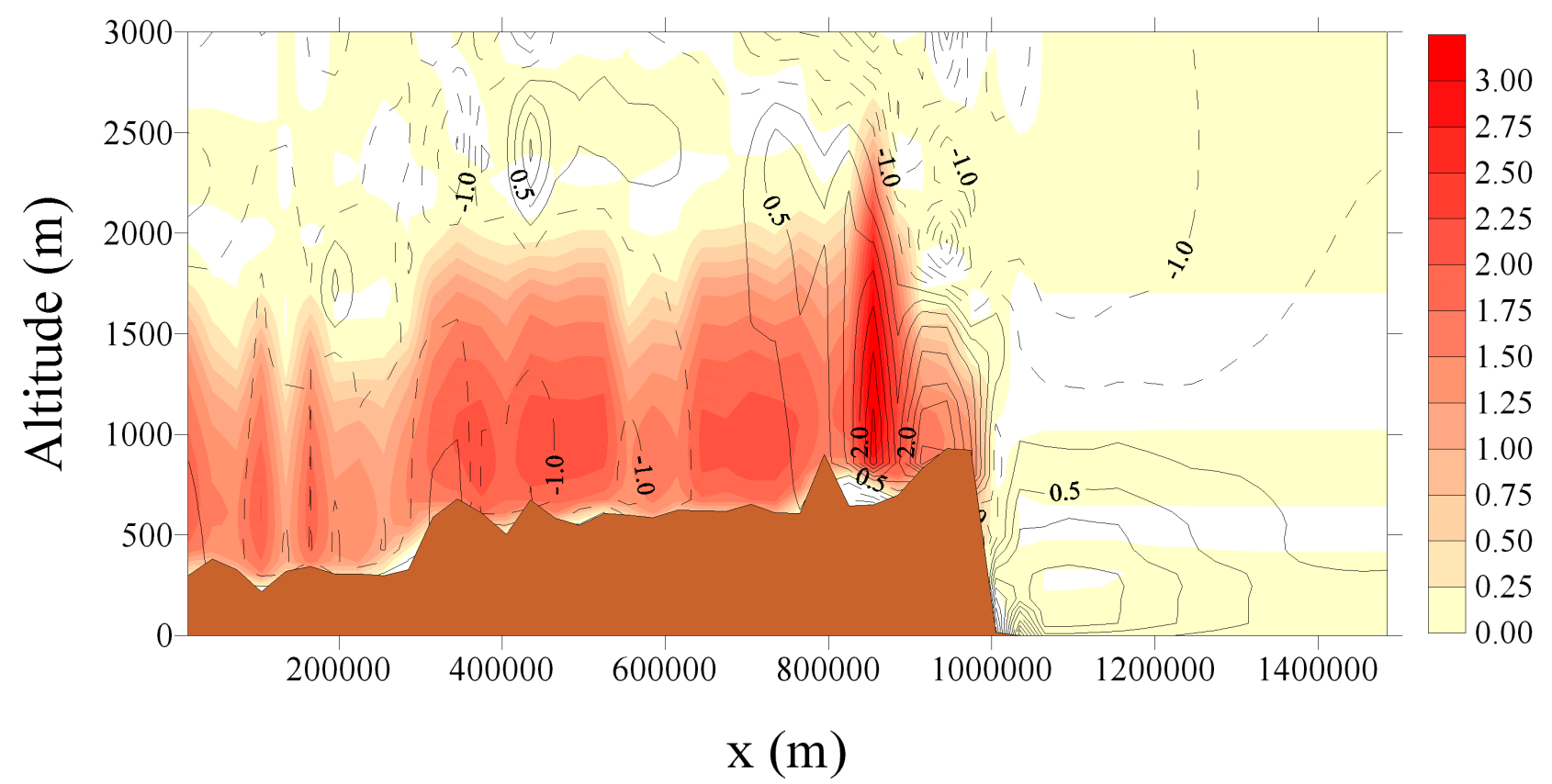

(a)

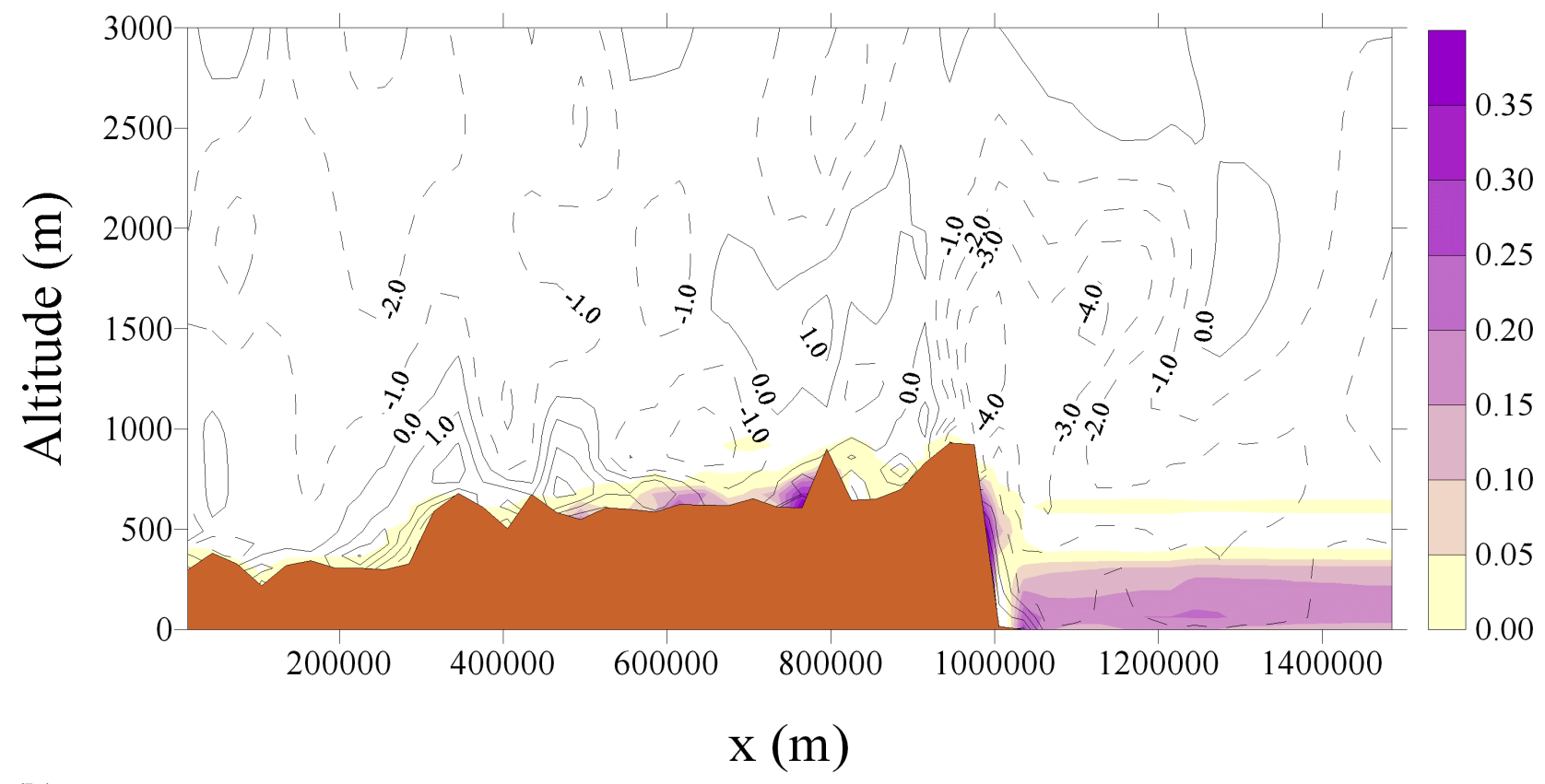

(b)

Figura 4.7 Corte vertical $(x ; z)$ passando por Iperó $(x=750 \mathrm{~km}$, linha $A B$ da Figura 4.18) mostrando a energia cinética turbulenta (escala de cores) e a componente meridional (isolinhas de contorno) para (a) 18 h e (b) 6 h do tempo local. Resultados da simulação L1500. 


\subsection{Estrutura Vertical do JBN}

Neste item, analisa-se a estrutura vertical simulada comparando-a àquela observada nos perfis verticais obtidos para o JBN do dia 13 de Março de 1993, no CEA em Iperó à 3 h (Figura 4.8 a e b). Nota-se que a intensidade e direção do JBN obtido na simulação L1500 (através da curva de traço-e-ponto) concordam qualitativamente com o observado em Iperó (i.e., quanto aos sinais e ordem de grandeza). As estruturas verticais do vento do JBN simulado e observado apresentam formas similares se forem normalizadas pela altura do máximo da velocidade do vento.

As estruturas verticais da componente zonal (u) simulada e observada apresentam semelhanças; embora o valor do máximo simulado apresente-se ligeiramente menor; e sua altura esteja $200 \mathrm{~m}$ abaixo do valor observado para este dia. O resultado numérico para a componente meridional apresenta o mesmo sinal da direção da componente observada para os níveis mais próximos àsuperfície $(\mathrm{z}<100 \mathrm{~m})$ e direção oposta para níveis mais altos.

A diferença entre a altura do máximo do JBN simulado e observado pode ser entendida pela dificuldade de representar a estrutura da turbulência associada ao JBN utilizando-se as parametrizações usuais do coeficiente de difusão turbulenta (i.e., baseadas na teoria $\mathrm{K}^{8}$ ). Note-se que neste caso, a escala do comprimento de mistura turbulento é função da altura em relação à superfície. A estrutura turbulenta do JBN não depende unicamente das condições do cisalhamento do vento a superfície, mas depende também do cisalhamento que ocorre localmente; por exemplo, acima do máximo do jato.

A curva hodógrafa do vento simulado é apresentada na Figura 4.9 a. A oscilação diurna do vento, com direção NE durante o dia e SE ànoite, corresponde qualitativamente à observações de Iperó (Figuras 4.9 b e c, respectivamente).

\footnotetext{
${ }^{8}$ A Teoria K representa os fluxos turbulentos de forma similar æ̀ equações utilizadas na descrição da difusão molecular. Neste caso, os conceitos de livre caminho médio e difusão molecular são substituídos pelos conceitos de comprimento de mistura turbulento e difusão turbulenta, respectivamente.
} 
(a) Componente Zonal do Vento

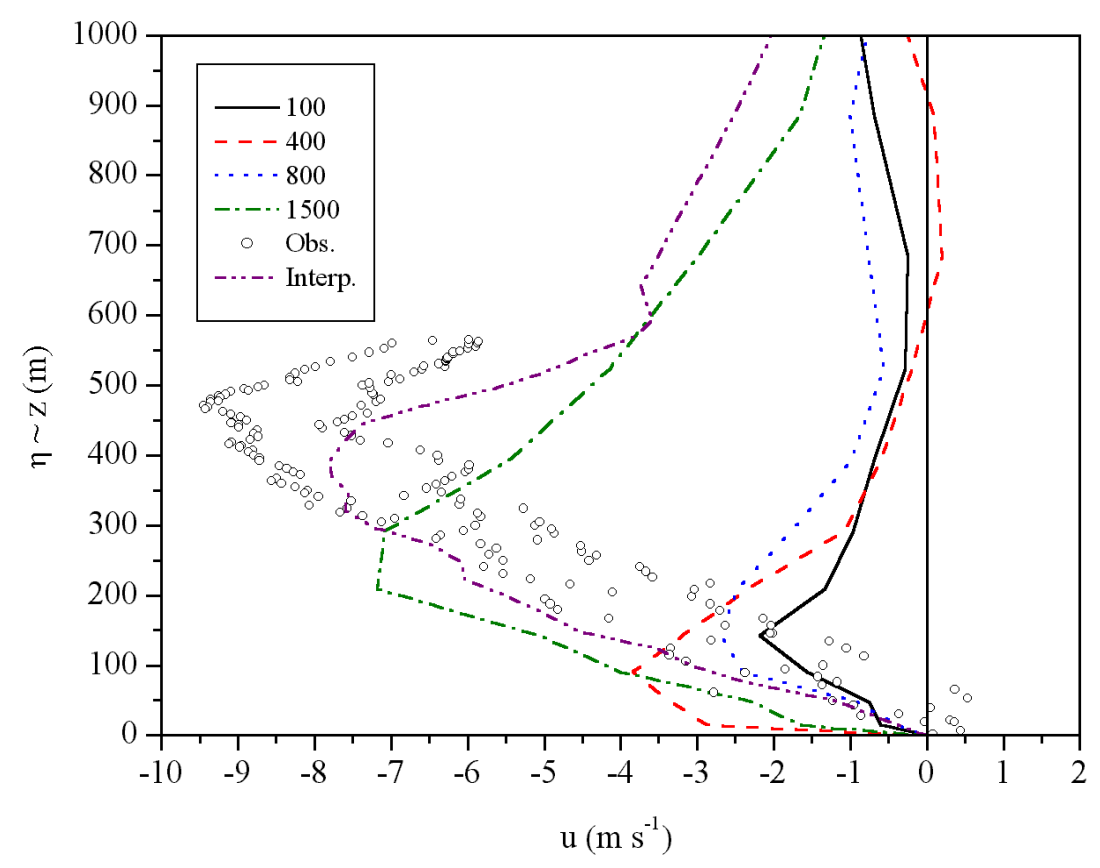

(b) Componente Meridional do Vento

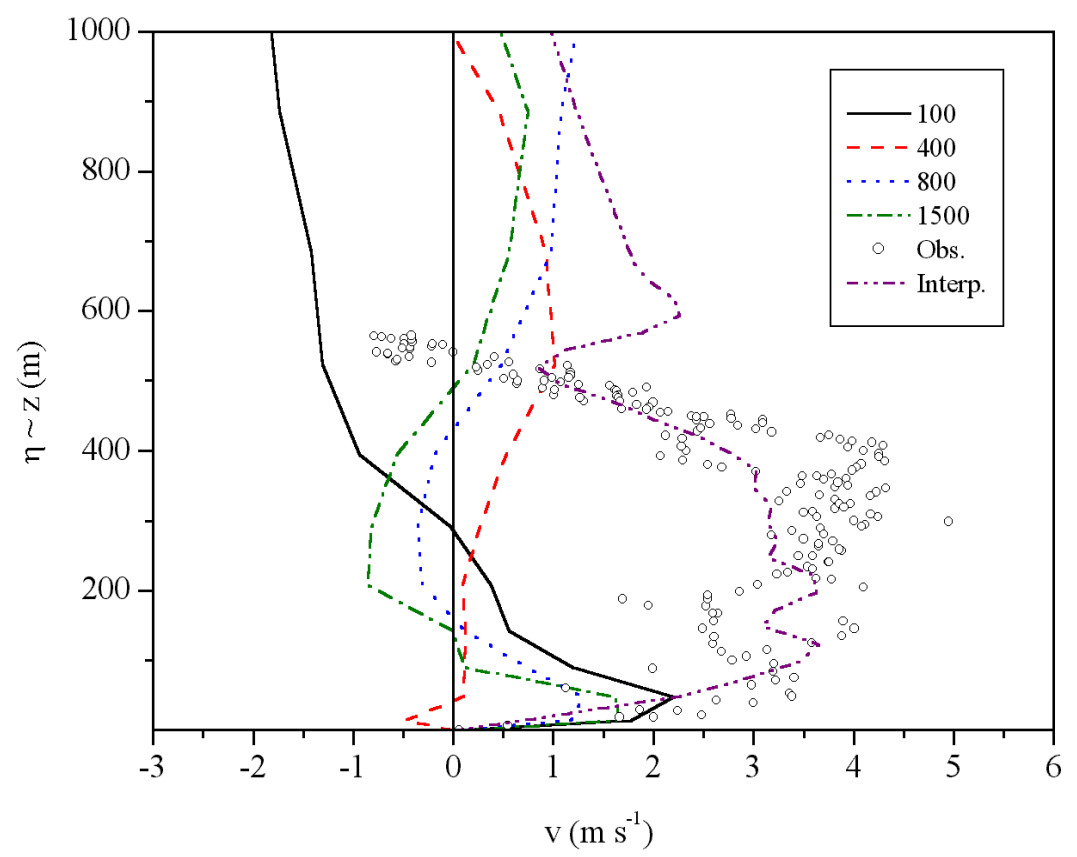

Figura 4.8 Estrutura vertical do momento associada ao JBN simulada e observada à 3 h em Iperó no dia 13 de Março de 1993. Apresenta-se em (a) a componente zonal e em (b) a componente meridional. Na legenda as linhas indicadas por 100, 400, 800, 1500, Obs e Interp correspondem, respectivamente, à simulações L100, L400, L800, L1500, observações de balão-cativo e ao conjunto de dados interpolados (conforme descrição do item 2.4, i.e., utilizando-se o modelo 1-D e assimilação 4-D das sondagens observacionais realizadas Iperó). 
(a) Simulação Numérica

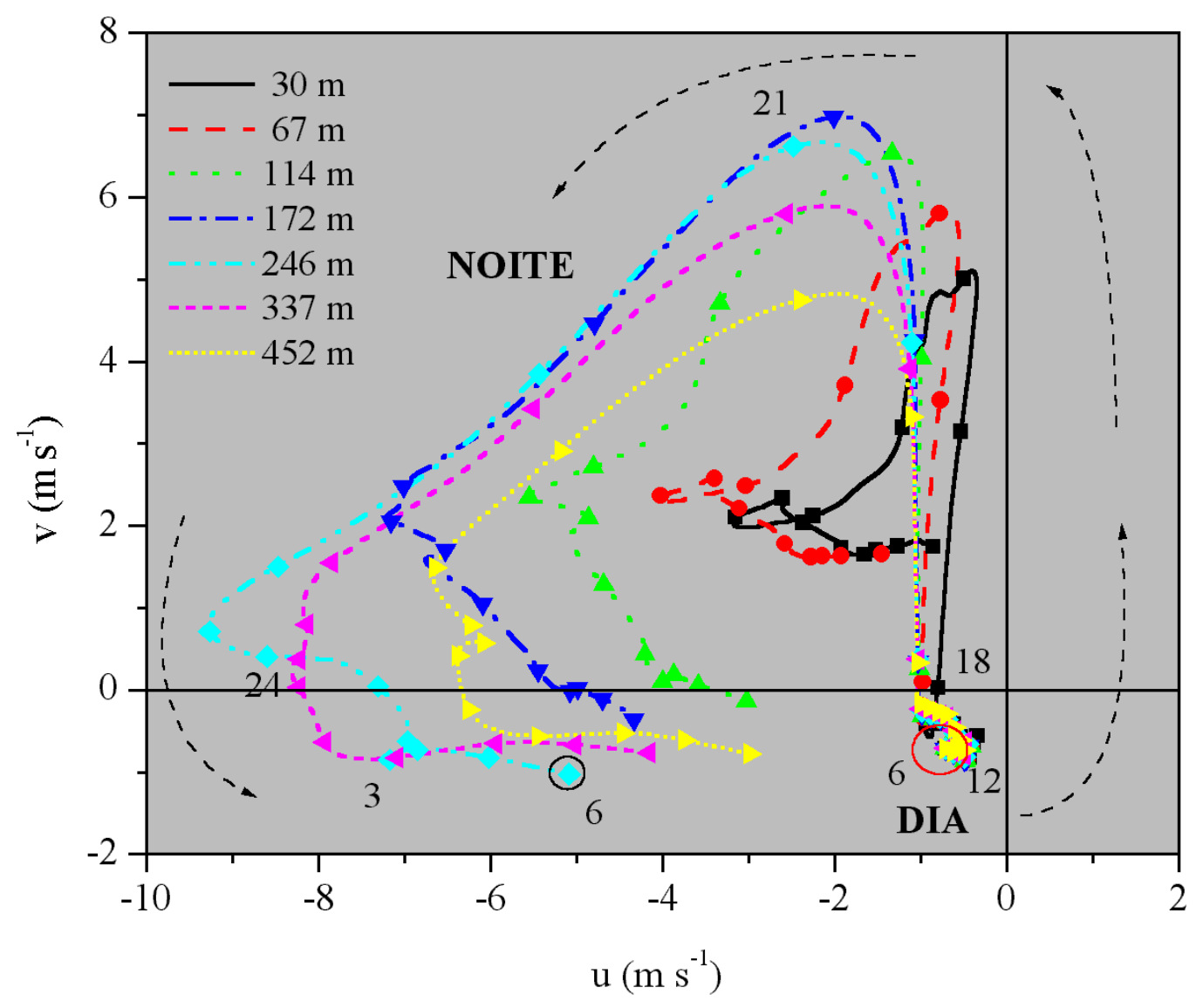

(b) Inverno

(c) Verão
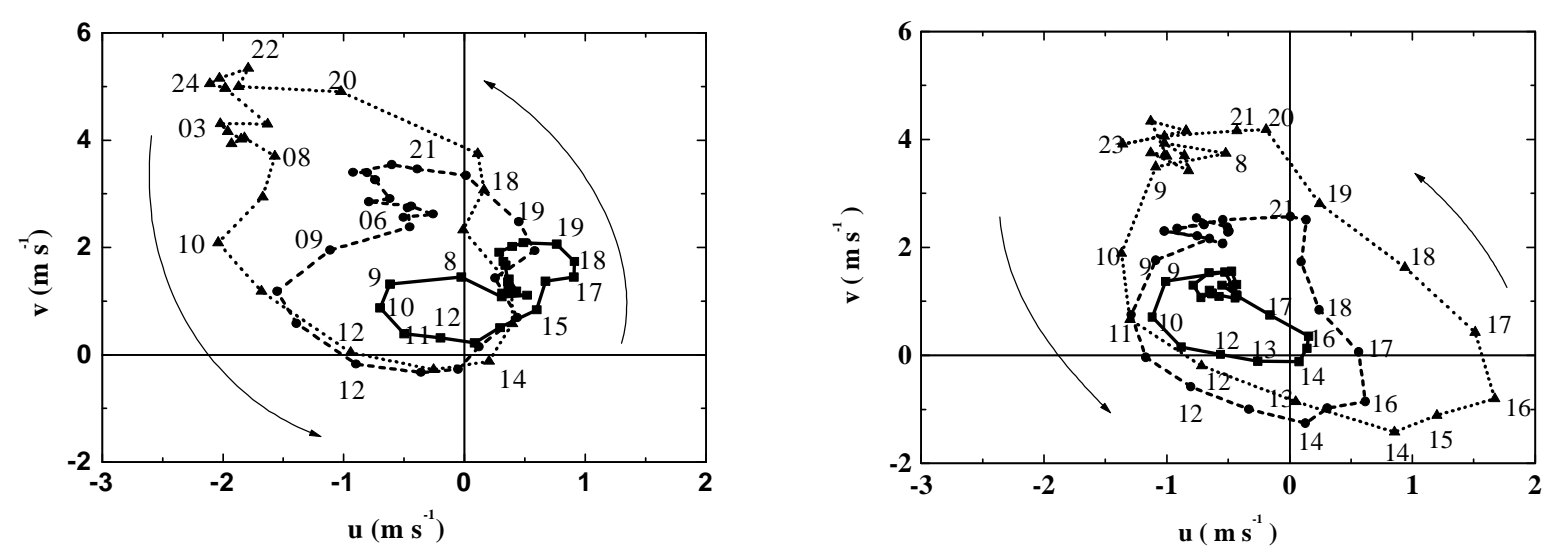

Figura 4.9 Hodógrafa do vetor velocidade do vento: (a) simulada para os níveis verticais $z^{*}=30$, 67, 114, 172, 246, 337 e 452 m (simulação L1500); (b) observada durante o inverno (c) idem para verão nos níveis de $10 \mathrm{~m}, 60 \mathrm{~m}$ e $80 \mathrm{~m}$ na torre em Iperó (quadrados, círculos e triângulos, respectivamente). Os números indicam a hora local. 
Os resultados da simulação L1500 mostram uma melhor caracterização da componente zonal que da componente meridional. A baixa resolução horizontal da simulação L1500, que não representa as feições topográficas mais importantes àvolta do CEA em Iperó, pode explicar o fato. De acordo com VELEDA (2002), o Morro de Araçoiaba, apresentando formato de domo e elevação de $350 \mathrm{~m}$ acima da altitude média da região de Iperó modifica sensivelmente o escoamento superficial do vento, principalmente durante o período noturno. Assim, bloqueio e a bifurcação do escoamento nos flancos do Morro de Araçoiaba são suficientemente intensos para aumentar a freqüência de ventos do quadrante SE no CEA, em Iperó, durante a noite. Neste caso, a escala vertical da perturbação do escoamento pode ser comparável a altura relativa do Morro de Araçoiaba.

A simulação ideal seria aquela que pudesse representar simultaneamente a topografia e distribuição de superfície regional e local, ou seja, cuja resolução variasse entre centenas de metros nas proximidades da área de interesse até dezenas de quilômetros para pontos mais distantes. Isso pode ser realizado utilizando-se grade com resolução variável ou aplicando-se diferentes grades aninhadas — o que é encaminhado para futuros trabalhos.

\subsection{O JBN de Iperó e a Circulação da Brisa}

Nesta seção investiga-se a origem dos JBN em Iperó como o ramo inferior da circulação da brisa marítima que desacopla à noite e é advectada sobre a região de Iperó para formar u ma CLP interna. Para que a circulação de brisa atinja a região de Iperó é necessário que ela apresente energia cinética inicial suficiente para vencer a barreira de energia potencial associada à topografia da escarpa da Serra do Mar.

A evolução temporal do vento simulado à superfície (L800) foi obtida ao longo de duas linhas NW-SE mostradas na Figura 4.10. Uma dessas linhas passa pela Grande São Paulo e outra passa por Iperó. A evolução temporal da velocidade e direção do vento para os pontos selecionados é apresentada nas Figuras 4.11 e 4.12. A análise dessas figuras mostra que:

1. A brisa marítima desenvolve-se no período convectivo sendo observada nos pontos mais próximos do litoral e sobre a escarpa inclinada da Serra do Mar;

2. A brisa simulada penetra na Cidade de São Paulo devido à características da topografia à volta da Cidade, que se encontra em um Platô de altitude inferior à elevações topográficas à 
SW das Serra Paranapiacaba e Serra José Bento; à NE da Serra do Mar e à NW da Serra da Cantareira e Serra do Itabera (pontos 6 e 7 da Figura 4.12);

3. As Serras de Paranapiacaba e da Cantareira bloqueiam a propagação da frente-de-brisa em direção ao interior (note-se diferença da evolução horária da velocidade e direção do vento entre pontos 1 e 7 da Figura 4.12)

4. Dois regimes aparentemente independentes da evolução diurna do vento em superfície podem ser discernidos. O primeiro associado ao ramo inferior da célula de circulação do interior para os pontos no interior do estado (pontos de 1 a 6 na Figura 4.11 b e pontos de 1 a 5 na Figura 4.12 b) e o segundo associado à brisa marítima para os pontos próximos ao litoral (pontos de 12 a 16 na Figura 4.11 d e pontos de 10 a 14 na Figura 4.12 d);

5. Pontos intermediários (do $7^{\circ}$ ao $11^{\circ}$ na Figura 4.11 e e do $6^{\circ}$ ao $13^{\circ}$ na Figura 4.12 c) apresentam padrões de desenvolvimento diurno com características intermediárias entre os padrões de Iperó e do litoral;

6. O desenvolvimento do vento superficial para os pontos próximos do litoral é caracterizado por um máximo de intensidade durante o período convectivo; enquanto para os pontos no interior próximos a Iperó, o máximo vento superficial simulado ocorre ànoite;

7. Durante o período noturno, a direção do vento para pontos próximos a Iperó é de SE enquanto para pontos junto ao litoral é de NE (Figura 4.11 f e h);

8. A velocidade máxima da brisa marítima ocorre próximo das $13 \mathrm{~h}$ com intensidade aproximada de $4 \mathrm{~m} \mathrm{~s}^{-1}$ para pontos junto ao litoral;

9. A direção do vento superficial da brisa simulada é de SE durante o período convectivo, girando para NE no período noturno dentro da camada residual;

10. A brisa não penetra pela superfície no interior, isto é, para as condições utilizadas na simulação (fracos ventos sinóticos e céu claro). Mesmo assim, podem estar ocorrendo interações pelos termos de transporte não-lineares, modificando o escoamento nos pontos intermediários entre as células de circulação do litoral e interior. 


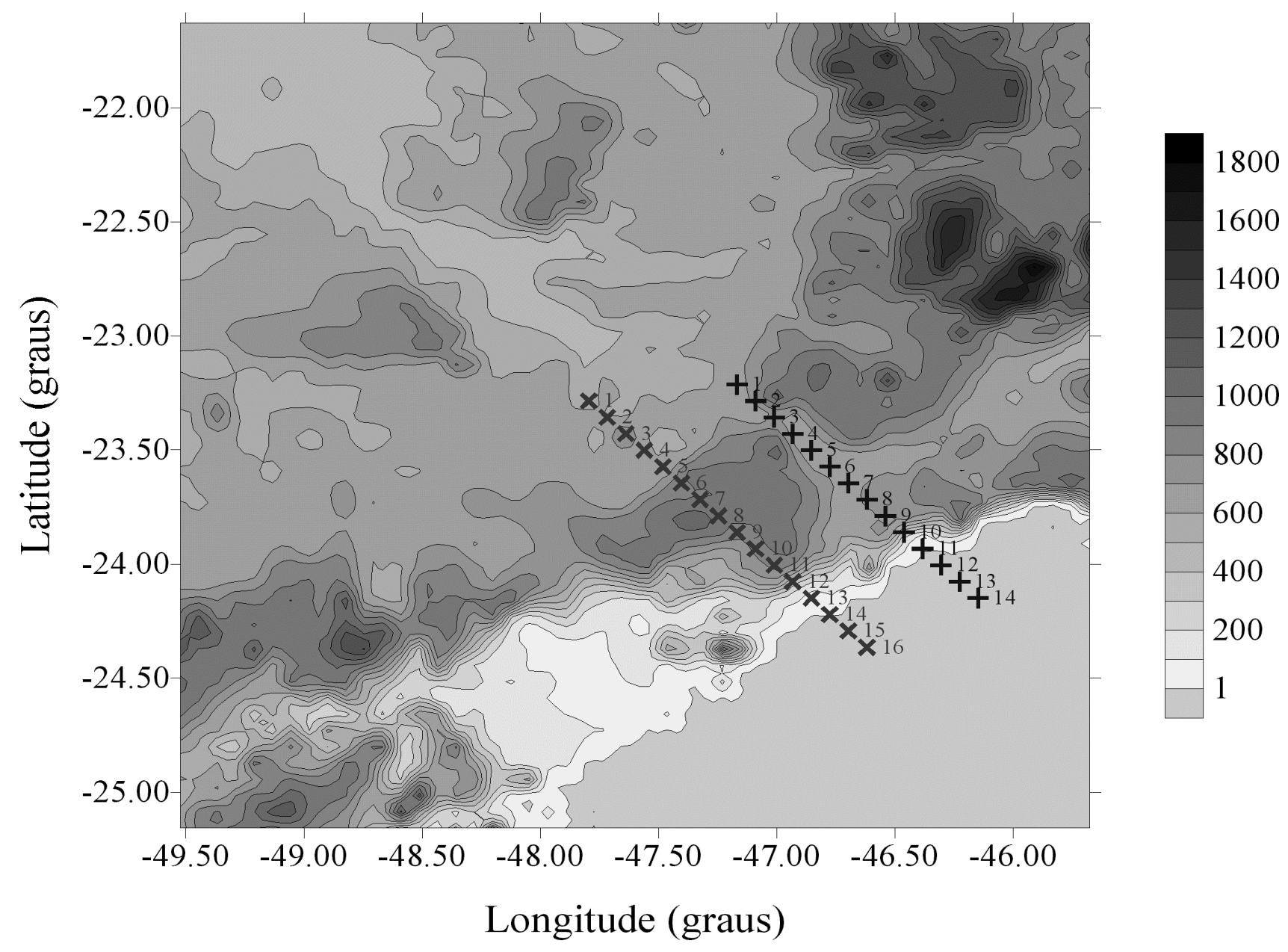

Figura 4.10 Linhas de pontos orientadas NW-SE entre Iperó e litoral (pontos $\times$ ) e entre São Paulo e litoral (pontos +) mostradas sobre as linhas de contorno da topografia. A área do CEA encontra-se junto ao ponto 3 do alinhamento a esquerda e a área da Região Metropolitana de São Paulo compreende o seguimento definido pelos pontos 3 e 8 do alinhamento àdireita. 

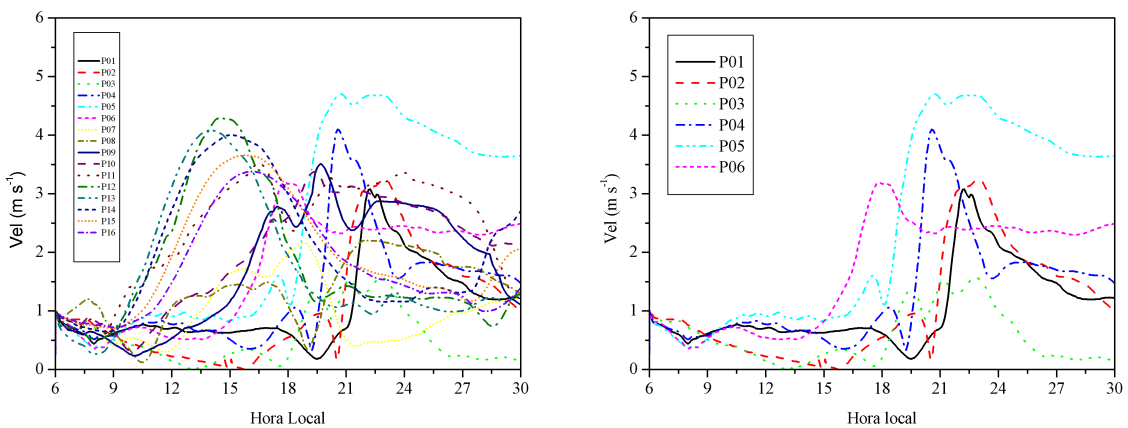

(a)

(b)
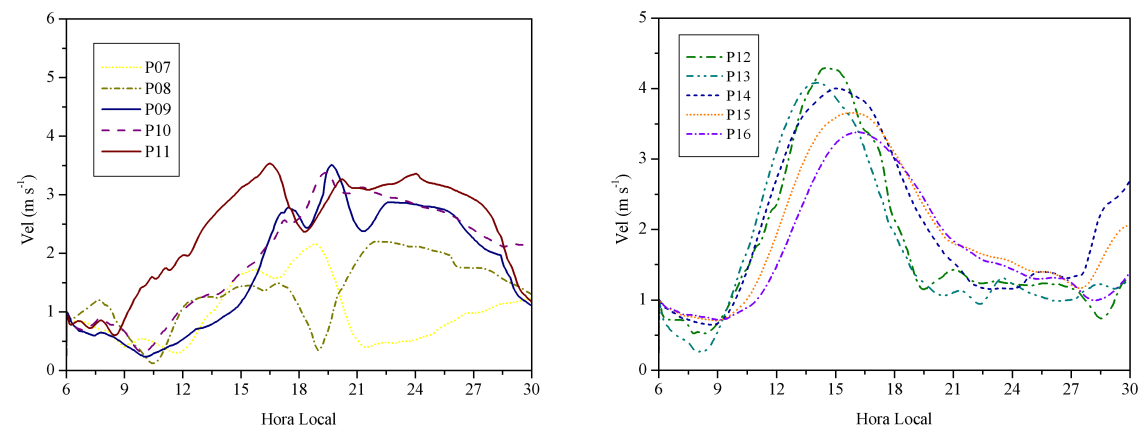

(c)

(d)
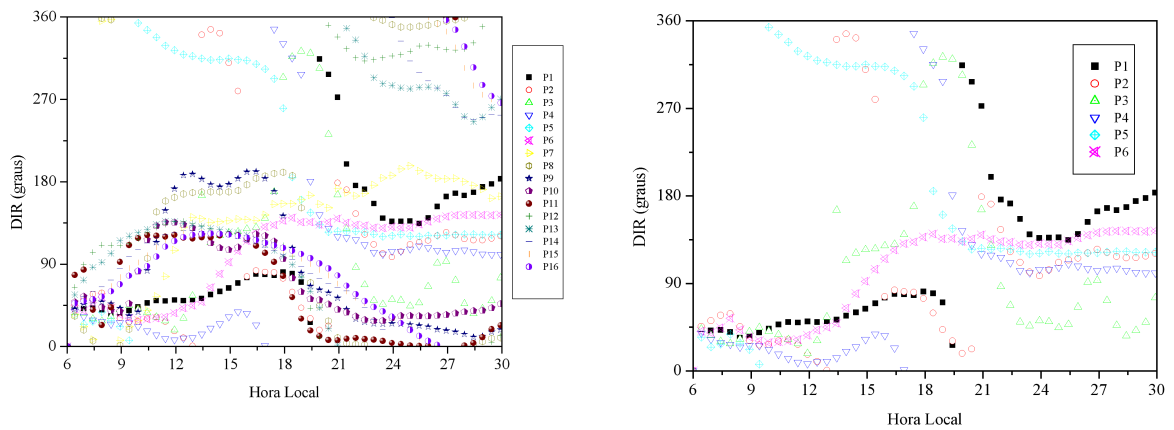

(e)

(f)
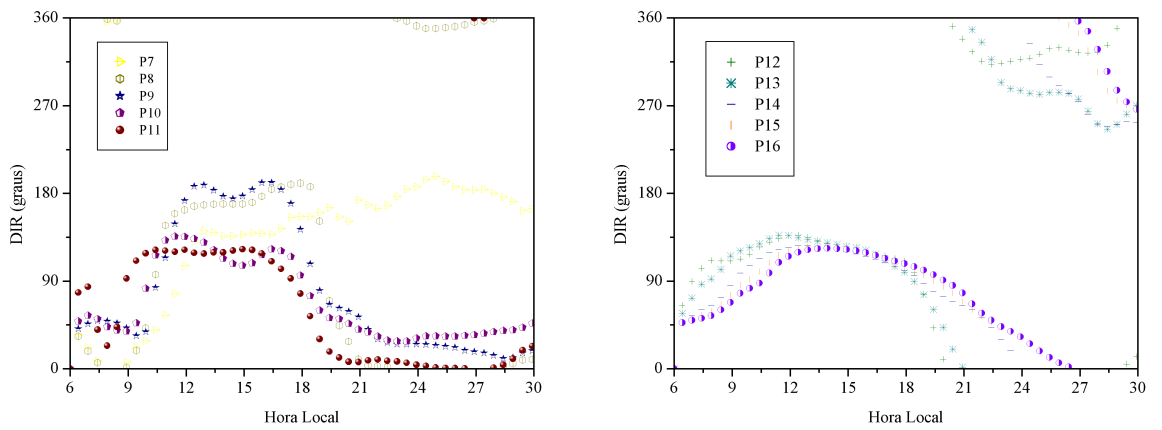

(g)

(h)

Figura 4.11 Evolução temporal diurna da velocidade e direção do vento àsuperfície $(\sigma=15 \mathrm{~m})$ simulado ao longo da linha de pontos na direção NW-SE (entre Iperó e litoral de SP) apresentada na Figura 4.10. Os gráficos assinalados por (a), (b), (c) e (d) são evoluções temporais da velocidade do vento ( $\mathrm{m} \mathrm{s}^{-1}$ ); e gráficos (e), (f), (g) e (h) são evoluções da direção do vento. Resultados da simulação L800. 


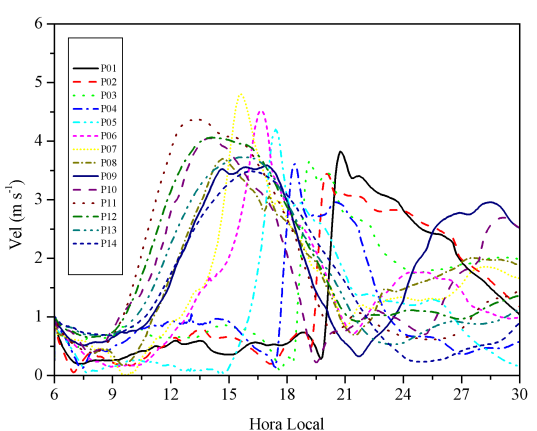

(a)

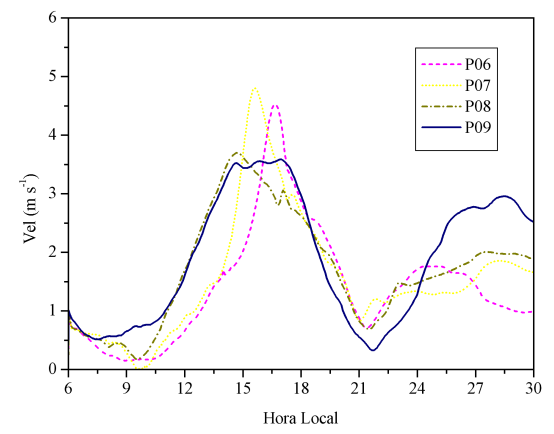

(c)

(d)

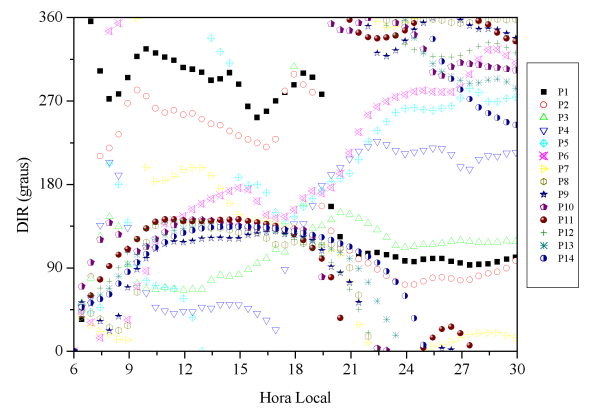

(d)

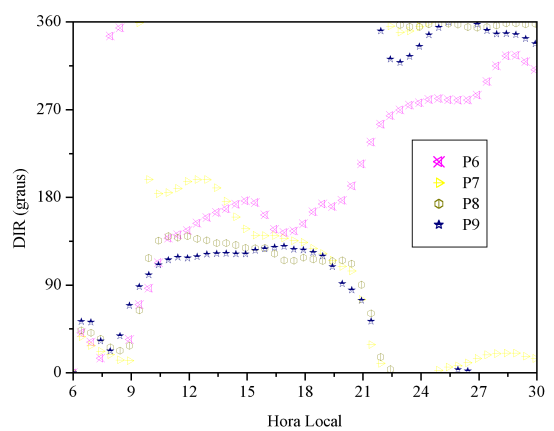

(f)

(b)

(e)

(g)
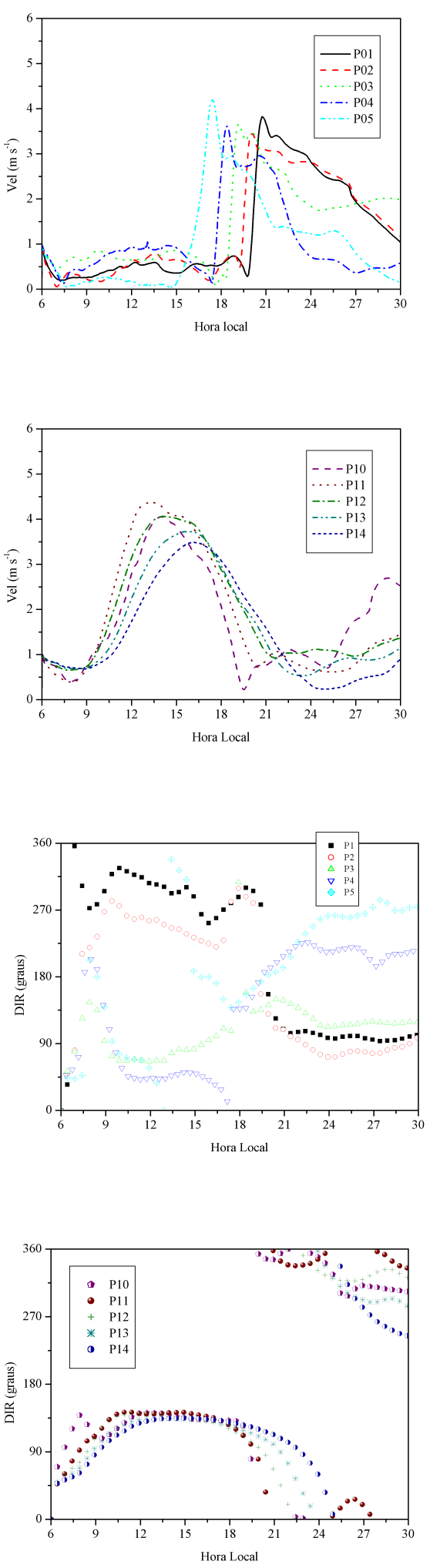

Figura 4.12 Evolução temporal diurna da velocidade e direção do vento àsuperfície $(\sigma=15 \mathrm{~m})$ simulado ao longo da linha de pontos na direção NW-SE (entre Jundiaí e litoral de SP) apresentada na Figura 4.10. Os gráficos assinalados por (a), (b), (c) e (d) são evoluções temporais da velocidade do vento ( $\mathrm{m} \mathrm{s}^{-1}$ ); e gráficos (e), (f), (g) e (h) são evoluções da direção do vento. Resultados da simulação L800. 


\subsection{Análise dos Efeitos da Topografia e Cobertura da Superfície}

Nesta seção, estuda-se a sensibilidade das circulações resultantes em relação à inclusão da topografia e dos tipos de superfície.

Definição dos ensaios experimentais - A análise numérica dos efeitos da topografia e tipo de superfície, apresentada neste item, corresponde a um planejamento fatorial $2^{2}$ completo (BARROS NETO et alli, 1995). Esse planejamento contém quatro ensaios numéricos combinando dois fatores (topografia e tipo de superfície); cada qual com dois níveis, representados pelo sinal (-) para exclusão do fator e pelo sinal (+) para inclusão. Os fatores considerados e a resposta são:

Fator 1: Topografia (sinal “-” para exclusão da topografia realística, topografia plana z = 0 e sinal “+” para inclusão da topografia realística);

Fator 2: Tipo de Superfície (sinal “-” para exclusão da variação dos tipos de superfície preservando-se apenas um tipo único sobre toda a área, que é o tipo 14 correspondente a uma área agrícola e ou mosaico de vegetação natural e o sinal "+" para inclusão de todos os tipos de superfície das Tabelas 2.1 e 2.2).

Resposta numérica: Analisa-se o campo de velocidade do vento sobre as superfícies de dois níveis da coordenada seguindo a topografia, $14 \mathrm{~m}$ e $321 \mathrm{~m}$.

Os efeitos associados aos fatores foram determinados a partir da análise estatística de quatro $\left(2^{2}\right)$ ensaios numéricos diferentes, representativos de todas as possibilidades de arranjo de dois fatores com dois níveis cada um (i. e., com ou sem topografia e com ou sem variação dos tipos de superfície). Os ensaios numéricos realizados utilizaram:

- $(-,-)$ topografia plana e tipo de superfície único;

- $(-,+)$ topografia plana e tipo de superfície realístico;

- $(+,-)$ topografia realística e tipo de superfície único e

- $(+,+)$ topografia realística e tipo de superfície realístico.

Obtidos os resultados numéricos, utilizou-se o algoritmo de YATES para se definir a média experimental, os efeitos individuais da topografia, dos tipos de superfície e da interação (não-linear) entre estes dois fatores. 


\subsubsection{Características do Escoamento Médio}

A Figura 4.13 apresenta o valor médio do experimento numérico $2^{2}$ à $6 \mathrm{~h}(24 \mathrm{~h}$ de simulação) para dois níveis acima da superfície: (a) $\mathrm{z}=14 \mathrm{~m}$ e (b) $\mathrm{z}=321 \mathrm{~m}$. Nesta e nas demais figuras, Iperó sempre se localiza no ponto central do domínio da simulação L1500. Nota-se um escoamento superficial catabático no interior de SP, apresentando direção E-SE e E-NE no litoral associado àrotação geostrófica da brisa. A região de máxima velocidade do escoamento entre 2 e 3 $\mathrm{ms}^{-1}$ encontra-se ao longo da Depressão Periférica no interior de SP e sobre o Oceano Atlântico mais àleste. A Figura $4.13 \mathrm{~b}$ mostra o escoamento no nível da coordenada $\sigma=337 \mathrm{~m}$ seguindo a topografia (aproximadamente $\mathrm{z}=321 \mathrm{~m}$ ). Neste nível, a região de máxima velocidade encontra-se deslocada para oeste, sobre as áreas mais elevadas da Serra do Mar, apresentando intensidade entre 4 e $5 \mathrm{~ms}^{-1}$ e direção E/NE. Ainda para este nível, o escoamento médio simulado indica também um domínio de ventos de direção SE em todo o Centro-Norte de SP e de ventos de NE em uma extensa região do Oeste e Noroeste paulista.

\subsubsection{Efeito do Fator 1: Topografia}

O efeito da topografia sobre o escoamento foi isolado e apresentado na Figura 4.14. Nota-se de forma clara o papel da topografia na formação de correntes de JBN de direção SE sobre todo o interior paulista. À superfície (Figura 4.14 a) escoamentos catabáticos são gerados no interior. Em especial, ao longo do arco da Depressão Periférica, em SP, geram-se escoamentos catabáticos com intensidade entre 2 e $4 \mathrm{~ms}^{-1}$. Mais acima, cerca de $337 \mathrm{~m}$ acima da superfície, escoamentos de intensidade 4 a $6 \mathrm{~ms}^{-1}$ e direção E, S e SE aparecem em todo interior paulista (Figura 4.14 b). Portanto, o papel da topografia sobre a formação de JBN, apresentando direção SE, S e E, no interior paulista é evidenciado pelos ensaios numéricos realizados. Em particular, a região de Ribeirão Preto pode estar sujeita a JBN com importante componente de Sul. Em Iperó, os ensaios numéricos indicam que JBN apresenta componentes SE e ESE mais destacadas. O experimento L1500 parece também indicar a existência de JBN de Sul sobre a região extensa àoeste das Serras Gerais do Paraná. 


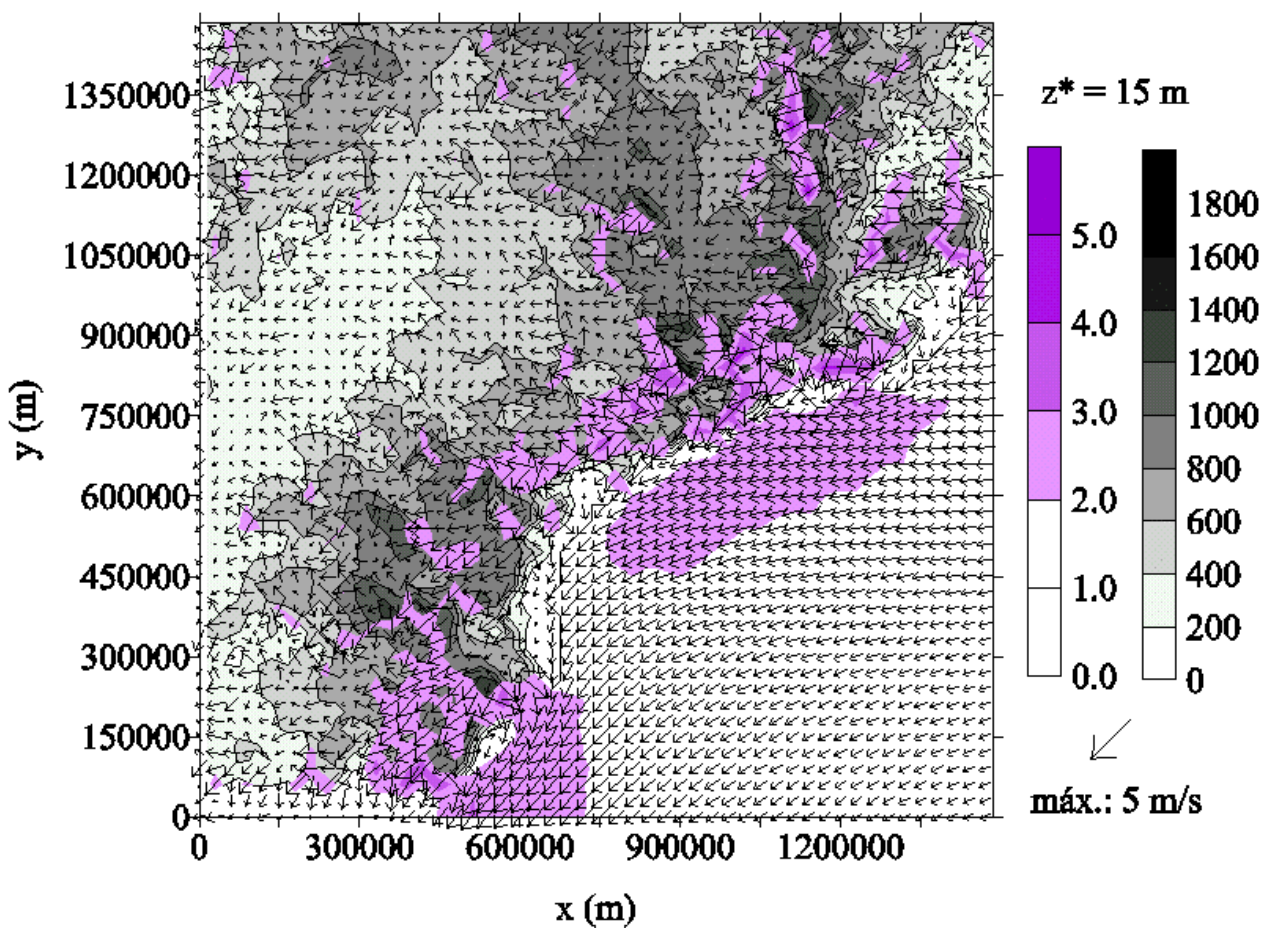

(a)

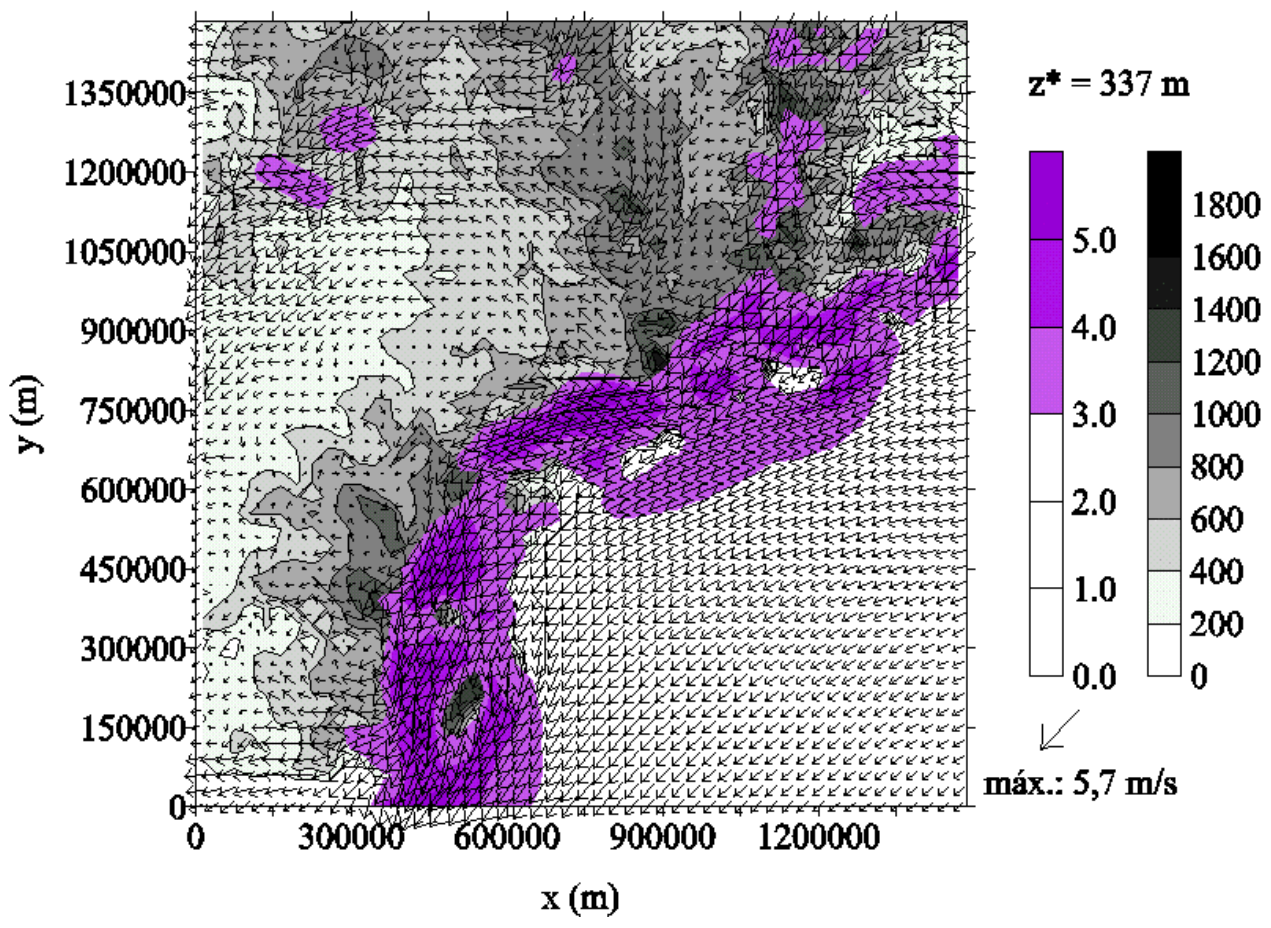

(b)

Figura 4.13 Média dos ensaios numéricos do planejamento experimental $2^{2}$ à $6 \mathrm{~h}(24 \mathrm{~h}$ de simulação) para níveis (a) $15 \mathrm{~m}$ e (b) $337 \mathrm{~m}$ da coordenada $\sigma$ (aqui chamada $\mathrm{z}^{*}$ ) seguindo a topografia. A topografia é representada pela escala em tons de cinza e as isotacas, pela escala em roxo. 


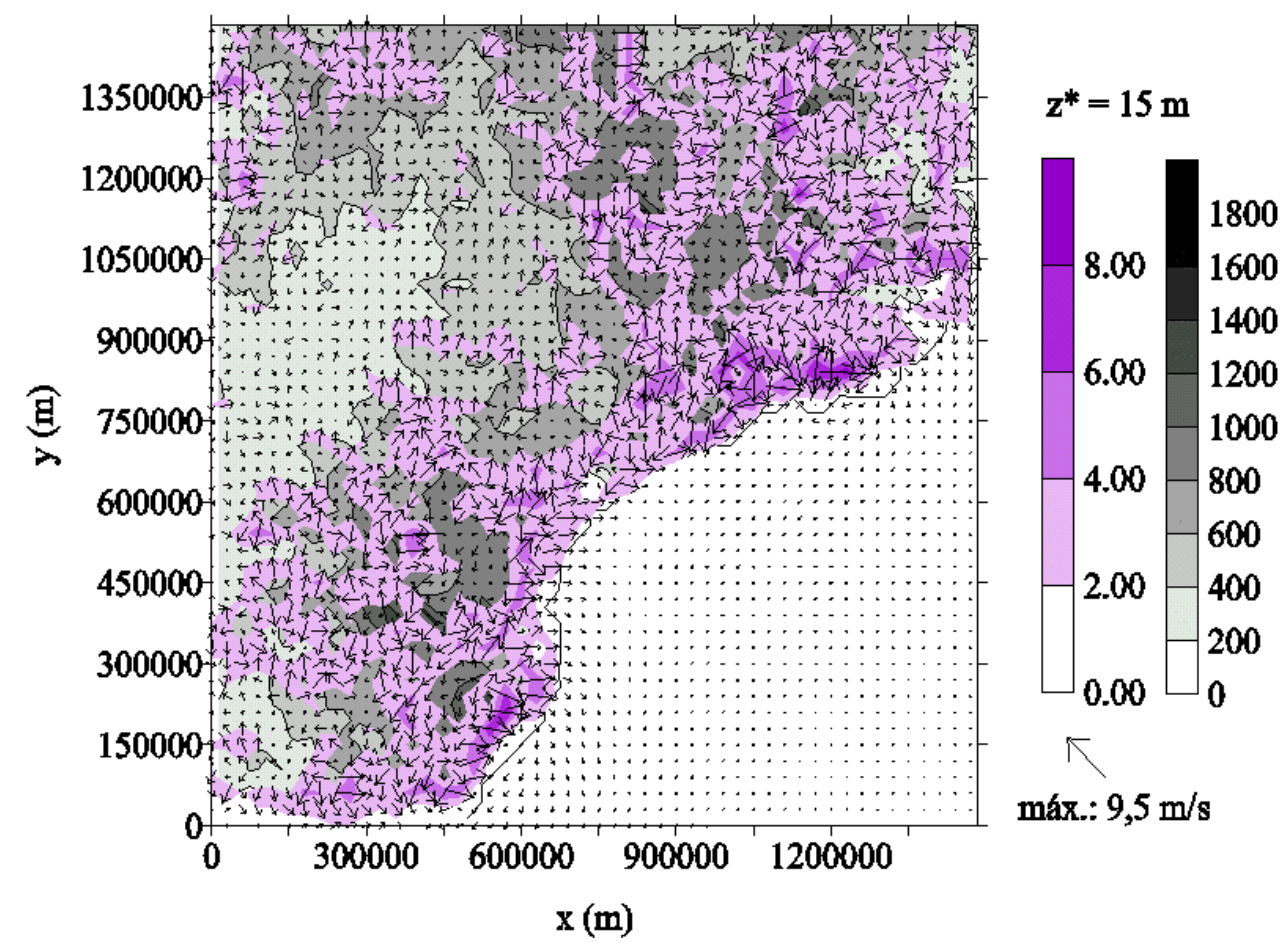

(a)

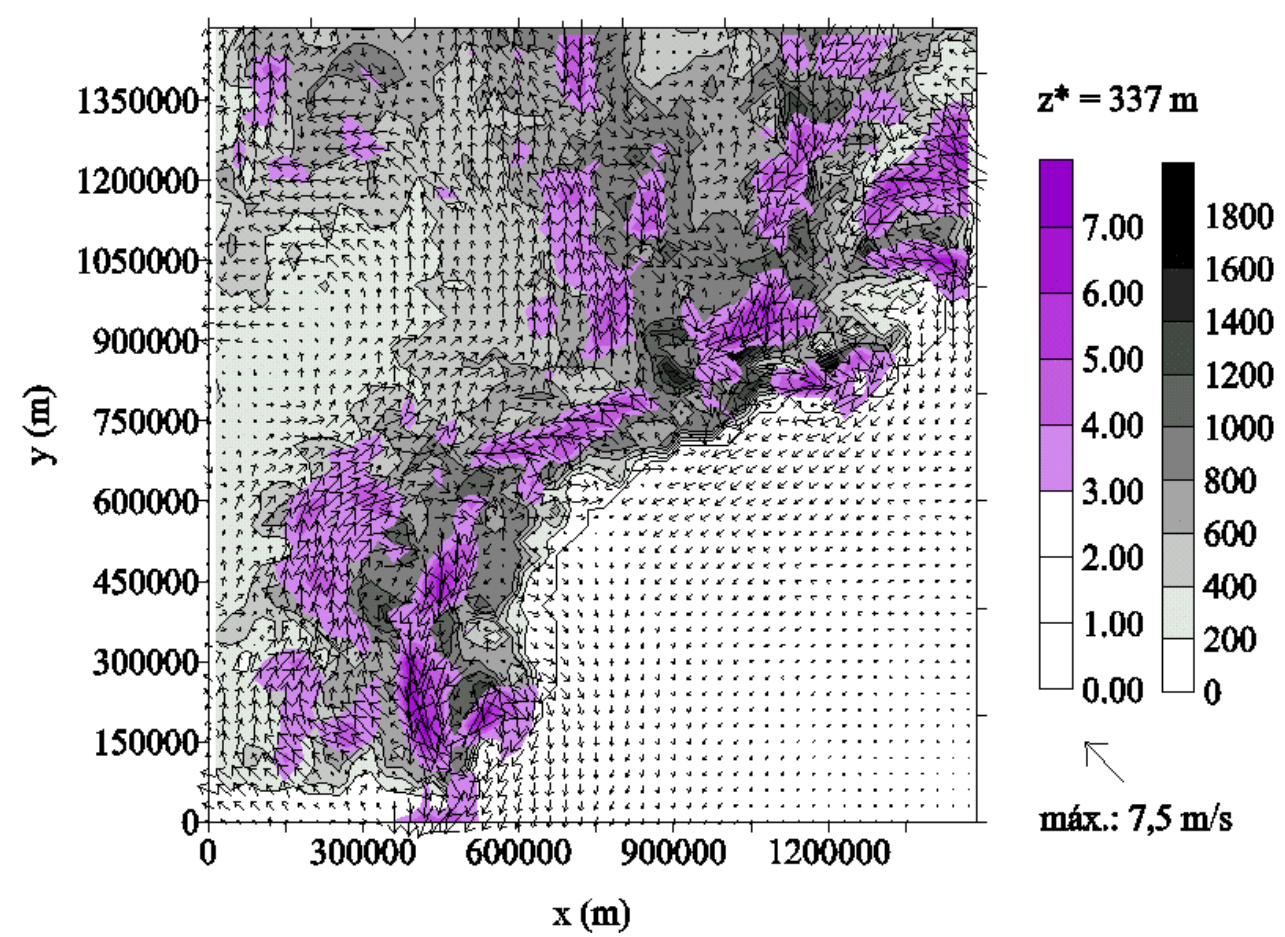

(b)

Figura 4.14 Efeito do Fator 1 (i.e., topografia) sobre o resultado do experimento com $2^{2}$ ensaios numéricos à $6 \mathrm{~h}$ (24 h de simulação) para níveis (a) $15 \mathrm{~m} \mathrm{e} \mathrm{(b)} 337 \mathrm{~m}$ da coordenada $\sigma$ ( $\left.\mathrm{z}^{*}\right)$ seguindo a topografia. A topografia é representada pela escala em tons de cinza e as isotacas, pela escala em roxo. 


\subsubsection{Efeito do Fator 2: Tipo de Superfície}

O efeito do tipo de superfície sobre o escoamento foi isolado e apresentado na Figura 4.15. Nota-se que o efeito do tipo de superfície é muito relevante na definição do escoamento ao longo da costa oceânica atlântica para níveis superficiais, gerando um escoamento de NE na faixa litorânea. O escoamento superficial na Depressão Periférica em SP também é influenciado pela introdução dos tipos de superfície, que gera uma perturbação do escoamento de SE (Figura 4.15 a).

No nível $\sigma=337$ m (Figura 4.15 b), o efeito da cobertura de superfície passa a estender-se ao longo de uma faixa sobre as áreas mais elevada da Serra do Mar, com ventos de direção NE. Assim, o efeito desloca-se de leste para oeste em relação ao seu efeito nos níveis superficiais (Figura 4.15 a). Conseqüentemente, esse efeito tende a se inclinar para oeste com a altura na CLP.

Mais para o interior de SP, o efeito da variação do tipo de superfície é pouco intenso, onde a intensidade da perturbação é de 1 a $2 \mathrm{~m} \mathrm{~s}^{-1}$, estando associada à macro-regiões com características ecológicas mais homogêneas, como aquelas presentes nas extensas manchas de ocupação agrícolas, nas áreas de irrigação e nas Matas de Araucária restantes no Paraná.

O efeito da introdução dos tipos de superfície, inclusive do contraste água do mar e superfície do continente, responsável pela brisa marítima, limita-se àfaixa litorânea e aos topos da escarpa da Serra do Mar, mas um pouco a Leste da região mais afetada pelo efeito da topografia sobre a Serra do Mar. Em geral, o efeito dos tipos de superfície se apresenta com menor intensidade quando comparado ao efeito da topografia (Figuras 4.14 a e 4.14 b).

\subsubsection{Efeito de Interação entre Topografia e Tipo de Superfície}

A interação não-linear entre os fatores 1 e 2 é apresentada na Figura 4.16. A interação afeta pouco o escoamento superficial, com uma perturbação de 1 a $2 \mathrm{~m} \mathrm{~s}^{-1}$, em núcleos espalhados pelas áreas mais elevadas. Isto se deve muito àgrande variedade de tipos de superfície presentes na área considerada. Acima, para $\sigma$ igual a 337 m acima da superfície, o efeito de interação se concentra e se organiza ao longo de uma faixa seguindo o litoral, mas localizada sobre as áreas mais elevadas da Serra do Mar. O importante do efeito de interação é que é representado por um escoamento de SE 
(Figura 4.16 b), contrário ao escoamento da brisa marítima de NE, possivelmente, ajustado pelo geostrofismo. Este efeito de inter-relação entre a topografia e a distribuição de tipos de superfície recorda um escoamento de brisa terrestre acoplado a um escoamento catabático sobre a encosta da Serra do Mar.

O efeito geral dessa interação (Figura 4.16 b) é reduzir o escoamento médio sobre uma estreita faixa entre o litoral e o interior do continente. Em outras palavras, essa interação não-linear tende a separar os escoamentos do litoral e do interior através da definição de uma faixa estreita na qual a velocidade do vento é relativamente menor. 


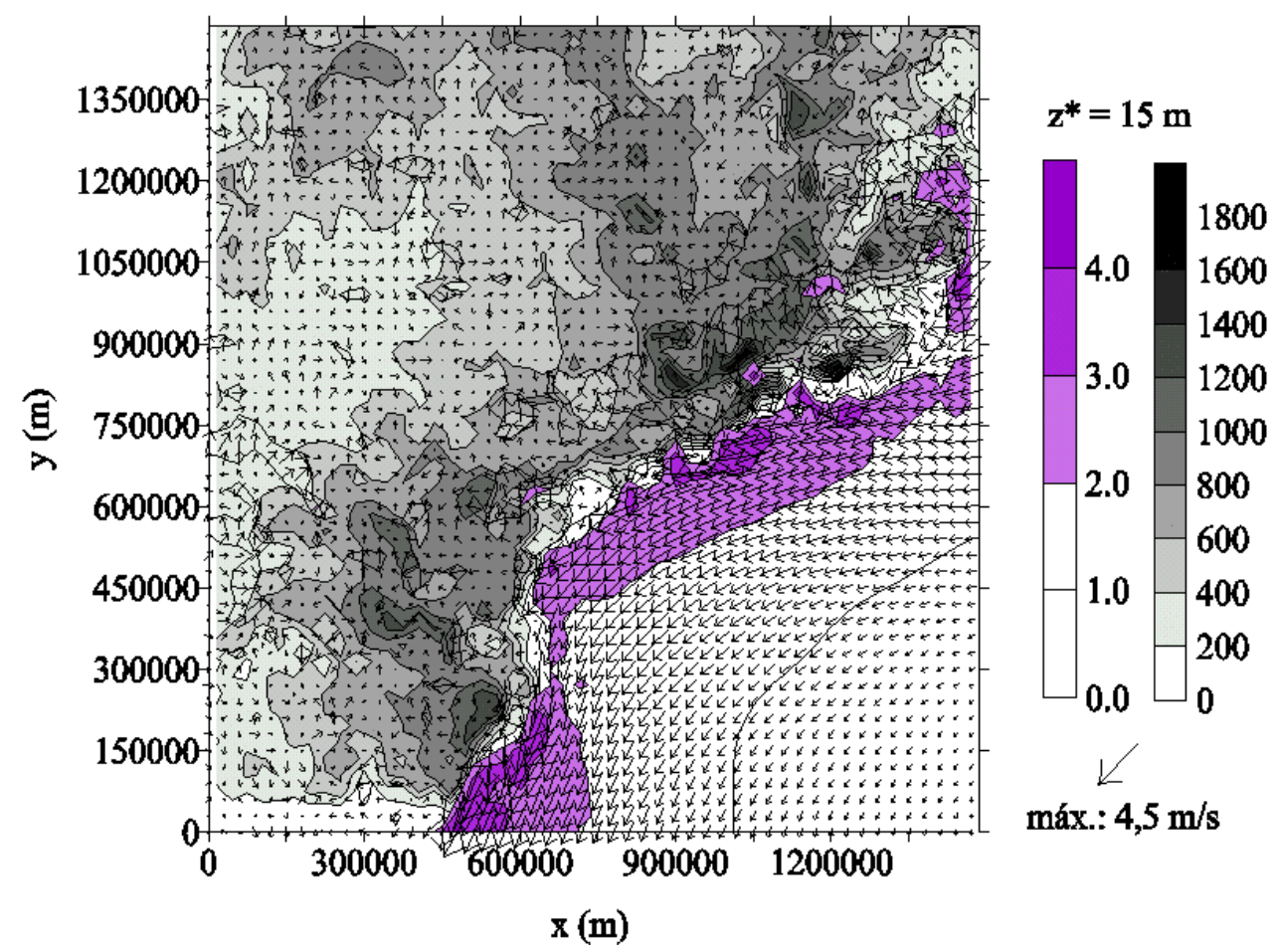

(a)

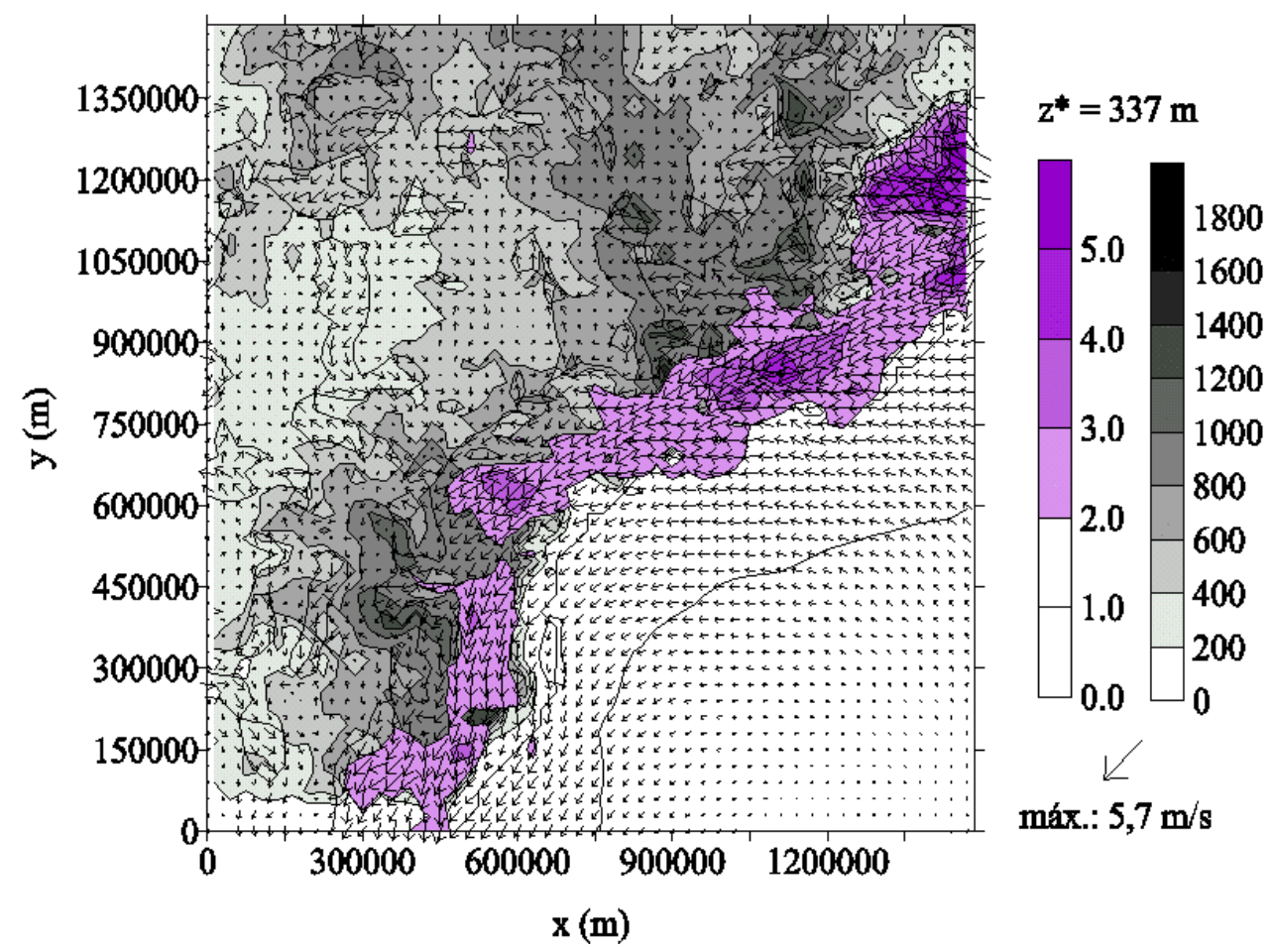

(b)

Figura 4.15 Efeito do Fator 2 (i.e., tipos de superfície) sobre o resultado do experimento com $2^{2}$ ensaios numéricos à $6 \mathrm{~h}$ (24 h de simulação) para níveis (a) $15 \mathrm{~m}$ e (b) $337 \mathrm{~m}$ da coordenada $\sigma$ (z*) seguindo a topografia. A topografia é representada pela escala em tons de cinza e as isotacas, pela escala em roxo. 


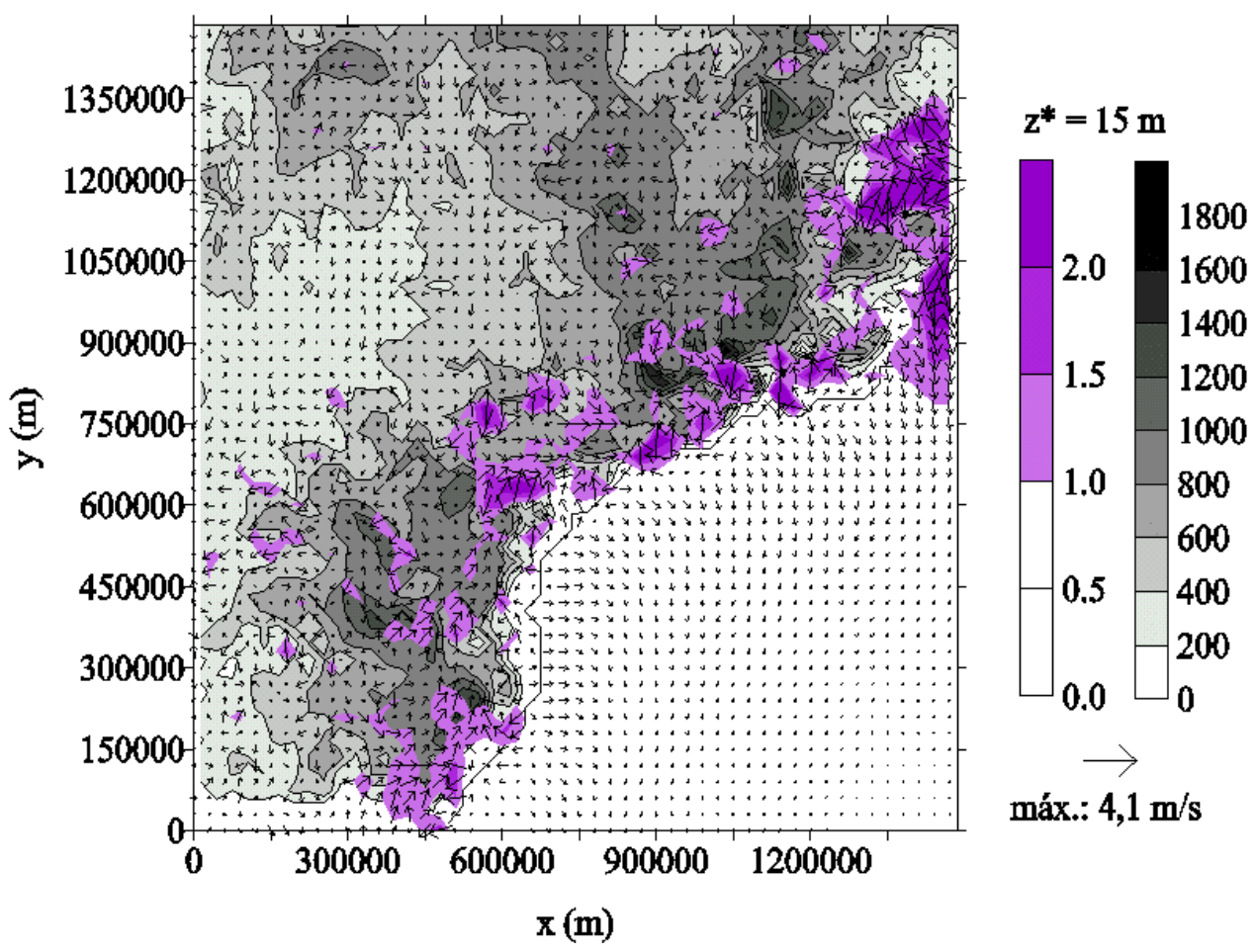

(a)

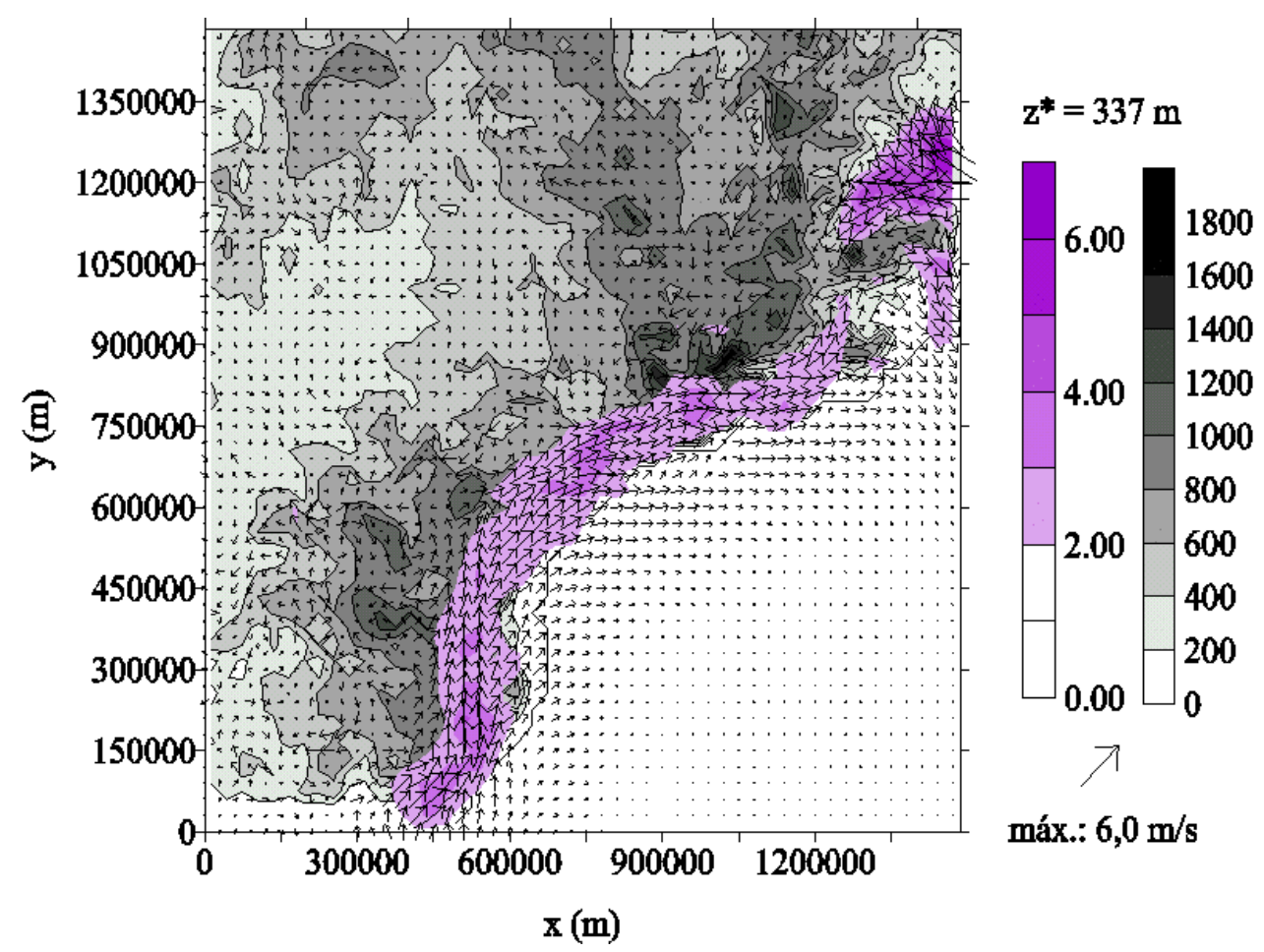

(b)

Figura 4.16 Efeito de interação entre fatores 1 e 2 (i.e., Topografia e Tipos de Superfície) sobre o resultado do experimento com $2^{2}$ ensaios numéricos æ̀ $6 \mathrm{~h}$ ( $24 \mathrm{~h}$ de simulação) para níveis (a) $15 \mathrm{~m}$ e (b) $337 \mathrm{~m}$ da coordenada $\sigma\left(\mathrm{z}^{*}\right)$ seguindo a topografia. A topografia é representada pela escala em tons de cinza e as isotacas, pela escala em roxo. 


\subsection{Distribuição do Máximo de Velocidade}

Nesta seção utiliza-se a simulação L1500 para localizar sobre o domínio as áreas de ocorrência de máximos no campo de velocidade de vento. A Figura 4.17 reapresenta o escoamento superficial obtido na simulação L1500 à 18 h (correspondente ao final do período convectivo). Nesta figura, as áreas de convergência do escoamento das células convectivas do litoral e do interior pode ser demarcada ao longo da faixa leste do Estado de São Paulo.

Nota-se que um bloqueio topográfico que impede o avanço da frente-de-brisa em direção ao interior para além da Capital, devido a presença da Serra do Mar (a NE e a SW da RMSP) e da Serra da Cantareira (ao NE da RMSP). Este bloqueio ocorre, de acordo com as simulações apresentadas, sob condições de vento fraco de grande-escala, céu claro e no período de final de verão.Para condições nas quais o escoamento sinótico é dominante das condições induzidas pela superfície e topografia (i.e., tipicamente durante a passagem de sistemas sinóticos no inverno) a penetração da brisa marítima até a região de Iperó pode ser possível, o que aparentemente pode ser inferido de algumas observações da evolução da temperatura e umidade em Iperó ao final da tarde ${ }^{9}$. Na simulação L1500, a brisa marítima possui energia cinética suficiente para penetrar pelo Vale do Rio Ribeira de Iguape. A brisa que entra pelo Vale do Ribeira ainda não atinge Iperó devido à presença das elevações da Serra do Mar, que se encontram para SE da planície do Rio Sorocaba.

A Figura 4.18 mostra o escoamento sobre a superfície $\sigma=15 \mathrm{~m}(\mathrm{z} \approx 14 \mathrm{~m}$ acima da superfície do terreno) æ̀ $3 \mathrm{~h}$. Áreas onde a velocidade do vento sobre a superfície $\sigma=337 \mathrm{~m}(\mathrm{z} \approx$ $321 \mathrm{~m}$ acima da superfície) aparece com intensidade maior que $4 \mathrm{~m} \mathrm{~s}^{-1}$ estão assinaladas (áreas em tons de roxo), sobrepostas à topografia (em tons de cor laranja). Neste horário, a região de Iperó (centro do domínio), a velocidade do vento atinge $10 \mathrm{~m} \mathrm{~s}^{-1}$ para o nível $\sigma=337 \mathrm{~m}$.

O escoamento sobre o Oceano Atlântico no setor Sudeste do domínio é de E. Já no setor Noroeste, sobre o interior do Estado de São Paulo, o escoamento segue a topografia, divergindo nos terrenos mais elevados e convergindo sobre os menos elevados. A área apresentando menores velocidades do vento que segue a linha da costa é uma indicação da presença do escoamento catabático que desce o aclive da Serra do Mar, seguindo ao longo linha da costa.

\footnotetext{
${ }^{9}$ A condição favorável à penetração da brisa em Iperó é o suporte de vento sinótico moderado de SE (ou NE) ainda sob condições de pouca nebulosidade e intensa irradiância solar (por exemplo, durante os veranicos de inverno). Neste ultimo caso, a aproximação de sistemas baroclínicos pode modular a intensidade e direção do vento sinótico produzindo escoamentos mais intensos do quadrante E que se sobrepõe àcirculação de brisa marítima no litoral.
} 
A Figura 4.19 mostra uma perspectiva 3-D da topografia do domínio $1500 \mathrm{~km} \times 1500 \mathrm{~km}$ sobreposta pelas áreas de maior intensidade de vento no nível $\sigma=337 \mathrm{~m}$ à $3 \mathrm{~h}$ (Figura 4.18). A apresentação sobre a perspectiva da topografia facilita a localização das áreas de máximos da velocidade do vento na simulação L1500. Uma área destacada de máximo aparece sobre a região de Sorocaba e Iperó, i.e., a oeste da Serra do Mar e Cantareira.

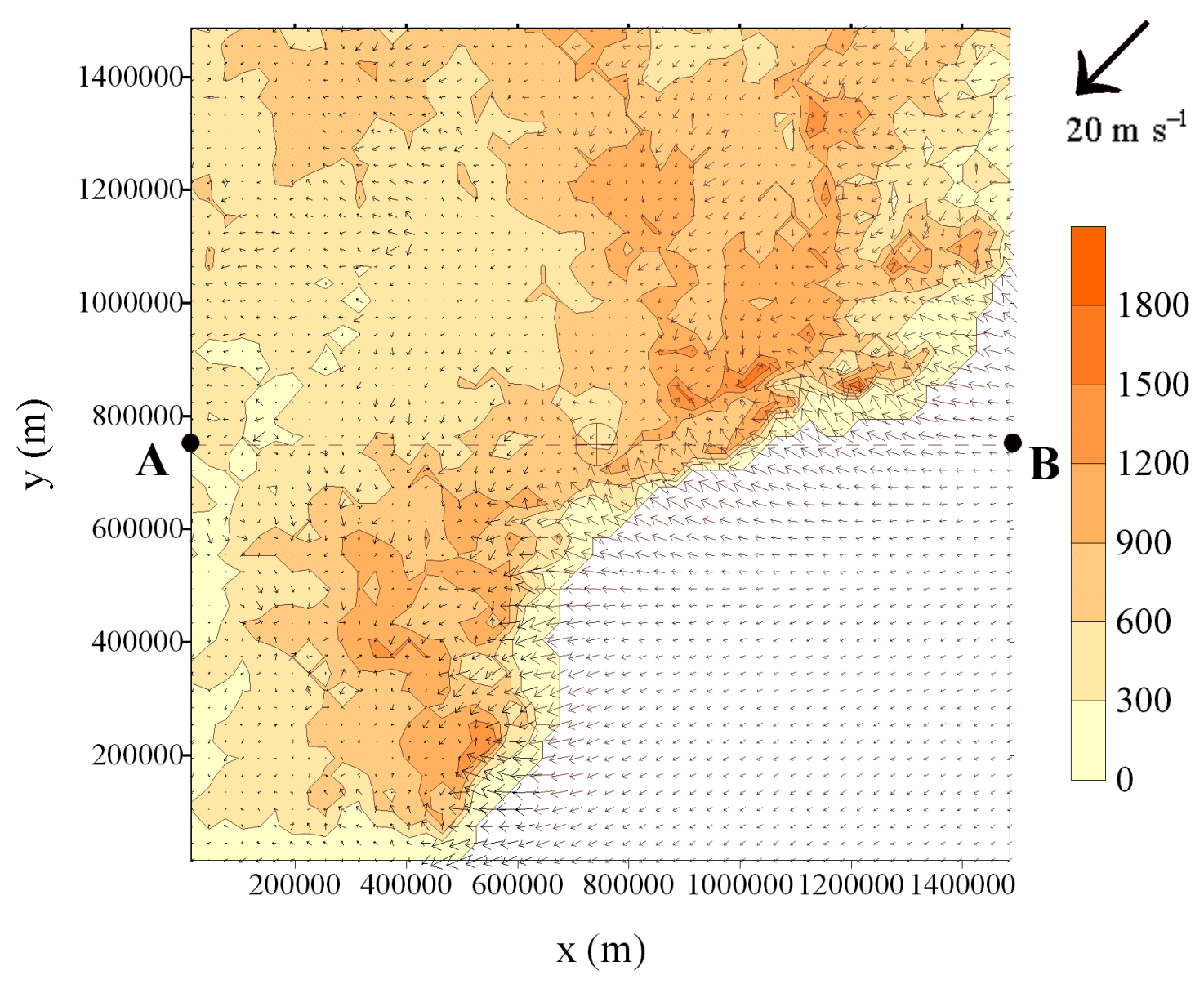

Figura 4.17 Campo de vento horizontal para $14 \mathrm{~m}$ acima da superfície à $18 \mathrm{~h}$ (tempo médio local). A topografia está indicada pela escala e contornos. O circulo no centro indica a posição geográfica de Iperó. As letras A e B definem a posição da secção transversal vertical apresentada na Figura 4.6. Vetor velocidade máximo apresenta módulo igual a $7,46 \mathrm{~m} \mathrm{~s}^{-1}$. 


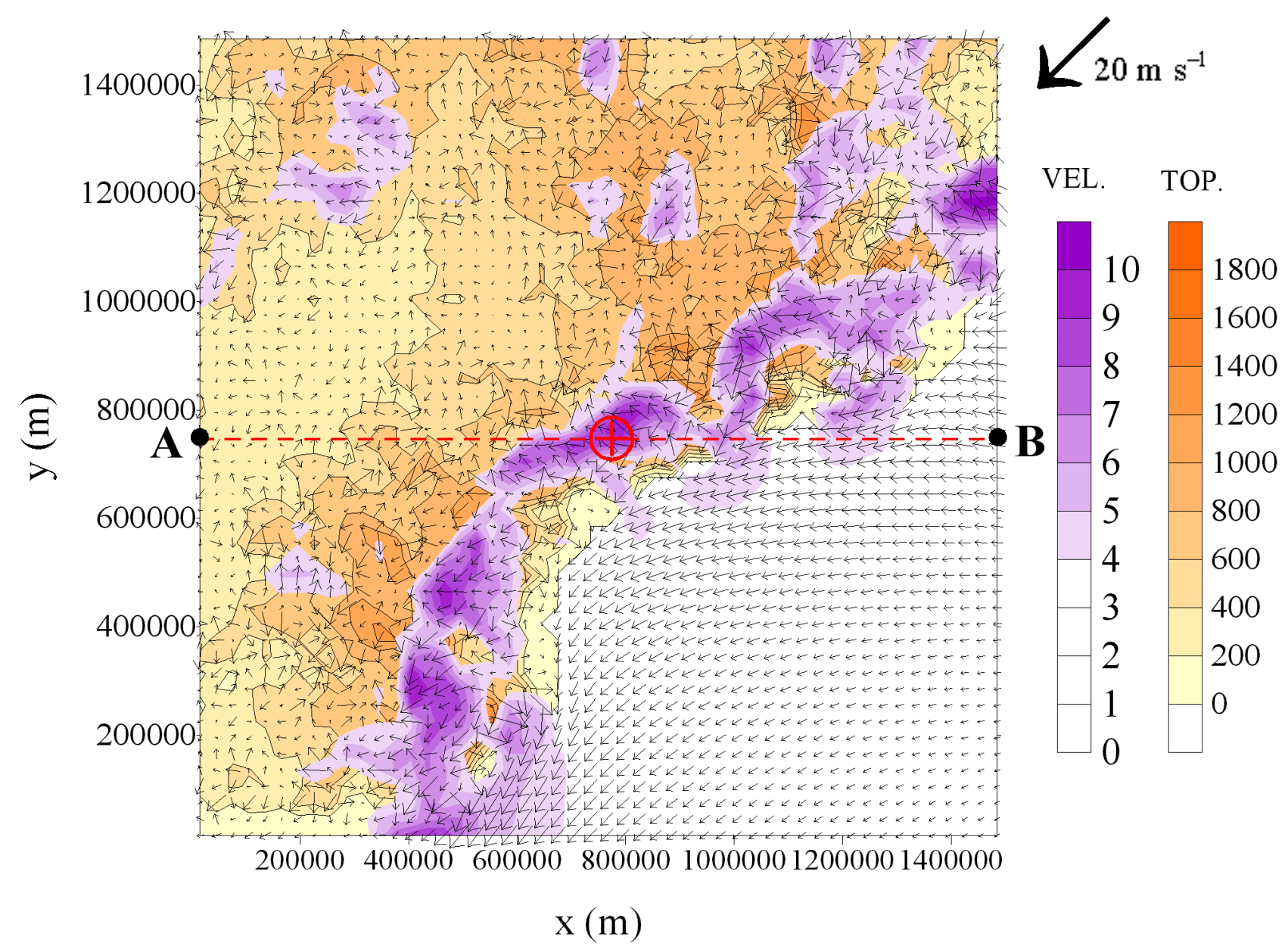

Figura 4.18 Campo de vento horizontal para $\sigma=15 \mathrm{~m}$ acima da superfície à $3 \mathrm{~h}$ (tempo local). A velocidade do vento para a superfície $\sigma=337 \mathrm{~m}$ seguindo da superfície $(\mathrm{z} \approx 321 \mathrm{~m})$ é indicada pela escala em roxo. A topografia é indicada pela escala em tons de laranja. $\mathrm{O}$ círculo aberto indica a posição de Iperó. As letras A e B definem a posição da secção transversal mostrada na Figura 4.6. Vetor velocidade máximo apresenta módulo igual a $8,81 \mathrm{~m} \mathrm{~s}^{-1}$.

\subsection{Modelo Conceitual}

Da análise dos dados numéricos e observacionais emerge um Modelo Conceitual (Figura 4.20) que se propõe a descrever de forma integrada as células de circulação mais importantes que ocorrem sobre o Estado de São Paulo, ao longo da latitude de Iperó.

O modelo conceitual é composto por duas células básicas de circulação de mesoescala cuja origem está na interação entre a topografia, os tipos de superfície e a dinâmica da CLP. A primeira célula se estabelece àleste do Estado, estando associada àbrisa marítima e ao escoamento induzido pela escarpa da Serra do Mar que se estabelecem durante o período convectivo. A segunda célula se 
estabelece sobre o Planalto Paulista, no interior do Estado de São Paulo, tem sua origem no efeito térmico da topografia do interior, caracterizada pela encosta que se inclina suavemente em direção ao vale do Rio Paraná.

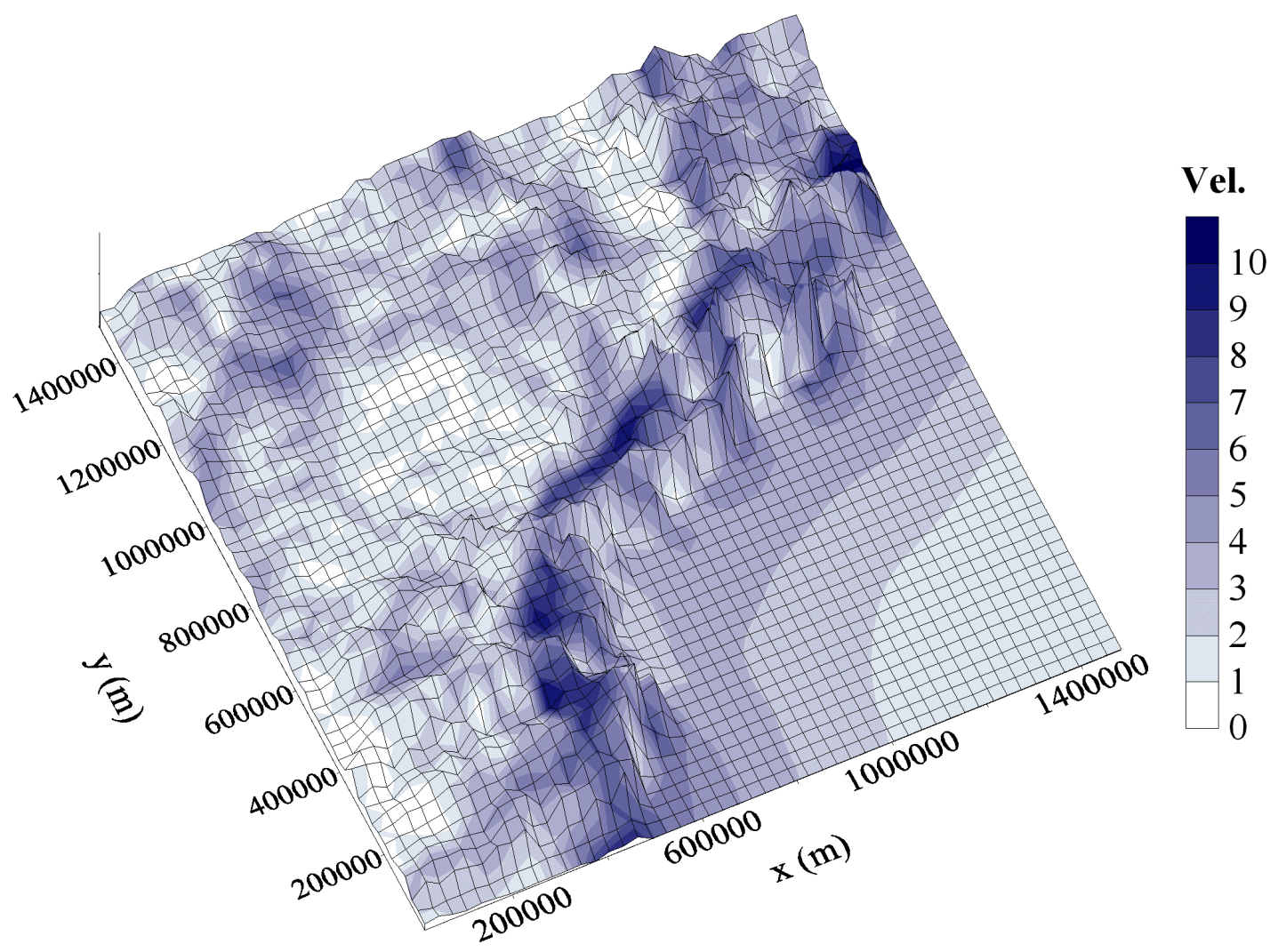

Figura 4.19 Perspectiva da topografia regional no domínio $1500 \mathrm{~km} \times 1500 \mathrm{~km}$ sobreposta pela velocidade do vento (em tons de azul) para o nível de $337 \mathrm{~m}$ acima da superfície à $3 \mathrm{~h}$ da hora local em Iperó. A região de Iperó localiza-se junto ao centro da figura nas coordenadas (750.000 m; $750.000 \mathrm{~m})$.

As células de circulação convectivas definem os escoamentos à leste e à oeste da Serra da Cantareira. Os ramos inferiores dessas células estão associados ao escoamento da brisa marítima e da escarpa (àleste) e ao escoamento anabático vale-montanha sobre o terreno inclinado do Planalto Paulista (àoeste) com inclinação da ordem de 1:1000.

Durante o período noturno, os ramos inferiores das células de circulação desacoplam da superfície, resultando no JBN de SE na região de Iperó (para o interior, em especial na área da Depressão Periférica) e no JBN de NE sobre a região correspondente ao Platô da Cidade de São Paulo (Figura 4.20).

A zona de contato entre estas duas circulações é uma área de convergência caracterizada por ventos relativamente fracos. Nesta zona de contato, a existência de um notável cisalhamento do 
vento pode induzir turbulência, contribuindo para a mistura das características das células do litoral e interior. Do ponto de vista prático, a dispersão de poluente atmosférico liberado no domínio da célula do litoral pode ser transferido por transporte e difusão turbulenta para o domínio da célula de circulação do interior, passando do ramo inferior da célula convectiva do litoral para o ramo superior da célula convectiva do interior.

Durante o período convectivo, a circulação na célula do litoral é relativamente mais intensa que a da célula do interior. Isso implica que a presença da célula do litoral é destacada na caracterização do escoamento nas áreas da Cidade de São Paulo ${ }^{10}$, da Serra do Mar e do Litoral Paulista.

$\mathrm{Na}$ atmosfera livre (bem acima da CLP), o escoamento é pouco perturbado pela superfície e as linhas de corrente não apresentam curvatura.

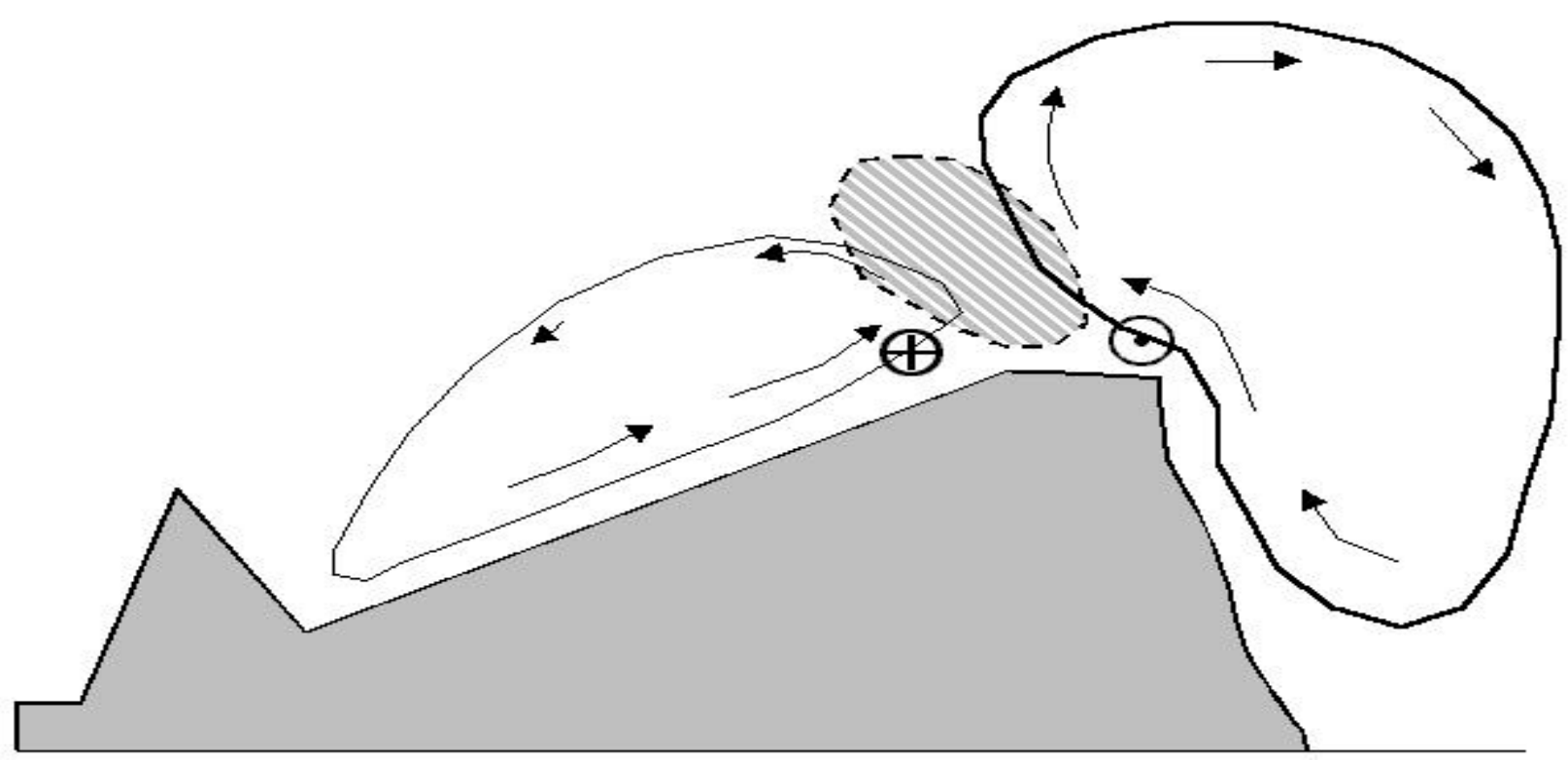

Figura 4.20 Modelo Conceitual de formação da Camada Limite caracterizada por cisalhamento do vento horizontal sobre a porção leste do Planalto Paulista, i.e., sobre Platô Paulista e Depressão Periférica. A célula de circulação convectiva formada na escarpa da Serra do Mar em associação com a brisa do litoral projeta-se ligeiramente sobre a célula desenvolvida sobre a encosta inclinada do Planalto Paulista (porção leste da bacia do Rio Paraná). A região entre as duas células é caracterizada por cisalhamento do vento horizontal, e esse cisalhamento pode implicar em aumento da dispersão de poluentes na região do Platô Paulista e circunvizinhança (através do termo de produção mecânica de ECT). Uma parcela de ar, originalmente no ramo inferior da célula de circulação da brisa marítima, segue para o interior de SP pelo ramo superior da célula de circulação do interior.

\footnotetext{
${ }^{10}$ A Grande São Paulo localiza-se em uma extensa área correspondente ao Platô Paulista, região à NW da Serra da Cantareira, morros à SW e a NE do Platô.
} 


\section{CAPÍtULO 5}

\section{Efeitos do JBN sobre a Trajetória de um Poluente Inerte Emitido de Iperó}

Neste capítulo estuda-se numericamente o efeito do JBN e das circulações induzidas pelo terreno complexo sobre a trajetória de um poluente atmosférico inerte, emitido continuamente por uma fonte pontual junto à superfície localizada em Iperó. Para isto, utilizase uma rotina de dispersão Lagrangiana de partículas acoplada ao modelo TVM.

\subsection{Caracterização do Poluente}

O Centro Experimental ARAMAR (CEA) em Iperó é responsável pela etapa de enriquecimento isotópico do urânio por ultracentrifugação gasosa de $\mathrm{UF}_{6}$. Sua tarefa visa gerar tecnologia para produção e abastecimento de combustível destinado ao submarino nuclear brasileiro.

O Urânio natural é composto de dois isótopos: U 235 (0,7\% do U natural) fissionável e U 238 (99,3\% do U natural) estável. Um reator típico utilizando U 235 trabalha com concentração entre 3,5 e 4,5 \% de U 235, o que significa que $80 \%$ do U 238 originalmente presente, precisa ser removido, no processo de enriquecimento isotópico. Dois processos básicos têm sido empregados industrialmente: (a) difusão gasosa de Hexafluoreto de urânio $\left(\mathrm{F}_{6} \mathrm{U}\right)$ e (b) ultracentrifugação gasosa de $\mathrm{F}_{6} \mathrm{U}$ (utilizada em Iperó). Após o enriquecimento isotópico de $\mathrm{F}_{6} \mathrm{U}$, que lhe incrementa a fração de $\mathrm{U} 235$, é convertido em óxido de urânio, que é prensado com altas temperaturas $\left(1400^{\circ} \mathrm{C}\right)$ na sinterização das pastilhas de cerâmica ("pellets"), que serão colocadas em tubos de metal, então arranjados em feixes ("fuel assembly") a serem inseridos prontos no tanque de água pesada do reator. Tanto a água pesada como as varas de controle ("control rods") inseridas no reator servem para moderar a velocidade dos nêutrons emitidos pela fissão dos núcleos de U 235. Os núcleos de U 238, que estão presentes, majoritariamente, não fissionam, mas podem absorver um nêutron para 
formar Plutônio 239 (Pu 239), que é fissionável e produz metade da energia térmica do reator. O U 235 que fissiona separa-se em fragmentos da fissão, i.e., produtos altamente radioativos, que no total apresentam massa menor que a do U 235 não fissionado por emissão de energia. Ao final, $90 \%$ da massa é constituída de U 238, mais uma fração de U235, não fissionado, plutônio e outros produtos da fissão. O reaproveitamento do rejeito quente pode ser feito implicando em novo combustível (i.e., reciclado) formado um óxido misto (MOX), pela junção de Óxidos de Plutônio e Urânio, que pode ser novamente aproveitado em reator que queime MOX.

De acordo com o EIA (CTMSP 1997), as unidades de processo em Iperó apresentam uma capacidade máxima de processamento de $102 \mathrm{~kg}$ de $\mathrm{U}$ por hora. O processo do combustível no CEA envolve as seguintes substâncias: (a) "yellow cake", que é minério natural dos óxidos de Urânio, contendo majoritariamente $60 \%$ de $\mathrm{U}_{3} \mathrm{O}_{8}$; (b) Ácido nítrico $\left(\mathrm{HNO}_{3}\right)$; (c) Nitrato de uranila (NTU), dado por $\mathrm{UO}_{2}\left(\mathrm{NO}_{3}\right)_{2}$ mais impurezas; (d) resíduos ácidos; (e) Trióxido de urânio $\left(\mathrm{UO}_{3}\right)$; (f) Dióxido de urânio $\left(\mathrm{UO}_{2}\right)$ craqueado; $(\mathrm{g}) \mathrm{HF}$ (Hidrato de Fluor); (h) Tetrafluoreto de urânio $\left(\mathrm{UF}_{4}\right)$; (i) Hexafluoreto $\left(\mathrm{UF}_{6}\right)$; (j) liga Monel $(60 \%$ de $\mathrm{Ni}, 35 \%$ de $\mathrm{Cu}$ e $5 \%$ de $\mathrm{Fe}$ ); (k) Hezafluoreto nas suas diferentes fases; (l) ultracentrifugação gasosa de $\mathrm{UF}_{6}$ em cascata a quente. Ao longo deste processo industrial ocorre perda inevitável de pequena quantidade da matéria-prima ou enriquecida isotopicamente para ao ambiente. Isto acontece, seja na forma de gases incontidos na instalação (cuja pressão interna é negativa), seja na forma de rejeitos industriais, de impurezas obtidas do processo de filtragem, durante o transporte e transferência entre vasos de estocagem, nos recipientes, destiladores, e aparatos de mudança de fase. As principais emissões correspondem a partículas do próprio minério radioativo e óxidos de nitrogênio $\mathrm{NH}_{3}, \mathrm{H}_{2}, \mathrm{HF}$ e $\mathrm{F}_{2}$ oriundas nos processos com $\mathrm{HNO}_{3}, \mathrm{NH}_{3}, \mathrm{~F}_{2}$ e $\mathrm{HF}$; de pequenas quantidades de $\mathrm{UF}_{6}, \mathrm{UO}_{2} \mathrm{~F}_{2}$ e $\mathrm{HF}$ incontidas; de materiais radioativos, de gases nobres e halogênios; do Hexafluoreto $\mathrm{UF}_{6}$ gasoso que em quantidades traço alcança a atmosfera e sofre hidrólise com o vapor de água para formar aerossóis e partículas aquosas de $\mathrm{UO}_{2} \mathrm{~F}_{2}$ e $\mathrm{HF}$; dos produtos de combustão do óleo de caldeira, $\mathrm{NO}_{\mathrm{x}}$ e $\mathrm{SO}_{2}$ e seus particulados e dos isótopos radioativos de $\mathrm{Kr}, \mathrm{Xe}, \mathrm{Br}$ e I. Nos níveis de emissão da instalação, medidas de concentração (em $\mathrm{Cu} / \mathrm{s}$ ou $\mathrm{Bq} / \mathrm{s}$ ) pontuais realizadas a volta do CEA indicaram concentrações de radionuclídeos da mesma ordem de grandeza da concentração de fundo ambiental da região. 


\subsection{Dispersão na Região de $100 \mathrm{~km}$ por $100 \mathrm{~km}$ à volta de Iperó}

O objetivo desta seção é mostrar como o JBN induzido pela topografia ao redor do CEA modula o desenvolvimento do campo de concentração gerado por uma emissão pontual e contínua de radionuclídeos de uma fonte a superfície.

KARAM et alli (2001) e PEREIRA et alli (2001) apresentam de forma suscinta a descrição do JBN e sua relação com as feições principais da topografia no Estado de SP e o impacto do JBN sobre a concentraçao do radionuclídeo.

A area de estudo corresponde a $10.000 \mathrm{~km}^{2}$ sobre uma região de terreno complexo (i.e., que apresenta diferentes escalas topográficas e diversidade de uso da terra, definindo um mosaico vegetal e ocupacional). A distribuição de cidades na área é mostrada na Figura 5.1. A instalação industrial piloto chamada Centro Experimental Aramar (CEA) está localizada no centro desta região no município de Iperó. Apesar do rigor na aplicação de procedimentos de segurança de proteção industrial, ocupacional e ambiental (CTMSP, 1997), o processo de enriquecimento isotópico de Urânio por ultracentrifugação do gás $U_{6}$ apresenta sempre um potencial de contaminação do ar, do ambiente em geral e do homem - que não pode ser desconsiderado.

As partículas emitidas foram liberadas continuamente de uma altura de $10 \mathrm{~m}$ acima da superfície (i.e., altitude $580 \mathrm{~m}$ em Iperó). Durante o período de simulação, correspondente a $24 \mathrm{~h}$, foram liberadas 20.000 partículas, resultando numa emissão de aproximadamente duas partículas por passo de tempo do modelo Lagrangiano. Nesta simulação as partículas representam um gás inerte. Processos de deposição e remoção não foram considerados aqui.

A Figura 5.2 mostra o logaritmo da concentração do radionuclídeo na camada de ar adjascente a superfície com $30 \mathrm{~m}$ de espessura. A concentração apresentada em termos de $\log _{10}$ corresponde à médias de $12 \mathrm{~h}$ durante o período diurno, entre $6 \mathrm{~h}$ e $18 \mathrm{~h}$ do tempo local (Figura 5.2 a) e noturno, entre 18 h e 6 h do dia seguinte (Figura 5.2 a). 


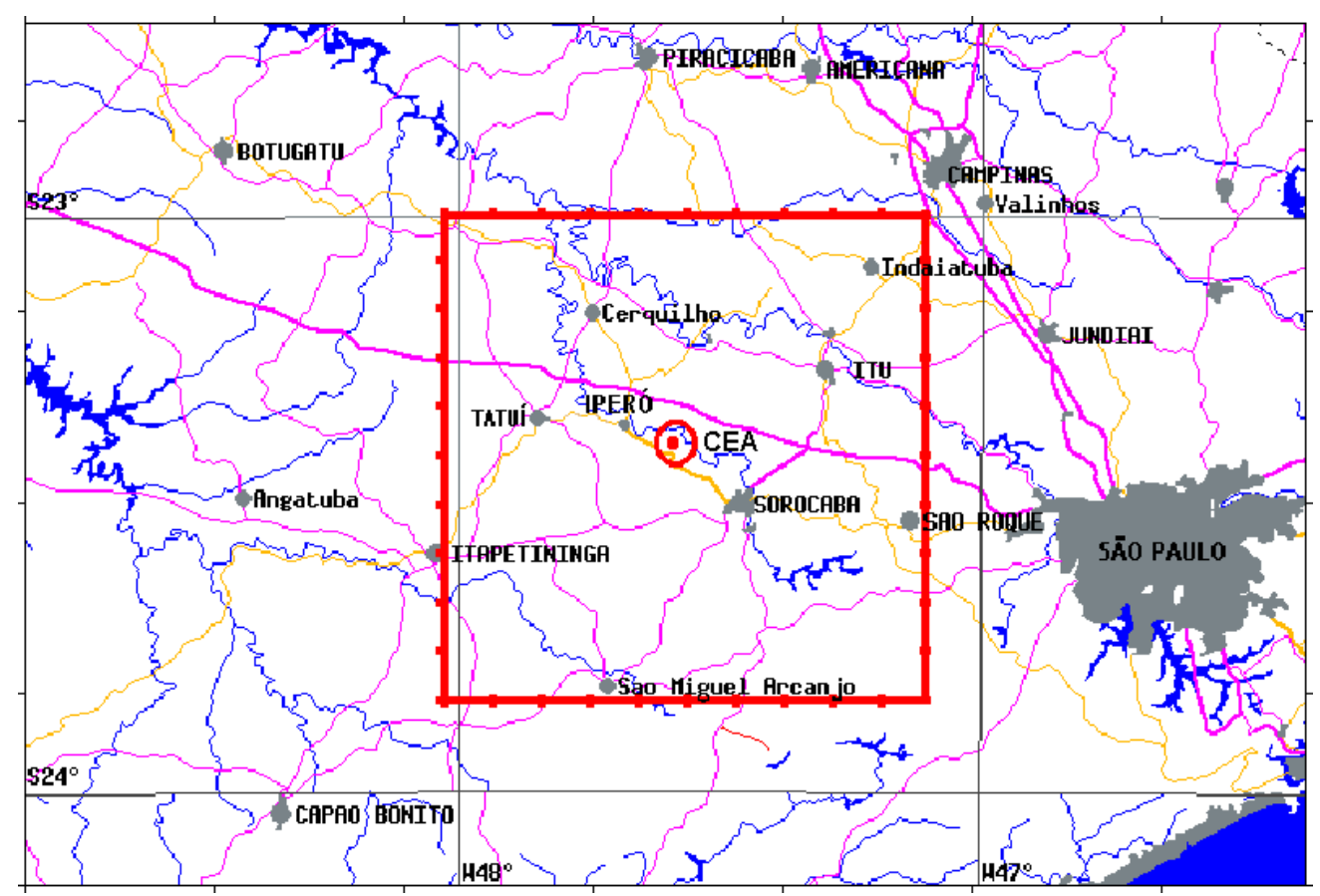

(a)

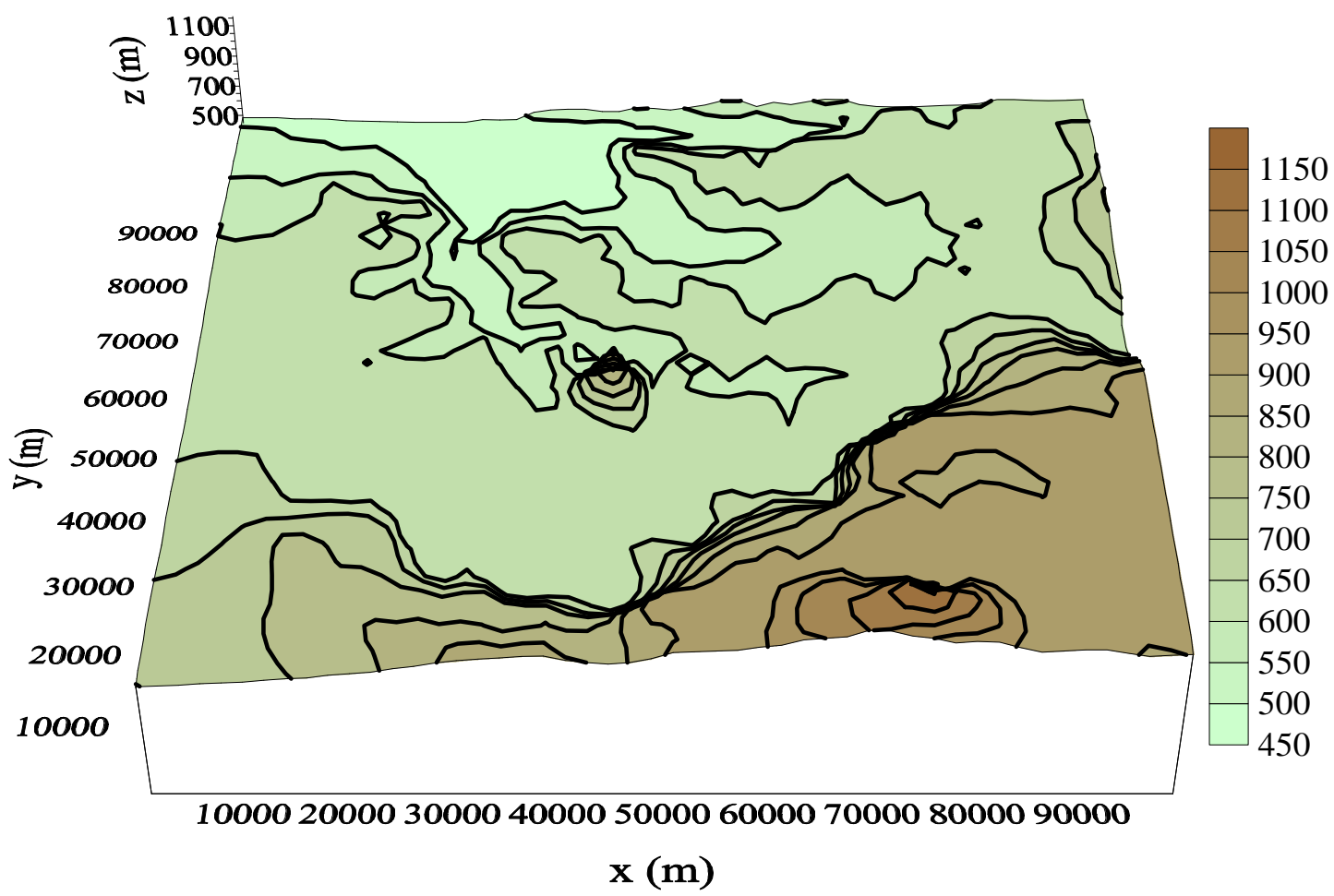

(b)

Figura 5.1 (a) Mapa Geográfico do Estado de São Paulo. A área de estudo está indicada pelo quadrado no centro, representanto $100 \mathrm{~km}$ por $100 \mathrm{~km}$. (b) A topografia da área de estudo. A fonte emissora de radionuclídeos, correspondente à posição geográfica do Centro Experimental Aramar (CEA), está localizada no centro do domínio (PEREIRA et alli, 2001). 
Durante o dia, a distribuição de concentração exibe um formato cônico que é tipicamente encontrado sob condições de turbulência homogênea e estacionária (Figura 5.2 a). A área de maior concentração está orientada na direção NE-SW. Este padrão é devido ao fato do vento soprar de NE durante a maior parte do dia (Figura 5.3). As maiores concentrações em superfície são localizadas junto à fonte, como esperado durante condições convectivas.

Durante a noite, a distribuição de concentração àsuperfície é mais complexa (Figura 5.2 b) devido ao fato do escoamento junto à superfície girar progressivamente de SSE para ESE entre 20 h e 6 h da manhã. Há um valor mínimo a barlavento (i.e., escoamento acima) do Morro de Araçoiaba causado por efeitos de bloqueio. De acordo com KARAM et alli (2001): (a) o máximo do JBN simulado ocorre dentro da camada de $300 \mathrm{~m}$ acima da superfície em Iperó; (b) apresenta uma direção de vento E-SE, entre 24 h e 6 h da manhã e (c) é responsável pelo máximo secundário na distribuição de concentração à superfície observado no se tor SE da Figura 5.2b.

Figura 5.4 apresenta a vista lateral da nuvem de radionuclídeos simulada æ̀ $6 \mathrm{~h}$ da manhã. Durante a noite, o JBN é responsável também pelo aumento na intensidade da turbulência. Há um aumento no transporte de radionuclídeos para baixo na camada residual, aumentando a concentração medida à superfície a sotavento da fonte (simulação). Do ponto de vista observacional, um efeito semelhante de transporte vertical de poluentes foi mostrado por CORSMEIER et alli (1997) em associação ao JBN da Alemanha. Durante o período diurno, conforme a CLP convectiva se desenvolve, a dispersão de radionuclídeos é dominada pela mistura vertical. Como conseqüência, as maiores concentrações de radionuclídeos são encontradas em uma distância horizontal entre 2000 e $2500 \mathrm{~m}$ da fonte. Isto ocorre devido æ̀ características de dispersão encontradas na CLP convectiva, onde predominam flutuações turbulentas intensas da velocidade vertical (majoritariamente negativas), associadas à convecção térmica e àpresença de grandes-turbilhões. Isto provoca que a trajetória do centro de massa de plumas de poluentes emitidas a partir de pontos elevados na CLP desça à superfície numa escala de tempo inferior a $t^{*}=z_{i} / W^{*}$ (i.e., $\sim 500 \mathrm{~s}$ ), onde $\mathrm{z}_{\mathrm{i}}$ é a alutra da CLP convectiva $\left(\mathrm{z}_{\mathrm{i}} \sim 1000 \mathrm{~m}\right)$ e $\mathrm{w}^{*}$ é a escala de velocidade vertical convectiva $\left(\mathrm{w}^{*} \sim 2 \mathrm{~m} \mathrm{~s}^{-1}\right)$. 


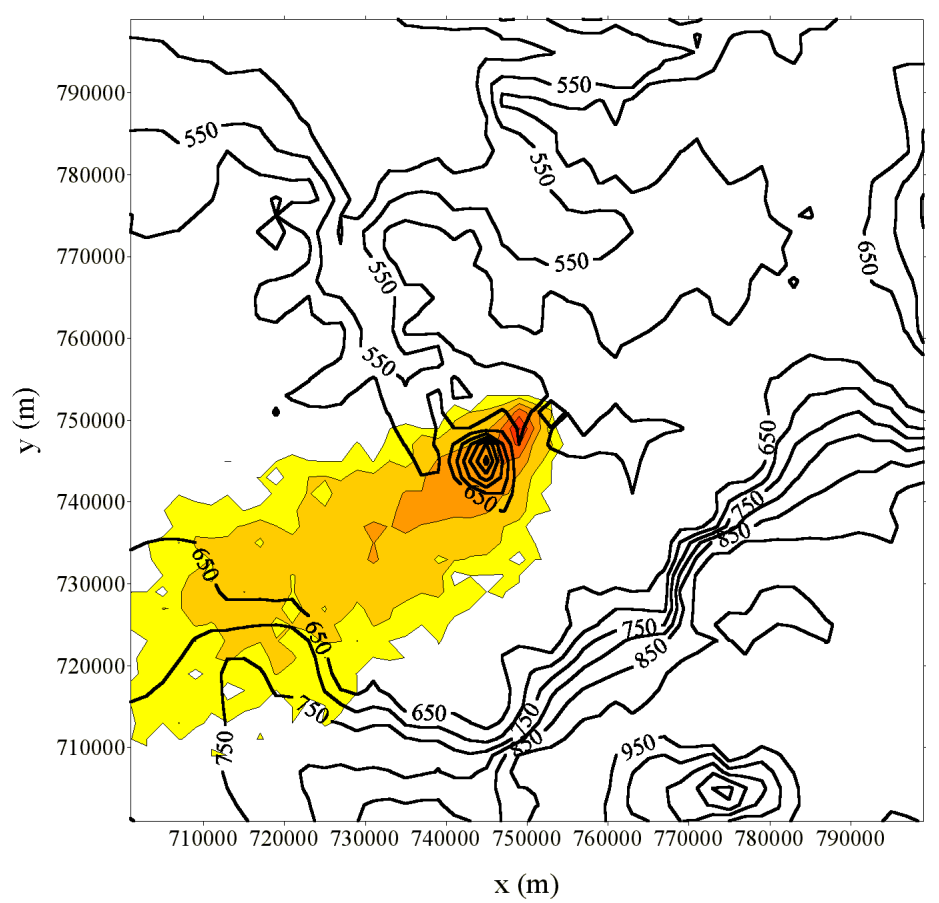

(a)

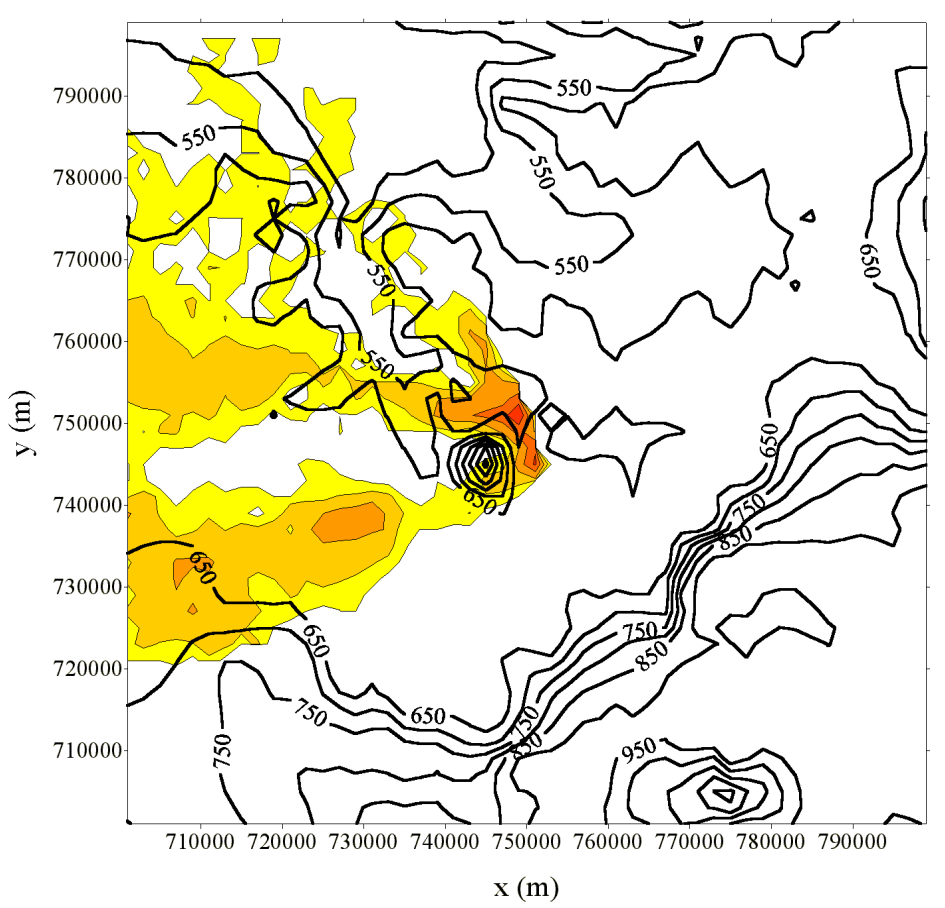

(b)

\begin{tabular}{|l|l|l|l|l|l|l|}
-10.0 & -10.5 & -11.0 & -11.5 & -12.0 & -12.5 & \multicolumn{1}{c}{-13.0} \\
\hline & & & & & & \\
\hline
\end{tabular}

Figura 5.2 Média de $24 \mathrm{~h}$ do logaritmo da concentração de radionuclídeos $\left[\log \left(\mu \mathrm{g} \mathrm{m}^{-3}\right)\right]$ na atmosfera, para a camada de espessura $30 \mathrm{~m}$ sobre a superfície topográfica na área de estudo sob condições: (a) instáveis e (b) estáveis na CLP. A fonte pontual contínua está localizada no centro do domínio. As isolinhas do logaritmo da concentração são mostradas em sobreposição à curvas de nível da topografia. 


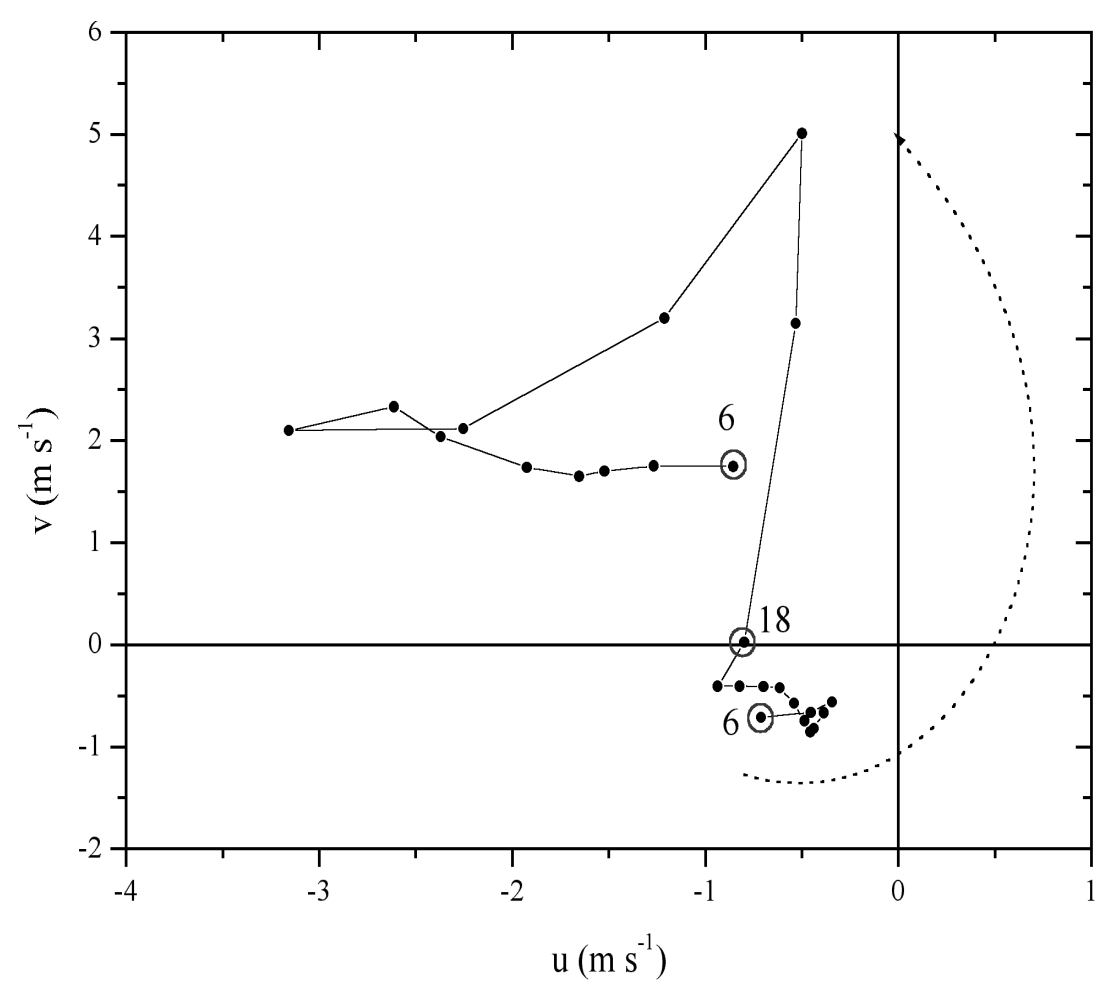

Figura 5.3 Gráfico da hodógrafa simulada para período de 24 h no nível intermediário da camada 0-30 $\mathrm{m}$ acima da superfície do terreno complexo.

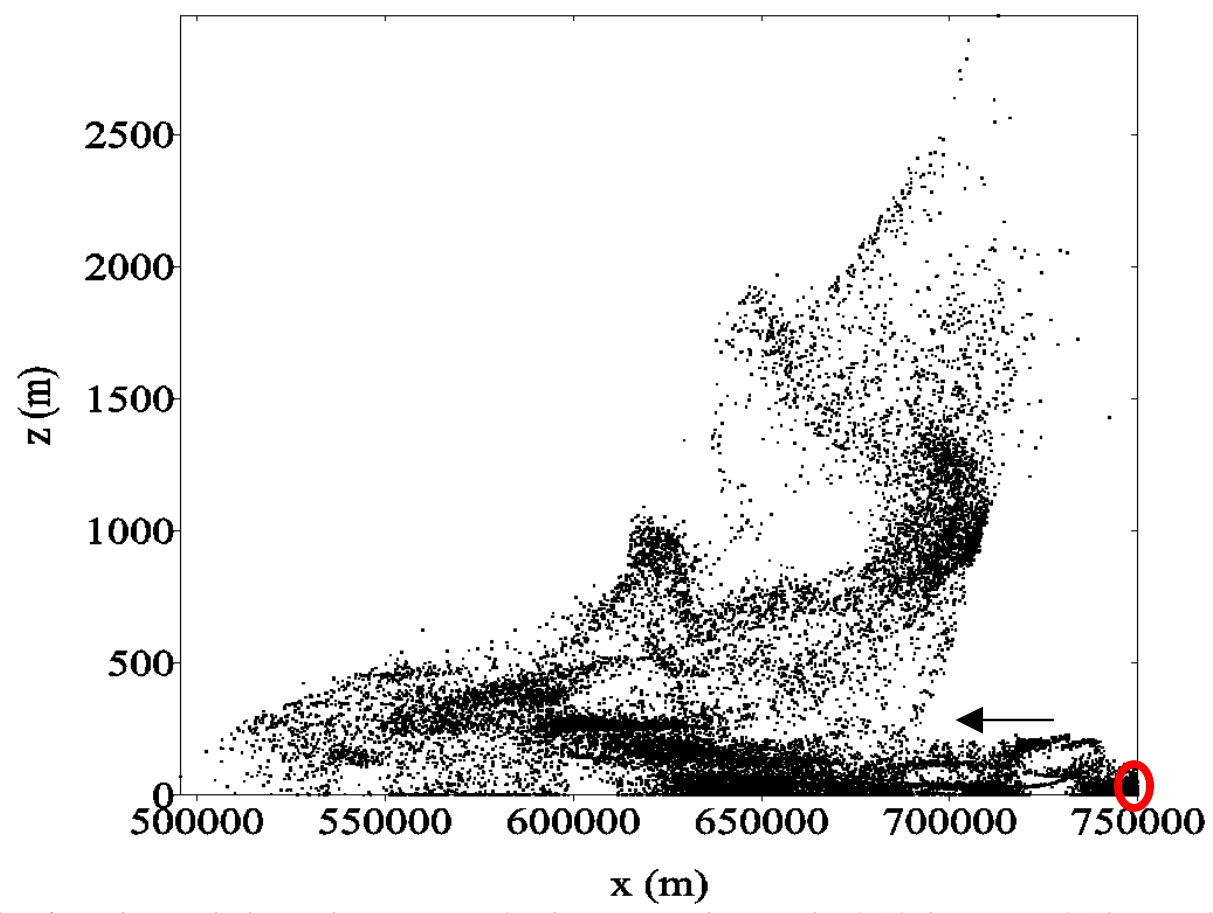

Figura 5.4 Vista lateral de todas as partículas no volume de $250 \mathrm{~km}$ por 250 por $3 \mathrm{~km}$ æ̀ $6 \mathrm{~h}$ da manhã (i.e., após $24 \mathrm{~h}$ de simulação). $\mathrm{O}$ círculo indica a posição da fonte e a seta, a altura aproximada do máximo do jato. 


\subsection{Evolução Temporal da Nuvem de Poluente em Escala Regional}

A Figura 5.5 apresenta a evolução temporal da nuvem de poluente, vista de topo sobre o plano (x, y), para os seguintes horários: (a) 12 h, (b) 18 h, (c) 24 h e (d) 06 h. O início da emissão de poluentes ocorre à $6 \mathrm{~h}$ da manhã.

Durante o período convectivo, a pluma apresenta grande dispersão lateral, mas os transporte pelo vento médio é pequeno no interior, devido ao pequeno valor de velocidade do vento à superfície (Figura 5.5 a). Às 12 h, o escoamento na CLP convectiva apresenta-se acoplado ao escoamento de grande-escala com velocidade $1 \mathrm{~m} \mathrm{~s}^{-1}$ e direção de vento NE. Às $18 \mathrm{~h}$, ao final do período convectivo, a nuvem de poluente avançou por cerca de $50 \mathrm{~km}$ para SW da fonte em resposta as condições de vento diurnas (Figura 5.5 b). A nuvem apresenta-se com formato aproximadamente cônico com alguma irregularidade.

Durante o início do período noturno, a nuvem de poluentes resultante do período convectivo (cone) é deslocada rapidamente para NW pelo JBN (Figura 5.5 c), ao mesmo tempo em que um novo regime de dispersão se estabelece com o início do período estável.

Durante o período estável, a condição de dispersão encontrada pelas partículas emitidas pela fonte é bastante diversa em relação àquelas do período convectivo. Neste caso, a difusão turbulenta é comparativamente menor em relação ao período convectivo. Note-se, por exemplo, a pequena dispersão lateral da nuvem de poluentes junto a fonte nas Figuras 5.5 c e $5.5 \mathrm{~d}$.

Após um período de $12 \mathrm{~h}$, a presença do JBN em Iperó implica no transporte do poluente a uma distância de $250 \mathrm{~km}$ da fonte em Iperó (Figura 5.5 d). A tendência da direção do máximo do JBN de girar de SE para E, entre o início e o final da noite, implica que uma extensa área do Estado pode ser afetada no período noturno pelo poluente de Iperó. A área atingida compreende a Serra de Botucatu, porção NW do Vale do Ribeira, porção NE da Serra Geral no Paraná e todo o Centro-Sul do Estado de São Paulo. Como resultado final do efeito do JBN, i.e., de seu cisalhamento direcional na vertical e de sua evolução durante a noite, a nuvem de poluente de Iperó torna-se fragmentada e segmentada sobre uma extensa área de $200 \mathrm{~km} \times 200 \mathrm{~km}$. 


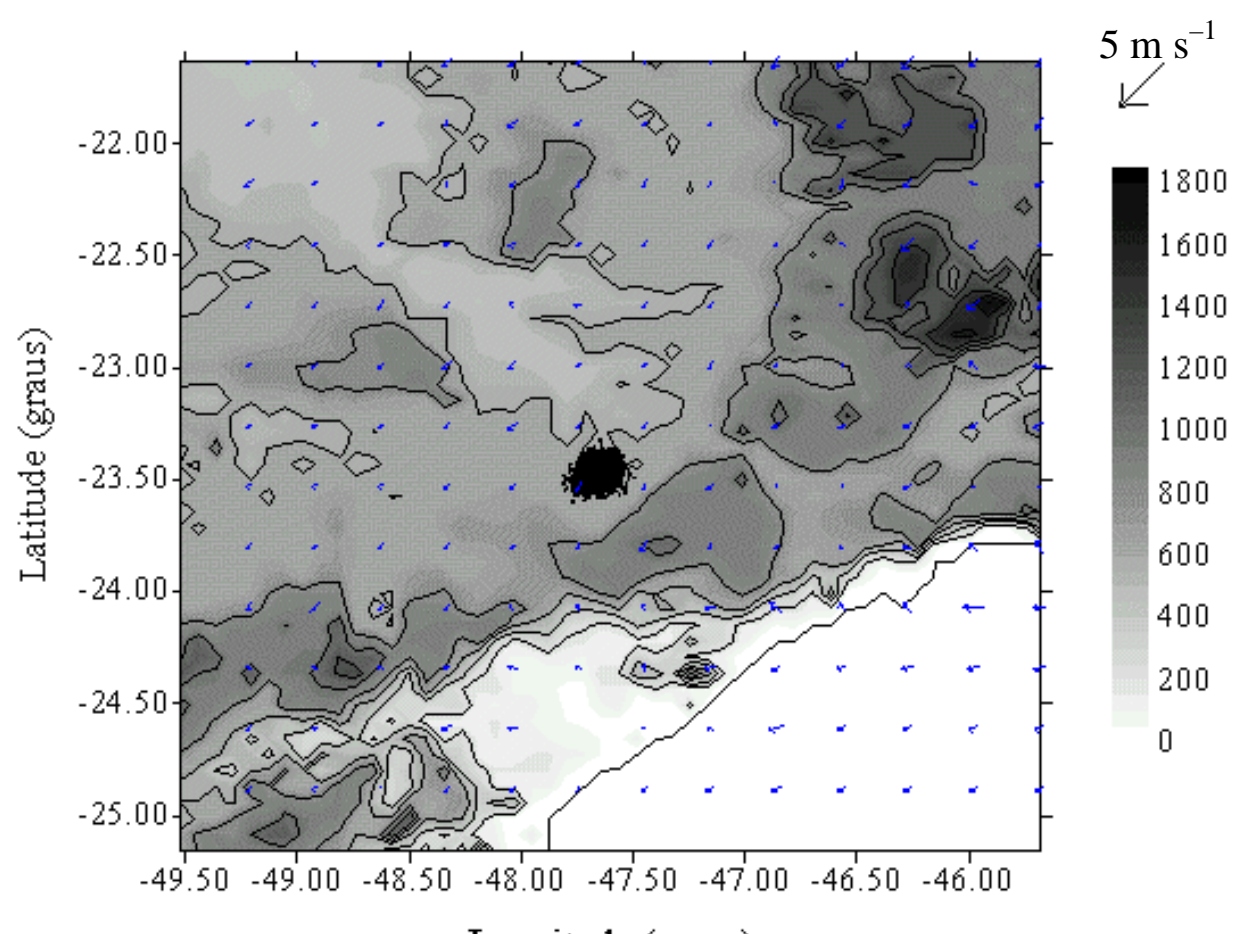

Longitude (graus)

(a)

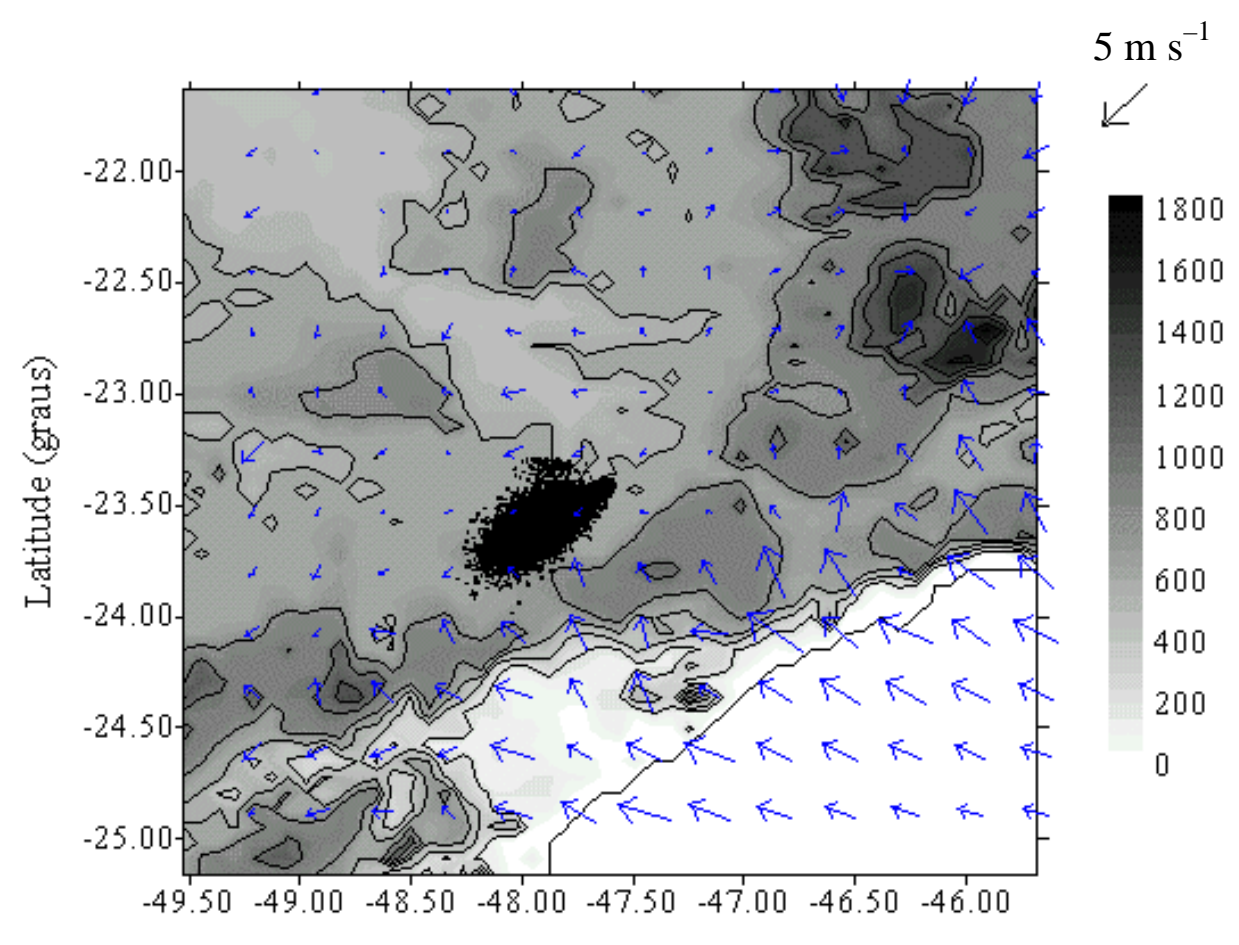

Longitude (graus)

(b)

Figura 5.5 Vista de topo da nuvem de poluentes de poluente em dispersão na atmosfera emitida a partir de fonte localizada junto àsuperfície $(\mathrm{z}=10 \mathrm{~m})$ no CEA em Iperó (localizado no centro da área mostrada) para os horários: (a) 12 h, (b) 18 h, (c) 24 h e (d) 06 h. Esta figura foi construída a partir da simulação L1500 e os resultados apresentados no domínio topográfico de $400 \mathrm{~km} \times 400 \mathrm{~km}$. 


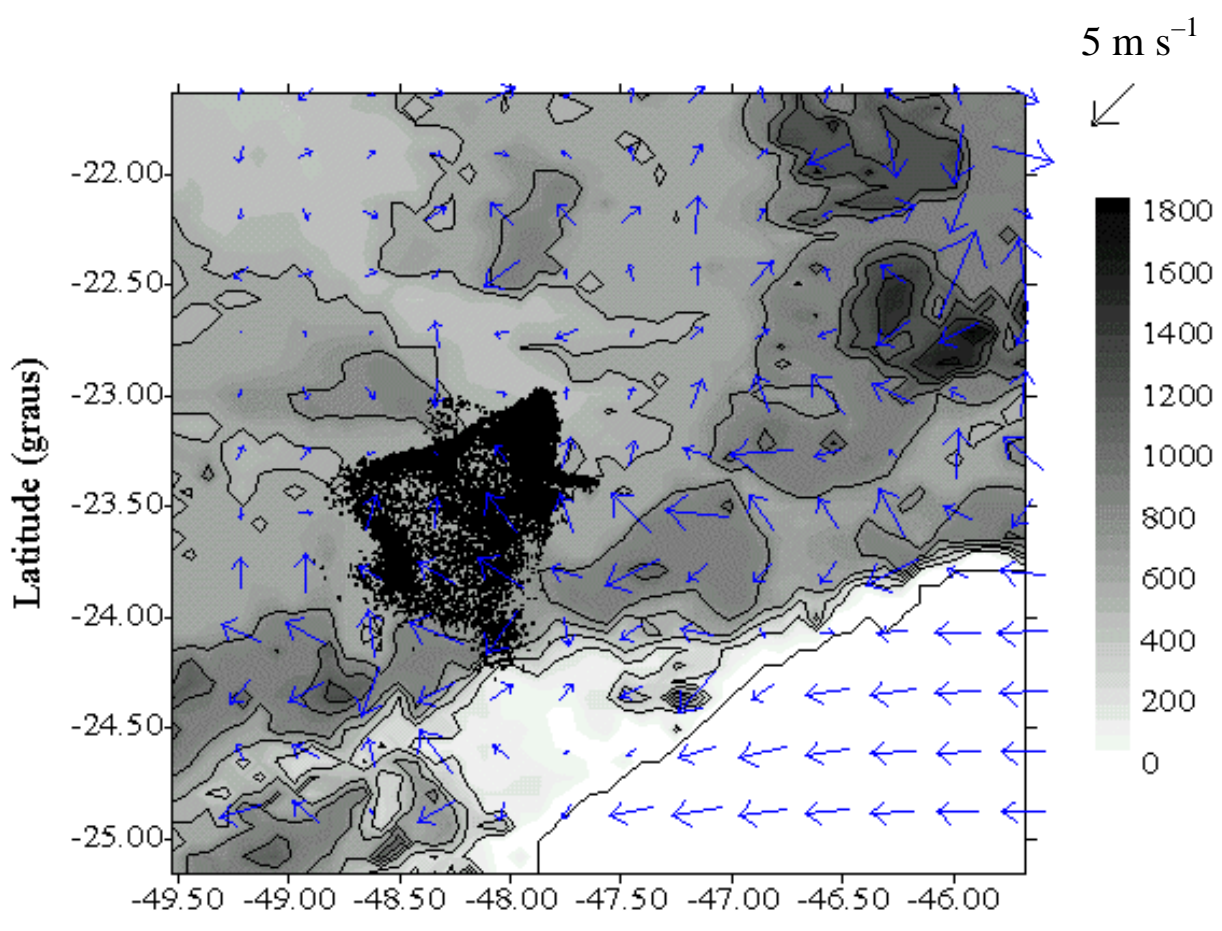

(c)

Longitude (graus)

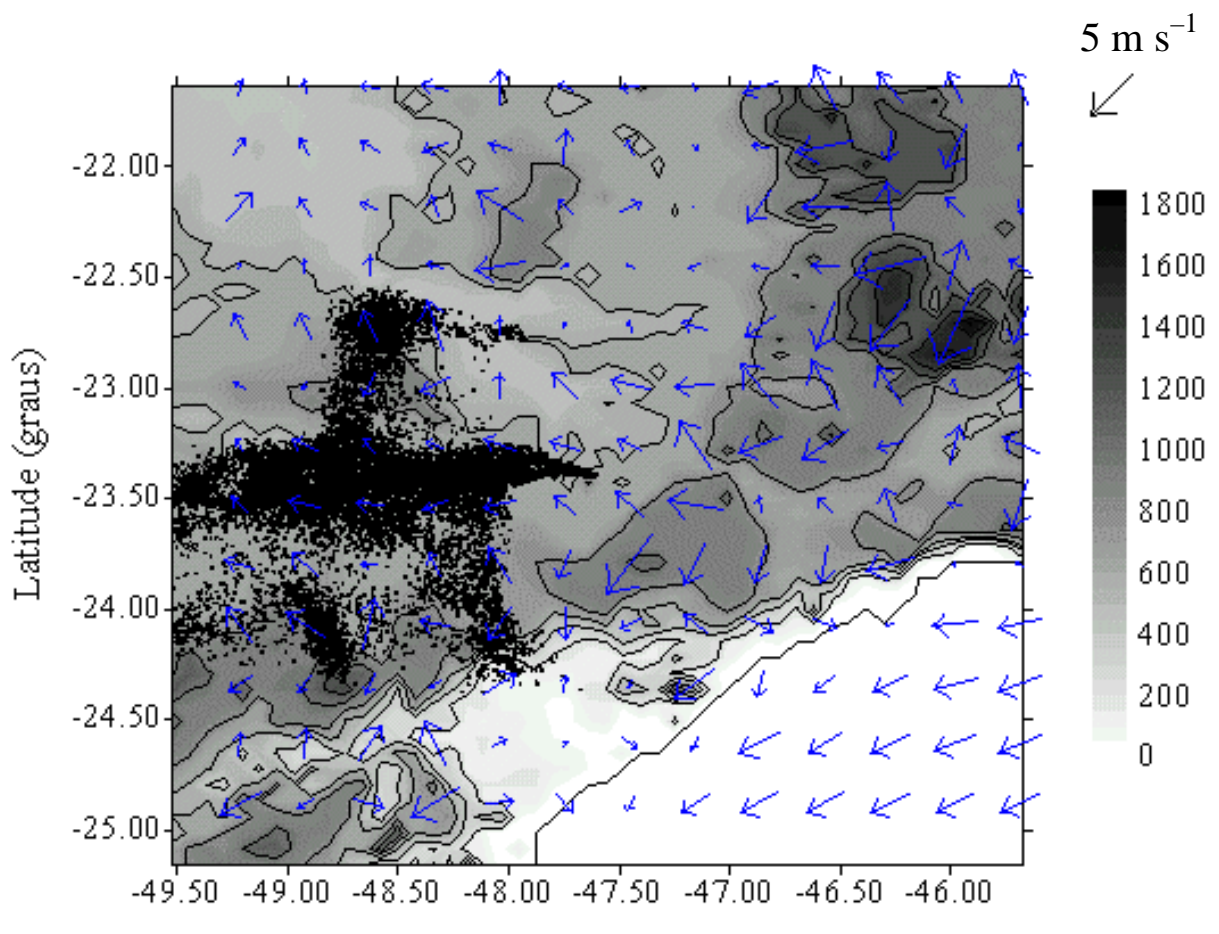

Longitude (graus)

(d)

Figura 5.5 (continuação). 


\subsection{Interação entre Fontes de Poluentes em Escala Regional}

Os diferentes tipos de poluente lançados na atmosfera no Estado de São Paulo possuem características bastante diferentes, conforme sua origem seja urbana ou rural.

No ambiente urbano destacam-se os poluentes de origem industrial e automotiva, associados àqueima de combustíveis derivados do petróleo e àevaporação de reservatórios de combustível e dos processos industriais. $\mathrm{Na}$ área rural, os poluentes são decorrentes do controle de pragas agrícolas, dos incêndios para preparação do solo e da queimada da palha da cana-de-açúcar. De acordo com (KIRCHHOFF, 1991 e MARINHO e KIRCHHOFF, 1991), as queimadas de palha de cana-de-açúcar contituem-se práticas que levam à formação de ozônio junto à áreas urbanas do interior do Estado de São Paulo. Por outro lado, substâncias químicas diversas contribuem à poluição atmosférica encontrada em ambientes urbanos (McEWAN e PHILLIPS, 1975). Na RMSP predomina o smog fotoquímico associado aos materiais e gases da exaustão automotiva. Os óxidos de nitrogênio são componentes essenciais da mistura de gases do smog. A cinética química desses óxidos é catalizada pela presença de traços de materiais orgânicos. A química do smog envolve a fotoquímica do $\mathrm{NO}_{2}$ puro; a fotólise da mistura de ar e $\mathrm{NO}_{2}$; a fotólise de $\mathrm{NO}_{2}$ no ar e hidrocarbonetos oleofínicos; levando a formação de gases secundários, como o gás Peroxiacetil Nitrato (PAN), Aldeídos e Ozônio. O gás CO nos centros urbanos é consequiência do processo de combustão incompleta em veículos automotivos e indústrias (NOVAIS, 1993).

Cubatão é uma fonte de poluentes atmosféricos com enorme impacto ambiental. De acordo com KUCINSKI (1982), os principais poluentes industriais emitidos na atmosfera em Cubatão apresentam grande toxidade, muitos deles carcinógenos e teratogênicos. Os danos associados a esses poluentes não atingem somente à população, mas também afetam o desenvolvimento da floresta tropical mais próxima da encosta da Serra do Mar. De acordo com KLUMPP et alli (2001) existem danos graves à vegetação na área da Serra do Mar associados ao complexo industrial de Cubatão. Esses pesquisadores observaram uma aguda degradação da cobertura vegetal, com a redução da área de floresta de estrutura primária e secundária na Serra do Mar (na região afetada) e também uma redução na capacidade de recuperação dessas áreas. Alterações químicas e o impacto de oxidantes fotoquímicos causam 
mudanças metabólicas e morfológicas, p. ex., na anatomia do lenho e nas folhas das árvores da área afetada. Em particular, efeitos aparecem na região apical das folhas onde se observa: (a) pontos de necrose com estômatos atrofiados e sem emergências, (b) alterações nas superfícies ornamentais, apresentando estrias e material particulado, (c) hifas de fungos e (d) destruição do aspecto do estômato, onde as cutículas se mostram levemente ou muito ondulada ou não-integras.

Já problemas graves de contaminação por agrotóxico têm sido encontrados na região do vale do Ribeira de Iguape, com elevado custo social, i.e., por intoxicação voluntária e involuntária (POLTRONIÉRI e MACHADO, 2000). Agrotóxicos têm sido aplicados em larga-escala no ambiente das plantações e a partir desses ambientes complexos penetra na CLP onde é transportando pelo escoamento atmosférico.

Realizou-se a simulação L1500 considerando-se simultaneamente o transporte de poluentes provenientes de diferentes fontes emissoras localizadas em SP (Tabela 5.1). O objetivo dessa realização numérica com plumas múltiplas é investigar os processos complexos de dispersão dos poluentes em SP, p. ex., identificando as áreas de ocorrência de interpenetração das nuvens de poluentes.

\begin{tabular}{|c|c|c|c|c|}
\hline Ponto & Longitude (graus) & Latitude (graus) & Denominação & Tipo de emissão \\
\hline 1 & $-46,433990$ & $-23,8706400$ & RPB - Petrobrás - Cubatão - SP & Industrial \\
\hline 2 & $-47,978500$ & $-21,1377800$ & Sertãozinho - SP & $\begin{array}{c}\text { Queima de palha de } \\
\text { cana }\end{array}$ \\
\hline 3 & $-46,6470600$ & $-23,5309700$ & São Paulo Capital & Automotiva \\
\hline 4 & $-49,3913000$ & $-20,800000$ & São José do Rio Preto - SP & Queimada \\
\hline 5 & $-50,4375000$ & $-21,2187500$ & Araçatuba - SP & Queimada \\
\hline 6 & $-51,3804900$ & $-22,0793000$ & Presidente Prudente - SP & Queimada \\
\hline 7 & $-49,0829300$ & $-22,3363200$ & Bauru - SP & Queimada \\
\hline 8 & $-47,8374400$ & $-24,4910700$ & Registro - SP & Biogênica \\
\hline 9 & $-47,5993700$ & $-23,3934700$ & CEA-Iperó - SP & Radionuclíneos \\
\hline
\end{tabular}

Tabela 5.1 Localização geográfica dos pontos de emissão utilizados na simulação com domínio horizontal de área 1500 km x 1500 km centrado em Iperó. 
A Figura 5.5 apresenta os resultados da dispersão lagrangiana das plumas múltiplas obtidos no ensaio numérico L1500. Estes resultados mostram que:

(a) As queimadas no interior do Estado de São Paulo emitem plumas de poluentes atmosféricos que atingem extensas áreas, penetrando no espaço urbano das cidades do interior. Nestas condições, os gases das plumas provenientes da queima de palha de canade-açúcar, p.g., implicam na produção líquida de ozônio troposférico no interior. Este fato pode explicar as elevadas concentrações médias anuais de fumaça registradas em cidades do interior acima do máximo secundário anual recomendado, $40 \mu \mathrm{g} \mathrm{m}{ }^{-3}$, p.g.: Franca 49; Sorocaba 56; Itu 46; Capinas 42 e Jundiaí 45 (relatório CETESP, 1989; Folha de São Paulo de 24/9/1990);

(b) Existem diferenças importantes entre as condições de dispersão do poluente atmosférico conforme a localização do ponto de emissão sobre o Estado de São Paulo, em particular, entre pontos localizados no litoral e no interior;

(c) As condições de dispersão, ao longo da faixa litorânea e sobre a Serra do Mar, associadas a diferentes circulações atmosféricas implicam num aumento da dispersão lateral, recirculação e segmentação da nuvem de poluentes;

(d) Nota-se uma interpenetração das nuvens emitidas na Grande São Paulo e em Cubatão. A pluma de Cubatão que é lançada por sobre a RMSP (Capital) devido àcirculação da brisa marítima acoplada ao efeito térmico da escarpa da Serra do Mar, contribuindo para um aumento da concentração de poluição na Capital;

(e) Durante o período noturno, o JBN de Iperó leva para o interior parte da nuvem de poluentes formada durante o período convectivo sobre o Platô Paulista. A região ao longo do vale do Rio Tietê pode ser particularmente atingida;

(f) Plumas de poluente geradas por queimadas de palha de cana e outras práticas agrícolas no interior podem ser afetadas por circulações locais e regionais. O JBN de Iperó influe nas condições de dispersão noturna, alterando a direção de transporte do poluente, gerando recirculações em áreas específicas como parece ocorrer na região de Bauru;

(g) Ao final do período de dispersão, as plumas emitidas da superfície de Sertãozinho atingem Bauru; as plumas emitidas de São José do Rio Preto atingem Araçatuba e aquelas emitidas de Araçatuba atingem Presidente Prudente, cada uma percorrendo mais de $111 \mathrm{~km}$, sob efeito somente das circulações locais e regionais induzidas pela superfície;

(h) O problema de poluição no Estado de São Paulo não se restringe aos locais de emissão.

A Figura 5.6 apresenta o resultado da dispersão, diferenciando as nuvens de poluente segundo sua origem. Isto é feito com a utilização de cores diferentes para cada fonte. Desta 
forma, é possível observar-se a interpenetração de diferentes plumas resultantes do processo de dispersão. Nota-se (a) que a pluma de Cubatão é formada por poluentes industriais; a pluma de São Paulo (RMSP) por poluentes automotivos e a pluma de Iperó é constituída de radionuclídeos em decaimento (i.e., associada a um hipotético acidente nas instalações de enriquecimento isotópico de Urânio no CEA); (b) as regiões de influência das plumas emitidas de Sertãozinho, Bauru, São José do Rio Preto, Araçatuba e Presidente Prudente se interpenetram após um período de $24 \mathrm{~h}$ de dispersão mostrando que problemas associados à poluição por fumação proveniente de queimadas no interior ultrapassam as fronteiras municipais exigindo uma estratégia estadual para seu controle efetivo; (c) os poluentes provenientes de Registro podem influir sobre uma extensa área, devido s̀ circulações atmosféricas induzidas pela superfície complexa da região; e (d) durante a noite, a área oceânica junto ao litoral de São Paulo é atingida pelos poluentes da Capital e Cubatão, devido a recirculação na baixa troposfera.

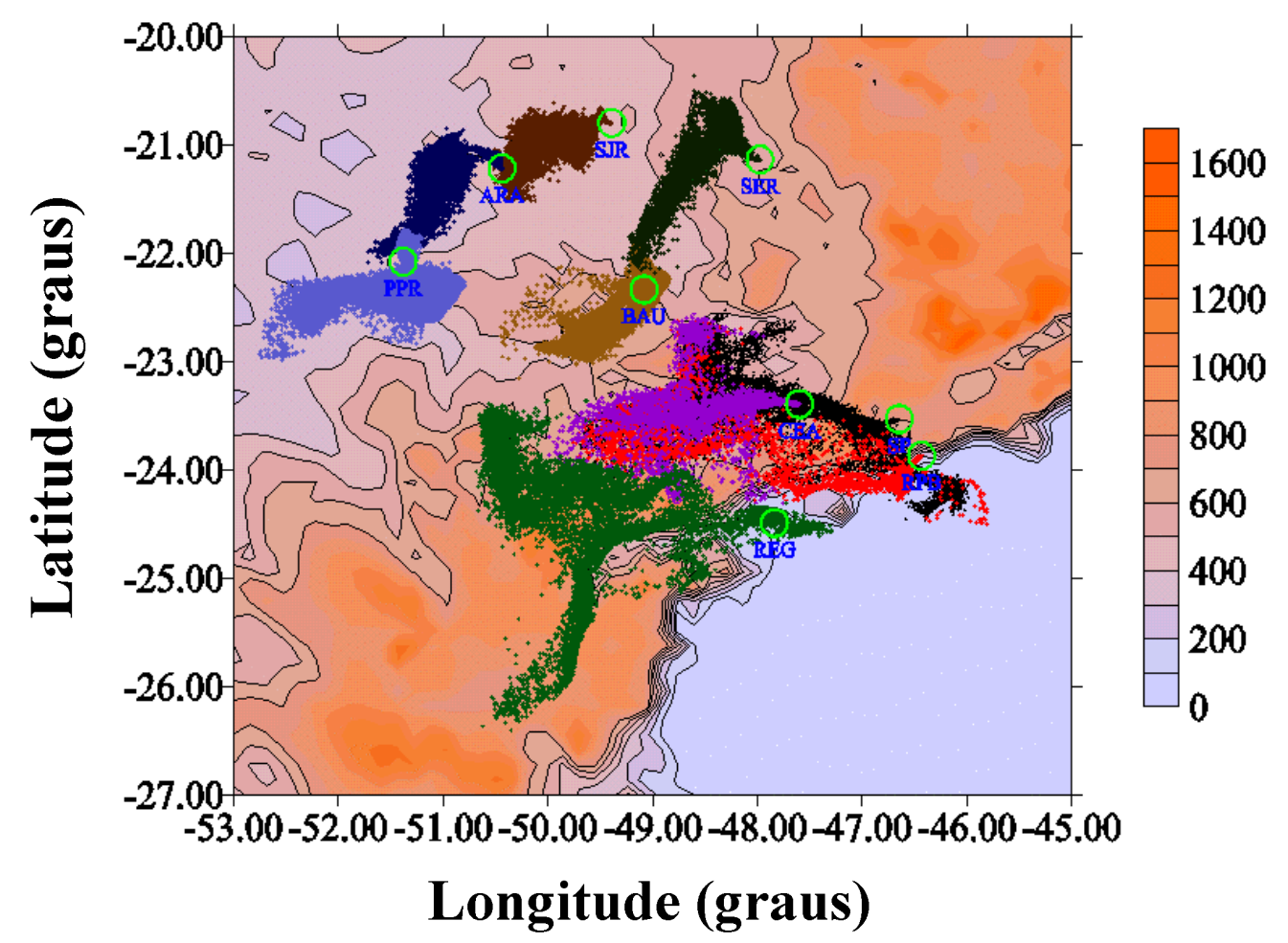

Figura 5.6 Representação da interação entre plumas emitidas de diferentes pontos à superfície no Estado de São Paulo, em vista de topo. As cores das partículas em dispersão estão associadas às diferentes fontes emissoras: em vermelho para fonte em Cubatão (RPB); em preto para São Paulo Capital (SP); em roxo para Iperó (CEA); em verde para Registro (REG); em ocre para Bauru (BAU); em cinza esverdeado para Sertãozinho (SER); em marrom para São José do Rio Preto (SJR); em azul escuro para Araçatuba (ARA) e em azul cobalto para Presidente Prudente (PPR). A topografia está representada ao fundo pela escala de cores entre azul claro e laranja; a linha de contorno mais elevada na figura corresponde à cota de $600 \mathrm{~m}$ e as áreas em laranja escuro correspondem a áreas ainda mais elevadas (Serra do Mar; Serra Geral à SW no PR e Mantiqueira à NE em MG). 


\section{CAPÍTULO 6}

\section{CONCLUSÕES}

Neste trabalho, a origem dos Jatos de Baixos Níveis (JBN) noturnos de Iperó (SP) e o seu papel na dispersão de poluentes no Estado de São Paulo são investigados. Para tanto são utilizados os dados coletados nas quatro campanhas de medidas em Iperó. Utilizou-se também um modelo numérico de mesoescala não-hidrostático TVM para simular a estrutura espacial 3-D do JBN em resposta às forçantes topográficas e associadas à ocupação da superfície.

Os resultados observacionais indicam que o JBN ocorre em Iperó com bastante freqüência nas noites de céu claro, com intensidade variando entre 8 e $10 \mathrm{~m} / \mathrm{s}$ e localizado em torno de $350 \mathrm{~m}$ acima da superfície.

Os JBNs em Iperó caracterizam-se por um cisalhamento direcional, com ventos de SE na superfície e de ENE na região de máximo.

Os JBNs ocorrem tanto no inverno como no verão, e afetam o ciclo diurno médio do vento observado nos primeiros 100 metros na região de Iperó.

Os JBNs são responsáveis pelo máximo noturno (21:00 HL) existente no ciclo diurno médio do vento na região.

Os resultados numéricos indicam que o JBN de Iperó é resultado da ação combinada de quatro fatores:

1. Circulação anabática no setor paulista do vale do Rio Paraná;

2. Oscilação inercial;

3. Circulação catabática noturna e

4. Brisa marítima.

Estes quatro fatores combinados sustentam JBNs com intensidade de 5 a $10 \mathrm{~m} \mathrm{~s}^{-}$

${ }^{1}$, localizados a uma altitude de 100 a $400 \mathrm{~m}$ acima da superfície, durante a maior parte da noite.

O JBN simulado numericamente encontra-se localizado no setor oeste da região de convergência da circulação anabática e da brisa marítima. Esta região de 
convergência em baixos níveis se forma durante o dia na parte mais elevada do Estado de São Paulo que acompanha da linha do litoral (Serra do Mar e da Cantareira).

$\mathrm{O}$ efeito do JBN sobre o transporte de poluente foi investigado com um modelo Lagrangiano de dispersão de partículas. Verificou-se que o JBN aumenta a dispersão horizontal das partículas, transportando o poluente atmosférico emitido na superfície até $250 \mathrm{~km}$ da fonte.

\subsection{Detalhamento}

Análise observacional - A estrutura vertical típica do JBN observado em Iperó indica que: (1) JBNs intensificam-se durante o período noturno; (2) a altura da velocidade máxima ascende, atingindo $400 \mathrm{~m}$ em torno das $8 \mathrm{~h}$; (3) a espessura da camada do jato aumenta e também sua capacidade de transporte de escalar, umidade, calor e momento; (4) o cisalhamento direcional da velocidade do vento aumenta à medida que o JBN se intensifica, com ventos do quadrante $S$ a superfície, giro antihorário com a elevação na vertical e ventos de NE a 600 m acima da superfície e (5) o cisalhamento do módulo da velocidade do vento é muito intenso (da ordem de $0,08 \mathrm{~s}^{-1}$ ), o que aumenta a produção mecânica de turbulência junto à superfície.

A direção do vento na superfície de Iperó apresenta um ciclo diurno marcado por um giro completo em sentido anti-horário, isto é, S-SE no período noturno, para ENE na manhã, N-NW à tarde e novamente para S-SE. Os dados de superfície obtidos durante as campanhas de observação no CEA apresentam grande coerência espacial e temporal com dados medidos a $10 \mathrm{~m}, 60 \mathrm{~m}$ e $80 \mathrm{~m}$ acima da superfície em outra torre no CEA, e também em relação a dados da estação da Fazenda Ipanema, localizada a $5 \mathrm{~km}$ para SE do CEA. Durante o período noturno, a direção predominante do vento é do quadrante Sul. Durante o período convectivo, a direção do vento gira em sentido antihorário, passando pela direção NW aproximadamente ao meio-dia. As hodografas construídas para três níveis da torre em Iperó, 10 m, 60 m e 80 m indicam intenso cisalhamento do vento, $(\partial \mathrm{v} / \partial \mathrm{z}) \approx 0,043 \mathrm{~s}^{-1}$, entre os níveis $10 \mathrm{~m}$ e $80 \mathrm{~m}$, durante o período noturno (Figura 3.8). Este cisalhamento está associado do giro anti-horário do vetor velocidade do vento com a altura e no tempo. Após atingir a máxima velocidade, pouco antes das $21 \mathrm{~h}$, o vetor resultante, diminui sua intensidade, provavelmente, devido ao desacoplamento da CLP superficial associado à intensificação da inversão de 
superfície. Este desacoplamento é, sobretudo observado durante a madrugada (entre 0 e 6 h) na camada entre a superfície e $80 \mathrm{~m}$. A direção do vento resultante pouco varia durante o período noturno. Quase toda oscilação anti-horária do vetor vento ocorre no período diurno, durante as transições da manhã e final da tarde.

A intensidade absoluta do vetor resultante (médias horárias) é muito pequena no período entre 12 e $15 \mathrm{~h}$. O valor deste vetor mostra-se inferior a $1 \mathrm{~m} \mathrm{~s}^{-1}$ em média. É muito provável que esse pequeno valor da velocidade resultante (média horária) ocorra devido à flutuações das componentes zonal e meridional em torno do zero no período convectivo. Já a intensidade do vetor velocidade médio horário obtido diretamente do valor do módulo da velocidade do vento instantâneo é relativamente maior, variando entre 2,5 e $5,5 \mathrm{~m} \mathrm{~s}^{-1}$ entre os níveis de 10 e $80 \mathrm{~m}$ na torre.

A hodógrafa do vento médio horário apresenta um formato elíptico no nível de 80 m. O eixo principal da elipse está orientado na direção SE-NW. Essa orientação indica qual é a direção e sentido do cisalhamento inferior do JBN em Iperó. Abaixo de $80 \mathrm{~m}$ o escoamento aparece bloqueado pelas feições da topografia próxima (raio $<20$ km) do CEA em Iperó. Em especial a presença do Morro de Araçoiaba que se eleva cerca de $400 \mathrm{~m}$ acima do vale do rio Sorocaba e Ipanema é suficiente para bloquear ventos de SW e W conforme rosa dos ventos obtida para a estação da Fazenda Ipanema, e também no CEA. Da comparação das curvas hodógrafas de verão, inverno e anual nota-se que: (1) durante o verão, a hodógrafa desloca-se em direção ao quarto-quadrante indicando ventos de NW durante a tarde, especialmente a $60 \mathrm{~m}$ e $80 \mathrm{~m}$ na torre. No inverno, durante à tarde, ventos resultantes de SW são mais freqüentes; (2) o cisalhamento do vento é mais intenso durante os meses de inverno para a camada entre a superfície e $80 \mathrm{~m}$ na CLP. Uma explicação plausível é o incremento do vento que ocorre nos meses de inverno quando a região de Iperó é sujeita à entrada freqüente de frentes-frias; (3) a forma elíptica é predominante no período de verão, aparecendo nos níveis 10 m, 60 m e 80 m em Iperó. O eixo principal é orientado na direção SE-NW. Durante o inverno, a forma elíptica aparece de forma mais clara no nível $80 \mathrm{~m}$, enquanto nos níveis inferiores há indícios marcantes de bloqueio topográfico e/ou efeitos aerodinâmicos da distribuição de rugosidade superficial. Durante o inverno, no nível de $10 \mathrm{~m}$, o desacoplamento é muito intenso à noite, resultando que a forma da elipse aparece muito mais deformada; (4) a análise da distribuição de frequiência do vento em Iperó medida ao longo da torre de $80 \mathrm{~m}$ ressalta a coerência espacial e temporal do ciclo diurno do vento na camada limite superficial em Iperó. A estrutura 
vertical do vento na CLP superficial e sua evolução temporal ao longo do dia mostramse consistentes com observações à superfície da Fazenda Ipanema e com períodos de inverno e verão tomados em separado.

O máximo da velocidade do vento instantâneo observado em superfície ocorre no início da noite, em correspondência àformação do JBN. Durante o período noturno, a direção do vento resultante é de S-SE a superfície, soprando praticamente, do quadrante $\mathrm{S}$ durante toda ànoite (com elevado valor da persistência). Durante o período convectivo, o vetor resultante gira em sentido anti-horário, começando pela manhã de $\mathrm{S}$, passando por SE, NE, e N ao meio-dia; para então soprar de NW, W e SW àtarde, até alcançar a direção SE no final da tarde. Portanto ocorre um giro completo de 360 graus durante o período entre 6 da manhã e 6 da tarde.

A persistência direcional do vento é muito intensa durante a noite e pequena durante o dia. $\mathrm{O}$ alto valor noturno é indício da presença de JBN. Rajadas aparecem durante o período convectivo associadas a um fator de rajada 2,2.

Dados de grande-escala apresentam oscilações diurnas dos campos de momento e temperatura na baixa troposfera.

As principais características do JBN médio observado em Iperó são: (1) o JBN apresenta cisalhamento direcional na camada entre a superfície e $500 \mathrm{~m}$ entre as $0 \mathrm{~h}$ e 10 h; (2) ao final da tarde, a estrutura térmica da CLP convectiva, define a estrutura vertical inicial na qual o JBN aparecerá; (3) a velocidade máxima média nos JBN observados foi igual a $6 \mathrm{~m} \mathrm{~s}^{-1}$ para a I Campanha; $5 \mathrm{~m} \mathrm{~s}^{-1}$ para a II Campanha; $8 \mathrm{~m} \mathrm{~s}^{-1}$ para a III Campanha (inverno) e $5 \mathrm{~m} \mathrm{~s}^{-1}$ para a IV Campanha; (4) a altura do máximo foi iual a $400 \mathrm{~m}$ para a I Campanha; $550 \mathrm{~m}$ para a II Campanha; $400 \mathrm{~m}$ para a III Campanha entre 250 e 300 m para a IV Campanha; (5) o jato apresenta cisalhamento da direção do vento, caracterizado por ventos do quadrante $S$ abaixo do máximo e ventos do quadrante $\mathrm{N}$ acima do máximo.

A brisa marítima modula o escoamento atmosférico à leste do Estado de São Paulo, i.e., ao longo da faixa litorânea. Sua presença à leste da posição de Iperó induz turbulência numa zona entre as células do litoral e do inteiror devido ao aumento do cisalhamento do vento. A transferência do momento entre as duas células é possível e modulações na intensidade e direção do JBN em Iperó podem ocorrer sob condições favoráveis.

Ao longo da estrutura vertical, o JBN noturno apresenta cisalhamento direcional do vetor velocidade do vento, com ventos de direção SE a superfície e NE a $600 \mathrm{~m}$ 
acima da superfície. O giro do vetor vento na vertical é anti-horário. A hodógrafa no nível de $80 \mathrm{~m}$ acima da superfície apresenta uma forma elíptica, com eixo principal orientado de SE para NW (com giro anti-horário). Nos níveis abaixo de $80 \mathrm{~m}$, observam-se modificações, possivelmente, associadas àtopografia local. Um exame da distribuição de freqüências em uma estação situada $5 \mathrm{~km}$ a SE do CEA confirma a distribuição de ventos dada pelas hodógrafas no CEA. Os ventos oriundos do quadrante SW e W aparecem bloqueados pela topografia do Morro de Araçoiaba da Serra.

Modelamento numérico - Variando-se o domínio do modelo entre as escalas de $100 \mathrm{~km}$ e $1500 \mathrm{~km}$ observa-se que o jato simulado torna-se mais intenso apresentando características mais similares às observadas durante o experimento de Iperó.

A intensidade média do vento em Iperó tende a aumentar com o aumento da extensão horizontal do domínio e incorporação das escalas regionais da topografia (Figura 6.1), isto é, durante a noite e após a formação do JBN. A evolução diurna da direção do vento para a região de Iperó é pouco afetada pela extensão do domínio das simulações. A incorporação de escalas locais da topografia na simulação L100 aumenta a velocidade do vento durante o período convectivo.

As circulações térmicas associadas à topografia aparecem nas quatro simulações (L1500, L800, L400 e L100).

$\mathrm{Na}$ escala de $100 \mathrm{~km}$, observa-se que o morro de Araçoiaba bloqueia o escomento proveniente de SE, sobretudo durante o período estável. A topografia do morro de Araçoiaba, feição topográfica em escala local (i.e., para a vizinhança de $10 \mathrm{~km}$ do CEA) que modifica sensivelmente o escoamento na CLP (gerando bloqueios, separações, bifurcações etc). Neste caso, o escoamento de SE de origem anabática que desce a encosta oriental dos cimos da Serra do Mar, é obrigado a se bifurcar separandose na horizontal para definir dois ramos do escoamento, à NE e a SW do Morro. Atrás, a sotavento o escoamento torna a se unir através de um turbilhonamento horizontal.

Durante a noite, efeitos de canalização mecânica se mostram destacados, definindo canalizações importante como ao longo dos vales do rio Tietê e Sorocaba.

$\mathrm{O}$ maior contraste térmico está associado à presença do oceano. As simulações com domínio acima de $400 \mathrm{~km}$ apresentam brisa, que penetra somente até a Serra da Cantareira. À noite, observa-se brisa terrestre asssociada ao vento com uma maior intensidade sobre a escarpa da Serra do Mar em direção ao litoral (simulações L400 a L1500). Nesta região devido à topografia, a brisa terrestre se acopla à circulação catabática, sendo difícil separar o que é vento catabático e o que é a brisa terrestre em si. 
Os resultados das simulações indicam que existe uma redução do escoamento no período convectivo na área da escarpa da Serra do Mar; e uma tendência àreversão de sua direção original (de SE para NW) na região litorânea. Mas a reversão aparece localizada na simulação L1500 e somente sobre a escarpa da Serra do Mar.
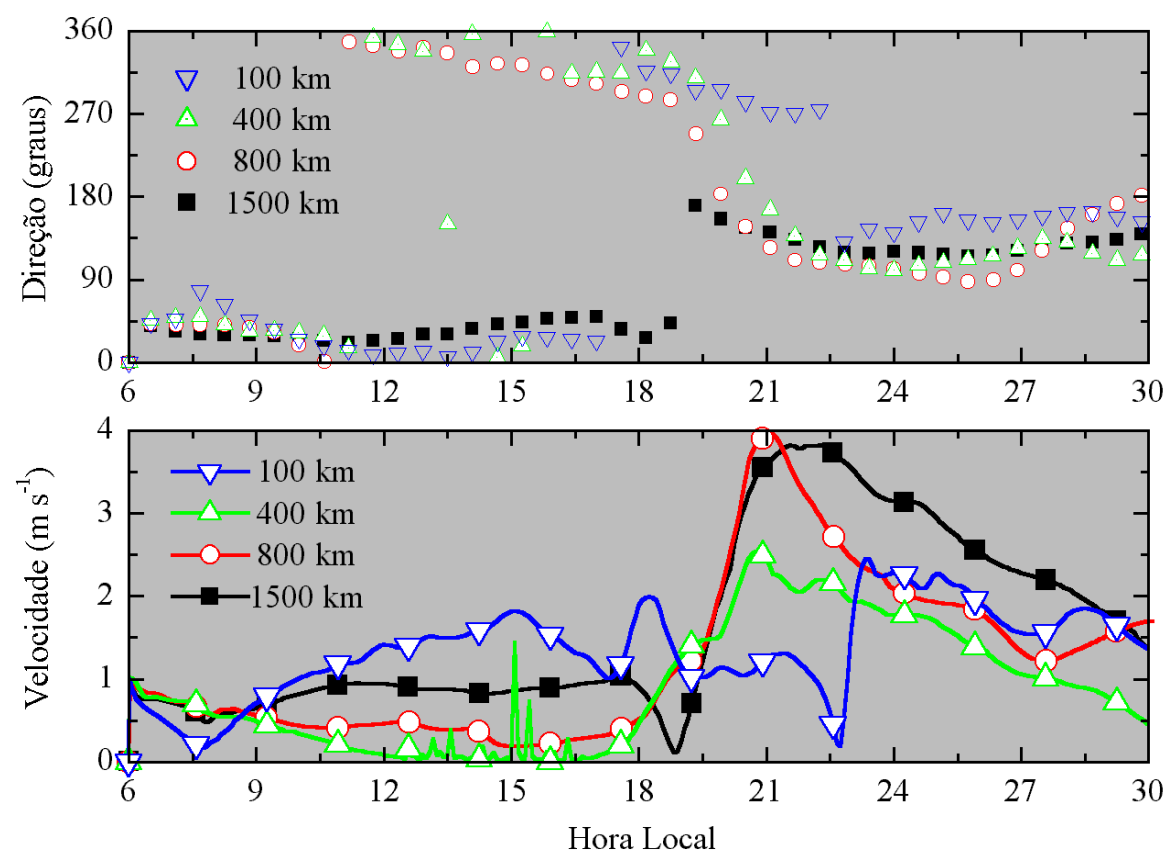

Figura 6.1 Comparação entre as evoluções diurnas da velocidade e direção do vento à superfície $(\mathrm{z}=14 \mathrm{~m})$ em Iperó simulada para diferentes extensões do domínio horizontal do modelo (1500 km, $800 \mathrm{~km}, 400 \mathrm{~km}$ e $100 \mathrm{~km})$.

À medida que o domínio é estendido, observa-se que as hodógrafas adquirem um caráter mais regional, respondendo ao ciclo diurno das forçantes térmicas induzidas pelo contraste térmico terra-oceano. O modelo não é capaz de responder as menores escalas da topografia e superfície (como no caso de L100). O ideal é que tivéssemos um modelo com capacidade de resolver todas as escalas, com a resolução de L100 e o domínio de L1500. As oscilações obtidas nas simulações são consistentes com aquelas observadas na CLP e que estão presentes nos dados do NCEP.

A topografia de escala inferior a $1500 \mathrm{~km}$ e superior a $100 \mathrm{~km}$ desempenha papel importante nas circulações locais estudadas. Isto se expressa pela formação de correntes de drenagem de ar frio (i.e., vento catabático) oriunda dos terrenos mais elevados e dos cimos da Serra do Mar, que durante a noite descem a encosta do Planalto Paulista em direção ao interior. 
O formato côncavo da Depressão Periférica, em especial, concentra o ar frio do escoamento de drenagem, intensificando-o em direção ao vale do rio Tietê (conforme apresentado na simulação L100).

O morro de Araçoiaba destaca-se na região de Iperó, caracterizada por vales e ondulações do terreno. A topografia deste morro é suficientemente para bloquear o escoamento noturno de superfície, resultando em uma bifurcação do escoamento segundo dois ramos que contornam o morro pelos seus lados (àdireita e à esquerda da direção média de SE do escoamento). O fluxo acelerado àdireita passa sobre o CEA, localizado a $7 \mathrm{~km}$ para NE do morro, o que define no local um escoamento de direção Sul. O vento de $\mathrm{S}$ predomina na superfície para a região do CEA durante o período noturno. Portanto, a predominância noturna dos ventos de $\mathrm{S}$ observada no CEA pode ser atribuída ao efeito mecânico do Morro de Araçoiaba sobre o escoamento de SE.

Duas áreas de recirculação do vento, horizontais, aparecem na retaguarda do Morro de Araçoiaba, após o escoamento ter sido bifurcado e ultrapassado o Morro.

Durante o período diurno (noturno), áreas de convergência (divergência) do escoamento aparecem sobre as áreas mais elevadas (baixas) do terreno.

Durante a noite, escoamento de ar na região de Bauru mostra-se convergente, sendo também canalizado ao longo dos vale do Rio Tietê, que passa entre as Serras de São Carlos e Botucatu.

A magnitude do JBN simulado para Iperó no experimento numérico L1500 é comparável (mas um pouco menor) que o JBN observado. Este fato indica o papel importante da topografia de escala regional $(1500 \mathrm{~km})$ na formação e sustentação do jato observado.

A evolução diurna do vento simulado concorda qualitativamente com a evolução média horária do vento em Iperó. Portanto, as simulações indicam que a circulação de mesoescala e o JBN aparecem como fenômenos característicos do interior sorocabano de São Paulo (i.e., em relação a sua freqüência e ocorrência).

Os efeitos da superfície sobre o escoamento são muito importantes para a região da Serra do Mar devido àpresença de complexidades tanto da topografia como dos tipos de superfície no local.

Dispersão de Poluentes - Aplicou-se um modelo de dispersão de partículas Lagrangiano para determinar o papel dos JBN sobre o transporte de curto e médio alcance de um poluente inerte com fonte pontual localizada na superfície. Determinouse que o papel dos JBN de Iperó sobre a trajetória de um poluente inerte emitido 
continuamente por uma fonte pontual junto à superfície é aumentar a dispersão horizontal das partículas ao longo do eixo da pluma. O cisalhamento do vento do JBN deforma a pluma conferindo-lhe um formato de cunha e aumentando a dispersão vertical. Além disso, o JBN é capaz de transportar o poluente por uma distância até 250 $\mathrm{km}$ a partir da fonte, durante o período noturno.

A natureza da estrutura vertical do JBN, que apresenta cisalhamento do vetor velocidade do vento pode deformar a nuvem de poluente, podendo segmentar e fragmentar a nuvem dispersada.

Devido à complexidade das circulações atmosféricas e da presença do JBN, nuvens de poluente emitidas continuamente da superfície $(10 \mathrm{~m})$ de diferentes fontes (Cubatão, Registro, São Paulo, Sertãozinho, Iperó, Bauru, Araçatuba e Presidente Prudente) podem se encontrar e misturar. Neste aspecto, pode ocorrer exportação do poluente de uma região para outra. Do ponto de vista dos receptores da poluição atmosférica, áreas de influência podem ser definidas sobre o Estado de São Paulo, em escala regional. Em particular, as plumas emitidas de São Paulo e Cubatão podem se misturar durante o período convectivo e depois, no período noturno, devido ao JBN, serem transportadas em parte para o interior.

\subsection{Recomendações para Trabalhos Futuros}

1. Realização de um experimento de observação do JBN no Estado de São Paulo. O objetivo desse experimento é determinar a estrutura vertical e espacial dos JBN noturno na ausência de forçantes de grande-escala. Observações da baixa tropofera devem incluir o lançamento simultâneo de radiossondas a partir de diferentes pontos ao longo de uma linha imaginária SE-NW, que parte do litoral de São Paulo e alcança o Pantanal em MT (Figura 6.2), com amostragem horária. A localização dos pontos de lançamento foi definida para se maximizar as observações dos ramos inferiores das circulações induzidas pela superfície.

2. Utilização da capacidade de modelamento do Túnel de Vento do IPT/ USP (Projeto Alfa) para: (a) estudar os efeitos da topografia e dos tipos de superfície na área de Iperó sobre o escoamento e seu impacto sobre a dispersão de poluentes em escala local e (b) estudar o efeito da superfície topográfica sobre o 
transporte e interpenetração de plumas de poluentes emitidas de diferentes pontos de SP e seu efeito sobre a qualidade do ar no interior paulista em escala regional;

3. Estudar-se observacionalmente a dispersão de poluentes no interior paulista utilizando-se emissões de elementos químicos traçadores nas escalas local e regional;

4. Desenvolver-se novas parametrizações para representar a dispersão associadas aos eventos de JBNs, com aplicações em modelagem de mesoescala e grandeescala;

O ganho futuro associado a esses trabalhos pode implicar:

- na melhoria da previsão de tempo regional, especialmente àquela associada às condições severas de tempo, como ventanias e temporais noturnos, resultando em uma melhor representação das condições de dispersão associadas aos eventos mais intensos de vento nos modelos numéricos;

- no estabelecimento das relações entre a qualidade do ar de pontos diferentes do Estado de São Paulo e o transporte regional de poluentes — definindo de forma precisa áreas de emissão (fontes) e área receptoras. O impacto da importação e exportação de poluentes atmosféricos pode ser efetivamente caracterizado e mapeado, possibilitando o controle da sociedade.

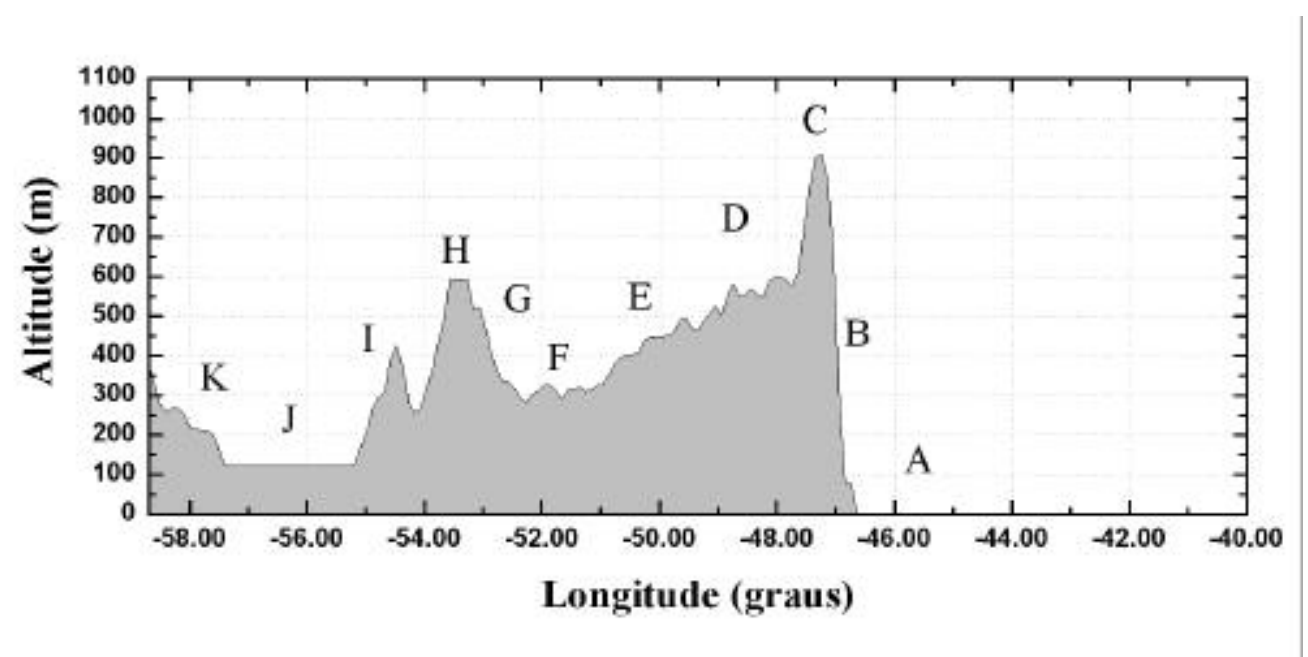

Figura 6.2 Proposta de localização das radiossondagens para experimento de observação de JBN no Estado de São Paulo ao longo da linha de corte SE-NW, indicada na Figura 1.5 do Capítulo 1. As letras indicam a localização aproximada de (A) Aeroporto de Santos; (B) Bairro Cota 500 m na escarpa da Serra do Mar; C: Aeroporto de São Paulo; D: Aeroporto de Sorocaba; (E) Aeroporto de Bauru; (F) Margem do Rio Paraná; (G) ponto na Serra de Maracaju; (I) margem do Rio Negro; (J) Pantanal e (K) ponto a oeste do Pantanal. 


\section{REFERÊNCIAS BIBLIOGRÁFICAS}

1. Ab'SABER, A., 1982: Um exemplo a não ser seguido (Cubatão), Ciência Hoje, Ano 1, No. 1, 1982, pp. 20-21.

2. ACEVEDO, O.C., 2001, Effects of Temporal and Spatial Transitions on Surface Atmosphere Exchanges. Vide Cap. 2: The early surface-layer transition: temporal and spatial variability. Phd. Thesis, Albany University, USA, 204 pp. Também em: ACEVEDO and FITZJARRALD, 2001, no Journal of the Atmospheric Sciences)

3. ADRIAN, G., 1995, On Similarity Laws in Regional Climatology, Meteorol. Atmos. Phys., 55, pp. 223-234.

4. AFANASYEV; Y.D. and PELTIER, W.R., 1998, The Three-dimensionalization of Stratified flow over two-dimensional topography. J. Atmos. Sci. 55: (1), pp. 19-39, JAN.

5. ALMEIDA, F.F.M. e CARNEIRO, C.D.R., 1998, Botucatu - o grande deserto brasileiro. Ciência Hoje, 24(143), pp. 37-43.

6. ANDERSON, D.L.T., 1976, The Low-level Jet as a Western Boundary Current. Mounthly Weather Review, 104, pp. 907-921.

7. ANDREAS, E.L., CLAFFEY, K.J. e MAKSHTAS, A.P., 2000, Low-level atmospheric jets and inversions over the western Weddell Sea, Boundary-Layer Meteor. 97, pp. 459-486, 2000.

8. ARRITT, R.W.; RINK, T.D.; SEGAL, M.; TODEY, D.P.; and CLARK, G.A. (1997) The great Plains Low-Level Jet during the Warm Season of 1993. Mounthly Weather Review 125: pp. 2176-2192, SEP.

9. ATWATER, M.; BROWN, P., 1974, Numerical Computation of the Latitudinal Variation of Solar Radiation for an Atmosphere of Verying Opacity. J. Appl. Met., Vol. 13, pp. 289297.

10. AUGUSTINE, J. A. e CARACENA, F., 1994: Lower-tropospheric precursors to nocturnal MCS development over the central United States. Wea. Forecasting, 9, pp. 116-135.

11. AURÉLIO, B.H.F., 1986, Novo Dicionário da Língua Portuguesa, $44^{\text {a. }}$ Impressão, Nova Fronteira, Rio, Brasil, 1838 pp.

12. AYLOR, D.E., 1999: Biophysical scaling and the passive dispersion of fungus spores: relationship to integrated pest manegement strategies, Agricultural and Forest meteorology, 97 (1999), pp. 275-292.

13. BALLING, R. C., 1985: Warm season nocturnal precipitation in the Great Plains of United States. J. Climate Appl. Meteor., 24, pp. 1383-1387.

14. BARNES, S. L., 1964, A Technique for Maximizing Details in Numerical Weather Map Analysis. Journal of Applied Meteorology, 3, pp. 396-409.

15. BARROS NETO, B.; SCARMINIO, I.S. e BRUNS, R.E., 1995: Planejamento e Otimização de Experimentos, Editora da UNICAMP, 2 ${ }^{\mathrm{a}}$. Edição, 299 pp., 1995.

16. BELWARD, A. S. (Ed.), 1996, The IGBP-DIS global $1 \mathrm{~km}$ land cover data set (DISCover)proposal and implementation plans: IGBP-DIS Working Paper No.13, Toulouse, France, $61 \mathrm{pp}$.

17. BERNADET, L.R., 2000, Comunicação pessoal.

18. BERROCAL, A.J. et al., 1984, Sismicidade do Brasil, CNEN e IAG-USP, Brasil.

19. BERRY, D.A and LINDGREN, B.W., 1990: Statistics: Theory and Methods. Brooks/Cole Publ. Comp. Pacific Grove, CA-USA. 763 pp.

20. BETTS, 1982a: Saturation point analysis of moist convective overturning, J. Atmos. Sci., 39, pp. 1484-1505.

21. BETTS, 1982b: Cloud thermodynamic models in saturation point coordinates, J. Atmos. Sci., 39, pp. 2182-2191.

22. BETZ, Albert, 1926: Wind-Energie. Em alemão, 1926.

23. BHUMRALKAR, C. M., 1975, Numerical Experiments on the Computation of Ground Surface Temperature in an Atmospheric General Circulation Model. J. Appl. Meteorol., 14, pp. 1246-1258. 
24. BLACKADAR, A.K., 1957: Boundary layer wind maxima and their significance for the growth of nocturnal inversions, Bull. Amer. Meteor. Soc., 38, No.5, 283-290, May 1957.

25. BOLTON, D., 1980: The computation of equivalent potential temperature, Monthly Weather Review, 108: pp. 1046-1053, 1980.

26. BONNER, W.D, 1966: Case study of thunderstorm activity in relation to the low level jet. Mon. Wea. Rev., 94, No. 3, pp. 167-178.

27. __ 1968: Climatology of the Low Level Jet. Monthly Weather Review, 96, No. 12, pp. 833-850.

28. __ ESBENSEN, S. e GREENBERG, R., 1968: Kinematics of the Low-Level Jet. Journal of Applied meteorology, 7, 339-347.

29. BORNSTEIN, R. D., 1975, The Two-dimensional URBMET Urban Boundary Layer Model. J. Appl. Meteor., Vol. 14, pp. 1459-1477.

30. __ and ROBOCK, A.D., 1976, Effects of Variable and Unequal Time Steps for Advective and Diffusive Processes in Simulations of Urban Boundary Layer, Monthly Weather Review, 104, pp. 260-267.

31. _ _ PECHINGER, U. ; MILLER, R.; KLOTZ, S. e STREET, R., 1987, Modeling the Polluted Coastal Urban Environment. Volume I: The PBL Model. Electric Power Research Institute EPRI; Report EA-5091, Vol. 1 Research Project 1630-13.

32. __ CORDOVA, J.; SALVADOR, R. e SHIEH, L.J., 1987, Modeling the Polluted Coastal Urban Environment; Electric Power Research Institute EPRI; Report EA-5091, Vol. 3 Research Project 1630-13.

33. BORNSTEIN, R., THUNIS, P., GROSSI, P. e SCHAYES, G., 1996. Topographic Vorticity-Mode Mesoscale-beta (TVM) Model. Part II: Evaluation. J. of Appl. Meteor., 35(10) October 96, 1824-1834,.

34. BROOK, R.R., 1985, The Koorin nocturnal low-level jet. Bound.-Layer Meteor., 32, pp. 133-154, 1985.

35. BROWNING, K. A. (Editor), 1982, Nowcasting, London: Academic Press, livro.

36. BURK, S.D. and THOMPSON, W.T., 1996, The Summertime Low-Level Jet and Marine Boundary Layer Structure along the California Coast. Monthly Weather Review, 124, pp. 668-686, ABR.

37. BUSINGER, J. A.; WYNGAARD, J. C.; IZUMI, Y. e BRADLEY, E. F., 1971, Flux-profile Relationships in Atmospheric Surface layer; Journal of the Atmospheric Sciences, 28, pp. 181-189.

38. BYRNE, D.N., 1999: Migration and dispersal by the sweet potato whitefly, Bemisia tabaci. Agricultural and Forest Meteorology, 97 (1999), pp. 309-316.

39. CÁRDENAS, Lionel D., 1990: Um Estudo dos Jatos Noturnos de Baixos Níveis na Região Central do Estado de São Paulo. Dissertação de Mestrado, IAG-USP, Brasil.

40. __ e SILVA DIAS, M.A.F., 1990, Características do Jato Noturno de Baixos Níveis Ocorrido no Dia 24/01/1983 na Região central do Estado de São Paulo. (In Portuguese) Proceedings, VI Brazilian Meteorological Congress, Salvador, BA, pp. 567-571, NOV.

41. CARDOSO, Manuel F., 1997, Produção e Transporte de Ozônio Troposférico em Cubatão, São Paulo, Dissertação de Mestrado, IAG-USP, Brasil. 163 pp.

42. CARMO, A.M.C., 1996, Estudo da estrutura termodinâmica da atmosfera sobre a Amazônia. Dissertação de Mestrado (INPE/MCT), 25/11/1996. Abstract available in the Revista Brasileira de Geofísica (website), Vol. 17(1), 1999.

43. CARPENTER, Jr., R.L.; DROEGEMEIER, K.K.; WOODWARD, P.R. and HANE, C.E., 1990, Application of the Piecewise Parabolic Method to Meteorological Modeling. Monthly Weather Review, 118, pp. 586-612.

44. CHEN, C.; TAO, W.K.; LIN, P.L.; et al., 1998, The Intensification of the Low-Level Jet during the Development of mesoscale Convective Systems on a Mei-Yu Front. Monthly Weather Review, 126: (2) pp. 349-371 FEB.

45. CHEN, Y.L.; CHEN, X.A..; CHEN, S.; et al., 1997, A Numerical Study of the Low-Level Jet during TAMEX IOP 5. Monthly Weather Review, 125: (10) pp. 2583-2604 OCT.

46. CHORIN, A.J., 1994, Vorticity and Turbulence, Springer-Verlag Inc., New York, 172 pp. 
47. CLARK, T.L.; JENKINS, M.A.; COEN, J. and PACKHAM, D., 1996: A coupled atmosphere-fire model: convective feedback on fire-line dynamics, Journal of Applied meteorlogy, 35, June (1996): pp. 875-901.

48. CLIMANÁLISE, 1996, Climanálise Especial (revista). Edição comemorativa de 10 anos sobre o Clima do Brasil. Co-editores: CAVALCANTE, I.F.A.; ABREU, M.L. e SATYAMURTY, P. Centro de Previsao de Tempo e Estudos Climáticos - CPTEC. Instituto de Pesquisas Espaciais - INPE/MCT (ISSN 0103-0019). São José dos Campos, SP, Brasil. $235 \mathrm{pp}$.

49. CORSMEIER, U.; KALTHOFF, N.; KOLLE, O.; KOTZIAN, M and FIEDLER, F., (1997), Ozone Concentration Jump in the Stable Nocturnal Boundary Layer During a LLJ-Event. Atmospheric Environment, Vol. 31, pp. 1977-1989, 1997.

50. COTTON, W. R. e ANTHES, R. A., 1989, Storm and Cloud Dynamics, New York: Academic Press Inc., livro, 883 pp.

51. CRUTZER, P., 1983: Atmospheric interations - homogeneous gas reactions of $C, N$ and $S$ containing coumponds. In Scope (B. Bolin \& R. Cook Eds.), John Wiley \& Sons, 67-114.

52. CTMSP, 1997, Relatório do Impacto Ambiental (RIMA) do Centro Experimental ARAMAR - CEA\}. Centro Tecnológico da Marinha em São Paulo (CTMSP), Ministério da Marinha, Brasil, quatro volumes, $289 \mathrm{pp}, 1997$.

53. DABAS, A.; PÉRIN, J. and FLAMANT, P.H., 1997, Variational Analysis for Airborne Conically Scanned Doppler Lidar to Retrieve Mesoscale Winds Fields, J. of Atmospheric and Oceanic Technology, 14 (1997), 1079-1090.

54. DEARDORFF, J.W., 1978, Efficient Prediction of Ground Surface Temperature and Moisture, with inclusion of a layer of vegetation, J. Geoph. Res., 83, C4, 1889-1903.

55. __, 1979, Prediction of convective Mixed-layer entrainment for realistic capping inversion structure. Journal of the Atmospheric Sciences, 36, 424-436.

56. __, WILLIS, G.E. and STOCKTON, B.H., 1980: Laboratory studies of the entrainment zone of a convectively mixed layer. J. Fluid. mech., 100, 41-64.

57. DE BASS, A.F.; VAN DOP, H. e NIEUWSTADT, F.T.M., 1986: An application of the Langevin equation for inhomogeneous conditions to dispersion in a convective boundary layer, Quart. Journ. Royal Meteor. Soc., 112, 165-180.

58. DELEERSNIJDER, (1992) Thesis (L.L.N.), pp. 59-61.

59. DONALDSON, C. duP., 1972, Construction of A Dynamic Model of the Production of Atmospheric Turbulence and the Dispersal of Atmospheric Pollutants. D. A. Haugen (Editor). In Workshop of Micrometeorology. American Meteorological Society (A.M.S.), Boston, Mass., USA, pp. 313-392.

60. DONGARRA, J.J.; BUNCH, J.R.; MOLLER, C.B. and STEWART, G.W., 1979: LINPACK Users' Guide. SIAM, 367 pp.

61. DOTY, Brian, 1995, The Grid Analysis and Display System GrADS. Manual reformatted and updatted by: Tom HOLT, Climatic research Unit, University of East Anglia, Norwich, UK (t.holt@uea.ac.uk) and Mike FIORINO, Program for Climate Model Diagnosis and Intercomparison. Lawrence Livermore national laboratory L-264, Livermore, CA 94551 (fiorino@typhoon.llnl.gov), September 1995 (e-mail: doty@ cola.iges.org), 148 pp.

62. DOUGLAS, M.W., 1995, The Summertime Low-Level Jet over the Gulf of California. Monthly Weather Review 123: 2334-2347, AUG.

63. DUTTON, J.A., 1976: The Ceaseless Wind - an introduction to the theory of atmospheric motion. Livro. McGraw-Hill, Inc, USA, 579 pp.

64. __ 1986: Dymamics of Atmospheric Motion (formerly The Ceaseless Wind), Livro, Dover Publications, Inc., New York, 617 pp.

65. EICHHORN, J.; SCHODIN, R. and ZDUNKOWSKI, W: Three-Dimensional Numerical Simulations of the Urban Climate. Contributions to the Atmospheric Physics (Beitr. Phys. Atmosph.), Vol. 61 (1988), No. 3, August, pp. 187-203.

66. EXLER, H., 1961, A Boundary Layer Interpretation of the Low-Level Jet. Tellus 13, pp. 368-378. 
67. FAST, J.D. and McCORCLE, M.D., 1990: A Two-Dimensional Numerical Sensitivity Study of the Great Plains Low-Level Jet. Monthly Weather Review, Vol. 118, January, pp. 151163.

68. Fitzjarrald, David R., 1984: Katabatic Wind in Opposing Flow. J. Atmos. Sci., 41, No. 7 , pp. 1143-1158.

69. FRISCH, A.S.; ORR, B.W., and MARTNER, B.E., 1992, Doppler Radar Observations of the Development of a Boundary-Layer Nocturnal Jet. Monthly Weather Review 120: pp. 316 , JAN.

70. FRISCH, A.S.; ORR, B.W. e MARTNER, B.E., 1992, Climatology of the simulated Great Plains low-level jet and its contribution to the continental moisture budget of the United States. J. Climate, 8, pp. 784-806.

71. FRISCK, U., 1995: Turbulence - the legacy of A.N. Kolmogorov. Cambridge Inversity Press. 296 pp.

72. GARRAT, J. R., 1985: Inland boundary layer at low latitudes. Part 1: the nocturnal jet. Bound.-Layer Meteor., 32, pp. 307-327.

73. __ 1990: The internal boundary layer - a review. Boundary-Layer Meteorology, 50, pp. 171-203.

74. GAGE, S.H.; ISARD, S.A. e COLUNGA-G., M., 1999: Ecological scaling of aerobiological dispersal processes. Agricultural and Forest Meteorology, 97, pp. 249-261.

75. GAL-CHEN, T. e SOMERVILLE, R.C.J., 1975, On the Use of a Coordinate transformation for the Solution of the Navier-Stokes Equations. Journal of Computational Physics, 17, pp. 209-228.

76. __ 1975, Numerical Solution of the Navier-Stokes Equations with Topography. Journal of Computational Physics, 17, pp. 276-310.

77. GHAN, S.J. and BIAN, X., 1996, Simulation of the Great Plains Low-Level Jet and Associated Clouds by General Circulation Models. Monthly Weather Review 124: pp. 1388-1408, JUL.

78. GRAHAN, D. I. E MOYEED, R. A., 2001, How many particles for my Lagrangian simulation? Powder Technology, 4454 (www.elsevier.com/locate/powtec).

79. GYR, A. e RYS, F-S. (Editors), 1995: Diffusion and Transport of Pollutants in Atmospheric Mesoscalae Flow Fields, Kluwer Academic Publishers, Dordrecht, 216 pp.

80. HALTINER, G.J. e WILLIAMS, R.T, 1980: Numerical prediction and dynamic meteorology, John Wiley \& Sons Inc., $477 \mathrm{pp}$.

81. HAN, Y.-J; UEYOSHI, K. and DEARDORFF, J.W., 1982, Numerical Study of terrainInduced Mesoscale Motions in a Mixed Layer. J. Atmospheric Sciences, Vol. 39, pp. 24642476.

82. HART, J.E.; RAO, G.V.; van de BOOGAARD, H.; YOUNG, J.A. e FINDLATER, J., 1978: Aerial observations of the E. African low-level jet stream. Mon. Wea. Rev., 106, pp. 1714-1724.

83. HAURWITZ, B., 1947, Comments on the sea-breeze circulation. J. Meteor., 4, pp. 1-8.

84. HELFAND, H.M. e SCHBERT, S.D., 1995: Climatology of the simulated Great Plain lowlevel jet and its contribution to the continental moisture budget of the United State. J. Climate, 8, pp. 784-806.

85. HENSON et al., 1979: Vegetation as an indicator of high wind velocity, RLP/2227-T24-791, Oregon State University. Dept. Atm. Sci, 1979.

86. HOECKER, W.L., 1963, Three southerly low-level jet systems delineated by Weather Bureau special pibal network of 1961. Mon. Wea. Rev., 91, pp. 573-582.

87. HOLTON, J.R., 1967: The diurnal boundary layer wind oscillation above sloping terrain. Tellus, 19, pp. 199-205, 1967.

88. HOVERMALE, J. B., 1986, Assimilation and Initialization of Atmospheric Data Into Numerical Prediction Models, Capítulo 25 em Mesoscale Meteorlogy and Forecasting, Peter S. Ray (Editor), AMS, Boston, 1986, $1^{\text {st }}$ ed., 793 pp.

89. IBANEZ, José B. I., 1995, Influência dos Andes nas circulações locais do Peru. Dissertação de mestrado, IAG-USP, São Paulo, 215 pp. 
90. INNOCENTINI, V., 1981, Simulação numérica da brisa marítima: teste de sensibilidade e efeito de parametrizações de transportes turbulentos, Dissertação de Mestrado, IAG-USP, São Paulo, 61 p. + apêndice.

91. IRWIN, M.E., 1999: Implications of movement in developing and deploying integrated pest management strategies. Agricultural and Forest Meteorology, 97 (1999), pp. 235-248.

92. IZUMI, Y., e BARAD, M.L., 1963: Wind and temperature variations during development of a low-level jet. J. Appl. Meteor., 2, pp. 668-673.

93. JEGER, M.J., 1999: Improved understanding of dispersal in crop pest and disease manegement: current status and future directions. Agricultural and Forest Meteorology, 97 (1999), pp. 331-349.

94. KAHL, J.D., 1990, Characteristics of the Low-Level Temperature Inversion along the Alaskan Artic Coast, Int. J. Climatol. 10, pp. 537-548.

95. KAIMAL, J.C. e FINNIGAN, J.J., 1994: Atmospheric Boundary Layer Flows - Their Structure and Measurements, Oxford University Press, NY, 289 pp.

96. KALNAY,E.;KANAMITSU,M.;KSITLER,R.;COLLINS,W.;DEAVEN,D.;GANDIN,L.;IR EDELL,M.;SAHA,S.;WHITE,G.;WOOLLEN,J.;ZHU,Y.;CHELLIAH,M.;EBISUZAKI,W.; HIGGINS,W.;JANOWIAK,J.;MO,K.C.;ROPELEWSKY,C.;WANG,J.;LEETMAA,A.;REY NOLDS,R.;JENNE,ROY; and JOSEPH, DENNIS. (1996) The NCEP/NCAR 40-Year Reanalysis Project. Bulletin of the American Meteorological Society. Vol. 77, No. 3, March 1996, pp. 437-471.

97. KARAM, H.A., 1995, Simulação Numérica tridimensional da Camada Limite Planetária em Iperó, São Paulo, Dissertação de Mestrado, IAG-USP, 112 pp., 1995.

98. __ e OLIVEIRA, A.P., 1998, Estudo do efeito topográfico no ciclo diurno do vento na superfície do Estado de São Paulo. Nos Anais do X Congresso Brasileiro de Meteorologia, 26 a 30 de outubro de 1998, Brasília, Brasil.

99. __ e OLIVEIRA, A.P., 2001, 'Patterns of Local Circulation Induced by Topography and $\overline{L L J}$ in São Paulo, Brazil: Observation and Numerical Modeling' (to be submitted after this issue).

100. — OLIVEIRA, A.P. e PEREIRA, M.M.R., 2001: Dispersion of a Hypothetically Release Radionuclides Over Complex Terrain - Part I: Local Circulations and LLJ. $7^{\text {th }}$ International Conference on Harmonization within Atmospheric Dispersion Modeling for Regulatory Purposes, Belgirate, Italy, pp. 28-31, May 2001.

101. _ _ OLIVEIRA, A.P; PEREIRA, M.M.R., 2001, Dispersion of a Hypothetically Release Radionuclides Over Complex Terrain - Part I: The Impact of Low-Level Jet in the Trajectories. In Proceeding of the 7th International Conference on Harmonization within Atmospheric Dispersion Modeling for Regulatory Purposes. Belgirate, Italy, May 2001.

102. _ e FREITAS, E.D., 2001, Difusão vertical no jato de baixos níveis pela teoria de turbulência transiliente. Trabalho submetido e aceito para publicação na Revista Ciência e Natura, RS, Brasil.

103. KATZ, J., 1991, Low-speed aerodynamics: from wing theory to panel methods, McGraw-Hill Ed., Series in aeronautical and aerospace engineering, 632 pp., 1991.

104. KERR, Américo A.F.S., 1995, Parametrização da dispersão de poluentes e sua associação com modelos receptores em Cubatão, Tese de Doutorado, IAG-USP.

105. KIRCHHOFF, W.J.H., 1991: As queimadas da cana - resumos das contribuições apresentadas ao workshop "Queima Cana", INPE, São José dos Campos, 27-28 de março de 1991, $92 \mathrm{pp}$.

106. __ 1992: Queimadas na Amazônia e Efeito Estufa (livro). Ed. Contexto, SCT/CNPq, Programa Trópico Úmido, 1992, 118 pp.

107. KLUMPP, A.; DOMINGOS, M.; KLUMPP, G. e GUDERIAN, R., 2001, Módulo de Vegetação em A poluição atmosférica e os danos à vegetação dos trópicos - A Serra do Mar como um exemplo (2001); KLOCKOW, D. VAUTZ, W. e TARGA, H. (Editores). Governo do estado de São Paulo, Secretaria do Estado do Meio Ambiente, pp. 151-185.

108. KOEN, de R. and SCHAYES, G., 1997, A Land Surface Transfer Scheme for Use in a Mesoscale Atmospheric Model. J. Appl. Meteorol. 36: (2) pp. 167-182. 
109. KOVÁCS, Z.L., 1996: Teoria da probabilidade e processos estocásticos. Livro. Edição Acadêmica, São Paulo, 1996, 120 pp.

110. KRAUS, H.; MALCHER, J. e SCHALLER, E., 1985, Nocturnal low-level jet during PUKK. Bound-Layer Meteor., 31, pp. 187-195.

111. KRISHNAMURTI, T.N. e WONG, V., 1979: A planetary boundary-layer model for the Somali jet, Journ. of the Atmosph. Sci., 36, pp. 1895-1907, 1979.

112. KUCINSKI, B., 1982: Cubatão, uma tragédia ecológica, (Revista) Ciência Hoje, Ano 1 No. 1,1982, pp. 11-24.

113. KUO, H. L, 1965, On the formation and intensification of tropical cyclones through latent heat release by cumulus convection. J. Atmos. Sci., 22, pp. 40-63.

114. _ 1974, Further studies of the parameterization of the influence of cumulus convection on large-scale flow. J. Atmos. Sci., 31, pp. 1232-1240.

115. LANDAHL, M.T. e MOLLO-CHRISTENSEN, E., 1986: Turbulence and random processes in fluid mechanics, livro, Cambridge University Press, NY, 154 pp.

116. LEE, B. E., 1978, Extreme wind data and building design, Weather (1978), 33, pp. 416422.

117. LEGG, B. J; RAUPACH, M. R., 1982, Markov-chain simulation of particle dispersion in inhomogeneous flows: the mean drift velocity induced by a gradient in Eulerian velocity variance. Boundary-layer Meteor. 24, pp. 3-13.

118. LIMPERT, E.; GODET, F. e MULLER, K., 1999, Dispersion of cereal mildews across Europe, Agricultural and Forest Meteor., 97 (1999), pp. 293-308.

119. LEGG, B.J. and RAUPACH, M.R., 1982: Markov-Chain Simulation of Particle Dispersion in Inhomogeneous Flows: The Mean Drift Velocity induced by a Gradient in Eulerian Velocity Variance, Boundary Layer Meteorology, 24, pp. 3-13, 1982.

120. LETTAU, H.H., 1967: Small to large scale features of boundary layer structure over mountain slopes. Proc. Symp. on Mountain Meteor., Colorado State Univ., Ft. Collins, Part 2, pp. 1-74.

121. _ 1990: The O'Neill Experiment of 1953. In the Special Volume of Boundary-Layer Meteorology, 1990, pp. 1-9.

122. McDONALD, J., 1960, Direct Absorption of Solar Radiation by Atmospheric Water Vapor. Journal of Meteorology, Vol. 17, pp. 319-.

123. MAHRT, L.; HEALD, R.C.; LENSCHOW, D.H.; STANKOV, B.B. e TROEN, IB , 1979: An observational study of the structure of the nocturnal boundary layer. Bound.Layer Met., 17, pp. 247-264.

124. MALCHER, J. e KRAUS, H., 1983, Low-level jet phenomena described by an integrated dynamic PBL model. Bound.-Layer Meteor., 27, pp. 327-343.

125. MALISKA, C. R., 1995, Transferência e Calor e Mecânica dos Fluidos Computacionais - Fundamentos e Coordenadas Generalizadas, LTC Editora, 424 pp.

126. MALONE, T. F. (Editor), 1951, Compendium of Meteorology, Boston: American Meteorological Society (AMS), 1334 pp.

127. MARCHUK, G. I., 1974, Numerical methods in weather prediction. Traduzido do russo Chislennye metody v prognoze pogody por K. N. Trirogoff e U. R. Lamb; editor da tradução A. Arakawa e Y. Mintz; New York: Academic Press; livro, 277 pp., biblioteca do IAG/USP.

128. MARENGO, 2002, Pre-print do Meeting sobre o Jato de Baixos Níveis da América do Sul - VAMOS/CLIVAR/WCRP, Bolívia, site (http://www-cima.at.fcen.uba.ar/sallj).

129. MARINHO, E.V.A. e KIRCHHOFF, V.W.J.H., 1991: Projeto Fogo: um experimento para avaliar efeitos das queimadas de cana-de-açúcar na baixa troposfera, Revista Brasileira de Geofísica; 1991: Vol. 9 (2), pp. 107-119.

130. MARTÍN, F., CRESPÍ, S.N. e PALÁCIOS, M., 2001a, Simulations of Mesoscale Circulations in the Center of the Iberian Península for thermal Low Pressure Conditions. Part I: Evaluation of the topography vorticity-mode mesoscale model, Journal of Applied Meteorology, Vol. 40, pp. 880-904.

131. _ _ PALÁCIOS, M. e CRESPÍ, S.N., 2001 b, Simulations of Mesoscale Circulations in the Center of the Iberian Península for thermal Low Pressure Conditions. Part II: Airparcel transport Patterns, Journal of Applied Meteorology, 40, pp. 905-914. 
132. MATSON, P.A. e HARRISS, R.C. (Editors), 1995: Biogenic Trace Gases: measuring Emissions from Soil and Water, Methods in Ecology Series, Blackweell MZV, Austria, 392 pp.

133. MAY, P.T., 1995, The Australian Nocturnal Jet and Diurnal Variations of BoundaryLayer Winds over Mt. Isa in North-Eastern Australia. Q. J. R. Meteorol. Soc., 121, pp. 9871003.

134. McEWAN, M.J. e PHILLIPS, L.F., 1975, Chemistry of the Atmosphere, Edward Arnold (Publishers) Ltd0, London, 300 pp.

135. McNIDER e PIELKE, R.A., 1981, Diurnal boundary-layer developent over sloping terrain. J. Atmos. Sci., 38, pp. 2198-2212.

136. MEANS, L.L., 1952, On Thunderstorm Forecasting in the Central United States. Monthly Weather Review 80: (10) pp. 165-189, OCT.

137. MENZEL, D.H. (Editor), 1960: Fundamental Formulas of Physics, vol. 1, Dover Publications, Inc., $364 \mathrm{p}$.

138. MESINGER, F. e ARAKAWA, A., 1979, Numeric Methods used in Atmospheric Models. GARP Publications Series No. 17, Vol. 1, August 1979 World Meteorological Organization, $64 \mathrm{pp}$.

139. __. 1981, Numerical Methods used in Atmospheric Models. Garp publications Series No. 17, Vol. 1, (November 1982). World Meteorological Organization; 64 pp.

140. MITCHELL, M.J.; ARRIT, R.W.; and LABAS, K., 1995, A Climatology of the Warm Season Great Plains Low-Level Jet using Wind Profiler Observations. Weather Forecasting, 10, pp. 576-895.

141. MO, K.J.; PAEGLE, J.N. and PAEGLE, J., 1995: Physical mechanisms of the 1993 floods. J. Atmos. Sci., 52, pp. 879-895.

142. MOLNARY, L., 1993: Caracterização de um Modelo de Camada Limite Planetária para Avaliar Liberações de Radionuclídeos em Instalações Nucleares. Dissertação de mestrado, IAG-USP, Brasil.

143. MONIN, A.S. e YAGLOM, A.M., 1981: Statistical Fluid Mechanics: Mechanics of Turbulence, Volume 1, The MIT Press (English edition updated, Edited by John L. Lumley).

144. MONTEITH, J. L. (Editor), 1975: Vegetation and the Atmosphere, Volume 1 Principles, Academic Press, London, 278 pp.

145. MONTEITH, J. L., 1981, Evaporation and Surface Temperature. Quart. J. R. Met. Soc., 107, pp. 1-27.

146. MOORE, J. T., 2002: Evolution of the Low-Level Jet (talk), COMET-COMAP Course, May-June 2002, Cooperative Institute for Precipitation Systems (CIPS), Saint Louis University (NWSLU), in website: http://mnw.eas.slu.edu/CIPS/Presentations.html.

147. MORAES, O.L.L.; OLIVEIRA, A.P.; CAETANO, NETO, E.S; and DEGRAZIA, G.A. (EDITORS), 1996. Proceedings of the Workshop "Air Pollution and Acid Rain: The Candiota Program". Financial support: FAPESP, Brazil.

148. MORAN, M.D. and PIELKE, R.A., 1996a: Evaluation of a Mesoscale Atmospheric Dispersion Modeling System with Observations from the 1980 Great Plains Mesoscale Tracer Field Experiment. Part I: Datasets and Meteorological Simulations. Journal of Applied Meteorology, 35, pp. 281-307, MAR.

149. MORAN, M.D. and PIELKE, R.A., 1996b: Evaluation of a Mesoscale Atmospheric Dispersion Modeling System with Observations from the 1980 Great Plains Mesoscale Tracer Field Experiment. Part II: Dispersion Simulations. Journal of Applied Meteorology, 35, pp. 308-329, MAR.

150. MOUSSIOPOULOS, N. and FLASSAK, Th., 1986: "Two Vectorized Algorithms for the Effective Calculation of Mass-Consistent Flow Fields". Journal of Climate and Applied Meteorology, June 1986, Vol. 25: pp. 847-857.

151. NIEUWSTADT, F. T. M. e TENNEKES, H., 1981, A Rate Equation for the Nocturnal Boundary-Layer Height. J. Atm. Science, 38, pp. 1418-1428.

152. __ 1984, Some Aspects of the Turbulent Stable Boundary Layer. Boundary-Layer Meteorology, 30, pp. 31-55. 
153. NEWTON, C.W. (1959) Synoptic Comparation of Gulf Stream and Jet Stream Systems. In Rossby Memorial Volume of The Atmospheric and the Sea in Motion, B. Bolin, Ed., Rochefeller Institute Press, pp. 288-304 (citada por ANDERSON, 1976 e EXLER, 1961).

154. NGUYEN, K.C., NOONAN, J.A., GALBALLY, I.E. and PHYSICK, W.L, 1997, Prediction of Plume dispersion in Complex Terrain: Eulerian Versus Lagrangian Models. Atmospheric Environment, 31, pp. 947-958, 1997.

155. NOVAIS, V., 1993, Físico-Química e Química Ambiental, Ed. Atual, São Paulo, Vol. 2, $430 \mathrm{pp}$.

156. NÚÑEZ, Marco A., 2000: Map projections and topography in atmospheric mesoscale modeling. Cidade do México. Comunicação pessoal (pré-print), 23 pp.

157. OLIVEIRA, A.P., 1992, Medidas de Turbulência efetuadas em Iperó (SP) em Março de 1991. Nos Anais do VII Congresso Brasileiro de Meteorologia. São Paulo. Brasil. Vol. 2, pp. $450-454$.

158. __ 1992, Projeto Estudo da Dinâmica da CLP em Regiões Tropicais e Subtropicais. Nos Anais do VII Congresso Brasileiro de Meteorologia -SP/BR. Vol. 2, pp 432-436, 1992.

159. __ 1993, Estudo da Dinâmica da Camada Limite Planetária em Latitudes Tropicais e Subtropicais. Processo No. 90/4402-1. Relatório Interno, Departamento de Ciências Atmosféricas. IAG-USP, Brasil, 70 pp, 1993.

160. — DEGRÁZIA, G.A., MORAES, O.L.L. and TIRABASSI, T., 1995, Numerical Study of Nocturnal Planetary Boundary Layer at Low Latitudes. Third International Conference on air Pollution (Air Pollution 95). In Air Pollution III - Theory and Simulation, Vol. I: Air Pollution, Editors: H. Power, N. Moussiopoulos, C. A. Brebbia, Computational Mechanics Publications. October 1995 in Greece.

161. _ _ FITZJARRALD, D.R., 1993, The Amazon River Breeze and the Local Boundary Layer: I. Observations, Boundary-Layer Meteor., 63: pp. 141-162, 1993.

162. _ e FITZJARRALD, D.R., 1994, The Amazon River Breeze and the Local Boundary Layer: II. Linear Analysis and Modelling, Boundary-Layer Meteorology, 67: pp. 75-96, 1994.

163. _ e SAKAY, R.K., 1991: Relatório Técnico do Projeto - Dinâmica da Camada Limite Planetária em Latitudes Tropicais e Subtropicais, Grupo de Micrometeorologia, Departamento de Ciências Atmosféricas, IAG-USP, Brasil, 120 pp.

164. _ _ e SILVA DIAS, P.L., 1982, Aspectos Observacionais da brisa Marítima em São Paulo, in the Proceedings of the II Congresso Brasileiro de Meteorologia, Pelotas, RS, Brazil, pp. 129-145, in Portuguese, 1982.

165. — DEGRAZIA, G. A., MOREAS, O. L. L., TIRABASSI, T., 1995, Numerical Study of the Nocturnal Planetary Boundary Layer at Low Latitudes. In: Third International Conference Air Pollution 95, 1995, Porto Carras, Proceedings of the Third International Conferecen Air Pollution 95, Porto Carras, Grécia, 1995, Vol. 1, pp. 167-174.

166. _ _ SOARES, J., DEGRAZIA, G.A. and MORAES, O.L.L., 1996, Numerical simulation of the planetary boundary layer at Candiota using a second order closure model. In the workshop "Air Pollution And Acid Rain: The Candiota Program", Bauru, SP, Brasil, July 1996, pp. 56-67.

167. _ SOARES, J., TIRABASSI, T. and RIZZA, U., 1998, A surface energy budget model coupled with a skewed puff model for investigation the dispersion of radionuclides in a Subtropical area of Brazil, Il Nuovo Cimento, Vol. 21(C), No. 6, pp. 631-646, 1998.

168. OKE, T.R., 1978: Boundary Layer Climates, Londres-UK, second edition (livro), Methuen Publ., 435 pp.

169. ORGAZ, M. D. M. e FORTES, J. L., 1998, Estudo das Brisas Costeiras na Região de Aveiro. In Proceedings of the: I Simpósio de Meteorologia de Geofísica Hispano-Português, Lagos, Portugal.

170. ORLANSKI, L., 1975, A rational subdivision of scales for atmospheric processes. Bull. Amer. Meteorl. Soc., 56, pp. 529-530.

171. PACITTI, T. e ATKINSON, C.P., 1983: Programação e Métodos Computacionais Vol. 2, livro, 2a. Edição, LTC Editora, RJ, Brasil, 667 pp. 
172. PANOFSKY, H.A. e BRIER, G.W., 1956: Some Applications of Statistics to Meteorology. The Pennsylvania State University, $224 \mathrm{pp}$.

173. PANOFSKY, H.A. e DUTTON, J.A., 1984: Atmospheric Turbulence - Models and Methods for Engineering Applications. John Wiley \& Sons, NY, 396 pp.

174. PARISHI, T.R.; RODI, A.R. e CLARK, R.D., 1988: A case study of the summertime Great Plain low level jet. Mon. Wea. Rev., 116, pp. 94-105.

175. PEAGLE, J. e McLAWHORN, D.W., 1983: Numerical modeling of diurnal convergence oscillations above sloping terrain. Mon. Wea. Rev., 111, pp. 67-85.

176. PEREIRA, M.M.R., OLIVEIRA, A.P. and KARAM, H.A., 2000, Estudo Numérico da Dispersão de Poluentes Sobre uma Região de Topografia Complexa XI Congresso Brasileiro de Meteorologia, pp. 2270-2277, 2000.

177. _ 2001: Dispersion of a Hypothetically Release Radionuclides Over Complex Terrain - Part II: The Impact of Low-Level Jet in the Concentration Field. $7^{\text {th }}$ International Conference on Harmonization within Atmospheric Dispersion Modeling for Regulatory Purposes, Belgirate, Italy, May(2001), pp. 28-31.

178. PETTERSSEN, Sverre, Ed., 1956: Weather Analysis and Forecasting: Vol. I - Motion and Motion Systems. New York: McGraw-Hill Inc., 428 pp.

179. PHILLIPS, N.A., 1966, The equations of motions for a shallow rotation atmosphere and the traditional approximation. J. Atmos. Scis., 23, $626 \mathrm{pp}$.

180. PITCHFORD, K.L. e LONDON, J., 1962: The low-level jet as related to nocturnal thunderstorms over the Midwest United States. J. Appl. Meteor., 1, pp. 43-47.

181. PIELKE, R.A., 1984: Mesoscale Meteological Modeling. Orlando: Academic Press, livro, $612 \mathrm{p}$.

182. POLTRONIÉRI, L. C. e MACHADO, L. M. C. P., 2000: Pesticide's impacts in São Paulo State, Brazil. Revista de estudos ambientais, Blumenau, Vol. 2, No. 1, pp. 37-41, jan/abr 2000.

183. PRANDTL, L., 1942, Furher durch die Strömungslehre. Braunschweig, Vieweg und Sohn, Brunswick, 452 pp. [Translated in English, 1952, as Essential of Fluid Dynamics, Brackie and Son.],[see also YE, SEGAL and PIELKE, J. Atmos. Sci., 44 (1987), pp. 33413351].

184. PRESS, W.H.; TEUKOLSKIY, S.A.; VETTERLING, W.T. e FLANNERY, B.P., 1986, Numerical Recipes in FORTRAN. Cambridge Univ. Press, Chapter 2, 10 e 11, 963 pp.

185. RASCH, P. J., 1986: Toward Atmospheres without Tops: Absorbing Upper Boundary Conditions for Numerical Models. Quart. J. R. Met. Soc., 112, pp. 1195-1218.

186. RASMUSSON, E.M., 1967: Atmospheric water vapor transport and the water balance of North America: Part I. Characteristics of the water vapor flux field. Mon. We. Rev., 95, pp. 403-425.

187. RAY, P. S. (Editor), 1986, Mesoscale Meteorology and Forecasting, Boston: American Meteorlogical Society (AMS), $793 \mathrm{pp}$.

188. RIVAS, E. K. de, 1972, On the Use of Nouniform Grids in Finite-Difference Equations. Journal of Computational Physics, Vol. 10, No. 2, October, pp. 202-210.

189. ROACHE, P. J., 1972, Computational Fluid Dynamics. Hermosa Publishers, New Mexico, USA, $434 \mathrm{pp}$.

190. RUTLLAND, J. e ULRIKSEN, P., 1979, Boundary-layer dynamics of the extremely arid northern part of Chile: The Antofagasta Field Experiment, Bound.-Layer Meteor., 17 (1979), pp. 41-55.

191. SAVIJÄRVI, H., 1991, The United States Great Plains Diurnal ABL Variation and the Nocturnal Low-Level Jet. Monthly Weather Rev. 119, March, pp. 833-840.

192. SAWFORD, B.L., 1999: Lagrangian Statistical Simulation of Concentration Mean and Fluctuation Fields. Journal of Climate and Applied Meteorology, 24, pp. 1152-1166, 1999.

193. SAZAMORI, T., 1968, The Radiative Cooling Calculation for Application to General Experiments; Journal of Applied Meteorology; 7, pp. 721-729.

194. SCHAEFER, 1986, texto do livro: Thunderstorm Morphology and Dynamics, editado por E. KESSLER, Vol. 2., $2^{\text {nd }}$ ed., rev. and enl., Norman: University of Oklahoma Press, 1986, 411 pp. Disponível na biblioteca do IAG-USP (IAG/551.515.4 T42). 
195. SCHAYES, G. e THUNIS, P., 1990, The Three-dimensional Mesoscale Model in Vorticity Mode (TVM). Contribution $\mathrm{N}^{\mathrm{o}}$ 60, Institut d'Astronimie et de Geophysique Georges Lemaitre. Université Catholique de Louvain. Louvein-la-Neuve. Septembre 1990. Belgium. 42 pp.

196. SCHAYES, G., THUNIS, P. e BORNSTEIN, R., 1996, Topographic Vorticity-Mode Mesoscale-beta (TVM) Model. Part I: Formulation. Journal of Applied Meteorology, 35(10), October 96, pp. 1815-1823.

197. SCHUMANN, Ulrich, 1990: Large-eddy simulation of the up-slope boundary layer. Q. J. R. meteorol. Soc. , 116, pp. 637-670.

198. SEGAL, M. e ARRITT, R.W., 1992, Nonclassical Mesoscale Circulations Caused by Surface Sensible Heat-Flux Gradients. Bulletin of the American Meteorological Society, Vol. 73, No. 10, pp. 1593-1604.

199. SELLERS, W.D., 1965: Physical Climatology, The University of Chicago Press, 272 $\mathrm{pp}$.

200. SHAPIRO, M. A. e KENNEDY, P. J., 1981: Research aircraft measurements of jet stream geostrophic and ageostrophic winds. J. Atmos. Sci., 38, pp. 2642-2652.

201. SHEPPARD, P.A., 1956: Airflow over mountains. Quart. J. Roy. Met. Soc., 82, pp. 528.

202. SHERMAN, Christine A., 1978, A Mass-Consistent Model for Wind Fields over Complex Terrain, J. of Applied Meteor., 17; March 1978, pp. 312-319.

203. SHIELDS, E.J. e TESTA, A.M., 1999, Fall migratory flight initiation of the potato leafhopper, Empoasca fabae (Homóptera: Cicadellidae): observations in the lower atmosphere using remote piloted vehicles. Agricultural and Forest Meteorology, 97 (1999), 317-330.

204. SIEVERS, U., 1995, Verallgemeinerung der Stromfunktionmethode auf drei Dimensionen. Meteorl. Zeitschrift. N.F. 4 (1995), pp. 3-15.

205. _ _ 1997, The Urban Climate Model MUKLIMO_3 of the German Meteorological Service. ACADEMIC TVM CENTER, THIRD TVM-USERS MEETING. Instittut d'Astronomie et de Geophysique Georges Lemaitre. Louvain-la-Neuve, 29-30, September (1997), Audutoire in building "Science 17".

206. e ZDUNKOWSKI, W.G., 1986, A Microscale Urban Climate Model. Contributions to the Atmospheric Physics (Beitr. Phys. Atmosph.), Vol. 56 (1986), No. 1, February, pp. 13-40.

207. SILVA DIAS, M.A.F. e MACHADO, A.J., 1997, 'The Role of Local Circulations in Summertime Convective Development and Nocturnal Fog in São Paulo, Brazil', Bound.Layer Meteor., 82, pp. 135-157, 1997.

208. SLADKOVIC, R. e KANTOR, H.J., 1977, Low-level jet in the Bavarian pré-alpine regime. Arch. Met. Geoph. Biokl., Ser. A., 25, pp. 343-355.

209. SMITH, R.B., 1989, Mountain-induced stagnation points in hydrostatic flow, Tellus 41A, pp. 270-274, 1989.

210. SMITH, R.; PAEGLE, J.; CLARK, T. et alli, 1997, Local and Remote Effects of Mountains on Weather: Research Needs and Opportunities. B. Am. Meteorol. Soc., 78(5), pp. 877-892, MAY, 1997.

211. SORBJAN, Z., 1986, On similarity in the atmospheric boundary layer. Bound.-Layer Meteor., 34, pp. 3777-397.

212. __ 1987, An examination of local similarity theory in the stable stratified boundary layer. Bound.-Layer Meteor., 38, pp. 63-71.

213. SOUZA, E.P.; RENNÓ, N.O. e SILVA DIAS, M.A.F., 2000: Convective circulations induced by surface heteorogeneities. J. of the Atmos. Sci., 57, 2915-2922.

214. STEINWAND, D.R., 1994, Mapping raster imagery to the Interrupted Goode Homolosine projection: International Journal of Remote Sensing, Vol. 15, No. 17, pp. 3,463-3,472.

215. _ _ HUTCHINSON, J.A. e SNYDER, J.P., 1995, Map projections for global and continental data sets and an analysis of pixel distortion caused by reprojection, Photogrammetric Engineering and Remote Sensing, Vol. 61, pp. 1,487-1,497. 
216. STIVARI, S. M. S., 1999: Estudo da Brisa Lacustre do Lago de Itaipu. Tese de Doutorado, IAG-USP, $126 \mathrm{pp}$.

217. __ OLIVEIRA, A.P. e KARAM, H.A., 2002: Patterns of local circulations in the area of the Lake Itaipu: observational and numerical simulation of lake breeze. Journal of the Applied Meteorology (no prelo).

218. STULL, R.B., 1976 a, Mixed-Layer Depth Model Based on Turbulent Energetics. Journal of the Atmospheric Sciences, Vol. 33, July 1976, pp. 1268-1278.

219. _ 1984: Transilient turbulence theory. Part I: The concept of eddy-mixing across finite distances. Journal of the Atmos. Sci., 41, No. 23, pp. 3351-3367, 1984.

220. _ 1984: Transilient turbulence theory. Part II: Turbulent Adjustment. Journal of the Atmos. Science, 41, No. 23, pp. 3368-3379, 1984.

221. __ 1985: Transilient turbulence theory. Part III: Bulk Dispersion Rate and Numerical Stability. J. Atmos. Sci., 41, pp. 3351-3367, 1985.

222. __ 1988: A Reevaluation of two Dispersion Theories. Notes and Correspondence. Journal of the Atmospheric Sciences, Vol. 45, No. 14, pp. 2082-2091.

223. __, 1988: An Introduction to Boundary Layer Meteorology, Kluwer Academic Publishers, 1988, $666 \mathrm{pp}$.

224. __ 1976b: Internal Gravity Waves Generated by Penetrative Convection. Journal of the Atmospheric Sciences, Vol. 33, July 1976, pp. 1279-1286.

225. __ 1985: A Fair-Weather Cumulus Classification Scheme for Moxid-Layer Studies. Journal of Climate and Applied Meteorology, January 1985, pp. 49-56.

226. __ 1988: An Introduction to Boundary Layer Meteorology, Dordrecht (Netherlands), Kluwer Academic Publishers, livro, 647 pp.

227. _ e KRAUS, E.B., 1987: Transilient model of the upper ocean. J. Geoph. Res., 92, pp. 10745-10755.

228. — e DRIEDONKS, A.G.M., 1987: Application of the transilient turbulence parameterization to atmospheric boundary-layer simulations. Boundary-Layer Meteorology, 40, pp. 209-239.

229. SUTCLIFFE, R. C., 1947: A contribution to the problem of development. Quart. J. Roy. Meteor. Soc., 73, pp. 370-383.

230. SYNGE, J.L. e SCHILD, A., 1949, Tensor Calculus. Dover Publications, Inc., NewYork, 324 pp.

231. TERRY, G. e LACARRÈRE, P., 1983, Improving the Eddy Kinetic Energy Model for Planetary Layer Description, Bound.-Layer Meteor., 25, pp. 63-88.

232. THOM, A. S. e OLIVER, H. R., 1977, On Penmann's Equation for Estimating regional Evaporation. Quart. J. R. Met. Soc., 103, pp. 345-357.

233. THOMPSON, J.F.; WARSI, Z.U.A. e MASTIN, C.W., "Numerical grid generation" (book). http://www.erc.msstate.edu/education/gridbook/...

234. THOMSON, D.J., 1984: Random walk modelling of diffusion in inhomogeneous turbulence, Quart. Journ. Royal Meteor. Soc., 110, pp. 1107-1120.

235. THOMSON, D.J., 1987: Criteria for the seletion of stochastic models of particle trajectories in turbulent flows, J. Fluid Mech., 180, pp. 529-556.

236. THUNIS, P., 1995, Formulation and evaluation of a non-hydrostatic vorticity mode mesoscale mode'. Ph.D. dissertation, Université Louvain-la-Neuve, Catholique de Louvain, Belgium, 116 pp.

237. _ _ GROSSI, P., GRAZIANI, G., GALLEE, H., MOYAUX, B. e G. SCHAYES.

Preliminary simulations of the flow field over the Attic Peninsula. Environmental Software, 8, pp. 43-54, 1993.

238. THYER, N.H.: A theoretical explanation of mountain and valley winds by a numerical method. Arch. Met. Geoph. Biocl. A15 (1966), pp. 318-347.

239. TRENBERTH, M. S., 1978: On the interpretation of the diagnostic quasigeostrophic omega equation. Mon. Wea. Rev., 101, pp. 573-593.

240. UCCELLINI, L.W. e JOHNSON, D. R., 1979, The coupling of upper and lower tropospheric jet streams and implications for the development of severe convective storms. Mon. Wea. Rev., 107, pp. 682-703. 
241. VAN DOP, H., NIEUWSTADT, F.T.M. e HUNT, J.C.R., 1985: Random walk models for particle displacements in inhomogeneous unsteady turbulent flows. Phys. Fluids, 28 (1985): pp. 1639-1653.

242. VENKATRAM, A. e WYNGAARD, J.C. (Editors), 1988: Lectures on Air Pollution Modeling, American Meteorlogical Society, Boston, 1988.

243. WALLACE, J.M., 1975: Diurnal variations in precipitation and thunderstorm frequency over the conterminous United States. Mon. We. Rev., 103, pp. 406-419.

244. WALLACE, J.M. e HOBBS, P.V., 1977, Atmospheric Science - An Introductory Survey. Academic Press, New York, USA. 467 pp.

245. WESTBROOK, J.K. e ISARD, S.A., 1999: Atmospheric scales of biotic dispersal. Agricultural and Forest Meteorology, 97 (1999), pp. 263-274.

246. WEXLER, H., 1961, A boundary Layer interpretation of the low-level jet, Tellus, 13, pp. 368-378, March 1961.

247. WHITEMAN, C.D.; BIAN, X. e ZHONG, S., 1997, Low-Level Jet Climatology from Enhanced Rawinsonde Observations at a Site in the Southern Great Plains. J. Appl. Meteor., 36 (10), pp. 1363-1376.

248. WILSON, J.D.; LEGG, B.J. e THOMSOM, D.J., 1983: Calculation of particle trajectories in the presence of gradient in turbulent-velocity variance. Boundary Layer Met. 27, pp. 163-169.

249. WILSON, J.D. and SAWFORD, B.L., 1996, Review of lagrangian stochastic models for trajectories in the turbulent atmosphere, Boundary-Layer Meteorology, 78, pp. 191-210, 1996.

250. WILCZAK, J.M., et al., 1995: Contamination of wind profiler data by migrating birds: Characteristics of corrupted data and potential solutions, J. Atms. Oceanic. Technol., 12, pp. 449-467.

251. WILDE, N.P.; STULL, R.B. and ELORANTA, E.W., 1985: The LCL Zone and Cumulus Onlset. Journal of Climate and Applied Meteorology, 24, July 1985, 640-657.

252. WMO, 1981: Meteorological Aspects of the Utilization of Wind as an Energy Source. World meteorological Organization, WMO, Technical Notes No. 175, 1981, 180 pp.

253. WIPPERMANN, F., 1973, Numerical Study on the Effects Controlling the Low-Level Jet, Beiträge zur Physik der Atmosphäre (Contributions to the Atmospheric Physics), 46 Band, 1973, pp. 137-154.

254. WU, Y.H.; RAMAN, S., 1997, Effect of Land-Use Pattern on the Development of LowLevel Jets. J. Appl. Meteorol., 36: (5), pp. 573-590.

255.__, 1998, The Summertime Great Plains Low-Level Jet and the Effect of its Origin on Moisture Transport. Bound. Layer Meteor., 88.

256. YAMADA, T., 1979, Prediction of the Nocturnal Surface Inversion Height. Journal of Applied Meteorology, 18, pp. 526-531.

257.__ e BUNKER, S., 1987, Development of a Nested Grid, Second Moment Turbulence Closure Model and Application to the 1982 ASCOT Brush Creek Data Simulation. Journal of Applied Meteorology, 27, pp. 562-578.

258. YNOUE, Rita Y., 2002, Impacto do Uso de Campos Meteorológicos Diagnósticos e Prognósticos na Produção e Dispersão de Oxidantes Fotoquímicos em São Paulo, Dissertação de Mestrado, IAG-USP, Brasil, 111 pp.

259.XUE, M.; DROEGEMEIER, K.K.; WONG, V.; SHAPIRO, A. e BREWSTER, K., 1995, Advanced Regional Prediction System (ARPS) Version 4.0 User's Guide, Center for Analysis and Prediction of Storms (CAPS), NSF, FAA, University of Oklahoma, $328 \mathrm{pp}$.

260. ZANNETTI, P., 1990, Air Pollution Modeling - Theories, Computational Methods and Available Software. Van Nostrand Reinhold Ed., 444 pp., 1990.

261. ZHONG, S.; FAST, J.D. e BIAN, X., 1996: A case of the Great Plains low-level jet using wind profiler network data and a high-resolution mesoscale model. Mon. Wea. Rev., 124, pp. 785-806.

262. ZILITINKEVICH, S. S., 1972, On the determination of the height of the Ekman boundary layer. Boundary-Layer Meteorology, 3, pp. 141-145.

263. __ (Ed.), 1991, Modeling Air-Lake Interactions. Springer-Verlag Publ., Berlin, (livro), $129 \mathrm{pp}$. 


\section{Apêndice A}

\section{Transformação do Termo de Difusão Horizontal}

Seja determinar a expressão do termo de difusão horizontal de temperatura potencial, que é uma função do Laplaciano horizontal da temperatura potencial, escrito para o sistema de coordenadas de GAL-CHEN e SOMMERVILLE (1975). Toma-se o termo de difusão escrito para o sistema cartesiano:

$$
\mathrm{D}=\mathrm{K}\left(\frac{\partial^{2}}{\partial \mathrm{x}^{2}}+\frac{\partial^{2}}{\partial \mathrm{y}^{2}}\right) \boldsymbol{\theta}
$$

Para isso, considere-se a notação: $(x, y, z, t)$ para as coordenadas do ponto no espaço físico e $\left(\xi_{1}, \xi_{2}, \eta, \tau\right)$ para as coordenadas do ponto no espaço transformado. Utilizandose esta notação define-se uma transformação tensorial:

$$
\begin{aligned}
& \xi_{1}=\xi_{1}(x, y, z, t) \\
& \xi_{2}=\xi_{2}(x, y, z, t) \\
& \eta=\eta(x, y, z, t) \\
& \tau=\tau(t)
\end{aligned}
$$

Neste caso, as derivadas parciais podem ser obtidas pela regra da cadeia:

$$
\begin{aligned}
\left(\frac{\partial}{\partial x}\right)_{y, z, t} & =\left(\frac{\partial}{\partial \xi_{1}}\right)_{\xi_{2}, \eta, \tau} \cdot\left(\frac{\partial \xi_{1}}{\partial x}\right)_{y, z, t}+\left(\frac{\partial}{\partial \xi_{2}}\right)_{\xi_{1}, \eta, \tau} \cdot\left(\frac{\partial \xi_{2}}{\partial x}\right)_{y, z, t} \\
& +\left(\frac{\partial}{\partial \eta}\right)_{\xi_{1}, \xi_{2}, \tau} \cdot\left(\frac{\partial \eta}{\partial x}\right)_{y, z, t}+\left(\frac{\partial}{\partial \tau}\right)_{\xi_{1}, \xi_{2}, \eta} \cdot\left(\frac{\partial \tau}{\partial x}\right)_{y, z, t}
\end{aligned}
$$

A equação simplifica-se para

$$
\begin{aligned}
\frac{\partial^{2}}{\partial x^{2}} & =\left(\frac{\partial}{\partial \xi_{1}}\right)\left(\frac{\partial^{2} \xi_{1}}{\partial x^{2}}\right)+\left(\frac{\partial}{\partial \xi_{2}}\right)\left(\frac{\partial^{2} \xi_{2}}{\partial x^{2}}\right)+\left(\frac{\partial}{\partial \eta}\right)\left(\frac{\partial^{2} \eta}{\partial x^{2}}\right) \\
& +\left(\frac{\partial^{2}}{\partial \xi_{1}^{2}}\right)\left(\frac{\partial \xi_{1}}{\partial x}\right)^{2}+\left(\frac{\partial^{2}}{\partial \xi_{2}^{2}}\right)\left(\frac{\partial \xi_{2}}{\partial x}\right)^{2}+\left(\frac{\partial^{2}}{\partial \eta^{2}}\right)\left(\frac{\partial \eta}{\partial x}\right)^{2} \\
& +2\left(\frac{\partial^{2}}{\partial \xi_{2} \partial \xi_{1}}\right)\left(\frac{\partial \xi_{2}}{\partial x}\right)\left(\frac{\partial \xi_{1}}{\partial x}\right)+2\left(\frac{\partial^{2}}{\partial \eta \partial \xi_{1}}\right)\left(\frac{\partial \eta}{\partial x}\right)\left(\frac{\partial \xi_{1}}{\partial x}\right)+2\left(\frac{\partial^{2}}{\partial \eta \partial \xi_{2}}\right)\left(\frac{\partial \eta}{\partial x}\right)\left(\frac{\partial \xi_{2}}{\partial x}\right)
\end{aligned}
$$

A derivada com respeito ao eixo y é obtida de forma análoga, resultando: 


$$
\begin{aligned}
\frac{\partial^{2}}{\partial y^{2}} & =\left(\frac{\partial}{\partial \xi_{1}}\right)\left(\frac{\partial^{2} \xi_{1}}{\partial y^{2}}\right)+\left(\frac{\partial}{\partial \xi_{2}}\right)\left(\frac{\partial^{2} \xi_{2}}{\partial y^{2}}\right)+\left(\frac{\partial}{\partial \eta}\right)\left(\frac{\partial^{2} \eta}{\partial y^{2}}\right) \\
& +\left(\frac{\partial^{2}}{\partial \xi_{1}^{2}}\right)\left(\frac{\partial \xi_{1}}{\partial y}\right)^{2}+\left(\frac{\partial^{2}}{\partial \xi_{2}^{2}}\right)\left(\frac{\partial \xi_{2}}{\partial y}\right)^{2}+\left(\frac{\partial^{2}}{\partial \eta^{2}}\right)\left(\frac{\partial \eta}{\partial y}\right)^{2} \\
& +2\left(\frac{\partial^{2}}{\partial \xi_{1} \partial \xi_{2}}\right)\left(\frac{\partial \xi_{1}}{\partial y}\right)\left(\frac{\partial \xi_{2}}{\partial y}\right)+2\left(\frac{\partial^{2}}{\partial \eta \partial \xi_{1}}\right)\left(\frac{\partial \eta}{\partial y}\right)\left(\frac{\partial \xi_{1}}{\partial y}\right)+2\left(\frac{\partial^{2}}{\partial \eta \partial \xi_{2}}\right)\left(\frac{\partial \eta}{\partial y}\right)\left(\frac{\partial \xi_{2}}{\partial y}\right)
\end{aligned}
$$

Agora, levando em conta a transformação de GAL-CHEN e SOMMERVILLE (1975) $(x, y, z, t) \leftrightarrow\left(\xi_{1}, \xi_{2}, \eta, \tau\right)$ definida por $\left\{\xi_{1}=x ; \xi_{2}=y ; \eta=H\left[\frac{z-z_{g}(x, y)}{H-z_{g}(x, y)}\right]\right.$; $\tau=t\}$ onde $H$ é a coordenada vertical do topo do modelo (no espaço físico) e $z_{g}(x, y)$ é o campo de topografia na base correspondente a $\eta=0$. Calculando-se as derivadas necessárias e substituindo, determina-se a expressão do operador laplaciano horizontal:

$$
\left(\frac{\partial^{2}}{\partial x^{2}}+\frac{\partial^{2}}{\partial y^{2}}\right)=\left(\frac{\partial^{2}}{\partial \xi_{1}^{2}}+\frac{\partial^{2}}{\partial \xi_{2}^{2}}\right)+\varepsilon
$$

onde

$$
\varepsilon=\left[\left(\frac{\partial^{2} \eta}{\partial x^{2}}\right)+\left(\frac{\partial^{2} \eta}{\partial y^{2}}\right)\right]\left(\frac{\partial}{\partial \eta}\right)+\left[\left(\frac{\partial \eta}{\partial x}\right)^{2}+\left(\frac{\partial \eta}{\partial y}\right)^{2}\right]\left(\frac{\partial^{2}}{\partial \eta^{2}}\right)+2\left(\frac{\partial \eta}{\partial x}\right)\left(\frac{\partial^{2}}{\partial \eta \partial \xi_{1}}\right)+2\left(\frac{\partial \eta}{\partial y}\right)\left(\frac{\partial^{2}}{\partial \eta \partial \xi_{2}}\right)
$$

Escrevendo-se $\varepsilon$ para o sistema transformado resulta:

$$
\begin{aligned}
\varepsilon=\{ & \left.-\left(\frac{\partial^{2} z_{g}}{\partial x^{2}}+\frac{\partial^{2} z_{g}}{\partial y^{2}}\right)\left(\frac{H-\eta}{H-z_{g}}\right)-2\left[\left(\frac{\partial z_{g}}{\partial x}\right)^{2}+\left(\frac{\partial z_{g}}{\partial y}\right)^{2}\right]\left(\frac{1}{H-z_{g}}\right)\left(\frac{H-\eta}{H-z_{g}}\right)\right)\left(\frac{\partial}{\partial \eta}\right) \\
& +H^{2} \frac{(H-z)^{2}}{\left(H-z_{g}\right)^{4}}\left[\left(\frac{\partial z_{g}}{\partial x}\right)^{2}+\left(\frac{\partial z_{g}}{\partial y}\right)^{2}\right]\left(\frac{\partial^{2}}{\partial \eta^{2}}\right) \\
& -2\left(\frac{H-\eta}{H-z_{g}}\right)\left(\frac{\partial z_{g}}{\partial x}\right)\left(\frac{\partial^{2}}{\partial \eta \partial \xi_{1}}\right)-2\left(\frac{H-\eta}{H-z_{g}}\right)\left(\frac{\partial z_{g}}{\partial y}\right)\left(\frac{\partial^{2}}{\partial \eta \partial \xi_{2}}\right)
\end{aligned}
$$

Resulta que $\varepsilon$ depende: (a) da curvatura da topografia, que é pequena em mesoescala; (b) da curvatura do campo na vertical, que para CM é um termo menor; (b) de fatores com denominador dado por potencial ao quadrado. Em geral, a combinação desses fatores implica em um valor de $\varepsilon$ relativamente menor comparado aos termos $\left(\frac{\partial^{2}}{\partial \xi_{1}^{2}}+\frac{\partial^{2}}{\partial \xi_{2}^{2}}\right)$. Note-se que $\varepsilon$ não pode ser desconsiderado quando a topografia apresenta valores de curvatura suficientemente grande. 


\section{Apêndice B}

\section{Estrutura Vertical do Vento Observada durante os Experimentos de Iperó}
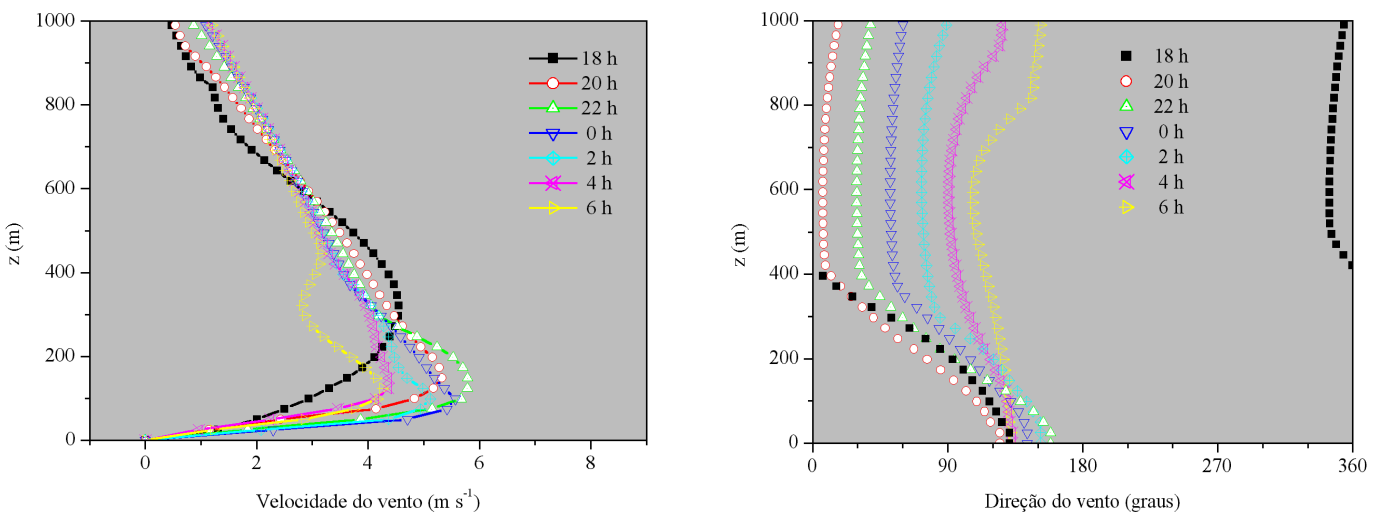

(a)
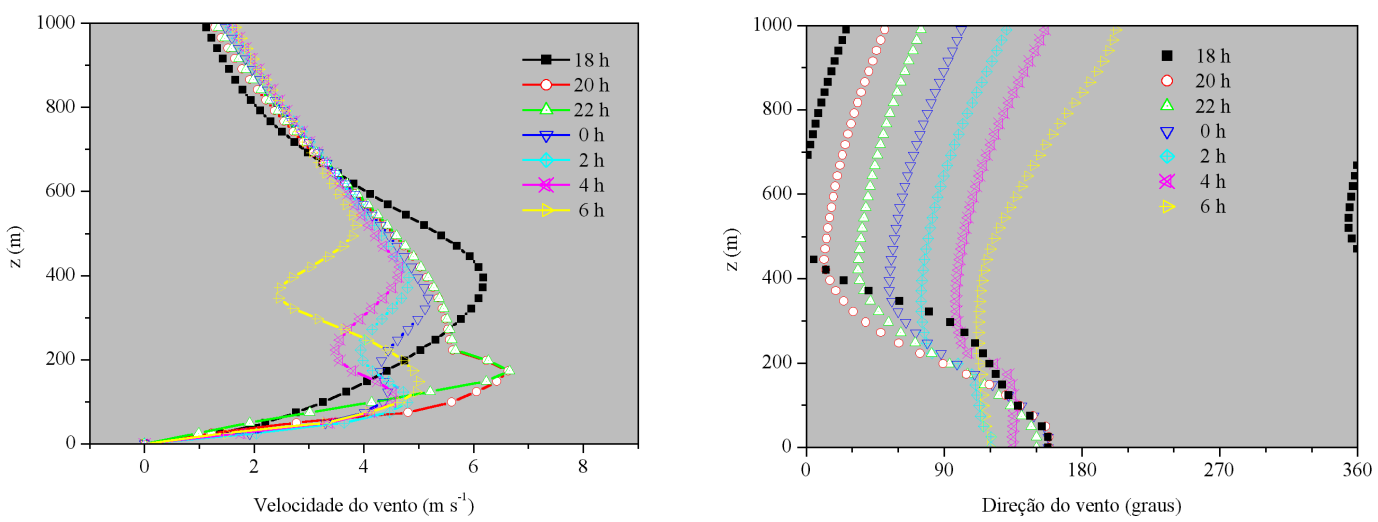

(b)
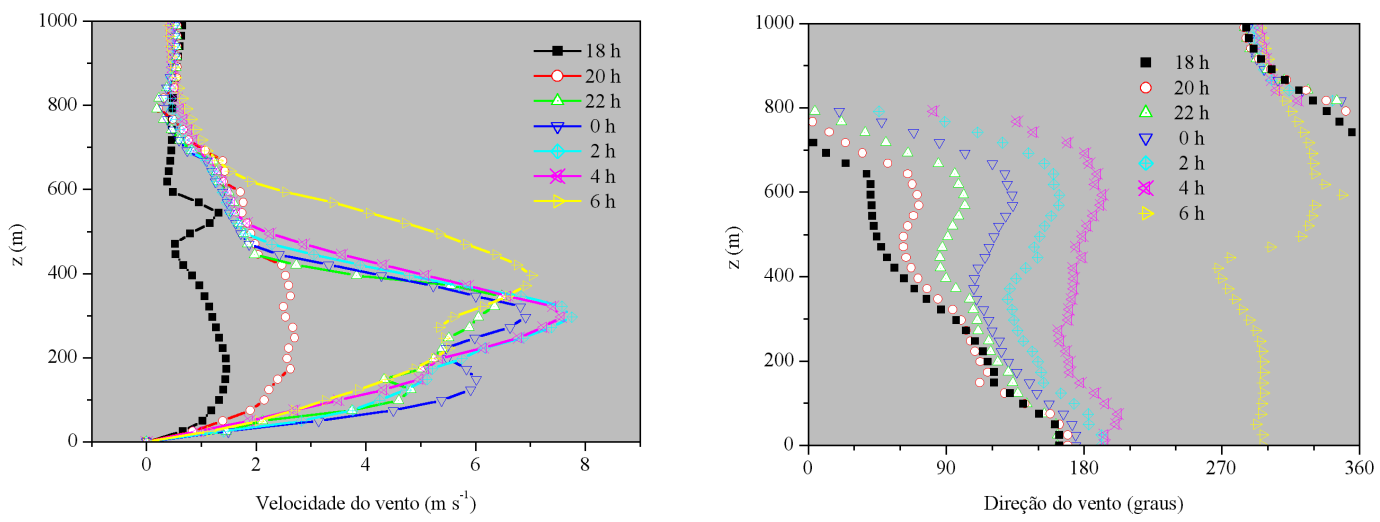

(c)

Figura B.1 Perfis verticais da velocidade e direção do vento para os dias da Primeira Campanha de Iperó, correspondentes às noites dos dias (a) 15-16, (b) 16-17, (c) 17-18, (d) 18-19, (e) 19-20 e (f) 20-21 de Março de 1991. 

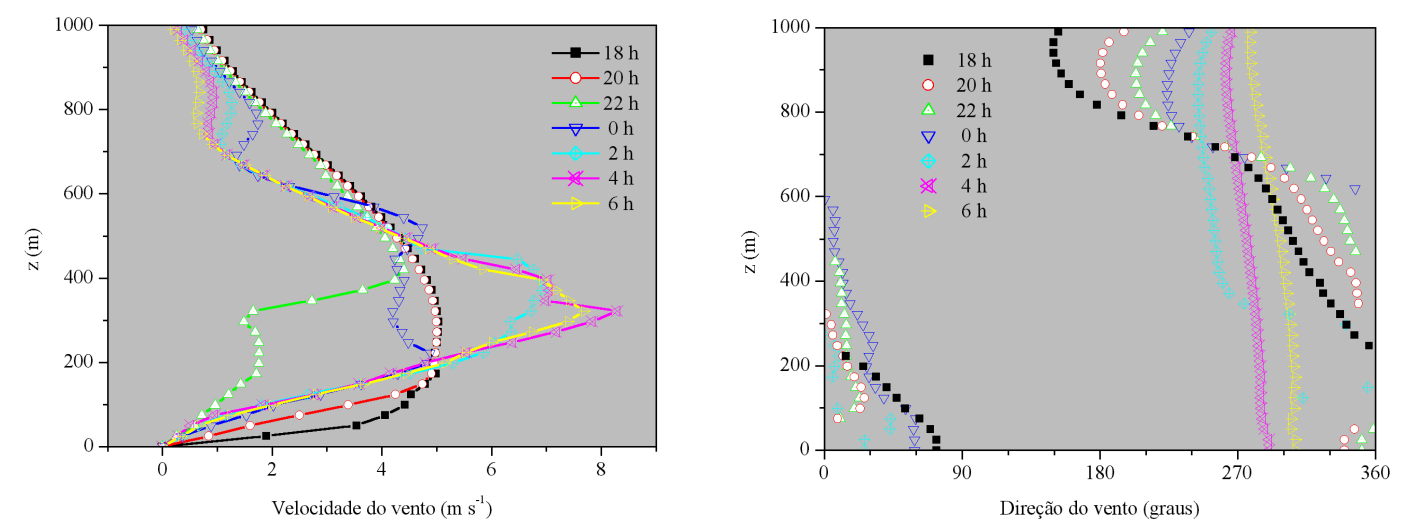

(d)
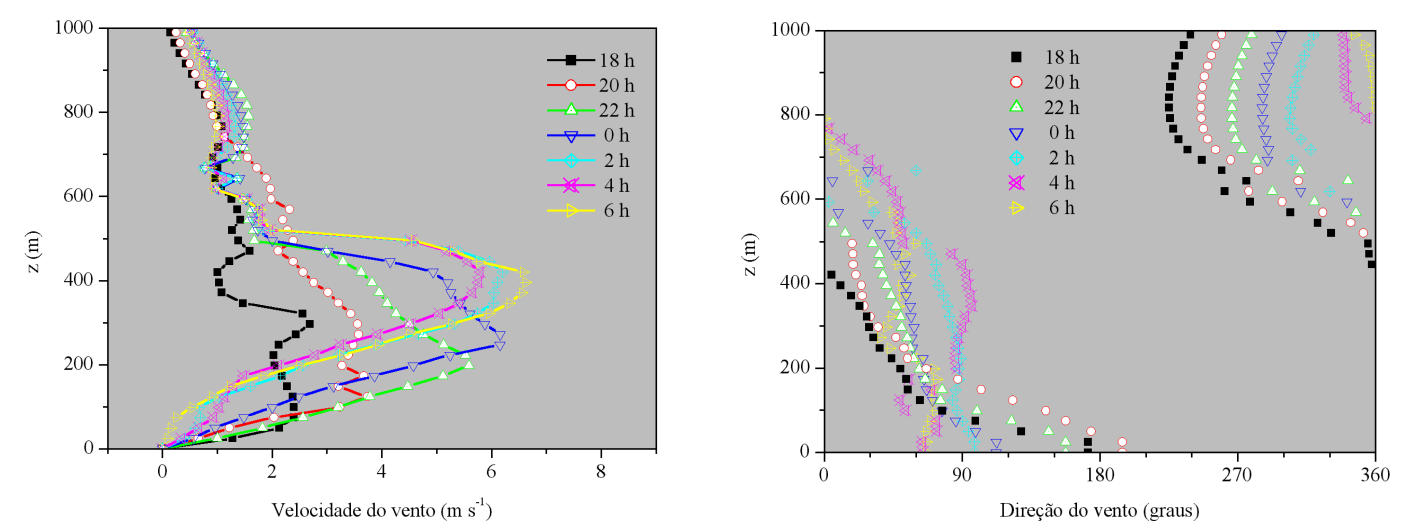

(e)
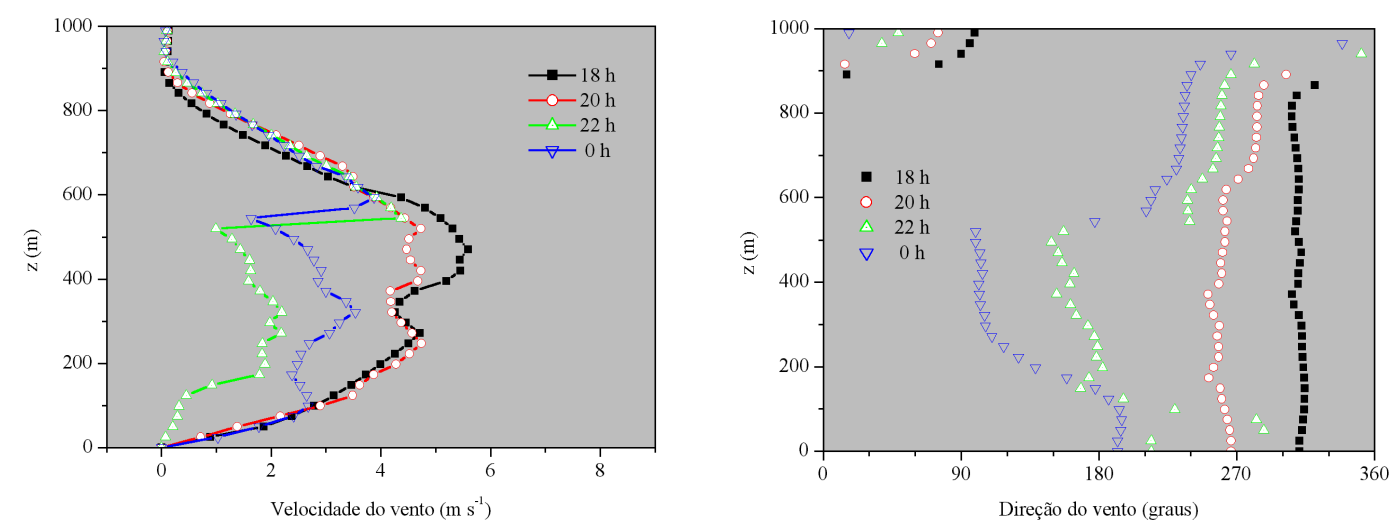

(f)

Figura B.1 Continuação. 

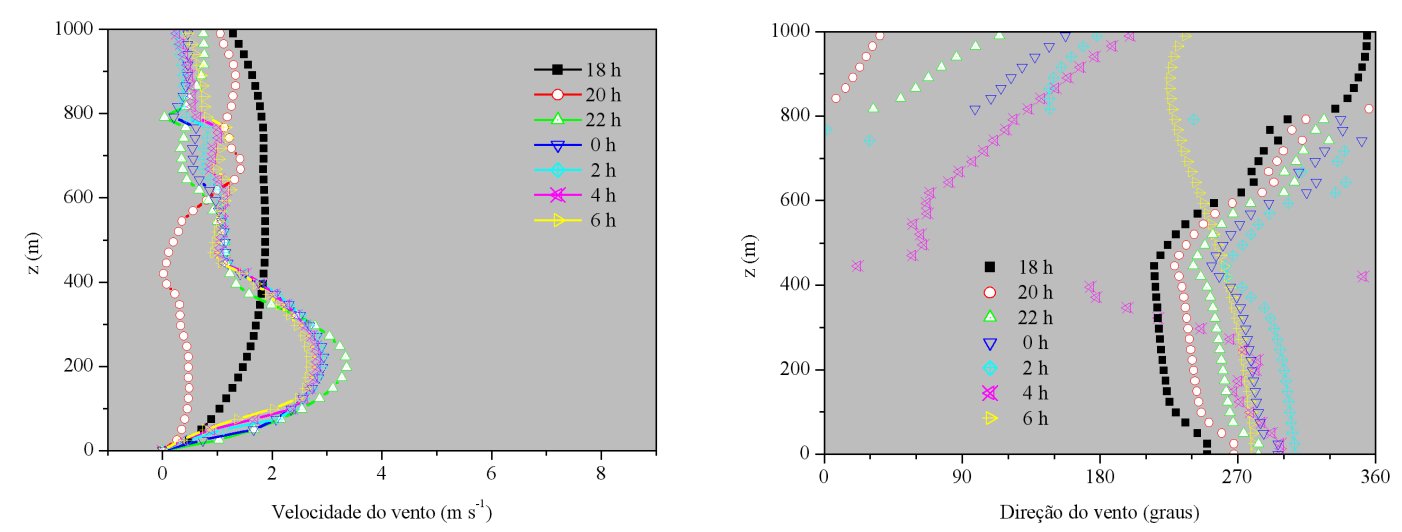

(a)
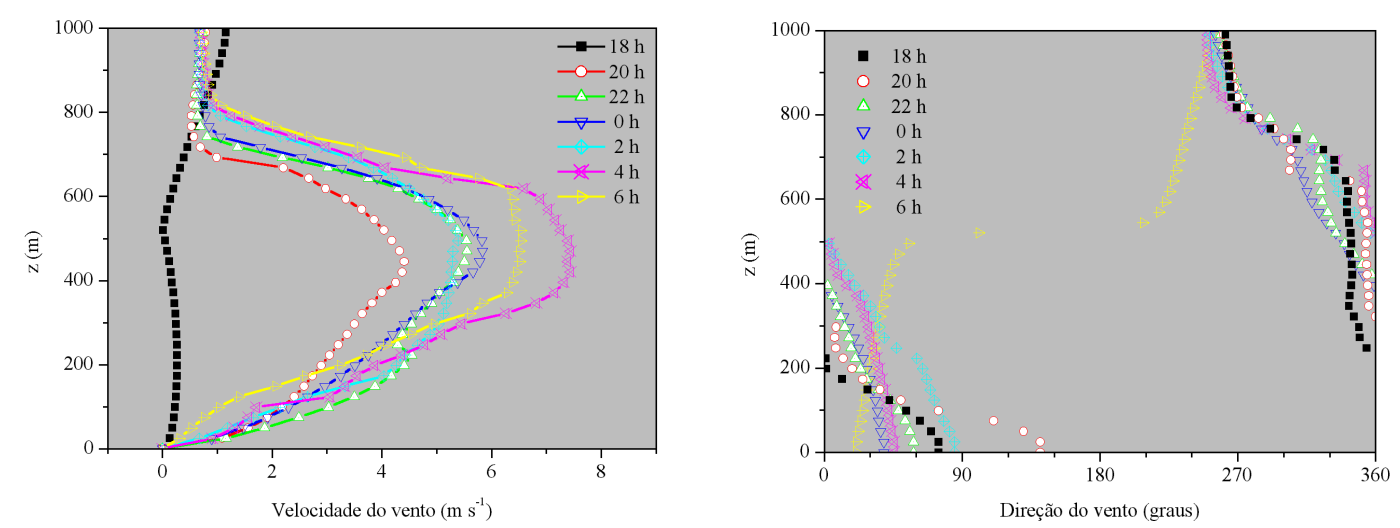

(b)
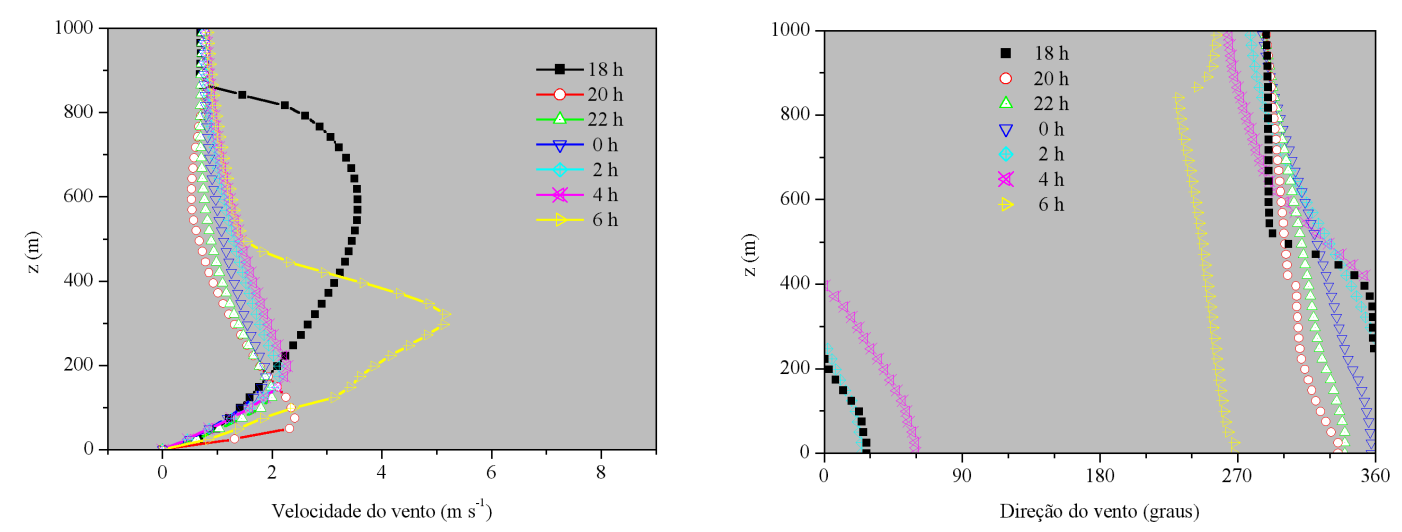

(c)

Figura B.2 Perfis verticais da velocidade e direção do vento para os dias da Segunda Campanha de Iperó, correspondentes às noites dos dias (a) 16-17, (b)17-18, (c)18-19 e (d) 19-20 de Março de 1992. 
Apêndice B - Página 188
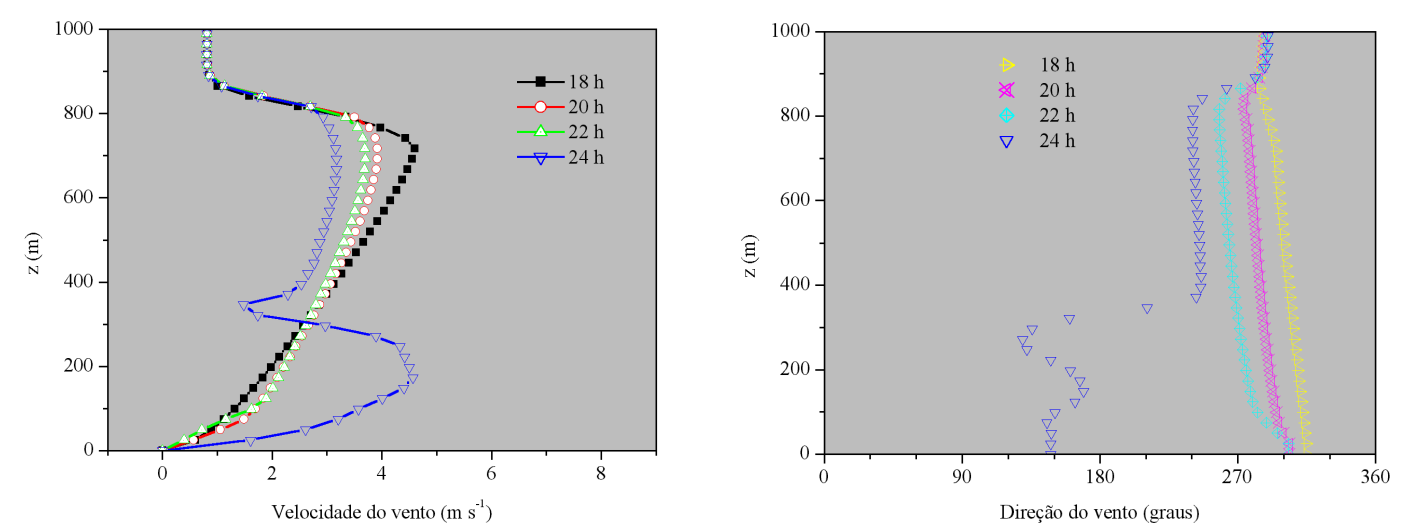

(d)

Figura B.2 Continuação. 

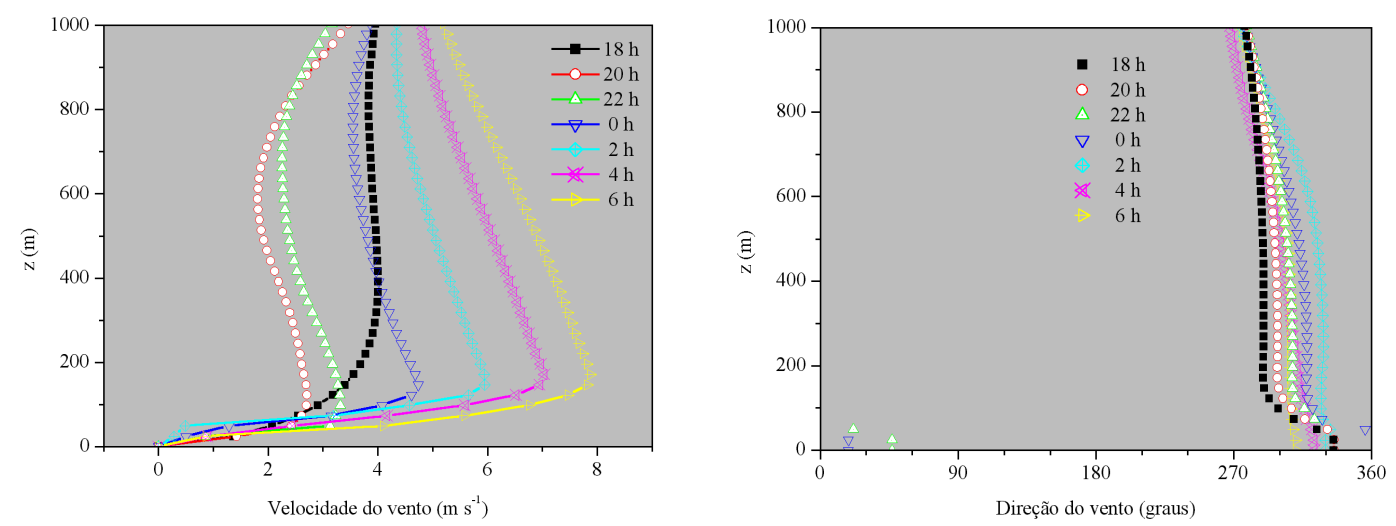

(a)
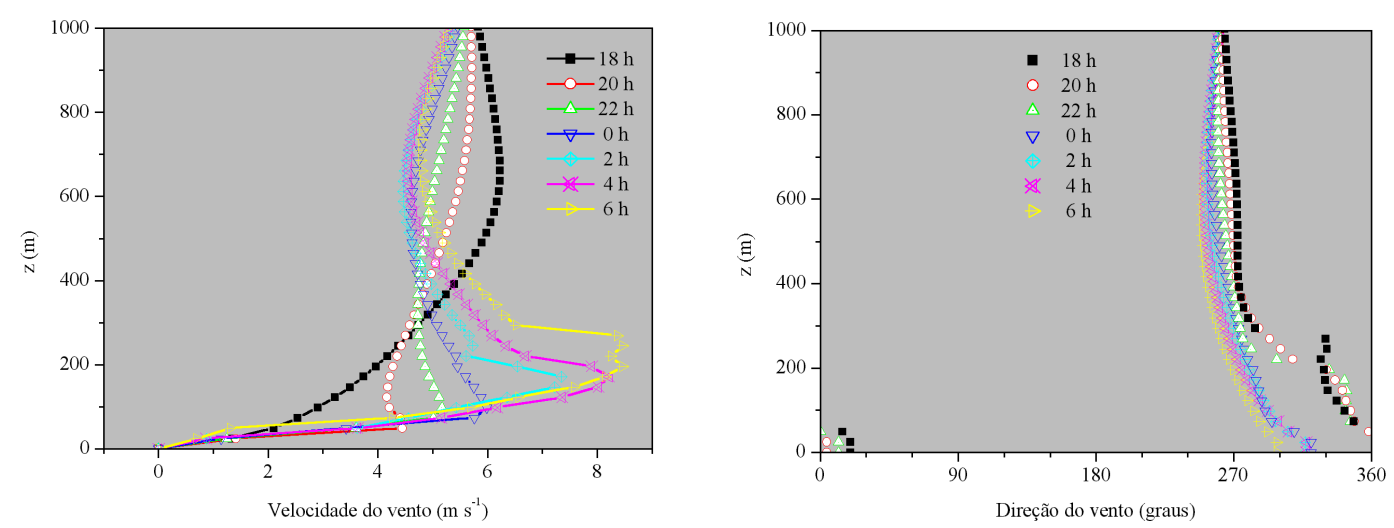

(b)
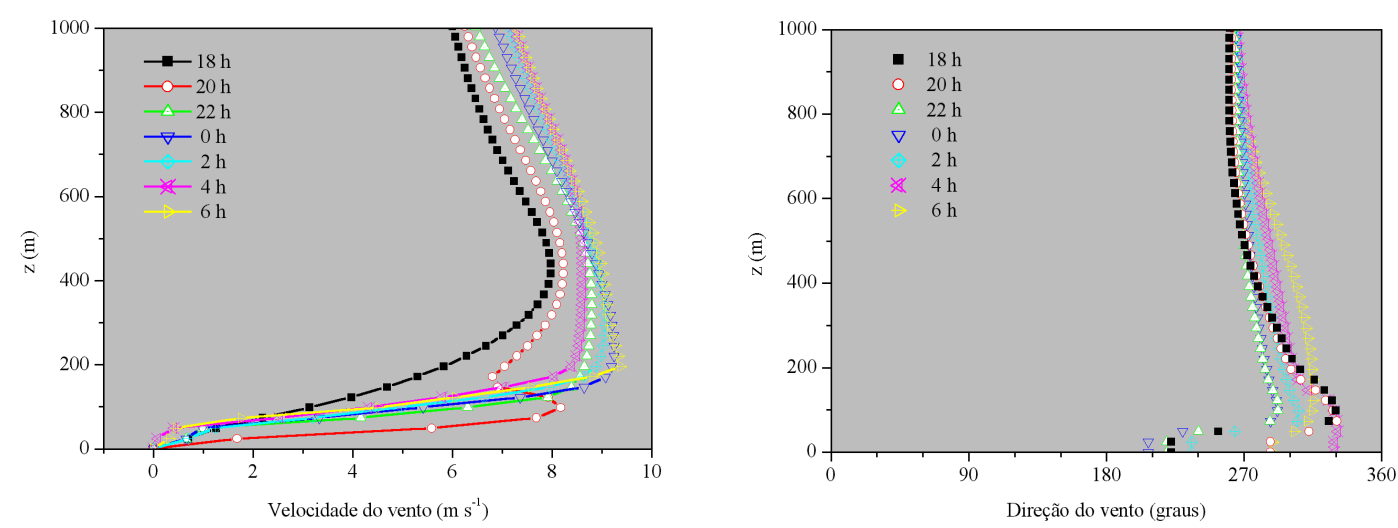

(c)

Figura B.3 Perfis verticais da velocidade e direção do vento para os dias da Terceira Campanha de Iperó, correspondentes à noites dos dias (a) 29-30, (b) 30-31, (c) 31 de Julho - 01 de Agosto, (d) 01-02, (e) 02-03, (f) 03-04, (g) 04-05, (h) 06-07 e (i) 07-08 de Agosto de 1992. 

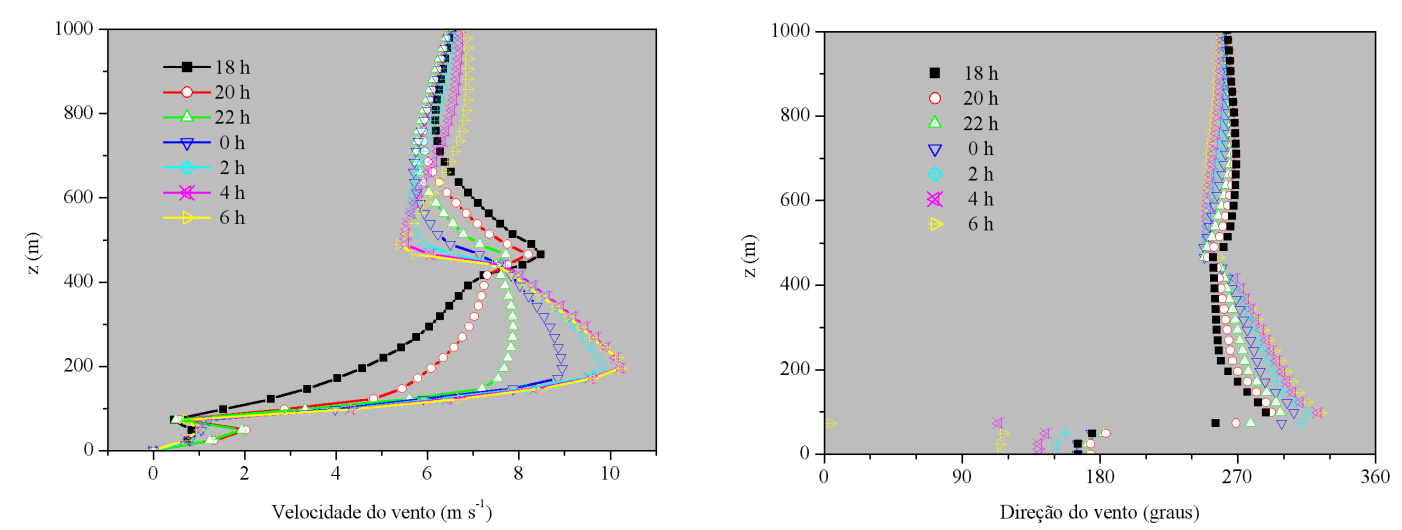

(d)
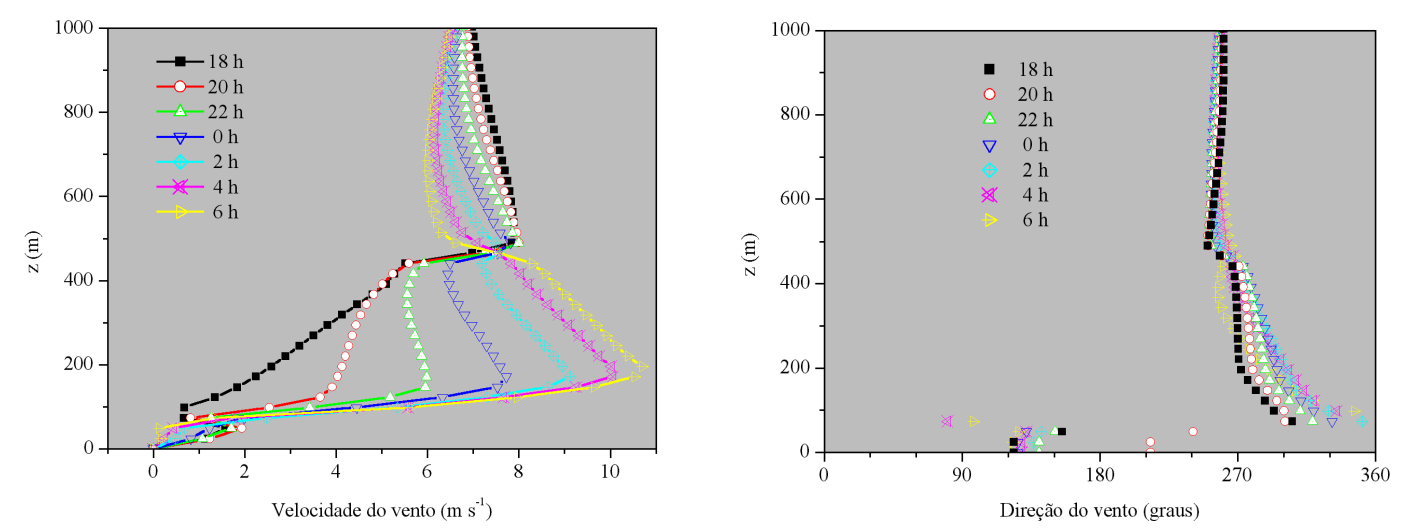

(e)
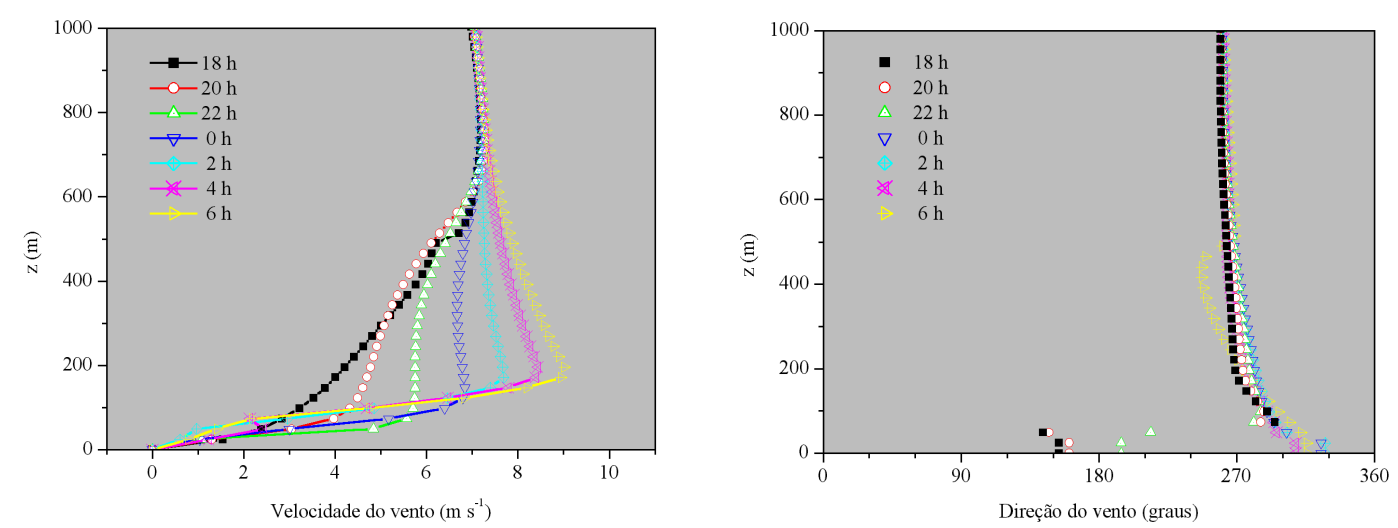

(f)

Figura B.3 Continuação. 

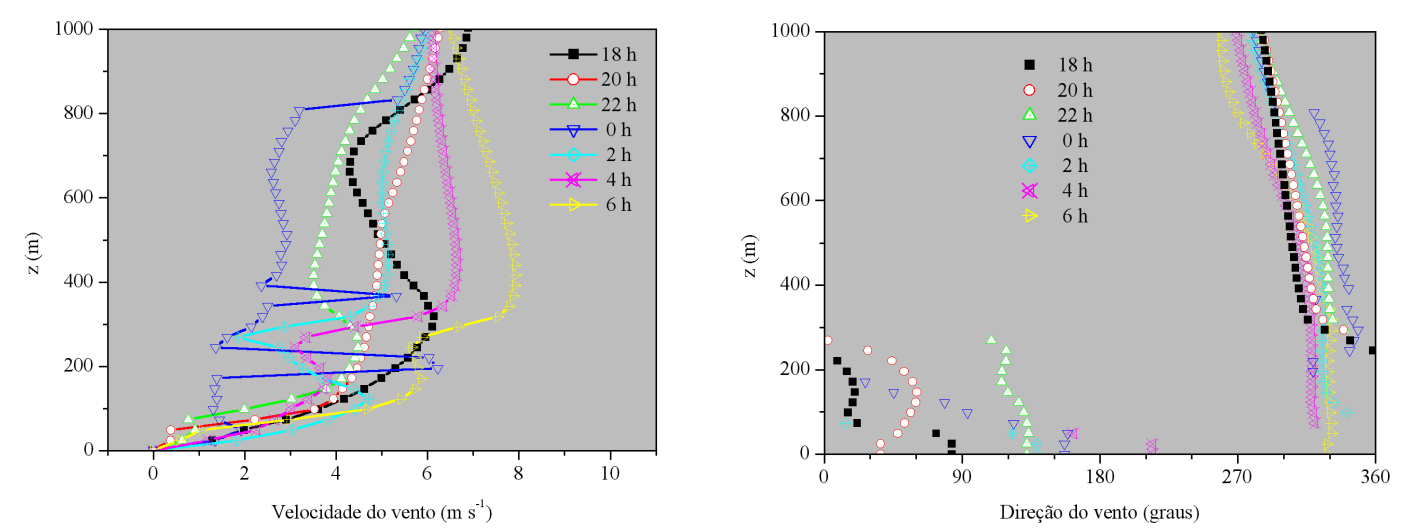

(g)
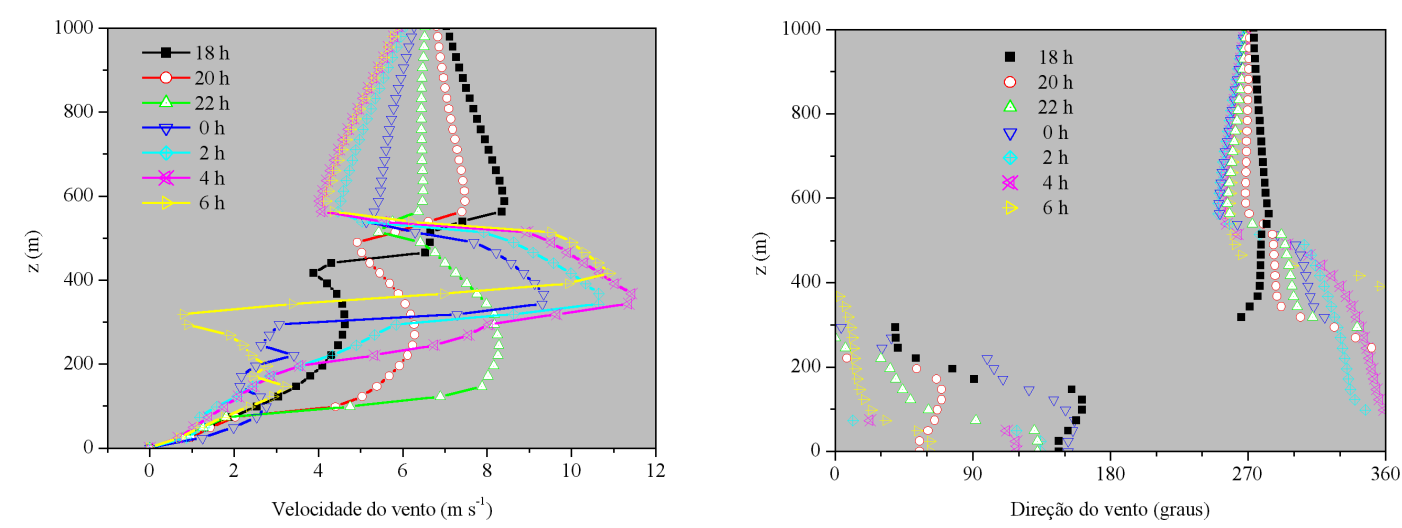

(h)
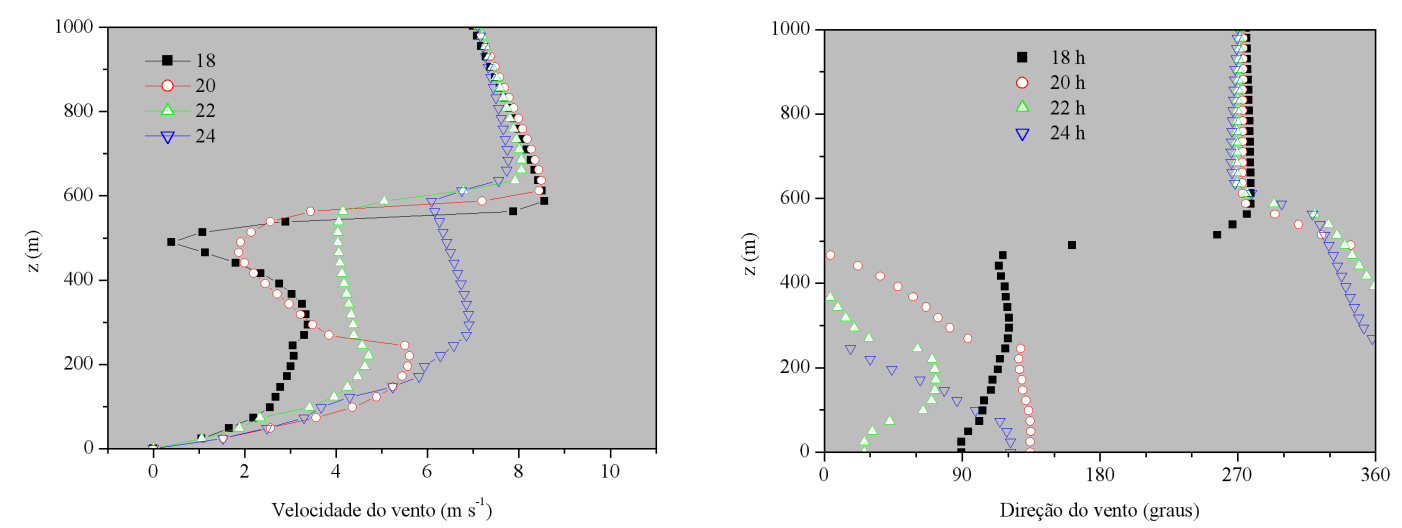

(i)

Figura B.3 Continuação. 

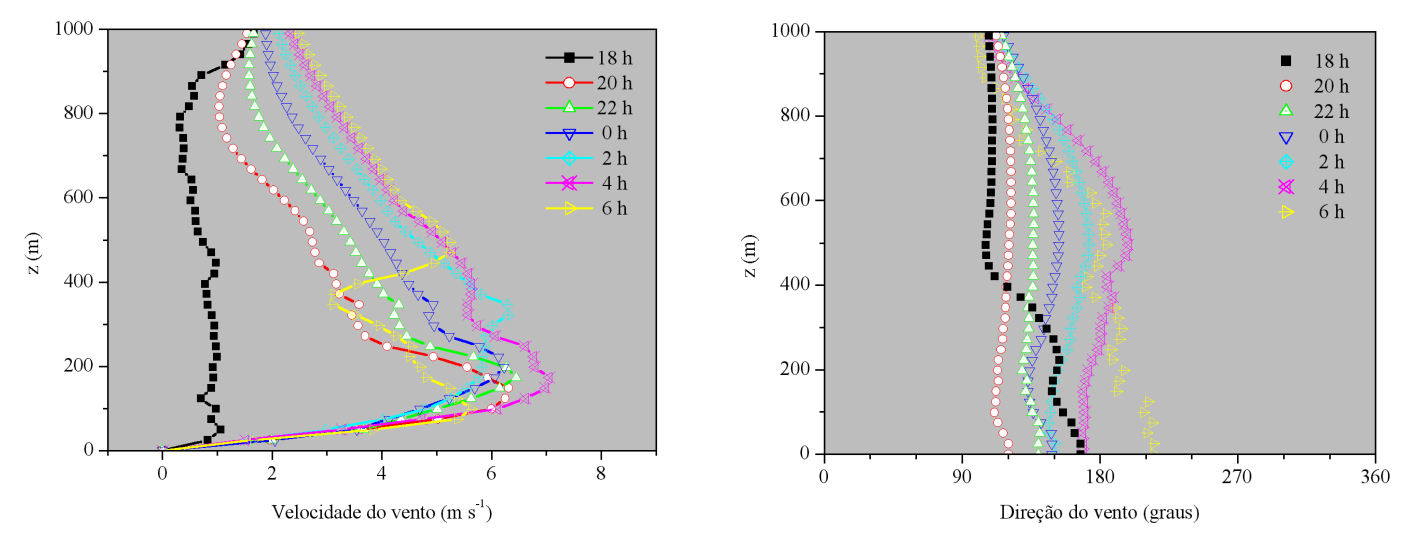

(a)
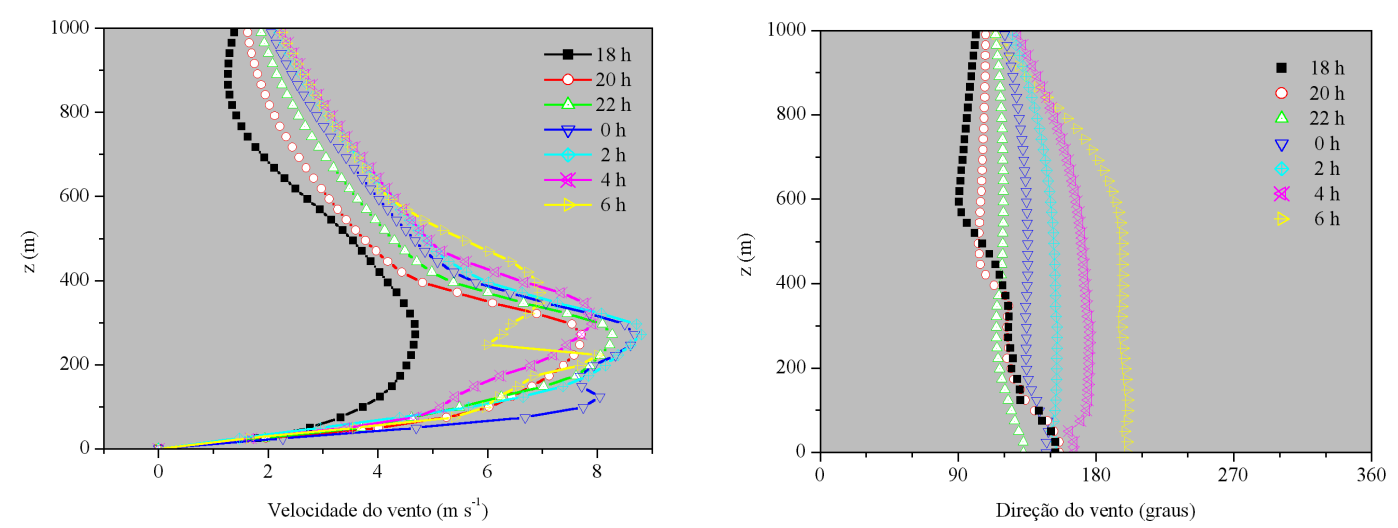

(b)
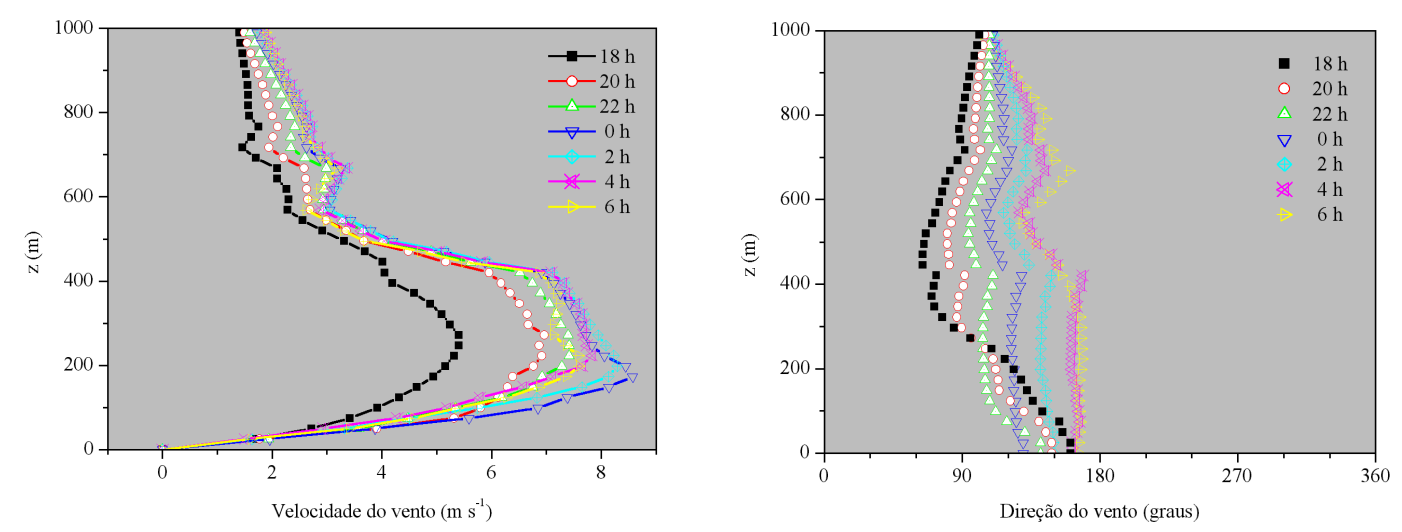

(c)

Figura B.4 Perfis verticais da velocidade e direção do vento para os dias da Quarta Campanha de Iperó, correspondentes à noites dos dias (a) 09-10, (b) 10-11, (c) 11-12, (d) 12-13, (e) 13-14, (f) 14-15, (g) 15-16, (h) 16-17 e (i) 17-18 de Março de 1993. 

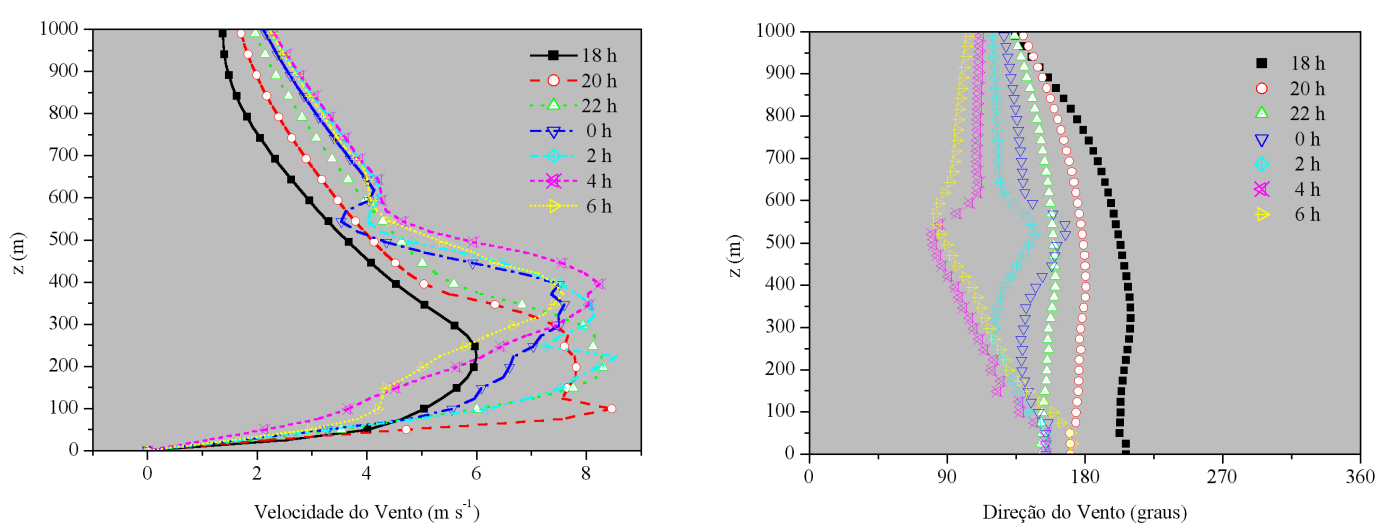

(d)
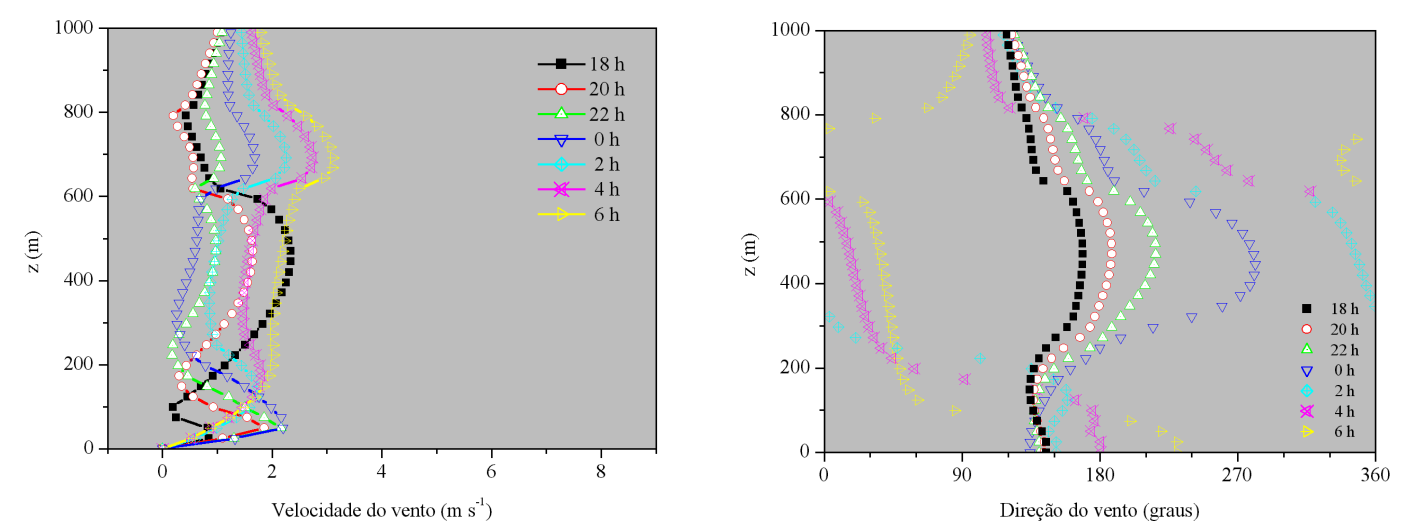

(e)
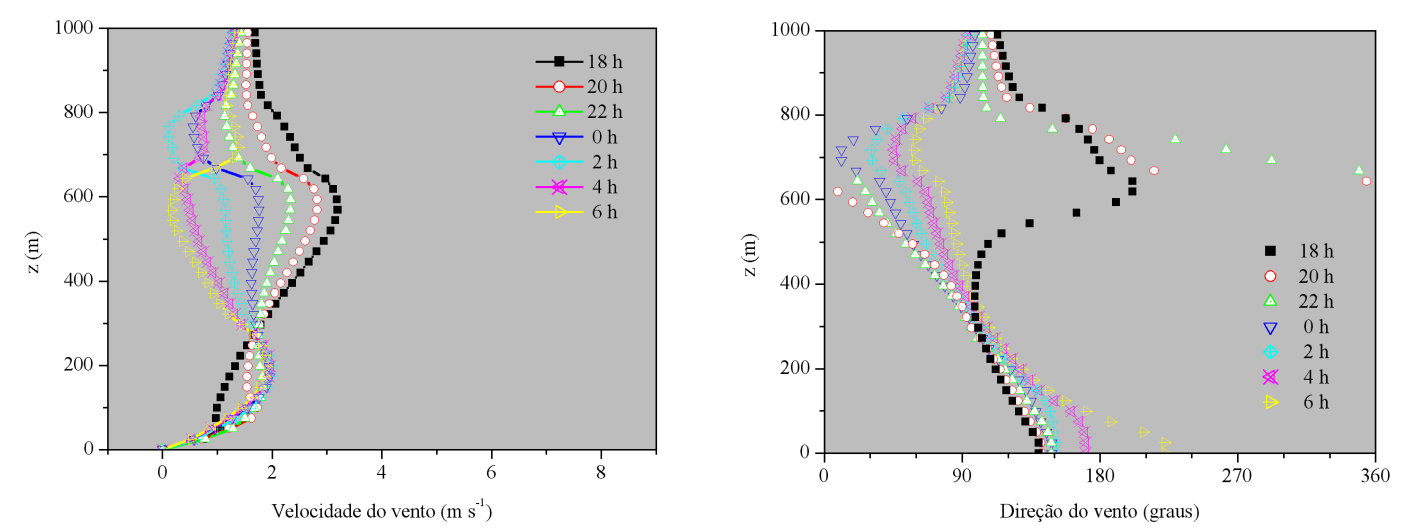

(f)

Figura B.4 Continuação. 

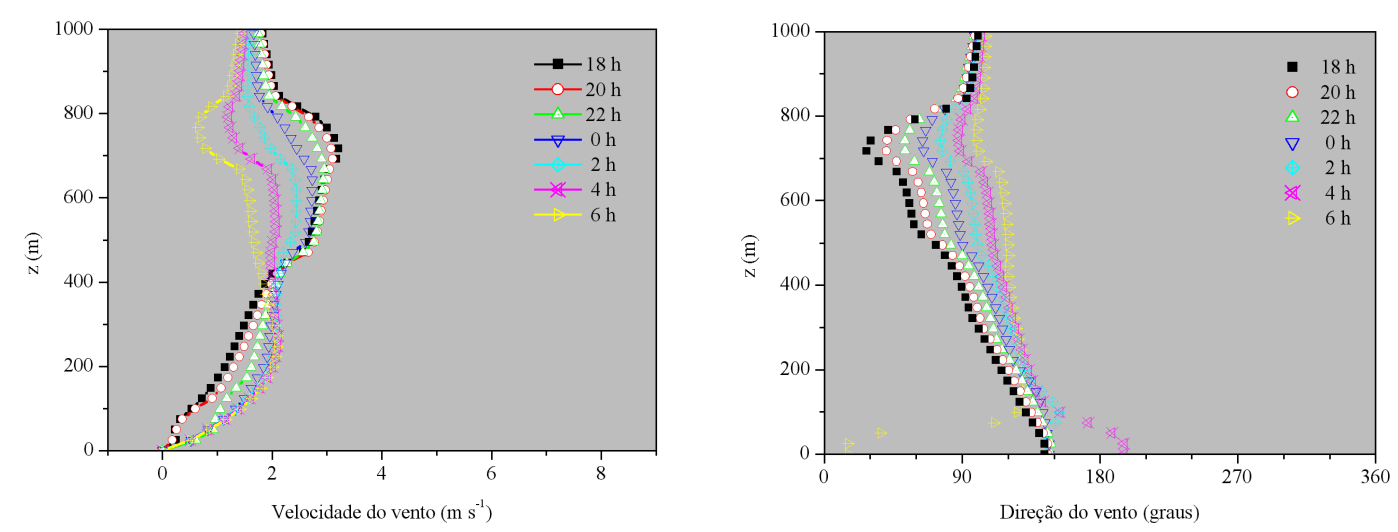

(g)
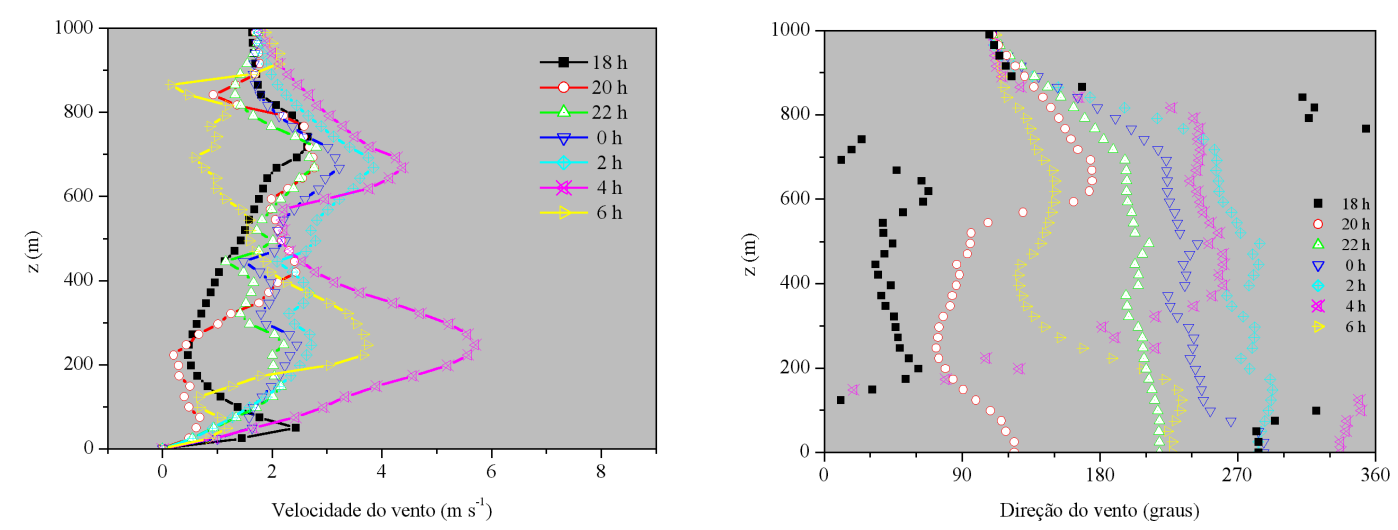

(h)
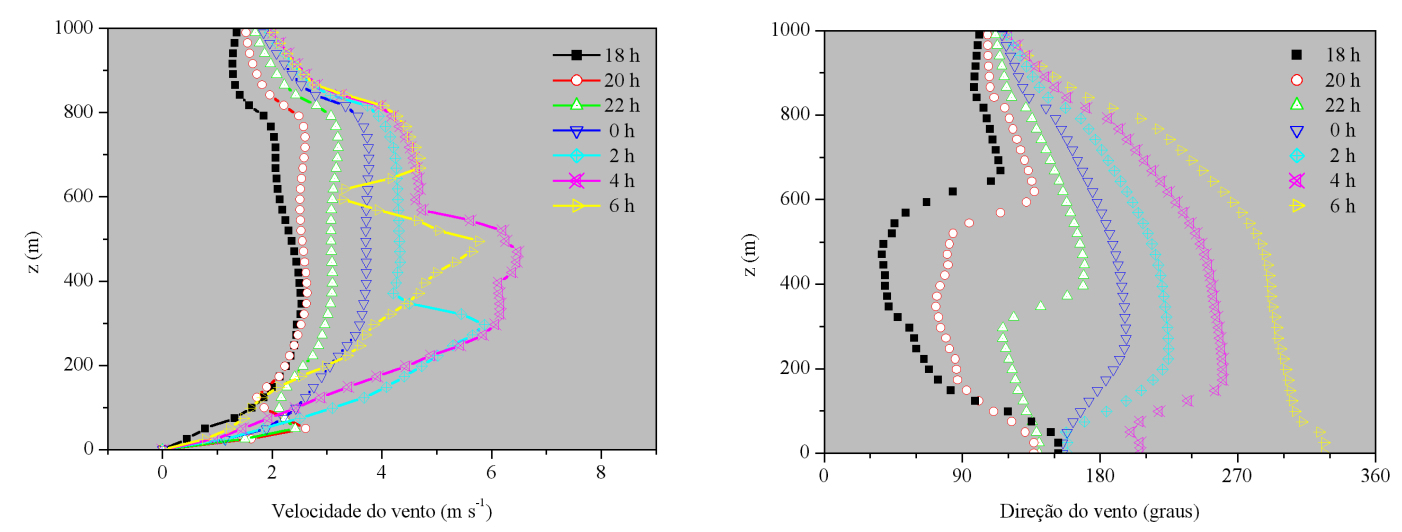

(i)

Figura B.4 Continuação. 


\section{Apêndice C}

\section{Projeção de Mapa}

De acordo com XUE et alli (1995: ARPS user's guide, cap. 7, p. 192) “quando o usuário do modelo escolhe a projeção do tipo conforme de LAMBERT e utiliza um domínio horizontal para sua simulação em domínio menor que $1000 \mathrm{~km}$, então, o efeito do fator do mapa sobre a dinâmica das equações é desprezível". De acordo com estes autores, a grande maioria dos modelos (incluindo a versão 4.0 do ARPS) não implementa fatores de correção da projeção nos termos das equações dinâmicas. Os responsáveis pelo modelo ARPS planejam essa implementação para as versões futuras. No caso do ARPS e de outros modelos de mesoescala, tais fatores de correção são utilizados somente no pré-processamento e no pós-processamento, mas não nas equações dinâmicas.

No modelo TVM, fatores de correção para a projeção conforme de Lambert de área igual são utilizados somente no pré-processamento para obtenção da topografia e cobertura da superfície a partir dos arquivos globais GTOPO30 e IGBP.

NÚÑEZ (2000) tem mostrado que os erros da estimativa da topografia nos modelos de mesoescala usuais são aceitáveis somente dentro da vizinhança de $60 \mathrm{~km}$ do ponto de tangência do plano de projeção, recomendando que versões futuras de modelos de mesoescala implementem estimativas mais precisas da topografia nos pontos de grade quando os domínios horizontais estendem-se por mais que $60 \mathrm{~km}$ (Figura C.1). Estas novas estimativas não estarão baseadas somente nas ternas (LON, LAT, $\mathrm{h}_{\text {interp }}$ do GTOPO30), mas também na geometria do geóide. Normalmente, os construtores de modelos têm implementado a forma esférica para a superfície da Terra (p. ex., no préprocessamento e utilização do arquivo GTOPO30), o que é uma fonte de erros para a previsão obtida com modelos de mesoescala.

Já os modelos globais utilizam sistema de coordenadas esféricas, i.e., os pontos que estão diretamente sobre a superfície planetária (HALTINER e WILLIAMS, 1980) e o sistema de coordenadas geográfico ( $\mathrm{LON}, \mathrm{LAT}, \mathrm{h}=\mathrm{z}+\mathrm{r}_{\mathrm{T}}$ ), o que também é diferente da superfície do trabalho sobre o geóide. Mas, de forma similar ao que é feita para a esfera, as equações dinâmicas apropriadas ao geóide de superfície elipsóide podem ser derivadas. 


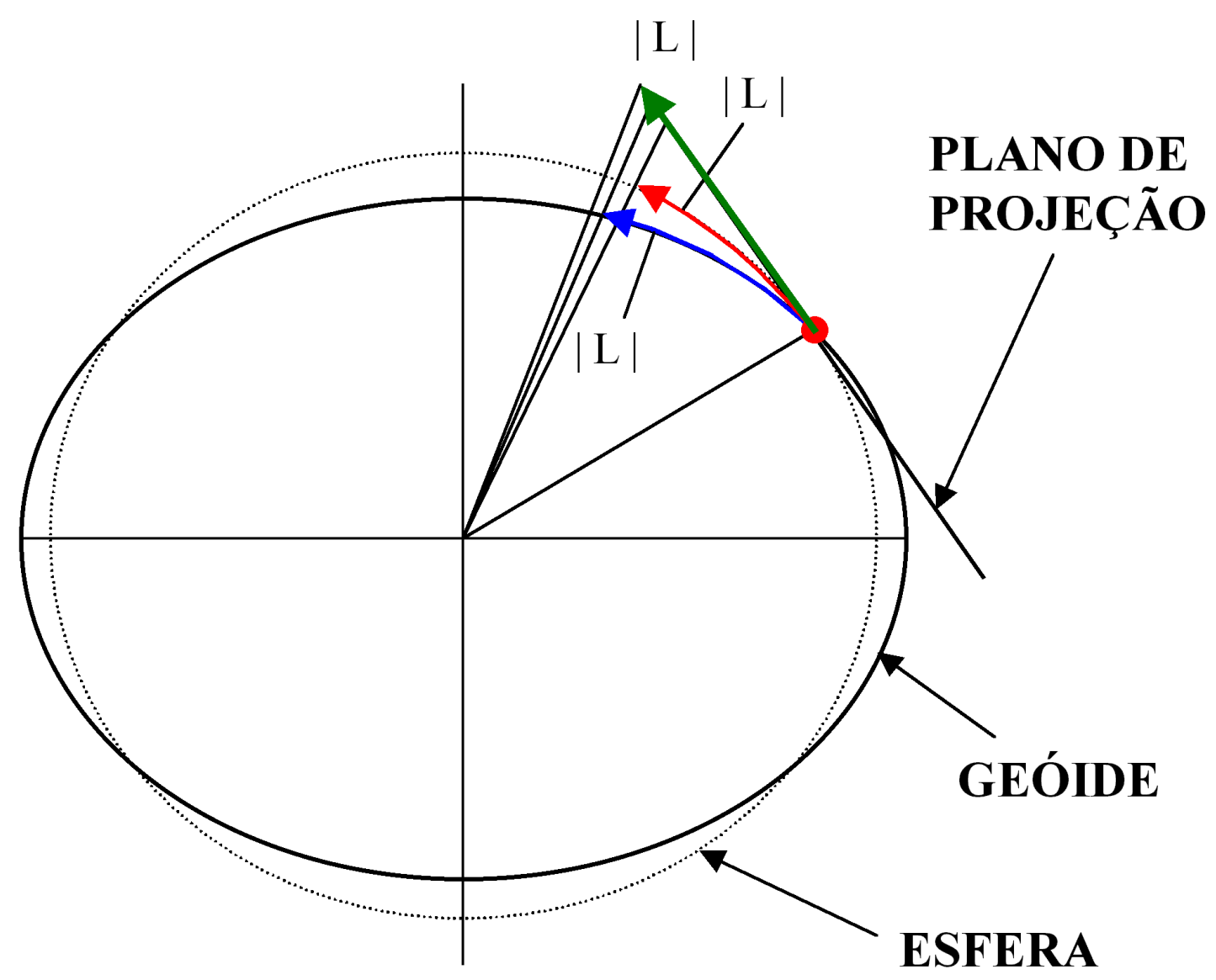

Figura C.1 Um mesmo comprimento | L | mostrado sobre três superfícies diferentes utilizadas em modelos da atmosfera. Estas superfícies são: (a) a superfície de um plano de projeção; (b) a superfície de uma esfera com raio igual ao raio médio da Terra e (c) a superfície de um geóide. A projeção das extremidades dos vetores curvilíneos sobre o plano e esfera correspondem a dois pontos diferentes sobre o geóide, embora os três vetores apresentem mesmo comprimento (NÚÑEZ, 2000). 